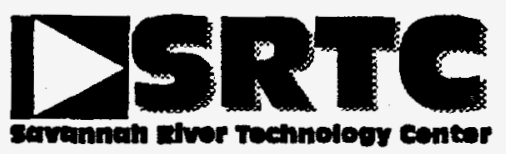

WSRC-RP-91-041

Key Words: PRA

Consequence Analysis

Safety Analysis

Risk Assessment

Severe Accidents

\title{
SAVANNAH RIVER SITE K-REACTOR PROBABILISTIC SAFETY ASSESSMENT (U)
}

Authors:

Westinghouse Savannah River Company

M. D. Brandyberry

R. T. Bailey

W. H. Baker

D. P. Kearnaghan

K. R. O'Kula

R. S. Wittman

N. D. Woody

Science Applications International Corporation

C. N. Amos

J. J. Weingardt

UNCLASSIFIED

DOES NOT CONTAIN UNCLASSIFIED CONTROLLED

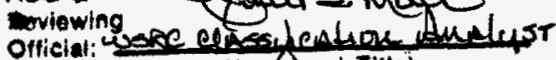

Issued: December 1992

Dats:

(Nametend Titlo)

(t): $8-16-93$

Westinghouse Savannah River Company Savannah River Site

Aiken, SC 29808

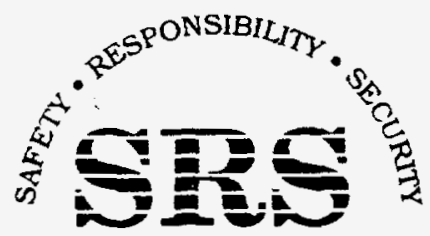

SAVANNAH RIVER SITE

PREPARED FOR THE U.S. DEPARTMENT OF ENERGY UNDER CONTRACT NO. DE-AC09-89SR18035

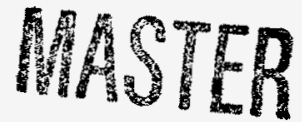


This page intentionally left blank. 
DESCLAMIXR

Portions of this document may be illegible in electronic image products. Images are produced from the best available original cocument 


\section{DISCLAIMER}

This report was prepared as an account of work sponsored by an agency of the United States Government. Neither the United States Government nor any agency thereof, nor any of their empioyees, make any warranty, express or implied, or assumes any legal liabiity or responsibility for the accuracy, completeness, or usefulness of any information, apparatus, product, or process disclosed, or represents that its use would not infringe privately owned rights. Reference herein to any specific commercial product, process, or service by trade name, trademark, manufacturer, or otherwise does not necessarily constitute or imply its endorsement, recommendation, or favoring by the United States Government or any agency thereof. The views and opinions of authors expressed herein do not necessar. ily state or reflect those of the United States Government or any agency thereof. 
Project:

Document:

Title:
PRA

WSRC-RP-91-041

Savannah River Site K-Reactor Probabilistic Safety Assessment

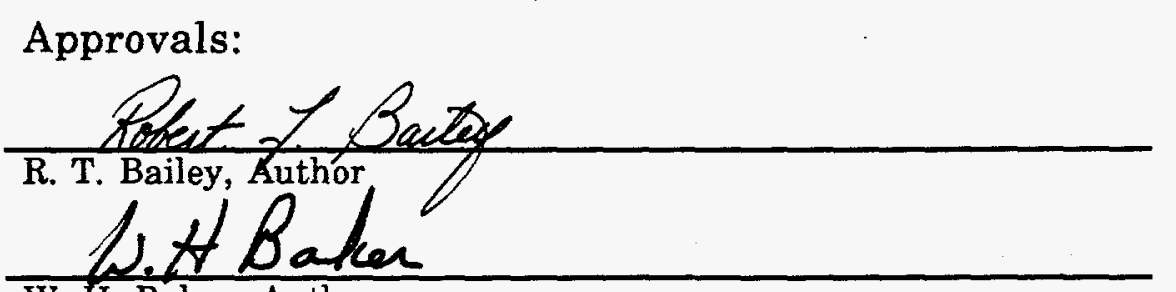

W. H. Baker, Author

\& 19

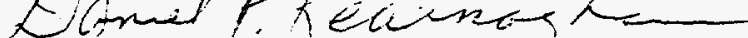

D. P. Kearnaghan, Author Mhed lotitum

R. S. Wittman, Author

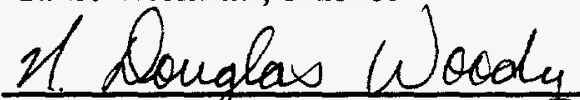

N. D. Woody, Author

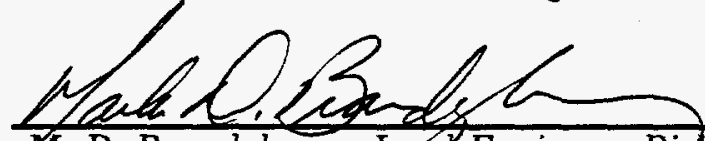

M. D. Brandyberry, Lagd Engineer, Rigk Methodology

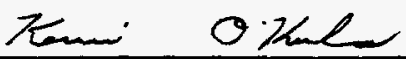

K. R. O'Kula, Manager, Risk and Source Term Technology Group m. Q. plitellon / trea

M. J. Hitchler, Manager, Safety Technology Section

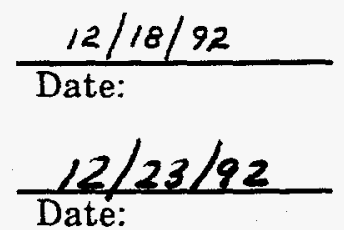

$12 / 28 / 42$

Date:

$\frac{12 / 23 / 92}{\text { Date: }}$

$\frac{12 / 22 / 92}{\text { Date: }}$ $\frac{12 / 23 / 92}{\text { Date: }}$

$\frac{22-29-92}{\text { Date: }}$

$\frac{12-30-92}{\text { Date: }}$ 
This page intentionally left blank. 


\section{PREFACE}

This report gives the results of a Savannah River Site (SRS) K-Reactor Probabilistic Safety Assessment (PSA). [The term "Probabilistic Risk Assessment" (PRA) has been used in earlier reports, but this report will consistently use PSA. The reader is advised that the two terms are used interchangeably in the nuclear field, but the recent trend favors the use of PSA.] Measures of adverse consequences to health and safety resulting from representations of severe accidents in SRS reactors are presented. In addition, the report gives a summary of the methods employed to represent these accidents and to assess the resultant consequences. The report is issued to provide useful information to the U. S. Department of Energy (DOE) on the risk of operation of SRS reactors, for insights into severe accident phenomena that contribute to this risk, and in support of improved bases for other DOE programs in Heavy Water Reactor safety.

The study summarized in this report spanned more than four years. Most of this effort was focused on constructing representations of the progression of severe accidents for these unique plants. These representations were constructed using models of severe accident phenomena and plant response that were developed specifically for the study. Only after analysis of these responses to severe accidents was it possible to conduct the assessment of consequences. Thus, the study encompasses two technical efforts: the development and application of methods to predict severe accident progression in SRS reactors, and the combination of these results with previously produced estimates of accident sequence frequencies to produce a detailed assessment of risk.

This document provides a summary of work that is fully documented in a series of technical reports. These reports are referenced throughout the text and provide the detailed technical bases for the analysis. 


\section{ACKNOWLEDGMENTS}

The study documented in this report incorporates the work of many individuals. Analysis to support the development of the Level 2 portion of the PSA was performed principally by Science Applications International Corporation (SAIC) under contract to Westinghouse Savannah River Company (WSRC). The principal analysts were

\section{SAIC}

S. E. Bayley

S. D. Clement

S. H. Kim

D. L. Y. Louie

L. T. Pong

R. F. Sartor

D. C. Smith

K. C. Wagner
WSRC

D. A. O'Brien*

W. W .F. Yau
WHC

K. N. Schwinkendorf

Other individuals who rnade significant contributions to the PSA are listed below.

WSRC - Level 1 SAIC Sr. Review Panel WSRC - Level 2/3

D. S. Cramer

W. H. Horton

D. R. Bradley

V. E. Denny

W. L. Ferrell

K. D. Kirby

D. A. Sharp

M. T. Leonard

P. R. Davis

T. D. Matteson

D. Okrent

J. A. Smith

P. R. McClure

N. C. Rasmussen

L.W. Christiansen

S. P. Tinnes

D. A. Ward

J. M. East

P. G. Ellison**

S. V. Topp

H. E. Wingo

A. Mertol

K. W. Ross

S. M. Santa Cruz

C. C. Schroeder

B. S. Singer

C. T. Stockman

K. A. Williams

Document preparation and assembly: Maudie Anderson assisted by Melanie Wellmaker.

* Currently with Los Alamos National Laboratory

** Currently with Idaho National Engineering Laboratory 


\section{TABLE OF CONTENTS}

PAGE

EXECUTIVE SUMMARY

S-1

1.0 INTRODUCTION.....................................................1-1

1.1 History of PSA at SRS............................................

1.2 Objectives of the SRS Level $2 / 3$ PSA .............................14

1.3 Overview of the SRS PSA ......................................14

$1.4 \quad$ Reactor Facility Description....................................1-7

1.4.1 Reactor Systems.........................................1-9

1.4.1.1 Primary Coolant System.......................1-9

1.4.1.2 Secondary Cooling System ................. 1-11

1.4.1.3 Reactor Core and Fuel

Assemblies .................................. 1-11

1.4.1.4 Reactivity Control System ................. 1-13

1.4.2 Confinement System...................................... 1-13

1.4.2.1 Airborne Activity Confinement

System .......................................... 1-15

1.4.2.2 Reactor Room Spray System................. 1-18

1.4.2.3 Confinement Heat Removal

System ....................................... 1-18

1.4.2.4 Water Disposal System................... 1-18

1.4.2.5 Contaminated Water Storage

System

1.5 Structure of the Report ...................................... 1-19

1.6 References..................................................... 1-19

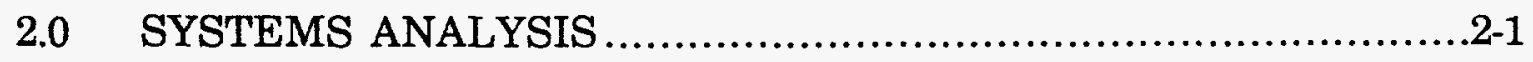

2.1 Internal Events Analysis.........................................2-2

$2.2 \quad$ External Events Analysis .......................................2-3

2.2.1 Seismic Analysis..........................................2-4 
PAGE

2.2.2 Fire Analysis .............................................2-6

2.2.3 Weather-Related Events ..................................2-7

2.2.4 Human-Related Events....................................2-8

2.3 Results of the PSA - Severe Core Melt Frequency ...............2-8

2.3.1 Summary of Internal Events Results....................2-9

2.3.2 Summary of External Events Results.................... 2-11

2.4 Plant Damage States..............................................2-14

2.4.1 Plant Damage State Descriptions: Internal

Initiators.

2-14

2.4.1.1 LOPA (PDS-I1) ............................2-16

2.4.1.2 Low Flooding Rate LOPA (PDS-I2).......2-16

2.4.1.3 LOCA Without ECCS (PDS-I3).............. 2-17

2.4.1.4 Small-Break LOCA With ECCS (PDS-I4)........................................2-18

2.4.1.5 LOCA With Internal Flooding (PDS-I5).........................................2-18

2.4.1.6 Localized Transient (PDS-I6) ..............2-18

2.4. 1.7 Loss of Primary Circulation (PDS-I7)........................................2-19

2.4.1.8 LOHS (PDS-I8) ............................ 2-19

2.4.1.9 Loss of River Water (PDS-I9) .............2-20

2.4.2 Plant Damage State Descriptions: Seismic Initiators.................................................. 2-20

2.4.2.1 LORW (PDS-S1) ......................... 2-21

2.4.2.2 LOPC (PDS-S2) ............................ $\quad 31$

2.4.2.3 LOPA (PDS-S3)............................. 1

2.4.2.4 LOCA (PDS-S4) .................................. 2 2

2.4.2.5 LOCA with Flood (PDS-S5)................ 2-22 
TABLE OF CONTENTS (continued)

2.4.2.6 Vented LOPC (PDS-S6) .....................2-22

2.4.2.7 Vented LOPA (PDS-S7) .................... 2-22

$2.5 \quad$ References...................................................... $2-22$

3.0 CORE MELT PROGRESSION ANALYSIS.................................

$3.1 \quad$ Accident Classes ................................................

3.1.1 Loss-of-Pumping Accidents.............................. $3-4$

3.1.2 Loss-of-Coolant Accidents .................................3-4

3.1.3 Loss-of-Heat-Sink Accidents ............................3-5

3.1.4 Transients.............................................. $3-5$

3.2 Phases of Core Melt Progression ................................3-6

3.2.1 Primary Cooling System Response .....................3-6

3.2.1.1 Loss-of-Pumping Accidents .................3-6

3.2.1.2 Loss-of-Coolant Accidents.......................3-7

3.2.1.3 Loss-of-Heat-Sink Accidents .................3-7

3.2.1.4 Transients................................... $3-7$

3.2.2 Assembly Melting and Debris Relocation ...............3-8

3.2.2.1 Debris Relocation in a Vessel Full of Water..............................................3-9

3.2.2.2 Debris Relocation in a Dry Vessel ........ 3-10

3.2.2.3 Debris Relocation as Particles ............. 3-11

3.2.3 Primary System Failure................................. 3-12

3.2.3.1 Dry Vessel .................................. 3-12

3.2.3.2 Water-Filled Vessel ........................ 3-13

3.2.4 Confinement Response ............................... 3-13

3.2.4.1 Fission Product Release .................... 3-14

3.2.4.2 Energetic Events.............................. 3-14 
TABLE OF CONTENTS (continued)

3.2.4.3 Presence of Water..........................3-15

3.3 Idealized L.OHS Accident......................................... 3-16

4.0 ACCIDENT PROGRESSION ANALYSIS..............................4-1

4.1 Accident Progression Event Tree.................................4-1

4.1.1 APET Development and Structure.......................44

4.1.2 Issues Affecting Accident Progression .................49

4.1.3 Approach To Accident Progression Issue

Resolution .............................................. 4-11

4.2 Solution of the APET .......................................... $4-16$

4.2.1 The Primary Binner ................................... 4-17

4.2.2 The Summary Binner.................................. 4-18

4.3 References................................................... 4-23

5.0 CORE MELT PROGRESSION PHENOMENOLOGY ..................5-1

5.1 Thermal-Hydraulic Analyses .................................5-2

5.1.1 Thermal-Hydraulic Modeling Techniques................5-2

5.1.2 Primary System Response.............................5-2

5.1.2.1 Loss-of-Pumping Accidents ................5-2

5.1.2.2 Loss-of-Coolant Accidents.....................5-3

5.1.2.3 Loss-of-Heat-Sink Accidents .................5-4

5.1.2.4 Transients...................................5-5

5.1.3 Particulate Transport ...................................5-5

5.2 Fuel Degradation Analyses..........................................5-7

5.2.1 Fuel Degradation Modeling Techniques.................5-9

5.2.1.1 Behavior Under Dryout

Conditions

5.2.1.2 Behavior Under Coolant Flow

Conditions 


\section{TABLE OF CONTENTS (continued)}

5.2.2 Results of Fuel Degradation Analyses.................5-12

5.2.2.1 Application of MELSRP and MELCOR/SR..............................5-12

5.2.2.2 MELSRP and MELCOR/SR Results 5-12

5.2.3 Additional Supporting Analyses .....................5-14

5.2.4 Conclusions From Fuel Melt Analyses ...............5-16

5.3 Debris Behavior Analyses.................................... 5-16

5.3.1 Debris Behavior Modeling Techniques ................5-17

5.3.2 Results of Debris Behavior Analyses................. 5-18

5.3.2.1 Bottom-End Fitting Coolability.............5-18

5.3.2.2 Coolability on the Bottom Shield........... 5-19

5.3.2.3 Penetration of Outlet Nozzle Muffs .........................................5-20

5.3.2.4 Coolability in the Outlet Piping........... 5-20

5.3.2.5 Behavior on the Confinement Floor

5.3.2.6 Coolability in the Heat Exchangers

5.3.3 Summary of PCS Coolability Analyses ............... 5-22

5.4 Fission Product Transport Analyses.......................... 5-23

5.4.1 Primary System Fission Product Transport Analysis..

5.4.1.1 Releases During Fuel Melt ..............5-24

5.4.1.2 Releases During Debris Heat-Up......... 5-24

5.4.1.3 Chemical Form of Iodine Released In-Vessel.................................5-26

5.4.1.4 Fission Product Retention.................. 5-26

5.4.1.5 Fission Product Revolatilization.......... 5-28 
TABLE OF CONTENTS (continued)

5.4.2 Ex-Vessel Fission Product Transport

PAGE

Analysis

5.4.2.1 Fission Product Release

5.4.2.2 Fission Product Retention Due to

Water Overlying MCCI

5.4.3 Summary of Results for PCS Fission Product

Transport.

5.5 Molten Core-Concrete Interaction Analyses 5-32

5.5.1 Modeling Techniques.................................... 5-34

5.5.1.1 Hydrogen Generation......................... 5-34

5.5.1.2 Fission Product Release .................... 5-35

5.5.2 Summary of Molten Core-Concrete Interaction Analysis. $5-36$

5.6 Confinement Response Analyses................................5-38

5.6.1 Confinement Response Analysis Techniques......... 5-38

5.6.2 Results of the Confinement System Response

Analysis.

5.6.2.1 Input Deck Description $5-40$

5.6.2.2 Results of MELCOR/SR

Simulations $5-42$

5.6.2.3 APET Filter Thermal Response Model (UFUN). $5-51$

5.6.3 Summary of Confinement System Response Analysis $5-52$

$5.7 \quad$ References...............................................

6.0 ENERGETIC EVENTS ANALYSES................................6-1

6.1 Recriticality and Reactivity Transient Analyses .......... .6-2

6.1.1 Modeling Techniques.....................................6-3

6.1.2 Results of Recriticality Analysis........................6-6 
TABLE OF CONTENTS (continued)

6.1.2.1 Potential for Recriticality in the BEF.

PAGE

6.1.2.2 Potential for Recriticality in Other

Configurations

6.1.2.3 Fuel Debris Entrainment into the Moderator

6.2 Molten Fuel-Coolant Interaction (Steam Explosion) Analysis

6.2.1 Modeling Techniques....................................6-12

6.2.1.1 Ideal Thermodynamic Steam Explosion Model

6.2.1.2 Best-Estimate Steam Explosion Model 6-15

6.2.2 Steam Explosion Scenarios...........................6-15

6.2.2.1 In-Vessel Scenarios......................6-16

6.2.2.2 Ex-Vessel Scenarios........................6-17

6.3 Hydrogen Combustion Analysis ...............................6-22

6.3.1 Hydrogen Generation ................................6-22

6.3.2 Hydrogen Combustion ...............................6-24

6.3.2.1 Deflagrations ..............................6-25

6.3.2.2 Detonations....................................6-25

6.3.3 Summary of Hydrogen Combustion Analysis ....... 6-26

6.4 Structural Response Analysis................................ 6-27

6.4.1 Structural Analysis of the Primary System

Boundary

6.4.2 Structural Analysis of the Confinement..............6-31

6.4.3 Summary of Structural Response Analysis .......... 6-34

$6.5 \quad$ References...................................................... 6-35 


\section{TABLE OF CONTENTS (contimued)}

7.0 SOURCE TERM QUANTIFICATION .............................. PAGE

7.1 Source Term Bins............................................. $7-1$

7.2 Source Term Algorithm Development............................7-7

7.2.1 Fission Product Groups ..................................7-8

7.2.2 Fission Product Reservoirs............................. 7-10

7.2.3 PRAST Time Periods ................................... 7-10

7.2.4 Fission Product Transport..................................7-13

7.2.5 Input Parameters ..................................... 7-14

7.2.6 Pararneter Interdependence........................... 7-14

7.2.7 Calculation of Source Terms................................ 7-21

7.3 Grouping of Source Terms........................................ 7-22

7.4 References...................................................... 7-22

8.0 CONSEQUENCE ANALYSIS.............................................

8.1 MACCS Code Description ...........................................8-1

8.2 Application to the SRS K-Reactor PSA ............................8-8

8.2.1 Offsite - The General Public............................... 8-21

8.2.2 Onsite - DOE and DOE Contractor Personnel ............ 8-22

8.3 References ......................................................... 8-26

9.0 UNCERTAINTY ANALYSIS ........................................

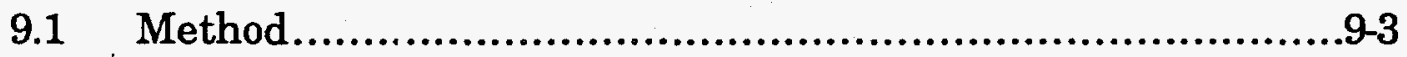

$9.2 \quad$ Sources of Uncertainty ........................................5

9.2.1 Plant, Damage State Frequency Variable Selection................................................... .9-7

9.2.1.1 Internal Events PDS Input Parameter Selection.......................... 8

9.2.1.2 Seismic Events PDS Uncertainty ............ -3

9.2.2 APET Uncertainties .................................... 9-11 
TABLE OF CONTENTS (continued)

9.2.3 Source Term Calculation Uncertainties................9-15

9.2.4 Consequence Calculation Uncertainties................9-16

9.3 Interpretation of Results ....................................9-16

9.3.1 LHS Sample Generation.................................. 9-17

9.3.2 Propagation of the LHS Sample Through the PSA models .................................................. 9-17

9.3.3 Risk Assembly ........................................ 9-19

9.4 Individual Parameter Importance to Uncertainty ............9-19

9.5 References.................................................... 9-21

10.0 SRS K-REACTOR RISK RESULTS................................ 10-1

10.1. Formats for Presentation of Risk Results..........................10-1

10.1.1. Complementary Cumulative Distribution Functions................................................ 10-2

10.1.2. Annual Risk.......................................... 10-3

10.1.3. Individual and Societal Risk........................... 10-3

10.1.4. Fractional Contributions to Risk ...................... 10-3

10.1.5. Statistical Analyses ..................................... 10-5

10.2. Results for Internal Initiators.................................. 10-5

10.2.1. Risk Results .......................................... 10-6

10.2.2. Contributors to Risk......................................10-15

10.2.3. Contributors to Uncertainty..........................10-20

10.3. Results for Seismic Initiators...................................10-21

10.3.1. Risk Results ..........................................10-21

10.3.2. Contributors to Risk......................................10-25

10.3.3. Contributors to Uncertainty............................10-34

10.4. Combined Results for All Initiators ............................10-35

10.4.1. Background on Safety Guidelines......................10-35 
10.4.2. DOE NuGE

10.4.2. DOE Nuclear Safety Goals .............................10-36

10.4.3. Comparison to Safety Goals ............................10-39

10.5. Comparison of PSA Results to Previous Risk

Estimates for K Reactor...........................................10-41

10.6 Supplementary Studies ......................................10-49

10.6.1 Economic Impacts And Land Contamination........10-49

10.6.2 Alternative Latent Health Effect Models...............10-51

10.6.3 Sensitivity To Parameter Values .......................10-54

10.6.4 Impact of Tritium In The Source Term.................10-56

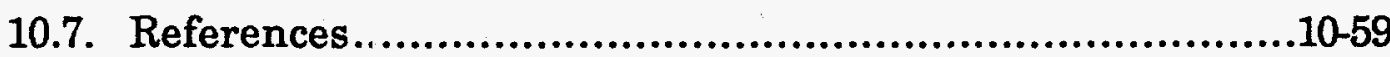

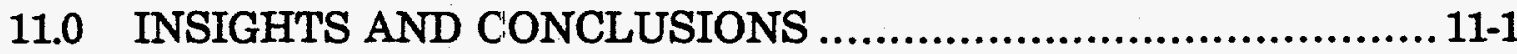

11.1 Confinement Performance .....................................11-1

11.1.1 Confinement Performance Matrix .....................11-2

11.1.2 Confinement System Effectiveness ................... 11-5

11.1.3 Early Confinement Failure Mechanisms .............11-6

11.1.4 Late Confinement Failure Mechanisms................ 11-7

11.2 Importance of System Failure Modes........................... 11-8

11.2.1 Primary System Integrity.................................11-9

11.2.2 Primary Coolant Pumps ................................11-9

11.2.3 Reactor Shutdown....................................... 11-9

11.2.4 Cooling Water Supply .................................11-10

11.2.5 Seismic Events........................................11-10

11.3 Importance of Accident Phenomenology ......................11-10

11.3.1 Steam Explosions ......................................11-13

11.3.2 Recriticality...........................................11-14

11.3.3 Pheromenological Uncertainties ......................11-14 


\section{TABLE OF CONTENTS (continued)}

114 Source Term Analysis

11.5 Conclusions........................................................11

11.6 References...................................................11-18

APPENDIX A EXTENDED DISCUSSION OF RESULTS ..................A-1

A.1. APET Questions .................................................

A.2. Internal Events ..............................................A-16

A.2.1. Summary Event Trees ..................................A-16

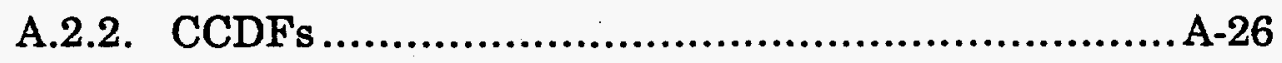

A.3. Seismic Events ............................................... A-31

A.3.1. Seismic Summary Event Trees ........................A-31

A.3.2. CCDFs ................................................ 


\section{LST OF FIGURES}

PAGE

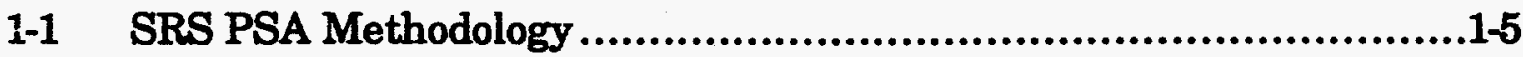

1-2 Representation of the Modular PSA Process .............................1-8

1-3 SRS Primary Cooling System ......................................1-10

14 Cross Section Of A Mark 22 Assembly.................................. 1-12

1-5 SRS Reactor Confinement Building ................................... 1-14

16 SRS Reactor Ventilation System ..................................... 1-16

3-1 Schematic Diagram of Core Melt Progression for

Representative Accident Classes .............................................3-3

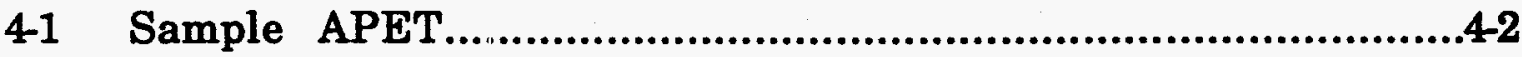

4-2 Overview of the APET Structure ......................................6

5-1 Schematic of the SRS MELCOR Model.....................................5-41

6-1 MCNP Supercell Model .................................................6-4

6-2 MCNP One-Sixth Sector Finite Model.........................................6-5

6-3 Phases of a Steam Explosion ......................................6-14

6-4 Roll Anchor ...........................................................6-29

7-1 PRAST Fission Product Reservoirs..................................... 7-11

7-2 Fission Product Transfers During Core Meltdown

(Period 1) .................................................................. 7-15

7-3 Fission Product Transfers During Debris Heat Up (Period 2)

7-4 Fission Product Transfers During Vessel Failure (Period 3)

7-5 Fission Product Transfers During MCCI (Period 4)................ $7: 8$

7-6 Fission Product Transfers During Delayed Releases

(Period 5) 7-1

8-1 Offsite Consequence Analysis - 1000 Mile Grid

8-2 Offsite Consequence Analysis - 0-100 Mile Grid ....................... \&-13

8-3 Offsite Consequence Analysis - Near Field Grid.......................8-14 


\section{LIST OF FIGURES (continued)}

84 DOE Safety Measure - 1 Mile Offsite Grid RAGE

8-5 Onsite Consequence Analysis - 20 Mile Radius............................ 8-16

86 Onsite Consequence Analysis - K Area 1 Mile Radius ................ \&-17

9-1 Data File Flow Between Computer Code Packages for the Integrated Uncertainty Risk Calculations (Internal Events Displayed)

9-2 Representation of the Seismic PDS/LHS/Hazard Curve Data Matrix.

9-3 Example Maximum Entropy Distribution With Only Quantile Constraints Imposed

10-1 Exceedance Frequencies for Risk for K Reactor - All Internal Initiators - Offsite $10-8$

10-2 Exceedance Frequencies for Risk for K Reactor - All Internal Initiators - Onsite

10-3 Mean Fractional Contributions from Internal Events Plant

Damage States to Selected Consequences.

10-4 Distributions of Fractional Plant Damage State Contributions to Annual Risk

10-5 Exceedance Frequencies for Risk for K Reactor - Seismic

Initiators - Offsite

10-6 Exceedance Frequencies for Risk for $\mathrm{K}$ Reactor - Seismic

Initiators - Onsite

10-7 Mean Fractional Contribution of Seismic Plant Damage

States to Selected Consequences. $10-31$

10-8 Distributions for Fractional Plant Damage State Contributions to Annual Risk $10-32$

10-9 Frequency of Exceedance of Risk for DOE Safety Guidelines........10-42

10-10 Fractional Contributions from Internal SID Plant Damage States to Selected Consequences. $10-47$

10-11 Fractional Contributions from Seismic SID Plant Damage States to Selected Consequences.

10-12 Onsite Individual Risk as a Function of Exit........................10-57

10-13 Collective Whole-Body Dose, (person-Sv) .............................10-58 


\section{IIST OF FIGURES (continued)}

11-1 Mean PDS Source Term Parameter Relationships to

Consequence Measures

A-1 Summary Tree for PDS-I1

A-2 Summary Tree for PDS-I2

A-3 Summary Tree for PDS-I3

A-4 Summary Tree for PDS-I4

A-5 Summary Tree for PDS-I5

A-6 Summary Tree for PDS-16

A-7 Summary Tree for PDS-I7

A-8 Summary Tree for PDS-I8

A-9 Summary Tree for PDS-I9

A-10 Exceedance Frequencies for Risk for K Reactor - All Internal Initiators - Offsite

A-11 Exceedance Frequencies for Risk for K Reactor - All Internal Initiators - Onsite

A-12 Summary Tree for PDS-S1 A-32

A-13 Summary Tree for PDS-S2 A-33

A-14 Summary Tree for PDS-S3 A-34

A-15 Summary Tree for PDS-S4 A-35

A-16 Summary Tree for PDS-S5 A-36

A-17 Summary Tree for PDS-S6 A-37

A-18 Summary Tree for PDS-S7 A-38

A-19 Exceedance Frequencies for Risk for SRS K Reactor Seismic Initiators - Offsite

A-20 Exceedance Frequencies for Risk for SRS K Reactor Seismic Initiators - Onsite 


\section{LIST OF TABLES}

PAGE

2-1 Categorization of External Events Considered..........................2-5

2-2 Severe Core Melt Frequency Contributions ............................ 2-10

2-3 Dominant Sequences From Internally Initiated Events.............. 2-12

2-4 System or Function Failures Contribution to Internal

Events Severe Core Melt Frequency............................................2-12

2-5 Mean Frequencies of Plant Damage States From Internal Initiators

2-6 Mean Frequencies of Plant Damage States From Seismic Initiators.

4-1 In-Plant Consequence Issues..........................................4-12

4-2 Summary Binner Dimensions And Attributes .......................4-21

5-1 Results of MELCOR/SR Calculations ................................5-13

5-2 Percentages of Gamma Energy Deposition as Calculated by MCNP for Various Accident Scenarios

5-3 Release Fractions During Fuel Melt .............................. 5-25

5-4 Release Fractions During Core Debris Heat Up..................... 5-26

5-5 Calculated Radionuclide Release During MCCI Based on the Results of the SRL-1 Experiment.

5-6 Comparison of the Below Grade Steam Pulse Results ............... 5-49

6-1 Estimated In-Vessel Steam Explosion Magnitudes................... 6-19

6-2 Estimated Ex-Vessel Steam Explosion Magnitudes..................... 6-20

6-3 Estimated Hydrogen Generation From In-Vessel Steam Explosions

6-4 Estimated Hydrogen Generation From Ex-Vessel Steam Explosions.

6-5 MELCOR Prediction of Confinement Responses Following Hydrogen Deflagration

6-6 The Ratio of Final to Initial Pressure for Detonation and Isochoric Combustion $6-26$

7-1 Source Term Bin Dimension and Attribute Definitions .74 
7-2 PRAST Fission Product Groups PAGE

7-3 PRAST Time Period Definitions ...................................... 7-12

7-4 Source Term Parameter Definitions ................................... 7-20

8-1 MACCS Fission Product Groups ......................................8-9

8-2 SRS Reactor End-of-Cycle Inventory...................................... 8-10

8-3 Consequence Measures Computed For Each Grid ................... 8-18

8-4 Mixing Layer Height Data Used In The SRS Analyses .............. 8-20

8-5 Mitigative Actions Included In The SRS Analyses.................... 8-20

8-6 Evacuation and Sheltering Parameters................................ 8-25

10-1 Distributions of Offsite and Onsite Annual Risk Measures for

10-2 K-Reactor Mean Annual Offsite Consequences Compared to Mean Consequences Calculated for Several Reactors (Internal Events)

10-3 K-Reactor Mean Annual Onsite Consequences Compared to Mean Consequences Calculated For N Reactor (Internal Events)

10-4 Mean Fractional Contribution of Internal Events Plant Damage States to Annual Risk.

10-5 Summary Source T'erm Bin Mean Fractional Contributions to Selected Consequence Measures - Internal Initiators.

10-6 Distributions of Offsite and Onsite Annual Risk Measures for K Reactor from Seismic Scenarios (per Reactor Year) $.10-26$

10-7 K-Reactor Mean Annual Offsite Consequences Compared to Mean Consequences Calculated for Several Reactors (Seismic Events).

10-8 K-Reactor Mean Annual Onsite Consequences Compared to Mean Consequences Calculated For N Reactor (Seismic Events)

10-9 Mean Fractional Contribution of Seismic Events Plant Damage States to Annual Risk

10-10 Summary Source Term Bin Mean Fractional Contributions to Selected Consequence Measures - Seismic Initiators... $.10-33$ 


\section{LIST OF TABLES (continued)}

10-11 Draft DOE Safety Guidelines

10-12 DOE Safety Guidelines Versus SRS K-Reactor Annual

Risks.

10-13 DOE Supplementary Safety Guidelines Compared to K-Reactor Calculated Values $.10-44$

10-14 Comparison of DOE Safety Guidelines to Base-Case PSA, Updated PSA \& SID Values

10-15 Economic and Land Contamination Risks From Severe Accidents

10-16 Sensitivity of Societal and Individual Latent Risks To Health Effect Models - K Reactor Level 2/3 PSA Rev. 0 at 2500 MW

10-17 Sensitivity of Onsite Risks To Evacuation Timing K Reactor Level 2/3 PSA Rev. 0 at 2500 MW

11-1 Fractional Contributions to Confinement Failure Modes in the K-Reactor. Level 2 PSA

11-2 PARTITION Input Consequence Estimates for Unmitigated Release of Total Inventory of Selected Isotopes.......... 11-6

11-3 Fractional Contributions of Source Term Attributes to Risk (Internal Events)

11-4 Sensitivity Case PARTITION-Generated Consequence Measures

11-5 Characteristics and Effects of Mean Internal Event Plant Damage State Source Terms

A-1 Event Descriptions For Savannah River Reactor Accident Progression Event Tree 


\section{LIST OF ACRONYMS}

\begin{tabular}{ll} 
AACS & Airborne Activity Confinement System \\
AICC & Adiabatic Isochoric Complete Combustion \\
APET & Actident Progression Event Tree \\
ATWS & Anticipated Transient Without Scram \\
BEF & Bottom End Fitting \\
BWR & Boiling Water Reactor \\
CCDF & Complementary Cumulative Distribution \\
& Function \\
CFM & Cubic Feet per Minute \\
CHF & Critical Heat Flux \\
CHRS & Confinement Heat Removal System \\
CWSS & Contaminated Water Storage System \\
CWST & Contaminated Water Storage Tank \\
DCF & Doise Conversion Factor \\
DF & Decontamination Factor \\
DOE & U. S. Department of Energy \\
ECCS & Ernergency Core Cooling System \\
EDE & Effective Dose Equivalent \\
EIS & Ervironmental Impact Statement \\
EPA & Environmental Protection Agency \\
EPRI & Electric Power Research Institute \\
EPZ & Ernergency Planning Zone \\
FCMR & Fractional Contribution to Mean Risk \\
HEPA & High Efficiency Particulate Aerosol \\
HWR-NPR & Heavy Water Reactor-New Production Reactor \\
LANL & Los Alamos National Laboratory \\
LHS & Latin Hypercube Sampling \\
LLNL & Lawrence Livermore National Laboratory \\
LOCA & Loss-of-Coolant Accident \\
LOHS & Loss-of-Heat Sink \\
LOPA & Loss-of-Pumping Accident \\
LOPC & Loss-of-Primary Circulation \\
LORW & Loss-of-River Water \\
LW & Light Water Reactor \\
MCCI & Molten Core-Concrete Interaction \\
MFCI & Molten Fuel-Coolant Interaction \\
MFCR & Mean Fractional Contribution to Risk \\
MIA & Manual Incident Action \\
MRS & Moderator Recovery System \\
MSL & Mean Sea Level \\
NRC & U. S. Nuclear Regulatory Commission \\
PAG & Protective Action Guide \\
PCS & Primary Coolant System \\
PDF & Pirobability Distribution Function \\
& Plant Damage State \\
\hline
\end{tabular}

AACS

ATWS

BEF

BWR

CFM

CHF

CHRS

CWSS

CWST

DCF

DOE

ECCS

EDE

EPRI

HEPA

HWR-NPR

LANL

LHS

LLNL

LOCA

LOPC

LORW

LWR

MCCI

MFCI

MFCR

MIA

MRS

PAG

PDF

PDS
Air:borne Activity Confinement System

Accident Progression Event Tree

Bottom End Fitting

Function

Critical Heat Flux

Confinement Heat Removal System

Contaminated Water Storage System

Decontamination Factor

Effective Dose Equivalent

Electric Power Research Institute

Emergency Planning Zone

Fractional Contribution to Mean Risk

High Efficiency Particulate Aerosol

Los Alamos National Laboratory

Lawrence Livermore National Laboratory

uss-of-Coolant Accident

Loss-of-Primary Circulation

Loss-of-River Water

Molten Fuel-Coolant Interaction

Manual Incident Action

Moderator Recovery System

Protective Action Guide

Probability Distribution Function

Damage State 


\section{LIST OF ACRONYMS (continued)}

$\begin{array}{ll}\text { PMF } & \text { Probable-Maximum Flood } \\ \text { PRA } & \text { Probabilistic Risk Assessment } \\ \text { PSA } & \text { Probabilistic Safety Assessment } \\ \text { PWR } & \text { Pressurized Water Reactor } \\ \text { REDAC } & \text { Remote Detection and Control } \\ \text { RF } & \text { Release Fraction } \\ \text { RRSS } & \text { Reactor Room Spray System } \\ \text { SAAP } & \text { Severe Accident Assessment Program } \\ \text { SAR } & \text { Safety Analysis Report } \\ \text { SCMF } & \text { Severe Core Melt Frequency } \\ \text { SG } & \text { Safety Guideline } \\ \text { SID } & \text { Safety Information Document } \\ \text { SNL } & \text { Sandia National Laboratories } \\ \text { SOG } & \text { Seismic Owners Group } \\ \text { SRL } & \text { Savannah River Laboratory } \\ \text { SRS } & \text { Savannah River Site } \\ \text { SRSOF } & \text { Savannah River Site Operations Facility } \\ \text { SRTC } & \text { Savannah River Technology Center } \\ \text { SRWA } & \text { Single Rod Withdrawal Accident } \\ \text { SSG } & \text { Supplementary Safety Guideline } \\ \text { SSS } & \text { Supplementary Safety System } \\ \text { TMI } & \text { Three Mile Island } \\ \text { TSC } & \text { Technical Support Center } \\ \text { USH } & \text { Universal Sleeve Housing } \\ \text { WDS } & \text { Water Disposal System } \\ & \end{array}$




\section{EXECUTTVE SUMTMARY}

\section{INTRODUCTION}

A probabilistic study of the overall safety of the special materials production reactors located at the U.S. Department of Energy's Savannah River Site (SRS) has been performed. Assessments of the risk posed to the work force at SRS and to the surrounding population due to reactor operation are among the results obtained. Safety assessment methodologies that have evolved from applications in the commercial nuclear power industry over the past twenty years were employed. The results of the study indicate that risks to individuals in the neighboring populace from severe reactor accidents are within levels that have been found to be acceptable for commercial nuclear power plants. Specifically, for individuals that live near the site boundary, direct fatality individual risk from a reactor accident has been determined to be negligible (evaluated at $5.3 \times 10^{-10} \mathrm{per}$ year). The mean individual latent cancer risk for individuals within ten miles of the site boundary has been estimated at $7.1 \times 10^{-8}$ per year. Latent cancer risk to the general population due to a reactor accident at SRS is again negligible (evaluated at $4.5 \times 10^{-8}$ per year-based on a population at risk of 610 thousand within 50 miles of the site). It should be noted that these risks are generally comparable to those assessed for commercial nuclear power reactors. For comparison, the population-average death rate from cancer in the U.S. is $2.0 \times 10^{-3}$ per year (i.e., the average person has 2 chances in a thousand of dying from cancer in any given year). The risk of individual worker prompt fatalities near the reactor has been found to be $1.9 \times 10^{-7}$ per year. This risk is negligible when compared to risks arising from normal occupational and transportation hazards in the U.S. The normal occupational risk of fatality due to on-the-job accidents in the United States is currently $1 \times 10^{-4}$ per year. The risk to an individual working on the SRS of contracting fatal cancer due to a reactor accident has been estimated to be $1.1 \times 10^{-7}$ per year.

\section{SCOPE OF THE STUDY}

The objectives of this Probabilistic Safety Assessment (PSA) were threefold. First, the assessment provides confirmation that the reactor system design provides an adequate margin of safety. Accidents analyzed in the Safety Analysis Report (SAR) are those that produce the greatest challenge to the safety systems when only one equipment failure is considered. These are not necessarily the most severe accidents. The possibility exists that multiple failures could occur, resulting in a more serious impact on the ability of the safety systems to provide core cooling. PSA provides a systematic method of examining the entire range of initiating events and possible system failures. Assessment of the frequency and consequences of these events provides a measure of the overall level of safety achieved by the design. Second, the risk measures obtained by the PSA provide a means to assess safety in terms of levels of risk that society has found to be acceptable. Third, and perhaps most importantly, the analytical models 
that constitute the PSA can be exercised to determine the equipment, human actions, and plant design features that contribute in greatest measure to the assurance of overall safety. This information can be used as a basis for improving certain aspects of the design or operating practices to achieve an even greater level of safety.

The study summarized in this document represents several years of effort directed toward performing a probabilistic assessment of safety for the SRS reactors. Initial results were obtained and published in 1987. Subsequent results were obtained using methods that are best characterized as representing the current state of the art in probabilistic safety assessment. The analysis performed consisted of three distinct phases. (Historically, these phases have been referred to as "Levels.") The Level 1 analysis is an assessment of the frequency of accidents that lead to damage of the nuclear fuel assemblies in the reactor core. Accidents initiated by both internal causes (e.g., random equipment failure, human error, etc.) and external causes (e.g., earthquake, fire, etc.) have been included. In the current assessment it has been conservatively assumed that damage from these initiators always leads to complete melting of the core. The Level 2 analysis consists of an evaluation of the amount of radioactive fission products that would escape the confinement system into the environment. The Level 3 analysis is an evaluation of the consequences of the predicted release. The results of these three evaluations are combined to produce the risk assessment. Risk is calculated as the product of the frequency of an accident and its consequences. Uncertainty in the results has been evaluated to the extent possible with currently available methods. The uncertainty analysis covers both the Level 1 and Level 2 analyses, and includes uncertainties arising from both data and modeling. In the Level 3, the uncertainty treatment is limited to meteorological conditions at the time of the accident. Methods for incorporating uncertainty due to consequence modeling in an integrated fashion have not yet been developed.

$\mathrm{K}$ Reactor as it was configured in June of 1987 is the basis for the Level 1 assessment. However, specific modifications that were committed to before the completion of the modeling effort were included. Thus the Level 1 results include consideration of four injection pathways in the Emergency Core Cooling System (ECCS). More recent improvements, such as the Moderator Recovery System (MRS), are not considered in the $r$ sent results but are being incorporated in an ongoing revision. Seismic lits for severe core melt frequency were obtained considering the $\mathrm{P}$ tor design combined with a soil analysis obtained from $L$ Area. The de the $\mathrm{P}$ and $\mathrm{K}$ Reactors are sufficiently similar that the results are consi i $\mathrm{d}$ applicable. The recently completed analysis of the K Area soils indic: ; that a lower core melt frequency would have been calculated had these 1 results been used. The Level 1 assessments have been published previou. [S-1, S-2] and are only briefly summarized herein. The primary focus of th : report is the work performed in the assessment of accident consequence This work, consisting principally of the Level 2 analysis, assumes $a$ confinement configuration that closely corresponds to that currently 
existing at $\mathrm{K}$ Reactor. Key upgrades, such as the chocks on the filter compartments and improvements to the exhaust fans have been included.

\section{SEVERE CORE MELT FREQUENCY ANALYSIS}

The Level 1 PSA began with an identification of events that could initiate an accident at the SRS reactors. These included events inside the plant, such as pipe breaks, pump failures, control circuit failures, and the loss of electrical power. The list of potential initiators was extended to include initiating events stemming from external sources such as earthquake, fire, high winds, and traffic accidents resulting in toxic spills. For those initiators that had frequencies of occurrence sufficient to merit further consideration, the reactor system design and operating procedures were studied to determine the sequences of actions that would be necessary (following the initiating event) to bring the reactor to a safe, stable, condition. Event tree models were formulated to indicate the logical progression and interaction of these actions. Fault tree models were then developed to evaluate the probability that the necessary actions would fail to occur when called upon in the required sequence. These fault trees include consideration of required equipment, human reliability, and the status of the plant as a consequence of the initiator. The fault trees were then solved in conjunction with the event trees to determine the probability that the sequence of necessary mitigative actions would not be successfully completed. A frequency of occurrence was thus calculated for all the sequences leading to failure (defined to be severe core melt). The total frequency of these sequences was determined to be $3.1 \times 10^{-4}$ events per year of reactor operation for accidents occurring at power.

To interface the Level 1 and the Level 2 analyses, the minimum combinations of hardware and human failures that result in severe core melt (called cut sets) were grouped into Plant Damage States (PDSs). Cut sets assigned to the same plant damage state include failures that result in the plant being in a similar condition when core melt begins. Sixteen plant damage states were analyzed. The results can be summarized as follows: Accidents initiated by primary system pipe breaks constitute $43 \%$ of the total severe core melt frequency; of this total about $8 \%$ was due to seismic events. The second largest contribution was from accidents involving loss of primary circulation due either to primary pump motor flooding or to relay chatter causing closure of valves in the primary coolant loop. These constitute $36 \%$ of the frequency; half of this as a result of seismic activity. Accidents involving loss of the ultimate heat sink (i.e., failure of the secondary cooling water) contributed $16 \%$ of the total frequency. More than $80 \%$ of this was attributable to seismically-induced damage. Finally, reactor transients that are not terminated by successful operation of the shutdown systems constituted $5 \%$ of the frequency. There was negligible seismic contribution to this type of accident. 


\section{SEVERE ACCIDENT PROGRESSION ANALYSIS}

The Level 2 analysis extends the PSA process past the determination of the severe core melt frequency. The goal of the Level 2 analysis is estimating the frequency of potential responses of the confinement system to the accidents identified. The Level 2 also includes an estimation of the fissior: product source term to the environment for each possible confinement response. Methodology used for the Level 2 and Level 3 portions of the analysis was developed by Sandia National Laboratories (SNL) as part of the U. S. Nuclear Regulatory Commission's (NRC) recently completed study of severe accident risks from five commercial reactors [S-3]. An Accident Progression Event Tree (APET) was constructed to represent the progression of a severe core melt accident from the incipience of core melt to the final long-term (i.e., 30 days) condition of the confinement system. The APET considers accident progression as a series of events that arise from physical phenomena, hardware failures, and human actions. The interaction of these events was represented in the logic-model structure of the APET. Extensive engineering analysis of core melt phenomena was undertaken as part of the PSA program. The results of this analysis and a limited amount of experimental data developed by other programs were used as the basis for assessing the probabilities associated with events included in the APET. The APET was then evaluated for each of the plant damage states to assess the frequency of all accident progression sequences. Sequences were then grouped on the basis of events that occurred, such that the source term would be similar for each sequence in a group. The source term for each group was then evaluated using a parametric model developed from the analyses.

\section{CONSEQUENCE ANALYSIS}

Population dose and related health effects due to each radiological source term were evaluated using accepted consequence analysis methodology. Models for the effects of tritium release have been included. Source terms resulting from the various accident progressions that were found to have significant frequencies were grouped together based on anticipated similarities in their consequences. Consequences were calculated for each of the sixty-three groups found to be necessary to adequately represent the range of source terms. Internal events and seismic events were treated separately. Onsite consequences (i.e., consequences to the SRS rork force) were calculated independently from the offsite consequ ses (i.e., consequences to the general population). A total of twenty-nine 1 asures of accident consequences were developed. Throughout this report, $a_{i}$ ntion is focused on a few of these measures that have historically beer sed as indicators of risk from reactor operation. Specifically, early fataliti latent cancers, and total dose received are reported in detail.

\section{INSIGHTS INTO SEVEIRE ACCIDENT BEHAVIOR}

The program that has produced this work included a significant effort directed toward understanding the progression of a severe core melt 
accident in an SRS reactor. This effort was in the form of engineering analysis of the phenomena that accompany a severe accident. Areas in which analysis was conducted include: two-phase primary system thermal-hydraulics, core melt behavior, recriticality, core debris interaction with primary system structures, fuel-coolant interaction, fission product transport, molten core-concrete interaction, hydrogen generation and combustion, structural response to loads, and filter behavior.

Initial work was directed at developing an understanding of how a core melt accident progressed. Core melting is preceded by fuel assembly dryout. It was found that if primary coolant circulation was stopped or a localized flow reduction or power increase occurred, fuel assembly dry-out and melting could occur with water in the reactor vessel. A model was developed to predict fuel melt behavior in an assembly. This model predicts the rate of debris relocation, the debris composition, the fission product release and the hydrogen generation rates from the melting fuel.

Debris composition affects the potential for recriticality. It was found that recriticality can occur if water is present in the reactor vessel and if the fuel debris is cooled and accumulates to a sufficient height in the bottom of the fuel assemblies. The potential energy release from recriticality events has been estimated under different debris composition conditions.

Analysis of debris behavior during melt indicated that the debris is unlikely to quench after melt and relocation out of the fuel assemblies, even if there is water in the vessel. Rather, the debris would flow from the reactor vessel into the effluent piping of the primary cooling system. If there is sufficient water in the pump room, the debris may be cooled in the piping. Otherwise, it will melt through and be deposited on the pump room floor. Hot debris that flows onto the floor of the confinement may collect in sumps and interact with the concrete. The result would be the generation of large quantities of hydrogen and aerosols. Also, when the primary system is penetrated by hot debris, the potential exists for molten debris to come into contact with water. Molten-fuel-coolant interactions (MFCIs) can lead to a steam explosion that can damage the filter system or cause a bypass of the confinement.

Airflow through the confinement system transports released fission products and aerosols to the filters where the majority are retained if the filters are available. It also serves to mitigate the accumulation of hydrogen to combustible levels. However, aerosol deposition on the filters leads to partial blockage and a subsequent reduction in airflow. The potential for hydrogen combustion and filter bypass then increases.

Consequence results generated from the various source terms were combined with the accident frequencies to produce risk results for each plant damage state. Depending on the risk measure considered, accidents involving loss of primary circulation, either as the result of flooding of the primary coolant pump motors or of closure of valves, are responsible for 
between 21 and 44 percent of the risk. Risk from accidents initiated by primary system pipe breaks constitutes between 37 and 73 percent of the total. Accidents involving loss of the ultimate heat sink contribute between zero and 17 percent. Onsite prompt consequences generate the zero contributions to the ultimate heat sink accidents. These consequences are negligible due to the effectiveness of the evacuation strategy for these slowto-develop accidents. Finally, transients represent 3 to 5 percent of the risk. These results lead to the conclusion that accidents involving primary system pipe breaks generate more severe consequences than the other types of accidents. This is a direct result of the phenomenology involved.

A key insight from the analysis is that the confinement system fails to perform as intended for more than $84 \%$ of the core melt accidents considered. This result is somewhat biased by the fact that seismic initiating events of magnitude sufficient to cause fuel damage will fail the confinement filters. Even so, approximately $66 \%$ of the internally initiated core melt accidents lead to some unfiltered releases. The principal cause of filter failure for internally initiated core melt accidents is fuel-coolant interaction leading to pressurization of the confinement building. A significant in-vessel molten-fuel-coolant interaction (MFCI) occurs in nearly $44 \%$ of core melt accidents. Those MFCI events cause primary system failure in $41 \%$ out of this $44 \%$. Considering both in-vessel and exvessel events, fuel-coolant interaction accompanies vessel failure in nearly $79 \%$ of core melt accidents. A large fraction of vessel failures induced by fuel-coolant interaction occur as a result of a recriticality event, which is present in approximately $63 \%$ of core melt accidents. Molten core-concrete interaction (MCCI) also contributes to filter failure. MCCI occurs in $58 \%$ of core melt accidents.

Analysis of the PSA results has lead to identification of the phenomena that contribute in greatest measure to the consequences of core melt accidents in SRS reactors. Risk reduction may be cost-effective under certain circumstances and can be achieved through an improved understanding of these phenomena and the selective implementation of measures designed to mitigate their effects. Improved understanding of these phenomena will certainly reduce uncertainty, perhaps eliminating the need for some risk reduction projects.

\section{INSIGHTS FROM CONISEQUENCE ASSESSMENT}

The primary findings from the consequence analysis portion of this PSA are (1) energetic event timing relative to the overall core melt progression and confinement response can lead to large radioactivity releases early after reactor severe accident initiation; (2) the general public bears minima: incremental risk from $\mathrm{K}$ Reactor operation; and (3) onsite risk to SRS workers within the first few miles of $\mathrm{K}$ Reactor is minimized with timely adherence to emergency preparedness plans. The source term partitions that dominate the consequence assessment are those predicted for early, large releases resulting from recriticality and/or steam explosions. The source term to the general public, given that a severe accident has 
occurred, tends to lead to larger population doses and, therefore, higher expected health effect risk than calculated for commercial reactors. However, lethal doses are not likely due to the distance factor afforded by the location of $\mathrm{K}$ Reactor and the SRS boundary. Onsite risk to SRS workers can be reduced by nearly an order of magnitude by implementation of current emergency planning in a timely manner.

\section{CURRENT APPLICATIONS}

The completed PSA for the SRS reactors is currently being applied to provide insights into the performance of SRS reactor systems. The Level 1 portion continues to be used as an integral part of risk based decisionmaking for reactor operation at the site. Engineering models of core melt progression and confinement response that were developed as a prerequisite to the Level 2 PSA have formed the principal analytical basis of a parallel severe accident assessment program (SAAP) at SRS. Experimental results from the SAAP have, in turn, provided valuable early insights into relevant phenomenology, in particular, fission product release, steam explosion likelihood, and filter performance- to the benefit of the PSA. Insights gained during the Level 2/3 PSA development were used as the foundation of an early estimate of site risk performed to support the Environmental Impact Statement (EIS) for continued reactor operation. These studies have also been used to assess current site emergency planning zone adequacy. Currently, insights from the PSA are being applied in evaluation of accident scenarios used in emergency response drills. Plans include extending the source term methodology used for the Level 2 program to improve technical bases for prediction of the timing and nature of radioactive releases assumed in such training exercises.

\section{FUTURE APPLICATIONS}

Beyond the results that have been obtained in terms of risk, system response and governing phenomena, the risk model that has been developed provides a valuable tool for use in future studies. The benefits of future research that would reduce phenomenological uncertainties can be assessed. Accident management strategies, currently under development in a parallel program, will be incorporated into the model and their effectiveness investigated. The model will be expressed in terms of its fundamental severe accident sequences to provide a training tool for educating plant personnel in severe accident behavior characteristic of site reactors.

Programs are currently underway to update the Level 1 PSA model for conformance to the restart reactor configuration. The Level 2/3 PSA will also be updated; both to match restart conditions and to take advantage of new methods of analysis and insights into severe accident phenomenology emerging from the PSA and Severe Accident research programs. 


\section{REFERENCES}

S-1. M. D. Brandyberry, et al., SRS PRA Of Reactor Operation - Level 1, Internal Events, WSRC-RP-89-570, Westinghouse Savannah River Company, Aiken, SC, June 1990.

S-2. M. D. Brandyberry and H. E. Wingo, SRS PRA Of Reactor Operation Level 1, External Events, WSRC-RP-89-733, Westinghouse Savannah River Company, Aiken, SC, June 1990.

S-3. U.S. Nuclear Regulatory Commission, Severe Accident Risks: An Assessment for Five U.S. Nuclear Power Plants, NUREG-1150, December 1990. 


\subsection{INTRODUCTION}

The highest priority of the Savannah River Site (SRS) is the safe operation of SRS reactor facilities and processes. To help ensure safe operation, SRS is continually expanding the technological understanding of the SRS reactors. One way that this is being accomplished is through a Probabilistic Safety Assessment (PSA). PSA is an analytical technique that is used to integrate diverse aspects of design and operation in order to assess the risk of operation and to develop an information base for analyzing plant-specific and generic issues with respect to operational safety. An assessment of the plant-specific risk provides both a measure of accident risk to the public and insights into the adequacy of plant design and operation. This assessment is achieved by (1) identifying those sequences of events that lead to the potential for release of radioactive material; (2) calculating their frequency; and (3) establishing which features of the plant contribute most to the frequency of such sequences. For those sequences that contribute significantly to the total frequency of radioactive release, the consequences (health effects) are evaluated. Risk for an individual accident sequence is defined to be the product of the sequence frequency and the sequence consequences. The total risk associated with a particular plant is the sum of the risk from all accident sequences.

The PSA is divided into three levels of analysis. Level 1 involves the identification of accident initiators and the succeeding sequences of events that may lead to core melt. Development of a component and human reliability data base to use in quantifying the sequence frequencies is also a part of the Level 1 analysis. The accident sequences (represented by event trees) reflect the response of the engineered safety features and plant operators to an initiating event. The sequence analysis identifies the combinations of system or operator failures that lead to melting of the core. Models for the reliability of each system (fault trees) are developed. The Level 1 is quantified according to the event tree model by combining the system reliability and human error analysis results to obtain the frequency of the combinations of failures leading to core melt. Detailed documentation of the methods employed, results obtained, and insights gained from the Level 1 PSA has been published previously [1-1, 1-2].

The Level 2 analysis identifies the various modes of radioactive release, evaluates their relative frequency (given a particular core damage sequence), and produces an estimate of the magnitude of the release (i.e., the source term). The principal results from the Level 2 analysis are

(1) an event tree (or trees) that characterize the possible progression of accidents beyond the point of core damage; and

source term estimates for all important accident progression sequences.

The Level 2 analysis is supported by mechanistic modeling of the progression of severe accidents. In many Level 2 PSAs like those performed for the U. S. Nuclear Regulatory Commission's (NRC) NUREG-1150 study 
[1-3], severe accident modeling was performed in advance of the PSA as part of a separate program. The SRS Level 2 PSA required a significant effort to model severe accident progression and the associated phenomena. In contrast to previous PSAs, this work was largely directed by the ongoing probabilistic modeling to focus resources on important phenomena. Sections 5 and 6 of this report summarize the severe accident modeling and analysis performed to support development of the Level 2 PSA.

The Level 3 analysis involves calculation of the consequences associated with the source terms resulting from the Level 2 analysis. These results are then combined with the Level 1 and Level 2 sequence frequency results to produce risk estimates.

The SRS PSA was conducted in order to analyze the response of SRS reactor facilities and system components to the entire range of potential accident initiators. A major objective was to identify areas where efforts can be focused on the most efficient and cost-effective ways to increase the reliability of reactor facilities and systems. Identification of approaches that can lead to the mitigation of the consequences of postulated accidents was also an objective. In addition, the PSA provides a measure of the risk of SRS reactor operation that can be assessed by the nuclear safety community and the U.S. Department of Energy (DOE).

Modeling the progression of possible accidents requires detailed knowledge of the plant systems, the neutronic and thermal-hydraulic conditions in the plant that would accompany each postulated core-melt sequence, the phenomenology associated with each sequence, and the timing of various events that constitute the accident progression. Thus, considerable effort has been devoted to the study of severe accidents and the accompanying phenomena as part of the PSA scope. Detailed models for many aspects of core-melt phenomena in uranium-aluminum alloy fueled reactors have been a result. These models can also be used to assess the safety significance of operational occurrences at the plant and can be used to provide a basis for evaluating alternative design changes to improve reactor safety.

This report summarizes the PSA that has been performed. The remainder of this introductory section presents a general discussion of the SRS PSA program and of the reactor facilities. The history of PSA at SRS is given in Section 1.1. The objectives and an overview of the PSA are presented in Sections 1.2 and 1.3 respectively. A brief description of the reactor facilities is given in Section 1.4, and the outline of this report is shown in Section 1.5.

\subsection{History of PSA at SRIS}

The first application of reliability techniques to nuclear power plants was the Reactor Safety Study, WASH-1400 [1-4]. The WASH-1400 study was sponsored by the NRC and provided the first in-depth assessment of the risks associated with the operation of light-water reactors (LWRs). Following the Three Mile Island (TMI) accident, the Kemeny [1-5] and Rogovin [1-6] reports recommended that in-depth studies on the probability 
and consequences of nuclear power plant accidents, including consequences of meltdown, should be continued. The NRC has recently issued a generic letter [1-7] requiring each licensee to examine its plant(s) for vulnerability to severe accidents. The examination will include identification of internal accident initiators (e.g., pipe breaks), estimation of core-melt frequency, and assessment of containment performance. The NRC is also requiring each licensee to consider external accident initiators (e.g., fire, earthquake), although not necessarily within the PSA context. Assessment of vulnerabilities and potential safety improvements, as well as the development of an accident management program are also required.

In 1985, SRS began a PSA of the SRS $K$ Reactor in order to assess the effectiveness of the reactor safety systems and to establish a technical basis for improving reactor safety. Performance of the PSA provided for the attainment of three principal goals: (1) to gain a strong understanding of reactor operating and safety systems; (2) to develop a consistent measure of the relative importance of credible reactor accidents; and (3) to develop a quantitative measure of the overall risk of reactor operation. A simplified Phase 1 analysis of plant system response to selected accidents was conducted to provide training of SRS personnel in PSA techniques and to gain early insights on reactor safety. The Phase 1 analyses were completed in 1987 [1-8]. These analyses led to the development of simple models of reactor and confinement system response. Recommendations for several plant upgrades to provide significantly increased reliability of system response to severe accidents [1-9 through 1-11] resulted.

The Phase 1 analyses were limited in scope. Specifically:

(1) The Level 2 analysis was developed considering only three accident initiators. Since there are more than three accident initiators, as well as a group of external (e.g., seismic) accident initiators, the Phase 1 analyses simply demonstrated the full PSA process.

(2) Recriticality and all thermo-chemical phenomena (e.g., hydrogen combustion and steam explosions) were ignored. These have the potential of being highly energetic events that could significantly alter accident progression.

(3) Engineering judgment, rather than mechanistic or deterministic analyses, was used to quantify early system thermal-hydraulic response, core-melt progression, fission product evolution and transport, and the performance of the Airborne Activity Confinement System (AACS).

(4) Engineering judgment was used to determine the radioactive release magnitudes.

Upon completion of the Phase 1 analysis, the Phase 2 analysis commenced. The Phase 2 analysis addresses a complete spectrum of accident initiators, as well as recriticality and important thermo-chemical phenomena. In 
addition, mechanistic and deterministic analyses were utilized to evaluate phenomena which can occur during all important periods of severe accident progression.

\subsection{Objectives of the SFA Level 2/3 PSA}

The specific objectives of the SRS PSA include:

(1) systematic definition of accident initiating events;

(2) development of accident sequence progression models which probabilistically evaluate accident progression from initiating event through radionuclide releases from the confinement;

(3) application of mechanistic and deterministic analyses to analyze plant and system response throughout the accident;

(4) development of a quantitative measure of the overall risk of reactor operation; and

(5) development of insights and recommendations for reducing the overall risk of reactor operation.

\subsection{Overview of the SRS PSA}

The approach taken to perform the SRS PSA makes use of the methods developed by the NRC during the NUREG-1150 program. A simplified overview of this methodology is shown in Figure 1-1. The figure shows all three levels of the PSA with emphasis placed on the Level 2 portion. The Level 1 analysis utilizes sequence event trees quantified with fault trees and plant system data to track system failures and identify core-melt sequences. The sequences which result from the Level 1 analysis are then grouped on the basis of similarities in the plant's condition. These groups are referred to as plant damage states (PDSs). The Level 2 analysis evaluates the progression of accidents resulting from the ensemble of plant damage states utilizing an Accident Progression Event Tree (APET) to probabilistically track accident sequence progression. Radiological source terms are then assigned to groups of accident progressions that have similar characteristics. Finally, the Level 3 analysis calculates consequences for each of the source terms defined by the Level 2 analysis. The discussion below describes the Level 2/3 methodology in more detail beginning with plant damage states and finishing with consequence analyses.

Plant damage states define system failures and plant conditions that provide the initial and boundary conditions for the APET. A PDS is defined by grouping cut sets (combinations of system failures defined by the Level 1 analysis) based upon a set of binning criteria. Binning criteria establish combinations of initiating events and subsequent system failures and plant conditions that would be expected to yield similar accident progressions. 


\section{○}

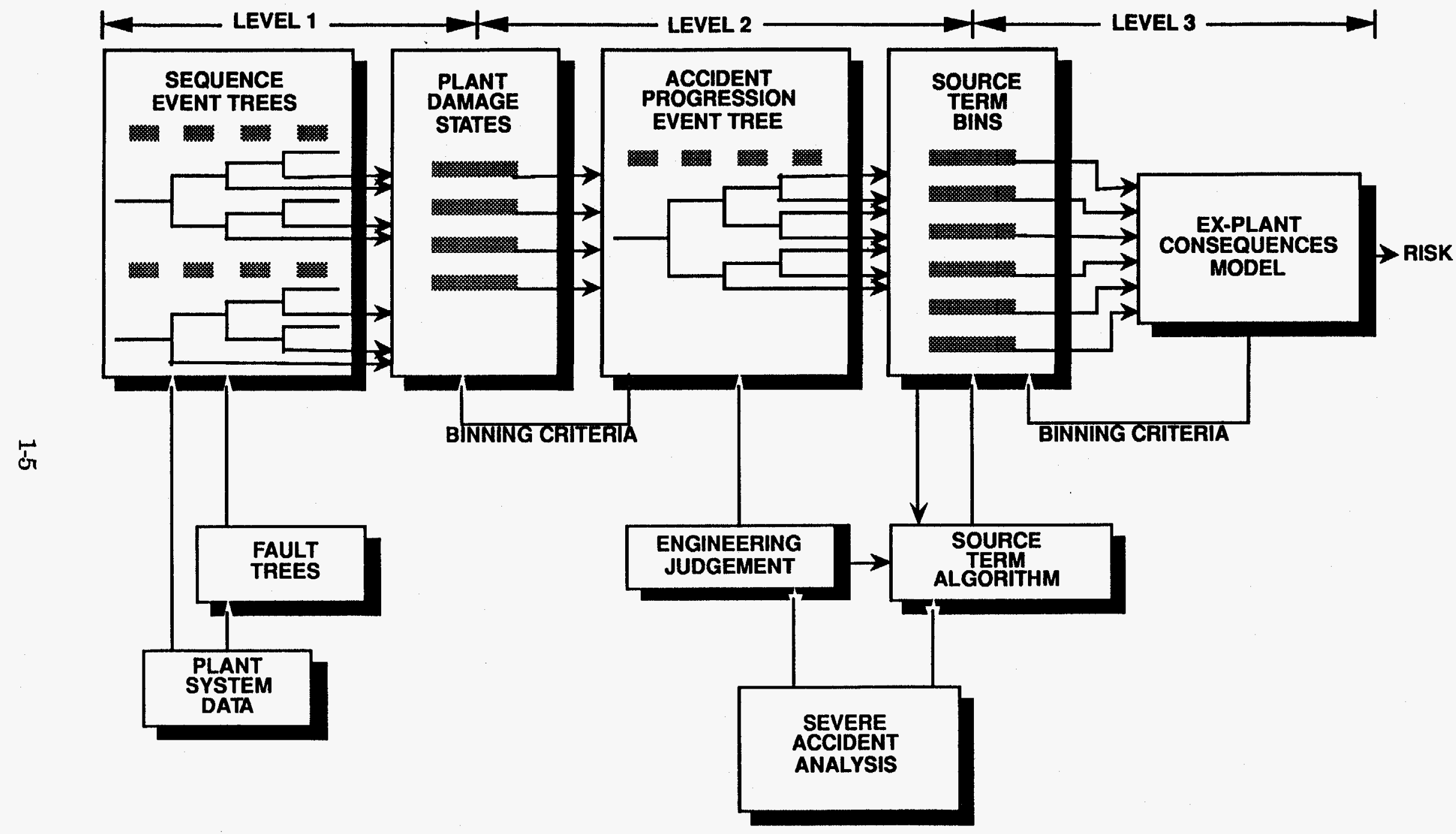

Figure 1-1. SRS PSA Methodology 
These criteria are defined in terms of fault tree base events and are applied to each Level 1 cut set. Thus, cut sets defined by the Level 1 sequence event trees that are binned into the same PDS would be expected to result in similar characteristic accident sequence progressions. The binning process greatly reduces the number of combinations of initial boundary conditions which must be evaluated by the APET (from many thousands to less than twenty).

The APET provides a probabilistic representation of potential sequences along which a severe reactor accident may progress. It is developed based on a systematic evaluation of the impact of core-melt phenomena on both releases of fission products from fuel and their retention by engineered safety features. The fundamental objective of the APET is to evaluate the success of the confinement system in mitigating releases. It consists of phenomenologically oriented questions that address important aspects of accident progression. The APET consists of a series of events (represented in the tree as questions) that could occur during progression of the accident. These events pertain to the state of the plant at the time core melt begins, the process of melting and relocation of the core and the phenomena that accompany this process, and the response of the confinement to the challenge posed by the core debris and/or radionuclides that exit the reactor vessel. A probability of occurrence (branch point probability) is associated with each outcome of each question in the APET. The probability that a particular branch is taken is evaluated based on the answers to previous questions (i.e., accident progression is sequence dependent). The sequence of outcomes then determines the course of the accident with an associated probability of occurrence and is referred to as an accident progression sequence.

To the extent possible, cletermination of the event outcomes, particularly phenomenological events, is based on mechanistic and deterministic analyses. In order to determine the outcome of complex phenomena, the APET is developed in such a way that information that defines the bounding conditions for these phenomena is included. For example, quantifying phenomena related to in-vessel recriticality requires prior knowledge of (1) fuel/target relocation rates; (2) the presence of water in the reactor moderator space; and (3) the debris coolability. The SRS APET defines outcomes of these supporting issues prior to quantifying the question of in-vessel recriticality. This approach helps to insure selfconsistency in the treatment of important phenomena and p ides a highly integrated model of accident progression.

Following development and quantification of the APET, binning teria were defined to group APET sequences into source term bins. T SRS APET includes 131 questions that can yield hundreds of thous. ; of potential accident sequences. Rather than defining source terms for ery possible sequence, sequences are binned (i.e., grouped) according to a . i of source term binning criteria. These binning criteria define ever . or combinations of events, that can have a significant impact 0 : the environmental source term. Thus, APET sequences binned into the same 
source term bin would be expected to yield similar source terms. This process is analogous to the binning of Level 1 cutsets into PDSs in that it reduces the number of APET sequences to a limited number of source term bins.

The definition of a source term bin includes the outcomes of events that directly affect the magnitude of the environmental release, but it does not quantify the release. The Production Reactor Algorithm for Source Terms (PRAST) was developed to quantify source terms. This algorithm, separate from the full phenomenological models for accident progression, was developed because of the large number of source term bins requiring quantification. Application of the full phenomenological models to quantify every source term would have been prohibitive. PRAST makes extensive use of the understanding of fission product evolution and transport developed during APET formulation to estimate the magnitude of environmental source terms. After PRAST calculates source terms for every source term bin, similar source terms are grouped (binned) together to reduce the number of consequence calculations that must be performed. Thus, the total number of source terms forwarded to the Level 3 consequence analysis is substantially reduced.

Throughout the PSA process of (1) developing Level 1 sequence event trees; (2) binning these sequences into PDSs; (3) developing an APET; (4) binning APET sequences into source term bins; (5) calculating source terms, and (6) binning similar source terms, the probabilities of all events are conserved. Thus, each source term forwarded to the Level 3 analysis has an associated probability so the consequences and the risk can be estimated.

The MELCOR Accident Consequence Code System (MACCS) [1-12] has been used to evaluate the consequences of a given source term. Input to MACCS includes the source term, site-specific meteorology, population demographics, evacuation timing and speed, and land usage. Health effects have been calculated for each binned set of source terms developed from the Level 2 analysis. Emergency response actions (evacuation and/or sheltering) have also been modeled in this analysis.

Figure 1-2 provides a more detailed representation of the PSA assembly process in terms of the computer codes and interfaces between the various levels described above. In this figure, the three PSA levels are further subdivided into modules in order to differentiate between the accident progression analysis and the source term analysis within the Level 2 portion of the PSA.

\subsection{Reactor Facility Description}

The Savannah River Site is located in South Carolina, approximately 25 miles southeast of Augusta, Georgia. The site, a controlled area which encompasses approximately 300 square miles, is owned by the U.S. Government and is responsible for the production of nuclear materials. Five nuclear production reactors are located at SRS. Two of the reactors (C and $R$ ) are non-operational. Of the remaining three (K, L, and $P$ ), only the 


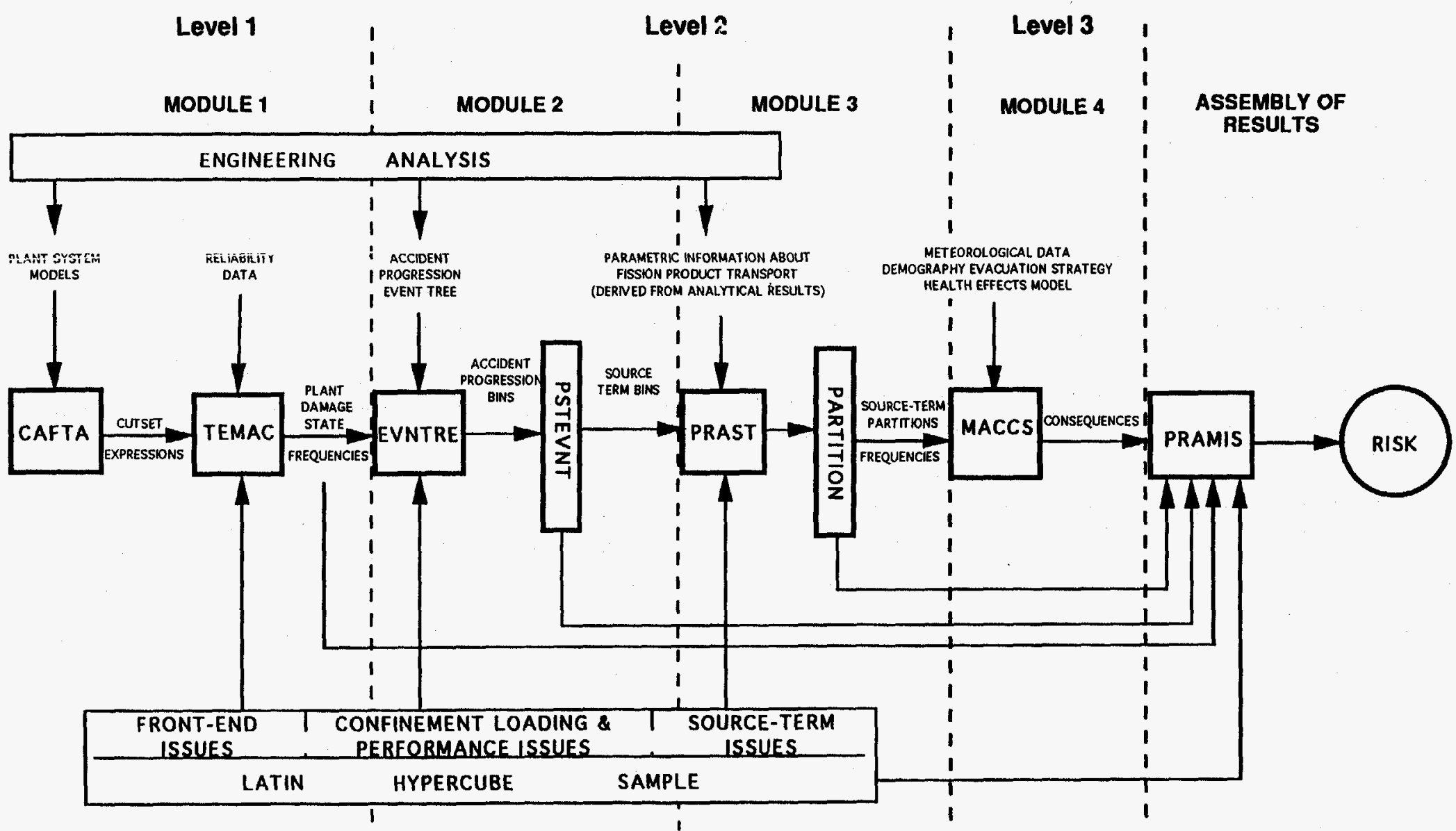

Figure 1-2. Representation Of the Modular PSA Process 
$\mathrm{K}$ Reactor is scheduled for future operation. The reactors are sited a minimum of 2.5 miles apart and a minimum of 4.5 miles from the site boundary. E.I. du Pont de Nemours and Company designed and built the SRS facilities and operated them under contract to DOE until 1989. Westinghouse Savannah River Company has operated the site under contract since April 1989. The site also has two separations facilities, a heavy water recovery plant, fuel fabrication and waste processing facilities, and the Savannah River Technology Center.

\subsubsection{Reactor Systems}

Several reactor systems, important from an operational standpoint and included in this study are:

(1) the primary cooling system;

(2) the secondary cooling system;

(3) the reactor core and fuel assemblies; and

(4) the reactivity control systems.

The following discussions provide brief introductions to each of these systems. These systems, as well as others important to reactor safety, are described in detail in Reference 1-1.

\subsubsection{Primary Coolant System}

The SRS reactors are heavy water $\left(\mathrm{D}_{2} \mathrm{O}\right)$ cooled and moderated and operate at low temperature and pressure. The primary coolant system consists of six symmetric coolant loops connected to inlet nozzles in the plenum at the top of the reactor vessel and to outlet nozzles at the bottom of the vessel. A schematic of one primary coolant loop is shown in Figure 1-3. Each coolant loop contains two, once-through, shell-and-tube heat exchangers and one Bingham pump capable of providing 25,000 gpm of coolant flow. AC motors provide normal power to the Bingham pumps. On-line DC motors operated in parallel with the $\mathrm{AC}$ motors provide backup power to the pumps in the event that $\mathrm{AC}$ power is lost. If power is lost to the $\mathrm{AC}$ motors, the reactors are immediately shut down. The Bingham pumps are capable of providing about $30 \%$ of normal coolant flow under DC power. Finally, 2.7 metric-ton flywheels located between the $\mathrm{AC}$ motors and the Bingham pumps store sufficient energy to continue to provide limited circulation for approximately four minutes following loss of all power to the pump motors.

The SRS reactor primary cooling system configuration is different from commercial reactor configurations in several important ways. first, pump suction is taken from the hot leg rather than the cold leg of the reactor. Second, the heat exchangers are located below the reactor inlet plenum rather than being elevated relative to the reactor core. Finally, coolant flow through the core is directed downward from the plenum located on top of the reactor vessel. In addition, the SRS reactors are not designed for electric power generation, so they operate at low pressures and temperatures. The coolant channel inlet pressure is approximately $80 \mathrm{psig}$, and the moderator 


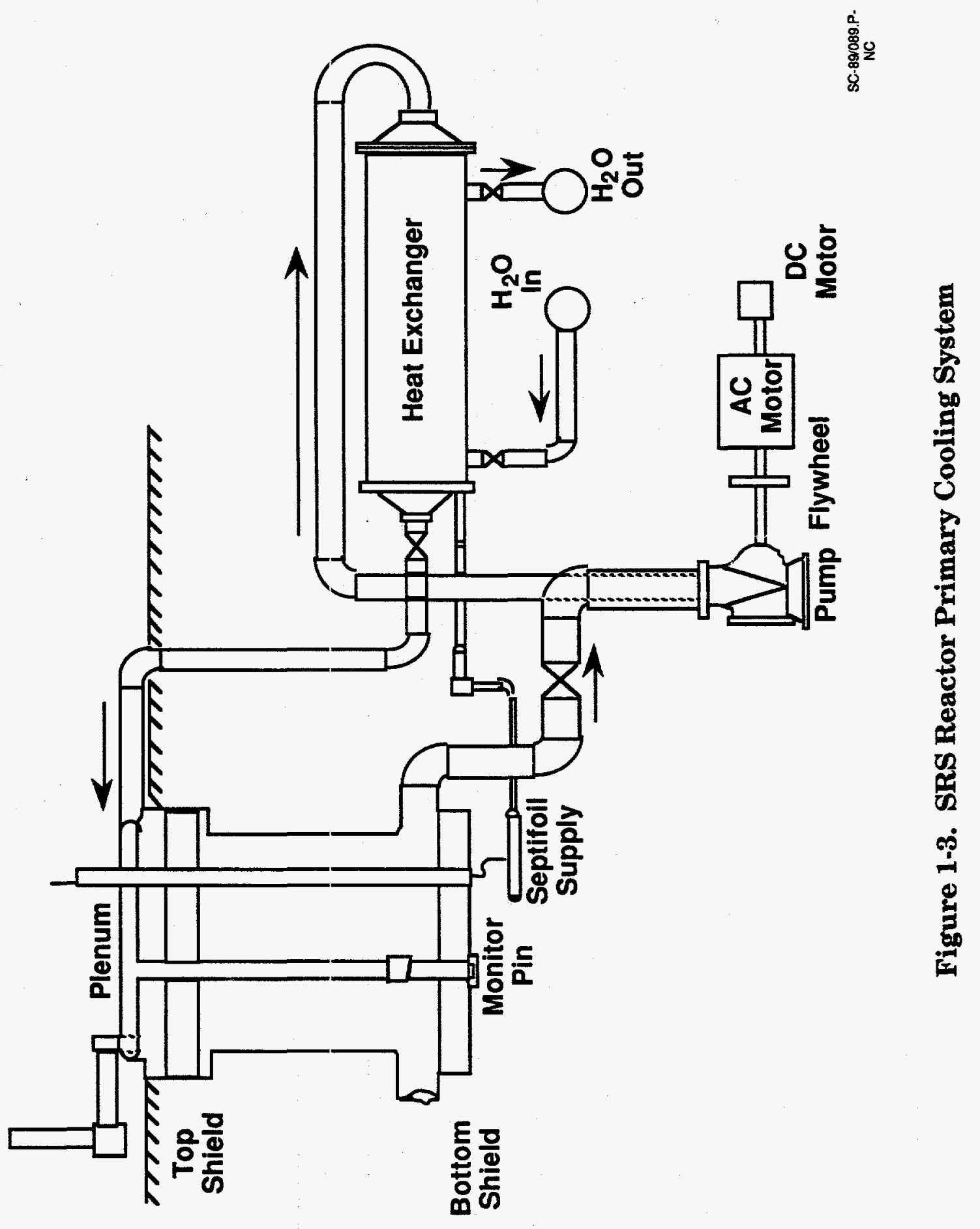


tank pressure is only 5 psig. The average assembly outlet temperature is approximately $105^{\circ} \mathrm{C}$. These features play important roles in the early thermal-hydraulic response of the reactor systems to the accident initiating events.

Emergency core cooling is required if the primary system develops a leak or if circulation in the primary system is lost. An emergency-core-cooling system (ECCS) is provided and is actuated if one of these conditions occurs. The primary source of water for the ECCS is the secondary cooling system.

\subsubsection{Secondary Cooling System}

Secondary cooling water is pumped from the Savannah River to a 25 million gallon storage basin in each of the reactor areas. The water is then pumped from the storage basin through the shell side of the heat exchangers and out to an effluent sump. Drainage from the effluent sump flows through a series of canals to the Savannah River. The cooling water to the heat exchangers is pumped at a rate of approximately $170,000 \mathrm{gpm}$ when the reactor is at full power. The basin is at a higher elevation than the effluent sump, so gravity driven flow will provide approximately 55,000 gpm to the heat exchangers if all cooling water pumps are lost. Gravity flow provides sufficient heat removal capability to cool the reactor under shutdown conditions.

Alternative means of providing secondary cooling water to the basin are available. Water from the effluent sump can be pumped back to the storage basin, or water can be drawn from the PAR Pond located on the site. These provide backup cooling water supply in case the pumping capabilities from the river are lost.

\subsubsection{Reactor Core and Fuel Assemblies}

The PSA was completed for reactor charges containing a uniform lattice of Mark 22 assemblies designed to produce tritium. A Mark 22 assembly (Figure 1-4) consists of two aluminum clad fuel tubes arranged concentrically between two aluminum clad target tubes. The fuel tubes are an enriched uranium-aluminum alloy, and the target tubes are a lithiumaluminum alloy enriched with lithium-6. The assemblies are about four inches in diameter and have an active length of $12.5 \mathrm{ft}$.

Six special assemblies (spargers) are used to promote moderator circulation. Each sparger assembly is provided flow from the inlet plenum (approximately the same amount provided to a fuel assembly) which is injected upward into the moderator space to promote mixing of the moderator. The moderator flow pattern is (generally) up through the center of the core, across the top of the vessel, and down the outer region of the core to the six effluent nozzles at the bottom of the vessel where it is pumped through the heat exchangers back to the upper plenum. 


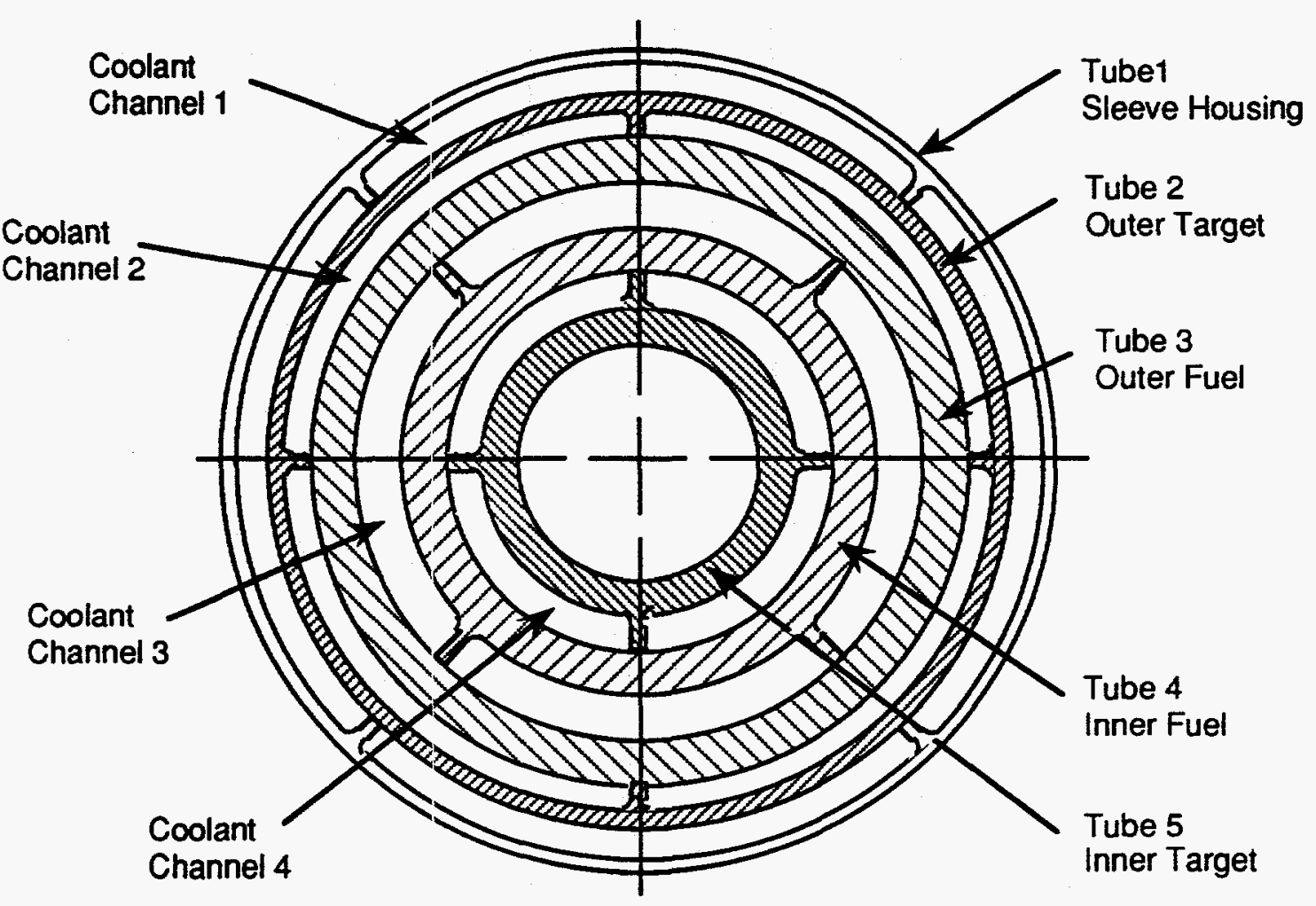

Figure 1-4. Cross Section Of A Mark 22 Assembly 
Annular passages between the tubes provide paths for coolant flow, which enters from the inlet plenum and exits through the bottom end fitting (BEF) into the moderator space within the vessel. The reactor assemblies do not thermally interact with each other and, for practical purposes, do not thermally interact with the moderator. It is important to note that the coolant and moderator are separated within the active core region. Assemblies are contained within a universal sleeve housing (USH) made of aluminum. It is the USH that limits the thermal interaction between individual assemblies and between assemblies and the moderator.

\section{1,4.1.4 Reactivity Control System}

The primary emergency shutdown system consists of 66 safety rods that are dropped into the core by gravity when their magnetic clutches are released by a scram signal. The scram signals originate from 30 scram channels monitoring 15 different reactor operating parameters. The safety rods subtend the full height of the core. The safety rods use cadmium as an absorber and are clad with stainless steel. Safety rods are withdrawn from the reactor at startup and remain out of the core during operation.

Each of the 61 control positions includes five full-length and two half-length control rods. Two of the full-length rods contain cadmium as an absorber and are clad with stainless steel. These rods are the first control rods withdrawn from the core during approach to criticality and remain out of the core during operation. The remaining rods are a lithium-aluminum alloy clad in aluminum. Control rods are used to make reactivity changes during normal operations and to control the radial and axial flux profile. Although the control rods may be moved independently, most adjustments are made by moving rods in gangs. A gang is a group of control rods within a given radial region of the core.

The reactivity control system includes a backup system, the supplementary safety system (SSS), to scram the reactor if the safety rods fail. Gadolinium nitrate can be injected into the moderator region of the core through the spargers discussed above.

\subsubsection{Confinement System}

The confinement system for Savannah River reactors is designed to limit the release of radioactive materials from the reactor building during normal operations and for design basis accidents. A release of radioactive material from confinement would require failure or bypass of major safety systems.

The confinement building is shown schematically in Figure 1-5. The key volumes identified in the figure are: the actuator tower, the reactor room, two heat exchanger bays (which are one connected volume), two pump 


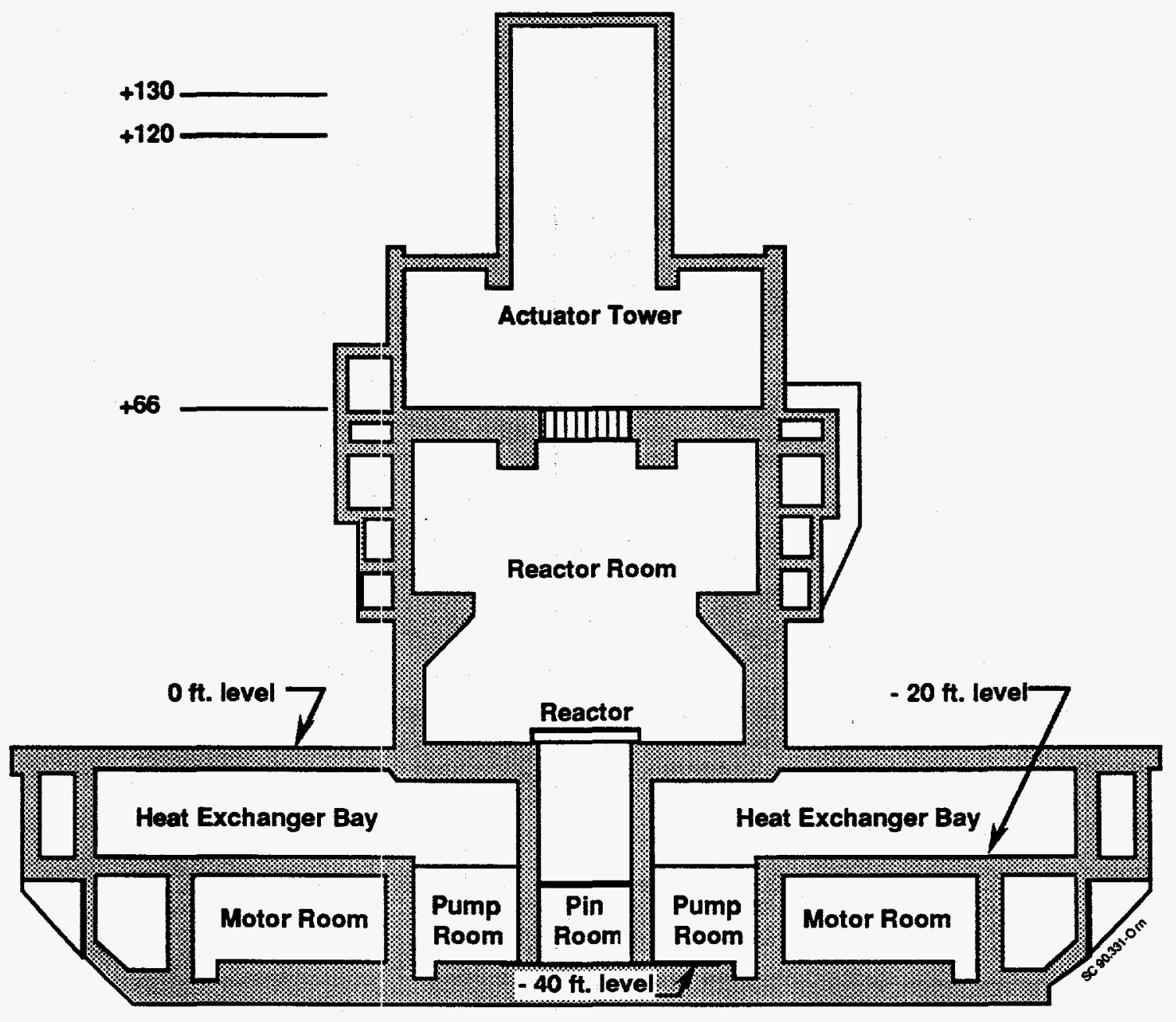

Figure 1-5. SRS Reactor Confinement Building 
rooms, and the pin room. The above-grade areas are the actuator tower and the reactor room. All other volumes are located below-grade. The combined volume of the confinement building above-grade is $320,000 \mathrm{ft}^{3}$, and belowgrade is $420,000 \mathrm{ft}^{3}$. The large volume provides for holdup of radionuclides that could be released during the course of an accident. The confinement system provides continuous, once-through air flow through the reactor building and maintains a slightly negative pressure within the confinement volume. The air flow exhausts through a filtration system which removes airborne particulates and halogens. The filtration system also includes a demister which reduces the vapor content of effluent air. The confinement system is not designed to remove tritium or noble gases from the exhaust air.

Elements of the SRS confinement system include several key subsystems:

(1) the airborne activity confinement system (AACS);

(2) the reactor room spray system (RRSS);

(3) the confinement heat removal system (CHRS);

(4) the water disposal system (WDS); and

(5) the contaminated water storage system (CWSS).

The following descriptions provide brief introductions to each of these important systems.

\subsubsection{Airborne Activity Confinement System}

The AACS includes the ventilation and filtration systems. The ventilation system, shown schematically in Figure 1-6, consists of exhaust fans that purge the confinement, supply fans that provide outside air, booster fans that can move air between areas, dampers that can be used to modulate or direct air flow, and a $200 \mathrm{ft}$ exhaust stack. The fans provide once-through ventilation of the confinement volume, continuously purging the volume with outside air and maintaining a slightly negative pressure within the confinement building. The filtration system, also shown in Figure 1-6, includes five filter compartments located outside of the reactor room at the base of the exhaust stack. The filters have three sequential stages: (1) demisters to reduce the vapor content of exhaust air; (2) high-efficiency particulate air (HEPA) filters to provide filtration of aerosols; and (3) charcoal filters to provide filtration of halogen activity in the effluent air.

Under normal operating conditions, the AACS is configured so that all effluent air is drawn through the filtration system and purged through the exhaust stack. Two of the three exhaust fans are normally operated to provide an airflow of 80,000 to 120,000 CFM through the building and confinement filters. The precise flow rate depends upon the number of filter compartments on line and the age and condition of the filters. Under normal conditions approximately $30 \%$ of the total air flow through the filters comes from above-grade volumes and $70 \%$ comes from below-grade volumes. Operation of only one fan is adequate to maintain negative pressure within the confinement, and the reactor is allowed to operate for 


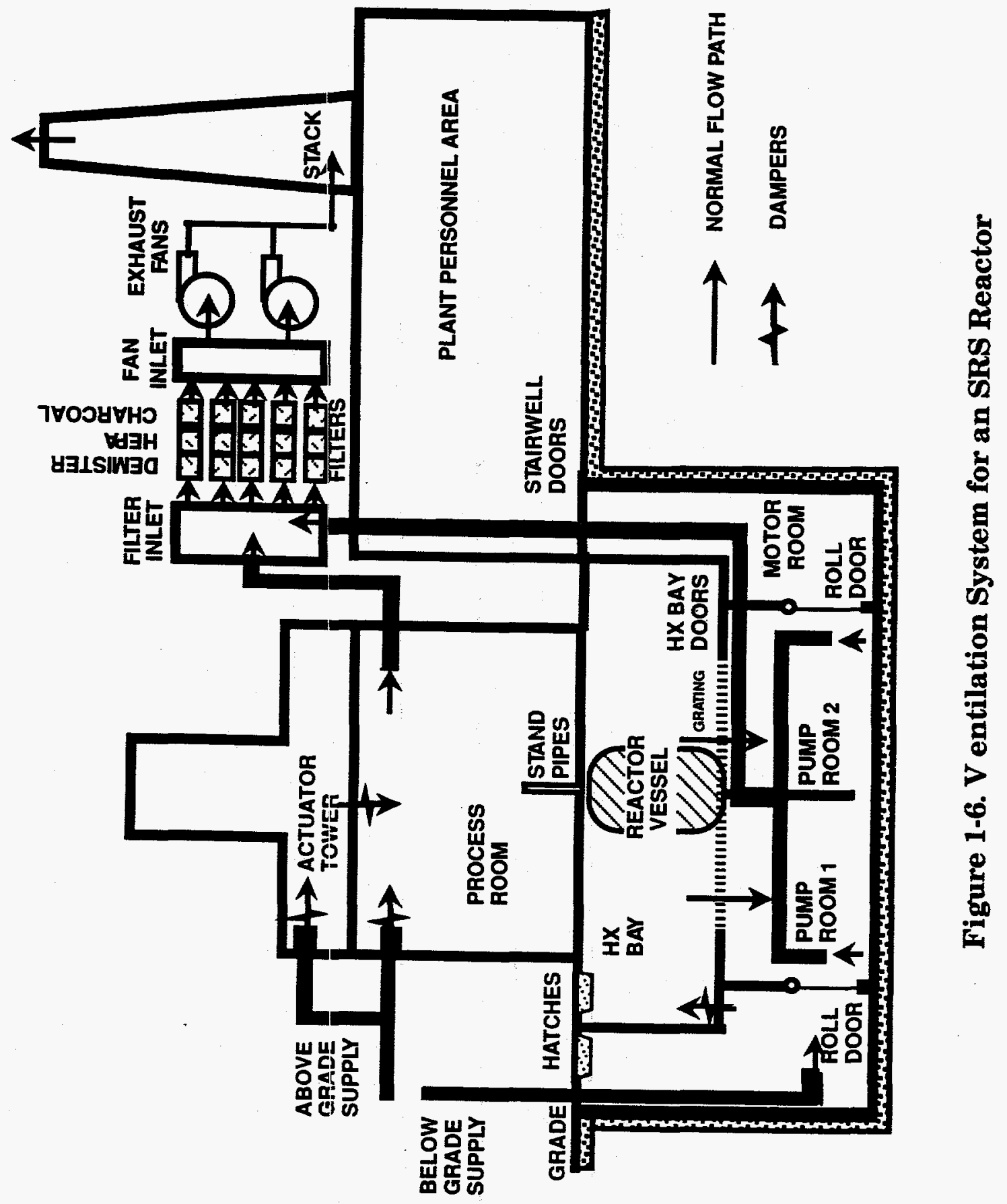


up to 8 hours with only one exhaust fan. The reactor is shut down immediately if all exhaust fans become inoperative.

The confinement filtration system is on-line continuously to filter all air exhausted from the confinement building during reactor operation. It is designed to remove more than $99 \%$ of all particulate radionuclides and iodine from the process area ventilating air. A minimum of four of the five filter compartments is normally on-line. Reactor operation may continue for up to 48 hours, however, with only three compartments on-line. The reactor is shut down immediately if fewer than three filter compartments are on-line.

The three sequential stages of the filters are:

Demisters: Demisters consisting of twenty parallel moisture separators provide the first stage of the filter system. They are designed to remove approximately 99 percent of entrained water particles of 1 to 5 microns in diameter and to protect against significant blinding of the water-repellent particulate filters. The moisture separators consist of mats woven from Teflon $^{\mathrm{TM}}$ yarn and stainless steel wire forming a pad 24 inches square and 2 inches thick. A drainage system is provided to return condensate to the reactor room.

Particulate filters: High Efficiency Particulate Air (HEPA) filters are the second stage of the filter system. The 32 parallel particulate filters are designed to retain more than $99 \%$ of all particles of 0.3 microns or larger diameter. The filters are composed of 18-mil-thick fire-resistant, waterrepellent glass felt sheet, with high wet strength characteristics.

Halogen Absorbers: Activated carbon beds make up the final stage of the filtration system. They are designed to retain over 99 percent of the elemental iodine that might be released if an accident should occur. Each of the 32 parallel carbon units is packed with roughly $57 \mathrm{lbs}$ of impregnated [type GX-176] activated coconut-shell carbon. Twelve separate pleats maintain a rigid one-inch-thick bed, retard settling, and expose about $15 \mathrm{ft}^{2}$ of perforated surface area to air flow. The efficiency of the halogen absorbers is determined by carbon age, the chemical form of iodine being captured, and radiation levels in the filter region.

Dampers are located at the inlet and outlet plenum nozzle extensions of each filter compartment. The dampers remain open during normal operations. Closed dampers block the flow path when the filters are off-line, thereby sealing the building opening. Flappers in each filter compartment cover the inlet and outlet openings when the compartment is pulled away from the plenum nozzles.

During shutdown, below-grade air flow is exhausted directly to the atmosphere through the stack. This is accomplished by closing the damper which blocks below-grade airflow to the filters, opening a below-grade exhaust damper and operating the fans that exhaust the below-grade area. 


\subsubsection{Reactor Room Spray System}

The RRSS is used to reduce the air temperature in the above-grade confinement volume (reactor room) and to reduce the level of airborne radioactivity that may be released to the reactor room in the event of an accident. The RRSS can provide up to $2100 \mathrm{gpm}$ of water to the reactor room from an elevation of $23 \mathrm{ft}$. This water is in the form of a spray with a droplet size of about 90 mils. The system is off-line but available during normal operations and is only actuated if an accident were to occur. When the spray system is actuated, about 75 percent of the spray water will be discharged directly from the reactor room to the contaminated water storage tank (CWST) or the retention basin. The remaining 25 percent flows through drains in the reactor room floor to the pump room, where it may subsequently be discharged to the CWST or retention basin.

\subsubsection{Confinement Heat Removal System}

In some postulated severe accident scenarios, molten core debris could penetrate the bottom of the reactor vessel or the effluent piping and be deposited on the pump room floor. Under such conditions, it may be necessary to provide cooling to the debris below-grade. The CHRS is designed to provide cooling water to below-grade areas in the event of such an accident.

The CHRS can dump at least 8 inches of water on the pump room floor from the disassembly basin within fifteen minutes. CHRS piping consists of a 16-inch supply line fron the disassembly basin to the pump room sump. Following the initial water dump, makeup water is supplied to the disassembly basin and subsequently to the below-grade floor by the Emergency Disassembly Basin Makeup System at the rate of $400 \mathrm{gpm}$.

\subsubsection{Water Disposal System}

The WDS is designed to prevent water from accumulating in the belowgrade areas during normal operation. The system is comprised of four pumps which draw water from below-grade floors and sumps and discharge the water to the contaminated water storage system. The WDS is off-line but available during normal operations. If water begins to accumulate in the sumps, the WDS is actuated to remove the water. Two nonsubmersible pumps draw water from the bottom of the belo ade sumps. The pump motors are located four feet above the pump roo: oor, so they will flood and cease operation if the water level reaches fou et. Two submersible pumps are mounted on the floor. These pumps wi be actuated and begin to draw water after the sumps have completely fi: l. The WDS is shutdown if the CHRS is actuated.

\subsubsection{Contaminated Water Storage System}

The CWSS is designed to retain water discharged by the WDS in the event of an accident. The principal components of the system include: 
(1) A 60,000 gallon concrete tank located below grade in an auxiliary building for the purpose of containing the initial water discharged from the WDS;

(2) A 500,000 gallon steel contaminated water storage tank (CWST), located above grade in the retention basin for the purpose of holding water not retained by the 60,000 gallon tank; and

(3) A 50,000,000 gallon earthen retention basin, which is used to contain the overflow from the CWST.

The concrete tank and the CWST are vented to the reactor building. Therefore, any volatile radionuclides that evolve from water in these tanks would be filtered by the filtration system.

\subsection{Structure of the Report}

This report is divided into sections which provide summaries of various aspects of the PSA. The final sections present the results and provide the conclusions. Section 2 provides a summary of the Level 1 systems analysis and the plant damage state descriptions. Section 3 provides a general overview of the progression of core-melt accidents in the SRS reactor. Section 4 discusses the approach used in conducting the Level 2 Accident Progression Analysis. In particular, the construction of the logic model (i.e., event tree) for accident progression is described. Sections 5 and 6 describe the engineering analyses that were performed in support of the PSA. The structure of these sections generally follows the approach taken during the analysis effort. Section 5 covers the analysis of accident progression in the absence of energetic events. This analysis essentially parallels the Phase 1, Level 2 analysis but at a much greater level of detail. Section 6 presents the analysis of energetic events such as molten fuelcoolant interactions, recriticality, and hydrogen combustion. The analysis of their effect on accident progression is also discussed. Section 7 describes methods used for the assessment of the source term to the environment. Section 8 describes the consequence analysis. Section 9 describes how the uncertainty analysis was conducted. The PSA results are presented in Section 10. Conclusions derived from the study and a summary of major insights are provided in Section 11.

\subsection{References}

1-1. M. D. Brandyberry, et al., SRS PRA Of Reactor Operation - Level 1, Internal Events, WSRC-RP-89-570, Westinghouse Savannah River Company, Aiken, SC, June 1990.

1-2. M. D. Brandyberry and H. E. Wingo, SRS PRA Of Reactor Operation Level 1, External Events, WSRC-RP-89-733, Westinghouse Savannah River Company, Aiken, SC, June 1990. 
1-3. U.S. Nuclear Regulatory Commission, Severe Accident Risks: An Assessment for five U.S. Nuclear Power Plants, NUREG-1150, December 1990.

1-4. U.S. Nuclear Regulatory Commission, Reactor Safety Study - An Assessment Of Accident Risks in U.S. Commercial Nuclear Power Plants, WASH-1400 (NUREG-75/014), October 1975.

1-5. J. G. Kemeny, et al., Report of the President's Commission on the Accident at Three Mile Island, October 1979.

1-6. M. Rogovin, et al., Three Mile Island - A Report to the Commissioners and to the Public, NUREG/CR-1250, Vol. 1, January 1980.

1-7. U.S. Nuclear Regulatory Commission, Individual Plant Examinations for Severe Accident Vulnerabilities - 10 CFR 50.54(f), Generic Letter 88-20, November 23, 1988.

1-8. W. H. Baker, et al., Analysis of The Response Of The Reactor Confinement Systems To Reactor Core Damage From Selected Initiating Events, DPST-87-352, Savannah River Laboratory, Aiken, SC, September 1987.

1-9. D. S. Cramer, Phase 1 Consequence Analysis - Report \#2, Confinement System Equipment Reliability, DPST-87-315, Savannah River Laboratory, Aiken, SC, July 1987.

1-10. S. F. Petry, et al., Technical Data Summary: Improved Confinement Facilities for SRP Reactors, DPSTD-86-1, Savannah River Laboratory, Aiken, SC, March 1986.

1-11. E. Nomm, Automatic Actuation of Confinement Heat Removal System, TA 1-2243, Savannah River Plant, Aiken, SC, May 1987.

1-12. D. I. Chanin, et al., MELCOR Accident Consequence Code System (MACCS), NUREG/CR-4691, Vols. 1-3, SAND86-1562, Sandia National Laboratories, Albuquerque, NM, February 1990. 


\subsection{SYSTEMS ANALYSIS}

The detailed systems analysis (i.e., the Level 1 PSA) was published in June $1990[2-1,2-2]$ and is summarized in this section for both internal and external events. An analysis of plant operational experience was performed in the Level 1 to identify types and frequencies of accident initiators, and to determine site-specific component failure rates. Event trees and fault trees were developed, based on site-specific analyses, to characterize safety system responses to accident initiators. Human reliability analyses were also performed to evaluate the reliability of operator implementation of plant emergency procedures in response to accidents.

Previously, a Phase 1 PSA had been performed to provide early insights into plant response to a subset of accident initiators [2-3 through 2-7]. The Level 1 analysis extended the Phase 1 analysis as follows:

(1) a full range of site-specific internal and external accident initiators was evaluated;

(2) logic models were developed and employed in the form of event trees and fault trees;

(3) a Markov model was developed to represent the Electric Power System availability and reliability;

(4) updated, site-specific equipment reliability data were developed and applied;

(5) sequence analysis was performed with upgraded computer techniques; and

(6) sensitivity and uncertainty analyses were performed.

The plant model used for the Level 1 PSA is based on K Reactor as configured in June 1987 and operating at historical power levels (2500 MW). An exception to this basis is the inclusion of a fourth injection line of the emergency cooling system. The principal assumptions made in the Level 1 PSA are discussed in Reference 2-1.

As of this writing, a full revision of the Level 1 PSA is being performed, including both internal and external events analyses. This upgrade will model K Reactor in its current (1992) state, including the effects of new systems, procedures, success criteria, etc. The reactor will also be assumed to operate at its new power limit of $720 \mathrm{MW}$. For the seismic and fire analyses, such things as a new seismic hazard analysis, and the results of the just completed fire hazards analysis will be addressed. This document, and the following discussion of the Level 1 PSA includes none of the above information. Upgrading the Full Scope Level 3 PSA to the current reactor state is the subject of ongoing work and a future report. 


\subsection{Internal Events Analysis}

The internal events analysis uses fault-tree linking methodology. The detailed technical efforts are divided into eight principal task areas:

(1) Initiating Event Identification and Analysis;

(2) Event Tree Development;

(3) System Fault Tree Development;

(4) Electric Power Model Development and Analysis;

(5) Component Fault Tree (Generic Subtree) Development ;

(6) Component and Human Reliability Data Base Development;

(7) Sequence Analysis and Compilation of Results; and

(8) Uncertainty Analysis.

Initiating events associated with other reactor types generally do not directly apply to the SRS reactors, so a detailed and systematic search for potential site-specific accident initiators was conducted. The approach is based on a systematic examination of the failure mechanisms for barriers to the release of radioactive material from SRS reactor assemblies. The result of this approach was a listing of site-specific initiators that were then assigned to more conventional classes of accident initiators. Five different classes of accidents that could yield severe reactor core-melt scenarios resulted:

(1) Primary LOCA: A leak in the primary $\left(\mathrm{D}_{2} \mathrm{O}\right)$ cooling system;

(2) Secondary LOCA: A leak in the secondary $\left(\mathrm{H}_{2} \mathrm{O}\right)$ cooling system that leads to flooding of the primary coolant pumps, i.e., a Loss of Pumping Accident (LOPA);

(3) Transient: An upset of the reactor power-to-flow ratio;

(4) LORW: Failure of the river water supply to the once-through secondary cooling system; and

(5) LOHS: Failure of heat transfer between the primary and secondary cooling systems.

For each of these accident classes, the potential accident progression scenarios were developed and modeled as event trees. For the branch points, the related plant system responses were identified and system sult trees were developed. These system fault trees were developed down $t$ he component level (e.g., pump, valve, etc.). Generic subtrees were develo .d for the components and linked to the system fault trees.

The generic subtrees trace the supply of electric power back to key bust. The availability and reliability of electric power at buses were represented as a series of basic events in the generic subtrees. Availability and reliability were then analyzed using a Markov model (developed for the PSA) that considers the frequencies of losing normal power, the 
probabilities of failure of emergency power, and the mean times to repair of the electric power supply. The Markov model calculates the probability of finding the system in any particular configuration (i.e., combination of buses $\mathrm{ON}$ or OFF), given an initial condition. Unavailability is calculated by admitting all possible transitions among configurations, both those caused by failures and those caused by recovery steps. Unreliability is calculated by allowing only failure transitions. The initial condition is prescribed by assigning probabilities to each of the 32 possible bus configurations.

SRS-specific design and operational information was used throughout the development of the Level 1 models. Plant design features and response strategies, including operator actions as specified by SRS procedures, were incorporated directly into the models. Actual plant experience, obtained from incident reports and operator logs, was used to compute SRS-specific component reliability data. The SRS experience base of 110 reactor-years of operation was available for these computations and was supplemented by generic industry data only when necessary.

The accident sequence frequencies were quantified by (1) linking the system fault tree models in the manner indicated by the event trees to represent the accident sequence of interest; (2) using the plant-specific data to estimate initiator frequencies and component failure rates; and (3) estimation of the human error rates. The SETS code [2-8] was used to solve fault trees and accident sequences for their minimal cut sets. The TEMAC code [2-9] was used for quantitative evaluation of probabilities, using as input the cut sets derived by SETS and best estimates of component and event probabilities or frequencies.

Uncertainty estimates were made for the core-melt frequency by assigning probability distributions to the basic events and propagating them through a simplified model of the cut set results. The simplified cut set model includes the dominant cut sets from all five contributing classes of accidents and yields results that include $97 \%$ of the core-melt frequency calculated with the full Level 1 model. Uncertainties in the basic events were taken to be described by either log-normal or maximum entropy distributions. Fifth and ninety-fifth percentiles of these distributions were derived from chi-squared confidence interval tests for events where SRS data are available, from error factors quoted for generic data, or from judgment and industry practices for human errors. The basic event distributions were propagated through this simplified model with the TEMAC computer code using Latin Hypercube Sampling (LHS) [2-10] to assess the distribution of the severe core-melt frequency. These uncertainty estimates were used to identify the important parameters for inclusion in the integrated uncertainty analysis discussed in Section 9.0.

\section{$2.2 \quad$ External Events Analysis}

The analysis of external events consists of characterizing the effects on reactor safety of initiating events that are "external" to the reactor. These events can be weather related events such as tornadoes, hurricanes, or ice 
storms; natural events such as forest fires, earthquakes or tsunamis; or human related events such as fires or vehicle crashes. The list of external events analyzed was developed from collective knowledge of events considered in other PSA and SAR studies. The list is considered to be exhaustive. All events were examined from the standpoint of hazard to the reactor, and those which could present a significant hazard were analyzed in detail. Identified events were grouped in the manner shown in Table 2-1. Those that were analyzed in detail are discussed below.

\subsubsection{Seismic Analysis}

The seismic risk assessment was performed using methods described in Reference 2-2. There are four main parts to the analysis:

(1) seismic hazard assessment;

(2) seismic fragility analysis;

(3) system logic model development; and

(4) model quantification.

The seismic hazard quantifies the frequency and magnitude of ground motion that is estimated to occur at the site. The uncertainty in the seismic hazard is characterized by a family of discrete hazard curves with a probability weight assigned to each curve. The weights are a measure of the degree to which it is believed that a curve represents the true site hazard. The weights sum to unity. The Electric Power Research Institute and Seismicity Owners Group seismic hazard evaluation project was used to estimate the seismic hazard for the SRS Reactors [2-11].

The seismic fragility analysis evaluates the conditional probability of failure of plant structures and equipment as a function of ground motion level. Component (structure or equipment item) failure is defined as the mechanical response level that would lead to a loss of function. The seismically-initiated failure of plant components is expressed in terms of the same ground motion parameter as that used in the hazard analysis, which, for this analysis, was the spectral acceleration at $5.0 \mathrm{~Hz}$. The $5.0 \mathrm{~Hz}$ frequency was selected because it lies between the fundamental frequency $(2.0 \mathrm{~Hz})$ of the reactor building, which houses much of the safety-related equipment, and the fundamental frequencies of the equipment. As : irt of the fragility analysis, the uncertainty in the mechanical capa. " of components was evaluated in a manner similar to the uncertainty a. sis performed for the internal events. An integrated uncertainty analy. as described in Section 9 was also performed.

To describe the performance of the reactor system during a seismic event logic model was developed that considered sequences of events and $t$. consequences of seismically induced component failure. A seismic ever. tree was constructed that considered the response of major structurer safety systems, and operator actions to earthquake ground motion. For eacil safety system included in the analysis, a fault tree was developed that 
Table 2-1. Categorization of External Events Considered

(1) Seismic

(2) Fire

(3) Weather Related Events

Extreme Cold
Ice Storm
Snow Storm
Hail
Extreme Heat/Drought
Dust Storm
Severe Electrical Storm
High Wind
$\quad$ Hurricane
Tornado

(4) Flooding

Flash Flood

Area Flood

Dam Failure

Tsunami

Seiche

(5) Other Natural Events

Forest Fires

Volcanoes

Glaciation

Animal/biota

Meteorite

(6) Human Related Events

Transportation Accidents

Aircraft Crash

Train/Vehicle Crash

Ship Crash

Pipeline Explosion

River Contamination

Site Chemicals/Other SRS Facilities Firearm Discharge 
defined the seismically-initiated and random component failures that could lead to the top event failure.

To quantify the risk of core melt, the seismic hazard, fragility, and system models were combined. The quantification was performed in two steps. First, the seismic event tree was evaluated using component fragility information. This produced a fragility curve for each core-melt sequence, and defined the conditional probability of sequence occurrence as a function of ground motion level. From these data, a plant fragility was then determined and the conditional probability of core melt as a function of ground motion level for all seismic sequences was computed. In the second step, the frequency of core melt was estimated by combining the sequence fragility curves generated in the first step with the seismic hazard. The frequencies of occurrence of each sequence as well as of core melt were determined.

\subsubsection{Fire Analysis}

The fire risk assessment was performed using methods described in Reference 2-2. The locations of cables and components of the systems of interest were identified from plant documents and drawings. Plant walkdowns were perforrned to verify the physical arrangements in each of the plant areas containing important equipment. A thorough review of fire fighting procedures was also conducted to determine the probability of manual fire suppression in a given length of time for all critical plant areas.

Important fire zones were determined using a screening analysis. The screening analysis included the following steps:

(1) Fire zones which have either safety-related equipment or power and control cables for that equipment were identified as requiring further analysis;

(2) Fire zones were screened on possible fire-induced initiating events. Determination of the fire frequency for all plant locations, and determination of the resulting fire-induced initiating events and off-normal plant states was then performed;

(3) Fire zones were screened on both order and frequency of c sets.

After the screening analysis eliminated all but the probabilis ly significant fire zones, quantification of dominant cut sets was completi $y$

(1) Determining the temperature response of vulnerable equipment to modeled fires in each fire zone; 
(2) Computing component fire fragilities. The latest version of the fire growth code, COMPBRN [2-12], was used to calculate fire propagation and equipment damage;

(3) Assessing the probability of barrier failure for all remaining combinations of fire zones. A barrier failure analysis was conducted for those combinations of two adjacent fire zones that, with or without additional random failures, remained after the screening analysis;

(4) Performing a recovery analysis. Recovery of non-fire-related random failures was addressed in a fashion similar to the internal event analysis; and

(5) Performing an uncertainty analysis to estimate error bounds on the computed fire-induced severe core-melt frequencies.

A unique aspect of the K-Reactor fire analysis was the availability of an extensive operating history and site specific fire experience. The site specific fire data base includes almost 100 reactor operating years of experience during which twenty fires in significant reactor fire areas are recorded. This extensive operating data allowed the quantification of the severe core-melt frequency with plant specific data as well as with commercial fire data combined with the plant specific data using Bayesian techniques. These two approaches yielded results whose mean values are within a factor of two. The results reported are those calculated using plant specific data only since this was the more conservative of the two approaches. The mean severe core-melt frequency from fire induced accidents is $1.4 \times 10^{-7}$ per reactor year.

\subsubsection{Weather-Related Events}

The risk of reactor building flooding from external sources is negligible due to the siting of the reactor. The K-Reactor building is sited at a minimum of $270 \mathrm{ft}$ above mean sea level. The nearest significant body of water, $L$ lake, is estimated to have a probable maximum flood (PMF) stage $80 \mathrm{ft}$ below K-Reactor grade. The Savannah River (5 miles from K Reactor) PMF stage is over $130 \mathrm{ft}$ below K-Reactor grade.

The only significant flooding scenario for $\mathrm{K}$ Reactor, therefore, involves dam failures upstream of SRS on the Savannah River. A postulated dam failure would flood the River Water Pump houses and deprive the reactor areas of the normal source of water to the 25 million gallon cooling water basin. These failures are modeled as an initiator in the internal event loss of river water sequences and are not explicitly treated as an external event.

The effects of other weather related events (wind, snow, ice and hail) are included in the internal events analysis as contributors to the frequency of loss of electric power or loss of the river water source, as appropriate. 


\subsubsection{Human-Related Events}

Transportation accidents were analyzed in detail. The only conceivable direct impact on the reactor itself would be from an aircraft impact. Since $\mathrm{K}$ Reactor is $20+$ miles from an airport, not on an airway (5 miles from a low altitude airway) and built with blast resistant construction, the risk from aircraft impact was shown to be negligible. Also, the nearest public highway is 2 miles away, the nearest pipeline is 17 miles away, the nearest public railway is 2.8 miles away, and, as indicated previously, the Savannah River is five miles away.

The risk of chemical releases from transportation accidents was assumed to be dominated by onsite transportation accidents. The risk from public sources is negligible due to the distances from public thoroughfares.

A study of the risks from onsite transportation of hazardous substances has been performed for the SRS [2-13]. Using the frequencies and types of releases described in this study, and postulating that any release would cause control room evacuation, the accident frequencies are coupled with the conditional frequency of core melt due to loss of heat sink (calculated in the Internal Events analysis) to arrive at a core-melt frequency from onsite transportation accidents of approximately $10^{-7}$ per year. The Loss of Heat Sink conditional probability was used since it incorporates events that could be classed as further component failures and not another initiator (double initiators are not consiclered in this PSA). Thus, a LOCA, LOPA, or other such initiator concurrent with the transportation accident would be considered incredible. However, an event such as loss of the process water pumps during a 24 hour period after the accident is reasonable to consider and will have a response identical to the nominal Loss of Heat Sink accident.

\subsection{Results of the PSA - Severe Core Melt Frequency}

The mean total severe core-melt frequency from all initiators is estimated to be $3.1 \times 10^{-4}$ per reactor year for all accidents that occur at power. Sixty-six percent $\left(2.06 \times 10^{-4}\right)$ of this total is attributed too internal initiating events, and thirty-four percent $\left(1.04 \times 10^{-4}\right)$ to external events. These values are lower than the core-melt frequency quoted in Reference 2-1 for two reasons. First, the crane failure accident considered as part of the external events PSA is not included here. The detailed external events analysis included a dropped heat exchanger due to crane failure during changeout while fuel remained in the reactor vessel. This sequence contributed $1.0 \times 10^{-4}$ per reactor year: to the external events results. Since this accident sequence is considered a shutdown accident, it is not included in this analysis, which is valid only for operation at power. Second, the mean coremelt frequency for external events (seismic) changed by $1.0 \times 10^{-5}$ when included in the Level 2 integrated uncertainty analysis (as compared to the stand-alone seismic analysis result presented in Reference 2-2). This is within the statistical uncertainty and is not considered significant. 
Contributors to the core-melt frequency are shown in Table 2-2 and are discussed in the following sections.

\subsubsection{Summary of Internal Events Results}

The mean severe core-melt frequency for the K-Reactor configuration is estimated to be $2.06 \times 10^{-4}$ per reactor-year from internal initiators. This result lies within the range of values calculated for currently operating nuclear power facilities, using similar techniques. Contributing to the result are 267 sequences from the initiating event classes. The distribution of this result among the contributing initiating event classes is also tabulated in Table 2-2, along with the associated initiating event frequency and percentage contribution to the core-melt frequency.

Within the Primary LOCA class, expansion joint breaks and subsequent response failures contribute most to the indicated frequency. Large break LOCAs contribute the difference. Response to LOCAs in the primary system involves shutdown, addition of emergency coolant for makeup of lost coolant inventory, leak control and/or isolation, water removal from the building to avoid flooding of the primary coolant pumps, and direct core cooling in the event of pump flooding.

For the Secondary LOCA class, most of the indicated frequency is related to large breaks, with small breaks contributing less than $1 \%$. Response to LOCA in the secondary system involves shutdown, leak control and/or isolation, water removal from the building to avoid flooding of pumps, and direct core cooling in the event of pump flooding.

Transients have no subclasses of initiators that dominate. Response to transients involves shutdown only. It is assumed for all classes of transients (i.e., reactivity-addition, flow-reduction, and coolant-heatup transients) that an automatic shutdown (Safety Rod System or SSS ink injection) is required to prevent severe core melt. If shutdown occurs, primary coolant $\left(\mathrm{D}_{2} \mathrm{O}\right)$ and secondary coolant $\left(\mathrm{H}_{2} \mathrm{O}\right)$ are maintained indefinitely to cool the reactor core. Primary coolant flow to the reactor core is maintained by the six online DC Caterpillar diesel generators that drive the six primary cooling water pumps. Cooling water flow is maintained to the reactor heat exchangers through gravity flow from the 25-milliongallon cooling water reservoir.

Within the Loss of River Water initiating event class, loss of plant grid power initiators and river water pump-house initiators contribute about the same indicated frequency. Response to Loss of River Water initiators involves event recognition, shutdown, and water conservation. The loss of plant grid initiator analysis is the only set of sequences that includes recovery modeling external to the fault tree models. The recovery deals with the restoration of the plant grid and is based on industrial experience.

The Loss of Heat Sink class has three subclasses of initiators. The total loss of primary system circulation accounts for $95 \%$, the total loss of secondary 
Table 2-2. Severe Core-Melt Frequency Contributions

\begin{tabular}{|c|c|c|c|}
\hline Class of Initiating Event & $\begin{array}{c}\text { Initiator } \\
\text { Frequency } \\
\text { (per reactor } \\
\text { year) }\end{array}$ & $\begin{array}{c}\text { Core Melt } \\
\text { Frequency } \\
\text { (per reactor } \\
\text { year) }\end{array}$ & $\begin{array}{c}\text { Percent of } \\
\text { Total Core } \\
\text { Melt } \\
\text { Frequency }\end{array}$ \\
\hline \multicolumn{4}{|l|}{ INTERNAL EVENTS: } \\
\hline Primary LOCA & $5.6 \times 10^{-3}$ & $1.2 \times 10^{-4}$ & $39 \%$ \\
\hline $\begin{array}{l}\text { Secondary LOCA (Loss of } \\
\text { Pumping - LOPA) }\end{array}$ & $3.3 \times 10^{-3}$ & $4.9 \times 10^{-5}$ & $16 \%$ \\
\hline Transients & 2.5 & $1.6 \times 10^{-5}$ & $5 \%$ \\
\hline Loss of River Water - LORW & $1.2 \times 10^{-3}$ & $1.0 \times 10^{-5}$ & $3 \%$ \\
\hline Loss of Heat Sink - LOHIS & $1.2 \times 10^{-4}$ & $9.9 \times 10^{-6}$ & $3 \%$ \\
\hline Subtotal - Internal Events & & $2.05 \times 10^{-4}$ & $66 \%$ \\
\hline \multicolumn{4}{|l|}{ EXTERNAL EVENTS: } \\
\hline Seismic & & $1.06 \times 10^{-4}$ & $34 \%$ \\
\hline $\begin{array}{l}\text { Flood - Included In Internal } \\
\text { Events Analysis }\end{array}$ & & $\mathrm{N} / \mathrm{A}$ & \\
\hline $\begin{array}{l}\text { Wind - Included In Internal } \\
\text { Events Analysis }\end{array}$ & & N/A & \\
\hline Fire & & $1.4 \times 10^{-7}$ & Negligible \\
\hline Transportation & & $<10^{-7}$ & Negligible \\
\hline Subtotal - External Events & & $1.06 \times 10^{-4}$ & $34 \%$ \\
\hline Total core-melt frequency & & $3.1 \times 10^{-4}$ & \\
\hline
\end{tabular}


cooling due to effluent header failures accounts for about $4 \%$, and the total loss of secondary cooling due to inlet header failures accounts for less than $1 \%$ of this class. Response to loss of heat sink initiators involves shutdown and direct core cooling with the ECCS.

The five most dominant sequences in the Level 1 PSA, which account for $76 \%$ of the internal core-melt frequency, are (1) an expansion joint (bellows) break in the primary cooling system with failure to inject emergency coolant; (2) a double-ended break in a secondary cooling water inlet header with failure to inject emergency coolant following flooding; (3) an expansion joint (bellows) break in the primary cooling system with over throttling of emergency coolant; (4) a transient and failure to shutdown; and (5) a large break in a reactor plenum inlet pipe containing an ECCS path with throttling of emergency coolant. The dominant sequences are shown in Table 2-3.

The sequence results are shown in Table 2-4 according to functions or systems that failed in the sequence. The information given in Table 2-4 is the percentage of the internal core-melt frequency associated with the sum of all sequences that include a failure of the indicated system or function. These fractions are not additive because sequences may contain more than one system or function failure and thus may be counted more than once in the set of values presented. Thus the sum of the damage percentages shown is more than $100 \%$. Given that a pipe break occurs, the emergency cooling and leak isolation functions dominate the Level 1 PSA severe core-melt frequency for internal events.

\subsubsection{Summary of External Events Results}

The core-melt frequency associated with all significant external contributors to risk is shown in Table 2-2. Due to the methodology employed in this PSA, core-melt frequencies resulting from wind and flood initiators are included in the internal events analysis. Thus, the incremental contribution of external events to the total core-melt frequency is shown in Table 2-2.

The results of the seismic risk quantification for the reactor in the base case assessment indicated that five sequences contribute $95 \%$ of the mean coremelt frequency of $1.06 \times 10^{-4}$ per reactor year. This base case assessment was evaluated for the reactor in an essentially unmodified state, and was done to help serve as a measure of improvement for subsequent restart modifications.

Sequences contributing most to core melt, were

(1) Failure of circulation of $\mathrm{D}_{2} \mathrm{O}$ (primary coolant). This sequence was dominated by relay chatter that caused closure of rotovalves in the $\mathrm{D}_{2} \mathrm{O}$ system; 
Table 2-3. Dominant Sequences From Internally Initiated Events

\begin{tabular}{llcc} 
Initiating Event & System Failure & $\begin{array}{c}\text { Initiator } \\
\text { Frequency }\end{array}$ & $\begin{array}{c}\text { Core-melt } \\
\text { Frequency }\end{array}$ \\
\hline $\begin{array}{l}\text { Primary LOCA-Bellows } \\
\text { Break }\end{array}$ & ECCS Injection & $5.6 \times 10^{-3}$ & $6.6 \times 10^{-5}$ \\
$\begin{array}{l}\text { Large Secondary LOCA } \\
\begin{array}{l}\text { Primary LOCA-Bellows } \\
\text { Break }\end{array}\end{array}$ & $\begin{array}{l}\text { ECCS Injection } \\
\text { ECCS Throttling }\end{array}$ & $5.9 \times 10^{-4}$ & $4.2 \times 10^{-5}$ \\
$\begin{array}{l}\text { Transient } \\
\text { Automatic } \\
\text { Shutdown (Safety }\end{array}$ & 2.5 & $1.9 \times 10^{-5}$ \\
& $\begin{array}{l}\text { Rod System \& } \\
\text { SSS) }\end{array}$ & & $1.6 \times 10^{-5}$ \\
$\begin{array}{l}\text { Large Primary LOCA. } \\
\begin{array}{l}\text { Plenum Inlet Line, ECCS } \\
\text { injection path }\end{array}\end{array}$ & \begin{tabular}{l} 
ECCS Throttling \\
\hline
\end{tabular} & $1.5 \times 10^{-5}$ & $1.5 \times 10^{-5}$ \\
\hline
\end{tabular}

Table 2-4. System Or Function Failures Contribution To Internal Events Severe Core-Melt Frequency

\begin{tabular}{lc} 
SYSTEM OR FUNCTION FAILURE & $\begin{array}{c}\% \text { of Internal } \\
\text { Events Core-Melt } \\
\text { Frequency* }\end{array}$ \\
\hline \hline Emergency Cooling (Makeup or Direct Cooling) & $78 \%$ \\
Leak Isolation For Primary or Secondary LOCAs & $22 \%$ \\
Shutdown & $8 \%$ \\
Water Disposal System & $6 \%$ \\
Loss of River Water Event Recognition & $2 \%$ \\
Water Conservation (Following LORW) & $2 \%$ \\
Electric Power & $2 \%$ \\
\hline
\end{tabular}

* Sequences may contain more than one system or function failure and thus may be counted more than once in the set of values presented. Thus, the sum of the damage percentages shown is more than $100 \%$. 
(2) Failure of cooling water piping. This sequence was dominated by failure of underground piping from soil consolidation;

(3) Failure of the cooling water basin. This sequence was dominated by failure of the cooling water reservoir from soil consolidation;

(4) Loss of river water supply to the cooling water reservoir followed by failure to respond to the loss. This sequence was dominated by failure of operating personnel to respond to the alarm for loss of cooling water supply to the cooling water reservoir; and

(5) Failure of the integrity of the $\mathrm{D}_{2} \mathrm{O}$ system. This sequence was dominated by a small leak in the $\mathrm{D}_{2} \mathrm{O}$ system and failure of the operating personnel to isolate the leak.

Values used to estimate the seismic hazard for the Savannah River Site had a significant impact on the calculated core-melt frequency. As part of the SRS Seismic PSA effort, Lawrence Livermore National Laboratory (LLNL) was contracted to calculate the seismic hazard at the SRS. While the seismic hazard methodologies used by the Seismic Owners Group/Electric Power Research Institute (SOG/EPRI) and LLNL [2-14] are similar, the two seismic hazard estimates for the SRS are different. A comparison of the SOG/EPRI and LLNL results indicates there is a large difference in the estimate of the 0.85 fractile hazard curves and the mean. By comparison, in most cases the median ( 0.50 fractile level) hazard curves are typically within a factor of 5 of each other. An analysis of the differences in the Hazard Curve estimates as applied to the SRS reactors has been performed and the results will be used in the ongoing upgrade to the Seismic PSA.

Values estimated for the probability of operator error also had a significant impact on the calculated core-melt frequency. When more pessimistic values were substituted for best estimate values, the calculated core-melt frequency increased by a factor of at least three.

The contribution to core-melt frequency from fire initiators $\left(1.4 \times 10^{-7}\right.$ per reactor year) is very low relative to results of fire risk analyses for other plants. There are several important plant-specific design features which contribute to this:

(1) The secondary cooling water system can withstand a complete loss of pumping power and still supply sufficient cooling water by gravity feed to remove decay heat and to cool all safety systems after shutdown. Furthermore, isolation valves for critical cooling water systems cannot close with the cooling water pumps running. Cabling for these valves is not routed near power cabling for coolant system pumps. 
Therefore, even if a fire-induced spurious valve actuation signal occurred, the system would still be functional, since a fire cannot both stop the pumps and close the valves (multiple initiator events such as having a loss of normal power coincident with a fire are very low frequency and are not considered).

(2) Power for the DC motors that drive the primary coolant pumps is independent of the control room. There are no plant areas where a fire can fail any more than three of the six primary coolant pumps. After reactor shutdown, the AC pump motors are tripped and no more than three DC driven pumps are required to remove decay heat. Therefore, additional random failures of the primary coolant pump systems are required to fail the pumps.

(3) There are several plant areas where fire induced damage can totally fail the ECCS system, but these areas are widely separated from DC power cable routing for the primary coolant pumps. 'Therefore, random failures of the primary coolant system must also occur to cause core melt. One cable run was discovered with control cabling for valves in both the ECCS and primary coolant systems. However, a minimum of five specific spurious actuations would be required to fail the primary coolant system. This scenario was judged to be probabilistically insignificant.

(4) No fire induced method for defeating all shutdown systems was identified.

\subsection{Plant Damage States}

As discussed in the preceding sections, the Level 1 PSA is used to estimate the frequency of events having the potential to lead to severe core melt. Cut sets from the Level 1 analysis indicate the combinations of initiating events and subsequent failures of equipment, or of the operators, that can lead to core melt. It is desirable to group these cutsets according to sequence similarities to simplify their subsequent analysis in the Level 2 PSA. These cut set groupings are referred to as plant damage states (PDS). The mean frequencies for the internal and seismic PDSs are presented in Tables 2-5 and 2-6, respectively. As expected, the internal PDSs are dominated by the LOCA and LOPA categories, and the seismic PDSs by the loss of river water and loss of primary circulation categories.

\subsubsection{Plant Damage Stake Descriptions: Internal Initiators}

The sequences resulting from internally initiated events have been binned into nine plant damage states for input to the Level 2 analysis. They are described briefly in the following subsections. 
Table 2-5. Mean Frequencies of Plant Damage States From Internal Initiators

\begin{tabular}{lcl}
\multicolumn{1}{c}{ PDS } & Mean Frequency & \multicolumn{1}{c}{ PDS Name } \\
\hline \hline & & \\
PDS-I1 & $4.8 \times 10^{-5}$ & LOPA \\
PDS-I2 & $3.9 \times 10^{-7}$ & Low Flooding Rate LOPA \\
PDS-I3 & $7.2 \times 10^{-5}$ & LOCA Without ECCS Injection \\
PDS-I4 & $4.3 \times 10^{-5}$ & Small Break LOCA With Partial ECCS \\
PDS-I5 & $7.9 \times 10^{-6}$ & LOCA With Internal Flooding \\
PDS-I6 & $1.5 \times 10^{-5}$ & Locally Initiated Transient \\
PDS-I7 & $9.4 \times 10^{-6}$ & Loss-of-Primary-Circulation (LOPC) \\
PDS-I8 & $1.7 \times 10^{-7}$ & Loss-of-Heat Sink \\
PDS-I9 & $1.0 \times 10^{-5}$ & Loss-of-Basin Water \\
Total & $2.06 \times 10^{-4}$ & \\
\hline
\end{tabular}

Table 2-6. Mean Frequencies of Plant Damage States From Seismic Initiators

\begin{tabular}{lll}
\multicolumn{1}{c}{ PDS } & Mean Frequency & PDS Name \\
\hline \hline & & \\
PDS-S1 & $4.1 \times 10^{-5}$ & Loss-of-River Water \\
PDS-S2 & $4.7 \times 10^{-5}$ & LOPC \\
PDS-S3 & $7.3 \times 10^{-6}$ & LOPA \\
PDS-S4 & $8.5 \times 10^{-6}$ & LOCA \\
PDS-S5 & $3.4 \times 10^{-7}$ & LOCA with Flood \\
PDS-S6 & $1.7 \times 10^{-7}$ & Vented LOPC \\
PDS-S7 & $\underline{4.2 \times 10^{-8}}$ & Vented LOPA \\
Total & $1.04 \times 10^{-4}$ & \\
\hline
\end{tabular}


This PDS involves an internal flood caused by a secondary cooling water pipe break. Pipe breaks can range in size from a full double-ended break to a small break that results in an equivalent hole size of approximately one square foot. Reactor scram occurs at the time of the break due to flow reduction in the cooling water system. Water continues to be added to the -40 foot level at a rate between 25 and 155 thousand gallons per minute, depending on the break size and whether or not the secondary coolant pumps have been tripped. The split between large and small breaks is calculated from the cutsets. The probability that the operators fail to trip the secondary cooling water pumps is assigned based on a human reliability assessment. The combinations of break size (large or small) and pump status (tripped or running) results in four discrete flooding rates, spanning the possible range, to be represented within this damage state.

The ECCS may not be operating because of operator failure to initiate Incident Action or mechanical failure of the system given operator action. However, a number of cut sets contributing to this damage state include partial, though inadequate, operation of the system following timely actuation. Because the reactor vessel is full of water and because a substantial amount of water is being added to the $-40 \mathrm{ft}$. level of the building from the secondary cooling water leak, addition of the ECCS water to the $-40 \mathrm{ft}$. level is not expected to affect the accident progression. The ECCS injection rate, however, is included in the pump room water level calculations.

The Confinement Heat Removal System (CHRS) is available and may be actuated by the operator. However, the addition or lack of the CHRS water would not influence the accident progression because of the large amount of water already flooding the $-40 \mathrm{ft}$. level.

The Water Disposal System (WDS) is fully operational initially (i.e., four pumps operating). However, since the WDS capacity is small relative to the rate of water addition (less than one third), the course of accident progression will not be greatly influenced. The non-submersible pumps will flood when the water level on the floor reaches a depth of 4 feet.

As for most PDSs that are internally initiated, the Reactor Room Spray system (RRSS) is subject to only random failure once the operator has actuated the system. The Airborne Activity Confinement System (AACS) is assumed to be initially at nominal conditions; two fans running and four filters on line.

\subsubsection{Low Flooding Rate LOPA (PDS-I2)}

This PDS involves an internal flood caused by a small secondary cooling water leak. The leak rate is between 8 thousand and 25 thousand gallons per minute, depending upon whether or not the secondary cooling water pumps have been tripped. The failure probability for a pump trip is treated 
in an identical manner to that for PDS-I1. It is assumed that reactor shutdown occurs at the time of the break due to secondary cooling system flow reduction.

The ECCS may not be operating because of operator failure to initiate Incident Action or mechanical failure of the system given operator action. However, a number of cut sets contributing to this damage state include partial, though inadequate, operation of the system following timely actuation. Because the reactor vessel is full of water and because a substantial amount of water is being added to the $-40 \mathrm{ft}$. level of the building from the secondary cooling water leak, addition of the ECCS water to the $-40 \mathrm{ft}$. level is not expected to affect the accident progression. The ECCS injection rate, however, is included in the pump room water level calculations.

The WDS is either fully or partially failed for this damage state. Failure probability is determined as the ratio of the frequency of cut sets with WDS failure to the PDS frequency. For the fraction of the frequency involving partial WDS failure, it is assumed that the non-submersible WDS pumps fail to operate. The discharge rate for the submersible pumps is $5000 \mathrm{gpm}$, less than the assumed leak rate from the secondary cooling system.

The CHRS is available and may be actuated by the operator. However, the addition or lack of the CHRS water would not influence the accident progression because of the large amount of water already flooding the $-40 \mathrm{ft}$. level.

The AACS is assumed to be operating with two exhaust fans and four filter compartments.

\subsubsection{LOCA Without ECCS (PDS-I3)}

Accidents in this PDS are initiated by a pipe break in the primary cooling system. The size of the leak is determined from the cut sets. The fraction of small leaks ( $\leq 5000 \mathrm{gpm}$ ) is about $90 \%$. For large leaks, the reactor will drain and the pumps will aspirate in less than 1 minute. Fuel damage will begin about three minutes after the break occurs. For the smaller leaks, draining of the tank and pump aspiration will require a longer time, with a corresponding delay in the initiation of fuel melt. This delay is not expected to impact the accident progression.

There is no injection from ECCS prior to core melt. The major cause of failure to inject emergency coolant is failure of the operator to initiate Incident Action. For cut sets where incident action did not occur, ECCS is assumed to be available and some probability of delayed recovery is applied. The probability that ECCS is available is calculated as the ratio of the frequency of cut sets not indicating ECCS hardware failure to the total PDS frequency. 
All four WDS pumps are initially operating. The CHRS and RRSS are subject to operator failure to actuate and random failure. The AACS is functioning at nominal conditions (i.e., two fans running, four filters on line).

\subsubsection{LOCA With ECCS (PDS-I4)}

The majority of accidents in this PDS are initiated by a small pipe break in the primary coolant system. ECCS injection occurs but the addition rate is assumed to be inadequate. A small fraction of the accidents involve large pipe breaks for which the success criteria are better known, but these accidents are assumed to progress similarly to the small break cases. The primary coolant pumps continue to circulate coolant through the core. However, it is assumed that reduced flow in the center fuel assemblies leads to melting in this region. Some reduction in flow may occur because melted fuel debris plugs the heat exchangers. Melting is then assumed to propagate to other assemblies. Thus, a full core melt with an essentially full vessel is assumed. No analysis of this accident has been performed and thus this picture of the progression is based solely on engineering judgment. This PDS was introduced to remain consistent with Level 1 success criteria definitions.

All four WDS pumps are initially operating. The CHRS and RRSS are subject to operator failure to actuate and random failure. The AACS is functioning at nominal conditions.

\subsubsection{LOCA With Internal Flooding (PDS-I5)}

Accidents in this PDS are initiated by a primary system pipe break. ECCS injection occurs through two or more of the four available pathways, and is assumed to add 14,000 gallons per minute to the pump room. Only the two submersible WDS pumps operate, or all of the pumps fail. The split between these two states is calculated from the cutsets involved in this PDS. Thus, approximately forty minutes after reactor scram, the primary coolant pump motors flood. Core melt ensues as for a LOPA. There are at least three feet of water on the pump and motor room floors when core melt begins.

The CHRS is available and may be actuated by the operator. Hower $r$, the addition or lack of the CHRS water would not greatly influence the dent progression because of the water supplied by the ECCS to the $-40 \mathrm{i}$ :vel. The RRSS is subject to random failure and operator failure to actuat The AACS is functioning at nominal conditions.

\subsubsection{Localized Transient (PDS-I6)}

This PDS is initiated by a localized power increase (i.e., control rods) withdrawal without corrective rod reversal), or a local or global flow reduction. Both the Safety Rod System and the SSS fail. Damage in one or more assemblies ensues. Fuel melting is assumed to result in particulate 
debris being swept from the affected fuel assemblies into the moderator region of the vessel. If the fuel is levitated by vessel circulation, a power increase occurs. If the fuel is swept out without being levitated, reactor power decreases due to the loss of fuel. In either case, fuel particles are assumed to be transported to the heat exchangers and obstruct primary system circulation. For localized events, propagation of the melt to the entire core is assumed.

For power transients, the ECCS may be available, but cannot add water to the reactor even if actuated by the operator, because the pressure in the primary system is too high at full pump flow. For flow reduction transients, the ECCS may also be available, however, the short time-scale for this accident makes it unlikely that the operators would have a chance to actuate it. Also, it would be inadequate to cool the core at power even if it were actuated immediately and worked correctly.

The WDS is not operating (because there is no water on the $-40 \mathrm{ft}$. level floor) but is available subject to random failure. The CHRS and RRSS are subject to operator failure to actuate and random failure. The AACS is functioning at nominal conditions.

\subsubsection{Loss of Primary Circulation (PDS-I7)}

The Loss of Primary Circulation (LOPC) is initiated by a complete stopping of flow in the primary system. There are two potential causes: either the primary system pumps fail, or spurious rotovalve closures and/or suction valve closures block flow in all the primary coolant loops. The progression of the accident from the standpoint of the primary system is thus quite similar to that for PDS-I1 and PDS-I2.

Injection of emergency coolant requires operator action, and there is a significant probability of failure in the time available (less than ten minutes). In the cut sets where ECCS injection occurs, the addition rate is inadequate and melting occurs. The probability that ECCS is available (i.e., could be actuated following core melt) is defined as the ratio of the frequency of cut sets with actuation failure to the total PDS frequency.

Only random failure of the WDS is modeled. The CHRS and RRSS are subject to operator failure to actuate and random failure. The AACS is functioning at nominal conditions.

\subsubsection{LOHS (PDS-I8)}

Accidents in this PDS are initiated by a complete stopping of cooling water flow to the heat exchangers. The initiating event for this PDS includes spurious cooling water header valve closures or spurious cooling water basin sluice gate closures. The reactor shuts down due to reduced cooling water flow. As the temperature of the water in the heat exchangers increases, the temperature of the primary coolant will reach the saturation temperature and start to boil. Both water and steam will be ejected though 
the reactor pressure relief system, depleting the inventory of primary coolant. Core melt is estimated to begin about four hours after reactor scram.

Injection of emergency coolant requires operator action and there is a significant probability of failure. There is one cut set where ECCS injection occurs, but the addition rate is inadequate to prevent melting. The probability that ECCS is available (i.e., could be actuated following core melt) is defined as the ratio of the frequency of cut sets with actuation failure to the total PDis frequency.

Only random failure of the WDS is modeled. The CHRS and RRSS are subject to operator failure to actuate and random failure. The AACS is functioning at nominal conditions.

\subsubsection{Loss of River Water (PDS-I9)}

This accident is initiated by a loss of the river water supply to the cooling water basin, which leads to complete depletion of the cooling water basin inventory. The reactor is shutdown. Failures in this PDS range from the operators not recognizing the loss of river water and doing nothing (depletion in two hours) to partially successful water conservation actions, which extend the time before core melt Thus, cut sets contributing to this damage state indicate a complete loss of cooling water which occurs from two to thirteen hours following the loss of river water makeup to the basin. A melt time of eight hours after scram will be assumed for this PDS.

Fuel melting for cutsets in this PDS develops slowly since the reactor is in a stable state until the basin supply is depleted. When the supply is exhausted, not only is the secondary cooling supply gone, but cooling water supply to other plant heat loads is also lost. This implies that the primary cooling system diesels will fail soon after the basin supply is exhausted. Thus, the primary system pumps fail and the accident progresses similarly to PDS-I1 or PDS-I2, but with no water in the pump room.

The ECCS and the RRSS are both failed due to the lack of cooling water makeup. There is no water on the pump room floor and no demand on the WDS, so the WDS is assumed to be in a failed state to simplify the analysis. CHRS is assumed to be available, subject only to actuation failu-..- (i.e., operator error) and random failure. However, the lack of water in th. Iasin means that there will be no CHRS makeup flow. The AACS is funci ing at nominal conditions.

\subsubsection{Plant Damage State Descriptions: Seismic Initiators}

Seismic PDSs are described in the following sections. The followisg assumed failures accompany each PDS. 
(1) River water make-up to the cooling water basin is lost due to loss of AC power to river water pumps, or due to failure of the feedwater pipes from the river to the basin.

(2) The ECCS is inoperative.

(3) The RRSS is inoperative.

(4) Reactor shutdown is coincident with the seismic event, caused by either the actuation of the SSS or from draining the moderator tank. Accident sequences with failure to scram occurred with a frequency of less than $10^{-10}$ per reactor year and were not included in the Level $2 / 3$ analysis.

(5) Confinement failure as the result of a seismic event is assumed in all of the plant damage states, and can occur by one of two mechanisms:

- Collapse of the fan/filter building or the reactor building resulting in a direct path from confinement to the environment, or

- Buildings remain intact but the filters fail mechanically resulting in direct bypass to the environment or the inlet dampers close blocking flow to the filters.

\subsubsection{1_LORW (PDS-S1)}

This PDS is characterized by the operator either failing to recognize low basin level or failing to throttle basin flow and to recirculate cooling water. The accident develops as a late loss of heat sink. Approximately 7 hours are required for the cooling water basin to drain through the heat exchangers under gravity-driven flow, so secondary cooling is maintained for 7 hours following scram. Accident progression is similar to PDS-I9 (Loss-of-River Water) except for the seismically-induced failures listed above.

\subsubsection{LOPC (PDS-S2)}

This PDS is characterized by a LOPC which occurs coincident with the seismic initiating event and reactor scram. Loss of circulation results primarily from relay chatter causing rotovalves in all six of the primary coolant loops to simultaneously close. Accident progression is identical to PDS-I7, except for the seismically-induced failures listed above.

\subsubsection{LOPA (PDS-S3)}

This accident is characterized by an internal flood (caused by a secondary cooling water header break) that results in flooding the AC and DC pump motors. The DC pump motors flood approximately 4 minutes after the 
initiating event. Accident progression is identical to PDS-I1, except for the seismically-induced failures listed above.

\subsubsection{LOCA (PDS-S4)}

This PDS is characterized by a primary cooling system pipe break. Piping or vessel rupture drains the vessel and results in fuel damage in a short period of time. Accident progression is identical to PDS-I3 except for the seismically-induced failures listed above.

\subsubsection{LOCA with Elood (PDS-S5)}

This PDS is unique to seismic events because it is characterized by a primary cooling system pipe break along with a secondary cooling water header break. Primary system pump motors flood within three minutes, and primary piping or vessel rupture drains the vessel and results in fuel damage in a short period of time. Accident progression for the PDS is similar to PDS-S4 or PDS-I3, but with a much greater quantity of water in the pump room.

\subsubsection{Vented LOPC (PDS-S6)}

This PDS is characterized by loss of primary circulation which occurs coincident with the seismic initiating event, as in PDS-S2. In addition, inlet plenum or inlet piping failure occurs due to seismically-induced building failure. Debris is assumed to fall onto the reactor tank and break the inlet plenum/piping. Rupture of the inlet plenum/piping leads to a configuration in which steam generated in-vessel can be vented without depressing the coolant channel water level. All other characteristics of this PDS are the same as PDS-S3.

\subsubsection{Vented LOPA (PDS-S7)}

This accident is characterized by an internal flood (caused by a secondary cooling water header break) that results in flooding the pump motors, as in PDS-S3. In addition, $\mathrm{D}_{2} \mathrm{O}$ plenum or inlet piping failure occurs due to seismically-induced building failure. Debris is assumed to fall onto the reactor tank and break the inlet plenum/piping. Rupture of the inlet plenum/piping leads to a configuration in which steam generated in-vessel can be vented without depressing the coolant channel water level. All other characteristics of this PDS are the same as PDS-S3.

\subsection{References}

2-1. M. D. Brandyberry, et. al., SRS PRA Of Reactor Operation - Level 1 Internal Events, WSRC-RP-89-570, Westinghouse Savannah River Company, Aiken, SC, June, 1990. 
2-2. M. D. Brandyberry and H. E. Wingo, SRS PRA Of Reactor Operation Level 1 External Events, WSRC-RP-89-733, Westinghouse Savannah River Company, Aiken, SC, June, 1990.

2-3. H. E. Wingo, Preliminary Seismic Probabilistic Risk Assessment of L Reactor, DPST-86-242, Savannah River Laboratory, Aiken, SC, January 22, 1986.

2-4. B. S. Spangler, et. al., Analysis of a Gang Withdrawal Transient, DPST-86-436, Savannah River Laboratory, Aiken SC, May 7, 1986.

2-5. W. H. Baker, et. al., Analysis of the Loss-of-Primary-Coolant From a Guillotine Break in the Control Rod Coolant Supply Header, DPST-86413, Savannah River Laboratory, Aiken, SC, June 2, 1986.

2-6. J. A. Smith, et. al., Analysis of the Loss of Power to the $115 \mathrm{KV}$ Electric Power Distribution System, DPST-86-580, Savannah River Laboratory, Aiken, SC, July 24, 1986.

2-7. B. S. Spangler and V. E. Logan, et. al., Analysis of a Medium Leak in the Cooling Water System, DPST-86-640, Savannah River Laboratory, Aiken, SC, August 29, 1986.

2-8. D. W. Stack, A SETS User's Manual for Accident Sequence Analysis, NUREG/CR-3547, SAND83-2238, Sandia National Laboratories, Albuquerque, NM, January, 1984.

2-9. R. L. Iman and M. J. Shortencarier, A User's Guide for the Top Event Matrix Analysis Code (TEMAC), NUREG/CR-4598, Sandia National Laboratories, Albuquerque, NM, August 1986.

2-10. R. L. Iman and M. J. Shortencarier, A FORTRAN 77 Program and User's Guide for the Generation of Latin Hypercube and Random Samples for Use with Computer Models, NUREG/CR-3624, Sandia National Laboratories, Albuquerque, NM, March 1984.

2-11. Seismic Hazard Methodology for the Central and Eastern United States, Vol. 1, Parts 1,2, (Revision 1), NP-4726-A, Electric Power Research Institute, Palo Alto, CA, November 1988.

2-12. V. Ho, N. Siu, and G. Apostolakis, "COMPBRN III - A Fire Hazard Model for Risk Analysis," Fire Safety Journal, 13, pp. 137-154, 1988.

2-13. Evaluation of Accident Risks in the Transportation of Hazardous Materials by Truck and Rail at the Savannah River Plant, WSRC-RP89-715, Westinghouse Savannah River Co., Aiken, SC, September 1989.

2-14. Jean Savy, Seismic Hazard Characterization of the Savannah River Plant, UCD-21596, November, 1988. 
This page intentionally left blank. 


\subsection{CORE MELT PROGRESSION ANALYSIS}

This section provides a brief overview of the treatment of the progression of core melt accidents in an SRS reactor beyond the point of incipient core damage. Its purpose is to provide perspective on the accidents that have been analyzed to accomplish the safety assessment. In general terms, the phenomena that determine core melt progression are similar to the phenomena that are assessed for commercial Light Water Reactors (LWRs). There are, however, important differences in the core melt progression in an SRS reactor because of differences in reactor materials, design, and operating conditions. The results of LWR analyses, therefore, cannot be directly applied to SRS reactors, and extensive mechanistic calculations of SRS reactor response were required. These are summarized in this section.

In this document, the term core melt progression analysis is used to refer to mechanistic analysis of a hypothetical core melt accident. It involves the application of mechanistic models for the physical processes and phenomena that accompany a severe accident. The term accident progression analysis is used to refer to the probabilistic analysis of the possible course of a severe accident. It involves the application of an event tree and simple parametric models to predict the conditional probabilities of various postulated accident results. Core melt progression analysis is the foundation upon which accident progression analysis is based. The need for accident progression analysis arises from uncertainties inherent in the current state of knowledge of severe accident modeling, combined with the stochastic nature of some of the processes involved. Were it not for the inherent uncertainties and stochastic nature of severe accident processes, mechanistic modeling alone could be used to predict the outcome of all severe accident scenarios. The discussion of accident progression analysis and how it fits into the probabilistic framework of the risk assessment is presented in Section 4.

A summary of core melt progression is presented in this section. The discussion, however, is not intended to cover all the possible plant conditions at the beginning of severe core melt. In particular, none of the seismically initiated accidents are discussed. Also, not all the phenomena or system failures that affect accident progression are described. Finally, the technical basis for the assumptions made and the outcome of the various phenomena is not provided. Much of this information is discussed briefly in subsequent sections of this document. More detailed information is supplied by the supporting documentation. These supporting documents are referred to during discussions of the specific phenomena later in this report.

\subsection{Accident Classes}

Severe core melt accidents involve either degradation of the heat removal capability or power increases beyond the heat removal capability of the reactor cooling systems. Thus, core melt occurs when there is a mismatch 
between heat generation and heat removal. During normal operation of the SRS reactors, the primary cooling system removes the heat generated by nuclear fission. Off-normal events that affect the primary cooling system's ability to remove this fission-generated heat can be postulated. In the vast majority of such events, the reactor shutdown system (consisting of the safety rods backed up by the Supplementary Safety System (SSS)) would stop the nuclear chain reaction, rapidly reducing fission power. If the offnormal event was a sufficiently large impairment to the primary cooling system, then the ECCS would be used to provide cooling for the shutdown reactor. Due to further heat generation from the radioactive decay of fission product elements, continued cocling is necessary following shutdown. Fuel melting occurs only if multiple failures occur, either in the reactor shutdown system, or in the actuation or operation of the ECCS following the initiating event. The analyst determines the conditions within the plant at the onset of core damage by knowing the nature of the initiating events and subsequent failures.

To provide a summary of core melt progression, accident sequences resulting in severe core melting have been grouped into four general classes of accidents. These classes are distinguished based on thermalhydraulic conditions in the primary system that are present when core melting begins. These conditions dictate the initial progression of the core melt. In the absence of operator intervention that arrests the accident, it progresses to the point where primary system components and structures are affected. As the accident progresses, characteristics that distinguish each of the accident classes lose importance. Moreover, accident progression following the completion of core melt relocation (and primary system failure if it occurs) is largely independent of the nature of the events that lead to core damage. The "loss of memory" that typifies severe accident progression is shown schematically in Figure 3-1.

Core melt sequences identified by the Level 1 analyses that are expected to share common behavior have been grouped into four accident classes:

(1) Loss-of-Pumping Accidents (LOPA);

(2) Loss-of-Coolant Accidents (LOCA);

(3) Loss-of-Heat-Sink Accidents (LOHS); and

(4) Transients.

The first three classes cover the various modes for reducing heat removal capacity, namely, stopping coolant circulation, losing the coolant through a break, or losing the ultimate heat sink. Transients include accidents in which local heat generation increases beyond the normal capacity for heat removal. All the important core melt sequences identified by the Level 1 analysis are placed into one of these broad classifications.

To simplify the description of core melt progression, a representative accident from each class is selected for consideration in the following discussion. Variations in the progression between accidents belonging to a 

particular class are not discussed. This approach allows the focus to be placed on the relevant phenomena rather than on the details of accident progression.

\subsubsection{Loss-of-Pumping Accidents}

This accident class is characterized by initiators involving a common-mode failure of the primary system coolant pumps. Failure of the pumps leads to a loss of the capability to transport heat generated within the core to the heat exchangers for removal. With the exception of a subclass of seismically initiated accidents, the primary system remains intact for this class of accident. Primary coolant inventory is only lost as a result of phenomena that accompany the accident (i.e., boiling in the assembly coolant channels). The reliability of the reactor shutdown systems is sufficiently high that all important sequences in this class of accidents include reactor scram. A characteristic of this accident class is that the reactor vessel contains a significant quantity of $\mathrm{D}_{2} \mathrm{O}$ when fuel melting begins.

The accident that typifies this class is initiated by a large break in a secondary cooling water inlet header that exceeds the capacity of the Water Disposal System (WDS). The reduction in cooling water flow to the heat exchangers results in reactor scram. Water from the break rapidly floods the pump and motor rooms. Within approximately three minutes, the primary coolant pump motors flood, and the pumps begin coasting to a stop. Flow in the primary system stagnates in approximately four minutes.

\subsubsection{Loss-of-Coolant Ascidents}

This accident class is characterized by initiators involving a break in the primary cooling system piping causing a loss of primary coolant inventory. Some or all the primary coolant pumps continue to operate. Reactor shutdown is ensured for this class of accidents. Not only does the reactor protection system respond reliably, but loss of the moderator from the vessel would terminate the nuclear chain reaction. Pipe break initiators will result in severe core melting if assembly coolant flow is not maintained through operation of the ECCS. A common trait of LOCAs is that the reactor vessel contains little water when fuel damage begins.

Results of the Level 1 analyses indicate that the most probable bre: occur in the expansion joints at the heat exchanger outlets or at the reactc essel outlet. However, the construction of the joints severely restricts the pcial flow area for coolant leakage. Other break locations also contribute the total frequency of accidents in this class. For simplicity, the ac nt selected to typify this class is an expansion-joint break in a pump si on leg resulting in a 5,000 gallon-per-minute leak. Reactor scram occurs is a result of low blanket-gas pressure. The ECCS fails because the inje: ion valves do not open. Aspiration of air into the coolant loops and subsequent pump cavitation begins within five minutes. 


\subsubsection{Loss-of-Heat-Sink Accidents}

This accident class is characterized by initiators involving a complete loss of cooling water supply to the secondary sides of the heat exchangers or loss of primary circulation through the heat exchangers as the result of valve closures. The reliability of the reactor shutdown systems is sufficiently high that all important sequences in this class of accidents include reactor shutdown. The decay heat generation in the reactor core causes the system temperature to increase until boiling in the primary coolant system occurs. Either pump cavitation or flow instability within the coolant channels would be the precursor to fuel melting.

The particular accident considered which typifies this class is initiated by a loss of river water supply to the cooling water storage basin. If water conservation measures fail, the cooling water basin will drain within a few hours (2.0 to 7.5 hours, depending on when or if the secondary cooling water pumps are tripped). Reactor operators may shut down the reactor when the river water supply is lost, as the basin inventory is depleted, or when cooling water flow to the heat exchangers is lost. Whatever the actual mechanism, primary system heatup takes place at decay heat power levels only. Fuel melting occurs within one to four hours after cooling water flow to the heat exchangers stops. The ECCS fails because the inventory of cooling water in the storage basin is depleted.

\subsubsection{Transients}

This accident class consists of initiating events and ensuing transients that are generally within the design basis (i.e., anticipated transients) combined with failure of the reactor shutdown system. These failures are modeled in this PSA to account for any contribution to overall risk posed by transients, even though the reactor shutdown system has a very high reliability. It is assumed that transients propagate to full core melt.

A localized power increase (such as would result from the inadvertent withdrawal of a single control rod) and a localized flow reduction (such as would result from the partial blockage of an assembly coolant flow channel) are contributors to this class of accidents. The inadvertent withdrawal of a control rod gang is also considered. This latter accident is not localized but would have similar characteristics given the assumptions that have been applied to this class of accidents.

Withdrawal of a single control rod has been used as an example of an accident in this class. The initiating event is the inadvertent withdrawal of a control rod at its maximum rate. Rod reversal is not modeled in the PSA, and, therefore, it is assumed to fail. Heat generation in the assemblies surrounding the control position increases. A scram signal would be generated, but the reactor shutdown system fails. Assuming withdrawal of the rod at the maximum rate, flow instability or fuel tube burnout occurs within one minute. Although total reactor power increases only a few 
percent, the local increase in assembly power is sufficiently large that melting will occur within seconds after the flow instability or burnout.

\subsection{Phases of Core Mlelt Progression}

Each of the accident classes described above progresses through se al common phases. Four phases have been identified for consideration:

(1) primary coolant system (PCS) thermal-hydraulic response,

(2) assembly melting and debris relocation,

(3) primary system failure, and

(4) confinement response.

These four phases are shown in Figure 3-1 and described in the subsequent subsections for each accident class.

\subsubsection{Primary Cooling System Response}

The first phase of the core melt progression is the thermal-hydraulic response of the Primary Cooling System (PCS). Response of the PCS to an accident initiator determines the time available until fuel melting begins and the conditions that exist in the primary system when it occurs. In this regard, each of the four accident classes has a significantly different response. The thermal-hydraulic response to each of the accidents is described briefly in the following subsections. The analysis that provides the basis for these descriptions is summarized in Section 5.

\subsubsection{Loss-of-Purnping Accidents}

As previously indicated, the LOPA being considered is characterized by cessation of primary coolant circulation caused by flooding of the primary coolant pump motors by secondary cooling water. Reduced secondary coolant flow to the heat exchangers triggers a reactor scram. The scram generally occurs sever:al minutes before primary circulation ceases. During this time, the temperature of the primary coolant decreases to approximately the temperature of the secondary cooling water. Once circulation stops, decay heat from the fuel tubes is transferred only to the cooling water in the assembly flow channels, not to the moderat $n$. This water quickly saturates and boiling occurs in the fuel channels. $F$-ever, water in the vessel (i.e., in the moderator space) remains subcoc The steam formed rises from the assembly flow channels into the $\mathrm{D}_{2} \mathrm{O}, \quad \mathrm{lm}$. Here, the steam contacts sub-cooled water and partially condense. The momentum imparted by the ejection of steam and water from :e assemblies pushes water from the plenum. Water displaced by the stee s expelled from the reactor through the pressure relief system. This pro ; continues until the steam and water in the plenum become saturated. that point, steam no longer condenses but instead accumulates in the $\mathrm{D}_{2} \mathrm{O}$ plenum. The plenum is pressurized by the accumulated steam causing the water level in the fuel assemblies to be depressed, uncovering the fuel. Once this occurs, the fuel tuibes heat up and begin melting (approximately 4 
minutes after circulation stops). At this point, the moderator space remains full of subcooled water.

\subsubsection{Loss-of-Coolant Accidents}

A LOCA is initiated when a large leak develops in the primary cooling system and the ECCS either completely or partially fails. Fuel melting occurs if the leak rate exceeds the ECCS capability to maintain a sufficient inventory of primary coolant, or if the leak is large enough to upset the flow distribution sufficiently to significantly degrade flow to some fuel assemblies.

For the expansion-joint bellows break, the moderator level in the vessel drops to the point at which air is entrained in the primary coolant loops. Flow out of the break decreases due to this air entrainment, but without water reserves, the primary coolant pumps cavitate. When this occurs, coolant drains from the fuel assemblies and inlet plenum, and the vessel level increases. The fuel tubes heat up in the absence of sufficient coolant flow. Partial restoration of level in the vessel allows the pumps to pump coolant again. However, when the level in the vessel drops, the pumps cavitate again. This oscillatory process continues until sufficient inventory has been lost through the break to prevent the vessel level from recovering. Melting begins soon afterward.

\subsubsection{Loss-of-Heat-Sink Accidents}

LOHS accidents are characterized by the loss of secondary cooling water flow to the heat exchangers. The primary cooling water continues to circulate. Without secondary cooling water, the primary cooling water heats up and eventually begins to boil. The assemblies remain cooled by the circulating saturated water.

Boiling occurs principally at the bottom of the reactor vessel, where the hot coolant from the assemblies flows under pressure to this comparatively low-pressure region. Steam and water are expelled from the reactor vessel vent paths. Eventually, the vessel level decreases to the point at which the primary pumps cavitate. The accident then behaves in a manner very similar to the LOCA except that the coolant is boiling. Boiling, rather than leakage, leads to inventory depletion and loss of cooling.

\subsubsection{Transients}

The initiator that is used to characterize this accident is an inadvertent withdrawal of a control rod in a single septifoil. When this occurs, the six fuel assemblies surrounding the septifoil location increase in power. Effective fuel tube cooling is lost by one of two possible mechanisms. If the fuel surface heat flux exceeds the critical heat flux (CHF), a transition from nucleate to film boiling will occur, and the fuel tubes will melt. The second possible mechanism is flow instability leading to dryout. The reactor is designed to cool the fuel assemblies with single-phase subcooled liquid flow. 
When power in an assemibly increases beyond normal operating limits, net vapor generation can occur and a two-phase mixture can flow to the assembly outlet. The pressure drop at the outlet for two-phase flow is much larger than that for a single-phase liquid. This retards flow in the affected assembly since the stagnation pressure is limited by the $\mathrm{D}_{2} \mathrm{O}$ plenum pressure. Reduction in the flow promotes further vapor generation. Eventually, vapor production slows within the assembly because the fuel tube surface becomes blanketed with steam. Cooling water then re-enters the assembly. This process can repeat itself, but eventually the fuel tube surface temperature exceeds the minimum film boiling temperature. When this happens, cooling will not be re-established, and the fuel will melt. Melting under these high flow conditions (approximately $6 \mathrm{~m} / \mathrm{sec}$ water flow rate) is assurned to lead to the formation of fuel particles that range in size from a few hundred microns to nearly $1 \mathrm{~cm}$ in diameter.

These particles may be entrained in the coolant flow, and a substantial fraction is assumed to be carried through the holes in the bottom end fitting (BEF) into the moderator. Heat generation continues within the particles as they are transported. Smaller particles will freeze, giving up their heat to the coolant. Larger particles will remain molten. At full power, sufficient heat is transferred to the coolant to produce boiling in the moderator when the particles enter from the BEF. A significant fraction of the particles escaping the BEF is swept from the vessel into the coolant loops by the coolant flow. Plugging of the heat exchangers to the extent that the reactor core can no longer be effectively cooled is assumed to occur. With the coolant flow paths blocked, it is expected that a full core melt would occur with the reactor vessel full of $\mathrm{D}_{2} \mathrm{O}$. The subsequent progression would be similar to that of a LOPA except that the water in the moderator space would not be subcooled.

\subsubsection{Assembly Melting and Debris Relocation}

The manner in which the fuel assemblies will melt depends upon the thermal-hydraulic conditions in the reactor. Generally, two types of melting behavior are considered to be possible, fuel melt by candling and fuel breakup into particles.

Candling behavior has been assumed for all low-flow or no-flow conditions. Nearly all the decay heat generation occurs in the fuel tubes, so these will begin melting before the target tubes or the Universal Sleeve Housing (USH). The target tubes will heat by radiation and convection heat transfer from the fuel tubes. It is also possible that heat conduction through the rib spacers that separate the fuel and target tubes will occur if significant contact is established. As the fuel material becomes molten, gaseous fission products trapped in the fuel material will migrate to grain boundaries and form bubbles, causing its volume to increase. Bubble formation and growth will lead to fuel swelling. Fuel foam is likely to be generated. The cladding, which has a slightly higher melting temperature than the fuel, is likely to crack. The fuel foam will then expand into the coolant channel. Contact between the foam and adjacent target tubes is likely. As the foam continues 
to heat, the foam will tend to collapse and the liquid fuel will relocate downward. The molten fuel material (debris) will run down the intact fuel as droplets, or perhaps as a molten film. The droplets may grow large enough to contact the adjacent target tubes and transfer heat to them by conduction. As the molten fuel relocates, it may freeze due to contact with colder fuel or target material and then re-melt as it continues to generate heat. When molten debris reaches the bottom of the tube, it will drop into the BEF.

During melting, the noble gases will be released along with some of the volatile fission products. Some aluminum-steam reaction may also occur, producing hydrogen (or deuterium) gas. It is probable that some of the target tubes will melt during this relocation process. Whether or not this occurs depends on the effectiveness of heat transfer from the fuel foam. In particular, if the fuel foam has a very high effective viscosity, it may remain in place long enough to cause target melting.

Fuel melting as particles can occur if melting takes place under high coolant flow conditions. These particles are assumed to be entrained in the coolant flow. The assumptions are based on the results of early experiments involving steam flow at Mach 0.5 past an inductively heated aluminum tube. Analysis techniques that will provide a more thorough understanding of these accidents are currently being developed. Preliminary results from this ongoing analysis suggest that much lower coolant flow velocities, which lower the potential for fuel fragmentation, would occur in these accidents.

It is the assumption of fragmentation that leads to the further assumption that a full core melt ensues for scenarios where damage begins locally. Two mechanisms are considered. First, relocation of the fuel debris to the moderator region of the vessel may lead to a reactor power excursion that results in inadequate cooling of other assemblies. Second, the debris may collect in the heat exchangers and cause a reduction in coolant flow. If the fuel did not fragment, or if fuel particles were sufficiently large so as not to be transported by the coolant flow, damage could be restricted to the assemblies affected by the initiator. The assumption of propagation to a full core melt is clearly conservative.

3.2.2.1 Debris Relocation in a Vessel Full of Water

Several of the accident classes can have fuel melt occurring with a substantial quantity of water in the reactor vessel. The LOPA has been selected to describe debris relocation when the reactor vessel is full of water.

During a LOPA, fuel melting will occur with steam flow velocities averaging less than $1 \mathrm{~m} / \mathrm{s}$. Thus, fuel is likely to melt by candling. Since the moderator space within the vessel will be filled with water, some water will be present in the bottom of the assemblies. The depth of water is established by the balance between the steam flow pressure drop and the hydrostatic head of the moderator. Debris that initially relocates from the fuel tubes into 
the BEFs would be experted to quench. The resulting steam generation will increase the pressure in the coolant channels forcing the water level down. It is expected that soon after debris relocation begins, the water level will have been depressed to the level of the shell holes in the BEF. Subsequent droplets of molten debris will contact structures in the BEF directly.

As debris accumulates in the BEF, boiling on the outside surface is expected to freeze the debris and prevent the BEF wall from melting. Both the shell holes in the BEF and the penetrations in the monitor pin below it are expected to become plugged with frozen debris. Thus, in the accident scenarios where water is present in the reactor vessel during fuel melt, the debris will likely collect in cylindrical columns separated by moderator. The debris in this configuration is composed principally of the aluminumuranium fuel with target and cladding material intermixed. Without substantial target material relocation (70 percent or greater), this configuration will become critical when a sufficient debris height is reached. Fission power is subsequently produced that will melt the debris and the BEFs, allowing the debris to slump into a sub-critical configuration. The debris temperature attained in this event may be as high as $1500-2000 \mathrm{~K}$ if little target material relocates. When debris at high temperatures contacts the moderator, an energetic interaction that rapidly produces steam and hydrogen may result. The pressures generated within the vessel may lead to failure of the vessel top shield or the bottom of the vessel.

The accident progression analysis considers events that can prevent the recriticality. These include early steam explosions during the melting phase that disrupt the core geometry, early melt-through of the BEF before a critical geometry is attained, and relocation of a large fraction of the lithium target material into the BEF. In addition, the rate at which energy is deposited in the debris from nuclear heating may be sufficiently small that the configuration slumps to the vessel bottom (where recriticality is very unlikely) before sufficient heat is deposited to drive an energetic interaction with the moderator. In the absence of an energetic event, the debris may be cooled in a layer on the bottom of the tank as a result of the combined effects of heat transfer to the steel structure of the vessel and boiling of the moderator. If no reserve is available from the ECCS, the moderator inventory will eventually boil off, and the debris will re-melt. Once molten, the accident will proceed as in the dry-vessel cases $c$ ibed in the following paragraphs.

\subsubsection{Debris Relocation in a Dry Vessel}

For the accidents that typify both the LOCA and LOHS classes, the ve 1 will be essentially dry when fuel relocation occurs. At most, a few ten: $f$ centimeters of $\mathrm{D}_{2} \mathrm{O}$ will remain on the vessel bottom. Without a substantial amount of $\mathrm{D}_{2} \mathrm{O}$ in the vessel, the debris will not cool in the $\mathrm{BEF}$, and the $\mathrm{BEF}$ will melt during the debris accumulation process. Without moderator, the debris cannot attain a critical configuration, so the possibility of recriticality is eliminated. The debris that is released when the BEFs melt will initially 
freeze on the vessel bottom because of heat loss to the vessel bottom plate. The debris will rapidly re-melt due to continuous decay heating and as a result of additional molten debris accumulating on the frozen material. Cooling water circulating in the bottom shield of the reactor will not be effective in cooling the debris because steam will become trapped against the underside of the bottom plate, restricting heat transfer. As the pool of molten debris deepens, it will spread out to the vessel walls. Here it will encounter the coolant outlet nozzles of the reactor and the muff structures within them. The muffs are stainless-steel plates that are located in the effluent nozzles to provide biological shielding. They are approximately $1.5 \mathrm{~cm}$ thick separated by approximately $1.5 \mathrm{~cm}$ gaps. The muffs occupy the first 20 or more centimeters in the effluent nozzles. It is possible that the debris will be held in the vessel for a long period of time due to freezing within the muff, but analysis indicates a high probability that the debris will flow rapidly through the muff into the vessel piping.

\subsubsection{Debris Relocation as Particles}

The transient is the only accident scenario in which fuel degradation can occur while the reactor remains at power. Experimental evidence has shown that the fuel may melt as particles under high flow conditions.

If debris is transported into the moderator space as particles, given the particle distribution obtained from the experiment, approximately 60 percent will quench. Debris would exit the reactor vessel through the outlet nozzles, and flow through the pumps into the heat exchangers. Much of the debris will probably be trapped here, since the flow passages through the heat exchanger are small. The heat exchangers may become partially or totally blocked by this debris and reduce primary coolant flow through the intact assemblies.

Fuel relocation will terminate the reactor power transient since the core inventory of fissile material is reduced. Analysis indicates that if the reactor is operating at $2500 \mathrm{MW}$, quenching of the particulate debris will lead to moderator voiding sufficient to produce rapid shut down or at least a rapid decrease in power. While the intact assemblies will likely be operating at a reduced power level, it has been assumed to be higher than can be cooled by the reduced flow. This will result in the accident propagating into a full core melt. If the primary coolant flow is reduced significantly because of debris plugging of the heat exchangers, it is probable that the remaining assemblies will melt with candling behavior with the vessel full of water as in a LOPA. The characteristics of a LOPA are expected to follow from this point in the sequence.

Another possible progression has been identified for this accident, based on the possibility of convection of small particles of fuel up into the active core region. The debris particles that exit the $\mathrm{BEF}$ in particulate fuel melts can be small. A significant fraction (perhaps half) of the particles may become entrained in the bulk moderator flow and may be convected up into the moderator space in the active core region. In the absence of large void 
production, this may result in an increase in reactivity and a reactor power excursion. The occurrence of a reactor power excursion is sensitive to particle distribution and void formation in the moderator. This is not considered to be a probable outcome but is a possibility. Were reactor power to increase, the intact fuel assemblies would transition to film boiling and exceed their melting point very quickly. A large steam explosion involving a substantial fraction of the fuel would probably follow. Such a steam explosion may result in the failure of both the top and bottom of the reactor vessel.

\subsubsection{Primary System Failure}

The fuel tube melting and relocation process is considered to have two possible outcomes. The first, more likely outcome, is that a debris bed will form on the reactor vessel bottom. The alternative is that an energetic event (i.e., a steam explosion) will result in the failure of the reactor vessel bottom. Failure of the vessel bottom would terminate the in-vessel phase of the accident. Core melt progression from the point at which a debris bed forms has been extensively analyzed. The overall picture of how primary system failure can occur is discussed in this section.

\subsubsection{Dry Vessel}

Debris from the melted assemblies first collects on the vessel bottom. Since the assemblies toward the center of the core operate at higher power than those on the periphery, clebris accumulates first at the center and spreads outward. Initially, the debris tends to solidify as a result of contact with stainless steel structure. As more debris is added from the melting assemblies the debris bed begins to liquefy and spread outward. Within approximately 5 minutes, a largely liquid debris pool covers the entire vessel bottom. If the debris is sufficiently inviscid it will penetrate the coolant outlet nozzle muffs at the periphery of the vessel. This is the expected outcome based on knowledge of the viscosity of liquid aluminum. Since the viscosity of U-Al melts is not readily determined, some uncertainty exists whether the debris will flow into the coolant pipes. If debris flows into the coolant piping, three dispositions are considered to be possible:

(1) Because the piping will contain water, an explosion may occur that causes the pipe to fail. The debris would then flow directly onto the pump room floor.

(2) If the pump room were filled with water to the extent that the piping is submerged above the level of debris collected within the pipe, the debris will eventually freeze within the pipe, terminating the melt progression.

(3) If the piping is not submerged, it will melt within 5 to 10 minutes. Liquid debris at temperatures that could be as high as $2000 \mathrm{~K}$ would flow onto the pump room floor. 
If flow into the piping is prevented by debris solidification within the effluent muffs, the debris would heat up while in contact with the vessel bottom. Heating of the top surface of the bottom shield (which forms the vessel bottom) will severely weaken the structure. Collapse of the bottom shield due to thermally induced buckling would occur when the debris temperature reaches $1500-1800 \mathrm{~K}$. The entire core, plus the bottom shield structure would then fall into the pin room.

\subsubsection{Water-Filled Vessel}

If water is present within the vessel, the timings associated with primary system failure may be different, but the modes of failure will generally be similar. In the absence of a steam explosion that fails the reactor vessel, debris from the melted assemblies will likely form a debris bed on the vessel bottom. If the vessel water is sufficiently subcooled, freezing of this debris without flowing through the muffs could occur. Eventually, however, heatup of the moderator will result in inadequate cooling, and failure of the bottom shield will take place. Alternatively, debris could flow into the reactor effluent piping, which will also contain water. The same three possibilities discussed above for a Dry Vessel are also valid for the wet vessel scenario.

\subsubsection{Confinement Response}

The AACS is intended to retain radioactive fission products that are released from the fuel and prevent their release into the environment. The AACS draws air through the reactor building, filters the air to remove water, airborne particles and iodine vapor, and then passes the filtered air up a stack. If negative pressure is maintained within the reactor building, virtually all the fission products (except for noble gases and tritium) will be retained on the filters. Severe accident phenomena present a significant challenge to the AACS that may limit its effectiveness. Three failure modes are considered to be associated with the progression of a core melt accident:

(1) Thermal failure of the filters may occur due to the decay heat of deposited fission products. Aerosols carrying fission products provide a heat source and tend to plug the filter reducing the airflow that provides cooling. Ignition of the charcoal filter elements and/or melting of the High-Efficiency Particulate Air (HEPA) filters may result.

(2) Mechanical failure of the filters (i.e., bursting or tearing of the filters or compartments) may occur as a consequence of energetic events within the building. Temporary elevation of the building pressure due to a steam explosion or hydrogen combustion may increase the flow rate to the point that excessive differential pressure is applied across the filters, resulting in failure. 
(3) Building failure leading to filter and stack bypass may occur as a consequence of larger energetic events within the building. Mechanical failure of the filters frequently, but not always, accompanies such failures. Dominant failure modes are failure of the actuator tower above the reactor and lifting of the heat exchanger and motor room hatch-covers that seal the below-grade equipment removal access hatches.

\subsubsection{Fission Product Release}

Since the AACS confines fission products, its performance and severe accident response must be viewed with respect to the release of fission products into the reactior building atmosphere. Fission products are released from the molten fuel debris in several stages. First, when the fuel and target tubes melt, gaseous fission products (and tritium) are released within the reactor vessel. As the debris heats up following relocation to the vessel bottom, the volatile fission products evolve from the debris. This process can happen in-vessel or after the vessel is breached. Nonradioactive carrier gases such as steam, hydrogen, and even lithium and cadmium that could be present in the core debris, may transport fission product aerosols. The fission products are generally given off as elemental vapor that rapidly oxidizes. Because the oxide is less volatile, the fission products condense to form aerosols. An important exception is iodine, which can remain as a vapor. The quantity and composition of the fission product release to the AA.CS depends upon the temperature that the debris attains, the time spent at temperature, and the location of the debris when the release occurs. Location is important, in that once the debris reaches the confinement floor, it may react chemically with the concrete basemat. The interaction further heats the debris to produce hydrogen gas and aerosols. Important mechanisms that can trap fission products within the confinement before they get to the AACS filters include scrubbing by overlying water, aerosol settling, and condensation on cold surfaces. Of these, scrubbing by water is the most significant.

\subsubsection{Energetic Events}

Energetic events, which result primarily from the interaction of molten debris with coolant (water or $\mathrm{D}_{2} \mathrm{O}$ ), may severely impact the confinement response. Combustion of the hydrogen produced from MCCI $I$ also impact the progression of a core melt accident. The principa. de of molten-fuel-coolant interaction (MFCI) is a steam explosion. - eam explosion results when intimate contact between debris and water. is to rapid superheating of the water and subsequent explosive expan :, as vapor. Steam explosions may cause damage to the confinement str re either by direct blast effect or by pressurization resulting from rapid $\mathbf{m}$ generation. The latter effect is more important to the response of he confinement system. Since the confinement building structure is gent ly massive, few important structures are susceptible to blast effects. 
Steam explosions may occur either in-vessel, during the debris relocation process, or ex-vessel subsequent to primary system failure. An ex-vessel steam explosion would occur only if water is present on the pump room floor. This is probable since procedures would direct that the CHRS be actuated. The CHRS would cover the pump room floor with water to a minimum depth of $20 \mathrm{~cm}$ ( 8 inches). Steam and hydrogen production from an ex-vessel steam explosion can burst open doorways from the below-grade areas to the personnel areas within the reactor building. The hatch covers over the equipment hatches at grade level may also be dislodged. This damage creates a bypass pathway by which fission products may escape directly to the environment. In-vessel steam explosions can cause belowgrade damage similar to ex-vessel steam explosions, and could cause a breach of the reactor vessel that would pressurize the reactor room. This may lead to failure of the filter elements and the exhaust fan casings as a result of excessive differential pressure. The filters are then assumed to be completely bypassed and the volatile fission products previously deposited are assumed to be at least partially revolatilized. Significant hydrogen generation occurs only during MFCI or MCCI.

The temperatures attained during assembly melting are not sufficiently high to allow substantial hydrogen production. The combustion of hydrogen produced during an MFCI augments the resultant pressure but does not alter the potential effect other than increasing the probability of damage. Operation of the exhaust fans prevents combustible concentrations of hydrogen produced by MCCI from forming. However, if the exhaust fans fail, below-grade hydrogen combustion may occur. In general, ignition sources are plentiful within the confinement; therefore, the hydrogen would likely burn before large concentrations were built up. Overpressurization failures of the below-grade confinement doors due to combustion events are unlikely, and dislodging the hatch cover(s) is even less likely. Since the fans will have already failed (otherwise, low hydrogen concentration would preclude combustion), and the filters will be bypassed or without cooling, hydrogen combustion will not dramatically influence accident consequences.

\subsubsection{Presence of Water}

Water on the confinement floor may affect the progression of a core melt accident in three ways. First, it can lead to MFCI which can reduce fission product retention. Second, water will tend to retain fission product vapors and aerosols thus reducing the filter loads. Third, it can quench the debris, alleviating, or terminating, the accident.

Dispersal of the debris into the water following MFCI may lead to debris quenching, which terminates the accident. If the debris does not quench, MCCI may occur beneath the water. The overlying water can scrub a significant quantity of aerosols from the escaping gas. Filter loading and the potential source term are thus reduced. The presence of water also reduces the thermal load to the pump room air which improves the ability 
of the airflow to cool the filters. Thus, water can either exacerbate or mitigate accident consequences depending upon the phenomena involved.

\section{Idealized LOHS Axcident}

At this point, it is instructive to consider the progression of a core melt accident that does not place excessive mechanical loads on the system. Accidents in the LOHS class, in which the primary coolant continues to circulate, seem most likely to evolve in this manner. Since the water available is generally limited to the original $\mathrm{D}_{2} \mathrm{O}$ inventory (which is substantially evaporated before severe core melt occurs) the potential for either a steam explosion or hydrogen production leading to energetic combustion is small.

As the fuel tubes melt, noble gases and tritium are released from the fuel and target tubes. Over the next hour, these materials will be exhausted through the stack. The debris temperature rises as the assemblies melt and the material collects on the vessel bottom. Iodine and cesium are released from the melt first. It is expected that most of the iodine will form cesium iodide and condense to an aerosol. Some, however, may transport as I2 vapor. Cesium iodide will be retained by the HEPA filters. The charcoal filter elements will retain the I2. Deposition of these fission products will tend to heat the air as it passes through the filters. The temperature of air drawn through the exhaust fans will then increase. If debris accumulates in the primary coolant pump casings and associated piping, continued heating of the debris leads to the release of cadmium, lithium, tellurium, and strontium. These materials oxidize as they transport to the filters. The resulting mass loading on the HEPAs reduces the airflow through the AACS. Reduced airflow combined with greater decay heat-loading further increases the temperature of both the filters and the air passing through the fans.

Following primary systern breach (either failure of the vessel or the reactor effluent piping), the liquid debris will likely accumulate in the pump room sumps. Due to the high temperature of the debris, molten core-concrete interactions (MCCI) may begin. MCCI involve ablation of concrete and subsequent reaction of the decomposition gases with the molten fuel. Hydrogen gas is released to the confinement atmosphere. The MCCI reaction is exothermic and the debris temperature will be maintained at approximately $2000 \mathrm{~K}$. The gas sparging through the liquid metal and concrete debris causes large quantities of aerosols to be generated. Rates of aerosol generation in excess of $100 \mathrm{~kg} / \mathrm{hr}$ may occur. These aerosols consist principally of aluminum and concrete constituents. Some of the less volatile fission products such as ruthenium, lanthanum, cerium, and barium are released by the sparging process. Any volatile species that remain will be evaporated by the high temperatures. Aerosols generated by MCCI will be transported to the HEPA filters by the AACS flow, and airflow will be reduced further. The airflow remains sufficiently large to prevent hydrogen gas from accumulating to combustible concentrations. However, the air 
from below grade is heated by the MCCI pool. This further increases the temperature of the filter elements. Desorption of any molecular iodine retained by the charcoal filters would likely occur, and subsequent ignition of the charcoal is possible. It is assumed that ignition of the charcoal would lead to melting of the HEPA elements and subsequent release of the more volatile fission product elements trapped by the HEPA elements. 
This page intentionally left blank. 
In the unlikely event of a core melt accident, the primary barrier to the release of fission products, the fuel cladding, will have been breached. The remaining barriers to the release of fission products are the primary system structure (i.e., reactor vessel and associated piping) and the confinement system. To determine the potential consequences of such an accident, the systematic tracking of the progression of the accident in terms of the extent of damage to these barriers is required. Accident progression analysis involves the application of logic models, supplemented by mechanistic evaluations, to track possible accident sequences from the initiating event, through fuel damage and primary system failure, to the final state of the confinement system. The principal goal of the analysis is to evaluate the success of the confinement system in mitigating the release of fission products to the environment.

\subsection{Accident Progression Event Tree}

The accident progression representation developed for SRS reactors is referred to as the APET. The APET consists of a series of questions pertaining to events that may occur during the progression of a severe accident. Each question is analogous to a top event in a classical event tree, and a graphical presentation of the APET resembles an event tree in which a node may have one or more branches. Figure 4-1 provides a simplified graphical presentation of an APET that considers some very limited aspects of accident progression. The possible answers to the questions are specified in terms of two or more discrete outcomes represented as branches. Assignment of the probability of a particular branch in a given accident progression may be dependent on the branches taken in previous questions. That is, the APET model allows for a sequence-specific representation of accident progression.

Each event in the APET pertains to either

(1) phenomena that occur in-vessel related to the progression of core melt,

(2) phenomena that occur within confinement after the core debris and/or radionuclides exit the reactor vessel, or

(3) the response of a mitigating system to the challenge posed by the core debris and/or radionuclides that exit the reactor vessel.

The APET contains 131 questions that detail the possible progression of core melt accidents. Approximately a dozen questions directly indicate substantial measures of confinement performance. The remaining questions provide the basis for evaluating the outcomes of those events directly affecting confinement performance. That is, those remaining questions define the outcomes of fundamental events (such as the water 


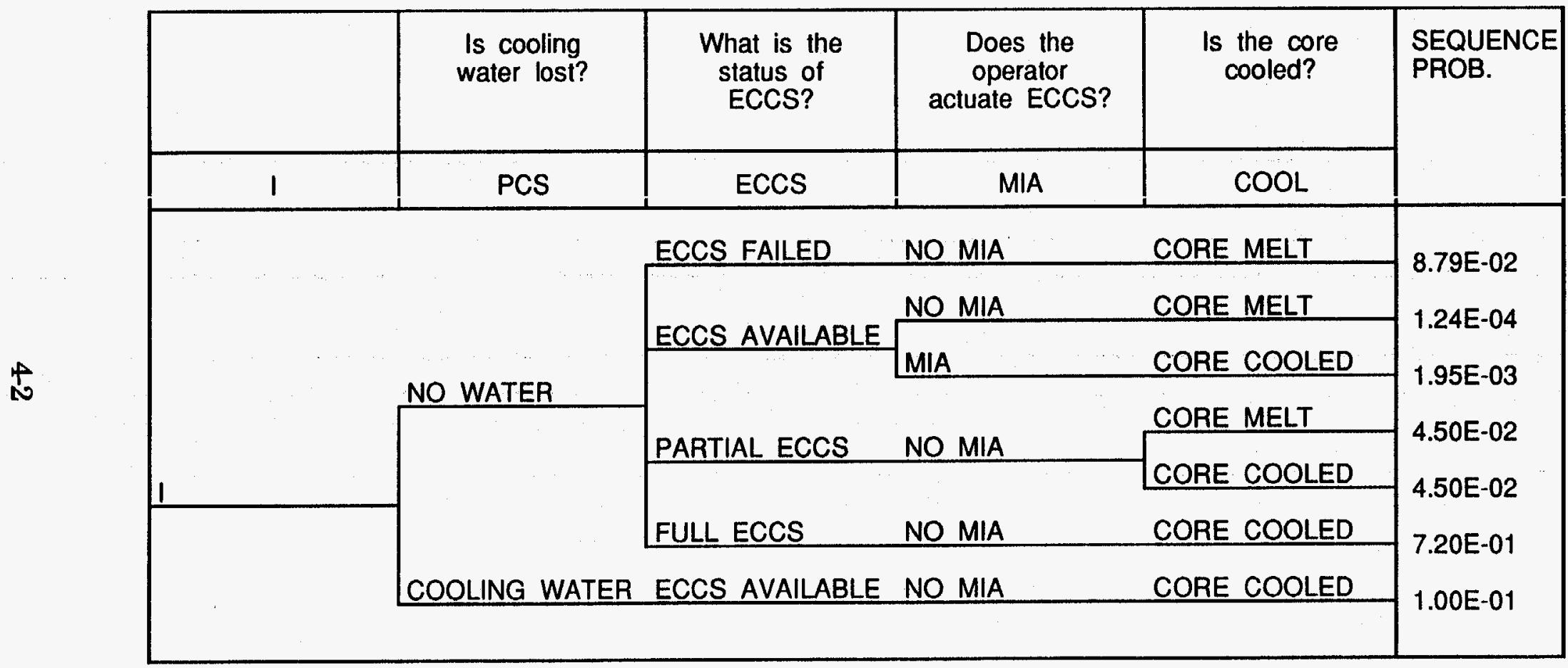

Figure 4-1. Sample APET 
level and degree of subcooling of the reactor vessel water) which are used to determine the outcomes of those events that directly affect confinement system performance (such as energetic steam explosions).

The APET incorporates sufficient detail to ensure that the answers to questions leading up to any point in the accident progression supply information adequate to provide a reasonable estimate of the outcome of the next event considered. The level of detail is such that the logic used to evaluate the outcome of phenomena is sufficiently represented in the APET. At the same time, the inclusion of questions at a level of detail greater than would be supported by the current level of understanding of the phenomena is avoided.

In a few instances, mechanistic calculations have been incorporated into the APET to determine the outcome of phenomenological events. This is accomplished by specifying the functional relationship between the outcome of an event and the parameters that describe it. The three uses of this functional relationship in the APET are calculations of

(1) the level of water in the pump rooms,

(2) the fission product and aerosol loading on the filters, and

(3) the temperature of the charcoal filter elements.

For these calculations, numerical parameters are assigned that quantify the outcome of an event indicated by a particular branch. For instance, the question pertaining to the status of the ECCS shown in Figure 4-1 may have a parameter associated with it. That parameter could indicate the amount of water that flows into the pump room. For the upper two branches, the value of the parameter would be zero. For the second two branches the value would be 7,000 and 14,000 gallons per minute, respectively. A subsequent question might determine the water level in the pump room. To evaluate the outcome of that question, the water level could be calculated based on the value of the ECCS flow rate and the elapsed time specified by yet another question. The numerical result of the calculation would be parsed into discrete levels, and the branching ratios in the pump room water level question would be set such that the appropriate branch had a probability of unity and the other three branches would be zero. The APET incorporates similar, although more complex, logic to evaluate the pump room water level at various times along each accident progression pathway.

The APET was developed in parallel with the mechanistic calculations that were being performed, and the results of the mechanistic calculations helped define the progression of the accident. Furthermore, insights gained from the preliminary APET development helped define analysis tasks so that the calculational effort remained focused on accident progression issues that were important to APET development and quantification. Previous PSAs have been initiated with a series of calculations to model the 
assumed progression of specific accidents. The PSA analyst was required to forecast the progression of sequences identified from the event trees as being important from existing analyses. A match between the sequences mechanistically analyzed and those found to dominate event tree results was rare. The PSA analysts often found it necessary to extrapolate available calculations into situations that could occur but were not analyzed. Most mechanistic codes incorporate assumptions relative to the behavior of phenomena when there is considerable uncertainty (i.e., the model removes or limits the uncertainty). The direct application of mechanistic codes predicts a specific accident progression for a given set of plant conditions at core melt, while the event tree model for progression may include many variations in the accident progression for the same set of core melt conditions. Such differences in modeling perspective are only realized when the event tree and mechanistic analysis work together to expand the range of possibilities covered by the mechanistic model and focus the event tree model on physically reasonable sequences. This is the basic function of accident progression analysis.

The development of the APET is summarized in the following subsections, and a summary of the APET is presented in Table A-1 (located in Appendix A). The table includes (1) a list of top events (questions considered in characterizing the progression of the accident), (2) the previous question that each top event is dependent upon, and (3) the succeeding questions that are affected by the question.

\subsubsection{APET Development and Structure}

Development of the APET was based on consideration of the phenomena that accompany a severe accident. First, the various phases of the accident were identified on the basis of experience gained from LWR PSAs. Analysis of the SRS reactors was then undertaken to study these phases individually. The initial results of these studies were used to develop a preliminary APET and establish the relationships between the phenomena that accompany various phases. Once this analysis was complete, the preliminary APET was refined, and the initial phases of the accident were further subdivided to recognize the importance of the time sequence of events. Questions were added that addressed all important phenomena. Areas of phenomenology that were judged to be important were further analyzed. The final analyses were used to make refinements to the structure of the APET and to quantify the branching ratios. The result was an APET that represents severe accident progression in an SRS reactor. The analytical bases for the APE ? are summarized in Sections 5 and 6 of this report. Supporting documen: provide descriptions of the analyses and a detailed presentation of result: These documents are individually referenced during discussion of the phenomena in Sections 5 and 6.

Four distinct time phases are considered within the APET. These phases are described in this section, and the phenomena that accompany each phase are indicated. Figure 4-2 shows the relationship between the time phases considered by the APET and the mechanistic analyses that were 
performed in support of the APET development. It should be noted that some aspects of the analyses were pertinent to more than one time period or accident phase. The figure indicates where certain types of analyses were considered in the APET development over several time periods. Other analyses are pertinent to only one period of accident progression. The following discussion explains the relationships between the areas of analysis and the APET accident phases indicated in Figure 4-2.

(1) The Early Phase includes the time from the onset of core melting up to (but not including) failure of the primary system. This time can range from a few (less than 5) minutes up to several (as many as 10) hours. This phase is represented by Questions 1 through 75. The progression of fuel damage, melting and relocation of the core material, and the subsequent behavior of the core debris are the primary considerations during this phase of the accident. The confinement response to releases of steam, water, and fission products from the primary system is also part of the accident progression for this phase. Each of these regimes of in-vessel behavior involves slightly different considerations, so this phase was further subdivided into three time periods:

(a) The Initial Period covers the state of the plant at the onset of core melting. Questions 1 through 24 in the APET represent this period. Most of the considerations for this period are provided by the plant damage state definitions (described in Section 2). Actions that the plant operators may take during the early phases of the accident are also included. Consideration is also given to the status of the AACS, RRSS, CHRS, and other systems that may act to mitigate the accident. Analysis of primary system thermal-hydraulics was undertaken to evaluate the conditions within the primary system at the onset of core melting and to identify possible regimes of behavior.

(b) The Second Period covers the progression of the accident during the melting and relocation of core materials. Questions 25 through 39 represent this period. Principal issues considered are the potential for recriticality and interactions between molten fuel and coolant (i.e., steam explosions), which could promote the release of fission products or even damage the confinement structure. The APET addresses the manner in which fuel melt occurs and the impact that this may have on these energetic events. Analysis of fuel melt behavior, including the potential for hydrogen production, was undertaken to support this phase of the APET development. 


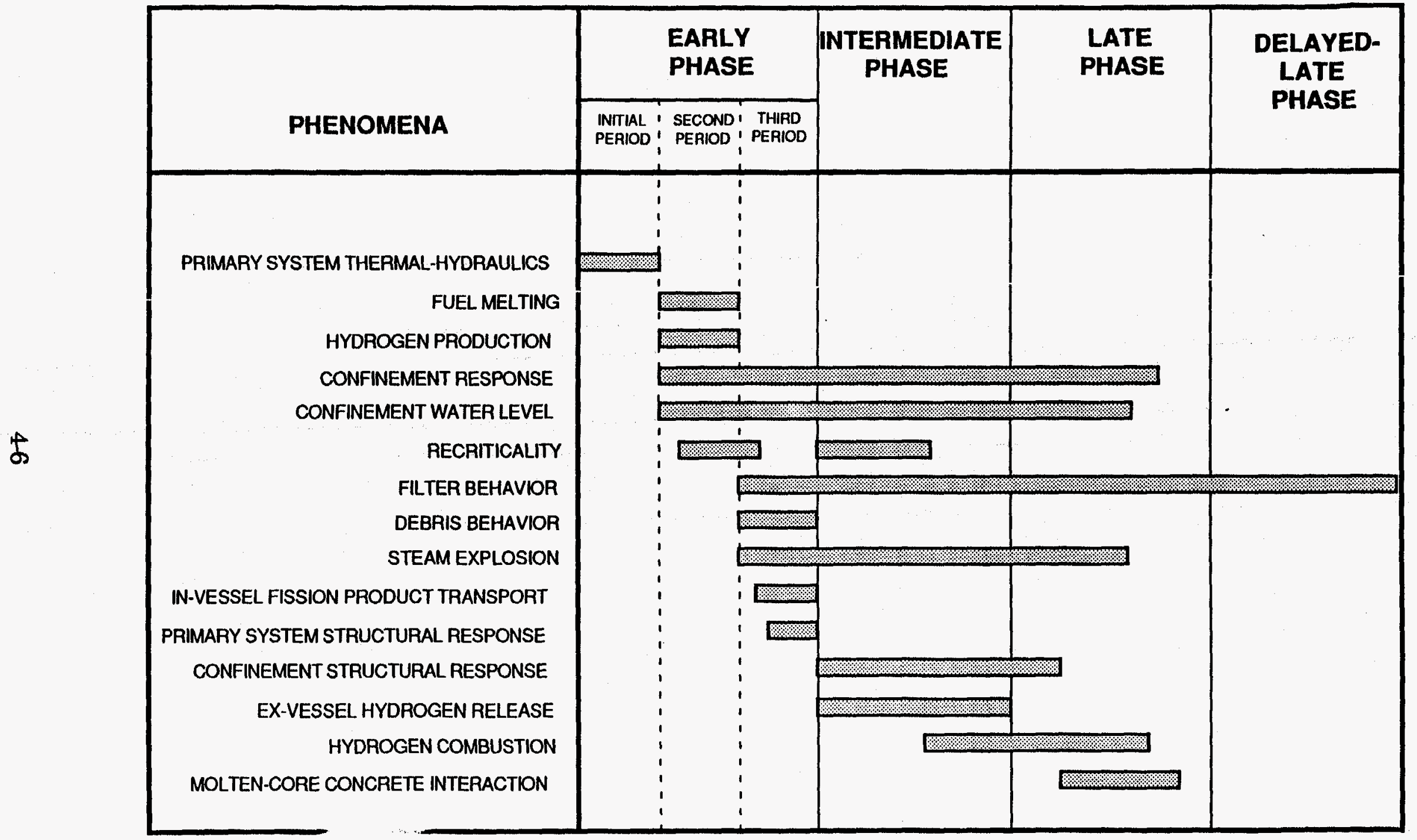

Figure 4-2. Overview of the APET Structure 
(c) The Third Period covers the primary system response to the accumulation of molten core debris below the core region. Questions 40 through 75 represent this period. The thermal interaction of the debris with the vessel structure and associated piping is the major concern. Fission product release from the debris, and the response of the primary system to loads resulting from energetic events are also important. Analysis that was undertaken to support the development of the APET for this time period included (1) evaluation of critical eigenvalues for possible relocation geometries, (2) calculation of debris relocation and heat transfer, (3) evaluation of primary system structural integrity, and (4) estimates of the damage potential from steam explosions.

(2) The Intermediate Phase lasts for only a brief time (at most a few minutes) but includes the possible effects of a primary system breach. This phase is represented by Questions 76 through 96 in the APET. Principal issues considered are the effects of energetic events on the integrity of the confinement structure and the AACS. The energetic events in question are either those that lead to a breach of the primary system or those that result when molten core debris flows from the primary system onto the pump room floor. What is more important, the APET considers the magnitude of the loads generated and the effect of those loads on structures and equipment. Analysis has been performed to ascertain the potential for recriticality and for steam explosions. The loads from steam explosions including the production and subsequent combustion of hydrogen have also been assessed. In addition, analysis of the response of confinement structures and equipment to the potential loads has been performed.

(3) The Late Phase covers the remainder of the accident progression until the accident is terminated. It includes the period beginning with the accumulation of debris and ending when the confinement atmosphere is purged of fission products after the termination of MCCI. Alternatively, if the core debris is cooled within the primary system, the late phase extends only for the time required to purge the confinement atmosphere of airborne fission products. This phase is represented by Questions 97 through 128 in the APET.

This phase includes all events and changes in the plant state that occurred after the core was on the pump room floor and MCCI started. Questions relate principally to the possible combustion of hydrogen produced from MCCI. The effects of combustion on confinement integrity and the AACS 
components are also considered. Additional questions address the extent of aerosol generation from MCCI and the accumulation of the fission products on the filter elements. The analysis that was undertaken to support the development of the APET for this time period included a series of calculations to predict confinement system response. Calculations were performed to assess the loads that result from hydrogen combustion, and to assess aerosol transport to the filters and the potential for filter bypass.

(4) The Delayed-Late Phase includes changes that occur in the long term (i.e., approximately 30 days) that may be caused by failures in the AACS after the accident is terminated. There are two principal considerations: (1) spurious closure of the exhaust dampers and (2) failure of the exhaust fans. Either failure results in a reduction of the airflow that provides cooling to the filter elements. This phase is represented by Questions 129 through 131 in the APET. These questions address the frequency of exhaust damper and fan failures over the 30-day period. Given exhaust damper closure or fan failure, thermal failure of the filters is also assessed. Filter temperature is estimated by a parametric model incorporated into the APET. It is assumed that exhaust damper closure leads to filter burn if any fission products are deposited on the elements.

The formulation of the quiestions that constitute the APET representation of each phase of the accident was supported by analysis. Once the appropriate questions were identified, cases for which the answers to the question were expected to be different; were developed. APET inputs (i.e., parameter values) and answers to the event tree questions (i.e., branching ratios) were evaluated by analyses specifically designed to determine the required information. These analyses both provided answers and led to the identification of additional APET development needs.

The case structure developed for each question separates circumstances for which an answer to the question was obvious from those where the answer required analysis. It is also used to distinguish regimes of behavior for the phenomena in question. For instance, the question of whether or not a steam explosion occurs in the pump room following primary system failure includes a case in which there was no primary system failure. The answer for this case is clear: no steam explosion occurs. Since experimental evidence suggests that the occurrence of a steam explosion depends on the temperature of the molten core debris, other cases were defined for this question, each considering a different range of debris temperature. Each of the accident phenomena was considered in this fashion. Cases where the outcome was clear were first identified and eliminated from further consideration. The remaining possibilities were screened to determine if different regimes of behavior could be distinguished. If so, the possibilities were divided among the various regimes by defining cases where the 
behavior within each case was the same (as far as available analysis techniques could determine).

\subsubsection{Issues Affecting Accident Progression}

During the progression of postulated core melt accidents, a number of uncertainties exist concerning the outcome of various phenomena that can potentially affect the confinement system response and the release of fission products to the environment. In this context, an uncertainty will be represented as a juncture (i.e., branch point) in an accident progression about which there is uncertainty and the outcome of which affects the analysis results. Resolution of an issue is indicated by relatively low uncertainty in the APET branching ratio that represents it. Quantification of the APET has been viewed in terms of resolving issues that affect accident progression. The more important issues affecting the accident progression analysis are described in this section.

Computer models have frequently been used in Level 2 PSAs to assist in the resolution of accident progression issues. To the extent possible with the particular model applied, the controlling phenomena can then be represented explicitly. The computer model predicts their interactions in a mechanistic way to reduce the uncertainty about the outcome. In the SRS PSA, some issues are understood through analyses, while other issues are unresolved and their outcomes are represented by considering the range of possible outcomes in the uncertainty analysis. To reduce the concern that the potential effects of some issues were being overlooked, sensitivity studies have been undertaken. A number of major issues relating to the progression of a core melt accident in SRS reactors were addressed through mechanistic modeling:

(1) the amount of water in the primary coolant system when fuel melting begins, and propagation of core melting to undamaged assemblies within the core;

(2) the transport of the core debris within the reactor vessel, to the primary system heat exchangers, and perhaps to the fuel assembly inlets;

(3) the potential for debris relocation to critical configurations and the magnitude of the subsequent energy release due to the recriticality;

(4) the possibility that debris from melting fuel assemblies may freeze on contact with structural components that are cooled by water, arresting further progression of the accident;

(5) core chemistry issues, including the rate and extent of clad oxidation, fuel and target oxidation, fission product release, and the results of interactions between core debris and the concrete floor following primary system failure; 
(6) the probability and severity of possible in-vessel molten fuelcoolant interactions (steam explosions) and the impact they would have on the accident progression;

(7) the extent to which fission product release and transport within the primary system results in retention (e.g., plateout), causing a reduction in the fraction of fission product inventory reaching the confinement system;

(8) the extent to which water in the vessel or on the confinement floor during MCCI can retain fission product vapors and aerosols, preventing their release;

(9) the probability and severity of possible ex-vessel energetic events (hydrogen combustion and/or steam explosions) and the impact this would have on the accident progression and operability of the confinement system;

(10) the probability of creating direct release paths from the vessel to the environment; and

(11) the retention of fission products in the confinement system and the effectiveness of the filters.

A top-down approach was used to identify the issues. This approach began with an identification of key determinants to the source term before embarking on detailed examination of phenomena. The processes that could result in the release of fission products from the fuel matrix (e.g., fuel melting, debris heat-up, and interaction with concrete) were identified, and barriers to the release of fission products were listed (e.g., primary system, confinement building, and filters). Examination of fuel release processes and of the status of barriers as an accident progressed was undertaken to establish the technical basis for issue resolution. These issues were then incorporated into the APET in the form of questions. As the APET developed, these issues vere refined and eventually restated in the APET case structure. Their resolution, or partial resolution, was reflected in the evaluation of the APET branching ratios for each of the cases considered. This approach reduced the likelihood that key issues or phenomena were overlooked.

In addition to analyses focused on issue resolution, analyses c eactor system behavior and of fission product chemistry were req: ed to determine the nature and timing of releases to confinement. In som ' these models were based on physical intuition. Where practical, c. uter modeling was applied. In every instance, efforts were directed to $\mathrm{m}_{\mathrm{i}}$ the best use of available data and modeling tools. In only one instanc: the modeling of fuel melt behavior, was a completely new model develo $d$ as part of this program. 
Determination of the response of the confinement system under accident conditions was required to realistically represent the nature and timing of radionuclide releases to the atmosphere. This determination was made using a variety of mechanistic models as described in Section 4.1.3. A detailed list of the accident progression issues that were addressed and the phenomena associated with each is presented in Table 4-1.

\subsubsection{Approach To Accident Progression Issue Resolution}

Core melt progression analysis (discussed more fully in Sections 3 and 5) describes the methodology applied to predict core melt progression and provides the technical basis for issue resolution. The core melt progression analysis was based on technology that has been developed for the analysis of postulated severe accidents in commercial LWRs. Where computer codes were available and appropriate, they were adopted for the SRS analysis. In the situations where none of the LWR codes were directly applicable, new tools were developed, and relevant phenomenological models that have been developed for LWRs were incorporated. In areas where computer models were either unavailable or were judged to be unnecessary, assessments based on hand calculations were made.

An integrated computer tool for the prediction of core melt progression at the SRS reactors has only recently become available. Such tools have been available for LWR analysis for almost ten years (e.g., the Source Term Code Package [4-1] and MAAP [4-2]). The MELCOR/SR code [4-3] was the result of an intensive development effort that paralleled completion of the PSA. The MELCOR/SR code development task relied heavily on models developed and insights gained from the analyses that were performed to support this PSA effort.

Computational tools for simulating severe accident progression were selected by dividing the in-vessel portion of the accident into periods during which the geometry and phenomena to be considered were similar. These periods correspond to the APET time periods described in Section 4.1.1. An analytical tool was then identified, or in some cases developed, to model the dominant phenomena for each time period. The division of the accident progression into time periods was done a priori based on experience in LWR analysis. Similarly, the identification of the various phenomena that would have to be modeled was based upon knowledge gained largely from the LWR industry. This identification process continued as the analysis for the SRS reactors was completed and new reactorspecific issues were raised. Information that was available from analyses and experiments done specifically for SRS was included, and a model for the confinement response to severe accidents was adapted from the MELCOR/SR development program. This model was an intermediate version of MELCOR/SR, referred to as Mod 1, which included new models for the AACS filters and had been assessed for application to modeling the confinement system. A description of the tools used for core melt progression modeling is provided in Section 5. 


\section{Table 4-1. In-Plant Consequence Issues}

\begin{tabular}{|c|c|c|}
\hline Issue & Controlling Phenomena & Importance \\
\hline $\begin{array}{l}\text { Steam Explosion in the } \\
\text { Confinement }\end{array}$ & $\begin{array}{l}\text { - Film-boiling heat } \\
\text { transfer } \\
\text { - Debris fragmentation } \\
\text { mechanics }\end{array}$ & $\begin{array}{l}\text { - Loads to confinement } \\
\text { - Potential for hydrogen } \\
\text { production } \\
\text { - Fission product release } \\
\text { from debris }\end{array}$ \\
\hline $\begin{array}{l}\text { Coolability of Core } \\
\text { Debris on Confinement } \\
\text { Floor }\end{array}$ & $\begin{array}{l}\text { - Film-boiling heat } \\
\text { transfer } \\
\text { - Debris fragmentation } \\
\text { mechanics }\end{array}$ & $\begin{array}{l}\text { Potential for Core debris } \\
\text { interaction with concrete }\end{array}$ \\
\hline $\begin{array}{l}\text { Effectiveness of } \\
\text { Confinement Ventilation }\end{array}$ & $\begin{array}{l}\text { Water accumulation in } \\
\text { confinement } \\
\text { - Severe environment } \\
\text { survival of Exhaust Fans }\end{array}$ & $\begin{array}{l}\text { - Potential for combustible } \\
\text { concentrations of } \mathrm{H}_{2} \\
\text { - Aerosol residence time in } \\
\text { confinement }\end{array}$ \\
\hline $\begin{array}{l}\text { Combustion in } \\
\text { Confinement }\end{array}$ & - Flammability limits & $\begin{array}{l}\text { - Loads to confinement } \\
\text { - Aerosol residence time }\end{array}$ \\
\hline $\begin{array}{l}\text { Nature of Core Debris } \\
\text { Interaction With } \\
\text { Concrete }\end{array}$ & $\begin{array}{l}\text { - Heat transfer from debris } \\
\text { - Debris oxidation } \\
\text { chemistry }\end{array}$ & $\begin{array}{l}\text { - Fission product release } \\
\text { from debris } \\
\text { Combustible gas } \\
\text { generation }\end{array}$ \\
\hline Spray Effectiveness & $\begin{array}{l}\text { - Aerosol mechanics } \\
\text { - Droplet surface } \\
\text { chemistry }\end{array}$ & $\begin{array}{l}\text { - Fission product retention } \\
\text { by water in confinement }\end{array}$ \\
\hline Filter Effectiveness & $\begin{array}{l}\text { - Thermal desorption } \\
\text { - Filter plugging } \\
\text { - Combustion of carbon } \\
\text { - Cooling effectiveness }\end{array}$ & $\begin{array}{l}\text { - Effectiveness of AACS } \\
\text { - Release to environment }\end{array}$ \\
\hline $\begin{array}{l}\text { Retention of } \\
\text { Radionuclides on } \\
\text { Confinement Surfaces }\end{array}$ & $\begin{array}{l}\text { - Aerosol behavior } \\
\text { - Heat transfer } \\
\text { - Confinement thermal- } \\
\text { hydraulics }\end{array}$ & $\begin{array}{l}\text { - Potential for filter failure } \\
\text { - Release to environment }\end{array}$ \\
\hline $\begin{array}{l}\text { Water Pathways for } \\
\text { Radioisotope Release }\end{array}$ & $\begin{array}{l}\text { - Aerosol scrubbing } \\
\text { - Solubility }\end{array}$ & - Release to environ $\quad t$ \\
\hline $\begin{array}{l}\text { Fraction of Core } \\
\text { Involved }\end{array}$ & $\begin{array}{l}\text { - System thermal- } \\
\text { hydraulics } \\
\text { - Fuel melt behavior } \\
\text { - ECCS effectiveness } \\
\text { - Two-phase flow behavior }\end{array}$ & $\begin{array}{l}\text { - Quantity of } \\
\text { radionuclides release } \\
\text { - Magnitude of } \\
\text { confinement loads }\end{array}$ \\
\hline
\end{tabular}




\section{Table 4-1, continued}

Issue

Amount of water in
Vessel at Melt Initiation

Recriticality in Vessel

Relocation of Absorber Materials (Cd \& Li)

In-Vessel Coolability of Core Debris

In-Vessel Radionuclide Retention

In-Vessel Steam

Explosion

\section{Hydrogen Production} During Core Damage

Location and Timing of Vessel Failure
Controlling Phenomena

Importance

- System thermalhydraulics

- Fuel melt behavior

- ECCS effectiveness

- Two-phase flow behavior

- Fuel melt behavior

- Heat transfer to control/safety rods and targets

- Melt relocation behavior

- Film-boiling heat transfer

- Aerosol behavior

- Chemical reactions

- Heat transfer

- System thermalhydraulics

- Film-boiling heat transfer

- Fuel fragmentation mechanics

- Fuel melt behavior

- Melt relocation behavior

- Chemical reactions

- Heat transfer from debris

- Structural mechanics
- Fission product release to confinement

- Steam explosion potential

- Recriticality potential

- Energy deposition in fuel and fuel debris

- Recriticality potential

- Maximum debris temperature

- Fission product release to confinement

- Potential for primary system failure

- Potential for hydrogen production

- Potential for combustion of gases

- Fission product release from fuel debris

- Potential for steam explosion in confinement 
In addition to core melt progression, consideration was given to the analysis of phenomena that could lead to the rapid release of large quantities of mechanical energy (i.e., energetic events). These phenomena can have a large impact on accident progression but are intrinsically more difficult to analyze. Phenomena such as these could not be adequately represented by the computer tools commonly used to model accident progression. Results from such codes have been supplemented by separate studies and engineering analysis. Section 6 of this document describes the methods used to analyze energetic events.

A modularized engineering representation of core melt accidents has been used to tie together the various parts of the PSA analysis. This approach served to guide the flow of information between the various analysis tasks and to structure thinking regarding the progression of postulated accidents. Each analysis task addressed a separate area of phenomenology. This assisted greatly in the development and quantification of the APET because analysis tasks were essentially devoted to answering specific questions in the APET. This was an advantage over the application of an integrated model where issue resolution involves trying to separate the information required fiom an integrated result that models several phenomena simultaneously. The disadvantage of this approach is that the interactions between various phenomena are not completely represented. The analyst in each taisk area has to assess the potential effects of interactions and attempt to represent them in the best way possible. Eight modeling tasks were undertaken:

(1) Primary Coolant System (PCS) Thermal-Hydraulics. Modeling here covers the period from the accident initiation up to the time that fuel melt begins. This modeling included consideration of the system thermal-hydraulic response during the early stages of fuel melting when two-phase flow and heat transfer phenomena govern the accident progression.

(2) Fuel Melting. Fuel melt models cover the time from the start of fuel damage until the fuel assembly geometry has been largely lost as a result of melting. At the end of this period, the core debris has collected on the vessel bottom or in the primary system piping. During this time, oxidation, melting, and relocation of fuel and target materials are the governing phenomena.

(3) Recriticality. Relocation of the debris from the fuel tubes can potentially lead to separation of the fuel from the target material. If neutron moderation (i.e., water) is still present, this could lead to the formation of a critical configuration. Analysis of the neutron multiplication for geometries that may form as a result of core debris relocation was undertaken. For circumstances where criticality was predicted, energy deposition was estimated. 
(4) Fuel Debris Relocation and Primary System Failure. Modeling of phenomena for this period covers the time from the start of fuel relocation until core debris is released from the primary system into the confinement. Note that this period partially overlaps the previous two. During this time, transport and deposition of the debris in the primary system, subsequent reheating of the debris bed, and heating and failure of primary system structures are the governing phenomena.

(5) Fission Product Transport to Confinement. This modeling is required during the period from the start of fission product release from the fuel, until core debris is released from the primary system into the confinement. This time period entirely overlaps the previous one. During this time period, the governing phenomena are fission product transport and retention (including gas thermal-hydraulics, surface chemistry, and aerosol physics).

(6) Confinement System Response. These models cover the period from the start of fission product release until the termination of releases from the confinement. This period will typically be several hours. During this time, flow in the confinement, the possible combustion of gases produced during the accident, the behavior of the active confinement system components (e.g., sprays, fans, and filters), and fission product transport phenomena govern the confinement response. Analysis of the releases from MCCI is part of this task.

(7) Energetic Events. Modeling of phenomena that can result in a large energy release is pertinent for three time periods throughout the accident: during fuel melting as debris relocates, at vessel failure, and during interactions between core debris and concrete. The most important of these is at vessel failure. Releases of energy large enough to induce structural damage are considered. The phenomena involved are molten fuel-coolant interactions, recriticality, in-vessel hydrogen burns, and detonation (or deflagration) of combustible gases in the confinement system.

(8) Structural Analysis. Energetic events lead to the potential for blast effects and static pressurization of structures (i.e., the primary system and the confinement) due to steam and hydrogen generation and to missile generation. These effects may lead to structural failures. Failures in the primary system and confinement structure due to these effects and pressurization were analyzed.

Both benefits and limitations are associated with this approach to the representation of core melt progression. Four benefits stand out as being the most significant. 
(1) This approach highlights the treatment of important issues and phenomena, giving them the appropriate attention by drawing heavily from established detailed analysis methods.

(2) Detailed models use mechanistic approaches in the key phenomenological areas, such as primary system ThermalHydraulics, assernbly meltdown, recriticality, and fission product behavior.

(3) A preliminary assessment of the capability and applicability of some of the available best-estimate codes resulted from selected application of the ILWR codes.

(4) The approach provides a consistent framework for achievement of all required objectives for completion of the Level 2/3 PSA.

There were limitations to this methodology. However, these are minor when compared to its beriefits. Two limitations have been identified.

(1) The extent of coupling and feedback between analyses is limited because of the use of separate codes that were not developed with the intent of exchanging data.

(2) Many of the methodologies and models were developed for very different reactor systems and can often only provide a limited assessment of the SRS reactors.

The exercise of this methodology was used as the basis for both the quantification of the branch points of the APET and the estimation of source terms to the environment. This self-consistent analytical description of core melt progression for the SRS reactors was developed as part of the SRS Level 2 PSA program and was a necessary prerequisite to APET evaluation.

\subsection{Solution of the APIT}

Quantification of the APET is performed with the EVNTRE computer code [4-4] developed as part of the NUREG-1150 effort. Before the APET can be solved, the branch ratios and parameter values for each case of the 131 questions must be assigned. Values may be determined from plant damage state definitions, from preceding questions, from fault tree analysis of active systems, or from mechanistic calculations. Once branch ratios and parameter values have been determined, the APET is solved to yield the sequences that lead to failure of the confinement system barriers and release to the environment.

The APET has been quantified for each of the plant damage states identified in Section 2. Resultant sequences from the APET can be grouped or binned based on similar characteristics or attributes of the accident progression. The result of the sequence binning process can be visualized as a much 
smaller event tree whose sequences are each an accident progression bin. The equivalent of a Level 1 cut set that corresponds to each sequence is a listing of the accident progression bin attributes. Although the number of accident progression bins may still be extensive (tens of thousands), they represent a substantial reduction from the total number of accident progression sequences developed by quantification of the APET.

For this analysis, binning is accomplished through a two-stage process involving an initial or primary binner and two secondary binners. The primary binner groups sequences that exhibit similar accident progression characteristics into accident progression bins. The EVNTRE program executes the primary binner during the initial program calculation. The PSTEVNT program executes the secondary binners (one at a time) during subsequent calculations. One secondary binner (the source term binner) further collapses the accident progression bins into groups such that the source terms within each group are expected to produce similar health consequences. These source term bins are carried through the rest of the risk calculations. Details on the processing of source term bins are discussed in Section 7.

Another secondary binner the (summary binner) is used to collapse the accident progression bins into groups that describe the most important aspects of the accident progression in a concise fashion for visual display as a summary event tree. The summary trees display many important phenomenological events in the progression for a particular plant damage state and permit review of the accident progression analysis.

The summary trees supported by a detailed APET (i.e., summary tree/APET methodology) are analogous to the event tree/fault tree methodology used in other PSAs. Each top event in a summary tree was quantified by combining the answers to several questions in the detailed APET. In other PSAs, each top event in an event tree was quantified by detailed fault trees. Thus, the methods used in this PSA are analogous to the methodology for previous PSAs.

\section{The Primary Binner}

The purpose of the primary binner is to reduce the total number of sequences calculated in the APET analysis to a limited number of accident progression bins. Accident progression bins characterize the accident progression analysis results in terms of the initiating PDS, subsequent operator actions, equipment failures, and severe accident phenomena that may occur during those sequences. The EVNTRE software ensures that every accident progression sequence identified as having significance (i.e., above a specified cutoff frequency) is assigned to a bin. Any sequence characteristic that is potentially significant to understanding the accident progression or to determining the source term is included in the list of attributes considered in developing the accident progression bins. Twenty groups or dimensions were used in developing the primary binner for the 
APET. This grouping is based on similar characteristics or attributes in the accident progression.

Once the sequences have been binned, all the information that went into the determination of the bin is no longer carried through the analysis. Therefore, a two-step binning process is used to preserve some of the details of the calculation. By themselves, summary results may not be sufficient to understand the APET results, yet it is clearly not possible to comprehend the unbinned sequences. Hence, the primary binning is used as an intermediate step in the interpretation of the results. For example, the question regarding the fraction of target material that relocates with the melting fuel tubes is not referenced in the primary binner. Thus, one cannot determine from an accident progression bin how much target was relocated for the particular sequences in that bin. Whether or not recriticality occurs, however, can be determined from the bin attributes, and recriticality is dependent on target relocation.

\subsubsection{The Summary Binner}

A visual representation of the APET solution can provide a tool to check the APET. It can also lead to insights into the nature of an accident progression. As discussed in the previous subsection, primary binning of the accident progression sequences can result in thousands of accident progression bins - a quantity that is analytically useful, but far too many to be visually displayed. A second binning, or rebin, is necessary to further reduce the number of accident progression bins for visual display.

The rebin reduces excessive detail in the representation of the accident progression represented by the primary bins. Eight (8) dimensions, which can be visualized as top events, were considered in developing the summary binner. (Additional dimensions can be assigned as necessary. For example, ten dimensions are assigned to the summary binner in the document that describes the APET [4-5].) Each of the attributes of the accident progression, grouped into dimensions, can thus be viewed as branches in a summary tree. The reduced detail is apparent from the fact that the primary accident progression bins contain 20 dimensions while the summary bins specify only 8 dimensions. Clearly, much detail of the APET is not available in the summary trees, but it should be noted that the summary trees are effective tools for visually displaying the APET solutions and play no role in the actual risk calculations.

The PSTEVNT software used in the rebinning, ensures that every accident progression bin with significant frequency is assigned to a summary bin. Thus, every accident bin is assigned eight attributes, one for each dimension. The combination of eight attributes assigned to each accident progression defines the summary bin to which it is assigned. If several accident progressions are assigned the same combination of attributes, they are considered to be in the same summary bin. The frequency of a summary bin is calculated as the sum of the frequencies of the accident 
progressions that have that particular combination of attributes (i.e., those assigned to the same bin).

Each of these eight dimensions of the summary binner is briefly described in the following paragraphs. Summary trees for all plant damage states are shown in Appendix A. The attributes for each summary bin dimension are defined in Table 4-2.

Dimension 1: Recriticality - The attributes of this dimension are concerned with whether or not a recriticality occurs in the vessel and how much energy is released as a result. The energy associated with a recriticality is used to estimate the final debris temperature. Debris at temperatures between $1500 \mathrm{~K}$ and $2000 \mathrm{~K}$ (indicative of an energetic recriticality) is assumed to always cause energetic steam explosions. Debris at temperatures between $1000 \mathrm{~K}$ and $1500 \mathrm{~K}$ (called a benign recriticality) may or may not cause damaging steam explosions.

Dimension 2: In-vessel Water - The attributes of this dimension are concerned with the amount of water in the vessel, not with the specific mechanism by which it is achieved. The amount of water in the reactor vessel during and after core melt is significant in determining the radionuclide retention of the vessel surfaces and water. In addition, the presence of water affects the occurrence of in-vessel energetic events (recriticality and steam explosions).

Dimension 3: Vessel Failure - Primary system boundary damage is assigned based on the location and degree of the in-vessel energetics. The attributes (modes of vessel failure) for this dimension are (1) an energetic failure of both the vessel top and bottom, (2) an energetic failure of the vessel top along with a thermal failure (melting) of vessel bottom, (3) the failure of the vessel top and effluent piping caused by a steam explosion, (4) an energetic failure of the vessel top only, (5) no failure of top of vessel but a thermally induced vessel bottom or effluent piping failure, and (6) no vessel failure.

Dimension 4: The Early Condition of Confinement System - The extent of damage sustained by the confinement system will determine the extent of early releases to the environment. Building failure as the result of a seismic event or steam explosion-generated missile is assumed to allow all fission products released from the vessel to go directly to the environment. A substantial or partial breach in confinement as the result of steam explosion or building overpressure will create a direct path to environment but 
will allow retention of fission products by confinement surfaces or systems. The extent of retention will depend upon the extent of the breach. If airflow to the filter system is blocked, a negative pressure cannot be maintained in confinement and fission products are assumed to be released to the atmosphere.

Dimension 5: Energetic Event at Vessel Failure - The attributes for this dimension report the energetics in confinement following vessel failure. Vessel failure may or may not be preceded by an energetic event.

Dimension 6: Disposition of Core Debris - The core debris may be cooled in-vessel or on the pump room floor; otherwise, MCCI will occur either immediately or following boiloff of any water present.

Dimension 7: The Late Condition of Confinement System - Late confinement system damage as it relates to fission product behavior is reported.

Dimension 8: The Late Performance of the Filter System - Late status of the filters as it relates to fission product behavior is reported. The confinement atmosphere temperature, the air flow through the filters, and the filter loading will determine the extent of possible carbon filter burn and release of previously adsorbed Iodine and other radionuclides. A partial release (without filter burn) of adsorbed molecular Iodine is possible. Prior loss of filters and late filter damage as the result of building overpressure or blockage are reported as well as the performance of the filters during the thirty day time period following the accident 
Table 4-2. Summary Binner Dimensions And Attributes

\section{DIMENSION 1: Recriticality [Recrit]}

$\begin{array}{lll}1.1 & \text { Recrit } & \text { Energetic recriticality of molten core in Reactor Vessel } \\ 1.2 & \text { bRecrit } & \text { Benign recriticality of molten core in Reactor Vessel } \\ 1.3 & \text { noRecrit } & \text { No recriticality of molten core in Reactor Vessel }\end{array}$

DIMENSION 2: Water in Reactor Vessel [Vsl-Wtr]

2.1 Dry Vessel empty late

2.2 WtrLost Water lost due to expulsion, boil-off, or vessel bottom

2.3 Water failure

DIMENSION 3: Vessel Failure [Vsl-Fail]

3.1 Egy-Vsl Top and bottom of vessel fail due to energetic event

3.2 TV\&Th Energetic failure of vessel top with thermal failure of vessel bottom

3.3 TV\&Pistx Vessel top \& effluent piping failure due to steam explosion

3.4 TV-Only Failure of vessel top due to energetic event

3.5 Bot-Stx Vessel bottom or effluent piping failure as the result of a steam explosion

3.6 Bot-Th Vessel bottom or effluent piping failure from overheating

3.7 None No Vessel Failure

\section{DIMENSION 4: Early Condition of the Confinement [E-Conf]}

4.1 EBldg-F Early building failure due to seismic event or missile generated by an in-vessel energetic event.

4.2 E-Brch/Fi Early partial confinement breach and filter failure

4.3 I-Brch/Fi Early partial confinement breach, filter failure at vessel failure

4.4 EPart-Br Early partial confinement breach

4.5 E-Block Airflow to filters blocked early

4.6 E-Filter Early confinement air filtered 


\section{DIMENSION 5: Energetic Event at Vessel Failure [I-Egy]}

5.1 StmX In-vessel steam explosion breaches vessel bottom and/or is followed by steam explosion in below grade confinement

5.2 StmX/Brn Steam explosion in below grade confinement immediately after vessel breach is followed by a hydrogen burn

5.3 Brn

A hydrogen burn occurs following vessel breach

5.4 None

Energetic event does not breach vessel bottom or occur in confinement at time of vessel breach

\section{DIMENSION 6:}

6.1 MCCI

6.2 DryMCCI 6.3 No-MCCI No Molten Core Concrete Interaction occurs
Concrete Interaction

Disposition of Core Debris [MCCI]

Molten Core Concrete Interaction occurs immediately Below grade water evaporated prior to Molten Core

\section{DIMENSION 7: Late Fission Product Behavior [L-Conf] \\ 7.1 L-Brch Late confinement breach \\ 7.2 LPart-Br Late partial confinement breach \\ 7.3 L-Block Air flow to filters blocked \\ 7.4 L-Filter Late confinement air filtered}

DIMENSION 8: Late P'erformance of Filter System [L-Filter]

8.1 L-Burn Carbon filters burn after MCCI begins or core in stable configuration

8.2 Lt-Burn Filters burn late because of damper closure

8.3 DesLFilt Iodine desorbs after MCCI begins or core in stable configuration

8.4 LDesDEs Iodine desorbs after MCCI begins or core in stable configuration and late because of damper closure

8.5 LFiltDes Filters function after MCCI begins or core in stable configuration but desorb late because of damper closure

8.6 L-nFilt Filters damaged or airflow to filters blocked after MCCI begins or core in stable configuration

8.7 Lt-nFilt Filters fail because of damper closure

8.8 Lt-Filter Filters perform function 


\subsection{References}

4-1. J. A. Gieseke, et al., Source Term Code Package: A User's Guide, Battelle Columbus Division, NUREG/CR-4587, BMI-2138, July 1986.

4-2. Fauske and Associates, Inc., MAAP Modular Accident Analysis Program User's Manual, Vols. I and II, IDCOR Technical Report 16.2-3, February 1987.

4-3. Code Requirements Document: MELCOR/SR, A Computer Code for Evaluating Severe, Accident Progression in Heavy Water Reactors, Westinghouse Savannah River Co., Aiken, SC, October 1990.

4-4. J. M. Griesmeyer and L. N. Smith, A Reference Manual for the Event Progression Analysis Code (EVNTRE), NUREG/CR-5174, SAND88-1607, Sandia National Laboratories, Albuquerque, NM, September 1989.

4-5. W. H. Baker and W. L. Ferrell, The Accident Progression Event Tree - A Logic Model For The Progression Of Postulated Severe Core Melt Accidents In SRS Reactors, WSRC-RP-91-965, Westinghouse Savannah River Company, Aiken, SC, March 1992. 
This page intentionally left blank. 
The analyses performed to support the SRS Level 2 PSA represent a significant enhancement to the understanding of severe accident progression in metal-fueled reactors. Work was directed toward developing a detailed understanding of the phenomena that accompany a severe accident.

Analytic efforts for the SRS PSA were focused by utilizing probabilistic insights derived during the course of the program. In addition, probabilistic insights were developed from the detailed analytic studies conducted throughout the program to support the ongoing accident progression analysis. This interchange proved highly effective in both maximizing the return on analytic efforts and developing a representative probabilistic model of core melt progression in the SRS reactors.

Core melt progression phenomenology as described in this section refers to more than the process of fuel degradation and relocation; it includes the full spectrum of phenomena that can accompany a severe accident. The discussion of energetic phenomena that may alter accident progression through sudden releases of heat or steam is deferred to Section 6. Six phenomenological areas are covered in this section:

(1) primary cooling system thermal-hydraulics;

(2) fuel melt and relocation;

(3) core debris coolability;

(4) fission product transport within the primary cooling system;

(5) molten core-concrete interactions; and

(6) confinement system response.

Detailed analyses were performed within each of these six phenomenological areas. Results of these analyses have been applied in both the development of APET logic as well as quantification of individual events (branching ratios and parametric input).

The following sections describe the non-energetic-phenomenological analyses performed in support of the SRS Level 2 PSA. Each section provides a brief synopsis of the general approach, including the modeling techniques that have been applied, and a summary of the results. The sections are not intended to provide complete documentation of the analyses. Instead, this document provides a description of the methods applied and a summary of the results obtained. Detailed documentation of each phenomenological area is provided in References 5-1 through 5-6. It is noted that many of the analyses described here were performed over four 
years ago. Some of the models have since been superseded, and these new models are currently being utilized for the Rev. 1 SRS PSA.

\subsection{Thermal-Hydraulic Analyses}

During severe accidents, the early response of the primary cooling system (PCS) will determine several characteristics of the accident sequence including the time to core melt and the conditions that exist in the reactor when core melt occurs. Thus, it is important to accurately model the behavior of the PCS during postulated severe accidents in order to reliably predict the progression of each accident. In this section, the thermal hydraulic (T-H) analyses performed to support quantification of several questions in the APET are summarized.

\subsubsection{Thermal-Hydraulic Modeling Techniques}

The computer code TRAC,-PF1/MOD2 [5-7] (henceforth referred to as TRAC) was selected as the tool for performing thermal-hydraulic (T-H) modeling of the SRS K Reactor. TRAC is a T-H systems analysis code developed at Los Alamos National Laboratory (LANL) specifically for the simulation of nuclear reactor transients. The code solves, approximately, the continuity, momentum, and energy equations of two-phase flow using a finitedifference technique; both one- and three-dimensional modeling capabilities are included.

A partial model of a representative SRS reactor was constructed using TRAC components. This model (with appropriate minor modifications) was used to simulate the response of $K$ Reactor to four basic severe accidents: (1) loss-of-pumping; (2) loss-of-coolant; (3) loss-of-heat-sink; and (4) anticipated-transient-without-scram. The response of the model during each of these accidents and the accidents themselves will be discussed in the next subsection. A detailed description of these T-H calculations and the TRAC model(s) used is given in References 5-1 and 5-2.

\subsubsection{Primary System Response}

In the following subsections, the predicted response of the PCS during the four types of severe accidents mentioned above is summarized. The intention of these analyses was to provide enough information to support the quantification of the portions of the Accident Progression Event Tree (APET) which deal with T-H phenomena. Specifically, the time from accident initiation to core melt, the amount of coolant present in the vessel at the time of core melt and its temperature, and the mechanism that lead to loss of flow to the assemblies and the attainment of CHF (or dryout) were all of interest.

\subsubsection{Loss-of-Pumping Accidents}

A Loss-of-Pumping Accident (LOPA) for the SRS reactors involves the stoppage of the primary cooling system Bingham pumps. The initiating 
event for the LOPA as modeled by TRAC is a double-ended guillotine break (DEGB) in one of the secondary cooling water inlet headers which rapidly leads to flooding of the pump motors (both AC and DC). The other secondary inlet header remains intact so that heat transfer from the primary to the secondary is still possible in six of the twelve heat exchangers. Reactor scram occurs within three seconds based on reduced flow in the affected secondary side header. With the ECCS partially or fully disabled, TRAC calculations indicate that the LOPA undergoes the following four stages [5-1].

(1) The primary coolant temperature decreases as the Bingham pumps continue to run after the reactor is scrammed. $0 \mathrm{~s}$ $170 \mathrm{~s})$

(2) The primary coolant undergoes subcooled heatup after the pumps flood and coast down to a stop. (170 s - $240 \mathrm{~s}$ )

(3) The primary coolant reaches its saturation temperature in the fuel assembly channels and begins a cyclic process dubbed "assembly chugging". During chugging, the coolant in the channels is heated by the fuel decay power and becomes steam. This steam is ejected into the $\mathrm{D}_{2} \mathrm{O}$ plenum and subsequently condenses due to the subcooled liquid also present in the plenum. When this condensation occurs, subcooled moderator from the vessel re-enters the fuel assemblies, and the process begins again. This process continues until the ever decreasing amount of liquid in the plenum reaches saturation and can no longer act as a heat sink to condense the ejected steam. The assemblies then fill completely with steam. (240 s - $340 \mathrm{~s})$

(4) The voided assemblies heat rapidly to fuel melt. (340 s - 410 s)

Calculations indicate that, at the time of fuel melt $(\sim 7$ minutes after the break), the assemblies are filled with superheated steam, and the vessel is essentially full of subcooled moderator.

\subsubsection{Loss-of-Coolant Accidents}

In a Loss-of-Coolant Accident (LOCA), a leak is assumed to develop somewhere in the primary cooling system. For the TRAC simulations, LOCAs were initiated by double-ended guillotine breaks in the expansion joint bellows at one of two locations: the heat exchanger exit or the Bingham pump inlet. Low $\mathrm{D}_{2} \mathrm{O}$ plenum pressure initiated reactor scram within two seconds. Due to the size of the assumed breaks, all LOCAs modeled by TRAC are classified as large-break LOCAs (LBLOCAs). Small-break LOCAs (SBLOCAs; i.e., LOCAs which involve partial pipe breaks and smaller leak rates) were not modeled. 
Each of the LBLOCAs was characterized by a fairly rapid draining of the reactor vessel, followed by aspiration of air by the pumps, reduction in flow to the plenum and assemblies, and subsequent heat up of the fuel assemblies to melt. In one case, a partially functional ECCS was able to provide adequate cooling to avoid core melt; however, model limitations were judged to be too restrictive to accept this result without further study.

In summary, the TRAC calculations indicate that in a LBLOCA with a partially or fully disabled ECCS, fuel melt takes place approximately two minutes after the pipe break [5-1]. For the no-ECCS case, the vessel is almost completely drained of moderator (moderator level $<1$ foot); with partial ECCS injection, moderator levels are somewhat higher (around 1 meter). In either case, the remaining moderator is subcooled to some dègree.

\subsubsection{Loss-of-Heat-Sink Accidents}

A Loss-of-Heat-Sink Accident (LOHSA) for the SRS reactors involves the loss of secondary cooling water flow to all of the heat exchangers. Primary cooling system operation continues, but heat transfer from the primary to the secondary is eliminated. For modeling purposes, a spurious closure of the two cooling water outlet header flow control valves was selected as the LOHSA initiator. Scram, initiated by low cooling water flow, occurred within five seconds. Thus, heatup of the primary coolant took place under decay power conditions. No ECCS injection is assumed.

The results of the TRAC calculation indicate that the LOHSA progresses through four distinct stages [5-1].

(1) The primary coolant temperature decreases after scram as the effluent header valves gradually close. $(0 s-30 s)$

(2) The primary coolant undergoes subcooled heatup due to the decay heat from the core. $(30 \mathrm{~s}-8500 \mathrm{~s})$

(3) The moderator in the tank begins to boil off after reaching its saturation temperature. Single-phase flow is maintained in the assembly channels since the pressure there is higher. Eventually, the moderator level drops to the point where the pumps begin to aspirate air/steam. ( $8500 \mathrm{~s}-13600 \mathrm{~s})$

(4) Boiling in the assemblies begins. Unsteady two-phase conditions in the tank lead to oscillatory flow from the pumps to the plenum. This behavior continues until the primary coolant is largely evaporated and assembly dryout occurs. $(13600 \mathrm{~s}-15600 \mathrm{~s})$

(5) Fuel melt takes place rapidly when the assemblies become completely voided. $(15,600 \mathrm{~s})$ 
Thus, fuel melt occurs approximately 4.3 hours after the initiating event with the reactor vessel nearly empty of liquid coolant (due to boiloff). The coolant remaining at the time of melt is saturated.

\subsubsection{Transients}

Transients are accidents which are initiated by events that are generally within the design basis (failure of one AC motor, withdrawal of a single control rod, spurious closure of one rotovalve, etc.). Timely reactor scram is all that is required to avoid core melt in a transient. Thus, a transient as defined here implies that no scram takes place, and for this reason, the term anticipated transient without scram (ATWS) is also used.

The accident taken as representative of all transients in terms of timing and general accident progression was the inadvertent withdrawal of one control rod in a single septifoil near the center of the core. This accident was simulated using a variation of the TRAC model which made use of the code's point kinetics model [5-2]. Results indicate that the withdrawal of the control rod leads to a power increase in the six assemblies immediately adjacent the affected septifoil. Film boiling quickly ensues on the fuel tube surfaces, and the fuel tubes begin to melt 19 seconds into the accident. It is assumed that melting of the fuel occurs with full coolant flow through the assembly, resulting in the formation of small particles of fuel debris.

The particulate debris is then entrained in the coolant flow and swept into the moderator space. This initially results in a significant positive reactivity insertion, however, the generation of a substantial amount of steam quickly acts to negate this effect. The debris is then carried along out of the vessel and through the outlet piping until it becomes trapped in the heat exchanger end bells, degrading or stopping primary coolant flow completely. The spatial distribution of debris as a function of time was determined using TRAC results. Calculations performed using the Monte Carlo Neutral Particle transport code (MCNP) indicate that a recriticality in the heat exchanger end bells is not possible [5-8].

\subsubsection{Particulate Transport}

Fuel melt may occur, under some circumstances, while flow is still established in the fuel assembly. The conditions that result in melting under flowing conditions are described in Section 5.2. Under these circumstances, particles may be torn from the surface of the fuel tube as it melts. Particles formed in this manner will be transported by the flow out into the primary system. These particles can have important influences on the progression of a severe accident including (1) particles swept into the moderator space can affect the reactivity of the reactor; and (2) particles swept into the heat exchangers can block flow, potentially stopping circulation in the reactor. 
In order to address both of these concerns, the following phenomena were studied:

- formation of the particles and their size,

- transport of the particles out of the assembly,

- transport of the particles into the moderator space,

- thermal/hydraulic behavior of the particles in the moderator space (particularly void formation that influences reactivity),

- transport of the particles through the loop piping, and

- trapping of particles in the heat exchangers.

The formation of particles will be discussed in Section 5.2.1.2. Each of the remaining issues deal with the transport of the fuel particles after their formation; they are discussed below.

Transport of the particles out of the assembly. Assuming that flow is maintained, particles removed from the fuel rod will be carried down the assembly to the bottom-end-fitting (BEF). Flow exits the BEF through 0.25 inch $(6.4 \mathrm{~mm})$ holes. It is likely that much of the particulate debris will be carried through the holes into the bulk moderator region of the reactor. In the SPERT tests, the particles exited the assembly through $3 / 8$ inch holes. The large agglomerations were found downstream of the holes, indicating that either the material was molten when it passed through the holes, or that numerous small particles agglomerated after passing through the holes. Predictions of particle trajectories in the BEF under this type of condition have been made [5-9]. These results have indicated that between $10 \%$ and $70 \%$ of the particles that come into the BEF are carried out and entrained in moderator, depending upon assumptions.

Transport of the particles into the moderator space. A circulation pattern exists in the reactor moderator. Moderator in the center of the reactor generally moves upward and radially outward. Moderator flows downward near the outer radius of the vessel. If particles become entrained in this flow, they can be carried up into the active core where they can influence reactivity. This circulation pattern has been measured in the cross-flow tank test facility at SRTC, but quantitative measurements of velocity are not available. The circulation pattern in the reactor was also predicted using the TRAC code [5-2]. The quantitative results from this prediction generally matched the qualitative results of the experiments. The motion of the particles within the moderator space was predicted based on their drag coefficient using a code developed for the purpose called DTRAC [5-2]. The results of this code showed that many particles are carried up into the active core in the center of the reactor, then carried outward and down in the outer portion of the core. The process takes several minutes with peak concentrations occurring between 20 and 50 seconds into the accident. 
Thermal/hydraulic behavior of the particles in the moderator space. Fuel particles swept into the moderator will be hot. Additionally, the particles will be producing heat from radioactive decay and by fission when they are in the active core. Because of this, the water adjacent to the particle surface will boil. This boiling can produce steam void in the moderator space. An analysis was performed with the TEXAS code to estimate this void formation [5-2]. The results of the TEXAS analysis indicate that relatively large void fractions are created in the moderator when these hot particles enter. In some parts of the core, the void fraction is predicted to exceed $50 \%$.

Transport of the particles through the loop piping. Particles that pass through the moderator will be swept into the loop piping. The velocity in the piping is relatively high and is expected to carry the particles along suspended in the flow [5-2]. There are no locations where particles could become trapped between the vessel outlet and the heat exchangers.

Trapping of particles in the heat exchangers. The heat exchangers pass the primary flow through tubes with an inside diameter of 0.402 inches. All but a few of the almost 9,000 tubes have a 0.296 inch diameter rod centered in the tube. Thus, the vast majority flow must pass through a 0.053 inch wide gap. Particles larger than this will likely be trapped in the heat exchanger. If a large mass of particles enters a heat exchanger, it will reduce or block the reactor primary flow. Particles smaller than 0.053 inch in diameter may pass through the heat exchanger and continue to circulate around the primary loop as may larger particles which encounter the small number of unrodded tubes. There are no passages in the primary loop that are smaller than the gap between the heat exchanger tubes and rods.

\subsection{Fuel Degradation Analyses}

Fuel degradation refers to the processes that accompany the heat-up, melting, and relocation of the reactor fuel assembly materials as a consequence of losing adequate cooling. The mode and timing of fuel assembly melting have the potential to significantly influence the course of an accident. Because the fuel assemblies contain both fuel and target materials, reactivity changes are a possible consequence of melt progression. Reactivity may increase if the fuel and target separate due to the melting process. In addition, the rate and temperature at which melted materials relocate will affect their final state. Materials that relocate rapidly and at high temperature are less likely to cool than materials that melt more gradually and at low temperature. Coolability of fuel assembly debris determines its temperature and geometry once the fuel assembly has melted. Finally, hydrogen production was a recognized consequence of heating aluminum structures in the presence of steam and water. The rate and extent of hydrogen production is sensitive to the characteristics of the melt and relocation processes.

The fuel degradation analysis focused on characterizing the progression of melting within an assembly. The four objectives of this analysis were 
(1) to characterize the potential for recriticality;

(2) to evaluate the extent of hydrogen production;

(3) to characterize the relocating fuel assembly debris; and

(4) to evaluate the extent of fission product release.

Understanding the potential for the fuel material to relocate away from the target material was the central objective. Since the fuel tubes contain the decay heat source and the target tubes do not, this is clearly a possibility. The probability that recriticality would significantly alter the progression of an accident had to be assessed. This probability was found to depend strongly on the extent to which the fuel and target tubes melted together. The National Academy of Sciences Committee had identified hydrogen production and subsequent combustion as another potential mechanism of exacerbating the consequences of a postulated fuel damage accident [5-10]. Hydrogen generation thus had to be characterized in order to assess the potential for combustion. Characterization of the fuel assembly debris and its relocation rate was required for two considerations. First, it would affect the energetics of a postulated recriticality. Second, and perhaps more importantly, it was found to influence the potential for freezing the debris. Melt rate evaluation naturally leads to the capability to estimate the overall timing of the fuel degradation phase of the accident. Accident timing is an important consideration in determining the offsite consequences of an accident.

Fuel tube melting can occur under two distinct sets of conditions. Dryout of the assembly under stagnant conditions as a result of primary coolant system inventory loss or coolant circulation failure leads to melt initiation with the coolant channels filled with steam. It is also possible to have fuel melting under flow conditions. This can occur if either coolant flow is reduced or fission power is increased to the point where the critical heat flux is exceeded at the fuel tube surface. A number of transient initiators can lead to these conditions within the fuel assembly in the unlikely event that the reactor shutdown systems should fail.

Characterization of fuel assembly degradation relied on three sources of information. Mechanistic models for fuel and target tube melting have been developed. These models are supported, in part, by more de: ed calculations of the heat-up process. Limited experimental data, obta ed from testing of reasonably prototypic materials, were also considered. n addition, empirical information, derived from observations of fuel a target performance, was also available. This information came fre observation of both fuel assemblies that suffered damage during react. operation and target tube behavior during tritium extraction. Thi empirical evidence is subject to interpretation, and the exact cause of fu damage during reactor operation is often difficult to determine. Thus, the interpretation of damage must include interpretation of the cause. This makes it difficult to determine whether the observed damage modes would 
actually occur under postulated severe accident conditions. Observation of target tube behavior during tritium extraction is also difficult to extrapolate to the postulated conditions of interest since they differ significantly.

\subsubsection{Fuel Degradation Modeling Techniques}

\subsubsection{Behavior Under Dryout Conditions}

In order to address each of the objectives for the fuel degradation assessment in a consistent fashion, an analytical model for fuel assembly melting was developed. Based on the available observations of fuel behavior, it was established from the beginning that this model would only be valid for low steam or liquid velocity in the coolant channels. The model was similar to those that have been developed to address core melt progression in light-water reactors. A two-dimensional representation of the fuel assembly is modeled. Fuel tubes, target tubes, their cladding, and the universal sleeve housing (USH) are all modeled explicitly. Conduction heat transfer is modeled within the assembly structures. Convection heat transfer between the structures and the surrounding fluid is considered. Radiant heat exchange between structures is also modeled. The presence of rib spacers is neglected.

Hydrogen generation and the associated heating is predicted based on empirical correlations, as is the release of fission products. Correlations for aluminum oxidation are based on the work of Baker [5-11]. The fission product release correlations were established based on data developed for the Savannah River Site. The form of the correlation used is the same as that used in the light water reactor version of MELCOR [5-12].

In order to model the relocation of melted fuel, target, and clad material, fundamental assumptions were made relative to how melting occurs and the flow regime of molten material. Conduction heat transfer between relocating debris and the assembly is predicted based on this model. Heat transfer between the debris is allowed to lead to blockage of the assembly coolant channels if the debris freezes in sufficient quantity. The high thermal diffusivity of aluminum presented a special challenge. Standard methods for calculating heat transfer between relocating debris and the substrate surface proved to be numerically unstable. In order to handle this difficulty, the computer code MELSRP [5-13] was developed based on the APRIL code [5-14] used to model fuel melting in Boiling Water Reactors (BWRs). MELSRP was subsequently included as the CSR package in MELCOR/SR [5-3]. Both MELSRP and MELCOR/SR employ an analytic solution to the conduction problem during the early stages of contact. Fuel swelling due to fission gas nucleation is represented in MELCOR/SR by increasing the volume occupied by the fuel and allowing some portion of the fuel material to contact the adjacent fuel tube and relocate down that surface.

The temperatures at which fuel, target, and clad materials relocate are important parameters in the model. To the extent possible, values used in 
the analysis were based on experimental data. Fuel relocation temperature, in particular, was deterrnined based on a recent test designed especially to measure this parameter [5-15].

In an attempt to validate the fuel melting model, observations of fuel damage characteristics clerived from operational experience were gathered and reviewed. In addition, data on target material response to heating during tritium extraction were reviewed. Selected portions of the available tritium extraction data were declassified in order to make some of the available data more accessible.

These observations indicated that fuel tube failure may occur somewhat differently than assumed in the MELCOR/SR model. The majority of observed fuel tube failures have involved cracking of the clad, typically adjacent to a spacer rib, followed by flow of the molten fuel through the crack. Fuel foaming can be seen to have occurred if the fuel was significantly irradiated. Droplet flow down the fuel tube surface was indicated in some instances. The current MELCOR/SR model does not allow representation of cladding breach prior to melting the clad material, but by setting the clad and fuel relocation temperatures equal, the timing of fuel relocation can be made to correspond to the data indications. The resulting debris is, however, higher in aluminum content than if clad cracking occurred. This could impact recriticality scenarios if MELCOR/SR were directly linked to a kinetics model. Since the recriticality calculations were performed separately (as described in Section 6), these possible differences between the MELCOR/SR prediction and actual melt progression can be taken into account.

Target tube material is known to swell significantly when annealed due to tritium gas nucleation. This phenomena is commonly observed, at temperatures much less than the material melting temperature, in the extraction process. The resulting material is similar to a foam. A greater that twofold increase in material volume has been measured. It has been postulated that target tube swelling to this degree could occur during assembly degradation. Target clad rupture may then precede fuel tube failure leading to target relocation along with, or even prior to, the fuel. It must be noted, however, that the fuel tubes heat-up and melt completely within five minutes of colant channel dryout. This is unlikely to provide sufficient time for significant annealing and bubble growth within the target.

\subsubsection{Behavior Under Coolant Flow Conditions}

Observations from two sets of experiments [5-16, 5-17] indicate that it e steam or liquid velocity in the channel is significant, fuel degradation le. is to the formation of particulate. Neither set of experimental results pertains to a situation that is prototypic with respect to conditions anticipated to accompany a severe accident. However, analysis has been performed to assess the hydrodynamics that would attend fuel melting with coolant flow. 
The analysis results substantiate the observations. Also, the observed size of particles can be approximately predicted [5-2].

The fuel may form particulate debris if melting occurs under full flow conditions. This occurs, for example, as a result of a single rod withdrawal accident (SRWA) without scram. In a SRWA the fuel assembly power exceeds the cooling capacity (see Section 5.2 for further discussion), and the fuel may melt in a water/steam flow environment. Some testing has been performed to study particle formation under such conditions. This work is summarized in Reference 5-18. Tests were conducted in the SPERT I reactor in 1958 [5-16] and in an induction furnace at SRL [5-19]. The SPERT tests were conducted using an aluminum-clad uranium-aluminum alloy fuel tube with nuclear heating of the fuel in a reactor with liquid water coolant. The SRL tests employed an aluminum tube heated inductively and high velocity steam flow. The mechanisms for melting were different in the two tests. Particles were formed in the SPERT tests when the core material melted first and flowed through breaches in the cladding. The particles resembled crumpled foil. The size of particles formed in the SPERT test were not carefully reported, however, they are described as ranging in size from 20 microns to over an inch long. A number of particles shown in a photograph in the test report appear to be in the range of 1 to $15 \mathrm{~mm}$ in diameter along with a few very large ones. In the SRL tests, particles were formed due to grain boundary melting producing particlès with an irregular granular shape. The size of the particles formed in the SRL tests was carefully recorded. The particles ranged in size from 0.25 to $6 \mathrm{~mm}$ in diameter. It is not clear which of the two melting mechanisms might occur in the reactor during a SRWA, but is possible that many particles might be formed. An investigation of the likely mechanisms for particle formation indicates that the range of expected particle sizes will be within the range measured in the SRL data [5-2], whatever the mechanism.

MELCOR/SR predicts that melting in the absence of significant flow in the fuel channels leads to temperatures little higher than the melting temperature. This is in agreement with the results from Reference 5-17 mentioned above. Hydrogen generation and fission product release are both dependent on the time the material spends at elevated temperature. MELCOR/SR results bounded the hydrogen generation and fission product release that would be expected to result from the particulate mode of degradation. Furthermore, as discussed in Section 5.1.3, particles generated in the early phases of fuel melting are expected to plug the primary system heat exchangers. Plugging the heat exchangers would reduce the coolant flow rate thus leading to the loss of flow to the coolant channels. Fuel fragmentation would stop, and from this point onward, the MELCOR/SR model would be applicable directly. No effort has been made to establish the time required to block primary system circulation, since the current modeling approach does not require this information.

When there is flow in the intervening coolant channels, heat transfer from the fuel to the target tubes is essentially limited to gamma heating (discussed below). The target tubes are thus expected to remain intact. This 
is valid during the period of fuel tube fragmentation. Once flow stops and the coolant channels fill with steam, heat transfer to the target tubes will occur. However, at this time, the temperature difference would be substantial. The fuel tulses should complete the melting process before the target tubes are heated significantly.

\subsubsection{Results of Fuel Degradation Analyses}

\subsubsection{Application of MELSRP and MELCOR/SR}

As stated previously, MELCOR/SR and MELSRP were the principal tools for evaluating the fuel degradation phase of postulated severe accidents. Both codes effectively model the aspects of fuel melting under dryout conditions. Predictions of hydrogen production, fission product release, and accident timing from MELCOR/SR were also applied selectively to the particulate mode of degradation, since no other model was available for this mode. Based on the unclerstanding of the particulate degradation process, this selective use of MEL,COR/SR results was judged to be reasonable.

\subsubsection{MELSRP and MELCOR/SR Results}

In order to quantify the rate of fuel melting during severe accidents, calculations were made for assemblies located at varying positions within the core using MELSRP [5-3]. Using this MEISRP data, the full-core average melt rate was calculated as a function of time [5-8]. Based on the results, an average fuel relocation rate of $0.1 \mathrm{~kg} / \mathrm{s}$ was specified for the recriticality and debris coolability analyses described in Sections 6.1 and 5.3.

To assist in the determination of the extent of target tube melting, MELCOR/SR was used to predict fuel assembly degradation using a range of assumptions relative to fuel relocation temperature, latent heat required for relocation, tube surface emissivity, and the flow regime assumed for molten materials. Table 5-1 summarizes these results. All of these calculations included effects of fuel foaming. Experimental evidence [5-15] suggests that the most likely relocation temperature is $925 \mathrm{~K}$. For temperatures in that range, MELCOR/SR results indicate no target relocation into the BEF . Fuel melting occurs very rapidly. A 5.8 MW (i.e., "average" power) assembly requires approximately 7 minutes from the time the coolant channels become voided for both fuel tubes to have $r$ npletely melted down into the BEF. It requires less that 4 minutes fron e time melting begins for most of the fuel tube material (i.e., approximates $0 \%$ ) to melt and relocate. This short period limits the time available to insfer heat between the fuel and target tubes. Since the temperature of fuel tubes remains low, radiation is not an important heat transfer mec $\quad \mathrm{sm}$. Convection in this geornetry is also relatively ineffective at trans. ing heat. 
Table 5-1. Results of MELCOR/SR Calculations

\begin{tabular}{ccccccc}
$\begin{array}{c}\text { Relocation } \\
\text { Temperature } \\
\text { (K) }\end{array}$ & $\begin{array}{c}\text { Latent } \\
\text { Heat (\%) }\end{array}$ & $\begin{array}{c}\text { Surface } \\
\text { Emissivity }\end{array}$ & $\begin{array}{c}\text { Relocation } \\
\text { Mode }\end{array}$ & $\begin{array}{c}\text { Fuel } \\
\text { Melted (\%) }\end{array}$ & $\begin{array}{c}\text { Target } \\
\text { Melted (\%) }\end{array}$ & $\begin{array}{c}\text { Target } \\
\text { Relocated to } \\
\text { BEF (\%) }\end{array}$ \\
\hline \hline 919 & 7.5 & 0.4 & Rivulet & 100 & 2 & 0 \\
919 & 100.0 & 0.4 & Rivulet & 100 & 2 & 0 \\
950 & 7.5 & 0.4 & Rivulet & 100 & 0 & 0 \\
950 & 7.5 & 0.9 & Rivulet & 96 & 0 & 0 \\
950 & 7.5 & 0.4 & Film & 100 & 0 & 0 \\
950 & 100.0 & 0.4 & Rivulet & 100 & 2 & 0 \\
950 & 100.0 & 0.9 & Rivulet & 96 & 4 & 0 \\
950 & 100.0 & 0.4 & Film & 97 & 0 & 0 \\
1338 & 7.5 & 0.4 & Rivulet & 81 & 56 & 35 \\
1338 & 7.5 & 0.4 & Film & 81 & 93 & 55 \\
1338 & 100.0 & 0.4 & Rivulet & 71 & 94 & 61 \\
1338 & 100.0 & 0.4 & Film & 71 & 94 & 68 \\
\hline
\end{tabular}

The assessment of hydrogen production and fission product release was made based primarily on results obtained from MELSRP [5-3]. These results also show the effects of rapid melting at low temperature. Both hydrogen production and fission product release rates have been shown to depend approximately exponentially on temperature. The combination of low temperature and short duration at elevated temperature is thus expected to yield low values for both these phenomena. Hydrogen production is predicted to be negligible. The predicted oxidation is less than $1 \%$ of the fuel tube during the melting process. This amounts to less than $1 \mathrm{~kg}$ of hydrogen produced from melting the entire core. The oxide layer that forms on aluminum surfaces is impermeable to steam at the low temperatures involved. It is the formation of this oxide layer that limits hydrogen production.

Noble gas release from the fuel is anticipated to be essentially complete during the melting process. The release of volatile fission products, principally iodine and cesium, is predicted to be less than $15 \%$. Using values for MELCOR/SR input parameters that are believed to be most 
representative of the actual situation, approximately $6 \%$ of the iodine and cesium groups are released. Tellurium group release is negligible. Other groups are also expected to have negligible release and are not included in the model due to their very low vapor pressures at the temperatures of interest. Again, low temperature and short periods over which the relocating material remains at elevated temperature are responsible for these low releases.

\subsubsection{Additional Supporting Analyses}

It has been recognized that while neither convection nor radiation heat transfer are effective in heating the target tubes, other mechanisms may be significant. Fuel foaming leading to physical contact between the fuel material and the target tube is already modeled. However, the model results indicate that the target tubes are not sufficiently heated prior to contact with the foamed fuel for the heat transferred during contact to cause significant target melting. This result is somewhat sensitive to the assumed viscosity and thermal diffusivity of the foamed fuel. There is insufficient data to support a clear resolution to this issue.

However, two mechanisms that are not included in the current model may lead to significant target heating. These are gamma smearing and heat conduction through the rib spacers. Gamma smearing is an effect that is commonly considered in light water reactor fuel performance calculations. It refers to the fact that since a significant portion of the decay heat energy is emitted as gammas, the energy may not be deposited locally. For the SRS reactor fuel assemblies this means that some portion of the decay heat will be deposited in the target tubes, the USH, and the moderator rather than in the fuel tubes. Rib spacer conduction refers to the fact that contact between the rib spacers on the fuel and target tubes may establish a pathway for direct conduction heat transfer. Both of these mechanisms have been analyzed through separate analysis to assess their potential effects on target heating [5-3]

Gamma smearing was addressed by performing detailed calculations of gamma transport in the fuel assembly lattice. The Monte-Carlo neutronphoton transport code MCNP was used for this analysis. The code and the input models for the SRIS Reactor Infinite Lattice Supercell are described in Section 6. For this application gamma transport within the lattice $\rightarrow m$ the distributed decay heat source within the fuel tubes was tracked. $F \quad n g$ of the lattice components was calculated based on the predicted abso on of gamma energy. The results for both LOPA and LOCA are shown 1. 'able 5-2. While the predicted heating of the target is not large, deposition " 'eat in the fuel tubes is considerably reduced, especially for LOPA sce os. The resulting reduction in the heatup rate, combined with $g_{\text {: }}$ na absorption in the targets would lead to smaller differences between the del and target tube temperatures. 
Table 5-2. Percentages of Gamma Energy Deposition as Calculated by MCNP for Various Accident Scenarios

\begin{tabular}{crrrrr} 
Component & $\begin{array}{c}\text { Case 1a } \\
\text { \% Dep. }\end{array}$ & $\begin{array}{c}\text { Case 2b } \\
\text { \% Dep. }\end{array}$ & $\begin{array}{c}\text { Case 3c } \\
\text { \% Dep. }\end{array}$ & $\begin{array}{l}\text { Case 4d } \\
\text { \% Dep. }\end{array}$ & $\begin{array}{l}\text { Case 5e } \\
\text { \% Dep. }\end{array}$ \\
\hline \hline Fuel Assembly & 44.27 & 82.50 & 54.61 & 89.21 & 88.64 \\
Target & 7.77 & 16.89 & 6.50 & 11.46 & 11.44 \\
Fuel & 33.84 & 6.50 & 30.84 & 46.15 & 46.18 \\
Coolant & 0.00 & 0.00 & 15.07 & 27.13 & 26.72 \\
USH & 2.66 & 6.81 & 2.20 & 4.47 & 4.30 \\
Septifoil & 3.15 & 10.68 & 2.60 & 7.42 & 7.26 \\
Moderator & 51.80 & 0.00 & 42.29 & 0.00 & 1.80 \\
Other & & & & & \\
& 0.79 & 6.82 & 0.50 & 3.37 & 2.28 \\
Total & 100.01 & 100.00 & 100.00 & 100.00 & 99.98 \\
\hline
\end{tabular}

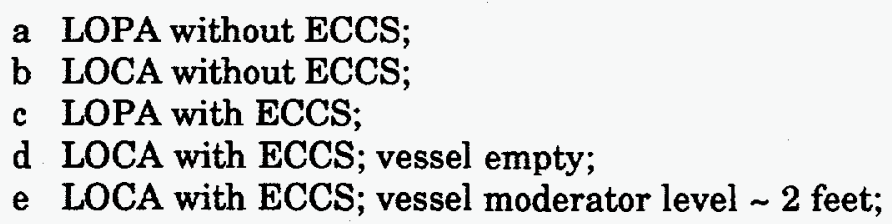

Rib spacer conduction was addressed using a detailed two-dimensional model of the fuel assembly cross-section. Conduction, radiation, and convection heat transfer were modeled. Intimate contact between the rib spacers and the adjacent fuel or target tube was assumed. At the onset of fuel melting, the predicted target tube temperatures were much higher than those calculated by MELCOR/SR. The LOPA calculation indicated sufficient conduction heat transfer that the outer fuel and target tubes would not melt as long as water was present outside the USH.

The results suggest that intimate contact, combined with gamma heating, and fuel foaming could lead to essentially simultaneous melting of the fuel and target tubes. 


\subsubsection{Conclusions From Fuel Melt Analyses}

The principal conclusions from the fuel melt analyses can be summarized as follows:

(1) Negligible amounts of hydrogen (considering either $\mathrm{H}_{2}$ of $\mathrm{D}_{2}$ ) are generated during the assembly melt-down process. This is true because the aluminum temperatures are well below the temperatures at which rapid oxidation can occur.

(2) Fission product releases are restricted primarily to noble gas release. Iodine and cesium releases are predicted to be in the range of 6 to $1.5 \%$. Again, the low temperatures contribute substantially to this result.

(3) An average fuel relocation rate of $0.1 \mathrm{~kg} / \mathrm{s}$ was determined based on MELSRP calculations performed for various positions within the core.

(4) The relocation of target with fuel under LOPA conditions is not predicted by MELCOR/SR unless relocation temperatures near the liquidus are assumed. However, additional factors such as gamma heating and rib spacer conduction have been considered, and the results of these studies suggest that significant target relocation is fully possible.

\subsection{Debris Behavior Analyses}

All of the severe accident progression scenarios considered in the Level 2 PSA result in fuel melting and subsequent relocation. The presence of water in the primary system and/or on the confinement floor during fuel relocation gives rise to the potential for freezing the debris, at least temporarily halting the relocation process. The accumulation of debris as a result of freezing can alter accident progression, and thus the eventual disposition of the debris. Analyses of the coolability of fuel debris have been performed.

The term coolable refers to the potential for no further debris relocation. Debris is coolable if the heat it transfers to the surroundings is equal to, or greater than, the heat it internally generates. If debris is coolable, and a source of continued cooling is available, the debris will not continue to relocate. If the debris is not coolable, it will eventually reach a temperature sufficient to fail its supporting structures, and will relocate. The specific purpose of these analyses was to quantify the potential for debris coolability in the various configurations in which debris has been postulated to collect.

Prior to performing the analysis it was necessary to identify these configurations. For scenarios in which primary coolant remains in the reactor vessel (i.e., LOPA, LOCA with partial ECCS, and LORWA), it is postulated that the debris will first collect within the BEFs. If this 
configuration is cooled, the debris will stack up within the BEFs as the melt progresses, otherwise the BEFs will heat up and fail. BEF failure will result in further relocation of the debris to the reactor vessel bottom. If the debris is not cooled in this configuration, the debris will likely flow out into the primary coolant piping via the outlet nozzles. (These nozzles each contain a structure known as a "muff", consisting of a series of horizontally stacked stainless steel plates separated by spacers.) Finally, the debris may fall onto the confinement floor if the debris is not cooled in the piping. In addition, for scenarios in which the moderator level and coolant flow are maintained (i.e., ATWS), debris is postulated to be entrained in the moderator and deposited in the heat exchanger end bells.

Both steady-state and transient heat transfer analyses have been performed to analyze each of the configurations described above. Coolability of the debris is not only important to accident progression but is also a very important issue in the source term analysis. The ultimate debris temperature, which is estimated along with the coolability analysis, strongly affects both the rate and total extent of fission product release from the primary system. It should be noted that recriticality and steam explosions are not considered here. These events are discussed in Section 6.

\subsubsection{Debris Behavior Modeling Techniques}

Initially, one-dimensional steady-state coolability calculations were performed for various geometries using a simple energy balance. Maximum dimensions for coolable spheres, cylinders, and flat plates were calculated for both stable nucleate and film boiling, assuming a fixed decay heat generation rate. When debris enters the water, an initial transient will occur as a stable boiling point is sought (the point at which heat generation within the debris exactly equals the heat transfer to the surroundings). Since two stable boiling points are generally possible (one in nucleate boiling, and one in film boiling), the stable point will depend upon the initial condition and the transient that ensues.

For most of the analyses, the short- and long-term transient analysis was performed using the two-dimensional thermal analysis code TAC-2D [5-20]. TAC-2D uses an alternating direction implicit finite-difference method to solve for time-dependent temperature distributions [5-21]. Modes of heat transfer modeled include conduction, convection to fluids, and onedimensional thermal radiation. Modifications were made to the code to facilitate its application to the issue of SRS core debris coolability including: (1) addition of a melting model; (2) addition of a debris movement model; and (3) addition of a pool boiling routine. These modifications are described in detail in Reference 5-4

The computer code PLUGM was used along with TAC-2D in the outlet nozzle analysis, as flow through the outlet nozzle muffs will resemble pipe flow with freezing occurring on both the top and bottom surfaces of the muff channels. PLUGM is a thermal-hydraulic computer model for freezing melt flow in a channel [5-22]. To address the confinement floor problem, a 
preliminary heat transfer analysis was completed by hand. The hand calculations included a comparison of the melt holdup time with the time to achieve substantial freezing in order to estimate the coolability of this configuration.

\subsubsection{Results of Debris Behavior Analyses}

All of the debris behavior results, except those related to the heat exchangers, are documented in detail in Reference 5-4. The assumptions used in most of the analyses were consistent with the LOPA scenario for the tritium-producing uniform Mark 22 charge, with the exception of the muff analysis which was completed for a dry reactor case. The effects of the moderator on the muff analysis are judged to be minimal [5-4]. Several series of calculations were performed to quantify the sensitivity of the coolability results to uncertain parameters. The most significant uncertainties in the analyses were the fuel relocation temperature and the thermophysical properties of the molten debris. The results are summarized below.

\subsubsection{Bottom-End Fitting Coolability}

For the majority of accident scenarios not involving coolant flow, it has been assumed that fuel debris will candle down the assembly. Initially, the debris comes into contact with the upper pressure plate within the BEF. If the debris temperature is near its solidus temperature $(913 \mathrm{~K})$, the plate remains intact and the debris flows outward contacting the BEF wall. It has been assumed that thermal expansion leads to intimate contact between the BEF wall and the USH once debris begins to accumulate. Film boiling is initiated almost instantly on the outer surface of the USH, covering the vertical extent of the debris. Axial heat conduction through the USH is sufficient to initiate nucleate boiling approximately 1 to $2 \mathrm{~cm}$ both above and below the debris region.

If the debris temperature is near $950 \mathrm{~K}$, the upper pressure plate which supports the debris is not coolable. The plate melts in less than 1 second, resulting in debris relocation to the lower pressure plate. Because of its similarity to the upper plate, the lower plate is assumed to fail as well. Analysis has shown that the debris will freeze in the BEF shell holes instead of running out, forcing the debris to collect on the stainless steel monitor pin. Film boiling is once again initiated on the outer surface of the USH. The total amourt of surface area undergoing nucleate boiling is substantially increased in this configuration relative to the configuration in which debris rests on the pressure plate. The increase is directly attributable to fin effects which increase the total axial heat conduction in the aluminum sleeve containing the debris. The combined thickness of the BEF and USH walls is substantially greater than the thickness of the BEF wall alone. The increased radial wall resistance lowers the temperature of the surface, promoting nucleate boiling. The absorption of heat by the cold monitor pin also promotes coolability of the debris. 
The debris quickly freezes after it contacts the BEF/USH wall. As the debris height increases, it contacts sections of the BEF wall where the thickness decreases to a minimum of $0.13 \mathrm{~cm}$, approximately $3 \mathrm{~cm}$ above the top of the monitor pin. For the best-estimate debris relocation temperature of $950 \mathrm{~K}$ and relocation rate of $0.1 \mathrm{~kg} / \mathrm{sec}$ [5-3], this configuration is cooled and debris will continue to accumulate. However, debris at $1073 \mathrm{~K}$ carries sufficient initial thermal energy to melt the BEF as it accumulates. In this case, the analysis suggests that the $\mathrm{BEF}$ will fail once the accumulated debris height exceeds $3 \mathrm{~cm}$.

Geometries that have been analyzed are idealized representations of the actual situation. In particular, it has been assumed that the interior of the fuel assemblies will be completely voided (i.e., filled only with steam) following a LOPA. Analysis suggests that this may not be the case. Steam produced when debris relocates into the water that remains within an assembly will tend to force the water out. However, water will certainly remain at the level of the shell holes within the BEF. Neglecting this water within the BEF results in an underestimation of the potential for cooling the debris. In reality, if no steam explosion occurs, debris entering water during the initial stages of assembly melting may freeze in droplets, forming a small debris bed that has the capacity to absorb heat from subsequently relocated debris. It is believed that these effects only enhance coolability and thus do not affect the conclusion that freezing within the BEFs is likely. (Once again, recriticality and steam explosion are considered in Section 6.)

\subsubsection{Coolability on the Bottom Shield}

If the debris is not cooled in the BEF, molten debris will spread over the bottom of the reactor vessel. Due to its high surface temperature, the debris will initially be in film boiling. Because of the very low surface heat flux accompanying stable film boiling, steady-state calculations indicate that if debris were to collect to a thickness greater than $0.28 \mathrm{~cm}$, it would not be coolable. However, it has been postulated that transient phenomena (such as debris contacting cold structures) might result in a transition from film boiling to nucleate boiling as debris contacted the vessel bottom. If this transition were to occur prior to failure of the supporting structures, the resulting configuration would most likely be coolable.

As instantaneous relocation of the entire debris volume is judged to be an unrealistic assumption, $25 \%$ of the debris was assumed to relocate instantaneously followed by relocation of the remaining debris over the next few minutes. Calculations were performed for debris bed depths of 4 and $16 \mathrm{~cm}$ at a relocation temperature of $925 \mathrm{~K}$. Axial conduction up the USH reduced the debris surface temperature enough to establish a nucleate boiling interface. Within 18 seconds the entire surface had quenched and the debris continued to cool. A sensitivity calculation was completed for a relocation temperature of $950 \mathrm{~K}$, in which case no transition to nucleate boiling occurred. 
Long-term coolability depends on maintaining nucleate boiling. The loss of nucleate boiling could occur if the vessel is boiled dry, or if phenomenological events lead to a transition back to film boiling. By quantifying heat rejection and moderator subcooling requirements for coolability, it was found that within 11 minutes, the moderator tempe ture will increase to saturation. The corresponding decrease in the critice heat flux will cause the surface to transition to film boiling, and the deb: s will no longer be coolable. Further relocation will take place at sa rated moderator conditions.

\subsubsection{Penetration of Outlet Nozzle Muffs}

Debris accumulating on the vessel bottom will spread radially and contact the vessel outlet nozzles. Penetration of the nozzles is retarded by the muff structure which may plug with frozen debris. The debris was assumed to freeze upon initial contact with the muff inlet. Because the flow properties of the molten debris are not well known, several cases were analyzed to set bounds on the problem.

Inviscid flow analyses suggest that no plugging occurs in the muff, and the debris flows through the nozzles into the primary piping in approximately five seconds. However, the most likely scenarios are those in which the debris freezes in the muff once or twice prior to flowing out. Penetration times in these cases range from 5 to 10 minutes. A comparison between the results of the muff perietration analyses and the vessel bottom analyses leads to the conclusion that debris will most likely exit the vessel through the outlet nozzles prior to vessel bottom failure [5-3].

\subsubsection{Coolability in the Outlet Piping}

When debris enters the reactor outlet nozzle and penetrates the muff, the debris will proceed to fill the pipe below the vessel. In the internal-floodinitiated LOPA scenario, this pipe may be submerged in highly subcooled water. The low thermal conductivity of the stainless steel piping and the thick pipe wall limit the heat flux through the pipe. The debris temperature was initially set at $1073 \mathrm{~K}$. The maximum surface heat flux will be relatively low (roughly a: factor of five below the critical heat flux) and stable nucleate boiling will be initiated on the piping surface. While surface nucleate boiling is sufficient to prevent the pipe from melting. a high temperature gradient through the pipe wall develops and th debris temperature increases to a steady state value well above the solidu noint. Thus, the pipe does not fail, but the debris within the pipe remains olten at high temperatures, enhancing fission product release.

The pipe wall slowly dissolves as a result of the chemical interaction vith the molten debris. As the pipe wall thins, the temperature difference through the wall decreases such that the outermost diameter of the fuel debris freezes, at which point further pipe dissolution ceases. The molten debris is contained within an annulus of frozen debris, and the heat generated within the debris is conducted to the pipe surface and removed by 
nucleate boiling. Even though the pipe centerline temperature may be very high, this configuration is stable as long as the pipe remains submerged, and the geometry is considered coolable. As the decay power decreases, complete freezing eventually occurs.

A similar calculation was done for the case in which only dry air surrounds the piping. The debris temperature was initially set at $925 \mathrm{~K}$, and it reached the stainless steel melting temperature of $1670 \mathrm{~K}$ in approximately 250 seconds. The primary piping was assumed to fail at that time. Thus, debris is not coolable in such a configuration.

\subsubsection{Behavior on the Confinement Floor}

Failure of the vessel bottom or the primary piping will result in debris relocation to the confinement floor. The type of failure will determine the exit temperature of the debris, which will be important to the analysis. Thermal failure will result in a debris temperature close to the melting temperature of stainless steel $(1700 \mathrm{~K})$, while a steam explosion failure will result in debris near the relocation temperature of $925 \mathrm{~K}$. Due to the system of trenches and the sloping of the pump room floor, the tendency of the debris contacting the floor is to drain into the pump room sumps.

Analysis was completed for cases in which the confinement floor is flooded. As the debris contacts the water on the floor, a steam explosion is assumed to occur that disperses the debris evenly over the entire floor area. For debris at $925 \mathrm{~K}$ and a uniform thickness of $1.7 \mathrm{~cm}$, the average time for the debris to reach the trenches was calculated to be 8 seconds. This time was compared to the time to freeze the debris to estimate the probability of coolability. One-dimensional unsteady heat exchange in film boiling between the draining debris and the overlying water was assumed. A comparison of the two times shows that it is unlikely that freezing of the debris will occur prior to drainage. However, the calculations were completed for debris in film boiling. Debris in nucleate boiling would be much more likely to be coolable because of the increased amount of heat transferred from the debris to the overlying water in that mode. The calculated minimum film boiling temperature and the crust surface temperatures were very close, thus the external boiling regime could not be conclusively determined. Whether or not the debris is coolable is within the uncertainty bounds of the calculation since the boiling regime is unknown.

For debris at an initial temperature of $1700 \mathrm{~K}$, the difference in the analysis is that the debris is superheated. Using the lumped capacitance equation, the debris was found to deplete its superheat and cool to $925 \mathrm{~K}$ in approximately 43 seconds. Thus, the effect of the superheat is to delay the freezing, making coolability highly unlikely.

\subsubsection{Coolability in the Heat Exchangers}

In the event of an accident in which coolant flow remains intact and the fuel degrades as particulate melt, particulate debris will likely be 
transported by entrainment in the moderator to the heat exchangers (see Section 5.2). The coolability of debris in the heat exchanger end-bell was analyzed for debris consisting of only fuel and clad, and for debris made up of fuel, clad and target material. For both cases, the debris was initially assumed at $400 \mathrm{~K}$, a temperature in the nucleate boiling region for water, to see if the configuration was coolable in nucleate boiling. In this analysis, the heat flux at the surface of the debris remained below the critical heat flux, and thus was coolable.

As the debris was found to be coolable in the nucleate boiling region, debris at any temperature was assumed to be coolable if it transitions back to nucleate boiling. At the relocation temperature of $925 \mathrm{~K}$, debris is initially in film boiling. The transition to nucleate boiling occurs between 37 and 50 seconds after the beginning of the transient depending on the debris content. Over time, the surface temperature and heat flux stabilize in the nucleate boiling region. The time to stabilize again depends upon the debris content, as pure fuel debris will have a much higher decay heat generation rate. In either case, however, the stainless steel of the end bell remains solid and the debris freezes in such a scenario.

The possibility of a recriticality in a heat exchanger due to the trapped debris was considered. The debris is exposed to the 304 Stainless Steel tube sheet on one side and to the end bell of the same material on the other side. The tube sheet is $23 / 4$ " thick while the end bell is only $15 / 8$ " thick. Thus, because the tube sheet is thicker, it is postulated that the end bell will always fail first, and the debris will exit the heat exchanger on the primary side into the confinement. It should be noted, however, that analysis indicates that a recriticality in one of the heat exchangers is not possible (see Section 6).

\subsubsection{Summary of PCS Coolability Analyses}

The coolability of molten debris has been analyzed for six possible configurations: (1) accurnulation in the BEF; (2) accumulation on the vessel bottom; (3) penetration of the outlet muffs; (4) accumulation in the pump suction piping; (5) behavior on the pump room floor; and (6) accumulation in the heat exchangers. If water is present in the vessel, or if the pump room is flooded (in the case of the piping), each configuration could be coolable. However, the coolability of debris in the various confi rations is sensitive to the initial debris temperature and/or the degree 0 voderator subcooling. If the debris is near the solidus temperature $(91,7)$ when relocation occurs, it is likely to stack up on the upper BEF pressui jlate in a coolable geometry. If the debris is near $950 \mathrm{~K}$, the debris will lt the pressure plate and then stack up on the monitor pin in a coolable $\xi$ netry. These analyses lead to the conclusion that, if water is present in th essel, core debris will remain in the BEF for a period on the order of $i \ldots$ nutes following the start of assembly melting.

Failure of the BEFs will result in debris relocation to the reactor vessel bottom. Debris will likely flow through the outlet muffs and into the reactor 
effluent piping; however, debris could plug the muffs and collect on the vessel bottom. When this occurs with subcooled water in the vessel, a rapid transition on the upper surface of the debris from film boiling to nucleate boiling results in freezing of the debris on the vessel bottom. As additional hot debris relocates, it contacts the cold debris and once again a transition from film boiling to nucleate boiling occurs. This configuration is coolable due to this transition phenomena, but is only possible with large degrees of moderator subcooling $(\sim 40 \mathrm{~K})$. Eventually, the moderator heats up, and failure of the vessel bottom occurs. Finally, if debris collects within the submerged primary coolant piping as a result of flow through the muffs, the limited surface heat flux from the pipe to the water results in stable nucleate boiling. While the configuration is coolable, the debris centerline temperature is extremely high due to the large temperature gradient through the stainless-steel pipe wall. For the case where dry air surrounds the piping, the debris heats up rapidly to the stainless steel melting temperature, and the piping fails.

Debris which relocates to the pump room floor will likely run to the sumps before freezing unless (1) extreme dispersal of debris takes place as the result of a steam explosion and (2) a significant amount of water is present for cooling. Finally, if particulate debris is transported to the heat exchangers, it will collect in the end bells. There, it will freeze if water is present to cool the end bell, or the end bell will fail if surrounded by air.

\subsection{Fission Product Transport Analyses}

The analyses described previously have focused on defining the progression of an accident: thermal-hydraulic conditions have been defined for each type of accident, characteristic fuel melting behavior has been evaluated, and the coolability of molten debris in the primary system has been analyzed. These analyses establish initial and boundary conditions from which fission product transport studies can be performed. Analysis of fission product evolution and transport provides an important link between accident progression analysis, confinement system response, and source term evaluation.

\subsubsection{Primary System Fission Product Transport Analysis}

Fission product transport analysis in the primary system can be divided into three phenomena: (1) release of fission products from melted fuel; (2) retention of fission products due to scrubbing by water pools and deposition on colder primary system structures; and (3) revolatilization of fission products from deposited structures at later times in the accident. The APET contains a number of questions which relate directly to the evaluation of fission product evolution and transport in the primary system. Most of these questions are quantitative in that they elicit radionuclide release fractions, decontamination factors for water pools and primary system surfaces, and the fractions of deposited radionuclides which revolatilize. Thus, each phenomenon must be analyzed to determine the APET parameter values associated with it. 


\subsubsection{Releases During Fuel Melt}

Most postulated severe accident sequences in the SRS reactors involve the formation of molten aluminum pools. These pools may form after fuel assemblies melt and relocate to the reactor vessel bottom or to the reactor outlet piping. They are generally composed of uranium and aluminum from the fuel assemblies, lithium from the targets, and fission products. Because the U-Al fuel melts at low temperatures (relative to LWR fuel) and quickly relocates, most volatile fission products (with the exception of noble gases) remain in the fuel at the time of pool formation. Consequently, fission product releases during the molten pool phase of the accident tend to dominate releases from all other phases.

Releases (for a non-energetic melt) from intact assemblies have been estimated by applying the CORSOR-M model [5-23]. CORSOR-M uses a correlation involving release data fit to an Arrhenius expression; this correlation defines the release rate as a function of temperature for a variety of radionuclide species. This model has been correlated to data derived from experiments performed at Oak Ridge National Laboratory (ORNL) [5-24] and Hanford [5-25]. CORSOR-M has been used extensively to model releases from LWR fuel. Its applicability to metal fuels has been questioned, but given the low releases predicted for the assembly melt phase, additional effort to refine the model is unwarranted.

The release fractions during fuel melt that includes a recriticality event were calculated by assuming that 25 percent of the core reaches $2000 \mathrm{~K}$ for a short period of time, and the remainder of the core is at the relocation temperature of $950 \mathrm{~K}$. The release fractions for a power excursion were calculated using the same method used to calculate the release fractions due to a recriticality event except that only 10 percent of the core is involved in the power excursion. Thus, 10 percent of the core reaches $2000 \mathrm{~K}$ for a short period of time and then cools to the relocation temperature. A list of the median release fractions that were used in the PSA during fuel melt is given in Table 5-3.

\subsubsection{Releases During Debris Heat-Up}

Once the metallic fuel has melted, two principal mechanisms control the release of fission products from the pool: (1) bulk diffusion from the pool surface and (2) the formation of bubbles within the pool and the release of these bubbles from the surface. The rate of fission product evolution attributable to these two mechanisms is determined by numerous considerations, the most important of which appears to be pool temperature. Fission product decay heat present in the pool causes thermal gradients and provides a strong driving force for natural convection which enhances release rates attributable to both mechanisms. 
Table 5-3. Release Fractions During Fuel Melt

\begin{tabular}{cccc} 
Group Name & $\begin{array}{c}\text { Non-Energetic } \\
\text { Melt }\end{array}$ & Recriticality & Power Excursion \\
\hline \hline & & & \\
Noble Gas & 0.80 & 0.85 & 0.85 \\
Iodine & 0.15 & 0.36 & 0.24 \\
Cesium & 0.05 & 0.29 & 0.15 \\
Tellurium & 0.00 & 0.2 & 0.08 \\
Strontium & 0.00 & 0.05 & 0.05 \\
Ruthenium & 0.00 & 0.00 & 0.00 \\
Lanthanum & 0.00 & 0.00 & 0.00 \\
Cerium & 0.00 & 0.00 & 0.00 \\
Barium & 0.00 & 0.03 & 0.05 \\
Tritium & 0.80 & 0.85 & 0.85 \\
& & & \\
\hline
\end{tabular}

Fission product evolution calculations have been performed with MELCOR/SR [5-26, 5-27]. The release of fission products from molten pools is estimated in MELCOR by applying a model developed as part of the SRS severe accident program [5-28]. The bulk diffusion model is based on a heat transfer analogy, and estimates of the mass transfer coefficient are taken from correlations for the heat transfer Nusselt number. The bubble dynamics model is broken into three smaller interconnected models. The first model uses correlations for boiling water to estimate a nucleation rate of bubbles in the melt. The second model solves for the concentration of bubbles in the melt as a function of nucleation rate, coalescence rate, and buoyant rise rate. Finally, the third bubble dynamics model determines the interaction of bubbles with the pool surface and the rate at which they escape. The sum of the release from bulk diffusion and bubble escape represents the total release. This is estimated for each fission product element.

The median release fractions for the fission product groups that were used in the SRS PSA during heat up are given in Table 5-4. These release fractions are determined by the maximum temperature of the core debris, which falls into one of the following categories: the debris reaches the melting temperature of stainless steel, the debris reaches the structural failure temperature of the vessel bottom shield, or the debris reaches $1000 \mathrm{~K}$ before a steam explosion fails the bottom of the vessel. 
Table 5-4. Release Fractions During Core Debris Heat Up

\begin{tabular}{cccc} 
Group Name & $\begin{array}{c}\text { Core Debris at } \\
\mathbf{1 7 0 0 K}\end{array}$ & $\begin{array}{c}\text { Core Debris at } \\
\mathbf{1 4 0 0 K}\end{array}$ & $\begin{array}{c}\text { Core Debris at } \\
\mathbf{1 0 0 0 K}\end{array}$ \\
\hline \hline & & & \\
Noble Gas & 1.00 & 1.00 & 1.00 \\
Iodine & 0.99 & 0.99 & 0.90 \\
Cesium & 0.99 & 0.99 & 0.50 \\
Tellurium & 0.75 & 0.70 & 0.00 \\
Strontium & 0.10 & 0.00 & 0.00 \\
Ruthenium & 0.00 & 0.00 & 0.00 \\
Lanthanum & 0.00 & 0.00 & 0.00 \\
Cerium & 0.00 & 0.00 & 0.00 \\
Barium & 0.05 & 0.00 & 0.00 \\
Tritium & 1.00 & 1.00 & 1.00 \\
& & & \\
\hline
\end{tabular}

\subsubsection{Chemical Form of Iodine Released In-Vessel}

Since the transport characteristics of iodine in the elemental form are much different than those of iodine in a compound, it is important to understand the chemical form of iodine released in a severe accident. An analysis to determine the behavior of iodine under accident conditions has been performed [5-29]. The results of this analysis state that iodine has a very high chemical activity, and none of the iodine is expected to come off in the elemental form. Iodine will combine easily with cesium or lithium. Cesium iodide is expected to be the predominant compound at lower temperatures $(800$ to $1100 \mathrm{~K}$ ). At $1400 \mathrm{~K}$, approximately $1 / 4$ of the iodine was calculated to be in the form of $\mathrm{LiI}$ and $3 / 4$ in the form of CsI.

\subsubsection{Fission Product Retention}

The retention of fission products in the SRS reactors is expected to be attributable to the same phenomena as for LWR reactor accidents. However, differences in reactor geometry, thermal-hydraulic conditions, and accident progression will affect the extent to which SRS accident conditions resemble those for an LWR. These conditions must be considered when determining values for parameters that govern fission product transport. 
Retention in the primary system of the SRS reactors has been estimated based on MELCOR/SR results and by making comparisons to evaluations published in NUREG/CR-4551 [5-30]. Differences between the Peach Bottom reactor and the SRS reactors have been accounted for by examining geometric and thermal-hydraulic differences and applying engineering judgment. The results are expressed as a decontamination factor (DF) for the primary system. A DF is defined for each volume or process through which fission products pass and represents the ratio of the mass entering a volume to the mass exiting that volume (i.e., $D F=m_{\text {in }} / m_{\text {out }}$ ). Thus, large values of DF indicate high retention. Six key phenomena are expected to affect retention: (1) gas flow rates; (2) geometric complexity; (3) natural circulation; (4) initial size of aerosol particles; (5) fission product density; and (6) chemical reactions between radionuclides and primary system materials. The potential effect of each of these phenomena on fission product retention are summarized below.

(1) The principal effect of high gas flow rates is to reduce the residence time of fission products in the primary system, thereby reducing retention. In postulated severe SRS reactor accidents, the vessel is either dry or contains a significant quantity of subcooled water. Either case leads to low steaming rates. If the vessel has been dried due to the debris heat up, the water is largely evaporated by the time the rate of fission product releases become large. If the vessel contains subcooled water, the steam generated by film boiling at the interface with the debris is condensed in the water. Since steam generation represents the only source for gas flow, residence times for fission products in the primary system are expected to be long in scenarios where energetic events do not result in an early breach of the vessel.

(2) The principal effects of a complex geometric configuration are a large surface area on which fission products can plateout and complex flow paths which reduce direct leakage from the primary system. The SRS reactors have relatively cool structures in the upper portion of the vessel and in the primary system loops. The top shield and heat exchangers both contain cooling water. Surfaces exposed to the primary system are thus initially cool and have a large effective heat capacity. The presence of cool surfaces enhances deposition by direct condensation of fission products from the vapor phase. Diffusiophoresis is also enhanced.

(3) Natural circulation generally tends to enhance fission product retention. Circulatory flows between hot regions (where fission products are released or suspended in quantity) to cool regions tends to expose cooler surfaces to gas flows containing fission products. The effect is to spread fission products over a greater volume, providing more area for deposition. 
(4) Aerosol size is an important parameter in primary system retention in that larger particles are more likely to be scrubbed by pools or settle before being released. Aerosol particle sizes will be smaller in the SRS reactors than in a commercial reactor with zircaloy-clad oxide fuel. There is no evidence to suggest that structural aerosols are formed during the melting of an SRS reactor core. Aluminum and/or uranium aerosols may be generated from foaming fuel, but this has not been observed. In the absence of structural aerosols, fission product vapors will tend to condense on homogeneously nucleated sites. This process leads to small aerosols $[0.2-0.5 \mu \mathrm{m}$ aerodynamic mass-mean diameter (AMMD)] which settle slowly. They are, however, susceptible to diffusiophoretic deposition, which may be important in the SRS reactor as noted under (2) above.

(5) Aerosol density is another important consideration. Collisions between aerosols leads to agglomeration, and clumps of aerosol particles settle more readily. Thus, higher densities lead to increased retention.

(6) Chemical reactions with steel structures within the primary system can be important under some conditions. This is particularly true for Cs, I, and Te. Gaseous forms of iodine can react with steel surfaces to form nickel iodide, while $\mathrm{CsOH}$ has been observed to react with stainless steel to form stable compounds such as cesium silicates. Similarly, tellurium has an affinity for metals in the steel and can form stable compounds such as nickel telluride. Formation of these stable compounds increases retention within the primary system and also reduces potential for later revolatilization.

In general, sedimentation has proven to be the governing mechanism for fission product deposition in severe reactor accident simulations. The simple geometry of the SRS vessel and the smaller aerosol particle size will lead to reduced deposition by sedimentation. Unless the heat exchanger surface areas are available for retention (which is likely to be prevented by the blockage of the piping by water or debris) deposition in the SRS primary system will be lower than in an LWR. However, considering the large uncertainty that attends these estimates, retention is judged to be comparable (i.e., roughly within a factor of two).

\subsubsection{Fission Product Revolatilization}

MELCOR/SR calculations have been performed for a few accident conditions to estimate the amount of fission product revolatilization that might be expected to occur. Due to uncertainties and model limitations, the calculations did not provide adequate results. Therefore, comparisons to 
NUREG/CR-4551 have been used to derive additional revolatilization information.

Revolatilization, like retention, can be expected to behave in a similar fashion for both SRS and LWR reactors. Phenomenological differences between the two reactor technologies have been taken into account by qualitatively defining their differences and applying engineering judgment to evaluate their impact on the level of revolatilization. Steam flow rates in the reactor and the potential for cooling of primary system structures are the two phenomena expected to most significantly contribute to differences in the level of revolatilization between the two reactor designs. The phenomena comparison and their potential effect on revolatilization are summarized below.

(1) The principal effect of high steam flow is to continuously purge the system's atmosphere. This tends to reduce the fission product concentration in the atmosphere leading to higher concentration gradients between the surface deposits of fission products and the gas. Higher concentration gradients enhance mass transfer from surface deposits to the vapor and thus increase revolatilization. Therefore, higher gas flow rates increase the level of revolatilization. Gas flow rates through the SRS primary system following breach by molten debris are expected to be higher than for an LWR. In the SRS reactors, the vessel is open to the confinement at the top through the control cluster stand pipes and the pressure relief system. If the bottom of the vessel is breached during core melt and relocation, a passage for airflow through the vessel may be established.

(2) The principal effect of cooling primary system structures is to reduce surface temperatures which reduces the level of revolatilization from those surfaces. SRS reactors have actively cooled top, bottom, and biological shields with water supplies that are independent of the primary cooling water supply. Therefore, SRS reactors have the potential for substantially greater cooling of primary system surfaces which could lead to dramatically lower revolatilization than that assumed in NUREG/CR-4551 for LWRs. However, the operability of the shield cooling systems during accidents has not been investigated. Furthermore, the efficiency of the top and annular shield cooling systems in cooling vessel surfaces which have deposited fission products has not been analyzed. It is known, for instance, that the design of the bottom shield renders the cooling system ineffective in cooling the vessel bottom if fuel debris has been deposited on it. In light of these considerations, the accident progression analysis has neglected the presence of these cooling systems. Revolatilization from primary system surfaces is thus expected to be significant and fairly rapid. 
An exception is made in the case of the heat exchangers, which are assumed to remain cool provided secondary cooling is not severely impaired. Decay heat from fission products which have plated out on heat exchanger surfaces would pose no significant challenge to the heat transfer capability of the heat exchangers. Heat exchanger structural components are thin with a large heat transfer surface area. Therefore, little or no revolatilization is expected from heat exchanger surfaces.

In summary, high steam flow rates and a relative lack of cooling of primary system surfaces favor revolatilization of deposited fission products in the SRS reactors. Volatile fission products deposited on the vessel walls (I, Cs, and Te) are judged likely to be released. Chemisorption of $\mathrm{CsOH}$ and Te by the stainless steel may reduce the Cs and Te revolatilization, but the surface area available is judged to be too small to retain the majority (i.e., more than half) of these elements. Fission products deposited in the heat exchangers after release from debris in the pipe are likely to be retained.

Comparisons to NUREG-4551 were used to estimate the revolatilization parameters for the APJIT. The physical phenomena accompanying the various scenarios at Peach Bottom were compared to scenarios in the SRS reactors. Estimates were made of the effects of differing physical phenomena on the results from Peach Bottom to obtain an estimate for the SRS reactors.

\subsubsection{Ex-Vessel Fission Product Transport Analysis}

All of the severe accident scenarios considered as part of the SRS risk assessment have the potential for leading to contact between molten fuel material and the concrete floor of the confinement building. Contact between molten fuel and concrete can occur as a result of two principal primary system failure modes. First, a steam explosion may occur in the reactor vessel, causing the reactor vessel bottom to fail. Partially molten core debris would then be deposited on the pump room floor. The molten portion may cool or, alternatively, could run through the drainage trenches into the sumps. If molten debris collects in the sumps, debris that was ejected from the vessel as a solid may also subsequently melt and collect in the drainage sump. Heating of debris in the sump due to its decay heat would result in the debris remaining at temperatures corresponding to a molten state. The second principal mode of primary system failure involves heating of the core debris within the primary system to temperatures in excess of the liquidus temperature. Molten debris can collect within the primary system piping below the vessel, or perhaps on the vessel bottom. The debris can heat up in these locations to temperatures in the range from $1400-2000 \mathrm{~K}$ before structural failure of the piping or bottom shield would occur. Debris at this temperature may again run through the drainage trenches and collect in pump room sumps. 
The scope of this section is limited to the analysis that was performed for ex-vessel fission product transport during molten core concrete interactions (MCCI). This includes the release of fission products during MCCI and the retention of fission products from the water overlying MCCI.

\subsubsection{Fission Product Release}

Sandia National Laboratories (SNL) has conducted three MCCI experiments to date for the Savannah River Technology Center (SRTC). Data from one of these tests, SRL-1 [5-31], has been incorporated into this analysis. The experiment involved inductively heating approximately $75 \mathrm{~kg}$ of aluminum in a concrete crucible. Aluminum and concrete temperatures, concrete erosion, evolved gas quantities and composition, aerosol generation and composition, and final melt composition were measured. The concrete used was typical of that used in the construction of the SRS reactor confinement buildings. Fission product simulants were added to the aluminum charge such that their concentration approximated that which might be expected in the reactor core debris following complete melting. No uranium was present in the charge. Predictions of fission product release and aerosol generation were derived solely from the SRL-1 test results. The MCCI computer code CORCON/SR [5-32] does not model fission product chemistry or aerosol generation. The approach taken was to scale the SRL-1 test results on the basis of the area of concrete exposed to attack. Release rates were then corrected to account for differences in the mass concentration of fission product elements between the test charge and the reactor core and expected differences in gas generation rates. This process and the release fractions calculated will be further discussed in Section 5.5 on MCCI.

\subsubsection{Fission Product Retention Due to Water Overlving MCCI}

The mechanisms governing aerosol removal by overlying water pools are the same as those governing aerosol removal by suppression pools in BWRs. Aerosol removal occurs by several different mechanisms, including sedimentation, impaction, diffusion, and condensation. Sedimentation occurs when aerosol particles settle out of vapor phase and onto the bubble surface. Impaction occurs when the aerosol particles are unable to stay within the flow of the circulating gas in the bubble, and subsequently impact the bubble surface. Particle diffusion occurs due to momentum exchange with surrounding gas molecules. Condensation can occur when the steam in the bubbles is supersaturated relative to conditions at the bubble surface (e.g., in a subcooled pool). The condensing steam carries with it aerosol particles, which are subsequently trapped by the bubble surface.

The magnitude of the decontamination factor depends on the depth and temperature of the water pool, the size of the rising bubbles, the aerosol particle size distribution, and the steam and noncondensible gas content of the bubbles. Given the uncertainty associated with many of these 
parameters, there is significant uncertainty in the magnitude of the water pool DF.

The decontamination factors for water pools overlying an ongoing MCCI are expected to be smaller than the DFs associated with in-vessel phenomena. This is true for two primary reasons. First, the bubbles rising in the ex-vessel water pool will have a higher concentration of noncondensible gases than for bubbles generated in-vessel. The higher concentration of noncondensible gas will lead to reduced condensation onto the bubble surface. Second, the ex-vessel bubbles are likely to be larger than the in-vessel bubbles (due in part to the greater amount of noncondensible gas). Larger bubbles are known to be less effective at trapping aerosols. For these reasons, the ex-vesisel DFs used in the APET were smaller than those defined for the in-vessel viater pool.

\subsubsection{Summary of Resulls for PCS Fission Product Transport}

Primary coolant system fission product release and transport has been analyzed. The principal tool for this analysis was the MELCOR/SR code. Fission product release from melting assemblies was evaluated with a CORSOR-M type model adjusted to reflect available data for SRS fuels. Fission product evolution from molten pools was evaluated with the MELCOR/SR molten pool release model. Results of these analyses indicate that relatively little fission product release occurs during assembly heat-up, melt, and relocation, because temperatures are low and these phases occur over a very brief time. The majority of the releases occur during the molten pool phase where the debris reaches and maintains fairly high temperatures. Integrated releases show that virtually all of the nobles and volatile species as well as a significant fraction of nonvolatile species can be expected to evolve if the fuel attains and maintains fairly high temperatures. Finally, primary system retention and revolatilization can be characterized as being similar to LWRs.

\subsection{Molten Core-Concrete Interaction Analyses}

All of the severe accident scenarios considered as part of this risk assessment have the potential for leading to contact between molten fuel material and the concrete floor of the confinement building. "ontact between molten fuel and concrete can occur as a result of two $y$. cipal primary system failure modes. First, a steam explosion may occ: the reactor vessel, causing the reactor vessel bottom to fail. Partially Iten core debris would then be deposited on the pump room floor. The ten portion may cool or, alternatively, could run through the drainage tre: es into the sumps. If molten debris collects in the sumps, debris thi. is ejected from the vessel as a solid may also subsequently melt and colle $n$ the drainage sump. Heating of debris in the sump due to its decay is at would result in the debris remaining at temperatures corresponding a molten state. The second principal mode of primary system failure invo es heating of the core debris within the primary system to temperatures in excess of the liquidus temperature. Molten debris can collect within the 
primary system piping below the vessel, or perhaps on the vessel bottom. The debris can heat up in these locations to temperatures in the range from $1400-2000 \mathrm{~K}$ before structural failure of the piping or bottom shield would occur. Debris at this temperature may again run through the drainage trenches and collect in pump room sumps.

Due to the chemical reactivity of aluminum, potentially vigorous interactions between the molten core and concrete can result. These interactions are termed molten core-concrete interactions (MCCI). Water vapor, released from concrete as a result of heat transfer from molten debris, can oxidize the molten aluminum-uranium mixture, releasing hydrogen. This reaction is exothermic. Therefore, rapid heating of the debris, at a rate much faster than would result from decay heat, would ensue. Heating of the debris, combined with the mechanical agitation that results from gas (principally hydrogen and steam) passing through the molten pool, will cause fission products and aerosols to be released. Thus, there are four mechanisms by which MCCI can affect accident progression and accident consequences:

(1) Heat transfer from the debris surface to the confinement atmosphere reduces the effectiveness with which this air can cool the filters.

(2) If combustion of the hydrogen generated during MCCI occurs, the heat produced can lessen the effectiveness of filter cooling, or even lead to filter heating or failure from hightemperature combustion gases.

(3) Fission product release and the subsequent transport of these materials to the filters increases the filter heat loading.

(4) Aerosol generation from both fuel and concrete materials, and the subsequent transport of these aerosols to the filters leads to filter plugging which reduces air flow, contributing to filter heating.

In order to assess the magnitude of these effects, analysis of the MCCI phenomena for uranium-aluminum alloy fuel has been conducted. The objectives of this analysis were to

(1) assess the temperature at which MCCI occurs in order to estimate the confinement heat load;

(2) predict the rate of hydrogen production;

(3) predict the total amount of fission product release; and

(4) predict the total mass of evolved aerosols. 


\subsubsection{Modeling Techniques}

The analysis of MCCI for: the SRS PSA rests on two sources of information: results from a newly developed computer code, CORCON/SR, and results from a single experiment. CORCON/SR is a modified version of the CORCON code developed by SNL to predict the ablation of concrete by molten LWR core debris [5-33]. The CORCON/SR modifications essentially incorporate aluminum and uranium metal properties into the code's data base. Heat transfer from molten debris to concrete and the resulting concrete erosion are mocleled by the same correlations that were employed in CORCON. Chemical reactions in CORCON are modeled assuming that chemical equilibrium is maintained in the debris. CORCON/SR predictions of concrete erosion, debris temperature, and hydrogen generation compare favorably with results published for one experiment ([5-34], described below).

SNL has conducted three MCCI experiments to date for the Savannah River Technology Center (SRTC). Data from one of these tests, SRL-1, has been incorporated into this analysis. The experiment involved inductively heating approximately $75 \mathrm{~kg}$ of aluminum in a concrete crucible. Aluminum and concrete temperatures, concrete erosion, evolved gas quantities and composition, aerosol generation and composition, and final melt composition were measured. The concrete was typical of that used in the construction of the SRS reactor confinement buildings. Fission product simulants were added to the aluminum charge such that their concentration approximated that which might be expected in the reactor core debris following complete melting. No uranium was present in the charge.

Both CORCON/SR and the SRL-1 test indicate that vigorous interaction between aluminum and concrete occurs when aluminum temperatures reach $1800-2000 \mathrm{~K}$. CORCON/SR results indicate that the interaction sustains temperatures in the range of $2000-2200 \mathrm{~K}$. Temperatures in the SRL-1 test reached at least $1900 \mathrm{~K}$. However, in SRL-1, the power supply used to simulate the effects of decay heat failed soon after vigorous MCCI began. It is thus reasonable to assume $2000 \mathrm{~K}$ temperatures for the debris and gas released from the debris surface. This value was used in confinement response evaluations.

\subsubsection{Hydrogen Generation}

Hydrogen gas generation rates were predicted by CORCON/SR as ming that the full core collected in one side of the pump room sump. The bris thus covered an area of $13.2 \mathrm{~m}^{2}$ to a depth of approximately $50 \mathrm{c}$ The resulting hydrogen production rate averaged approximately $0.05 \mathrm{~kg} /: \therefore$ In the SRL-1 test peak hydrogen generation rates in the range of 0 ) to 120 standard liters per rninute (slpm) were reported (corresponding to $: 3 \mathrm{x}$ $10^{-4}$ to $1.8 \times 10^{-4} \mathrm{~kg} / \mathrm{sec}$ ). In this test the debris covered an area of $0.13 \mathrm{~m}-$ to a depth of approximately $26 \mathrm{~cm}$. The composition of the gas evolved was 85 to $90 \%$ hydrogen indicating that this depth of debris was sufficient to react 
most of the water evolved from the concrete. If one assumes that the gas generation rate is proportional to the area of concrete exposed to attack from the debris, scaling the experiment results by the ratio of the pump room sump area (one side) to the test crucible area yields hydrogen generation rates in the range of 0.014 to $0.019 \mathrm{~kg} / \mathrm{sec}$. These generation rates are approximately one-third those predicted by CORCON/SR. However, in the SRL-1 test, significant degassing of the concrete occurred during a long heat-up phase prior to the onset of MCCI. Therefore, the concrete was dried out when vigorous MCCI began. Since water in the concrete leads to hydrogen generation, it is judged that the CORCON/SR results are appropriate. It has thus been concluded that a rate of $0.05 \mathrm{~kg} / \mathrm{sec}$ is a reasonable rate to assume for hydrogen production. This rate has been used for the confinement response analyses described in Section 5.6.

\subsubsection{Fission Product Release}

Predictions of fission product release and aerosol generation were derived solely from the SRL-1 test results. CORCON/SR does not model fission product chemistry or aerosol generation. A new code to predict fission product release and aerosol generation that will be linked with CORCON/SR, is currently under development, but no mechanistic predictive tool is available at present. The approach taken was to scale the SRL-1 test results on the basis of the area of concrete exposed to attack. Release rates were then corrected to account for differences in the mass concentration of fission product elements between the test charge and the reactor core and expected differences in gas generation rates. This approach to estimating the release is best demonstrated by example.

It was assumed that fission product elements were released and transported with the concrete and aluminum aerosols generated in the SRL-1 test. This is equivalent to saying that fission product elements released as vapors (as I, Cs, Te, and $\mathrm{Sr}$ may have been) were assumed to condense in the vicinity of the melt pool. In SRL-1, total aerosol generation was inferred from the measured density of aerosols in the effluent gas stream. The product of the aerosol density and the volumetric gas generation rate was used as a measure of the total aerosol production rate. In SRL-1, the measured aerosol density during vigorous MCCI was reported to be approximately $35 \mathrm{~g} / \mathrm{m}^{3}$. The gas generation rate was approximately $100 \mathrm{slpm}$. At the point the aerosol density was measured, the gas temperature was probably close to $350 \mathrm{~K}$ and the pressure slightly subatmospheric. Thus, the actual volumetric flow rate was close to $140 \mathrm{l} / \mathrm{min}$. The aerosol generation rate is thus estimated at $0.082 \mathrm{~g} / \mathrm{s}$. It is assumed that aerosol generation rate scales with the area of concrete being eroded. As indicated above, the gas generation rate in SRL-1 was approximately one-third of that expected were the concrete not dehydrated from pretest heating. Aerosol density is not expected to be significantly affected by the increased gas generation. Thus, aerosol generation from 
MCCI during a reactor accident was estimated at $24 \mathrm{~g} / \mathrm{sec}^{*}$. Assuming that the peak hydrogen generation rate of $0.05 \mathrm{~kg} / \mathrm{sec}$ is maintained, all the aluminum in the core would be oxidized in 10 hours. This is the assumed duration for MCCI. The total aerosol release would then be approximately $1000 \mathrm{~kg}$. Based on the variation in the experimental data, the uncertainty in this assessment has been estimated to be a factor of three.

Fission product release was estimated by multiplying the mass fraction of the element in question, determined for SRL-1 aerosols from post-test analysis of collected samples, by the total quantity of aerosol estimated to be released. The mass fraction measured was corrected for the difference in inventories between the test charge and the SRS reactor core. The resultant mass release was then normalized by the assumed core inventory to produce a release fraction.

Several samples of SRL-1 aerosol were analyzed to determine chemical composition. Three filter samples (\#2, \#5, and \#8) taken before, during, and after vigorous MCCI respectively, were used as the basis for determining the measured mass fraction of the $i^{\text {th }}$ fission product element in the collected aerosol, $f_{i}$. If the values of $f_{i}$ decreased monotonically from Sample 2 to Sample 8, it was assumed that the element in question was depleted significantly during the experiment, and $f_{i}$ from Sample 2 was used. If the Sample 5 value of $f_{i}$ wass higher than either of the others it was assumed that vigorous MCCI enlanced the release and the Sample 5 value was assumed to characterize the interaction that would occur in a reactor accident. If neither pattern was exhibited, an average of the three was used. Uncertainty in release fractions was assumed to be dominated by the uncertainty in the amount of a particular element present in the aerosol. Other uncertainties were neglected. The calculated release fractions from MCCI are listed in Table 5-5.

\subsubsection{Summary of Molten Core-Concrete Interaction Analysis}

The consequences of MICCI have been estimated by a combination of computational models and experimental results. The results point to three significant conclusions.

(1) Hydrogen generation rates for molten aluminum interacting with concrete are high. The expected rate in a severe accident at an SRS reactor is $0.05 \mathrm{~kg} / \mathrm{s}$.

(2) Relatively large amounts of aerosol will be released into the confinement atmosphere, and rates are expected to average $100 \mathrm{~kg} / \mathrm{hr}$.

$* 24 \mathrm{~g} / \mathrm{s}=0.082 \times$ Area Ratio $\times \mathrm{H}_{2}$ Ratio $=0.082 \mathrm{~g} / \mathrm{s} \times\left(\frac{13.2 \mathrm{~m}^{2}}{0.13 \mathrm{~m}^{2}}\right) \times\left(\frac{0.05 \mathrm{~kg} / \mathrm{s}}{0.017 \mathrm{~kg} / \mathrm{s}}\right)$ 
(3) Volatile fission products (i.e., those with elemental boiling points below $2000 \mathrm{~K}$ ) will be largely released. Those with higher boiling points are released at very low rates, consistent with mechanical aerosolization of the debris due to hydrogen sparging.

Hydrogen and aerosol generation from MCCI will thus pose a significant challenge to the AACS. If airflow in the confinement is near nominal, the hydrogen is not expected to accumulate to combustible concentrations. However, flow degradation due to aerosol accumulation on the HEPA filters or obstruction of the air ducts could lead to concerns in this regard. Aerosol generation at the rates indicated could lead to filter loadings at a level that would challenge the AACS function. This behavior is discussed in Section 5.6. MCCI does not appear to lead to the release of large quantities of fission products that would not already be released in substantial quantity during the in-vessel phase. Direct contribution to the source term is therefore likely to be small.

Table 5-5. Calculated Radionuclide Release During MCCI Based on the Results of the SRL-1 Experiment

Element Group

Release Fraction

\begin{tabular}{ll}
\hline \hline $\mathrm{I}$ & 1.0 \\
$\mathrm{Cs}$ & 1.0 \\
$\mathrm{Te}$ & 0.9 \\
$\mathrm{Sr}$ & 0.022 \\
$\mathrm{Ru}$ & $3.8 \times 10-4$ \\
$\mathrm{Mo}$ & $1.6 \times 10-3$ \\
$\mathrm{La}$ & $6.8 \times 10-5$ \\
$\mathrm{Ce}$ & $4.9 \times 10-5$ \\
$\mathrm{Ba}$ & $7.3 \times 10-3$ \\
\hline
\end{tabular}

* Te was not included in the SRL-1 test. This estimate reflects engineering judgment based on the volatility of $\mathrm{Te}$ relative to $\mathrm{Cs}$ and $\mathrm{Sr}$ combined with recognition of its potential for reacting chemically with metals to reduce volatility. 


\subsection{Confinement Response Analyses}

The SRS confinement system is the final barrier against fission product release during postulated severe accidents. As such, its performance under severe accident conditions has a substantial effect on the risk of reactor operation. A significant fraction of the effort in the Level $2 / 3$ portion of the PSA has thus been directed toward confinement system analysis. The confinement system includes the AACS, the CHRS, and the RRSS. The action of these systems, combined with the natural processes that tend to deposit fission products in water or on confinement surfaces, mitigate the amount of fission products released to the environment. Substantial detail was included in the AFET to consider the response of the confinement during severe accident conditions. The APET structure and quantification for confinement resporise was based largely on insights gained from confinement system response calculations made using the MELCOR/SR computer code [5-35].

Section 5.6.1 includes a brief discussion of the code used to analyze the SRS confinement response. In Section 5.6.2, (1) the scope of the confinement response analyses; (2) the methodology used to establish the APET confinement response model; and (3) the APET UFUN model for AACS flow and filter temperature response (as a function of mass deposited on the filter) are discussed. Finally, Section 5.6.3 presents a summary of the confinement response analyses.

\subsubsection{Confinement Response Analysis Techniques}

The SRS confinement is similar in many ways to the secondary containment or auxiliary buildings of light water reactors (LWRs). These structures have similar construction and volume as compared to the SRS confinement. Both the LWR secondary containment and the SRS confinement house large amounts of equipment and contain doors, hatches, and a ventilation system with fans and filters. The LWR secondary containment was designed to ventilate and filter fission products leaked into the containment or inadvertently released during refueling operations. However, the LWR systems are generally not effective during severe accident conditions due to their relatively small flow capacities (a few thousand cubic feet per minute). Some LWR secondary containments and auxiliary buildings employ water spray systems for fire suppres $n$. The SRS confinement system also includes a spray system. How $;$, the primary function of the SRS reactor room spray system (RRSS) i. : cool fuel assemblies that may be dropped during discharge.

For the purpose of analyzing the AACS response to severe core $\dot{a}$ ge accidents, modeling of single-phase incompressible flow (i.e., low ch number flow), hydrogen combustion, MCCI, and the behavior of aes sol fission products is required. In addition, the action of the AACS filters ind fans must be modeled. Modeling of incompressible flow is straightforw r.rd. A control volume representation of the building can be used. The prediction of gas composition, flow rate, and temperature involves the solution of the 
conservation equations of mass, momentum, and energy. Thermal interaction between the gases and structures is modeled with heat convection and steam condensation correlations. The thermal response of the solids is predicted using a one-dimensional conduction calculation. The static and thermal loads from combustion are modeled within the overall treatment of incompressible flow largely by inclusion of the appropriate heat source. Experimentally based correlations can be used to determine the flame speed and burn completeness as a function of the temperature and gas composition when ignition occurs. Superimposed on the bulk gas movement is the fission product aerosol behavior. Aerosol agglomeration, natural settling and deposition mechanisms, and active removal mechanisms due to spray operation must also be considered.

The MELCOR code was selected for calculation of the SRS confinement response. MELCOR is being developed by Sandia National Laboratories (SNL) for the United States Nuclear Regulatory Commission (US NRC) [5-35]. It is an integrated, fast running computer code for the analysis of severe accident behavior in LWRs. Many of the separate effects codes which had been validated for source term evaluations [5-36] were incorporated directly into MELCOR. MELCOR offers significant advantages over other similar codes including sensitivity analysis capability, control system modeling, a two fluid thermal-hydraulic model, and a building block control volume formulation. The MELCOR computer code was enhanced as part of the SRS Severe Accident Assessment Program to extend modeling capabilities for SRS-specific hardware and materials [5-37]. In particular, an enhanced filter model was added to permit more accurate simulation of the AACS filter response and source term estimation [5-38]. Models were included for both thermal and mechanical degradation or failure due to thermal-hydraulic and fission product loads on the filter media.

\subsubsection{Results of the Confinement System Response Analysis}

A systematic approach was taken to evaluate the confinement response to postulated severe accident loads [5-39]. First, separate effects calculations were performed to characterize the confinement response to the range of expected loads with potential hardware configurations. The principal objective was to identify thresholds where the confinement effectiveness to retain fission products changed abruptly. To accomplish this, a series of calculations were performed. In each calculation, a heat and/or mass source was defined that was intended to simulate the effects of a single severe accident phenomenon (e.g., hydrogen burn, MCCI, steam explosion). A fission product source was typically included to act as a tracer for the gas flow. These fission product sources were not intended to simulate expected severe accident releases. In addition to these separate effects assessments, a limited set of integral calculations were performed to evaluate synergistic effects from severe accident loads. Due to programmatic constraints, a full set of integral calculations were not undertaken. 
Section 5.6.2.1 discusses the SRS confinement model (input deck for MELCOR/SR) used for the separate effects and integral calculations. It is beyond the scope of this section to describe the results from all the calculations performed to support the APET confinement rest ise. Consequently, the discussion of the confinement system response in ? tion 5.6.2.2 is limited to the scope of the separate effects and it sral calculations and the methodology used to collapse the information $f f i$ the code calculations into the response model for the APET [5-40]. The pecific application of the selected results to quantification of the APE will be discussed in Section 5.6.3. The APET required a quantitative eva sation of the potential for thermal degradation or failure of the filter sysiem. The evaluation of the "user function" (a FORTRAN subroutine for the EVNTRE code named UFUN) for the filter response used in the APET is described in Section 5.6.2.3.

\subsubsection{Input Deck Description}

An input deck was developed for the MELCOR/SR computer code to represent the SRS confinement. The input deck includes both geometric and process model input. Figure 5-1 provides a schematic of the SRS model. The system nodalization used for the calculations described in this report had 16 control volumes, 27 flow paths, and 40 heat structures. The belowgrade nodalization contained enough detail to permit a natural circulation pattern between the pump rooms and the heat exchanger bay (three nodes). The AACS supply and exhaust ducts were explicitly modeled using control volumes because of their length and importance as a deposition pathway. Included in the 16 control volumes are three that represent the surrounding environment. These volumes were used to track fission product releases at the ground, roof, and stack elevations separately. Subsequent atmospheric dispersion and health consequence calculations use the detailed fission product release information. Special input was included to model potential failure paths (personnel doorways, roll doors, and machinery access concrete hatches), flow dampers, and the Deposit and Exit (D\&E) Canal from the reactor room through to the disassembly basin. An RRSS model was also included for calculations with confinement sprays (i.e., Reactor Roorn Spray System (RRSS)).

The confinement model has been benchmarked against AIRFLOW code results [5-5]. AIRFLOW is a hydrodynamic flow program de : gned to calculate complex flow distribution systems [5-41]. The results fror he SRS AIRFLOW resistances were tuned to match measured AACS pre ${ }^{-e}$ and flow distributions. The MELCOR/SR SRS Confinement model - flow resistances were adjusted so that the results matched the $\mathrm{AI}$. OW calculations. Agreement between the two models is very good for a v. y of hardware (e.g., damper positions, filter loadings) configurations. 


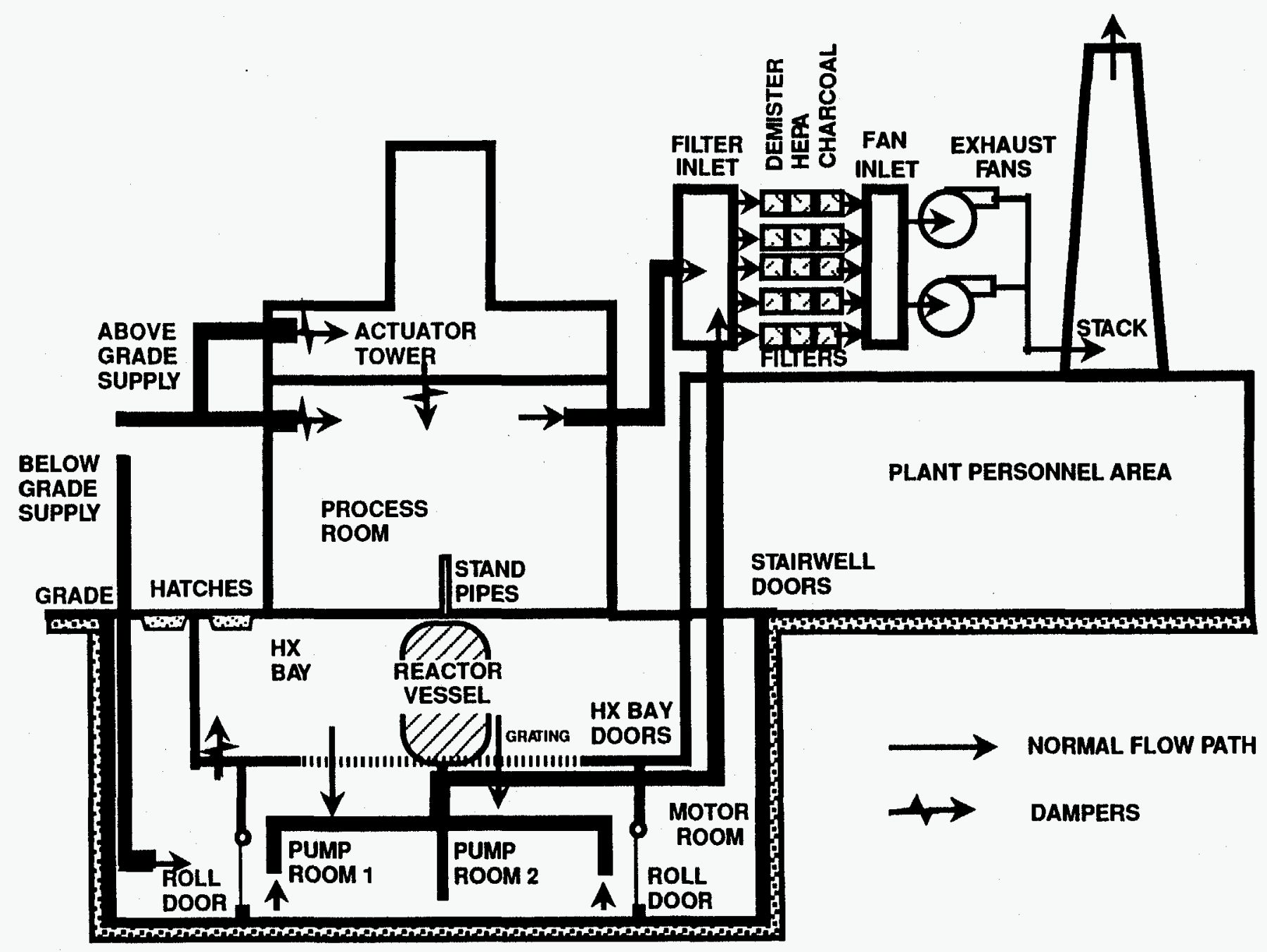

Figure 5-1. Schematic of SRS MELCOR/SR Confinement Model 


\subsubsection{Results of MELCOR/SR Simulations}

Two series of MELCOR/SR calculations were performed to produce predictions of the confinement response to loads that were believed $t$ accompany severe accidents [5-39]. The first series consisted of separat effects calculations to identify the regimes of confinement behavior unde anticipated severe accident loads. These calculations provided the basis ${ }^{r} r$ identifying thresholds that the confinement system could tolerate befor a failure or other general change in behavior would occur. This informs on was used to delineate events that would cause significant changes in the progression of a severe accident. The major topics addressed by the separate effect calculations were the following:

(1) Air flow changes in response to AACS and confinement status. Single fan failure, below-grade flooding of air ducts, and HEPA filter plugging by aerosols were specifically studied. The effect of air flow changes on filter temperatures for a specified fission product loading were examined.

(2) Filter temperature response to steam flow following AACS failure. Various modes of confinement building and AACS failure were considered. Failure of all fans and confinement building breach were included. Steam and aerosol sources within the confinement were specified in an idealized fashion to reflect in-vessel accident progression.

(3) Filter temperature response to non-condensable gas flow following AACS failure. This study was similar to that described under (2) above. Hydrogen and aerosol sources within the confinement were specified in an idealized fashion to reflect MCCI.

(4) Confinement structure response to steam spike loads. Steam generation rates within the confinement were varied over the range of expected conditions to accompany fuel-coolant interactions. Induced failures, such as breach of the filter media, doorways, or other confinement structures were studied.

(5) AACS bypass resulting from structural failures. The extent of confinement system bypass by airborne aerosols was examined. Various degrees of confinement breach and a range of gas sources within the confinement were considered.

(6) Potential for hydrogen combustion. Confinement air flow rates and hydrogen source rates were varied 
parametrically to determine the potential for hydrogen concentrations attaining combustible levels. Peak pressures resulting from combustion were evaluated for various hydrogen concentrations in the above- and below-grade regions.

(7) Filter behavior. The sensitivity of filter response to uncertainties in the mass loading versus pressure drop correlation was investigated. It is known from the experimental studies of SRS Demister and HEPA filter media that moisture in the gas flow can have a large impact on filter resistance for a given aerosol mass loading [5-42 and 5-43]. In addition, the performance of the Demister can affect the amount of fission products reaching the HEPA.

The purpose of the studies was to understand the confinement response to events and phenomena that accompany severe accidents. A closely associated goal was the identification of the various regimes of confinement and AACS behavior so that these could be incorporated into the structure of the APET. In other words, these studies aided in the identification of levels of confinement system loading that resulted in responses that were significant in terms of the accident progression or source term.

The second series of calculations addressed integrated severe accident behavior. These calculations covered the entire accident from the beginning of core damage up to the point at which the final distribution of released fission products could be established. Two major topics were investigated in the integral calculations:

(1) Response of the confinement system to core melt progression in the absence of energetic events. The effects of confinement sprays, MCCI, and fan operation on the early and late fission product distribution were examined.

(2) Response of the confinement system to energetic events and vessel failure. The effect of an energetic event on the early and late fission product distribution was examined.

It must be noted that these calculations were performed with MELCOR/SRMod 1, which did not incorporate modeling of in-vessel melt progression, fuel coolant interactions, or MCCI. Mass and heat sources were thus used to approximate the relevant severe accident phenomena. These calculations thus reflect an early attempt to characterize the interactions between phenomena. MELCOR/SR-Mod4 is available at the time of this writing and is capable of a far more complete simulation. 


\section{Fission Product Response Characterization}

The results from the MELCOR/SR calculations described above were reviewed, and based upon the insights gained, the key parameters affecting fission product retention, confinement bypass, and filter loading were identified. The total set of all logical combinations of these parameters were grouped into a handful: of AACS configurations that had distinct responses [5-5]. Due to differences in the phenomena that affect the fission product behavior, the early or above-grade response was considered separately from the late or combined above- and below-grade response. A description of both the early and late fission product behavior models follows.

Prior to vessel failure, thermally-driven circulation patterns will release fission products through the reactor-vessel stand pipes and vacuum breakers to the above-grade confinement. Consequently, the early confinement fission product response is affected by the above-grade AACS configuration. Three parameters that influence the above-grade fission product response are the mode of circulation, the magnitude of the structural damage, and operation of the sprays. The mode of circulation was subdivided into forced circulation, natural circulation (fans off but open flow through the stack), and isolated (filter dampers closed). The building damage configurations included a large failure (complete failure of the actuator tower or other gross building damage), a medium failure (damage to the actuator tower with the floor still in place), and a small failure (leakage around the shield doors or flow through the disassembly basin pool). Eighteen possible AACS configurations were identified based on these three considerations. The results from the MELCOR/SR calculations, which depicted each configuration, were then reviewed. Retention, bypass, and filter loading fractions for each configuration were evaluated. For some configurations, there were no available calculations. Consequently, results from similar configurations were extrapolated or interpolated using engineering judgment.

The results obtained showed significant variation between most of the cases. However, the existence of some similarities allowed the eighteen early above-grade confinement configurations to be collapsed into eleven distinct cases. In the APET, only the aerosol and iodine retention and the aerosol bypass fractions were specified. The filter loading was deduced by a mass balance in UFUN. The aerosol retention fractions (percent ' of the aerosol which where retained in the confinement) ranged from $\left(\right.$ to $_{0} 0.9$. However, most of the retention fractions were less than 0.25 . Th ypass fractions ranged from 0.0 to 1.0. Gross failure of the confinemen i ?d to complete bypass of the AACS while most forced circulation calcu ions maintained negative pressure in the reactor room leading to neglig. 3 or very small bypass.

The late response was characterized as the time period after vessel failure. During this time period, MCCI, energetic events, and revaporization of fission products initially deposited in the primary system were the fission product release mechanisms. Since, for some cases, the revaporized fission 
products would be released above-grade, the previously assigned early above-grade retention and bypass fractions were used. In a fashion similar to that for the early fission product behavior model, important parameters which affect below-grade releases were developed. The important parameters affecting the below-grade fission product behavior were the magnitude of the below-grade structural damage, the mode of circulation, the existence of a below-grade to above-grade flow path through the vessel, the existence of a below-grade to above-grade flow path through the exhaust ducts, and the amount of water covering the debris bed. The structural damage configurations included a large failure through the heat exchanger hatches, a medium failure through the personnel doors or back through the AACS inlet line, and normal leakage paths. The modes of circulation were identical to those used in the above-grade studies (i.e., forced, natural, and isolated).

The below-grade to above-grade connectivity information was important to determine the extent of communication with the above-grade area. The measure of connectivity, (i.e., size of the failure path through the reactor vessel) and the status of the AACS exhaust ducts (i.e., flooded, crushed, or closed by dampers), were combined to determine the effective connectivity between the above- and the below-grade regions. If there was "good" connectivity, AACS fan operation was found to preclude combustion (by preventing hydrogen accumulation), increase fission product loading on the filters, and more effectively transmit energetic loads from the belowgrade areas to the filter compartments and fan casings. Conversely, "poor" connectivity could result in below-grade hydrogen combustion, no additional mass or thermal loading on the filters, and poor transmission of energetic loads from the below-grade regions. Under conditions of poor connectivity, the potential for the below-grade regions to collect hydrogen or heat up due to MCCI was directly affected by the degree of below-grade bypass.

Finally, the MELCOR/SR calculations showed that thermal radiation from the debris bed was a significant heat source to the atmosphere. The depth of any below-grade water pool indicates the extent to which thermal radiation is attenuated in the pool above the MCCI. The depth of the pool also affected the amount of aerosol and iodine scrubbing from MCCI releases. These effects were also considered in developing the confinement configurations.

There were 108 logical combinations of the five parameters affecting fission product distribution from below-grade releases. Following a collapse of similar configurations, all applicable MELCOR/SR calculations were assigned to one of twenty-eight configurations. Similar to the early release analysis, bypass, retention, and filter loading fractions were assigned to each configuration. The effects of energetic events, hydrogen burns, MCCI, and pool scrubbing were considered when performing these response groupings and developing the associated fission product distribution parameters (i.e., confinement DF and filter bypass fraction). Further reduction (based on similarities in the assigned fission product distribution 
parameters) led to twelve distinct cases for the airborne fission products and four levels of below-grade pool scrubbing for the APET.

The below-grade airborne fission product retention fractions ranged from 0.0 to 0.8 . Once the aerosols were airborne, most configurations had low retention. The tendency for a water pool to allow passage of aerosols in the size-range that is not significantly affected by dominant removal mechanisms (i.e., sedimentation) was considered in these analyses. Pool retention factors ranged from 0.0 to 0.9 as the pool depth was varied. The aerosol bypass fractions ranged from 0.0 to 1.0 . The failed heat exchanger removal hatch configuration, with poor connectivity to the above-grade, had the highest bypass fractions ( 0.8 to 1.0$)$ for the aerosols which escaped from the below-grade pool.

\section{Effect of Steam Pulse Loads on Structures and Releases}

MELCOR/SR calculations were performed to examine the thresholds at which a steam pulse would damage various confinement structures [5-5]. Vulnerable structures included filter elements, fan casings, personnel access doorways, and hatch covers. Three configurations were parametrically tested for different magnitude steam pulses: (1) an abovegrade steam pulse; (2) a below-grade steam pulse with the exhaust vents clear; and (3) a below-grade steam pulse with the vents covered by water. A secondary objective was to study the aerosol behavior during the steam pulse. Two sets of steam pulse calculations were performed. In the first set, the calculations were initially performed with the reactor vessel at an elevated pressure and filled with saturated water. The steam pulse was simulated by rapidly failing either the upper or lower head of the reactor vessel. Subsequent steam generation caused the steam pulse. In the second set of calculations, a steam explosion was simulated by simultaneously introducing a specified amount of steam and hydrogen source into a control volume. The key results from these calculations are discussed below.

The structural vulnerabilities identified from an above-grade steam pulse were characterized. Iluring a steam pulse, the reactor room was pressurized. The resulting flow pattern caused flow (1) out the filter exhaust ducting; (2) out through the disassembly basin pool; and (3) to the below-grade confinement. At a peak reactor room pressure of $10^{5} \mathrm{~Pa}$ (23 psia), the exhaust fan casing and the HEPA filters as well as relowgrade personnel doorways were breached. The largest steam pr. peak reactor room pressure of $\left.4.2 \times 10^{5} \mathrm{~Pa}(61 \mathrm{psia})\right]$ also failed the bel c rade roll doors. The magnitude of the aerosol bypass was related the magnitude of the steam pulse and the number of structural fail $\cdots \quad A$ significant portion of the aerosols that were airborne during the . $m$ pulse were calculated to be immediately released to the environment.

In reviewing the results from these calculations, it was determined at failure of the dampers between the reactor room and the actuator tower was not considered. It is likely that failure of the flow dampers between the reactor room and the actuator tower would occur at high pressures. When 
failure of these dampers was considered, the peak pressure in the reactor room was negligibly lower $\left[\sim 4.1 \times 10^{5} \mathrm{~Pa}(60 \mathrm{psia})\right]$. However, the peak in the actuator tower for the largest steam pulse was $1.27 \times 10^{5} \mathrm{~Pa}(3.9 \mathrm{psi})[5-5]$. The weakest structural components in the above-grade confinement (besides the flow dampers) are the actuator tower walls. Reference 5-44 indicates that a static load of 5 psig is required to fail the actuator tower. Therefore, gross failure (i.e., failure of the actuator tower) is unlikely. However, it is likely that bypass flow paths would be opened through the inlet and outlet ducting including failure of the filter elements and fan casing. These combined failures are expected to have a comparable effect to a local failure in the actuator tower wall (assuming that the failure leading to pressurization of the actuator tower is no more severe than damper failure).

In the second set of above-grade steam explosion calculations, the specified steam sources were introduced into the reactor room with hydrogen. The two cases simulated a large ( $400 \mathrm{~kg}$ of steam and $100 \mathrm{~kg}$ of hydrogen) and a small ( $80 \mathrm{~kg}$ of steam and $20 \mathrm{~kg}$ of hydrogen) in-vessel steam explosion. The peak pressures were $1.9 \times 10^{5} \mathrm{~Pa}(28 \mathrm{psia})$ and $1.03 \times 10^{5} \mathrm{~Pa}$ (15 psia), respectively. The significant differences were partially attributed to the large steam explosion case having sufficient hydrogen for combustion versus an insufficient amount in the smaller steam explosion calculation. The large hydrogen to steam mass ratio in these calculations was consistent with high temperature, molten fuel interactions with water (i.e., following a recriticality or other power excursion transient) [5-45]. These calculations did not include failure of the actuator tower dampers and pressurization of actuator tower. However, based on the above-grade results, little reduction in the peak pressure would be expected, and the pressure in the actuator tower would not lead to failure. The peak pressure is roughly consistent with failure of the reactor vessel from $2.3 \times 10^{5} \mathrm{~Pa}$ in the first series of calculations. When actuator tower damper failure is considered following abrupt failure of the reactor vessel from $4.2 \times 10^{5} \mathrm{~Pa}$, the decrease in the peak reactor room pressure was negligible [5-5].

The structural vulnerabilities identified considering below-grade steam pulses (with and without below-grade flooding) were also characterized [5-5]. The prototypic accident for the MELCOR/SR calculations was a steam pulse in the pump room. This simulated a steam explosion in the pump room either due to or as a consequence of vessel breach. For all the belowgrade steam pulse calculations, the roll doors and the personnel doors failed. The primary flow patterns were (1) flow through the exhaust ducts; (2) backflow through inlet ducts; (3) flow out the personnel doors; and (4) flow out the failed heat exchanger hatches (for the largest steam pulses). Due to the flow resistance in the exhaust ducts, the heat exchanger hatches were calculated to fail prior to the filters. This opened a large relief path that tended to mitigate the magnitude of the below-grade pressure transient. Consequently, very large pressure pulses were required to fail both the heat exchanger hatches and the fans or filters. Bounding calculations show filter failure following steam explosions with very large 
hydrogen generation rates simulating, to a limited extent, chemical reaction in the MFCI [5-5]. The magnitude of the aerosol bypass was related to the magnitude of the steam pulse and whether the heat exchanger hatches or filters failed. The preferred release path was through the heat exchanger hatches when they failed. Since the exhaust fans continued to operate for all but most severe steam pulses, the normal flow patterns were restored following the steam spike. The fans restored negative pressure in the below-grade region following the steam pulse which minimized or prevented further releases.

The below-grade deep flooding calculations (i.e., pool depth $>3 \mathrm{~m}$ ) show larger peak pressures than the corresponding shallow pool cases [5-5]. The calculations were performed by introducing a specific mass of steam into the pump room atmosphere and monitoring the resultant static pressurization loads. The higher pressurization during the deep flooding cases was attributed to the less effective pressure relief (i.e., the AACS exhaust ducts where covered and the relief paths to the motor room and pin rooms were partially blocked by the water) and the smaller gas volume. The integrated effects of condensation as the steam is generated in deep pools or the mechanical effects from shock waves were not considered.

In the second set of below-grade steam explosion calculations [5-5], specified steam sources were introduced into the pump room with a hydrogen source. The eight cases are summarized in Table 5-6. The effects of AACS operation and deep flooding were investigated parametrically in the first six cases for two different steam/hydrogen source sizes. The next two cases examined the effects from a large steam spike with no hydrogen generation. The peak pressures and resulting structural damage for the non-flooded cases were not affected by the operation of the AACS. All of the simulations resulted in similar structural damage except for the largest deep flooding steam explosion cases (i.e., Cases 807 and 823). The baseline failures included the roll doors, the heat exchanger hatch covers, and the personnel access doors. The higher pressure in the deep flooding cases (Cases 807 and 823 ) was a direct result of the blockage of a primary pressure relief path (i.e., the AACS exhaust ducts). These two cases resulted in the additional failure of the motor removal concrete access plugs.

As a consequence of programmatic constraints, the assessment, fuelcoolant interaction phenomena, described in Section 6, could not begi. itil after the MELCOR analyses were largely completed. The inputs . he MELCOR calculation were thus based largely on engineering judgn. t. Comparing the steam source input used for the second set of below-gri ? calculations with the three ex-vessel steam explosion calculations [5-4 the steam volume from the first six MELCOR cases roughly corresponds the smallest steam explosion (i.e., Steam Explosion Case 6, $126 \mathrm{~kg}$ However, the assumed hydrogen production in the MELCOR/S? calculations was substantially larger than predicted in the steam explosio analyses. MELCOR/SR Cases 822 and 823 had significantly more stean. than the largest steam explosion simulations [5-45]. However, no hydrogen production was considered in these cases. If the hydrogen production and 
the resulting combustion were considered in Case 822 and Case 823, it is relatively certain that the motor removal access plugs would fail. If no hydrogen combustion was considered, and the pressure rise results were linearly scaled to the value in the steam explosion analyses, the pressure rise would be approximately $40 \%$ smaller, or $19.2 \mathrm{kPa}(2.8 \mathrm{psig})$ and $33.0 \mathrm{kPa}$ (4.8 psig) for Cases 822 and 823 , respectively. Consequently, it is unlikely that steam explosions of the magnitude of Cases 804,806 , and 808 would cause failure of the heat exchanger plugs unless hydrogen combustion was considered. As discussed in Section 6, these calculations do not consider possible increased steam generation due to chemical reaction during the steam explosion.

Table 5-6. Comparison of the Below Grade Steam Pulse Results

\begin{tabular}{|c|c|c|c|c|c|}
\hline $\begin{array}{c}\text { Case } \\
\text { Number }\end{array}$ & $\begin{array}{c}\text { Steam } \\
\text { Source } \\
(\mathbf{k g})\end{array}$ & $\begin{array}{c}\text { Hydrogen } \\
\text { Source } \\
\text { (kg) }\end{array}$ & $\begin{array}{l}\text { Deep } \\
\text { Flooding }\end{array}$ & $\begin{array}{c}\text { AACS } \\
\text { Operational } \\
\end{array}$ & $\begin{array}{c}\text { Pressure } \\
\text { Rise } \\
\end{array}$ \\
\hline 803 & 400.0 & 100.0 & No & Yes & $\begin{array}{l}13.8 \mathrm{kPa} \\
2.0 \mathrm{psig}\end{array}$ \\
\hline 804 & 100.0 & 20.0 & No & Yes & $\begin{array}{c}6.4 \mathrm{kPa} \\
0.93 \mathrm{psig}\end{array}$ \\
\hline 805 & 400.0 & 100.0 & No & No & $\begin{array}{l}13.8 \mathrm{kPa} \\
2.0 \mathrm{psig}\end{array}$ \\
\hline 806 & 100.0 & 20.0 & No & No & $\begin{array}{c}6.4 \mathrm{kPa} \\
0.93 \mathrm{psig}\end{array}$ \\
\hline 807 & 400.0 & 100.0 & Yes & - & $\begin{array}{c}31.0 \mathrm{kPa} \\
4.5 \mathrm{psig}\end{array}$ \\
\hline 808 & 100.0 & 20.0 & Yes & - & $\begin{array}{l}8.9 \mathrm{kPa} \\
1.3 \mathrm{psig}\end{array}$ \\
\hline 822 & 4340.0 & 0.0 & No & Yes & $\begin{array}{c}30.7 \mathrm{kPa} \\
4.5 \mathrm{psig}\end{array}$ \\
\hline 823 & 4340.0 & 0.0 & Yes & - & $\begin{array}{l}54.0 \mathrm{kPa} \\
7.8 \mathrm{psig}\end{array}$ \\
\hline
\end{tabular}


Effect of Hydrogen Gas Generation Rate on Combustion Limits and Structural Damage

MELCOR/SR calculations were performed to determine the hydrogen source rates needed for combustion and the subsequent confinement response [5-5]. The hydrogen source rate needed for combustion was quantified for three different AACS configurations: (1) AACS operating (one or two fans); (2) filter compartment isolation due to damper closure; and (3) natural circulation due to exhaust fan failure. For each AACS failure configuration, the effects of steam sources, below-grade flooding, and aerosol loading on the filters were parametrically examined. A second objective was to asseiss structural vulnerabilities during hydrogen combustion. The magnitude of the pressure rise as a function of the minimum hydrogen concentration for combustion was also assessed. The key results from these calculations are discussed below.

The hydrogen source rate calculations for combustion in the reactor room showed that relatively long-term sources of 0.03 to $0.09 \mathrm{~kg} / \mathrm{s}$ of hydrogen were needed to achieve a $7 \%$ molar concentration. A $6 \%$ molar concentration in the reactor room corresponds to approximately $60 \mathrm{~kg}$ of hydrogen. Combustion can occur at concentrations as low as 4\% [5-46]; however, non-uniform hydrogen distributions, the amount of steam and oxygen, and the presence of adequate ignition sources influence the concentration required for combustion. Using the default parameter value, MELCOR/SR models a deflagration when the volume-average hydrogen concentration reaches a value of $7 \%$ molar concentration. This conservatively increases the amount of hydrogen participating in the burn and the magnitude of the subsequent pressure rise. (Simulation of standing flame fronts or continuous burning at the top of the melt is not possible with the MELCOR/SR models.) For the Mark 22 charge, sustained hydrogen generation rates of this magnitude during core melt are extremely unlikely. However, an energetic in-vessel event could generate large quantities of hydrogen. The release of hydrogen would be coincident with large quantities of steam which are also generated during the fuel-coolant interactions. Consequently, the possibility of an above-grade hydrogen burn cannot be ruled out. Peak pressures following combustion in the reactor room ranged from $169 \mathrm{kPa}$ (24.5 psia) for a $6 \%$ concentration of hydrogen to $321 \mathrm{kPa}$ (46.6 psia) for a $12 \%$ concentration of hydrogen.

The below-grade results showed that hydrogen generation rates rang $g$ from $0.02 \mathrm{~kg} / \mathrm{s}$ to $0.15 \mathrm{~kg} / \mathrm{s}$ were needed to attain a combustible mixt $?$ depending on the confinement configuration. In general, the resui suggest that high below-grade airflow configurations (i.e., fans runnin and the ducts clear) require very large hydrogen generation rates to reach combustible mixture $(\sim 0.15 \mathrm{~kg} / \mathrm{s})$. For low airflow through the below-grade area, smaller hydrogen generation rates are needed $(<0.04 \mathrm{~kg} / \mathrm{s})$. This is below the expected hydrogen generation rate during molten core-concret $\epsilon$ interactions $(0.05 \mathrm{~kg} / \mathrm{s}$; see Section 5.5$)$. Consequently, hydrogen burns are certain if the airflow from the below-grade regions is degraded and MCCI occurs. 
Similar to the above-grade results, the peak pressures in the below-grade are dependent upon the minimum hydrogen concentration for combustion. The peak pressure is also dependent upon the amount of hydrogen mixing in adjacent rooms prior to ignition. In the absence of an energetic event, which generates a large amount of hydrogen quickly, none of the calculations resulted in peak pressures which would fail the heat exchanger hatches. However, most of the calculations with combustion resulted in peak pressures which would fail the below-grade personnel doorways and the roll doors.

\subsubsection{APET Filter Thermal Response Model (UFUN)}

Two analytic expressions were developed to predict the thermal response of the charcoal filters in the APET [5-5]. The first correlation predicts the AACS mass flow rate as a function of the aerosol mass loading, the number of fans operational, and the number of filters operational. The pressure head from the AACS exhaust fans was equated to a set of pressure loss terms in the confinement, in particular

$$
\begin{aligned}
& \Delta \mathrm{P}_{\text {fan head }}=\left[\Delta \mathrm{P}_{\text {laminar filter losses }}+\Delta \mathrm{P}_{\text {filter entrance losses }}+\Delta \mathrm{P}_{\text {fan losses }}\right. \\
& \left.+\Delta \mathrm{P}_{\text {gross building losses }}\right]
\end{aligned}
$$

Review of the MELCOR/SR calculations and the input deck showed that these particular pressure drops were the most important. Empirical corrections were determined for the special cases of blocked below-grade flow and natural circulation from existing MELCOR/SR calculations. In addition, logic in the APET ignored the calculation of the filter response if the filter dampers were isolated or the filters had previously failed. Friction and abrupt loss terms from the MELCOR/SR deck were put into the pressure drop equation. Solving for the mass flow rate resulted in a quadratic equation in terms of the number of fans (or natural circulation), the number of filters, the aerosol mass loading, and the below-grade blockage fraction. The correlation was benchmarked against nineteen MELCOR/SR calculations representing a wide range variety of AACS configurations and thermal-hydraulic conditions. The analytic expression had very good agreement with the MELCOR/SR results [5-5].

Given the filter flow rate and aerosol loading, the carbon filter temperature can be determined. The thermal response model used in the APET was based on the same analytic expression used in MELCOR/SR. However, the transient term included in MELCOR/SR was neglected due to its relatively small effect. The resulting expression was only a function of the AACS mass flow rate, the filter inlet temperature, and the amount of fission product decay heat. The fission product decay heat was estimated by massaveraging the total decay heat of all the volatile fission products in the uniform charge inventory. The APET model monitors the amount of aerosol and vapor (elemental iodine) fission products captured by the filters. Therefore, the total decay heat and the filter temperature can be determined. The temperature response expression was also benchmarked 
against several MELCOR/SR calculations. The temperature comparisons were also very good (generally within $\pm 25 \mathrm{~K}$ ). If the filters were isolated, mechanically failed, or previously thermally failed, the APET bypasses the flow and temperature calculations.

\subsubsection{Summary of Confinement System Response Analysis}

An understanding of the source term to the environment from a range of postulated severe accidents identified by the PSA has been developed by studying the effects of loads that may result from severe accident phenomena on the engineered safety features and structures. The MELCOR/SR code was used as the principal analytic tool. Two series of calculations were performed to predict the confinement response to loads that are believed to accompany severe accidents. The first series consisted of sensitivity calculations intended to identify the regimes of confinement behavior associated with anticipated severe accident loads. These calculations provide the basis for identifying the size of a particular load that the confinement system can tolerate before a failure or other significant change in behavior would occur. This information has been used to identify events that would cause significant changes in the progression of a severe accident. The second set of calculations address integrated severe accident behavior. These calculations covered the entire accident from the beginning of core melt up to the point at which the final distribution of released fission products was established. Their principal application has been in determining filter response to accident sequences and providing the basis for source term estimation.

The separate-effects calculations examined numerous issues that affect the response of the confinement. Interactions between various hardware configurations (e.g., fan operation and filter isolation), accident-specific conditions (below-grade flooding, steam and hydrogen generation rates, and aerosol release rates), structural failures (principally doors and hatches), and phenomenological uncertainties (hydrogen burns, MCCI, filter performance, and aerosol behavior) were assessed. The effects of a specific condition or configuration were isolated through parametric calculations. Several integrated calculations were also performed for various AACS configurations. The integral calculations aided in assessing the interaction between competing phenomena. For example, the effect of hydrogen burns or spray operation on fission product transport for ifferent AACS configurations was analyzed.

The knowledge gained from the separate-effect and integral analy: has been translated into a fission product behavior model for the APET'. "The model predicts both early (prior to vessel failure) and late (following i sel failure) fission product behavior in the confinement. The key parame:ers which affect the aerosol and vapor retention, bypass (release to the environment), and filter loading fractions were identified. These parameters define unique AACS confinement configurations. The results from the MELCOR/SR confinement analysis calculations corresponding to the unique confinement configurations were reviewed, and an estimation of 
the retention, bypass, and filter loading fractions was determined. These results have been translated into APET questions and FORTRAN mass balance subprograms (UFUN). Once the filter loading was determined, analytic expressions coded as FORTRAN subprograms in UFUN were used to determine the thermal response of the filters during the early and late time periods. This same information was used as the basis for the evaluation of parameters used in the source term algorithm (described in Section 7).

\subsection{References}

5-1 R. Sartor, D. L. Y. Louie, and C. N. Amos, Analysis of ThermalHydraulic Transients (LOPA, LOCA, and LOHSA) at Savannah River Site Reactors for the PRA, WSRC-RP-92-920, Westinghouse Savannah River Company, Aiken, SC, July 1992.

5-2 N. Morris, et al., Analysis of Thermal-Hydraulic/Reactivity Transients at Savannah River Site Reactors for the PRA, WSRC-RP92-1013, Westinghouse Savannah River Company, Aiken, SC, December 1992.

5-3 K. W. Ross, et al. Analysis of Fuel Melting at Savannah River Site Reactors for the PRA, WSRC-RP-92-1012, Westinghouse Savannah River Company, Aiken, SC, November 1992.

5-4 S. D. Clement et al., Analysis of Debris Behavior at Savannah River Site Reactors for the PRA, WSRC-RP-92-836, Westinghouse Savannah River Company, Aiken, SC, July 1992.

5-5 K. C. Wagner, et al., Analysis of Confinement Response at Savannah River Site Reactors for the PRA, WSRC-RP-92-978, Westinghouse Savannah River Company, Aiken, SC, November 1992.

5-6 D. R. Bradley, Analysis of Molten Core Concrete Interaction at Savannah River Site Reactors for the PRA, WSRC-RP-92-1010, Westinghouse Savannah River Company, Aiken, SC, November 1992.

5-7 N. M. Schnurr, R. G. Steinke, U. Martinez, and J. W. Spore, TRACPF1/MOD2 User's Guide, November 1990.

5-8 S. D. Clement, et al., Analysis of Recriticality at Savannah River Site Reactors for the PRA, WSRC-RP-92-443, Westinghouse Savannah River Company, Aiken, SC, March 1992.

5-9 M. Epstein, Fuel Particle Separation Efficiencies for the Loss-of-Fuel Accident, FAI/90-82, Fauske \& Associates, Inc., Burr Ridge, Illinois, November 1990.

5-10 R. A. Meserve et al., Safety Issues at the Defense Production Reactors, National Academy Press, Washington, DC, 1987. 
5-11 L. Baker, "Metal Water Reactions," Nuclear Safety, 7:25, 1965.

5-12 R. M. Summers et al., MELCOR 1.8.0: A Computer Code for Severe Nuclear Accident Source Term and Risk Assessment Analyses, NUREG/CR-5531, Sandia National Laboratories, Albuquerque, NM, July 1990.

5-13 C. N. Amos, S. H. Kim, and K. W. Ross, The Development of MELSRP: A Computer Code for Core Meltdown Accident Analysis of Savannah River Site Reactors, WSRC-RP-92-763, Westinghouse Savannah River Company, Aiken, SC, October 1992.

5-14 S. H. Kim, et al., The Development of APRIL - A Computer Code for Core Meltdown Accident Analysis of Boiling Water Nuclear Reactors, NUREG/CR-5157, July 1988.

5-15 P. G. Ellison et cl., A Phenomenological Assessment of Nuclear Metallic Fuel Mel: Behavior During Severe Accidents, WSRC-RP-901130, Westinghouse Savannah River Company, Aiken, SC, October 1990.

5-16 J. R. Seaboch and J. W. Wade, Fuel Meltdown Experiments, DP-314, Technical Division, Savannah River Laboratory, October 1958.

5-17 J. P. Morin memo to J. M. Boswell, "Fuel Melting and Transient Analysis Studies," DPST 72-407, Technical Division, Savannah River Laboratory, June 27, 1972.

5-18 G. F. Merz memo to V. Whatley, "Melting Tests of Fuel Tubes," DPST 78-543, Technical Division, Savannah River Laboratory, February 14, 1979 .

5-19 J. P. Morin memo to J. M. Boswell, "Fuel Melting and Transient Analysis Studies," DPST 72-407, Technical Division, Savannah River Laboratory, June 27, 1972.

5-20 J. F. Peterson, TAC-2D, A General Purpose Two-Dimensional Heat Transfer Computer Code - User's Manual, GA-8868, Gulf General Atomic Incorporated, San Diego, California, September 1969.

5-21 D. W. Peaceman and H. H. Rachford, "The Numerical Solut. of Parabolic and Elliptic Differential Equations," Journal of the So: ty of Industrial and Applied Mathematics, Vol. 3, March 1955.

5-22 M. Pilch and P. K. Mast, PLUGM, A Coupled Thermal-Hydrau. Computer Model for Freezing Melt Flow in a Channel, NUREG/Cl. 3190, SAND82-1580.

5-23 M. R. Kuhlman, et al., CORSOR User's Manual, NUREG/CR-4173, BMI-2122, Battelle Memorial Institute, 1985. 
5-24 F. R. Bruce, et al., Nuclear Safety Program Semiannual Progress Report for Period Ending June 30, 1963, ORNL-3483, Oak Ridge National Laboratory, 1963.

5-25 P. G. Whitkop, Summary of the Second Series of SRL Fuel Melt Experiments, DPST-87-412, E.I. du Pont de Nemours and Company, Savannah River Laboratory, July 1987.

5-26 M. T. Leonard, et al., MELCOR/SR-Mod3 A Computer Code For Evaluating Severe Accident Progression in Heavy Water Reactors; Reference Manuals and User's Guide, SAIC 91/6504, September 1991.

5-27 M. T. Leonard, K. A. Williams and J. P. Church, "Modifications to MELCOR For the Analysis of Heavy-Water Moderated, U-Al Fuel Reactors," Proceedings of the ANS Topical Meeting on the Safety, Status and Future of Non-Commercial Reactors and Irradiation Facilities, Vol. I, pp. 104-111, Boise, ID, October 1990.

5-28 P. R. McClure, M. T. Leonard, and P.G. Ellison, "A Parametric Model for Fission Product Release From Molten Pools of U-Al Mixtures," Proceedings of the ANS Topical Meeting on the Safety, Status and Future of Non-Commercial Reactors and Irradiation Facilities, Vol. I, pp 55-64, Boise, ID, October 1990.

5-29 S. Wisbey, et al., Iodine Behavior in Containment Under LWR Accident Conditions, NUREG/CP-0078, Oak Ridge National Laboratory, Oak Ridge TN, September 1986.

5-30 C. N. Amos, et al., Evaluation of Severe Accident Risks: Peach Bottom, Unit 2, NUREG/CR-4551, SAND86-1309, Sandia National Laboratories, Vol. 3, Draft for Comment, 1987.

5-31 E. R. Copus, et. al., Core Concrete Interactions Using Molten Aluminum on a Siliceous Basemat: The SRL-1 Experiment, SAND892166, Sandia National Laboratories, Albuquerque, NM, 1992.

5-32 D. R. Bradley, et al., CORCON-MOD3: An Integrated Computer Model for Analysis of Molten Core-Concrete Interactions, Users Manual, NUREG/CR-5843, SAND92-0167, Sandia National Laboratories, Albuquerque, NM, 1992.

5-33 R. K. Cole, et al., CORCON/Mod2: A Computer Code for Analysis of Molten-Core Concrete Interactions, NUREG/CR-3920, Sandia National Laboratories, August, 1984.

5-34 E. R. Copus, et al., Core Concrete Interactions Using Molten Aluminum on a Silicious Basemat: The SRL-1 Experiment, Sandia National Laboratories, SAND89-2166, September 1989. 
5-35 R. M. Summeris, MELCOR 1.8.0: A Computer Code for Severe Nuclear Accident Source Term and Risk Assessment Analyses, NUREG/CR-5531., July 1990.

5-36 M. Silverberg, et al., Reassessment of the Technical Bases for Estimating Sourise Terms, NUREG-0956, July 1986.

5-37 M. T. Leonard, et al., MELCOR/SR-Mod3 - A Computer Code for Evaluating Severe Accident Progression in Heavy Water Reactors, Reference Manual and User Guides, SAIC 91/6504, September 1991.

5-38 M. T. Leonard, $e^{t}$ al., "A Model for Transient Analysis of a MultipleMedium Confinement Filter System," Proceeding of the Safety, Status, and Future of Non-commercial Reactors and Irradiation Facilities, September 31 - October 4, 1990, Boise, Idaho, American Nuclear Society.

5-39 C. N. Amos, "SRiS Confinement Analysis Plan," TskP-WSRC-PRA15, Science Applications International Corporation, May 14, 1990.

5-40 W. H. Baker and W. L. Ferrell, The Accident Progression Event Tree - A Logic Model for the Progression of Postulated Severe Accidents in SRS Reactors, WSRC-RP-91-965, Westinghouse Savannah River Company, Aiken, SC, March 1992.

5-41 S. P. Tinnes, Airborne Activity Confinement System Performance Greater Than Five Hours After DBA, DPST-80-588, October 1980.

5-42 V. J. Novick and A. Gupta, Effect of Particle Hygroscopicity and Ambient Humidity on the Mass Loading Capacity of SRP HEPA Filter Material, Argonne National Laboratory, (Appendix 1 in WSRCRP-92-645), July 1991.

5-43 V. J. Novick, et al., Characterization of the Airborne Activity Confinement Sy'stem Prefilter Material, Argonne National Laboratory, (Appendix 1 in WSRC-RP-92-582), August 1991.

5-44 W. W. F. Yau, memo to J. R. Knight, "Structural Evaluation for Probabilistic Risk Assessment of SRS Reactor Operations," W $>$ RCRP-90-738.

5-45 B. E. Vonderfecht and D. C. Smith, Steam Explosion Analysi in Support of the SF'S Reactor Safety Assessment, WSRC-RP-92-7. Westinghouse Savannah River Company, Aiken, SC, October 1992.

5-46 R. E. Blose, et al., SWISS: Sustained Heated Metallic Melt/Concrel Interactions with Overlying Water Pools, NUREG/CR-4727, SAND85 1546, Sandia National Laboratories, Albuquerque, NM, 1987. 


\section{0}

\section{ENERGETIC EVENTS ANALYSES}

This section describes the analyses that have been performed to assess the potential impacts of energetic events on severe accident progression. An energetic event, in this context, refers to the rapid generation of thermal energy or rapid transfer of thermal energy in a phase-change process. These events are characterized by the sudden expansion of a gas, liquid, or mixture at a rate sufficient to do significant mechanical work on the surroundings. Mechanical work (i.e., structural damage) may be either a direct consequence of blast or shock wave damage, or may result from static pressurization due to gas-phase expansion. In Section 5, the analyses described dealt with to events that stemmed from the heating and relocation of core materials. When hot debris contacts water or steam, energetic interactions can result. The potential for structural damage means that the accident progression can be significantly altered.

An energetic event in the primary system can cause failure of that system and may lead to a breach of the confinement system, as well. An energetic event in the confinement can potentially damage the confinement system, leading to an unfiltered radiological release into the environment. Three types of energetic events are relevant to the progression of a severe coremelt accident in an SRS reactor:

(1) Recriticality. Collection of the core debris in a critical configuration could lead to large energy generation as a result of nuclear fission. If this occurs in a geometry in which the debris can contact water, a steam explosion may occur [see (2) below].

(2) Molten fuel-coolant interaction (MFCI). Under certain conditions, contact between molten fuel and water can result in an explosive interaction known as a steam explosion. During this interaction, very high pressure steam is produced by a nearly instantaneous transfer of heat from the fuel to the water.

(3) Hydrogen Combustion. Collection of hydrogen in the confinement building could result in low energy burns, deflagrations, or energetic detonations.

Analyses of these energetic events include determining of the conditions supporting their occurrence and, given that they occur, quantifying the energy generation and the subsequent conversion of thermal energy to mechanical work. Once the mechanical work potential of an energetic event has been quantified, the impacts of the mechanical work available are assessed. The analyses performed to determine the energy releases for these energetic events are discussed in Sections 6.1 through 6.3. The discussion of the structural response of the reactor and the confinement to these energetic releases is presented in Section 6.4. 


\subsection{Recriticality and Reactivity Transient Analyses}

Recriticality refers to the formation of a critical geometry outside of the active core region as a result of core debris relocation during a core melt accident. Because the fuel material in an SRS reactor contains highly enriched uranium, there is a potential for a critical geometry to develop outside of the active core region. The occurrence of a recriticality can lead to heat generation in excess of nominal decay heat levels, may accelerate the progression of the accident, and could lead to an energetic steam explosion.

Evaluating the potential for a recriticality requires the identification of locations and geometries into which core debris might relocate. The locations have been determined based upon the characteristics of accident progression as delineated by the APET and the supporting analysis. Mechanistic analyses have been performed to evaluate the likelihood that a sufficient mass of debris could accumulate to cause a recriticality in each of the locations identified. Geometric details for potentially critical configurations have been obtained from system descriptions and plant drawings, and eigenvalue ( $k_{\text {eff }}$ ) calculations have been performed for each location. Finally, an estimate of the energy yield that would result from a recriticality has been made for those configurations in which a recriticality could occur.

In this report, a reactivity transient refers to a transient resulting from a core reactivity increase (with the reactor initially operating at nominal power) that would lead to a power increase. If the reactivity insertion were sufficiently large and multiple failures occurred in the shutdown systems, the fuel from one or more assemblies could melt and relocate into the moderator space where its reactivity worth is greater. In such a scenario, the reactor power might increase at a rapid rate, which could lead to additional fuel melting and a potentially energetic steam explosion.

Six locations were identified in which the accumulation of core debris could yield a recriticality or cause a reactivity-driven transient:

(1) the assembly bottom end-fitting (BEF);

(2) the vessel bottom;

(3) the pump suction line (i.e., primary coolant effluent piping);

(4) the heat exchangers;

(5) the confinement sumps; and

(6) the vessel moder:ator region (reactivity transient).

If core debris relocates into any of these locations and a recritica ' - or reactivity-driven event occurs, the further progression of the accide. an be influenced in two ways. First, the additional energy gener on attributable to fission heating can quickly raise the temperature of mo en debris and may lead to rapid melting of previously solid core material he principal effect of additional heating is to accelerate further melt ind relocation and to yield molten debris that could contain significant superheat. Second, the likelihood of an energetic steam explosion 
increases, because more molten core debris is available to participate in the steam explosion, and superheating favors an energetic interaction.

\subsubsection{Modeling Techniques}

Eigenvalue calculations have been performed with the Monte Carlo Neutron Photon (MCNP) computer code [6-1]. MCNP is a general Monte Carlo code that employs pointwise-continuous energy cross-sections. The code was developed and is currently maintained by Los Alamos National Laboratory (LANL). Among the advantages of using MCNP, as compared to either diffusion theory or $\mathbf{S}_{\mathbf{n}}$ computer codes, are highly-versatile geometric modeling capability, sophisticated cross-section structure, and the lack of restrictive approximations in the representation of the physics of particle interactions. The three-dimensional geometric modeling capability requires little or no approximation in the representation of the various potential critical configurations. The cross-sections used by MCNP are pointwise-continuous data from the Evaluated Nuclear Data File (ENDF/B-V) [6-2], the Evaluated Nuclear Data Library (ENDL) [6-3], the Activation Library (ACTL) [6-4], and the Applied Nuclear Science Group [6-5 through 6-7] at LANL.

The first step in applying MCNP to the SRS reactors was to develop and benchmark an input model of an intact core. Two models of an intact core have been developed. The first model, referred to as a supercell, is one hexagonal segment of the core as shown in Figure 6-1. The model includes six fuel assemblies and one septifoil (i.e., control rod housing). The surface boundary conditions of the supercell are reflective, thus yielding an infinite lattice representation of the SRS core. The second or finite model, has been developed to represent a one-sixth segment of the reactor core as shown in Figure 6-2. The model includes all of the fuel assemblies, septifoils, sparjets, safety rods, and blanket assemblies present in one-sixth of the reactor core. The radial boundary includes a light water shield representative of the reactor's annular shield tanks. The azimuthal boundaries are reflective which provides for a 360-degree representation of the reactor core. Both models have been benchmarked against operating data, control rod worth curves, and test reactor experimental data. The agreement between the MCNP models and the benchmarking data is excellent [6-8].

Both the supercell and finite models were applied to the evaluation of criticality in the BEF. Reactivity insertion estimates for fuel-melt-induced reactivity transients were also made with the finite model. Circumstances in the BEF under which a recriticality could occur were identified. Where a recriticality was found to be credible, estimates of the energetic yield have been performed. These estimates were made by performing a point reactor kinetics analysis which utilizes the dynamic period equation [6-9] and a one-dimensional, two-group, space-time kinetics analysis of the resulting transient [6-8]. The calculations require reactivity insertion rates and 


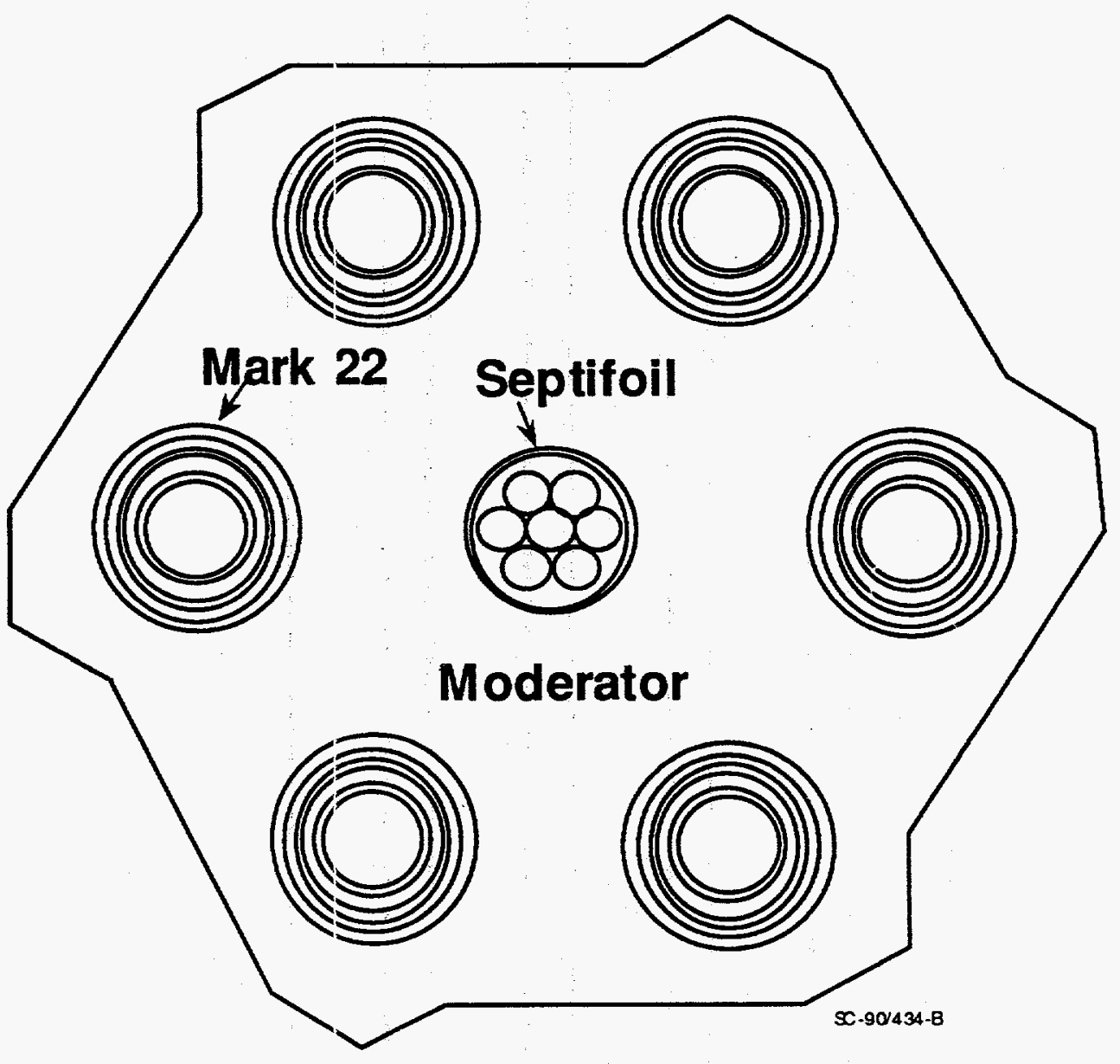

Figure 6-1. MCNP Supercell Model 


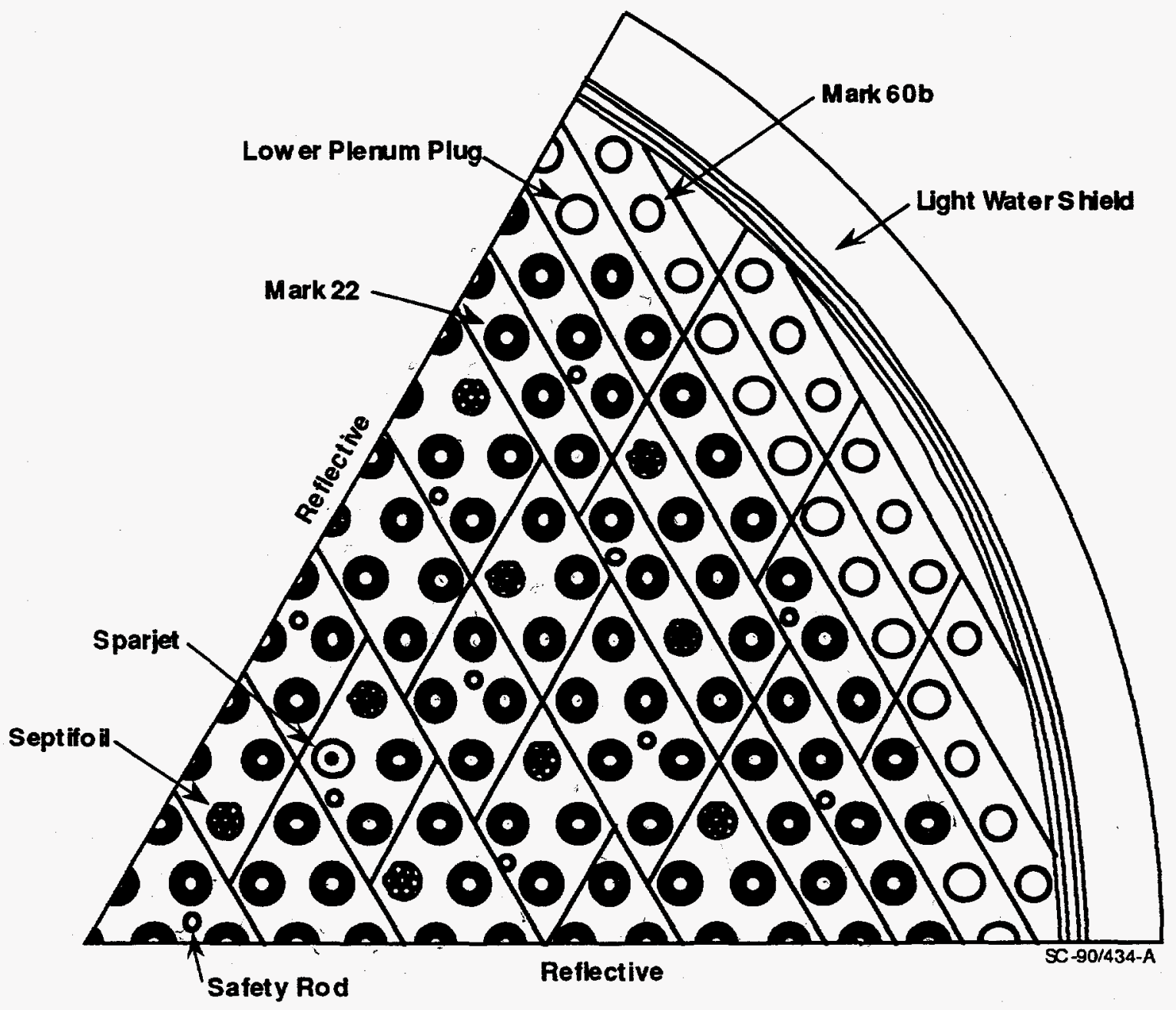

Figure 6-2. MCNP One-Sixth Sector Finite Model 
reactivity feedback coefficients as input. Feedback coefficients considered included volumetric expansion, geometric relocation, and Doppler broadening. The kinetics calculations provide the period of the critical configuration (i.e., the time required for the power to change by a factor of $e$, often called the " $e$-folding time"), the time-dependent power for the resulting transient, and the integrated energy deposition in the debris.

For the other locations identified as potential sites for a recriticality, separate MCNP models were developed. Four MCNP models were used in addition to the supercell and finite reactor models. These represented: (1) a debris pool on the vessel bottom; (2) a slug of debris in the effluent piping; (3) a debris bed collected in the heat exchanger end bell; and (4) a debris pool in the confinement sump. Eigenvalues calculated for the pump suction pipe location served to confirm initial scoping estimates made with the ANISN code. Examination of the potential for recriticality in the confinement sumps and during debris flow through the trenches on the pump room floor had previously been made using KENO [6-10]. Confirmation of the earlier results was also provided [6-8].

\subsubsection{Results of Recriticality Analysis}

This subsection discusses the results from each of six separate MCNP analyses that were performed to provide estimates of eigenvalues for the various configurations identified. Where appropriate, the quantity of debris involved and the amount of water present was varied in a parametric fashion. If the eigenvalue of a given configuration indicated that recriticality was possible, a discussion of potential energy yield is also included.

\subsubsection{Potential for Recriticality in the BEF}

The analysis of recriticality in the BEF was predicated upon the conclusion that debris would collect and be cooled within the BEFs during core melt. The potential for debris coolability within the BEFs was discussed in Section 5. Eigenvalue calculations consider debris collected within the BEF as columns separated by the heavy water moderator. Initial calculations were performed assuming a fresh core and no fission product poisons (i.e., $\mathrm{Xe}$ and $\mathrm{Sm}$ ). Since the target material has a large negative effect on reactivity, parametric calculations considering various amounts of ta: ret material mixed with the fuel debris were performed as variations on $e$ base case. A light water impurity of 0.25 atom percent (a/o) was assume... All safety and control rods were modeled as being fully inserted sinc accidents where recriticality is of concern involve previous reacto shutdown. The debris has been assumed to be a homogeneous mixture o: fuel and clad.

Using the finite reactor model, the reactivity of the configuration has been calculated as a function of debris bed height $(\partial \rho / \partial z)$. With no target material present, the results indicate that a recriticality is likely to occur when the 
debris height reaches approximately $29 \mathrm{~cm}$, measured from the top of the monitor pin. This is approximately $23 \%$ of the fuel and clad. With thirty percent of the target melting homogeneously with the fuel, the critical debris height was found to be approximately $40 \mathrm{~cm}$.

The MELSRP code [6-11] has been used to estimate the fuel melt rate under LOPA conditions. These calculations indicate that a melt rate of $0.1 \mathrm{~kg} / \mathrm{s}$ in each assembly can be expected [6-12]. The melt rate can be interpreted in terms of a volumetric melt rate which, in turn, provides the linear rate of increase in debris height within the $\mathrm{BEF}$ (dz/dt). Using the MCNPcalculated change in reactivity as a function of height $(\partial \rho / \partial z)$ and the debris collection rate (dz/dt) from MELSRP, the rate of reactivity insertion $(\partial \rho / \partial t)$ has been calculated to be $0.93 \$ / \mathrm{s}$ with no target melting and $0.56 \$ / \mathrm{s}$ with thirty percent target melting homogeneously with fuel. Here, $\$ 1$ is based on a total delayed neutron fraction of

$$
\bar{\beta}=0.00756 \text {. }
$$

In addition to the target melt fraction, the major uncertainties in this recriticality analyses are the radial coherence of the fuel melt and the effect of fission product poisons. Investigation of these potential issues led to the conclusion that they were unlikely to affect the results significantly. Analysis of the variation in draining rate due to initial assembly power was investigated using historical assembly power data. The tritium-producing uniform lattice charge operates with a relatively flat radial power profile. Thus, the study demonstrated that the variations in draining rate due to initial power are small. It was concluded that core melting is radially coherent and can be represented by a single draining rate. The only fission products with a significant neutron cross-section are xenon and samarium. Xenon is a gas which is expected to largely escape the debris before relocation, and the small amount of samarium in the debris is not expected to have a significant reactivity effect.

Calculations were performed to determine if a recriticality could be prevented if target relocated with the fuel or if gadolinium nitrate ink from the SSS was injected. These calculations assumed a range of target melt fractions for various target loadings. The results indicated that, for a total fuel slump with no ink injection, a minimum of $70 \%$ of the target needs to melt and homogeneously mix with the fuel/clad debris to preclude a recriticality. Similar calculations have been performed to quantify the ink concentration required to preclude a recriticality. The MCNP-calculated reactivity worth of the ink for an intact core was compared to an independent calculation used to support the SAR [6-13]. Agreement was found to be excellent. In the slumped core configuration, the worth of the ink has been calculated to be $9.5 \% \Delta \mathrm{k} / \mathrm{k}(\$ 13.6)$ for a single 40 -gallon injection. The results indicate that six 40 -gallon injections ( 240 gallons of ink) would be required to preclude a recriticality for a total fuel slump when the targets remain intact. 
Throughout the transient that ensues from recriticality, the system reactivity, the $e$-folding period, the system power, and the total energy yield were calculated. The computation of system reactivity includes reactivity insertion from additional fuel melting as well as feedback from thermal expansion and Doppler broadening. Reactivity feedback from moderator heating and void production are negligible because of the limited heat transfer from the fuel to the moderator that can occur during the times characteristic of these transients.

It is postulated that the mechanism which ultimately terminates the recriticality is slumping of the columns of core debris following failure of the BEFs. This mechanism has been modeled in the analyses. The large negative reactivity insertion attributable to the slumping of the debris columns is calculated based upon the velocity with which debris would "fall" out of its critical configuration. The slumping velocity, $v(t)$, is the freefall velocity corrected for buoyancy effects. Given the slumping velocity and the previously calculated change in reactivity as a function of debris height, the negative reactivity insertion rate can be calculated. This rate is subsequently used to estimate a new $e$-folding period. Analyses have shown that once BEF failure and fuel slumping occur, the negative reactivity insertion rate is very large, and a subcritical configuration is rapidly attained. Calculations have been performed for initial debris temperatures ranging from $373 \mathrm{~K}$ to $900 \mathrm{~K}$. The initial debris temperature directly influences the total energetic yield because it affects the time required for the debris to reach the failure temperature of the BEF. A low initial debris temperature means that more time will be required to reach BEF failure than for a high initial debris temperature. This additional time allows more fuel to relocate into the critical configuration, thus increasing the total amount of reactivity involved. As a result, the power level increases more rapidly. If the lower debris temperatures were assumed, the amount of excess reactivity exceeded $\$ 1$, thereby making the configuration prompt critical. Conversely, a high initial debris temperature means that little time will be required to reach $\mathrm{BEF}$ failure. For these cases, the amount of reactivity added was substantially less than $\$ 1$. Since the amount of reactivity determines the $e$-folding period, and the $e$-folding period determines the final fission power level attained, the amount of reactivity added directly affects the total energetic yield from a recriticality.

With no target relocation, the energy yields calculated for initi- 'ebris temperatures of $373 \mathrm{~K}, 650 \mathrm{~K}$ and $900 \mathrm{~K}$ are $10.8,6.2$, and $1.8 \mathrm{MJ} / \mathrm{s}$ nbly, respectively. Based on the debris cooling calculations, it is estima. that $650 \mathrm{~K}$ is the most probable initial debris temperature [6-8]. A yield of $\mathrm{C}$ ' MJ per assembly for this initial temperature will raise the debris tempe- ure

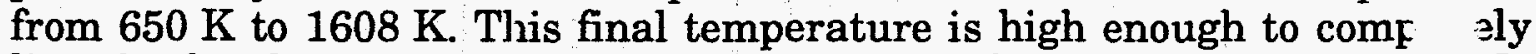
liquefy the debris and increase the potential for a steam explosior. No vaporization of the debris is expected. When fifty percent of the target is included at an initial temperature of $650 \mathrm{~K}$, a yield of $3.3 \mathrm{MJ} /$ assei_ibly resulting in a final debris temperature of $1008 \mathrm{~K}$ is expected. 


\section{1,2.2 Potential for Recriticality in Other Configurations}

The potential for recriticality in four additional configurations has been evaluated. Fresh core debris with no entrained structural materials was assumed for each of the calculations. In addition, no target is modeled in the analyses (neither in the melt nor above the debris in the reactor vessel). The results of these analyses are as follows:

(1) Fuel debris on the vessel bottom. This configuration has been modeled as debris collecting as a flat plate on the vessel bottom covered with an infinite heavy water reflector. The presence of the bottom shield tank below the debris was modeled. Other core structures such as the USHs, control and safety rods, and BEFs were neglected. This model is believed to overestimate the reactivity of any achievable configuration of debris on the vessel bottom. Calculations indicate that even with the full core on the vessel bottom, the configuration would be well subcritical $\left(k_{e f f}=0.9183\right)$. A sensitivity study on the moderator-to-fuel ratio indicates that to form a critical configuration, a homogeneous mixture of fuel and moderator would be required. No mechanism for achieving such a configuration has been identified.

(2) Fuel debris in the primary coolant outlet piping. The outlet pipe was modeled as a $1 \mathrm{~cm}$-thick stainless-steel tube, $0.61 \mathrm{~m}$ in diameter and $3 \mathrm{~m}$ long. The tube was filled with debris, and an infinite light water reflector was assumed to surround the pipe (i.e., corresponding to the pump room floor being flooded). As with the case of debris on the vessel bottom, this configuration would be subcritical $\left(k_{e f f}=0.6320\right)$. Additional analyses indicated that a homogeneous mixture of moderator and fuel would be required to form a critical configuration. Again, mixing of water with hot debris is not credible.

(3) Debris within the end bell and adjacent piping of the heat exchangers. The fuel debris from one assembly was assumed to melt as particulate and to be transported by entrainment in the coolant flow into the end bell of one heat exchanger. Two configurations within the end bell have been considered. The first is a homogeneous mixture of heavy water and fuel debris. In this case, the mixture would have to contain over 75 percent (by volume) heavy water in order to achieve a critical configuration, which is not credible. The second configuration is a rubble bed settled in the lower portion of the end bell with a void fraction of 40 percent. This configuration is also subcritical.

(4) Debris within the sumps on the confinement floor. The smaller of the two pump room sumps (with a floor area 
of $13.31 \mathrm{~m}^{2}$ ) was assumed to contain the entire fuel debris inventory. This provides for the greatest depth of debris so as to maximize the potential for a criticality event. The debris was modeled as being surrounded on five sides by $1 \mathrm{~m}$ of concrete and on the top with $1 \mathrm{~m}$ of heavy water. The results indicate that this configuration is also subcritical $\left(\mathrm{k}_{\mathrm{eff}}=0.9076\right)$.

These modeling efforts lead to two significant conclusions. First, that recriticality requires that neutron moderation occur. Fast criticality is not of concern even though the fuel material is highly enriched. Second, criticality can only ocisur if the moderator is dispersed into the fuel material. Solid slabs or cylinders that may form from the debris during a core melt accident will not be critical (with the exception of the BEF analysis, described earlier).

\subsubsection{Fuel Debris Entrainment into the Moderator}

The final configuration analyzed in conjunction with the recriticality analyses was debris disjersal into the moderator region of the vessel. This configuration is unlike any of the other configurations in that it is assumed to occur within the active core region while the reactor is still at power. By definition, it is not a recriticality scenario, but an anticipated transient without scram (ATWS). Two series of calculations have been performed. For the first series, fuel debris from one assembly was assumed to melt and be swept into the moderator space. This series simulated transient initiating events that affected a single assembly. Partial blockage of the coolant channels of an assembly by a foreign object in the primary coolant system would be one example. The second series involved debris from six fuel assemblies. This series simulated transient initiators involving several assemblies. In particular, the uncontrolled withdrawal of a single control rod was considered. Should this occur, and the shutdown systems fail, the six assemblies adjacent to the affected septifoil would experience a significant power increase. For both sets of calculations $100 \%$ of the debris available was assumed: to be entrained by the moderator. The spatial distribution of debris particles in the moderator as a function of time has been estimated based upon this conservative assumption. These estimates were based upon TRAC calculations of the flow distribution within the vessel [6-14]. Recent analysis has shown this assumption to be gro sly conservative. A more realistic estimate would be that less that half ie debris would be entrained. However, the original estimates were not rev d when this new information became available because it had little impact ? the results of this assessment.

Particle distributions in the vessel at various points in time were selecte for the reactivity analysis. MCNP was used to produce an estimate of the reactivity for each distribution. Total core reactivity as a function of time was inferred from these point estimates by extrapolating reactivity between the calculated points. This process relies on the implicit assumption that the process is quasi-static. This assumption may not be valid when the 
prompt neutron lifetime is on the same order as the reactor period. During the early stages of the transient, however, the results obtained are valid.

In order to obtain a more realistic assessment of these transients, feedback mechanisms were investigated. Because of the time necessary for heat transfer from the fuel tubes to the coolant, temperature increase due to the reactor power increase was dismissed as a possible source of significant feedback. Doppler feedback had already been identified as being somewhat important in the recriticality assessments. However, the high enrichment of the fuel makes the magnitude of this feedback effect small relative to these large reactivity insertions. Void production in the moderator as a consequence of direct contact with the hot fuel particles that were being expelled from the fuel assembly was postulated to be a viable feedback mechanism that would alter the course of this accident. In order to calculate the extent of void production the TEXAS [6-15] code was employed. TEXAS has been developed by SNL to calculate the extent of mixing between molten fuel and relatively higher volatility coolant during MFCIs. While these interactions are usually considered in the context of a steam explosion, contact between hot fuel particles and heavy water in the vessel would be governed by the same physical processes that are represented in TEXAS. Calculations performed with the code indicated that particles expelled from the fuel assembly quench rapidly due to their small size. The high heat transfer rate results in very rapid void formation which is aided by the low pressure of the SRS reactor vessel.

Additional MCNP calculations were performed which incorporated the predicted void production as a function of time. The results indicated that the net change in reactivity was negative. Based on these results it was concluded that transient events were unlikely to result in a significant reactor power excursion. These results do not eliminate the possibility entirely since the models in the TEXAS code have not been completely validated. However, the TEXAS calculations indicate a similar outcome regarding negative reactivity as those predicted by Morin [6-16].

\subsection{Molten Fuel-Coolant Interaction (Steam Explosion) Analysis}

When molten fuel debris comes into contact with water, rapid steam generation and even explosive interactions may occur. Explosive interactions of this kind are often referred to as steam explosions. Many occurrences of steam explosions have been reported in the aluminum industry and during foundry operation, where large quantities of molten metal are routinely handled. Several steam explosions have occurred during accidents in test reactors as well. Farawila and Abdel-Khalik [6-17] report four such occurrences, all involving reactors that employ metallic uranium-aluminum fuel. The SRS reactors employ similar uraniumaluminum fuel. Therefore, historical evidence suggests that steam explosions should be a consideration for any reactor accident analysis involving molten fuel. 
This section identifies the conditions that may result in a steam explosion, estimates the magnitucle of such explosions, and suggests the type of mechanical damage in the vicinity of the explosion that may result. The magnitude of the stearn explosion is estimated in terms of the peak pressure, the mechanical work, and the quantity of steam and hydrogen produced. These measures allow an assessment of the resulting mechanical damage.

\subsubsection{Modeling Techniques}

Models have been developed to calculate the magnitude of a steam explosion that might occur in a postulated severe accident. In general, the models must address necessary preconditions for the occurrence of a steam explosion and the mechanisms of the explosion itself. Explosive interactions of this type affect structures by creating a high pressure mass of expanding fluid and large quantities of steam. The high pressure fluid produced in a steam explosion causes damage by radiating shock waves that impact structures, and by pressurizing volumes. The dynamic failure mechanisms are quite complex, so the failure process has been assessed based purely on the mechanical energy produced by the explosion. The peak pressure and mechanical work predicted by a steam explosion model have been compared to the estimated capacity of structural elements in the vicinity of the explosion. This simplifying approach replaces detailed examination of blast effects. Given the large uncertainties that exist in the prediction of steam explosion mechanisms, and thus the size of the blast, more detailed treatments cannot be justified at this time. Steam produced by the explosion will tend to pressurize the primary cooling system and/or the reactor building as it expands away from the source. Prediction of this steam generation is necessary in order to assess the load on structures due to the resultant static pressure. Failure has been assessed based on the comparison of these static loads to the estimated capacity of the filter components, fan casings, doors, hatches, and structural elements.

Researchers in this field consider the mechanisms leading to a steam explosion to be understood reasonably well. However, the mechanisms determining the conversion of thermal energy to mechanical work are not understood well enough that a reliable predictive model can be produced. The approach taken in this analysis has been to use relatively simple models to bound the magnitude of the explosion. Two models have been used. The first model is an ideal thermodynamic model. This model can be considered to produce an upper bound on the steam explosion in terms of its potential to do mechanical work. The second model includes nonequilibrium mechanistic calculations of the thermodynamic and heat transfer processes that have been postulated to constitute a steam explosion. It represent; one possible best-estimate model for steam explosions. Other models exist that would produce perhaps different predictions for the same steam explosion situation. The results from both of the models were checked for consistency with the available experimental data. Conclusions regarding the effects of a steam explosion are based primarily on the best-estimate model, but results from both models were 
considered in the formulation of uncertainty. Both models consider a steam explosion to be primarily a thermally driven event. Additional energetic effects due to chemical reactions between water and molten metal have not been included in these analyses. Chemical energy can be important above a threshold temperature where vapor burning becomes possible. For atmospheric pressure, this is estimated to be approximately $2000 \mathrm{~K}$. It can be postulated that the high pressures that would be generated in a steam explosion may depress the ignition temperature.

Both models treat a steam explosion as occurring in three basic steps. As illustrated in Figure 6-3, these are

(1) The mixing phase, when hot molten debris enters the water pool and breaks up into droplets that produce film boiling at their surfaces;

(2) The triggering/expansion (i.e., explosion) phase, when a pressure pulse, or "trigger", causes collapse of the vapor film separating fuel and coolant. This film destabilization causes the fuel and coolant liquids to fragment, increasing local vapor pressure; and

(3) The expansion phase, when the superheated water/steam expands against its surroundings producing mechanical work.

A brief description of both models follows.

\subsubsection{Ideal Thermodynamic Steam Explosion Model}

The simple model makes assumptions that result in the maximum explosion magnitude. These assumptions, attributed to the work of Hicks and Menzies [6-18], include

(1) All the available debris mixes with water and is involved in the explosion;

(2) The maximum amount of heat is instantaneously transferred from the debris to the water in the explosion (i.e., thermal equilibrium between the debris and the water is established);

(3) A thermodynamically reversible (i.e., isentropic) expansion occurs producing the maximum mechanical work.

In the context of steam explosions, the concept of a conversion ratio is used to quantify the amount of mechanical work that is done by the system. The conversion ratio is defined as the ratio of the mechanical work produced to the total available thermal energy. The conversion ratio predicted by the 


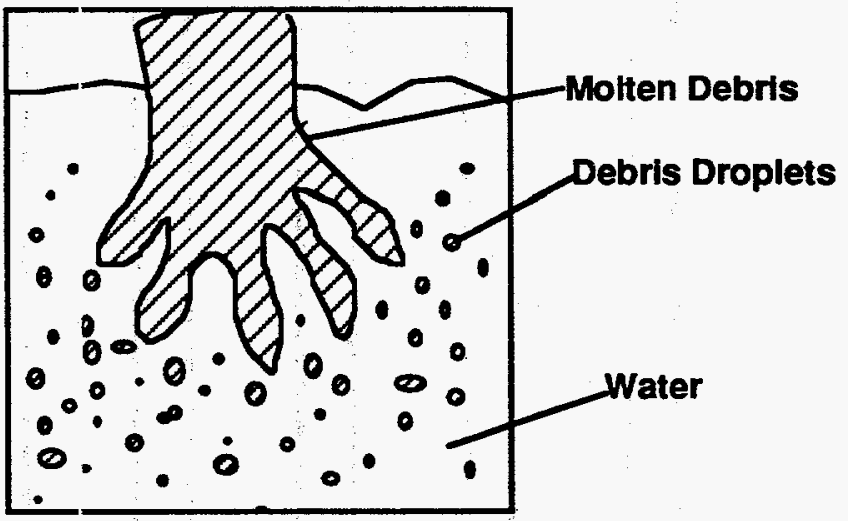

Coarse Mixing

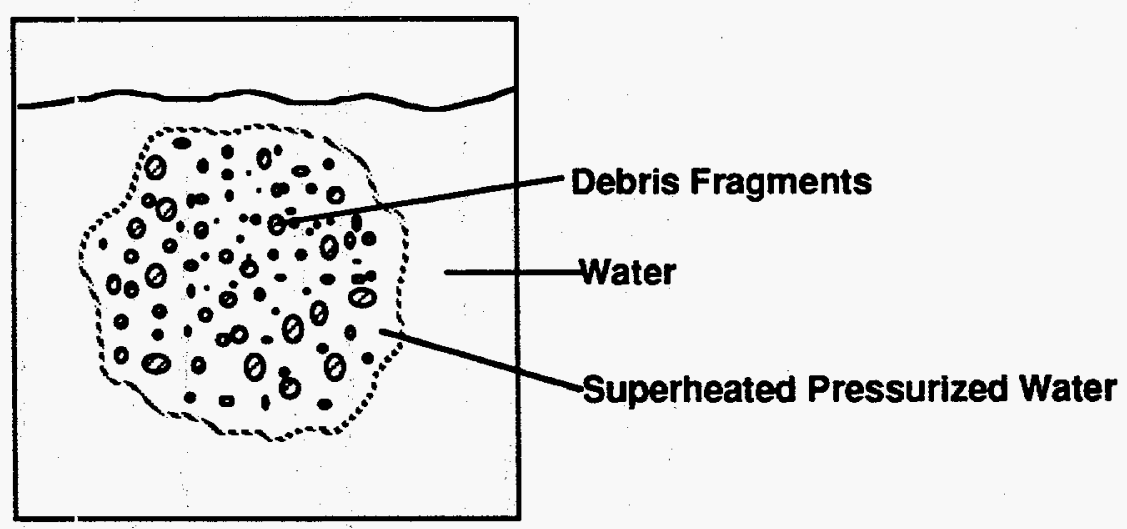

Triggering/Fragmentation

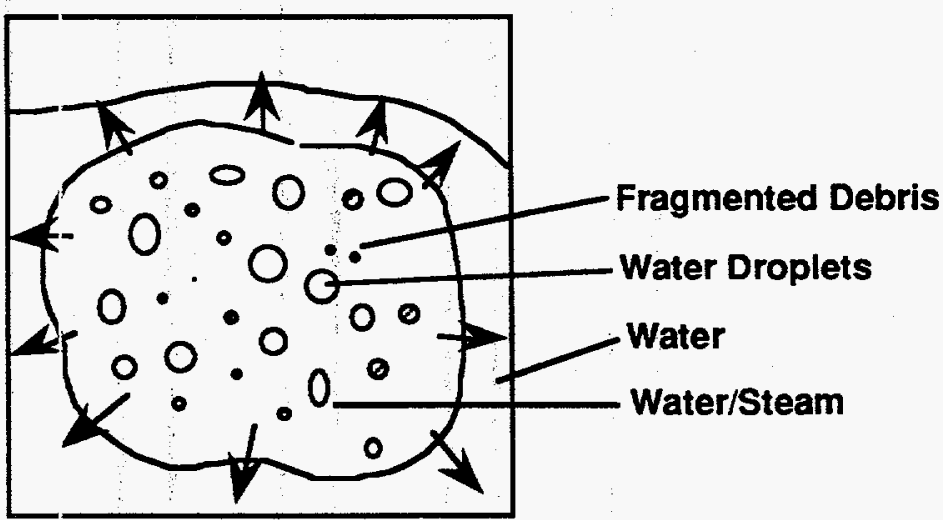

Expansion

Figure 6-3. Phases Of A Steam Explosion 
ideal model depends upon the debris-to-water mass ratio that is assumed for the explosion. Worst-case results (that is, results yielding the highest conversion) generally occur for values of this ratio between 5 and 10 (i.e., five to ten times more debris, by mass, than water). The bounding conversion ratio for each situation analyzed was found by applying the model over a range of debris-to-water ratios and selecting the maximum value. The maximum thermodynamic pressure predicted by this model is dependent upon the initial void fraction assumed, as well as the debris-towater ratio. The upper bound pressure is produced for zero initial void and an infinite debris to water ratio. However, this limit is only theoretical. A reasonable estimate of bounding peak pressure is that associated with the debris-to-water ratio that yields the maximum conversion ratio, and a moderate initial void fraction. Although this peak pressure is not strictly an upper bound, it represents a reasonable upper limit on pressure.

\subsubsection{Best-Estimate Steam Explosion Model}

The best-estimate model used in these analyses was developed by Corradini [6-19]. This model is a one-dimensional, time-dependent model that includes mechanistic formulations to

(1) account for vapor generation and void fraction in the initial mixing phase based upon heat transfer and two phase flow correlations;

(2) limit the mass of debris that mixes based on fluidization principles;

(3) limit the debris-water contact by calculating the portion of the debris that mixes and actually fragments into fine particles;

(4) limit the mass of water heated in the explosion by considering the liquid and vapor phases separately;

(5) limit heat transfer from the debris to the water by employing mechanistic heat transfer correlations; and

(6) account for some irreversibility in the expansion process.

This model has been found to produce results that are qualitatively consistent with experimental results and generally bounds conversion ratios that have been inferred based on levels of observed damage.

\subsubsection{Steam Explosion Scenarios}

The scenarios that could result in steam explosions have been defined based on the severe accident progression sequences delineated by the APET. At several points in the accident progressions, molten core debris may come into contact with water. When this happens, there is a potential for a steam 
explosion. These cases are broken down into in-vessel, and ex-vessel cases. The thermodynamic state of debris and water when contact occurs has been established using the analysis techniques described in Section 5. The scenarios where debris-water contact occurs are described in the followin discussion.

\subsubsection{In-Vessel Scenarios}

Case 1: During; some accident progressions, the fuel assemblies will fill with steam while the moderator region of the vessel remains filled with water. This may occur, for example, during a LOPA without ECCS actuation. After the fuel assemblies dry out (i.e., fill with steam), the fuel tubes in the assembly will melt. As the tubes melt, the molten debris will relocate to the assembly BEFs. Water will be present in the $\mathrm{BEF}$, creating the potential for small-scale steam explosions with only a few grams of debris participating. These would probably be indistinguishable from the rapid steam generation associated with debris quenching. At most, they may fail the BEF. If the BEFs fail, either as a result of contact with hot debris or from a sinall steam explosion, molten debris from the melting fuel and target tubes would flow into the moderator, creating conditions for a steam explosion. Although a LOPA will likely involve most of the fuel assemblies in the core, no mechanism (other than recriticality) couples melt progression between individual assemblies. Thus, individual assembly BEFs would fail at slightly different times. This slight incoherency leads to the assumption that only the mass of molten fuel in one assembly would participate in a single steam explosion.

Case 2: In some accident progressions, the water will drain from the reactor vessel, and the fuel will melt in an empty vessel. This occur's, for example, in a LOCA without ECCS actuation. As fuel melts, it will relocate to the bottom of each assembly and melt through the assembly BEF wall. It is possible that the debris will remain in a pool on the bottom of the reactor vessel for a brief period of time. If the ECCS is recovered during this time period, water will be injected on 0 the pool of molten debris. This manner of introduction molten fuel and coolant is termed a stratified configurati and may result in a steam explosion.

Case 3: Under some circumstances, the fuel assemblies may rapidly melt in place while coolant is flowing in the assembly. A typical event of this type is a transient resulting from the inadvertent withdrawal of a control rod. In this case, the fuel tubes in six assemblies surrounding the affected septifoil could rapidly increase in power. Heat generation will increase to the point that either How instability or burnout would occur. The 
surface of the fuel tube would subsequently transition into film boiling. Once this happens, the fuel tubes melt while water is still flowing in the coolant channel (i.e., an inverted-annular flow regime is established). A steam explosion may occur within the assembly under these conditions.

Case 4: When the moderator region of the vessel contains water, debris from the melting fuel assemblies may be cooled inside the BEF (as discussed in Section 5). The debris would form cooled cylinders of debris separated by moderator. The analysis described in Section 6.1 has shown that this configuration may be critical when a sufficient amount of fuel relocates into each BEF. The associated production of fission power will rapidly raise the debris temperature, and BEF failure and relocation of the debris into the moderator will occur as the debris temperature rises. At the time of BEF failure, the debris would be at a much higher temperature than in the less likely case that the debris does not initially freeze within the BEF. In addition, many of the debris columns would melt simultaneously, so a large coherent steam explosion could result.

Case 5: A steam explosion may not occur when the fuel tubes melt in the flow stream, as discussed in Case 3. This may be the case, for instance, if the debris particles are solid, or if no trigger occurred. In this event, the debris particles may be swept out of the BEF and into the moderator space. Convection within the moderator may then carry the debris fragments up into core region of the reactor. These fragments may have a high reactivity worth in this configuration, since they are no longer shielded by the target material, and they are more homogeneously mixed with the moderator. A power excursion may result that could cause melting of fuel in some or all of the assemblies. This material could mix with the flow stream within the assemblies and might produce a large coherent steam explosion.

\subsubsection{Ex-Vessel Scenarios}

Case 6: In several of the accident scenarios, molten debris will eventually accumulate on the reactor vessel bottom. This debris will spread out on the bottom and may flow through the outlet nozzles into the effluent piping to the pump. For most accident scenarios, water will be present in the outlet piping at this time. A steam explosion can occur when debris encounters water in the piping or in the pump.

Case 7: An ex-vessel steam explosion may occur if the primary system is breached by hot debris. Two types of primary system structural failure are considered: 
(1) Debris in the reactor outlet piping may fail the piping and fall onto the pump room floor; and

(2) Debris on the reactor vessel bottom will be blocked from flowing into the outlet piping if it freezes in the effluent piping nozzle muff structure. If this occurs, the debris will heat up on the reactor vessel bottom and eventually fail the bottom shield. The likely mode of failure of the bottom shield is collapse of the shield as a whole [6-20]. If it collapses, the entire shield, as well as the molten debris, will fall into the pin room below the reactor vessel. The debris will then flow across the floor into the pump room.

In either event, a large portion of the reactor fuel inventory will be deposited on the pump room floor. The pump room floor will be covered with water in many scenarios. A steam explosion may result when the debris enters this water.

Case 8: If a steam explosion does not occur when the debris falls onto the pump room floor, it is expected to run into the trenches in the floor and be channeled into the sumps. If the sumps are filled with water, a steam explosion may occur.

In order to model a particular case, the initial conditions for the explosion must be known. Specifically, it is necessary to know the quantity of molten debris involved, its composition, and its temperature. It is also necessary to know the quantity and temperature of the water that is available. These values can be estimated by examining the existing accident progression analyses. Some range of possible initial conditions exists for each of the cases described. The steam explosion analyses have been performed for the values considered most likely for each of the cases. The initial conditions for each scenario are summarized in Tables 6-1 and 6-2. Based upon these initial conditions, the magnitudes of the steam explosions that might occur in each scenario can be estimated. The results of the estimations are also listed in Tables 6-1 and 6-2.

The most severe results for in-vessel cases are those driven by continued nuclear fission reaction (i.e., recriticality or reactor power excursion). In these cases (4 and 5) a large fraction of the core mass is involved in ie explosion. These explosions may produce a large amount of mechani 1 work. In addition, large quantities of steam would be produced.

The case in which ECCS water is introduced into a pool of molten debris $i$ the reactor (Case 2) can lead to a stratified geometry steam explosion. I this case, water is introduced over the top of the debris as opposed to debris flowing into the water. Because the water is significantly less dense than the molten debris, the falling water will not penetrate the surface of the debris more than a few centimeters. The majority of the water will float on 
Table 6-1. Estimated In-Vessel Steam Explosion Magnitudes

Case 1 Case 2 Case 3 Case 4 Case 5

\begin{tabular}{|c|c|c|c|c|c|}
\hline \multicolumn{6}{|l|}{ Initial Conditions } \\
\hline Mass of Molten Debris (kg) & 32.6 & 14,080 & 125 & 2,160 & 9,000 \\
\hline Temperature of Molten Debris (K) & 950 & 950 & 950 & 2,000 & 950 \\
\hline Total Debris Thermal Energy (MJ) & 20.6 & 8,920 & 76.2 & 3,880 & 5,486 \\
\hline Water Temperature (K) & 323 & 323 & 350 & 323 & 350 \\
\hline Water Depth (m) & 4.7 & 0.75 & N/A & 4.7 & $\mathrm{~N} / \mathrm{A}$ \\
\hline Water Pool Horizontal Area $\left(\mathrm{m}^{2}\right)$ & 0.046 & 19.2 & 0.32 & 19.2 & 19.2 \\
\hline \multicolumn{6}{|l|}{ Ideal Model Results } \\
\hline Conversion Ratio & 0.30 & 0.30 & 0.32 & 0.43 & 0.32 \\
\hline Debris-to-Water Mass Ratio & 7 & 7 & 7 & 3 & 7 \\
\hline Mechanical Work (MJ) & 6.15 & 2,650 & 24.4 & 1,820 & 1,760 \\
\hline Peak Pressure (bar) & 454 & 454 & 465 & 1,746 & 465 \\
\hline Steam Mass (kg) & 4.66 & 2,010 & 17.9 & 719 & 1,290 \\
\hline Steam Volume $\left(\mathrm{m}^{3}\right)$ : & 9.43 & 4,070 & 36.9 & 1,940 & 2,660 \\
\hline \multicolumn{6}{|l|}{ Best-Estimate Model Results } \\
\hline Mass of Debris Mixed (kg) & 27.0 & $1,250^{* *}$ & 108.9 & 1,180 & 7,840 \\
\hline Mass of Debris Fragmented (kg) & 15.0 & 629 & 58.4 & 577 & 4,200 \\
\hline Peak Pressure (bar) & 170 & 141 & 66.2 & 87.9 & 66.2 \\
\hline Conversion Ratio* & 0.072 & 0.105 & 0.114 & 0.0796 & 0.114 \\
\hline Adjusted Conversion Ratio & 0.0596 & 0.0093 & 0.0993 & 0.0435 & 0.0993 \\
\hline Mechanical work (MJ) & 1.75 & 119 & 11.23 & 170 & 809 \\
\hline Steam Mass (kg) & 3.70 & 1,140 & 13.6 & 248 & 979 \\
\hline Steam Volume $\left(\mathrm{m}^{3}\right)$ & 4.34 & 1,920 & 22.9 & 409 & 1,650 \\
\hline
\end{tabular}

* based on mixed debris only

** limit based on stratified explosion 
Table 6-2. Estimated Ex-Vessel Steam Explosion Magnitudes

Case 6

\begin{tabular}{|c|c|c|c|}
\hline \multicolumn{4}{|l|}{ Initial Conditions } \\
\hline Mass of Molten Debris (kg) & 7,040 & 14,080 & 14,080 \\
\hline Temperature of Molten Debris (K) & 950 & 1,470 & 950 \\
\hline Total Debris Thermal Energy (MJ) & 4,550 & 20,100 & 9,100 \\
\hline Water Temperature (K) & 308 & 308 & 308 \\
\hline Water Deptih (m) & 2.86 & 2.0 & 1.65 \\
\hline Water Pool Horizontal Area $\left(\mathrm{m}^{2}\right)$ & 0.193 & 30.0 & 13.3 \\
\hline \multicolumn{4}{|l|}{ Ideal Model Results } \\
\hline Conversion Ratio & 0.29 & 0.39 & 0.29 \\
\hline Debris-to-Water Mass Ratio & 7 & 4 & 7 \\
\hline Mechanical Work (MJ) & 1,300 & 7,910 & 2,600 \\
\hline Peak Pressure (bar) & 484 & 1,480 & 484 \\
\hline Steam Mass (kg) & 1,010 & 3,520 & 2,010 \\
\hline Steam Volume $\left(\mathrm{m}^{3}\right)$ & 2,010 & 8,980 & 4,025 \\
\hline \multicolumn{4}{|l|}{ Best Estimate Model Results } \\
\hline Mass of Debris Mixed (kg) & 927 & 10,060 & 14,080 \\
\hline Mass of Debris Fragmented (kg) & 495 & 5,007 & 6,864 \\
\hline Peak Pressure (bar) & 314 & 28.0 & 117 \\
\hline Conversion Ratio* & 0.049 & 0.037 & 0.066 \\
\hline Adjusted Conversion Ratio & 0.0065 & 0.026 & 0.066 \\
\hline Mechanical Work (MJ) & 41.4 & 575 & 838 \\
\hline Steam Mas:s (kg) & 126 & 1,610 & 1,453 \\
\hline Steam Volume: $\left(\mathrm{m}^{3}\right)$ & 220 & 2,652 & 2,670 \\
\hline
\end{tabular}

* based on mixed debris only 
the debris in a stratified geometry. Investigation into this type of steam explosion has shown that only a thin layer (approximately $1.8 \mathrm{~cm}$ ) of debris will participate in the steam explosion [6-19].

The two remaining in-vessel cases (Cases 1 and 3) are those that involve the debris from only a few assemblies. The mechanical work and steam produced in these cases is relatively small because the small debris mass only provides a small amount of thermal energy. The conversion ratio and the amount of steam and hydrogen produced have been evaluated.

The steam explosion that may occur within the primary coolant effluent piping (Case 6) could involve a large amount of debris. Hence, the ideal model predicts a large steam explosion magnitude. However, the reality of the situation is that the confined geometry of the pipe is such that only a fraction of this debris can participate in the explosion. The best-estimate model accounts for the geometric limitation and predicts that only a small amount of debris can mix. Thus, it is concluded that only a small quantity of mechanical work will be produced, but the pressure created in this explosion could fail the outlet pipe.

The explosions that may occur on the pump room floor following vessel failure or in the sump (Cases 7 and 8 respectively) involve a large mass of high temperature debris. The resulting explosions may be quite large, both in terms of mechanical work and steam production.

The most important factor affecting the magnitude of steam explosions is the quantity of debris mixed with coolant. In this regard, all of the scenarios fall into one of two categories: (1) steam explosions involving the entire core mass or a large fraction of the core mass and (2) steam explosions involving the mass of only a few fuel assemblies. The first category includes recriticality and power excursion-driven steam explosions as well as several ex-vessel steam explosions. The second category includes in-vessel steam explosions in which only a few assemblies melt or in which the melt and relocation process is not coherent.

As will be discussed in the Section 6.4, the large in-vessel events will likely lift the top of the reactor vessel, may fail the bottom shield, and may, under certain extreme conditions, lift the top of the vessel with sufficient energy to impact the top of the confinement. In this case, there is a remote possibility that confinement could be breached. The smaller events may fail the top of the vessel but not permanently displace it. The explosion that may occur in the reactor outlet piping will probably not involve a large mass of debris, but may generate a pressure of sufficient magnitude to fail the piping.

Ex-vessel explosions may occur in the pump rooms, the pin room under the reactor vessel, or in the sumps. The most important structures in the below grade area are the walls that form confinement. They are very strong, relative to potential steam explosion magnitudes, and will certainly 
withstand an explosion. Damage to the roll doors is essentially certain; however, the function of the roll door is not critical. Failure of the pump room dam can affect the level of water in the pump and motor rooms, but failure of the dam is urlikely. Damage to the AACS duct work is also probable, but it is unlikely that it would be rendered completely nonfunctional.

\subsection{Hydrogen Combustion Analysis}

The primary impact of ex-vessel hydrogen combustion in the SRS reactor confinement is that the resultant high pressure might cause a filter element or fan casing failure or breach confinement. In addition, the pressure transient might cause airborne fission products to bypass the confinement filtration syistem. The intent of the following analysis was to quantify the amount of hydrogen generated and the pressure loadings that could be caused by its combustion.

\subsubsection{Hydrogen Generation}

Hydrogen can be generated by (1) the oxidation of aluminum during molten fuel-coolant interactions (MFCI); (2) by molten core-concrete interactions (MCCI); (3) by aluminurn oxidation during core degradation; and (4) by radiolysis of water. The latter two mechanisms have been shown to be negligible [6-12, 6-21]. MFCI can rapidly generate hydrogen, both inside the reactor vessel and in the below grade areas, creating the possibility of energetic events. MCCI can result in the release of hydrogen due to oxidation of unreacted aluminum in the melt. However, the rate of hydrogen generation fron MCCI constitutes a long-term (i.e., over a time period of hours) concern to confinement performance rather than an energetic concern. For this reason, the discussions in this section consider only the effects of hydrogen generation due to MFCI.

The results of experimerital studies [6-22 through 6-27] strongly suggest that the temperature reached by the aluminum metal is the key factor in determining the nature of the reaction. Meltdown tests in TREAT [6-22 through 6-24] have been performed with aluminum-uranium alloy plates (both clad and unclad) and aluminum-clad cermet core plates. Extensive reaction (75 to 90\%) takes place in experiments with heated water (393 K and $558 \mathrm{~K}$ ) at energies above $500 \mathrm{cal} / \mathrm{g}$ (estimated peak temperature is between $1,470 \mathrm{~K}$ and $1,670 \mathrm{~K}$ ). At energies below $500 \mathrm{cal} / \mathrm{g}$, the extent of reaction is less than $5 \%$. The threshold temperature for extensive aluminum-water reaction observed from these experimental studies varies from $1,450 \mathrm{~K}$ to $2,025 \mathrm{~K}$.

The amounts of hydrogen generated from the steam explosion scenarios are listed in Tables 6-3 and 6-4. For an initial fuel temperature of $950 \mathrm{~K}$, the extent of reaction is between $0.1 \%$ and $0.6 \%$ according to TREAT results. For fuel temperatures greater than $1,450 \mathrm{~K}$, it is assumed that aluminum will react extensively. In his case, the extent of reaction will be limited only 
Table 6-3. Estimated Hydrogen Generation from In-Vessel Steam Explosions.

Case 1 Case 2 Case 3 Case 4 Case 5

\begin{tabular}{lccccc}
\hline Mass of Molten Material (kg) & 32.6 & 14,080 & 125 & 2,160 & 9,000 \\
Temp. of Molten Material (K) & 950 & 950 & 950 & 2,000 & 950 \\
Steam Mass* $(\mathrm{kg})$ & 3.7 & 1,140 & 13.6 & 248 & 979 \\
Percentage of Metal Reaction & 0.6 & 0.6 & 0.6 & 11.4 & 0.6 \\
Hydrogen Mass (kg) & 0.02 & 9.3 & 0.08 & 27.6 & 6.0 \\
\hline
\end{tabular}

* calculated from the best-estimate model

Table 6-4. Estimated Hydrogen Generation from Ex-Vessel Steam Explosions.

\begin{tabular}{lccc} 
& Case 6 & Case 7 & Case 8 \\
\hline Mass of Molten Material (kg) & 7,040 & 14,080 & 14,080 \\
Temp. of Molten Material (K) & 950 & 1,470 & 950 \\
Steam Mass* (kg) & 126 & 1,610 & 1,453 \\
Percentage of Metal Reaction & 0.6 & 9.5 & 0.6 \\
Hydrogen Mass (kg) & 4.7 & 148.8 & 9.4 \\
\hline
\end{tabular}

* calculated from the best-estimate model 
by the available steam present in the system. The amount of steam calculated from the best-estimate model is assumed to react entirely with aluminum.

During steam explosions, the rate of chemical reaction depends on the rate at which molten material is fragmented into small particles (complete reaction will occur in particles that are on the order of $500 \mu \mathrm{m}$ diameter or less) and the rate at which particles react with water. The characteristic time for coarse fragmentation is less than a second [6-28], and the time for fine fragmentation is as:ound several hundred microseconds [6-29]. At a temperature of $2000 \mathrm{~K}$, aluminum particles smaller than about $0.5 \mathrm{~mm}$ in saturated water will react in $100 \mathrm{~ms}$ [6-30]. Therefore, the overall reaction rate depends mainly on the coarse fragmentation rate.

Depending on the initial mass and temperature of the molten material, an in-vessel steam explosion is predicted to generate from 0.02 to $27.6 \mathrm{~kg}$ of hydrogen while an ex-vessel steam explosion is predicted to generate from 4.69 to $149 \mathrm{~kg}$. The estimate of $27.6 \mathrm{~kg}$ (or $149 \mathrm{~kg}$ for the ex-vessel cases) of hydrogen comes from assuming that $60 \%$ (or 100\%) of the core is melted and that the molten material attains a very high uniform temperature. In reality, a steam explosion could happen before the melt temperature reaches $2000 \mathrm{~K}$. Also, the temperature distribution in the portion of the core which becomes molten is likely to be nonuniform. Melts at temperatures below the ignition threshold would yield little or no reaction. Therefore, less hydrogen than this will likely be generated.

\subsubsection{Hydrogen Combustion}

Postulated hydrogen combustion events in the confinement may take on one of the following forms: deflagrations, diffusion flames, accelerated flames, or detonations. If the gas concentrations are within certain limits and an ignition source is present, one of the four forms will occur. A deflagration is a combustion wave that travels at subsonic speeds relative to the unburned gas. The pressure loads developed are quasi-static loads. A diffusion flame is one in which the burning rate is controlled by the rate of mixing of oxygen and fuel. Detonations are combustion fronts the travel at supersonic speeds relative to the unburned gas. Detonations c. fevelop transient pressures that are much higher than those obtain in an adiabatic isochoric complete combustion (AICC). Accelerated fla. ire a form of combustion internediate between deflagrations and detona.

The existence of diffusion flames is not considered to pose a direct thr to confinement integrity in a severe accident since the resulting overpre re is quite low. Therefore, analysis has been focused toward the assessme. of pressure loadings which may be expected from deflagrations and detonations. It has been assumed that six volume-percent hydrc en concentration is the lower limit for deflagration and thirteen volumepercent [6-31] is the lean detonation limit. 
Only an in-vessel steam explosion that involves $60 \%$ of the core mass and $2000 \mathrm{~K}$ melt temperature can generate detonable concentrations in the reactor room. An ex-vessel steam explosion that involves all of the core mass and a melt temperature greater than $1073 \mathrm{~K}$ can generate a detonable mixture in the pump room. Neither of these scenarios is considered to be credible due to the large fractions of the core required.

\subsubsection{Deflagrations}

Hydrogen deflagration test data for reactor safety evaluations have been obtained in eight different test vessels varying in volume from 0.3 to $2100 \mathrm{~m}^{3}$ [6-32]. The data suggest that peak pressures in large vessels are likely to be closer to AICC pressures than those from smaller vessels. The data obtained from those tests have been compiled into empirical correlations (ignition limit, flame speed, combustion completeness and propagation criteria) for use in lumped parameter codes such as MELCOR/SR [6-33]. Reference 6-34 lists the correlations developed for deflagrations that were used to calculate flame speeds for this study.

The value of the combustion completeness is assumed to be near unity (i.e., 0.995 ) for these analyses. It is possible for a deflagration wave to propagate up a long vertical passage (i.e., the reactor room, which is $20 \mathrm{~m}$ in height). The induced fluid motion may generate turbulence and induce a more complete burn. The presence of internal equipment, structures, and connections between compartments can also promote turbulence. In addition, judging from the available data, large volumes may burn out more completely. Therefore, it is concluded that the degree of combustion completeness is large in a full-scale confinement.

Using these combustion parameters, the predicted peak pressures in the reactor room and the pump room were calculated with MELCOR/SR, and the results are shown in Table 6-5 for different initial $\mathrm{H}_{2}$ concentrations.

\subsubsection{Detonations}

Detonation can be developed by direct initiation or flame acceleration. Direct initiation of detonation requires a large energy input $(\sim 10 \mathrm{~kJ})$ while ignition of deflagration requires only tenths of a millijoule. Therefore, it is likely that combustion in a detonable mixture will begin as a deflagration and propagate to a detonation.

The maximum pressure loads that can be predicted by MELCOR/SR are the AICC values, so the code cannot be used to predict the dynamic loads resulting from detonations. Thus, pressure loads predicted for simple geometries are used in this study. According to Reference 6-32, the generated pressure spike in the lean detonation limits is about twice the isochoric pressure. The pressure ratios due to isochoric combustion and detonation are summarized in Table 6-6 for given initial hydrogen concentrations. The peak pressure in confinement is predicted to be about ten times the pressure prior to the detonation. 
Table 6-5. MELCOR Prediction of Confinement Responses

Following Hydrogen Deflagrations

\begin{tabular}{lccc} 
& \multicolumn{3}{c}{ Hydrogen } \\
& $6 \%$ & $10 \%$ & $12 \%$ \\
\hline \hline Peak Pressure $(\mathrm{kPa})$ in Reactor Room & 169.1 & 272.9 & 320.7 \\
Peak Pressure $(\mathrm{kPa})$ in Pump Room & 105.8 & 108.6 & 110.7 \\
Peak Pressure $(\mathrm{kPa})$ in Heat Exchanger Bay & 105.8 & 108.6 & 110.6 \\
Filter Failure & yes & yes & yes \\
Fan Failure & yes & yes & yes \\
Roll Doors Failure & yes & yes & yes \\
Hatch Cover Failure & no & no & no \\
\hline
\end{tabular}

\section{Table 6-6. The Ratio of Final to Initial Pressure for Detonation and Isochoric Combustion}

Initial hydrogen concentration

\begin{tabular}{lccc} 
Pressure Ratio* & $13 \%$ & $14 \%$ & $15 \%$ \\
\hline \hline Isochoric Combustion & 4.8 & 5.1 & 5.3 \\
Detonation & 9.6 & 10.2 & 10.6 \\
\hline
\end{tabular}

* Based on $1 \mathrm{~atm}$ pressure, $100 \%$ relative humidity, and $308 \mathrm{~K}$ temperature.

\subsubsection{Summary of Hydrogen Combustion Analysis}

The mass of hydrogen generated ranges from 0.02 to $27.6 \mathrm{~kg}$ dur1, invessel steam explosions and from 4.7 to $149 \mathrm{~kg}$ during ex-vessel am explosions. The major uncertainties in the analysis are

(1) the amount of molten material and the resulting temperature distribution during nuclear excursions; 
(2) the threshold temperature for extensive aluminum-water reaction; and

(3) the amount of steam available for aluminum-water reaction.

MELCOR/SR predicts that the pressure load caused by a deflagration in the reactor room is between 169 and $321 \mathrm{kPa}(24.5$ and $46.6 \mathrm{psi})$. The generated overpressure would be expected to damage both the filters and AACS exhaust fans. For a deflagration occurring in the pump room, the generated peak pressure varies from 106 to $111 \mathrm{kPa}$ (15.4 and $16.1 \mathrm{psi}$ ). This is shown to damage the roll doors but would not lift either the heat exchanger bay or motor tunnel hatch covers.

A hydrogen detonation can be expected to occur following a large coherent in-vessel or ex-vessel steam explosion which involves more than $60 \%$ of the core mass. Detonations can produce more than $1000 \mathrm{kPa}$ (145 psi) pressure pulses. If these pressures are produced within the confinement, the filters, fans, personnel access doorways and hatch covers will all fail.

\subsection{Structural Response Analysis}

The potential for structural damage to the SRS reactor and its confinement has been evaluated. Structural damage may result from energetic events such as steam explosions or hydrogen burns, or may result from overheating or melt-through. Damage may influence the progression of a severe accident and is therefore addressed by the APET.

The approach to structural analysis was to assess the capacity of the structural elements to sustain loading. The object of this assessment was to derive a best estimate of failure capacity. For this reason, ultimate material capacities were employed, in general, making the implicit assumption that the element would experience large inelastic deformation to the failure point. The analytical methods employed were simple methods. In general, failure was assessed based on two factors: the ultimate static loading capacity and the capacity of the element to absorb mechanical energy. This approach does not yield a precise appraisal of the response of an element to a specific challenge. Rather, it provides a guideline for assessing the probability of failure that is consistent with the knowledge of the energetic events that challenge the system. That is, the APET can only resolve the general conditions that result in an energetic event. It is possible to ascertain, based on these conditions, the order of magnitude of the structural challenge. Usually, the challenge can be classified as either (1) far too small to fail the element; (2) so large that failure of the element is inevitable; or (3) in the range that suggests a finite probability of failure. This is precisely the information required by the APET.

The logic of the APET represents all phases of accident progression. Based on this description of accident progression, locations of potential failures have been identified, and structural analyses have been performed for each location. The locations for structural damage have been divided into two 
categories: (1) the primary system boundary, consisting of the reactor vessel and its piping; and (2) the confinement, consisting of the walls above and below grade and the confinement building systems such as the AACS. The order in which they are discussed generally follows the progression of a severe accident, as presented by the APET.

\subsubsection{Structural Analysis of the Primary System Boundary}

The reactor primary system boundary contains the reactor coolant and forms a barrier to the release of radioactive fission products in the event of a fuel melt. During the course of several of the severe accident sequences, failure of this boundary is possible.

The primary system is subject to two types of failure: mechanically induced failure and thermally induced failure. Locations that are challenged are (1) the top of the reactor: vessel; (2) the bottom of the reactor vessel; and (3) the effluent piping. Wach of the challenges to specific elements of the primary system that arise in the APET are discussed below, along with an assessment of the structural capacity of the element. Conclusions are then presented regarding the likelihood of element failure under the identified loads.

Six challenges to the primary system arise in the APET:

- mechanical failure of the top of the reactor;

- mechanical failure of the bottom of the reactor;

- thermal failure of the bottom of the reactor;

- mechanical failure of the effluent piping;

- thermal failure of the effluent piping; and

- thermal failure of the heat exchanger boundary.

Each of these events is described below:

Mechanical failure of the top of the reactor. The top of the reactor vessel consists of the inlet plenum and the top shield assembly. The top of the reactor is generally held in place by its own weight and the weight of the fuel assemblies in the reactor. The inlet plenum piping and the weight of the forest (the large steel framework that supports and aligns the control and safety. rod guide tubes) restrain large displacement of the top of the reactor. Six "roll anchors" secure the inlet piping to the reactor room floor (see Figure 6-4). Static load capacity of the roll anchors is estimated 1 be $4600 \mathrm{kN}(1,000,000 \mathrm{lbf})$ corresponding to an over-pressure in the reacto of approximately $200 \mathrm{kPa}$ (29 psi) [6-35]. The roll anchors can accommods 3 relatively little deflection prior to failure. Therefore they are capable . absorbing only a modest amount of mechanical work, estimated to $\mathrm{b}$ approximately $35 \mathrm{~kJ}$ [6-36]. The consequences of roll anchor failure are tha the seal at the top of the reactor will be broken and that the core assemblies will be disengaged from the fittings on reactor bottom (monitor pins, upflow pins, etc.). A relatively small energetic event would be capable of inducing this damage [6-36, 6-19]. If a significantly larger force is exerted on the top 


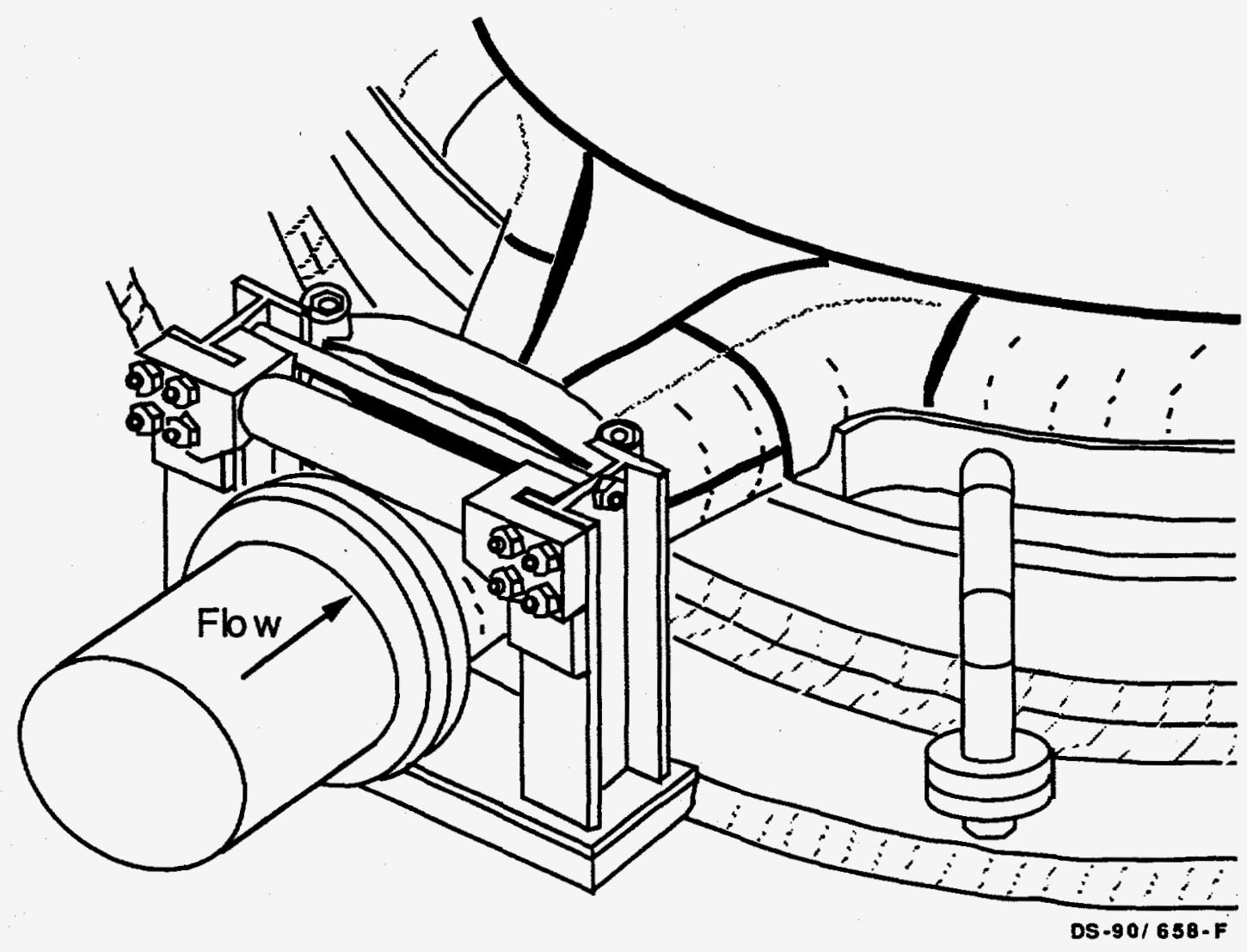

Figure 6-4. Roll Anchor 
of the reactor, it will be lifted against the constraint of the inlet piping and the actuator system. (The plenum can be displaced upward approximately one inch before contacting the forest.) The inlet piping is capable of absorbing considerable mechanical energy before experiencing gross failure. Rupture of the inlet piping is estimated to require approximately $27 \mathrm{MJ}$ of mechanical energy [6-36]. The consequences of gross failure of the inlet piping are that the top of the reactor will be left ajar and major disruption of the core geometry will occur. Such damage is likely to require a large in-vessel energetic event involving a significant fraction of the core (i.e., more than $1000 \mathrm{~kg}$ of debris producing well in excess of $30 \mathrm{MJ}$ of mechanical work).

Mechanical failure of the bottom of the reactor. The reactor vessel sits on a reinforced concrete ledge. A transient pressure pulse inside the reactor may create an impulsive loading sufficient to fail the ledge. If this were to occur, the bottom of the reactor would fall into the pin-room below the reactor. The static load-loearing capacity of the ledge is estimated to be approximately $45,000 \mathrm{kN}(10,000,000 \mathrm{lbf})$. This is equivalent to a static pressure on the bottom of the reactor of $2.1 \mathrm{MPa}$ (305 psi) [6-36]. The capacity of the concrete ledge to absorb mechanical work is estimated to be $12 \mathrm{MJ}$ [6-36]. A relatively large energetic event could have the capacity to fail the bottom of the reactor [6-36, 6-19].

Thermal failure of bottom of the reactor. In the event of a core melt accident, molten core delbris will likely flow to the bottom of the reactor vessel. Two possibilities exist for the disposition of the debris [6-37]. The first (and more likely) possibility is that the molten debris will flow into the effluent piping. Alternatively, the debris may be held up by freezing in the outlet nozzle, allowing the debris to pool on the bottom of the reactor vessel. If this occurs, the decay heat generated within the debris will raise its temperature sufficiently, over a period of time, and heat the bottom shield. Rather than experiencing melt-through, it is anticipated that the bottom shield will fail mechanically when heated. The bottom shield may be considered to be a mechanical "truss" with its load bearing capacity derived from the combination of the top plate acting as a compressive member, and the bottom plate acting as a tensile member. Thermal failure of the top plate will transfer the loads to the bottom plate in bending. The bottom plate has insufficient strength to carry the mechanical load, and can be expected to collapse once the top plate fails [6-20]. Failure of the top plate is estimated to take at least 15 minutes, and debris temperatures is estimated to exceed $1700 \mathrm{~K}$ at failure [6-37].

Mechanical failure of reactor effluent piping. The capacity of the effluent piping was assessed based on the actual piping itself. The pump casing, valve bodies, and bellows expansion joint did not receive careful scrutiny. The ultimate static pressure capability of the 24 " dia. $\times 0.5$ inch wallthickness reactor effluent pipe is estimated to be $26 \mathrm{MPa}$, (3770 psi) [6-36]. This capacity is generally at the upper bound of realistic steam explosion pressure magnitudes [6-36, 6-19]. 
Thermal failure of effluent piping: The reactor effluent piping and the primary circulation pumps are the lowest point in the primary system. In many postulated core-melt accidents, the molten core debris will collect at this low point. In the absence of cooling, the decay heat generated within the debris will heat to the point of failing the effluent pipe or pump casing. The structure experiences very low mechanical stress, therefore meltthrough of the pipe is the likely outcome. It is estimated that it will take approximately $5 \mathrm{~min}$. to melt-through the piping, once the debris relocates [6-37]. Debris temperatures in excess of $1700 \mathrm{~K}$ are expected.

Thermal failure of the heat exchanger boundary. In Section 5.3, it was stated that, if debris were transported to a heat exchanger, it would quickly plug the tubes and collect between the end bell and the tube sheet. Since secondary cooling water would be present in the heat exchanger, the thicker tube sheet would be cooled, and failure of the end bell would be possible. Failure of the end bell would release debris to the confinement, but no direct path to the environment would be opened.

\subsubsection{Structural Analysis of the Confinement}

The confinement system is designed to retain fission products if they should escape through the primary system boundary. In several of the severe accident sequences, energetic events such as steam explosions or hydrogen burns may cause failure of certain elements of the confinement. The following paragraphs describe the potential failures and the analyses performed to ascertain the structural capacity of the elements involved. The likelihood of failure is assessed based on a comparison of the structural capacity with the loadings possible for the range of severe accident scenarios. The structural capacities of some elements, including the fans, filters, and roll doors, have been incorporated into the MELCOR/SR computer code, which has been used to perform the confinement response analysis as discussed in Section 5 . The potential failures discussed below are generally presented in the order in which they would occur during the course of severe accident progression, and in the order in which they appear in the APET.

The confinement is challenged by three types of loading: static pressurization, shock loading, and missiles. The confinement is constructed principally of very heavy reinforced concrete, and is challenged only by very large energetic events. Considered with the confinement, however, are various pieces of equipment such as doors and ductwork that are relatively fragile and subject to failure from smaller energetic events. The elements of the confinement that may be challenged in a severe accident are

(1) the confinement walls, both above and below grade;

(2) doors including personnel doors, the roll doors, the pump room dams, and the heat exchanger hatch covers; and 

AACS ductivork.

Each of these components is discussed in this section, along with the challenges they may face.

Ten conditions in the APET require assessment of the structural capacity of the confinement or equipment that is part of confinement. These conditions are listed below by confinement element.

Reinforced concrete structure:

- $\quad$ pressurization of the above-grade walls,

- $\quad$ missile failure of the top of confinement, and

- shock loading of pump-room walls.

Doors and hatchways:

- personnel doors into confinement,

- the roll doors between the pump and motor rooms,

- the pump room dams, and

- the heat exchanger hatch covers.

Equipment:

- the AACS fans and filters,

- below grade AACS ductwork, and

- the reactor room spray system.

Each of these items is discussed briefly below.

Pressurization of the above-grade walls. A large energetic event in the reactor vessel might release a great deal of steam into the reactor room, tending to pressurize it. The walls of the reactor room are quite heavy, however, and are estima.ted to be capable of withstanding over 65 psi of pressure [6-36]. This is far in excess of potential challenges from steam explosions and hydrogen burns.

The "top hat" region of the confinement building may become pressurized by flow from the reactor room in such an event. Because of restric ons to flow, the pressure in the top hat region will be much less than the 1 ssure that might exist in the reactor room. The capacity of the top hat also much less, however. The pressure capacity of the top hat is reportec i be 5 psi $(34.5 \mathrm{kPa})[6-38]$.

Missile failure of the top of confinement. The top of confinement (i.e., he floor between the reactor room and the top hat) is quite strong. A large energetic event in the reactor vessel may propel the top of the reactor and the actuator upward with sufficient velocity to impact it, however. The mechanical energy capacity of the top of confinement is estimated to be 
approximately $220 \mathrm{MJ}$ [6-36]. Although some large energetic events may approach this energy [6-19], it is very unlikely that this much could be imparted to the top of confinement.

Shock loading of pump-room walls. The below-grade walls are very thick reinforced concrete. The highest loading faced by these walls is from shock waves that might be produced by below grade steam explosions. The most vulnerable wall is the one separating the pump room from the D \& E canal. Other walls are thicker, backed up by earth, or more remote from the potential sites of energetic events. Calculations show that this wall can easily tolerate the largest shock wave pressure from the closest potential steam explosion [6-36].

Personnel doors into confinement. The personnel doors are assumed to fail at a differential pressure of $0.25 \mathrm{psi}(1.72 \mathrm{kPa})[6-36]$.

The roll doors between the pump and motor rooms: The roll doors are assumed to fail at a differential pressure of $0.5 \mathrm{psi}(3.45 \mathrm{kPa})[6-36]$.

The pump room dams. The pump room dams are expected to be capable of withstanding somewhat in excess of $1 \mathrm{psi}(6.89 \mathrm{kPa})$. Since the roll doors will fail and relieve pressure before the dam, it is likely that only shock loadings could result in dam failure [6-36].

The heat exchanger hatch covers. The heat exchanger hatch covers are four-foot-thick segmented concrete plugs that are inserted in the concrete pad that serves as the roof of the heat exchanger bays. These plugs allow access to the heat exchangers from outside the reactor building. The plugs are held in place by their own weight. A differential pressure of 4 psi $(27.6 \mathrm{kPa})$ is sufficient to begin lifting the plugs from their seats [6-36].

The AACS fans and filters. The failure pressure for the fans was assumed to be the design pressure for their casings-0.556 psi differential $(3.83 \mathrm{kPa})$ [6-39]. The failure pressure for the filters was conservatively assumed to be 0.217 psi differential $(1.50 \mathrm{kPa})$-the maximum differential pressure at which the filters are required to operate under test conditions [6-39].

Below grade AACS ductwork. The AACS ductwork is fabricated of lightweight sheet metal. Segments of the ductwork exist in the pump room in the vicinity of potential below-grade energetic events. The ducts are open to the below-grade atmosphere, so the same static pressure exists inside the ducts as outside them. Pressurization of the below-grade space will therefore not affect the ducts. Shock waves generated by energetic events may, however, fail the ducts.

Relatively little detail of the construction of the ductwork is shown on the drawings. The ducts are fabricated out of fairly heavy gauge steel sheet metal. No analysis of the ductwork was performed. The judgment applied here is that the ducts will buckle and collapse under a shock pressure on the order of $2 \mathrm{psi}(13.8 \mathrm{kPa})$. A shock is required since static pressure will 
act on the inside of the duct as well as on the outside. In their deformed state, the ducts will have a limited capacity to carry airflow. Under the action of about $5 \mathrm{psi}(34.5 \mathrm{kPa})$, it is judged that the ducts would tear, with the sheet metal separating from the structural steel reinforcement [6-36].

The reactor room spray system. The reactor room spray system is attached to the walls of the reactor room. In this location, it has limited vulnerability to missiles that might be generated in an in-vessel energetic event.

\subsubsection{Summary of Structural Response Analysis}

Each of the potential structural failures that can influence accident progression has been assessed in sufficient detail to allow the range of accident progressions to be incorporated in the APET. In general, no sophisticated analyses have been performed, but the structural capacity has been determined with sufficient resolution to address the loadings presented by the range of severe accident conditions.

The following paragraphs summarize the results for the potential primary system boundary structural failures and the potential failures of the confinement.

Primary System Boundary Failures:

(1) Heat exchangers: The heat exchangers are unlikely to fail in such a way as to allow debris to breach the primarysecondary boundary.

(2) The top of the reactor vessel: In the event of large in-vessel steam explosions (those that involve a large fraction of the core), gross failure of the top of the vessel is likely. Explosions involving the fuel mass of just a few assemblies can cause a puff failure of the top of the vessel.

(3) The bottom of the reactor vessel: Large in-vessel steam explosions can impulsively load the bottom of the reactor and cause failure of its supports.

(4) Reactor effluent piping: Core debris that flows into the primary coolant effluent piping may result in a ste explosion, but this explosion is unlikely to fail the piping. the piping (and pump casing) is not cooled by below-grac water, the pipe will melt through, releasing debris at temperatures near or above the stainless steel melting point.

Confinement Failures:

(1) Above-grade confinement walls: No energetic events are postulated that can fail the building walls. 
(2) The top of confinement: Large in-vessel steam explosions have the potential to propel the top of the reactor as a missile that can breach the top of confinement. This eventuality is very remote.

(3) AACS fans and/or filters: The failure pressure of the fan casings and filters is low enough that failure is possible for steam explosions and hydrogen burns that pressurize confinement.

(4) Reactor building hatch covers: Below-grade pressurization can lift the hatches in the heat exchanger bays or pipe tunnel.

(5) Personnel doors into confinement: Personnel doors connecting the confinement area to the environment can be breached by pressurization of confinement.

(6) Below-grade walls of confinement: No energetic events are postulated that are capable of breaching below-grade confinement walls.

(7) Below-grade AACS duct work: Shock waves resulting from an energetic event below-grade may partially collapse or sever the AACS duct work.

(8) Pump room roll doors: The roll doors will likely fail in the event of any significant shock wave caused by below-grade steam explosions or hydrogen burns.

(9) Pump room dams: The pump room dams could fail as a result of a large steam explosion in the motor room.

(10) Reactor room spray system: It is unlikely that a missile could disable the reactor room sprays.

\subsection{References}

6-1. J. A. Briesmeister, ed., MCNP - A General Monte Carlo Code for Neutron and Photon Transport, LA-7396-M, Rev. 2, Los Alamos National Laboratory, 1986.

6-2. R. Kinsey, Data Formats and Procedures for the Evaluated Nuclear Data File, ENDF, BNL-NCS-50496 (ENDF 102), 2nd ed. (ENDF/B-V), Brookhaven National Laboratory, October 1979.

6-3. R. J. Howerton, et al., The LLL Evaluated Nuclear Data Library (ENDL): Evaluation Techniques, Reaction Index, and Descriptions of Individual Reactions, UCRL-50400, Vol. 15, Part A, Lawrence Livermore National Laboratory, September 1975. 
6-4. M. A. Gardner, and R. J. Howerton, ACTL: Evaluated Neutron Activation Cross-Section Library - Evaluation Techniques and Reaction Index, UCRL-50400, Vol. 18, Lawrence Livermore National Laboratory, October 1978.

6-5. E. D. Arthur, and P. G. Young, Evaluated Neutron-Induced CrossSections for 54-56 Fe to $40 \mathrm{MeV}$, LA-8626-MS (ENDF-304), Los Alamos Scientific Laboratory, December 1980.

6-6. D. G. Foster, Jr., and E. D. Arthur, Average Neutronic Properties of 'Prompt' Fission Products, LA-9168-MS, Los Alamos National Laboratory, February 1982.

6-7. E. D. Arthur, P. G. Young, A. B. Smith, and C. A. Philis, "New Tungsten Isotope Evaluations for Neutron Energies Between 0.1 and $20 \mathrm{MeV}$," Trans. Am. Nucl. Soc., 39, 793, 1981.

6-8. S. D. Clement, et al., Analysis of Recriticality in Savannah River Site Reactors for the PRA, WSRC-RP-92-443, Westinghouse Savannah River Company, Aiken SC, March 1992.

6-9. J. A. Gernard, "Derivation of the Standard Dynamic Period Equation," Trans. Am. Nucl. Soc., 55, 598, November 1987.

6-10. R. L. Reed memorandum to G. F. Merz, "Reactivity of Melted Fuel Arrays," RTR-2518, Westinghouse Savannah River Company, Aiken, SC, March 1988.

6-11. C. N. Amos, S. H. Kim, and K. W. Ross, The Development of MELSRP: A Computer Code for Core Meltdown Accident Analysis of Savannah River Site Reactors, WSRC-RP-92-763, Westinghouse Savannah River Company, Aiken, SC, November 1992.

6-12. K. W. Ross, et al., Analysis of Fuel Melting at Savannah River Site Reactors for the PRA, WSRC-RP-92-1012, Westinghouse Savannah River Company, Aiken, SC, November 1992.

6-13. Savannah River Site Production Reactor Safety Analysis Report, WSRC-RP-89-383, Westinghouse Savannah River Company, Aiken SC, July 1989.

6-14. N. Morris, et al., Analysis of Thermal-Hydraulic/Reactivity Transients at Savannah River Site Reactors for the PRA, WSRC-RP92-1013, Westinghouse Savannah River Company, Aiken, SC, December 1992.

6-15. M. F. Young, The TEXAS Code for Fuel-Coolant Interaction Analysis, ANS/ENS LMFBR Safety Topical Meeting, Lyon-ECULLY, France, 1982. 
6-16. J. P. Morin memo to J. M. Boswell, "Fuel Melting and Transient Analysis Studies," DPST-72-407, Savannah River Laboratory, Aiken SC, June 27, 1972.

6-17. Y. M. Farawila and S. I. Abdel-Khalik, A Literature Survey of Vapor Explosion Phenomena - DRAFT, GTRSR---001, Georgia Institute of Technology, Atlanta, Georgia, May 1988.

6-18. E. P. Hicks and D. C. Menzies, Theoretical Studies on the Fast Reactor Maximum Accident, ANL-7120, Argonne National Laboratories, Argonne, Illinois, 1965.

6-19. B. E. Vonderfecht and D. C. Smith, Steam Explosion Analysis in Support of the SRS Reactor Safety Assessment, WSRC-RP-92-720, Westinghouse Savannah River Company, Aiken, SC, October 1992.

6-20. D. A. O'Brien, Analysis of the Response of the SRP Reactor Confinement System to Postulated Core Melt Sequences-Top and Bottom Shield Failure Analysis, WSRC-RP-89-279, Westinghouse Savannah River Company, Aiken, SC, August 1989.

6-21. L. Hyder memo to A Frain, "Hydrogen Generation During a Reactor Accident," October 25, 1989.

6-22. R. O. Ivins, F. J. Testa, and P. Krause, Studies of the AluminumWater Reaction in TREAT, Chemical Engineering Division Summary Report, Oct., Nov., Dec., 1962, USAEC Report ANL-6648, p. 201, Argonne National Laboratory, 1963.

6-23. R. O. Ivins, F. J. Testa, and P. Krause, Studies of the AluminumWater Reaction in TREAT, Chemical Engineering Division Summary Report, Jan., Feb., March, 1963, USAEC Report ANL-6687, p. 179, Argonne National Laboratory, 1963.

6-24. R. O. Ivins, F. J. Testa, and P. Krause, Studies with AluminumU3O8 Cermet Fuels (HFIR Fuel) in TREAT, Chemical Engineering Division Summary Report, July-Dec. 1965, USAEC Report ANL-7125, p. 201, Argonne National Laboratory, 1966.

6-25. R. E. Wilson, L. Mishler, and C. Barnes, Metal-Water Reactions: Studies of the Aluminum-Water Reaction by the Levitation-Melting Method, Chemical Engineering Division Summary Report, Oct., Nov., Dec., 1962, USAEC Report ANL-6648, p. 196, Argonne National Laboratory, 1963.

6-26. H. M. Higgins and R. D. Schultz, The Reaction of Metals in Oxidizing Gases at High Temperatures, Report IDO-28000, Aerojet-General Corp., 1957. 
6-27. D. F. Beck and M. J. Rightley, FCI Test NPR-1 - Preliminary Report, SAND90-2715 (DFAFT), Sandia National Laboratories, Albuquerque NM, October 31, 1990.

6-28. G. C. Park, and M. L. Corradini, Estimates of Limits to Fuel/Coolant Mixing, UWRSR-60, University of Wisconsin Report, August 1989.

6-29. M. F. Young, M. Berman, and L. T. Pong, "Hydrogen Generation During Fuel/Coolant Interactions," Nuclear Science and Engineering, 98,p. 1-15, 1988.

6-30. L. T. Pong, A Theoretical Study of the Reactions of Molten $\mathrm{Zr}, \mathrm{Fe}$ and Al with Water, SAND88-7119, Sandia National Laboratories, Albuquerque, NM, 1988.

6-31. M. Berman, "A Critical Review of Recent Large-Scale Experiments of Hydrogen-Air Detonations," Nuclear Science and Engineering, 93, p 321-347, 1986.

6-32. Technical Aspects of Hydrogen Control and Combustion in Severe Light-Water Reactor Accidents, National Academy Press, Washington, D.C., 1987.

6-33. M. T. Leonard, et al., MELCOR/SR-Mod3 - A Computer Code for Evaluating Severe Accident Progression in Heavy Water Reactors, Reference Manual and User Guides, SAIC 91/6504, September 1991.

6-34. C. C. Wong, HECTR Analysis of the Nevada Test Site (NTS) Premixed Combustion Experiments, SAND87-0956, Sandia National Laboratories, Albuquerque, NM, 1988.

6-35. W. W. F. Yau, memo to J. D. Spencer, "Roller Anchor Resistance to Uplifting," DPST-87-780, Savannah River Laboratory, Aiken, South Carolina, October 1.987.

6-36. S. Santa Cruz, I). C. Smith, and W. W. F. Yau, Analysis of Structural Response at Savannah River Site Reactors for the PRA, WSRC-RP-92-1011, Westinghouse Savannah River Company, Aiken, SC, November 1992.

6-37. S. D. Clement, et a.l., Analysis of Debris Behavior at Savann $\quad$ River Site Reactors for the PRA, WSRC-RP-92-836, Westinghouse Sa inah River Company, Aiken, SC, July 1992.

6-38. W. W. F. Yau memo to J. R. Knight, "Structural Evaluatio or Probabilistic Risk Assessment of SRS Reactor Operations," W RP-90-7389, Westinghouse Savannah River Company Savannah River Laboratory, Aiken, South Carolina, July 1990. 
6-39. S. P. Tinnes and S. F. Petry, Systems Analysis - Airborne Activity Confinement System of the Savannah River Production Reactors, DPSTSY-100-10, Savannah River Plant, Aiken, South Carolina, March 5, 1986. 
This page intentionally left blank. 


\subsection{SOURCE TERM QUANTIFICATION}

The third module of the SRS PSA methodology quantifies radionuclide release to the environment for accident sequence groups. Specifically, the source terms to the environment are determined for accident progression sequences that have significant probabilities. In this context, a source term refers to the timing, duration, elevation magnitude, and energy characterizing the radiological release from the postulated reactor accident.

A two-step process has been employed to evaluate sequence-specific source terms for the SRS PSA. First, accident progression bins are grouped according to similarities in their characteristics that significantly impact the resulting source term. These groups are referred to as source term bins. Second, the source term is evaluated for each source term bin using a parametric source term algorithm.

\subsection{Source Term Bins}

The SRS PSA accident progression analysis for K-Reactor operation described in Section 4 results in a large number of accident progression bins that provide more detail about accident progression than is required for source term estimation. Consequently, accident progression bins are grouped (or binned) on the basis of similar characteristics (or attributes) that directly affect the source term. Source term binning is accomplished through a two-stage process involving a primary binner and a secondary binner. The primary binner groups sequences that exhibit similar accident progression characteristics into accident progression bins. The secondary or source term binner groups the accident progression bins that are likely to produce similar source terms into source term bins.

Sixteen groups or dimensions are included in the source term binner. In addition to events and conditions that affect the source term magnitude, the dimensions include effects on the timing, elevation, and thermal of the release. Source term bins are defined by combinations of one attribute from each of the 16 dimensions.

The relationship between the source term bin dimensions and the parameters used in PRAST is described below. The PRAST time periods (described in Section 7.2.3) in which the dimensions have effect are also given.

Dimension 1: Release Timing indicates the time elapsed from scram until the initial release (Period 1) to the environment.

Dimension 2: Level of Release From Fuel indicates the fraction of the fission products released during assembly melting. It is also used to define the duration, elevation and thermal energy of the release (Period 1). 
Dimension 3: Level of Primary System Retention indicates the fission product decontamination factors of the reactor vessel water and structures (Periods $1 \& 2$ ).

Dimension 4: Level of Confinement Retention indicates the fission product decontamination factors of the above grade confinement and the sprays (Periods $1,2 \& 4$ ). It is also used to determine the elevation of release for time Periods $1,2 \& 4$, the thermal energy of release for Period 2 and transfer fraction of fission products to leave the above grade confinement in Period 3.

Dimension 5: Spray Status indicates the status of the reactor room spray system (Periods $1,2 \& 4$ ). It is also used to determine the transfer fraction of fission products from the below grade confinement to the above grade confinement (Period 4).

Dimension 6: Level of Filter Bypass indicates the fraction of fission products in the above grade confinement that bypass the filters (Periods $1 \& 2$ ). It is also used to determine the elevation of release (Periods $1 \& 2$ ) and to set the decontamination factor for the filters (Period 3).

Dimension 7: Level of Heat up Release indicates the fraction of the fission products released during debris heat up on the bottom of the reactor vessel (Period 2). It is also used to determine the duration of Periods 2 \& 3.

Dimension 8: Level of Energetic Event describes energetic events that accompany vessel failure (Period 3). It is also used to determine the release fraction from fuel during an energetic event, the fission product transfer fractions from confinement to the environment, the thermal energy, the duration, and the elevation associated with the release (Period 3 ).

Dimension 9: Level of Core-Concrete Interaction Release $c$ cribes the fraction of the fission products released ring molten-core concrete interactions in the belo: ade areas (Period 4). It is also used to determ. he duration of the Period 4 release.

Dimension 10: Level of Revolatilization Release describes the frac of the fission products revolatilized from the ves surfaces and below grade confinement water (includ'. water that has relocated from the vessel) in Period 4. 
Dimension 11: Level of Late-Release Thermal Energy describes the conditions which control the quantity of thermal energy that is released during Period 4.

Dimension 12: Level of Below-Grade Confinement Retention describes the conditions which affect the fission product decontamination factors of the below grade confinement in Period 4.

Dimension 13: Level of Late Filter Bypass describes the conditions which affect the decontamination factor for the confinement filters, the fission product transfer fractions from above and below grade confinement to the environment, and the elevation of fission product release (Period 4$)$.

Dimension 14: Late Filter Status describes the conditions which affect the decontamination factor and release fraction for the confinement filters (Period 4). It is also used to set the duration, the elevation and the thermal energy of release during Period 4.

Dimension 15: Level of Delayed Filter Burn describes the conditions which affect the release fraction for the confinement filters (Period 5). It is also used to set the duration, the elevation and the thermal energy of release during Period 5.

Dimension 16: Level of Iodine Revolatilization describes the conditions which affect the release fraction for the water in confinement (Period 5). It is also used to set the duration and the elevation of release during Period 5.

The source term bins are input to PRAST using a 16-character bin ID, one character for each of the sixteen dimensions. As previously indicated, each source term bin is a combination attributes from each of the 16 dimensions. Each of the 16 characters then represents a specific attribute for the corresponding dimension. The attributes available for each dimension are given in Table 7-1.

For example, in the bin ABCDDCBAAAABBBAA, Dimension 3 is a "C" which means "water was present in the vessel initially but was expelled", and Dimension 13 is an " $A$ " which means "all late releases completely bypass the filter system" (see Table 7-1).

Previous PRAs have typically used a small number of source term bins. For example, the Reactor Safety Study [7-1] used nine bins for PWRs and five bins for BWRs. This coarse binning means that the effects of changes in a scenario cannot be readily determined because so many dissimilar scenarios are assigned to the same source term bins. The finer binning 
used in the SRS PSA means that the sensitivity of the source terms (and hence the risk) to most of the major phenomena can be investigated.

The approach used for the SRS PSA has two distinct advantages. First, the source term bins are not defined in advance of the accident progression analysis; the analysis actually determines the bins. Thus, the uncertainties that introduce combinations of events which were not anticipated prior to completing the accident progression analysis are taken into account in the source term analysis. This occurs since an unanticipated combination automatically creates a new bin. The second advantage is that the rationale used to assign a particular accident progression to a particular source term bin is clearly documented. Input to the PSTEVNT computer code [7-2] includes the logic that is used to map characteristics of an accident progression into one of the specified source term bin attributes for each dimension. Subjective judgments regarding the effects of specific phenomena on the source term are formalized in this manner.

Table 7-1. Source: Term Bin Dimension and Attribute Definitions

\section{Dimension}

Number Dimension Title Attributes

1 Release 'Timings

(A) Immediate (0-10 minutes)

(B) Delay (10-60 minutes)

(C) Long Delay (1-3 hours)

2

Level of Release From Fuel

(A) Non-energetic melt down

(B) Recriticality of debris on tank bottom

(C) Power excursion

3 Level of Primary System Retention
(A) Water present initially
(B) No water present initially
(C) Water present initially, but energetically expelled
(D) Water present initially, but boils away




\section{Table 7-1. Source Term Bin Dimension and Attribute Definitions}

(Continued)

\section{Dimension} Number

$4 \quad$ Level of Confinement Retention

$5 \quad$ Status of Sprays

$6 \quad$ Level of Filter Bypass

$7 \quad$ Level of In-Vessel Release During Core Heat up
Attributes

(A) Building failure (seismic or missile induced) - Sprays are irrelevant

(B) Building breach with path to filters blocked by closed exhaust dampers

(C) Building breach with path to filters open

(D) No building breach with fan/filter system operating

(E) No building breach with fans failed, path to filters open

(F) No building breach with path to filters blocked by closed exhaust dampers

(A) Sprays on early only

(B) Sprays on late with release to above-grade

(C) Sprays off

(A) Complete bypass

(B) Partial bypass (energetic event)

(C) No bypass

(A) High release, debris at melting temperature of steel

(B) Moderate release, debris at structural failure temperature

(C) Low release, debris exits primary as two-phase mixture or is cooled invessel

(D) No additional in-vessel release 
Table 7-1. Source Term Bin Dimension and Attribute Definitions (Continued)

\section{Dimension}

Number Dimension Title

Attributes

$8 \quad$ Energetic Event at Vessel Failure
(A) Steam explosion resulting in confinement breach
(B) Hydrogen burn resulting in confinement breach
(C) Steam explosion with no confinement damage
(D) Hydrogen burn with no confinement damage
(E) No energetic event
(A) None
(B) Dry
(C) Submerged
(D) Flooded

9 Level of Core-Concrete Interaction Release

10 Level of Fievolatilization
(A) High revolatilization from vessel surfaces plus water boil-off in pump room
(B) Moderate revolatilization from vessel surfaces plus water boil-off in pump room
(C) High release from vessel surfaces
(D) Moderate release from vessel surfaces
(E) Water boil-off releases to pump room
(F) No delayed revolatilization of in-vessel releases

11 Level of Late Release (A) Filter burn Thermal Energy
(B) Sustained hydrogen .urn
(C) Core-concrete only
(D) None

12 Level of Below-Grade Confinement Retention
(A) High ( $\mathrm{DF}=1.2$ to 1.3$)$
(B) Moderate $(\mathrm{DF}=1.1)$
(C) None $(\mathrm{DF}=1)$ 
Table 7-1. Source Term Bin Dimension and Attribute Definitions (Continued)

\begin{tabular}{cll}
$\begin{array}{c}\text { Dimension } \\
\text { Number }\end{array}$ & Dimension Title & Attributes \\
\hline \hline \multirow{2}{*}{13} & Level of Late Filter Bypass & (A) Complete $(100 \%)$ \\
& & (B) High $(80-90 \%)$ \\
& & (C) Moderate (60\%) \\
& & (D) Low $(20-30 \%)$ \\
& & (E) Very Low (10\%) \\
& & (F) None (0\%) \\
14 & Late Filter Status & (A) Burn \\
& & (B) Iodine Desorption \\
& & (C) Normal \\
15 & Delayed Filter Burn & (A) Delayed burn occurs \\
& & (B) Delayed burn does not occur \\
16 & Late Iodine & (A) Occurs \\
& Revolatilization & (B) Does not occur
\end{tabular}

\subsection{Source Term Algorithm Development}

The source term for a specific source term bin is determined by the phenomena that are included in that bin and their relative timings. Given the large number and wide range of bins, direct calculation of source terms by applying mechanistic models to calculate the release to the environment as a function of time is impractical. A simplified approach allowing rapid estimation of source terms is required. The approach used was similar to that developed for the NUREG-1150 [7-3] study. A computer program that considers severe accident phenomena and their effects on fission product release and transport has been developed to perform these estimates. The source terms predicted by the model consist of:

(1) the fraction of the initial fission product inventory released;

(2) the time (relative to reactor scram) that release occurs;

(3) the duration of the release;

(4) the elevation of the release point above-grade; and

(5) the thermal energy of the plume that carries the release.

This source term algorithm called Production Reactor Algorithm for Source Terms provides a framework for-synthesizing the results of experiments and mechanistic calculations into a fast-running tool capable 
of predicting source terms for the large number of source term bins generated. PRAST [7-4] does not calculate the behavior of the fission products from chemical and physical properties or from the flow and temperature conditions in the reactor and confinement. Instead, it represents, in a parametric manner, an interpretation of the results of more detailed calculations that do consider these phenomena.

This approach rests on two key assumptions. First, it is assumed that the source term from an accident is determined solely by the in-plant conditions and the events that accompany the accident progression. Second, it is assumed that the influence of preceding events or prevailing conditions on a particular event under consideration is negligible, or follows simple, easily characterized (from a mathematical perspective) behavior. Under these assumptions, a source term is determined from an essentially linear combination of terms (i.e., parameters) that characterize the events and conditions attributed to the accident progression.

The application of this approach begins by considering an accident progression as a series of events or processes (e.g., a steam explosion) that occur under a set of prevailing conditions (e.g., AACS operating). A simple parametric model that evaluates the source term based on the outcome of these events and a characterization of the prevailing conditions is developed. Only events that affect the source term and conditions that influence release are included.

The source term algorithm development proceeded by answering the following questions:

(1) How will the fission products be grouped?

(2) Where within the confinement can fission products reside?

(3) How will timing; be incorporated into the source term algorithm?

(4) How will fission product transport be modeled?

(5) What input parameters will be used to describe the accident conditions?

(6) How will the known interdependencies between $t$ input parameters be rnodeled?

(7) How will the soirce term be calculated from the input data

\subsubsection{Fission Product Groups}

The major task performed by PRAST is the tracking of the large $r$ "mber of isotopes that exist in an irradiated SRS Reactor core from the dam ged fuel to the environment. Since many fission product isotopes are released and 
transported in a similar fashion, it was logical to classify the isotopes into a limited number of fission product groups.

Ten fission product groups are included in PRAST. These groups are listed in Table 7-2. In this analysis, it is assumed that the in-plant transport of tritium is identical to that of noble gases. Since tritium would be present as water or water vapor (HTO), much of the released tritium would probably be retained, or significantly delayed in escape to the environment. Each of the fission product groups considered has potentially different transport characteristics, so PRAST considers each of the ten groups separately.

Table 7-2. PRAST Fission Product Groups

Group Number

\begin{tabular}{cll} 
Number & Group Name & Constituent Elements \\
\hline \hline 1 & Noble Gas & $\mathrm{Kr}, \mathrm{Xe}$ \\
2 & Iodine & $\mathrm{I}$ \\
3 & Cesium & $\mathrm{Cs}, \mathrm{Rb}$ \\
4 & Tellurium & $\mathrm{Te}, \mathrm{Sb}$ \\
5 & Strontium & $\mathrm{Sr}$ \\
6 & Ruthenium & $\mathrm{Mo}, \mathrm{Tc}, \mathrm{Ru}, \mathrm{Rh}$ \\
7 & Lanthanum & $\mathrm{Y}, \mathrm{Zr}, \mathrm{Nb}, \mathrm{La}, \mathrm{Pr}, \mathrm{Nd}, \mathrm{Am}, \mathrm{Cm}$ \\
8 & Cerium & $\mathrm{Ce}, \mathrm{Np}, \mathrm{Pu}$ \\
9 & Barium & $\mathrm{Ba}$ \\
10 & Tritium & $3 \mathrm{H}$
\end{tabular}

The radionuclides in the second fission product group, iodine, are released as elemental iodine and cesium iodide. Since the transport characteristics of elemental iodine and cesium iodide differ greatly, an eleventh fission product group which represents cesium iodide is created within PRAST. The elemental iodine is released and transported as iodine, however, the cesium iodide is released as iodine and transported as cesium (i.e., the decontamination factor (DF) of vessel water applied to iodide is equal to the DF that is applied to cesium). Thus, each of the release fraction and decontamination factor parameters in the algorithm has eleven values. The release fractions are calculated for each group separately. Eleven sets of equations are solved to predict the release fractions in PRAST. There is no similar situation with transfer fractions (i.e., the fraction of radionuclides that bypass confinement) since a single transfer fraction is applied to all radionuclides for each transfer. (See Section 7.2.4 for the definition of 
release fractions, decontamination factors, and transfer fractions.) The release fractions of elemental iodine and cesium iodide are recombined before the results are written to the output file. The reason for recombining the eleventh group with the second group is that consequences from cesium iodide do not significantly differ with those of elemental iodine. In addition, including an additional element group would significantly increase the computational time required in the remaining steps of the PSA quantification process.

\subsubsection{Fission Producl Reservoirs}

The water in the reactor vessel and the confinement, as well as the reactor vessel and confinement structures themselves, are known to decontaminate airborne fission products that have been released from damaged fuel. In order to apply decontamination factors (DFs) for these potential reservoirs, the mass of fission products being affected by a particular decontaminator must be known. The system developed for the XSOR codes under the NUREG-1150 program identified locations where fission products could reside under accident conditions. PRAST was developed in a similar manner.

PRAST considers the fuel, the reactor vessel and the confinement system as a series of reservoirs that may contain fission products. There are a total of twelve fission product reservoirs in PRAST including the environment. Figure 7-1 gives a representation of the fission product reservoirs. It may be observed that the core is represented three times: (1) damaged fuel in the vessel; (2) core debris on the bottom of the vessel; and (3) core debris on the confinement floor. These three locations are considered one reservoir since all three are the remains of the core and the three never exist in the same time period. Transport of fission products from one reservoir to another is determined by the algorithm. Fission products that are transported out of the confinement reservoirs are assumed to be released to the environment, and therefore constitute the source term.

\subsubsection{PRAST Time Periods}

To simplify developrnent of the source term algorithm, the accident progression was divided into five separate time periods (shown in Tarle 7-3) that correspond to the last five of the six APET phases desc ad in Section 4. In the APIST modeling, the initial period of the ear. hase considers melt initiation and primary system thermal-hydraulics up the point of fuel melting. Fission product release has not begun at this poi so this time period is not modeled in PRAST. The specific time per ds considered in PRAST were:

(1) Core Meltdown begins with clad blistering (fission gas release) and ends when fuel debris has collected on the vessel bottom (corresponding to the second period of the APET early phase). 


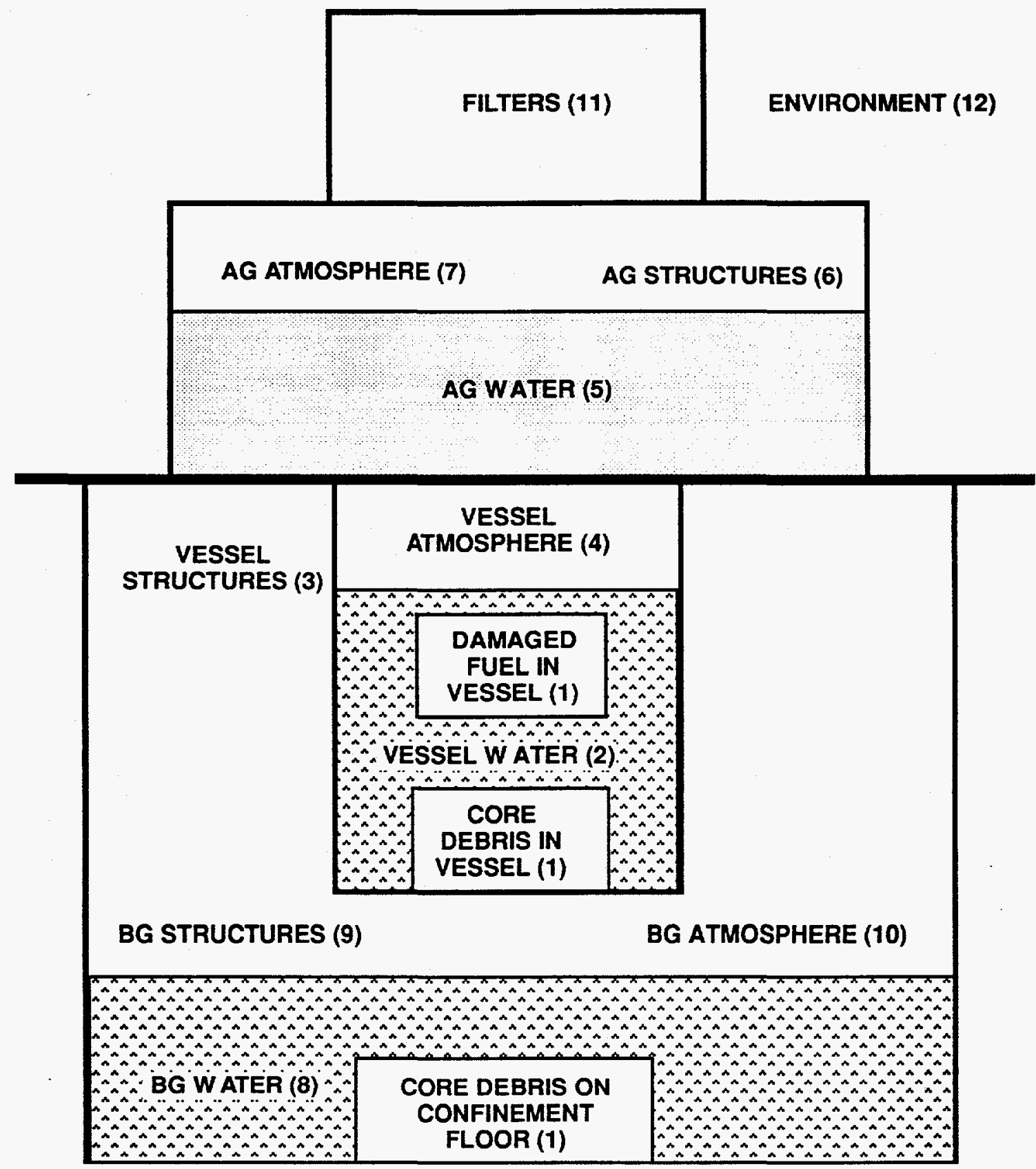

AG - Above Grade

BG - Below Grade

Figure 7-1. PRAST Fission Product Reservoirs 
Table 7-3. PRAST Time Period Definitions

\begin{tabular}{cll}
$\begin{array}{c}\text { Period } \\
\text { Number }\end{array}$ & Period Title & Period Duration Definitions \\
\hline 1 & Core Meltdown & $\begin{array}{l}\text { Normal Meltdown } \\
\text { Recriticality Vessel Failure } \\
\text { Power Excursion Vessel Failure } \\
\text { Energetic Vessel Failure } \\
\text { Early Vessel Failure (pipe steam } \\
\text { explosion) } \\
\text { Thermal Vessel Failure }\end{array}$ \\
2 & Debris Heat-Up & $\begin{array}{l}\text { Energetic Event Occurs } \\
\text { No Energetic Events }\end{array}$ \\
3 & Vessel Failure & $\begin{array}{l}\text { MCCI } \\
\text { Filter Burn }\end{array}$ \\
4 & Core-Concrete Interaction & Filter Desorption \\
& & Filter Burn \\
Iodine Revolatilization
\end{tabular}

(2) Debris Heat-Up begins with the heat-up of the debris on the vessel bottom and ends with primary system failure or permanent cooling of the debris (corresponding to the third period of the APET early phase).

(3) Vessel Failure considers the phenomena that accompany primary system failure (corresponding to the APET intermediate phase);

(4) Core-Concrete Interaction begins at primary system failure and extends over the time that the core debris interacts with the concrete basemat. Revolatilization from confinement structures and confinement water (due to water boil-off) may occur (corresponding to the APET late phase).

(5) Delayed Releases covers the period following core-concrete interaction during which filter combustion (due to exhaust fan failure) or revolatilization of fission products absorbed in water 
and discharged from the building may occur (corresponding to the APET long-term phase).

Time periods may be dropped from consideration or modified based on events that occur during the accident progression. Possible alterations in the time period sequence are as follows:

(1) Vessel bottom failure during core meltdown or cooling of the core debris on the vessel bottom leads to the elimination of Time Period 2.

(2) Non-energetic primary system failure (i.e., primary system failure neither caused nor accompanied by a steam explosion) eliminates Time Period 3, since the primary system failure is not accompanied by a sharp increase in fission product releases from the damaged fuel.

(3) Cooling of the core debris in the reactor vessel eliminates Time Periods 3 and 4.

(4) Cooling of the core debris in the below-grade confinement eliminates the releases from core-concrete interaction in Time Period 4.

(5) Filter failure or combustion during the accident progression (i.e., through the time core-concrete interaction is terminated) eliminates Time Period 5. This time period is also eliminated if filter combustion never occurs.

Fission products in a reservoir at the end of one time period were considered to be present in that reservoir at the start of the next time period with two exceptions. Fission products in the vessel water during Period 3 were transferred to the water on the confinement floor. Similarly, fission products in the vessel atmosphere during Period 3 were transferred to the above grade confinement atmosphere. Primary system failure was simulated in this manner.

\subsubsection{Fission Product Transport}

The classes of parameters used to describe the transport of fission products are release fractions, decontamination factors, and transfer fractions. A release fraction is simply the fraction of a radionuclide that is released from a fission product reservoir (e.g., the fuel) during a given time period. A decontamination factor is the ratio of the fission product mass that enters a reservoir to the mass that exits the same reservoir in a given time period. A transfer fraction is the fraction of fission product mass that moves from one reservoir to another reservoir in a given time period.

PRAST tracks the release of fission products from fuel, structural surfaces, and contaminated water. In a postulated severe accident, fission products 
could be released to the confinement atmosphere from fuel during (1) initial meltdown; (2) heat up on the bottom of the vessel; (3) steam explosions; and (4) molten core concrete interactions. Revolatilization of fission products deposited on primary and confinement structural surfaces and in water (in-vessel and ex-vessel) may also contribute to the radionuclides in the confinement atmosphere. PRAST also tracks the effects of the decontamination factors of structural surfaces and overlying contaminated water on the airborne fission products releases. In a postulated severe accident, fission products could plate out on structural surfaces or be trapped in a pool of overlying water (i.e., water overlying MCCI). In addition to release and decontamination, PRAST tracks the fission product transfer between various fission product reservoirs. Fission product movement within the confinement for each of the five time periods modeled within PRAST is shown schematically in Figures 7-2 through 7-6.

\subsubsection{Input Parameters}

The parameters used in the evaluation of each source term bin are selected on the basis of the attributes associated with that bin. PRAST reads the definition of a source term bin as the combination of the attributes that define it. The definition is used by the code to assign values to the variables used in the source term algorithm. Each of the 16 dimensions listed in Table 7-1 corresponds to either a value or set of values for one or more of the parameters listed in Table 7-4. Each attribute within a dimension corresponds to a particular value for the associated parameter(s). The parameter values input to the PRAST code are documented in [7-5].

\subsubsection{Parameter Interdependence}

During design of the algorithm, the time periods, fission product locations and fission products transfers were chosen to include the most important processes that effect fission product release. If all the fission product transfers were phenomenologically independent of one another, the user could separately determine each input parameter, and the results of PRAST for a given accident scenario would be equivalent to that of an integrated whole-accident mechanistic simulation. For most of the fission products transfers, it is assumed that there is little or no interdependence. For example, it is highly unlikely that the release fraction during in-vessel fuel heat-up is dependent on the release fraction from the filters due to filter burning during Period 4. Several transfers, however, are clearly dependent on common phenomena. The in-vessel decontamination factor for the vessel walls and for the vessel water are both dependent on the presence or absence of water in the vessel. Similarly, the decontamination factor of the above-grade confinement walls and the decontamination factor for the sprays are both dependent on whether the sprays are on. These interdependencies are accounted for in the source term algorithm. 


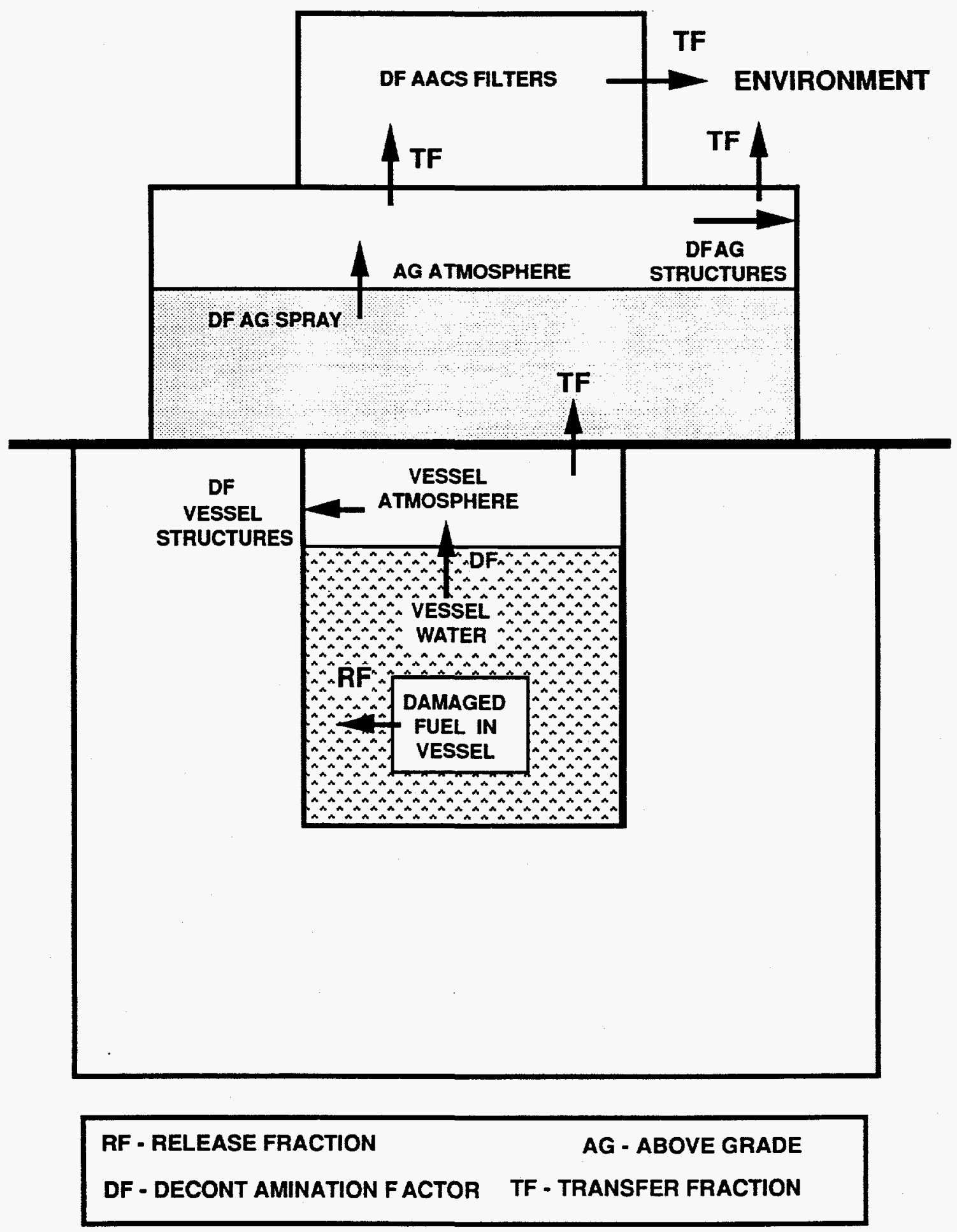

Figure 7-2. Fission Product Transfers During Core Meltdown (Period 1) 


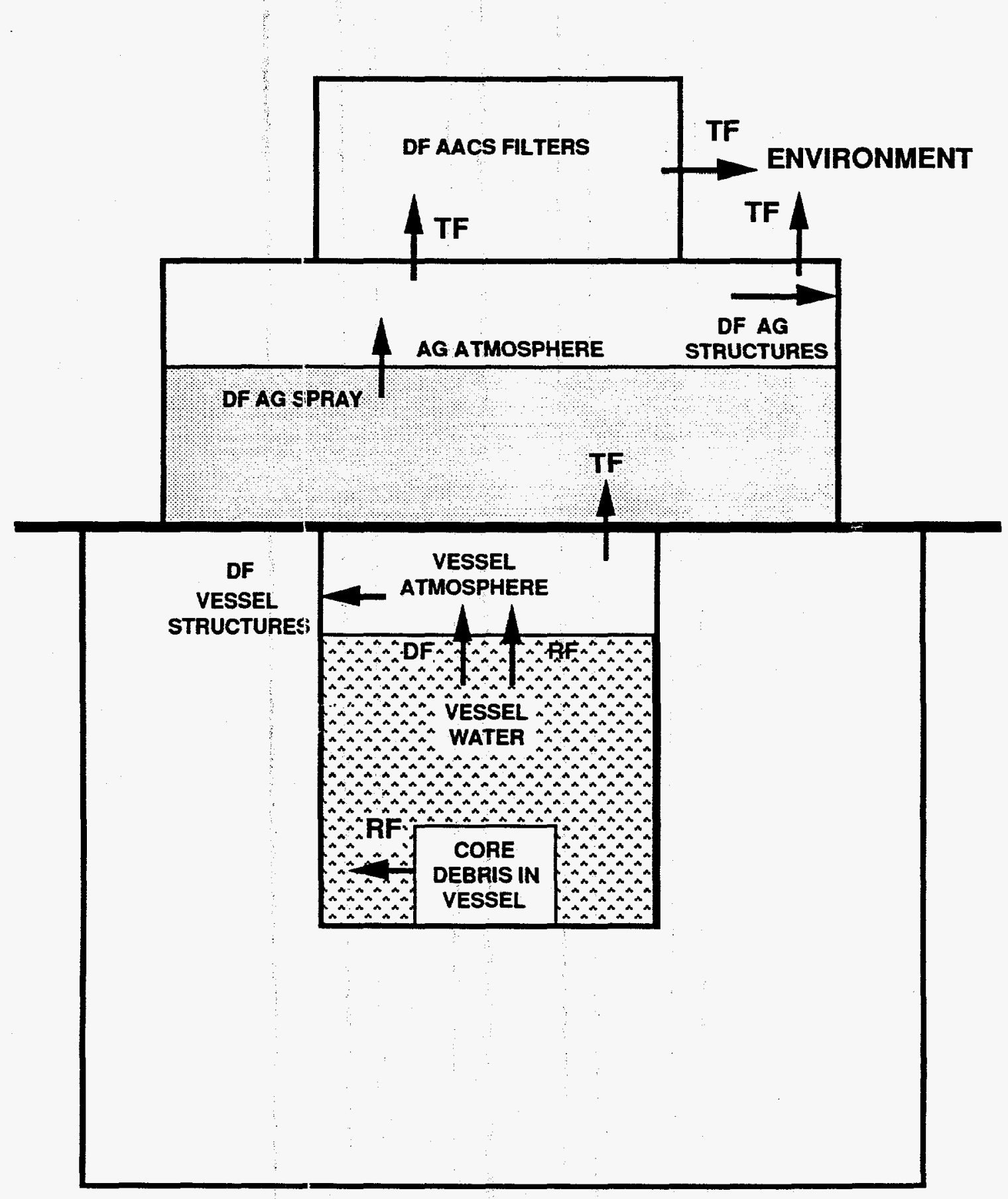

$\begin{array}{lr}\text { RF - RELEASE FRACTION } & \text { AG - ABOVE GRADE } \\ \text { DF - DECONT AMINATION F ACTOR } & \text { TF - TRANSFER FRACTION }\end{array}$

Figure 7-3. Fission Product Transfers During Debris Heat Up (Period 2) 


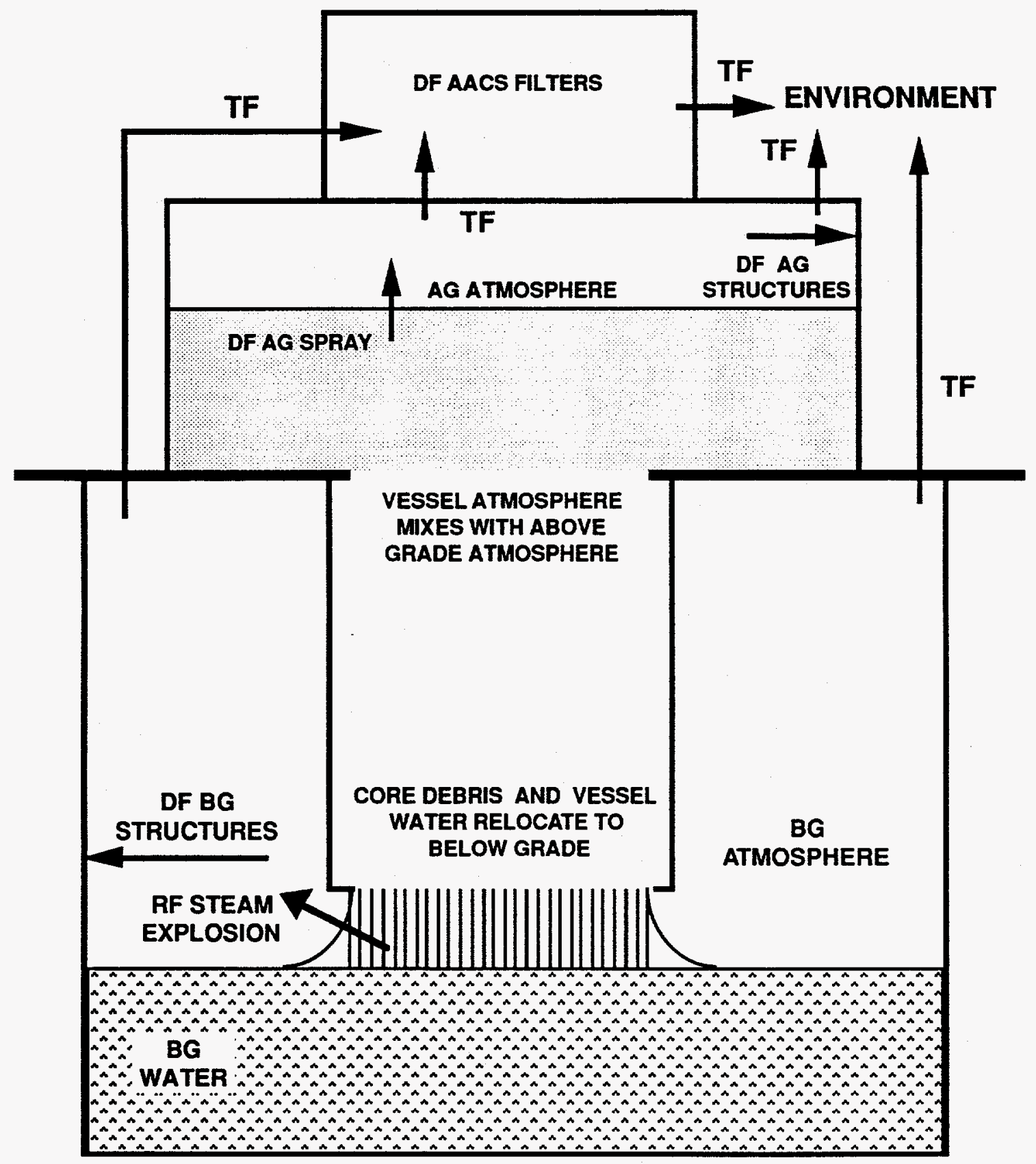

RF - RELEASE FRACTION

AG - ABOVE GRADE

DF - DECONT AMINATION F ACTOR

BG - BELOW GRADE

TF - TRANSFER FRACTION

Figure 7-4. Fission Product Transfers During Vessel Failure (Period 3) 


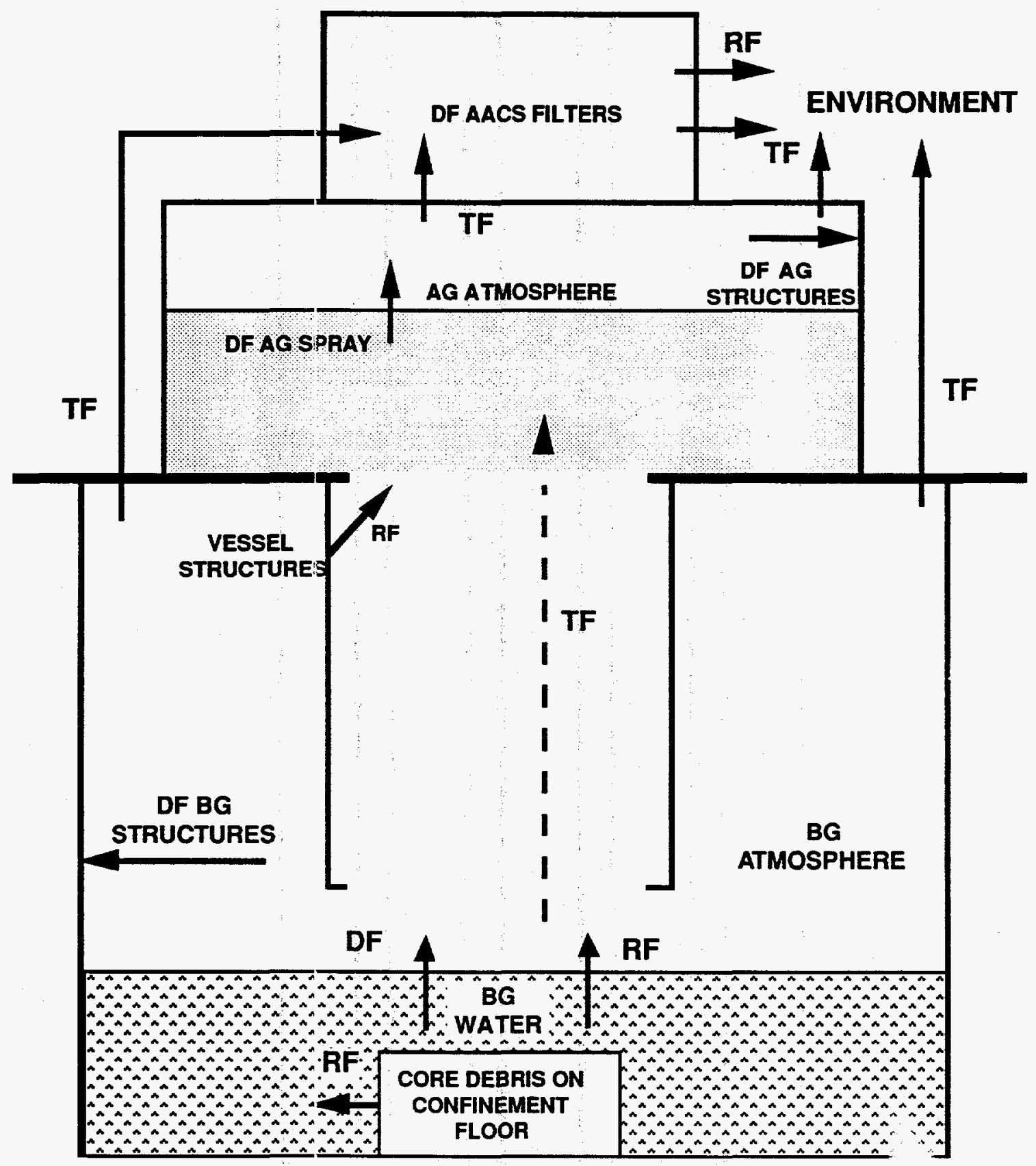

\begin{tabular}{|ll}
\hline RF - RELEASE FRACTION & AG - ABOVE GRADE \\
DF - DECONT AMINATION F ACTOR & BG - BELOW GRADE \\
TF - TRANSFER FRACTION & \\
\hline
\end{tabular}

Figure 7-5. Fission Product Transfers During MCCI (Period 4) 


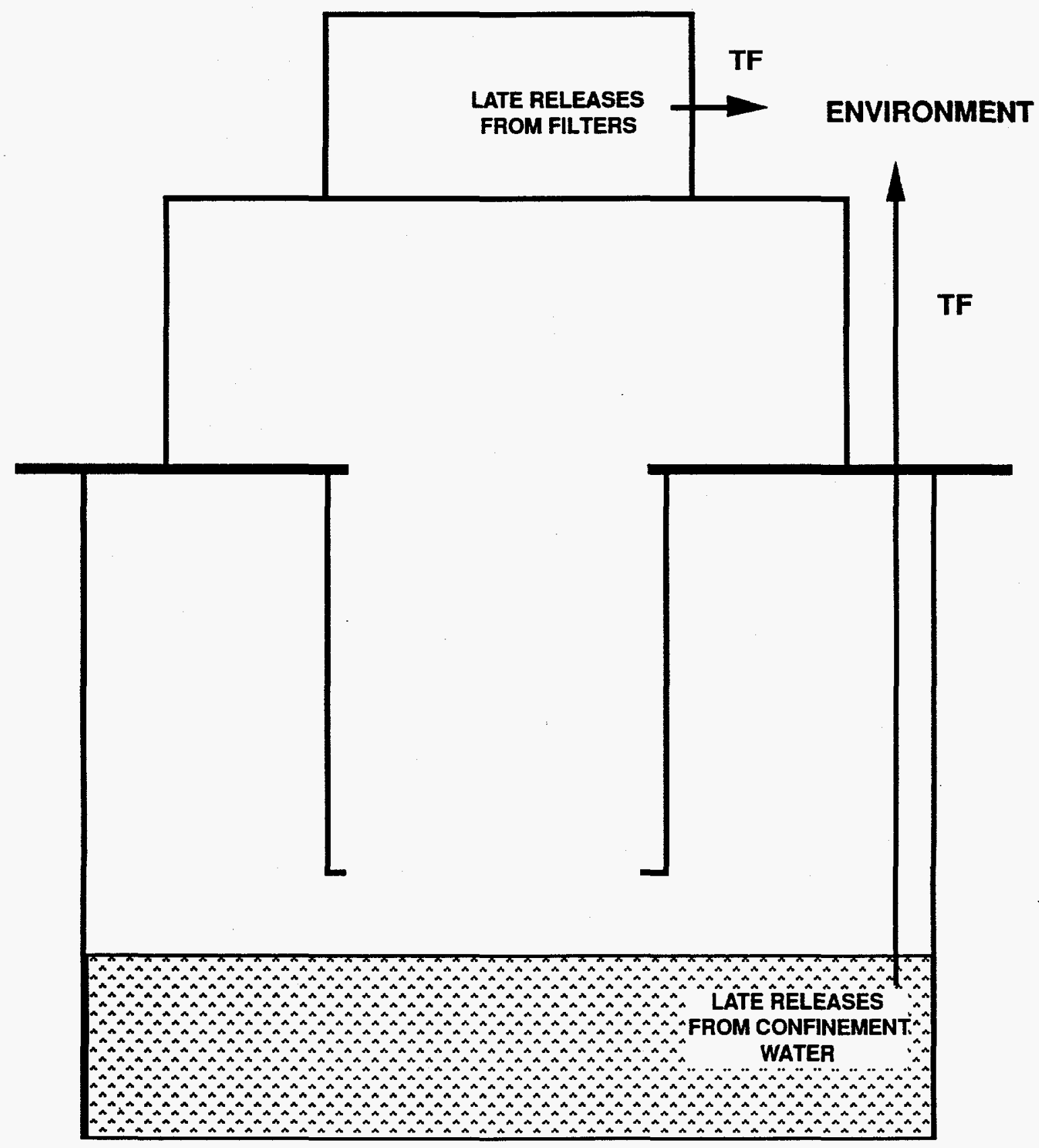

Figure 7-6. Fission Product Transfers During Delayed Releases (Period 5) 
Table 7-4. Source Term Parameter Definitions

\section{Variable Description}

Name

TRELSE Time after scram at which release begins

VERF Release from fuel of radionuclides during fuel degradation

DFIVW Decontanination factor (DF) for the vessel water

DFIV Decontanaination factor (DF) for the vessel structures

ECDF Decontamination factor (DF) for the above-grade confinement structures

ECDFMN Minimum decontamination factor (DF) for the above-grade confinement structure when sprays are operating

FRACFL Fraction of the release that exits the building during the early phase

ESPDF Decontamination factor for sprays

EBYP Fraction of release that bypasses the filters when the energetic event at vessel breach causes a breach of the confinement building

ERF Release of radionuclides from fuel during fuel heat-up

LRF Release from fuel of radionuclides due to molten coreconcrete interaction (MCCI)

CCIDF Decontanination factor for water overlying MCCI

VRF Revolatilization release from primary system surfaces following primary system failure

LCDF Decontarnination factor for the below-grade confinement system for late releases

LBYP Fraction that bypasses the filters during the late phase

LFTRF Late release fraction of radionuclides from filters due to thermal degradation 
Table 7-4. Source Term Parameter Definitions (Continued)

\begin{tabular}{|c|c|}
\hline $\begin{array}{l}\text { Variable } \\
\text { Name }\end{array}$ & Description \\
\hline TPERD1 & Duration of Period 1 \\
\hline TPERD2 & Duration of Period 2 \\
\hline TPERD3 & Duration of Period 3 \\
\hline TPERD4 & Duration of Period 4 \\
\hline TPRED5 & Duration of Period 5 \\
\hline ELEV & Possible elevations for radionuclide release \\
\hline HEATR & $\begin{array}{l}\text { Possible gas sensible heat accompanying radionuclide } \\
\text { release }\end{array}$ \\
\hline VLRF & $\begin{array}{l}\text { Late revolatilization release of radionuclides from } \\
\text { contaminated water }\end{array}$ \\
\hline FLTDF & $\begin{array}{l}\text { Effective decontamination factor for filters, includes nominal } \\
\text { bypass }\end{array}$ \\
\hline RFSTMX & $\begin{array}{l}\text { Release from fuel of radionuclides that occurs during a } \\
\text { whole-core steam explosion at vessel breach }\end{array}$ \\
\hline MBYP & $\begin{array}{l}\text { Fraction of release that by-passes the filters when an } \\
\text { energetic vessel breach does not fail the confinement building }\end{array}$ \\
\hline FI2 & Fraction of iodine released that is elemental iodine \\
\hline
\end{tabular}

\subsubsection{Calculation of Source Terms}

The source term for a particular accident progression can be determined by substituting the set of parameter values for that progression into the parametric model expression(s) and evaluating them. The expressions that constitute the parametric model do not vary according to the accident progression under consideration. The calculation of all the source terms in the PSA analysis requires only that substitution of the appropriate parameter values be made and the model expressions be evaluated. This substitution and evaluation process is automated, allowing for rapid and 
efficient source term estimation. The need to accommodate uncertainty analysis is provided by allowing the actual parameter values that correspond to a particular event outcome, or which characterize a specific range for a condition, to vary.

\subsection{Grouping of Solurce Terms}

The number of unique source term bins that are produced during this analysis is over 10,000. Furthermore, the use of LHS sampling to propagate uncertainties through the source term calculations results in a very large number of source terms (approximately 200,000) that are calculated by PRAST. Since it would be impractical to calculate the consequences for each source term individually, the PARTITION code [7-6] was utilized to group the source terms into a set of partitions. The result of the partitioning process is a binning of the source terms on the basis of three dimensions: early fatality potential, chronic fatality potential, and evacuation timing with respect to the start of the radiological release. The source terms in the current analysis were grouped into approximately 60 partitions. Consequence calculations were then performed for each of these partitions as discussed in Section 8.

\subsection{References}

7-1. Reactor Safety Study-AN Assessment of Accident Risks in U.S. Commercial Nuclear Power Plants, USNRC Report WASH-1400, NUREG-75/014, 1975.

7-2. S. J. Higgins, A Users Manual for the Postprocessing Program PSTEVNT, NUREG/CR-5380 SAND88-2988, Sandia National Laboratories, Albuquerque, NM, 1989.

7-3. Severe Accident Risks: An Assessment for Five U. S. Nuclear Power Plants, NUREG-1150, Vol. 1 Sandia National Laboratories, Albuquerque, NM, 1990.

7-4 D. P. Kearnaghan, The Production Reactor Algorithm for Source Terms (PRAS1), A Computer Code Used in Estimating Source Terms for SRS Reactors, WSRC-RP-92-700, Westinghouse Savannah River Company, Aiken, SC, September 1992.

7-5 D. P. Kearnaghan, Input to the PRAST Computer Code as used in the SRS Probabilistic Risk Assessment, WSRC-RP-92-973, Westinghouse Savannah River Company, Aiken, SC, October 1992.

7-6. R. L. Iman, FARTITION: A Program for Defining Source Term/Consequence Analysis Interface in the NUREG-1150 Probabilistic Risk Assessments. U.S. Nuclear Regulatory Commission Report NUREG/CR-5253, SAND88-2940 RG, Sandia National Laboratories, Albuquerque, NM, 1990. 


\subsection{CONSEQUENCE ANALYSIS}

The purpose of this section is to describe the methods used to calculate consequences of hypothetical severe accidents in the SRS K Reactor. Severe accident consequences to both the onsite population (i.e., the SRS work force) and to the general public are computed. Estimated consequences are due to exposure to ionizing radiation and are presented as health effects incurred by the receptor populations. Individual, deterministic calculations predict the dispersal of radioactive material away from its release point, account for the deposition of radionuclides released, and predict the health effects that could occur. The health effects are expressed as the probabilities of injuries, prompt fatalities, and latent (cancer) fatalities. Population doses, i.e. the collective doses incurred by a population in a specific region, are also computed.

The MELCOR Accident Consequence Code System (MACCS) [8-1, 8-2, 8-3] is the primary computer code used for determining consequences of source terms due to hypothetical severe accidents. The code performs a series of deterministic calculation of the consequences to be expected from each source term. Population distributions, agricultural and land descriptions and exposure mitigation models are combined in MACCS with a statistical sampling of site-specific meteorological data to yield consequence output in a probabilistic format.

MACCS Version 1.5.11 from Sandia National Laboratories (SNL) was officially released in 1990 and is used in this analysis. A maintenance version of the MACCS code (1.5.11.1) [8-4] was received in August, 1992. This version corrects errors identified since 1990 and offers updated latent health effects models. It is used here in one sensitivity study.

The MACCS code is described in the following section. Next, key aspects. of the database common to both offsite and onsite analyses are summarized. A discussion of the specific public (offsite) and DOE worker (onsite) calculations then follows. Discussion of the sensitivity studies associated with the baseline model is found in Chapter 10.

\subsection{MACCS Code Description}

The MACCS code was developed for the U.S. Nuclear Regulatory Commission to provide a unified, best-estimate methodology for consequence assessment in commercial nuclear plant PSAs. MACCS is based on the CRAC (Calculation of Reactor Accident $\underline{\text { Consequences) series }}$ of codes developed originally to support severe accident analysis published in the Reactor Safety Study, WASH-1400 [8-5]. Version 1.5 of MACCS supported the calculation of consequences due to assumed severe accidents in two comprehensive severe accident assessments: (1) the Environmental Impact Statement supporting the New Production Reactor design process [8-6], and (2) the NUREG-1150 risk assessment of five commercial plants [8-7]. 
MACCS performs the following series of sequential calculations:

(1) The atmospheric transport of radioactivity away from the release point, dispersion of the plume, and deposition of fission products;

(2) The radiation closes to exposed personnel and offsite populations based on cloudshine, groundshine, inhalation, skin deposition, and food/water ingestion pathways;

(3) Health effects, including early (prompt) fatalities and injuries, and latent (cancer) fatalities, based on the collective population doses; and

(4) Contaminated land area, population relocated, and total economic penalties.

The populations affected by radiological releases may be modeled as participating, non-participating, or partially participating in a countermeasure (dose avoidance) activity. These measures are defined later in this section.

MACCS models the effects of radiological releases to the atmosphere. Other methodology must be applied to calculate the dose and health effects associated with radionuclide release to soil (lithosphere) or to groundwater (hydrosphere).

The basic MACCS input model is a radial-polar coordinate system with the radiological release point defined to be the origin. This coordinate system or grid is configured with sixteen compass sectors to reflect directional dependence. Circular concentric rings overlay the directional grid. The outer radius extends to incorporate the most distant population group of interest. Radial increments are user-specified to capture sufficient resolution for dose determination. In the remaining discussion, a $22.5^{\circ}$ sector of limiting inner and outer radii is referred to as a grid element.

Source terms are input 1sing discrete time internals, or plume segments. Each plume segment is described in MACCS by distinct start time (specified time after shutdown), thermal energy content, duration, and release height specifications. The code models travel of each plume segment beginning at the origin of the coordinate system or grid defined above. MACCS uses an empirical Gaussian model with wind-shift capabilities to calculate transport and dispersion of the radioactivity in the plume. Hourly meteorological data for the release site are used to direct the transport and dispersion of the plume, beginning at the start of the release and lasting until the plume is fully depleted of its initial radioactivity. Typically, each sequence includes 120 hours of meteorology from the sitespecific data base. Vertical plume rise is calculated using a Briggs model. The overall growth of a released plume in vertical and crosswind directions as a function of downwird travel is governed by the geometry of the plume 
and the ambient conditions during the release. In particular, prevailing environmental conditions including the Pasquill-Gifford stability class, wind speed and direction, presence of rainfall, and the vertical zone above the ground available for plume growth ultimately determine the transport and deposition fate of each plume segment. Radionuclides in a plume are subject to removal or depletion by radioactive decay and by response to atmospheric physics. Two mechanisms are modeled for the latter process in MACCS: (1) dry deposition (gravitational settling); and (2) wet deposition (rainfall). As each plume is transported downwind by the MACCS code, the calculation accounts for the ground regions contaminated by the two deposition processes.

Because calculated consequences are strong functions of the weather at the time of release, probability distributions are used to represent the statistical variability of seasonal and meteorological patterns occurring during the accident. MACCS models the variability by repeating the calculation for hundreds of site-specific weather sequences. The sequences are statistically selected by a limited Latin Hypercube Sampling (LHS) or a Stratified Random Sampling process of site-specific meteorological data. In a typical analysis, the LHS approach bins a year's worth of hourly meteorology into defined meteorological bins. The bins are defined by similar stability class, wind speed, and rainfall intensity characteristics. Once the binning is complete, the code then randomly selects several start times from each bin for the hypothetical radioactivity release. Each start time marks the beginning of a weather trial consisting of 120 hours of sequential hourly data. The source term release is "repeated" until all selected start times from the bin are processed. The process is repeated until each bin is processed.

To develop a statistically sufficient number of sequences to achieve a distribution representative of the site's annual meteorological conditions, the MACCS analyst must elect a weather sequence rotation option. Under this option, each set of meteorological modeling results is rotated through sixteen $\left(22.5^{\circ}\right)$ compass directions. Thus, each weather trial yields sixteen sets of results. The results are weighed by the wind rose probability for the compass direction (fraction of the time the wind blows toward the direction), for each meteorological bin.

The Stratified Random Sampling approach may also be used in PSA applications. This approach is different than LHS in that a day of the year rather than a meteorological category constitutes a bin. Sampling is based on randomly selecting several start times per day, and then processing all 365 days in a year. The rotation process may or may not be elected in the Stratified Random Sampling process and is applied in the same manner as a LHS selected trial.

Once the plume's radioactivity has been dispersed via the Gaussian model, doses are incurred by populations by exposure to one or more "pathways". These include cloudshine, groundshine, inhalation, and food/water ingestion. Radiological doses are computed for a set of target organs based 
on evaluation of contributing exposure pathways. The target organs included in MACCS are the stomach, small intestine, lungs, red marrow, thyroid, lower large intestine, bone surface, breast, testes, ovaries, and Effective Dose Equivalent (EDE) whole-body. The maintenance version 1.5.11.1 of the MACCS code also treats adrenals, bladder wall, kidneys, liver, pancreas, spleen, and thymus organs. EDE whole-body dose is the weighted average of the dose to certain organs, with weights determined by the stochastic risk factors for the generation of fatal cancers associated with the respective organs. Radionuclide-specific dose conversion factors (DCFs) indicating the absorbed dose per specified time interval from a given pathway, are required to complete the computation. The MACCS DCFs are based on recommendations by the ICRP [8-8] and the Department of Energy's Office of Environment, Safety, and Health [8-9, 8-10].

After a user-specified seven-day emergency period, a long-term or chronic phase is modeled in MACCS. MACCS calculates chronic phase doses due principally to food and water ingestion of a subset of the isotopes considered. Expanded food chain models are being furnished by Idaho National Engineering Laboratory for SNL updates to MACCS. The food ingestion isotopes are ${ }^{89} \mathrm{Sr},{ }^{90} \mathrm{Sr},{ }^{134} \mathrm{Cs},{ }^{137} \mathrm{Cs},{ }^{131} \mathrm{I}$, and ${ }^{133} \mathrm{I}$. The water ingestion isotopes considered are ${ }^{89} \mathrm{Sr},{ }^{90} \mathrm{Sr},{ }^{134} \mathrm{Cs},{ }^{137} \mathrm{Cs}$, and ${ }^{3} \mathrm{H}$. The water pathway doses account for material deposited on: (1) potable water bodies; or (2) land, with subsequent run-off into consumable water.

Tritium dose conversion clata have been added to MACCS by WSRC. These data account for tritium close to target organs via cloudshine, groundshine, inhalation, and water ingestion. However, the principal pathway for tritium dose over periods greater than the initial ( $\sim 7$ days) emergency phase of a given accident, food ingestion, is not part of the current MACCS model. Long-term uptake of tritium from the food chain has been assessed through standalone calculations using the FUSCRAC3 code. FUSCRAC3 is a FUSion-based code for Calculation of Reactor Accident Consequences that has the capability to handle a tritium source term and to provide a probabilistic treatment of site-specific meteorology. FUSCRAC was originally developed at the Massachusetts Institute of Technology by Piet [8-11] and subsequently upgraded as FUSCRAC3 at the Idaho National Engineering Laboratory [8-12, 8-13]. Analysis of long-term tritium uptake in the food chain due to accidental release of the tritium inven "y is summarized in Section 10.0.

Health effects are estimated in the MACCS analysis based on the get organ doses. The health effects include short- and long-term. The _ rt term effects are radiation exposure-induced fatalities and inje: $s$ occurring within about one year of the release. These are due to relati, $r$ short-duration, high-dose exposures. The long-term effects (canc : fatalities and injuries) are incurred because of exposure in both the ea $y$ and long-term phases after the accident. Although some cancers mi.y appear within five years of the time of exposure, the majority of cancerrelated fatalities would be manifest over a much longer time frame. Models 
to predict health effects in MACCS resulting from NRC-sponsored research are based on recommendations by the School of Public Health at Harvard and the Inhalation Toxicology Research Institute [8-14, 8-15].

Early or prompt fatalities are those deaths predicted in the emergency phase of a reactor accident from large, lethal radiological doses. The prompt fatality consequence model is based on consideration of dose to three organs (red bone marrow, lung, and lower large intestine). MACCS uses a dose threshold model to predict prompt fatalities for these organs of $1.5 \mathrm{~Sv}$ $(150 \mathrm{rem}), 5.0 \mathrm{~Sv}(500 \mathrm{rem})$, and $8.0 \mathrm{~Sv}(800 \mathrm{rem})$, respectively. MACCS allows the consequence analyst to defined a prompt fatality type as long as it is based on one of target organs defined in the DCF data base. If the dose to one of these organs is below the organ's threshold dose, then acute fatalities are not predicted. Instead, injuries may be predicted or the dose may accumulate towards the prediction of latent fatalities.

Radiation-induced injuries are predicted by MACCS with mathematical models similar to the prompt fatality measures of consequence. Again, the MACCS user must define the types of injuries to be predicted based on target organ dose accumulation. Illustrative of the injury types with target organs included in a PSA application are hypothyroidism (thyroid), thyroiditis (thyroid), skin erythema (skin), transepidermal injury (skin), diarrhea (stomach), prodromal vomiting (stomach), and pneumonitis (lungs) [8-1].

The latent (cancer) fatality estimates in MACCS consider leukemia, bone, breast, lung, gastrointestinal, thyroid, and other organ types (reflecting combined risks of multiple myeloma, lymphoma, and cancers of the bladder, kidney, brain, ovary, uterus, and cervix). The MACCS 1.5 models are based on the central estimate models discussed in the NUREG/CR-4214 Rev. 1 reports for reactor accident radiation exposures. The current MACCS assessment for latent fatalities reflect the BEIR-III [8-16] estimates of latent fatalities in its model parameters. The models for cancer fatalities are non-threshold. During the emergency phase, a linear-quadratic dependence is used to predict cancer fatality risk for target organ doses below a threshold of $1.5 \mathrm{~Sv}$ (150 rem). For doses greater than $1.5 \mathrm{~Sv}$ in the emergency phase, an upper bound linear fit is employed. In the chronic phase, a linear model reflecting a low-dose and low dose rate effect is implemented by MACCS.

The BEIR-V report was issued early in 1990 by the National Research Council [8-17]. Review of the BEIR V findings and considerations of other data by Abrahamson et al. [8-15] have led to MACCS latent health effect modification. The maintenance version 1.5.11.1 of MACCS has capabilities to model the revised risk estimators for cancer as part of an overall consequence assessment. Not only are risk factors increased per the arguments contained in Ref. 8-14, but the non-linear dose response function has been replaced in MACCS with a piecewise linear function that is continuous. Two equations for latent health effect risk, $R(D)$, as a function of dose may be implemented: 


$$
\begin{array}{ll}
R(D)=\quad \alpha \cdot D ; & \text { "High Exposures" } \\
R(D)=\quad \alpha \cdot D / D D R E F ; & \text { "Low Exposures" }
\end{array}
$$

where $\alpha$ is a parameter, $\mathrm{D}$ represents incurred dose, and DDREF is a "dose and dose rate reduction factor." A "Low Exposures" condition is interpreted for total dose less than 0.2 Gray (20.0 rads) and for higher doses when the dose rate is less than 0.1 Gray per hour ( $10 \mathrm{rad} /$ hour).

Sensitivity Studies using the new BEIR-V-based health effects models are discussed in Section 10.

Calculation of the individual latent fatality risk is necessary to compare against safety measures, e.g. the DOE Safety Goals [8-18]. The reference population is usually defined to be residing in a specified region within some radius of the reactor. The calculation is performed by utilizing the population-weighted risk result option in the MACCS. The individual latent risk is a measure of the risk from direct exposure to the resident population. Pathways included are cloudshine, groundshine, direct inhalation, and resusperssion inhalation. In MACCS, a determination is made of the expected latent deaths to occur over a period of one million years based on the population assumed present at the time of the assumed accident. This quantity is divided by the current resident population to yield the individual latent risk.

Total cancer fatalities calculated by MACCS in a population group include both direct and indirect exposure. The latter include contaminated food and water ingestion and doses to decontamination workers in the affected area.

Consequences may be computed for emergency, intermediate, and chronic phases following the assumed release of radioactivity in MACCS. However, for this PSA application, only two phases of each accident are considered, after the format contained in NUREG-1150 [8-7]. In either phase, the resident population may be modeled as avoiding full potential dose by using criteria for relocation of populations prescribed by cognizant federal agencies (viz. U.S. EPA, Department of Health and Human Services, or the Federal Emergency Management Agency). The MACCS analyst may set projected dose criteria to limit accumulated doses over a time ame. Populations projected to receive the limiting doses are moved or $r$ ated from affected grid elements by the code until ambient dose exposu. fall under the user-prescribed criteria. Relocation of population on rid element downwind from the release point is based on a reference orgar; $\mathrm{ld}$ projected dose criteria. MACCS does not account for dose received a population group is relocated.

The first phase considered is an emergency phase. This phase begins n the radiological release and lasts for seven days from the arrival of the fi:st plume segment in a given grid element. During the emergency phase, external radiation from the radioactive plume passage (cloudshine), 
and internal radiation from inhalation of radionuclides from the plume and from resuspended material originally deposited on the ground (after plume passage) are considered.

The second phase is a chronic or long-term phase. It lasts for five years following the end of the emergency phase. In the chronic phase, external exposure groundshine is again considered as is the internal inhalation exposure pathway due to resuspended material. However, additional pathways are due to ingestion and include:

(1) directly contaminated crops and milk;

(2) crop and meat foodstuffs grown on contaminated land; and

(3) contaminated water.

MACCS considers contaminated crop and meat foodstuffs from two mechanisms. First, crops may be directly contaminated from wet and dry deposition. Secondly, crops may be contaminated in years following the assumed accident by root uptake of radioactivity from the soil.

MACCS models each of these phenomena with either a stationary distribution of population or one that may be at least partially engaged in a coordinated effort to avoid doses. Exposures in either the emergency phase or chronic time periods are reduced or eliminated entirely through coordinated emergency response and long-term counter-measure activities. The emergency-phase response models in MACCS include evacuation and sheltering. Implicit in both actions is that populations would be advised of an impending release and would act based on directives from local and state officials. Evacuation in MACCS moves populations located in specific concentric rings in the grid radially outward. A starting time, radial evacuation speed, and percentage of the population assumed to participate are user-prescribed parameters for the evacuation. Once the evacuees reach a user-set outer radius, the assumption that they are no longer subject to any additional doses during the emergency phase of the accident.

Relocation may be modeled in both emergency and chronic phases. In this strategy, people are moved from contaminated regions to unaffected locations based on projected doses. Long-term counter-measure models assume more deliberate actions. Decontamination of land and property to permit continued use, or temporary or permanent interdiction (condemnation) of highly contaminated land, property, and foodstuffs that cannot be effectively or economically decontaminated are included in the analyses.

Dose reduction through any mitigation is implemented by MACCS with the assignment of sets of shielding factors by the user. Shielding factors account for the presence of shielding between the receptor population in a grid element and the source of the radiation (cloudshine, groundshine), or active systems to filter breathable air (ventilation fan control or the wearing of filtering masks). Three receptor populations which exist in the MACCS framework are described by three sets dose reduction factors: those who 
conduct normal activities, those evacuating by vehicle transport, and those actively taking shelter.

The results of the consequence analysis are given by a conditional complementary cumulative distribution function format, whereby the conditional probability of exceeding a level of consequence is plotted as a function of the magnitude of the consequences. A typical curve shows the conditional exceedance probability versus number of consequences, and would range from a high conditional probability/low consequence portion to a low probability-high corsequence portion.

Greater detail on the MACCS structure and models may be found in the supporting User's Guide, Model Description, and Programmer's Reference Manual [8-1, 8-2, 8-4]. The Idaho National Engineering Laboratory has completed an independent quality assurance and verification review of MACCS 1.5 for the NRC [3-17].

\subsection{Application to the SRS K-Reactor PSA}

The consequence analysis code described in Section 8.1 is combined with SRS-specific input data and parameters to determine estimates of consequences associated with hypothetical reactor accidents. This section will outline the input used. A more detailed description is found elsewhere [8-20].

Source terms for input to MACCS are due to either external (e.g. seismic) or internal (in-plant initiators) events. The K-Reactor inventory of radionuclides potentially available for release is the same for internal and external initiating events. The inventory is calculated using the GLASS depletion module executed under the SHIELD system [8-21]. A nominal Mark 22 assembly operation and an end-of-cycle, full exposure condition are assumed for the analyses [8-22]. A total of sixty-one radionuclides are considered by MACCS, and are binned into ten radionuclide groups. The members of each group are similar by radiological, chemical, and half-life characteristics. The fission product groups and radionuclides considered are shown in Tables 8-1 and 8-2, respectively.

Although many features; of the consequence calculation are the same regardless of the event class, many key aspects must be handled s $r$ arately. The common characteristics and those dependent on the natu - of the initiating event shall be described.

Both offsite and onsite consequences are calculated for this: -el 3 assessment. Offsite consequences are those incurred by the genera. blic, external to the SRS reservation boundary or while traversing the Sa nah River Site property on a principal state road for traffic between the $\mathrm{Au}_{-}$...sta, Georgia area and coastal South Carolina, viz. SC-125. Onsite conseq ices are defined as those borne by DOE and DOE contractor workers while a the SRS reservation. DOE contractor staff located in North Augusta, Augusta, 
Aiken, and other offsite locations are not considered as onsite. They instead are part of the offsite, general public population group.

Each source term is matched to one of five grids for calculation of consequences. The process is repeated until all five population/site data/emergency response combinations are processed. The five grids and the specific purpose of each are as follows:

(1) A "far-field" offsite grid, extending $1610 \mathrm{~km}$ (1000 miles) from $K$ Reactor, is used to calculate societal consequences. It includes only the general public in the distributed population. Fifty-mile radius ingestion dose consequences, to assess radioiodine, food and water ingestion doses to the ingestion planning zone, are computed in MACCS execution using this grid.

(2) A "near-field" offsite grid is used for determination of societal and individual risks to the general public within the local vicinity of the Site. It extends $40 \mathrm{~km}$ ( 25 miles) from K Reactor but does not include SRS nor land area with the SRS reservation. This grid is used to calculate the radiological impacts to the general public in the immediate vicinity of SRS.

Table 8-1. MACCS Fission Product Groups

Group

Number

Group Name

Constituent Elements

\begin{tabular}{cll}
\hline \hline & & \\
1 & Noble Gas & $\mathrm{Kr}, \mathrm{Xe}$ \\
2 & Iodine & $\mathrm{I}, \mathrm{Cs}, \mathrm{Rb}$ \\
3 & Cesium & $\mathrm{Te}, \mathrm{Sb}$ \\
4 & Tellurium & $\mathrm{Sr}$ \\
5 & Strontium & $\mathrm{Mr}, \mathrm{Tc}, \mathrm{Ru}, \mathrm{Rh}$ \\
6 & Ruthenium & $\mathrm{Y}, \mathrm{Zr}, \mathrm{Nb}, \mathrm{La}, \mathrm{Pr}, \mathrm{Nd}, \mathrm{Am}, \mathrm{Cm}$ \\
7 & Lanthanum & $\mathrm{Ce}, \mathrm{Np}, \mathrm{Pu}$ \\
8 & Cerium & $\mathrm{Ba}$ \\
9 & Barium & ${ }^{3} \mathrm{H}$ \\
10 & Tritium & \\
\hline
\end{tabular}


Table 8-2. SRS Reactor End-of-Cycle Inventory

Core

Isotope Inventory $(\mathrm{Bq})$

\begin{tabular}{rcc} 
& $(\mathrm{Bq})$ & Number \\
\hline $\mathrm{Co}-58$ & $7.109 \mathrm{E}+18$ & 6 \\
$\mathrm{Co}-60$ & $8.510 \mathrm{E}+18$ & 6 \\
$\mathrm{Kr}-85$ & $6.969 \mathrm{E}+15$ & 1 \\
$\mathrm{Kr}-85 \mathrm{M}$ & $1.051 \mathrm{E}+18$ & 1 \\
$\mathrm{Kr}-87$ & $2.041 \mathrm{E}+18$ & 1 \\
$\mathrm{~K}-88$ & $2.872 \mathrm{E}+18$ & 1 \\
$\mathrm{Rb}-86$ & $2.269 \mathrm{E}+15$ & 3 \\
$\mathrm{Sr}-89$ & $3.516 \mathrm{E}+18$ & 5 \\
$\mathrm{Sr}-90$ & $5.685 \mathrm{E}+16$ & 5 \\
$\mathrm{Sr}-91$ & $4.879 \mathrm{E}+18$ & 5 \\
$\mathrm{Sr}-32$ & $4.920 \mathrm{E}+18$ & 7 \\
$\mathrm{Y}-90$ & $5.984 \mathrm{E}+16$ & 7 \\
$\mathrm{Y}-91$ & $4.282 \mathrm{E}+18$ & 7 \\
$\mathrm{Y}-92$ & $4.931 \mathrm{E}+18$ & 7 \\
$\mathrm{Y}-93$ & $5.211 \mathrm{E}+18$ & 7 \\
$\mathrm{Zr}-95$ & $4.513 \mathrm{E}+18$ & 7 \\
$\mathrm{Zr}-97$ & $4.900 \mathrm{E}+18$ & 7 \\
$\mathrm{Nb}-95$ & $3.741 \mathrm{E}+18$ & 7 \\
$\mathrm{Mo}-99$ & $5.068 \mathrm{E}+18$ & 6 \\
$\mathrm{Tc}-99 \mathrm{M}$ & $4.373 \mathrm{E}+18$ & 6 \\
$\mathrm{Ru}-103$ & $2.516 \mathrm{E}+18$ & 6 \\
$\mathrm{Ru}-105$ & $9.053 \mathrm{E}+17$ & 6 \\
$\mathrm{Ru}-106$ & $9.964 \mathrm{E}+16$ & 6 \\
$\mathrm{Rh}-105$ & $7.687 \mathrm{E}+17$ & 6 \\
$\mathrm{Sb}-127$ & $9.457 \mathrm{E}+16$ & 4 \\
$\mathrm{Sb}-129$ & $5.381 \mathrm{E}+17$ & 4 \\
$\mathrm{Te}-127$ & $8.937 \mathrm{E}+16$ & 4 \\
$\mathrm{Te}-127 \mathrm{M}$ & $9.923 \mathrm{E}+15$ & 4 \\
$\mathrm{Te}-129$ & $5.056 \mathrm{E}+17$ & 4 \\
$\mathrm{Te}-129 \mathrm{M}$ & $1.350 \mathrm{E}+17$ & 4 \\
Te-131M & $3.054 \mathrm{E}+17$ & 4 \\
$\mathrm{Te}-132$ & $3.545 \mathrm{E}+18$ & 4 \\
& & \\
\hline
\end{tabular}

Core

\begin{tabular}{|c|c|c|}
\hline Isotope & Inventory & ap \\
\hline
\end{tabular}

\begin{tabular}{|c|c|c|}
\hline I-131 & $2.377 \mathrm{E}+18$ & 2 \\
\hline I-132 & $3.561 \mathrm{E}+18$ & 2 \\
\hline I-133 & $5.621 \mathrm{E}+18$ & 2 \\
\hline I-134 & $6.355 \mathrm{E}+18$ & 2 \\
\hline I-135 & $5.279 \mathrm{E}+18$ & 2 \\
\hline $\mathrm{Xe}-133$ & $5.599 \mathrm{E}+18$ & $\overline{1}$ \\
\hline $\mathrm{Xe}-135$ & $5.192 \mathrm{E}+17$ & 1 \\
\hline Cs-134 & $5.974 \mathrm{E}+16$ & 3 \\
\hline Cs-136 & $2.386 \mathrm{E}+16$ & 3 \\
\hline Cs-137 & $5.652 \mathrm{E}+16$ & 3 \\
\hline Ba-139 & $5.335 \mathrm{E}+18$ & 9 \\
\hline $\mathrm{Ba}-140$ & $5.215 \mathrm{E}+18$ & 9 \\
\hline La-140 & $5.296 \mathrm{E}+18$ & 7 \\
\hline La-141 & $4.902 \mathrm{E}+18$ & 7 \\
\hline La-142 & $4.923 \mathrm{E}+18$ & 7 \\
\hline Ce-141 & $4.758 \mathrm{E}+18$ & 8 \\
\hline $\mathrm{Ce}-143$ & $4.946 \mathrm{E}+18$ & 8 \\
\hline $\mathrm{Ce}-144$ & $1.592 \mathrm{E}+18$ & 8 \\
\hline Pr-143 & $4.880 \mathrm{E}+18$ & 7 \\
\hline Nd-147 & $1.847 \mathrm{E}+18$ & 7 \\
\hline Np-239 & $1.525 \mathrm{E}+18$ & 8 \\
\hline $\mathrm{Pu}-238$ & $1.049 \mathrm{E}+15$ & 8 \\
\hline $\mathrm{Pu}-239$ & $1.021 \mathrm{E}+13$ & 8 \\
\hline $\mathrm{Pu}-240$ & $7.384 \mathrm{E}+12$ & 8 \\
\hline $\mathrm{Pu}-241$ & $2.146 \mathrm{E}+15$ & 8 \\
\hline $\mathrm{Am}-241$ & $3.726 \mathrm{E}+11$ & 7 \\
\hline $\mathrm{Cm}-242$ & $9.235 \mathrm{E}+13$ & 7 \\
\hline $\mathrm{Cm}-244$ & $3.052 \mathrm{E}+12$ & 7 \\
\hline Tritium & $2.590 \mathrm{E}+18$ & 10 \\
\hline
\end{tabular}


(3) An offsite one-mile grid, extends one mile from the SRS boundary for each compass direction. This grid is used to calculate the early fatality likelihood to offsite populations immediately surrounding the SRS.

(4) An onsite grid, extends 20 miles from $\mathrm{K}$ Reactor, in one-mile increments from one to ten miles, then two-mile increments between ten and twenty-two miles. Three radial increments model distribution of onsite workers from zero to one mile. Both individual worker and worker population risks are assessed with this grid.

(5) An onsite one-mile grid, is used to assess individual risk at $1.6 \mathrm{~km}$ (one mile) from $\mathrm{K}$ Reactor. It contains one nonevacuating individual at one mile in each of the sixteen compass sectors.

These grids are shown in Figures 8-1 through 8-6.

For the "far-field" grid alone, a residual radioactivity feature is used in the code execution. Any fission product remnant of the original plume after travel to a radius of 500 miles is gradually depleted over the next 500 miles by using a boundary weather condition. The Savannah River calculations use a specified rain intensity to remove all but the noble gases from the plume.

A listing of the particular collective doses and measures of consequence based on each grid is given in Table 8-3.

MACCS-applicable meteorological data files for K Area for the years 1982 to 1986 inclusive were developed in 1987 by WSRC and consist of hourly information derived from $\mathrm{K}$ Area meteorological tower and Augusta (Bush Field) Airport data [8-23]. For this study, 1986 weather is used; it was shown that execution of MACCS with this year gives mid-range or high results relative to the other four years of hourly data [8-24]. Mixing layer height data is included seasonally in the same datasets and shown in Table 8-4. These heights limit buoyant plume rise and vertical growth for the Gaussian plume model. The offsite MACCS calculations use seasonal afternoon mixing layer heights. The onsite MACCS calculations assume a peak SRS population to be present regardless of the start time for the hypothetical radiological release. Thus, for consistency purposes with the presence of the SRS peak worker levels, the onsite calculations also use afternoon mixing layer heights.

A listing of the general dose mitigation models available in MACCS is given in Table 8-5. A notation is made under "offsite" and "onsite" population headings to indicate if the model is implemented for either offsite or onsite consequence analysis supporting this PSA. Specific details for these models are covered in the following section. 


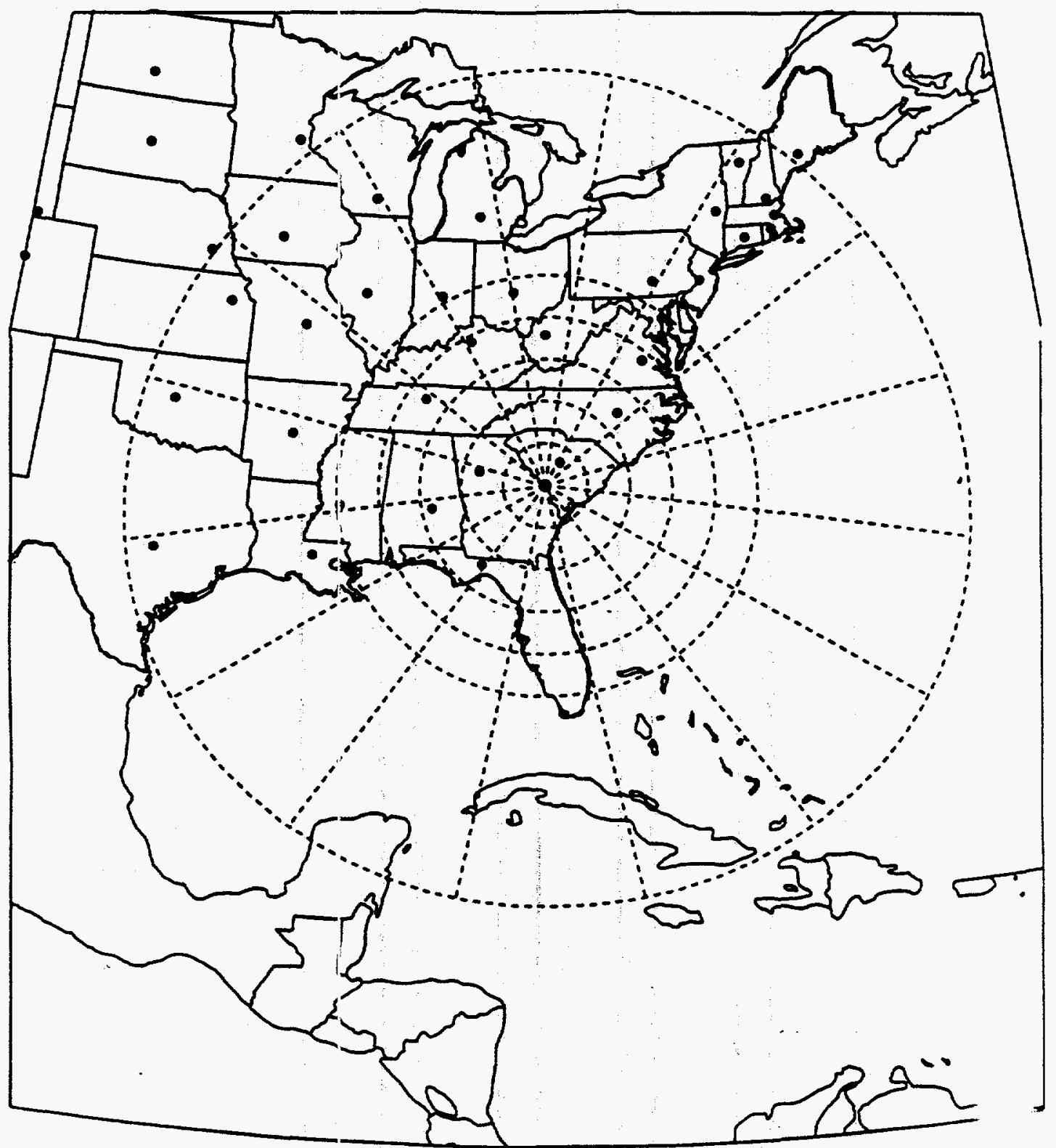

Figure 8-1. Offsite Consequence Analysis - 1000 Mile Grid 


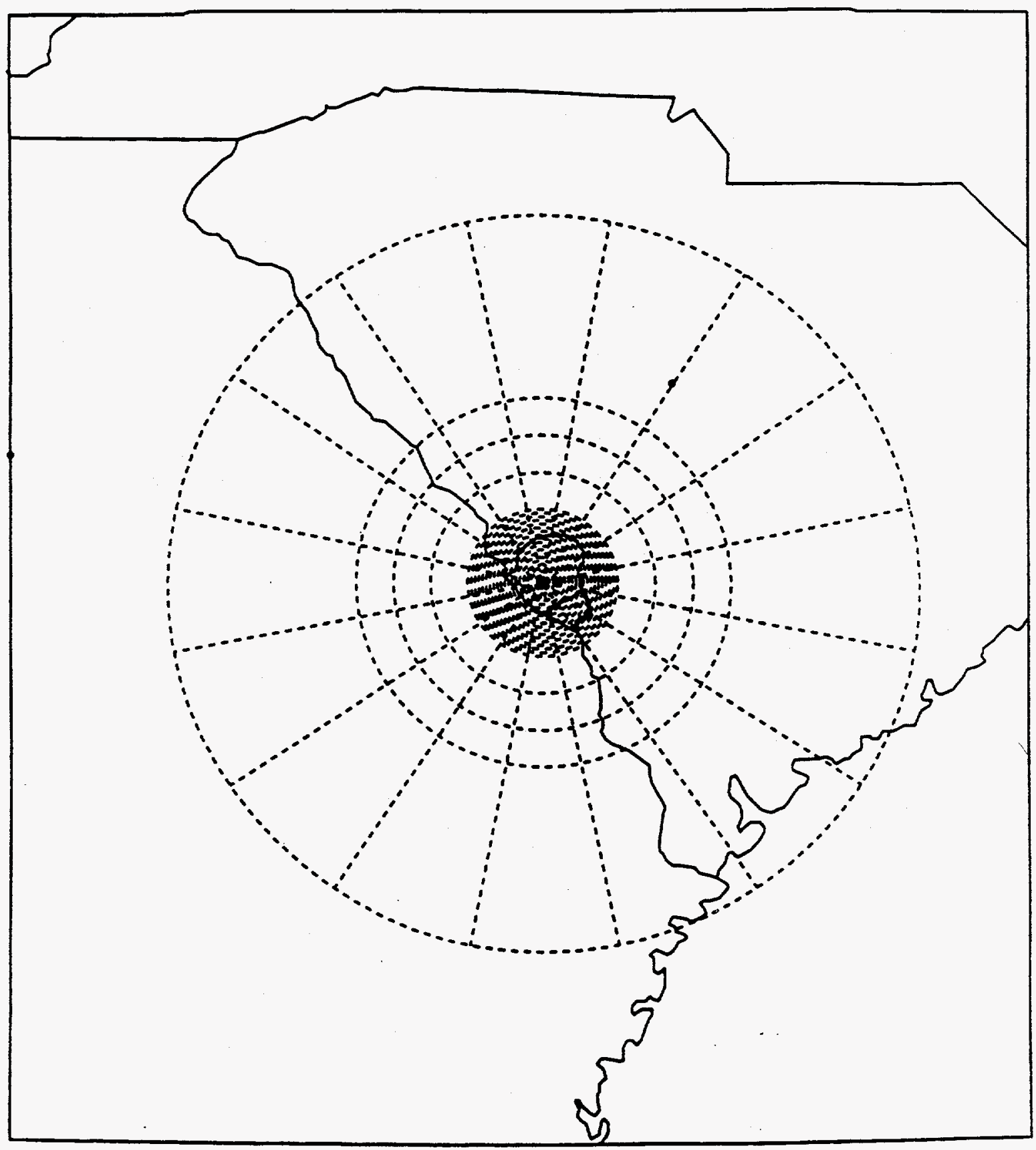

Figure 8-2. Offsite Consequence.Analysis - 0-100 Mile Grid 


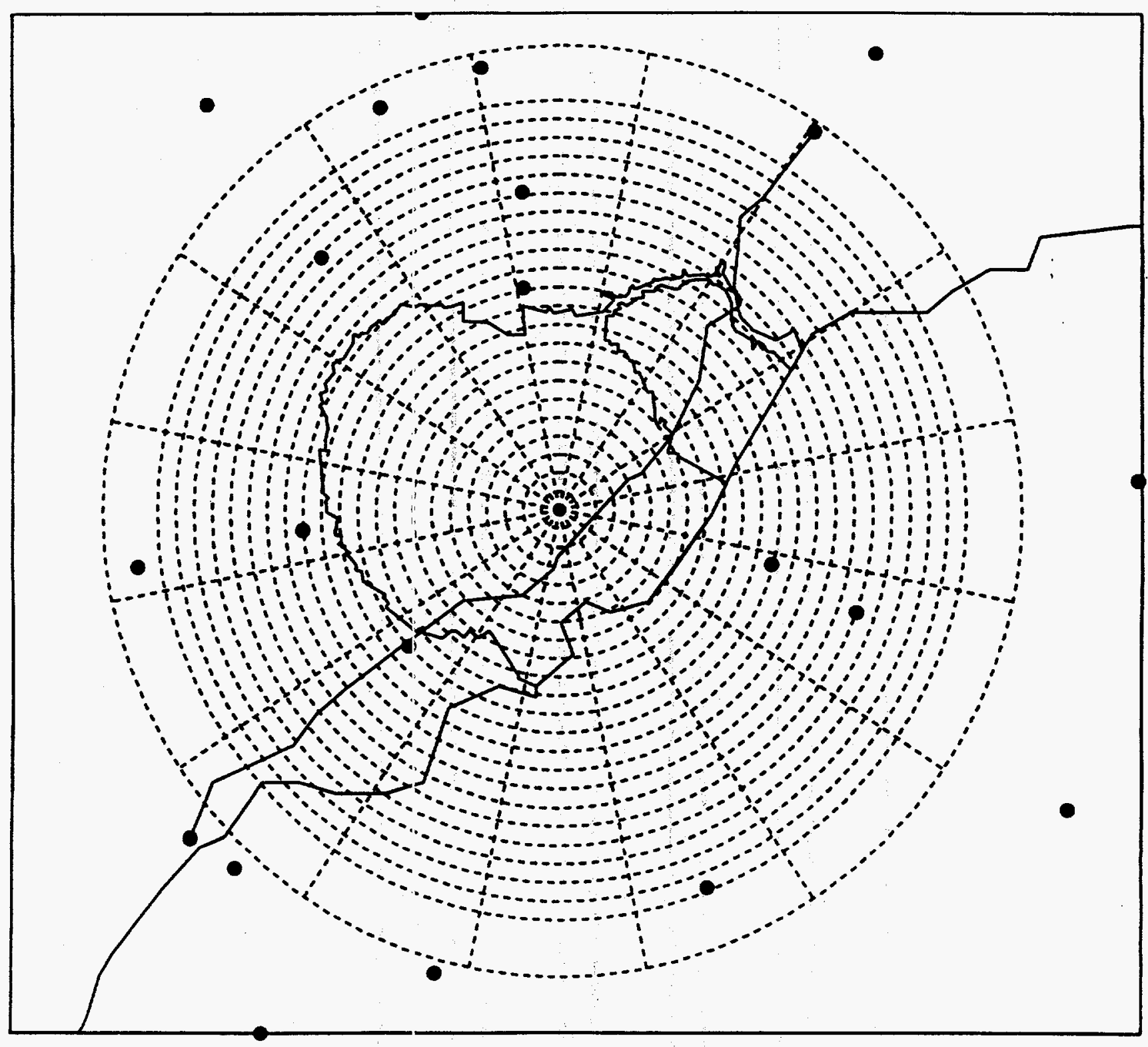

Figure 8-3. Offsite Consequence Analysis - Near Field Grid 


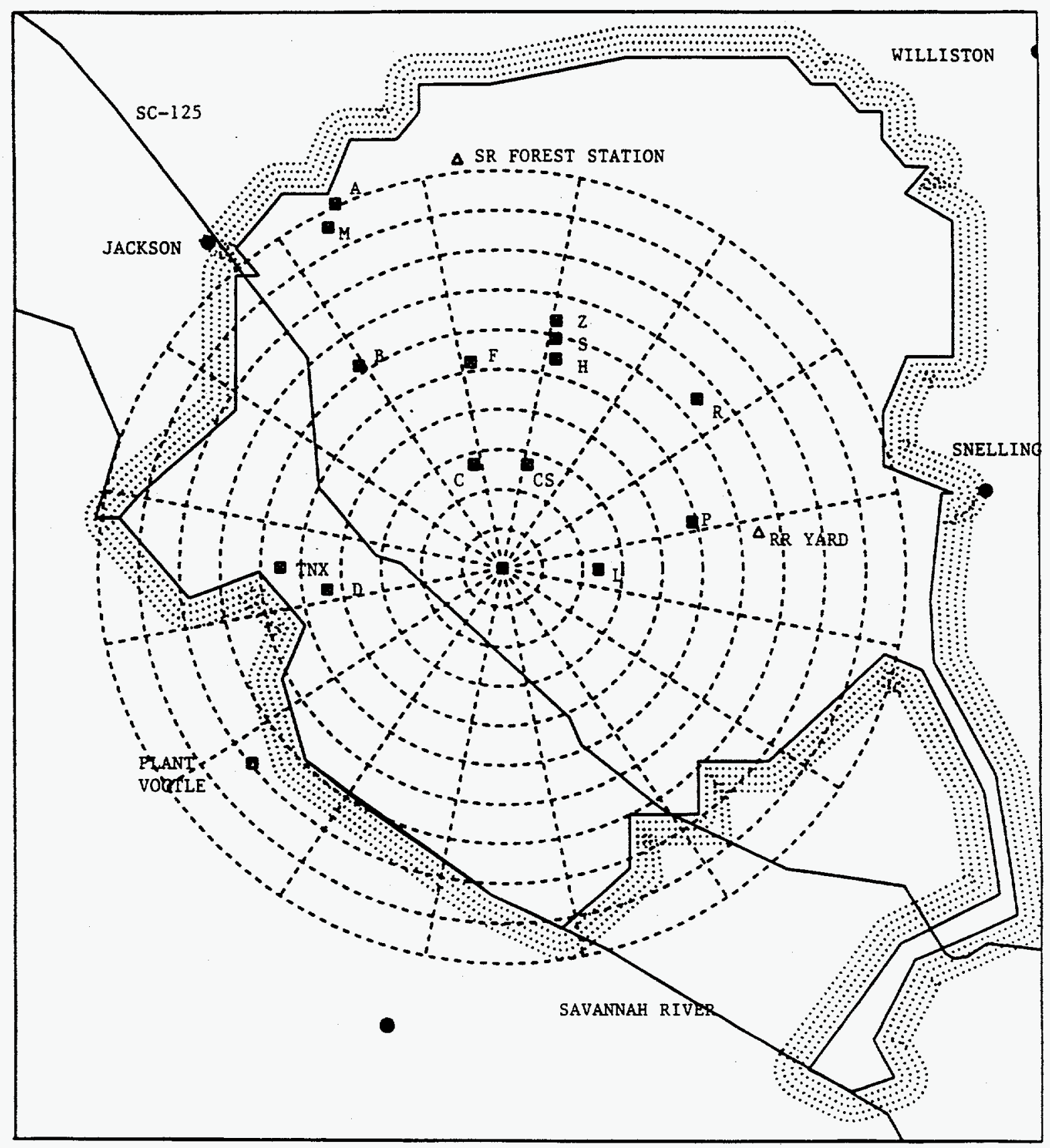

Figure 8-4. DOE Safety Measure - 1 Mile Offsite Grid 


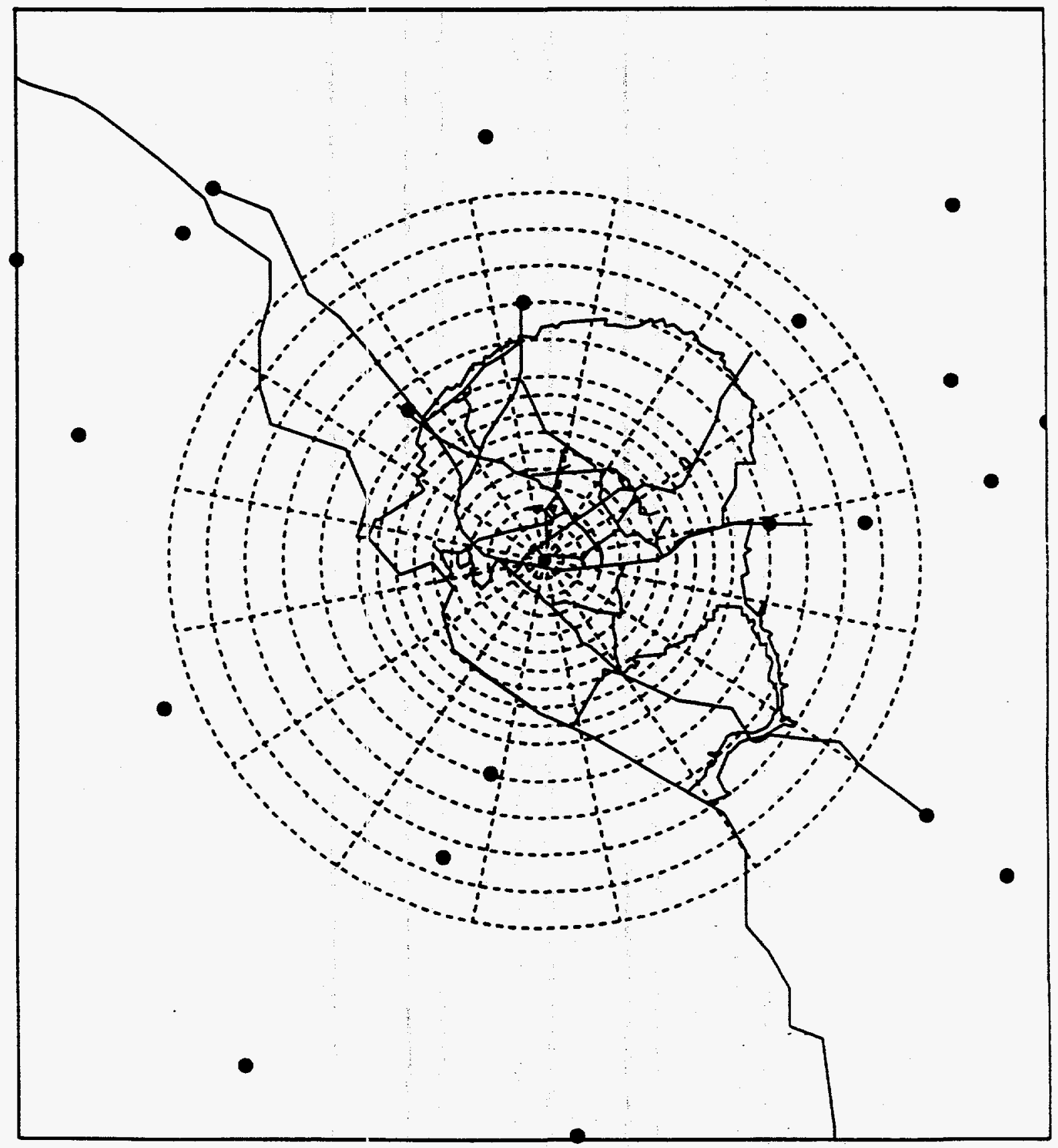

Figure 8-5. Onsite Consequence Analysis - 20 Mile Radius 


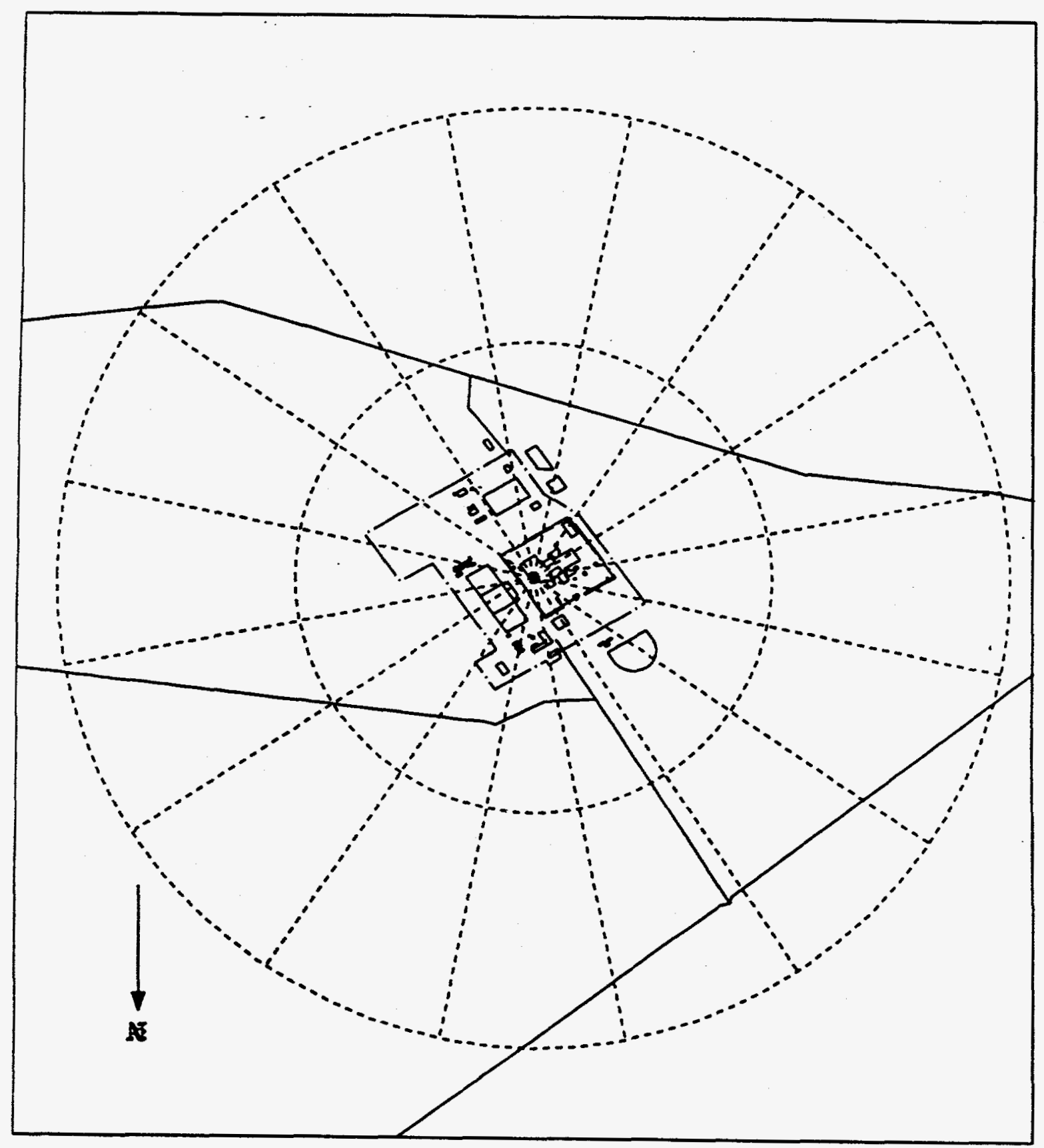

Figure 8-6. Onsite Consequence Analysis - K Area 1 Mile Radius 
Table 8-3. Consequence Measures Computed For Each Grid

A. Far-Field/Offsite/0 - 1000 miles from K Reactor (Figures 8-1 and 8-2)

Collective Dose or Consequence

Units

Specified Region

Population Dose to Red Bone Marrow

Population Dose to Red Bone Marrow

Population Dose to Thyroid

Population Dose to Thyroid

Total Early (Prompt) Fatalities

Total Latent (Cancer) Fatalities

Total Latent (Cancer) Fatalities

Total Leukemia Cases

Total Leukemia Cases

Decontamination Area

Interdicted Land Area

Condemned Area

Milk Disposal Area

Total Economic Cost

$$
\begin{array}{cl}
\text { person-Sv } & 0-1000 \text { miles } \\
\text { person-Sv } & 0-50 \text { miles } \\
\text { person-Sv } & 0-1000 \text { miles } \\
\text { person-Sv } & 0-50 \text { miles } \\
- & \text { Full Grid } \\
- & 0-1000 \text { miles } \\
- & 0-50 \text { miles } \\
- & 0-1000 \text { miles } \\
- & 0-50 \text { miles } \\
\mathrm{km}^{2} & 0-1000 \text { miles } \\
\mathrm{km}^{2} & 0-1000 \text { miles } \\
\mathrm{km}^{2} & 0-1000 \text { miles } \\
\mathrm{km}^{2} & 0-1000 \text { miles } \\
\$ & 0-1000 \text { miles }
\end{array}
$$

\section{B. Near-Field/Offsite/0-25 miles from K Reactor - 0-10 miles from SRS Boundary (Figure 8-3)}

Collective Dose or Consequence

Population Dose to Red Bone Marrow

Population Dose to Thyroid

Total Early (Prompt) Fatalities

Total Early (Prompt) Injuries

Total Latent (Cancer) Fatalities

Total Leukemia Fatalities

Individual Cancer Risk
Units

Specified Region

0 - 25 miles from

$\mathrm{K}$ Reactor

$0-25$ miles from

$\mathrm{K}$ Reactor

Full Grid

Full Grid

Full Grid

Full Grid

per reactor- $\quad 0-10$ miles from year
SRS Boundary

C. 1-mile SRS Boundary/Offsite/0 - 1 mile from SRS Boundary (Figure 8-4,

Collective Dose or Consequence

Units

Specified Region

Total Prompt Fatalities

0 - 1 mile from

Individual Prompt Fatality Risk

per reactor-

SRS Boundary

year

0 - 1 mile from

SRS Boundary 
Table 8-3 (continued)

D. Onsite/0 - 20 miles from K Reactor (Figure 8-5)

Collective Dose or Consequence Units Specified Region

Total Prompt Fatalities

Total Early Injuries

Population Dose to Red Bone Marrow

Population Dose to Thyroid

Total Latent (Cancer) Fatalities

Total Leukemia Cases

Prompt Fatalities

Latent (Cancer) Fatalities

\begin{tabular}{cl} 
Units & Specified Region \\
\hline & Full SRS \\
- & Full SRS \\
person-Sv & Full SRS \\
person-Sv & Full SRS \\
- & Full SRS \\
- & Full SRS \\
- & $0-1$ mile from K \\
& Reactor \\
- & $0-10$ miles from K \\
per reactor- & Reactor \\
year & $0-1$ mile from K \\
per reactor- & Reactor \\
year & $0-10$ miles from \\
& K Reactor \\
\hline
\end{tabular}

Individual Prompt Fatality Risk

Individual Latent Fatality Risk

E. 1-mile Person/Onsite/ 1 mile from $\mathrm{K}$ Reactor in each of sixteen compass sectors (Figure 8-6)

Collective Dose or Consequence

Total Prompt Fatalities

Individual Prompt Fatality Risk
Units

Specified Region

1 mile from $\mathrm{K}$

Reactor

per reactor- 1 mile from $\mathrm{K}$

year

Reactor 
Table 8-4. Mixing Layer Height Data Used In The SRS Analyses

\begin{tabular}{|c|c|c|c|c|}
\hline \multirow[b]{2}{*}{ Grid } & \multicolumn{4}{|c|}{ Seasonal Mixing Layer (Height Above Grade, m) } \\
\hline & Winter & Spring & Summer & Fall \\
\hline Afternoon & 1020 & 1700 & 1800 & 1400 \\
\hline $\begin{array}{l}\text { Average of } \\
\text { Morning and } \\
\text { Afternoon data }\end{array}$ & $7: 10$ & 1050 & 1100 & 850 \\
\hline
\end{tabular}

Table 8-5. Mitigative Actions Included In The SRS Analyses

Emergency Phase Onsite Offsite

Evacuation: Rapid movement of people away from the release area with the intention of escaping before the radioactive plume reaches their location

Sheltering: People in affected areas remain $\mathbf{x}$ indoors during plume passage with ventilation systems turned off

Relocation: Long term movement of population $\mathbf{x}$ outside interdicted area

Long-Term Phase

Interdiction (Food): Destruction of contaminated food until the radioactivity decays below some acceptable level

Interdiction (Land, Property): Long-term $\mathbf{X}$ prohibition of land inhabitation due to unacceptably high radiation levels 


\subsubsection{Offsite - The General Public}

The offsite analyses incorporate 1990 projected population data. The offsite cases also consider an average traffic density traveling through the SRS on public highway SC125. This accounts for the general public not being informed early enough to prevent the start of onsite travel. Normally notification of an impending radiological release will prevent the start of general public vehicular travel. The year-average number is an estimate to account for traffic that may be within SRS boundaries before public entry can be limited.

River traffic along the western border of the site is insignificant. Commercial and recreational traffic on the Savannah River, accordingly, are not modeled in the offsite risk assessment.

Dose reduction factors used for the offsite calculations are the same as the reference set of factors given in the MACCS code user's guide [8-1]. The factors account for the reduction in dose received from cloudshine, inhalation, skin contamination, and groundshine during: (1) evacuation; (2) sheltering; and (3) normal activity in the shelter/evacuation zone (i.e., factors appropriate for a population while waiting to evacuate or shelter). Factors of unity imply that the full dose is received from the dose pathway in question.

The offsite evacuation model assumptions for the internal events initiators are similar to those for NUREG-1150. It is assumed that $99.5 \%$ of the population within ten miles of $K$ Reactor, or those in the current Emergency Planning Zone (EPZ), would begin evacuation two hours after the release of the first plume segment. The remaining $0.5 \%$ do not participate; these people are assumed not contacted or choose not to leave the area. All evacuees move radially outward at a speed of $1.8 \mathrm{~m} / \mathrm{s}(3.96$ miles per hour). Once reaching the ten-mile radius, evacuees are not subject to any additional dose within the emergency phase of the accident. The offsite model beyond the ten-mile ring does not actively evacuate anyone, but instead may relocate or interdict depending on projected dose criteria discussed in the previous section.

It is assumed that seismic cases will present more difficulties to the evacuating public. Specifically, roadways and traffic control systems may be disrupted and the start to any emergency response may be delayed. In the MACCS model, seismic initiators halve the speed and delay the start of evacuation. Therefore, $99.5 \%$ of the offsite population within ten miles of $\mathrm{K}$ Reactor does not evacuate until a four-hour delay time from the time of the first released plume and once evacuating, the participants move at a speed of $0.9 \mathrm{~m} / \mathrm{s}$ (1.98 miles per hour). Again, once this population reaches the ten-mile radius, they are removed from incurring any additional dose during the seven day emergency phase time frame. 
If the average EDE whole-body dose from groundshine to an individual is projected to be greater than $0.25 \mathrm{~Sv}(25 \mathrm{rem})$ in the seven-day period, then the entire population in that grid element is relocated at twenty-four hours from the arrival of the plume in the grid element for the remainder of the emergency phase. A "hot-spot" criterion is also invoked: if the average EDE whole-body dose from groundshine to an individual is projected to be greater than $0.50 \mathrm{~Sv}(50 \mathrm{rem})$ in the seven-day period, then the entire population in that grid element is relocated at twelve hours from the arrival of the plume in the grid element for the remainder of the emergency phase.

If an average EDE whole-body dose of more than $0.04 \mathrm{~Sv}$ (4 rem) from groundshine and resuspension is projected to be exceeded over a five-year period, then decontamination and/or interdiction actions are employed to reduce or limit the critical organ dose. This dose criterion for relocation is an approximate model for implementing action levels prepared by the U.S. Environmental Protection Agency [8-25]. The consequences for the longterm phase include both the dose to resident populations on a grid element and the incremental dose incurred through decontamination efforts.

The decision to incur the above costs is based on projected dose levels exceeding Protective Action Guidelines (PAGs). Specifically, Food and Drug Administration PAG levels are implemented for directly contaminated foods and animal feeds, and Environmental Protection Agency PAGs are used for relocation from the contaminated area. Decontamination of both land and structures was assumed to reduce the levels of radioactivity by a factor of 3 or 15. A redixction of 3 was assumed to require 60 days of decontamination work while a reduction of a factor of 15 was assumed to require 120 days. DOE facility loss or downtime and cost of replacement of equivalent production capacity are not included.

Land usage factors and economic input data are used in the calculation of chronic, long-term health effects and economic costs. The long-term health effects are primarily due to food and water pathway uptake of radionuclides. The data for this study are taken from the Statistical Abstract of the United States, published by the U.S. Department of Commerce [8-26] and sample input data supplied in the MACCS code documentation [8-1]. The data describe thirteen states and thirteen multistate regions augmented by factors applicable to the Savannah River Site, the Atlantic Ocean, and international zones.

\subsubsection{Onsite - DOE and DOE Contractor Personnel}

There are important differences in the magnitude, training. nd notification capability between the offsite and onsite popula is. Fundamentally different models and input data and parameters for or ite consequences must be used to represent these differences in the consequence assessment [8-27]. First, the magnitude of the SRS work force distribution is cyclic, viz. a peak daytime presence spanning eight to ten hours is followed by twelve to fourteen hours of relatively low numbers. Other than critical-function, multi-shift process areas, many SRS areas 
will have only security and maintenance workers during the off-peak periods. Second, the onsite emergency preparedness plans are more detailed than the offsite plans. The SRS plans exercise all parties involved and must demonstrate readiness on a periodic basis per DOE order. The response to impending radiological releases is closely coordinated with onsite weather monitoring at SRS, dose assessment staff, management decision-makers and the onsite Safety and Security force. Third, onsite evacuation is constrained to a limited number of roads. The options within a few miles of $\mathrm{K}$ area in particular would force the emergency response coordinators to direct evacuees to use one or two preferred exit roadways based on the direction of the released plume.

Although a draft network evacuation model is available for testing, the reviewed MACCS model for evacuation and sheltering can be applied as a function of radial distance only. While this is appropriate for offsite general public consideration, even within a few miles of the Exclusion Area Boundary for a nuclear plant, the model oversimplifies the application for DOE facilities. Roadways surrounding the K-Reactor facility are limited directionally, and in many sectors, roads are non-existent or natural barriers preclude travel. Security and Safety personnel may be able to be effective in initiating and coordinating an evacuation, however the options are constrained to two or three routes.

Given these characteristics, onsite evacuation is modeled by using the radial evacuation framework in the MACCS code in conjunction with initially concentrating the work force in those two to three sectors whose radial vector best matches the compass direction options available to the evacuees. This approach is used for the work force in the first two miles from K Reactor only. The modeled evacuees are preferentially placed in the three identified exit directions at a radius approximately that of the reactor building Facility Control Perimeter fence. At radii greater than $3.2 \mathrm{~km}$ ( 2 miles), the SRS roadways are better represented by the standard radial evacuation model, so the onsite population at greater than two miles from the reactor building is not preferentially positioned for each MACCS start time.

The code for onsite consequence calculation has been modified to identify the direction of the first plume segment and then use one of sixteen work force distributions. The one selected is based on the wind direction of the start time read by MACCS from the meteorological file. The input distributions account for human error in the onsite response. The model assumes that some personnel will evacuate outside of the recommended direction(s) or will exit too early to follow the best evacuation direction. Studies reported in Chapter 10 indicate the sensitivity to recommended direction and timing.

The rotation procedure performed in MACCS was described in Section 8.1. The purpose of this procedure is to generate a sufficient number of calculations in an economical manner. The procedure credits radial evacuation, but is completely "blind" to directional evacuee motion. Any 
attempt to identify directional evacuation route benefits relative to others is defeated by the rotation step. Another option is therefore chosen in concert with the modified onsite evacuation, a no-rotation option. In this case one set of consequence results is achieved per chosen start time rather than sixteen with the rotation option. To adequately sample enough weather from the site-specific meteorology, the Stratified Random Sampling option is selected for onsite consequence assessment with several start times chosen per day. Each day of the year is sampled.

The onsite calculations implement a peak daytime condition in the March, 1990 period developed from conservatively weighted occupancy assumptions for weekday afternoon conditions [8-28]. Shielding factors for onsite workers input to MACCS are the same set as used for the general public. A more realistic set, accounting for onsite structural differences, has been established for SRS [8-29].

The onsite consequence analysis considers only the first, or emergency phase of the reactor accident. The onsite calculations, accordingly do not model interdiction/decontamination activities. Relocation parameters are identical to those assumed for offsite.

Emergency response input to the onsite calculations is based on Emergency Plan developed for the SFiS. The onsite work force is assumed to be informed of the impending radiological release by the SRS communication network. In the event of a reactor accident, directives to workers would be coordinated by the Savannah River Site Operations Facility SRSOF and its Technical Support Center (TSC) in the administrative area of the Site, approximately ten miles from $\mathrm{K}$ Reactor. Workers in the first five miles of the K-Reactor area are assumed to begin evacuation at 0.5 hours after reactor scram and travel radially outward at a speed of $3.86 \mathrm{~m} / \mathrm{s}(8.5$ miles per hour). The evacuees in this case include all $\mathrm{K}$ Area employees. Once the evacuees reach a radius of five miles, they no longer are subject to any influence of the radioactive plume nor to resuspended radioactivity for the remainder of the calculation. The onsite model assumes that sheltering will also be recommended by TSC communications. All site employees from 5 miles outward will shelter beginning at one hour from scram. The onsite workers sheltered remain so for twelve hours. Upon the end of the period, the sheltered workers receive no additional dose while being removed from the Site.

It is assumed that seismic initiators will impact onsite eme ncy evacuation efforts to the same extent as for the offsite general $\mathrm{p}$ lic. Therefore, the time for evacuation is delayed by a factor of two (to one $r \quad r$ ), and the evacuees move at half the speed of the internal events or 1. : $_{\text {: }} \mathrm{s}$ (4.25 miles per hour). It is assumed that $100 \%$ of the onsite wor : $\mathrm{s}$ participate regardless of the type of initiating event. The start time ir sheltering remains at one hour. Table 8-6 lists the evacuation, shelter. 's, and shielding factors specified for the onsite calculations. 
Table 86. Evacuation and Sheltering Parameters

\begin{tabular}{lccc} 
& $\begin{array}{c}\text { Radius of } \\
\text { Applicability (miles } \\
\text { from K Reactor) }\end{array}$ & $\begin{array}{c}\text { Evacuation Start } \\
\text { Time } \\
\text { (hours after scram) }\end{array}$ & $\begin{array}{c}\text { Radial Evacuation } \\
\text { Velocity (m/s) }\end{array}$ \\
\hline \hline OFFSITE : & $\mathrm{SB}^{*}-10$ & & \\
$\begin{array}{l}\text { Internal } \\
\text { Initiators }\end{array}$ & & 2.0 & 3.86 \\
External & $\mathrm{SB}^{*}-10$ & 4.0 & 1.93 \\
Initiators & & & \\
ONSITE : & & & \\
Internal & $0-5$ & 0.5 & 3.86 \\
Initiators & $5-\mathrm{SB}^{*}$ & 1.0 & Shelter for 12 hours \\
& & & \\
External & $0-5$ & 1.0 & Shelter for 12 hours \\
Initiators & $5-\mathrm{SB}^{*}$ & 1.0 &
\end{tabular}

* SB = Site Boundary

Shielding Factors Applicable During Evacuation:

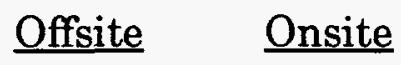

Cloudshine Protection Factor

$1.00 \quad 1.0$

Inhalation Protection Factor

$1.00 \quad 1.0$

Skin Protection Factor

$1.00 \quad 1.0$

Groundshine Protection Factor

$0.50 \quad 0.5$

Shielding Factors Applicable During Sheltering:

$\begin{array}{lll}\text { Cloudshine Protection Factor } & 0.60 & 0.34 \\ \text { Inhalation Protection Factor } & 0.33 & 0.20 \\ \text { Skin Protection Factor } & 0.33 & 0.20 \\ \text { Groundshine Protection Factor } & 0.20 & 0.15\end{array}$

Shielding Factors Applicable During Normal Activity In Sheltering And Evacuation Zone:

Cloudshine Protection Factor

0.75

0.87

Inhalation Protection Factor

0.41

0.79

Skin Protection Factor

0.41

0.79

Groundshine Protection Factor

0.33

0.48 
The emergency response models and applicable dose reduction factors are provided in Table 8-6. Onsite shielding factors reflect greater concrete structures availability for sheltering protection than offsite conditions. These shall be implemented in later revisions to the Level $2 / 3$ analysis.

The MACCS analysis produces conditional CCDFs and tabulations of numerous statistical measures (e.g., mean, median, 95th quantile, etc.) for each consequence measure. Section 10 of this report describes the format used in this assessment for weighting and summarizing these results to produce annualized risk estimates. Section 10 also reports the results of the base-case consequence arialysis. Included are assessments of risk for both offsite and onsite populations. MACCS model sensitivities and the relative tritium dose impacts are also discussed.

\subsection{References}

8-1. D. I. Chanin, J. L. Sprung, L. T. Ritchie, and H-N Jow, MELCOR Accident Conseg'uence Code System (MACCS), User's Guide, Vol. 1, NUREG/CR-4691, SAND-86-1562, Sandia National Laboratories, Albuquerque, NM, February, 1990.

8-2. H-N. Jow, J. L. Sprung, J. A. Rollstin, L. T. Ritchie, and D. I. Chanin, MELCOR Accident Consequence Code System (MACCS), Model Description, Vol. 2, NUREG/CR-4691 (SAND-86-1562), Sandia National Laboratories, Albuquerque, NM, February, 1990.

8-3. J. A. Rollstin, D. I. Chanin, and H-N Jow, MELCOR Accident Consequence Code System (MACCS), Programmer's Reference Manual, Vol. 3, NUREG/CR-4691, SAND-86-1562, Sandia National Laboratories, Albucquerque, NM, February, 1990.

8-4. D. I. Chanin, J. A. Rollstin, J. Foster, and L. Miller, MACCS Version 1.5.11.1: A Maintenance Release of the Code, Sandia National Laboratories, Albuquerque, NM, July 1992.

8-5. U.S. Nuclear Regulatory Commission (NRC), Reactor Safety Study An Assessment of Accident Risks in U.S. Commercial Nuclear Power Plants, WASII-1400, NUREG-75014, October 1975.

8-6. U.S. Department of Energy/Office of New Production Reactors, Preliminary Draft Environmental Impact Statement for the Siting, Construction, and Operation of New Production Reactor Capacity, Volumes 1 - 4, DOE/EIS-0144, August 1990.

8-7. U.S. Nuclear Regulatory Commission (NRC), Severe Accident Risks: An Assessment for five U.S. Nuclear Power Plants, Office of Nuclear Regulatory Research, NUREG-1150, December 1990.

8-8. ICRP, Limits for Intake of Radionuclides by Workers, ICRP Publication 30, Oxford: Pergamon Press, 1979. 
8-9. U.S. Department of Energy, External Dose-Rate Conversion Factors for Calculation of Dose to the Public, Office of Environmental Guidance and Compliances, DOE/EH-0070 DOE/ES\&H, July 1988.

8-10. U.S. Department of Energy, Internal Dose Conversion Factor for Calculation of Dose to the Public, DOE/EH-0071, July, 1988.

8-11. S. J. Piet et al., FUSCRAC: Modifications of CRAC for Fusion Applications, PFC/RR-82-20, M. I. T. Plasma Fusion Center, June 1982.

8-12. S. J. Brereton and S. J. Piet, Modifications to FUSCRAC2 in Creating FUSCRAC3, Idaho National Engineering Laboratory, SJB-33-88, December 16, 1988.

8-13. S. J. Brereton et al., Offsite Dose Calculations For Hypothetical Fusion Facility, IAEA Workshop on Fusion Reactor Safety, Jackson Wyoming, April 1989.

8-14. U.S. Nuclear Regulatory Commission (NRC). Health Effects Model for Nuclear Power Plant Accident Consequence Analysis, Low LET Radiation, Part I: Introduction, Integration and Summary, NUREG/CR-4214, SAND85-7185 Rev. 1, Harvard University, Boston, MA, 1990.

8-15. S. Abrahamson, M. A. Bender, B. B. Boecker, E. S. Gilbert, and B. R. Scott, Health Effects Models for Nuclear Power Plant Accident Consequence Analysis, Modifications of Models Resulting From Recent Reports of Health Effects of Ionizing Radiation, Low LET Radiation, Part II: Scientific Bases for Heath Effects Models, NUREG/CR-4214, Rev. 1, Part II, Addendum 1, LMF-132, Inhalation Toxicology Research Institute, Albuquerque, NM, August 1991.

8-16. National Research Council, Committee on the Biological Effects of Ionizing Radiations. 1980. The Effect on Populations of Exposure to Low Levels of Ionizing Radiation (BEIR III). Washington D.C. National Academy of Sciences, National Academy Press 524 pp.

8-17. National Research Council, Committee on the Biological Effects of Ionizing Radiations. 1980. Health Effects of Exposure to Low Levels of Ionizing Radiation (BEIR V). Washington D.C.: National Academy of Sciences, National Academy Press 421 pp.

8-18. U.S. Department of Energy, Nuclear Safety Policy, SEN-35-91, September 9, 1991.

8-19. C. A. Dobbe, E. R. Carlson, N. H. Marshall, E. S. Marwil, and J. E. Tolli, Quality Assurance and Verification of the MACCS Code, Version 1.5, NUREG-CR-5376, EGG-2566, February 1990. 
8-20. K. R. O'Kula and I. M. East, Consequence Analysis for the SRS $K$ Reactor Operation PRA, WSRC-RP-91-771, Westinghouse Savannah River Company, Aiken, SC, December 1992.

8-21. D. R. Finch, The SHIELD System User's Manual, DPSTM-87-700-2, Savannah River Laboratory, Aiken, SC, October 1988.

8-22. K. R. O'Kula, Mark 22 Charge Inventories for PRA Applications, WSRC-RP-91-1115, Westinghouse Savannah River Company, Aiken, SC, December 1991.

8-23. J. E. Laurinat, Meteorological Data for PRA Offsite Consequence Analysis, Savannah River Laboratory, Aiken, SC, DPST-87-513, July 1987.

8-24. K. R. O'Kula and 'Z. T. Mendoza, SRP PRA of Reactor Operation Level 3/Phase 1 Off-Site Consequence Analysis, Savannah River Site, Aiken, SC, DPST-88-1043, March 1989.

8-25. U.S. Environmental Protection Agency, Manual of Protection Action Guides and Protective Actions for Nuclear Incidents, Office of Radiation Programs, Draft, (To Be Published).

8-26. U.S. Department of Commerce, Statistical Abstract of the United States, 107th Edition, Washington, D.C., 1987.

8-27. K. R. O'Kula and J. M. East, Onsite Consequence Modeling For The SRS $K$ Reactor PRA, Westinghouse Savannah River Company, Aiken, SC, (To Be lssued).

8-28. J. M. East, Onsite Census for PRA Applications, WSRC-RP-92-343, Westinghouse Savannah River Company, Aiken, SC, March 1992.

8-29. N. Q. Pritchard memo to J. M. East, SRT-RST-920006, Westinghouse Savannah River Company, Aiken, SC, July 1992. 
In Section 4, the method for obtaining an estimate of the risk of plant operation was described. The value of risk thus obtained will be referred to as a point estimate. It is preferred not to characterize this as a "bestestimate" value of risk, since limited effort was spent by the analysts to assure that all the inputs to the various codes, and the models themselves, were truly the best available estimates. There is an additional complication in interpreting this result as "best-estimate", since the consequence result produced by MACCS is a mean value, averaged over a sample of one year's weather.

Whether the risk estimate is thought of as merely a point estimate or as a best-estimate value, the single value has little real meaning. As with any engineering analysis, some representation of the uncertainty associated with the value obtained is essential. Since PSA results may well be used in making decisions relative to overall plant safety and the need for design improvements, the importance of putting the point-estimate result in the context of the associated uncertainty is crucial. Considering the sparseness of the data and the incompleteness of knowledge regarding some of the phenomena that are modeled, the uncertainty is significant. Both the analysts and decision-makers would like to know which of the various uncertain aspects of the PSA models contribute most to the uncertainty in risk. This information can then be used to guide data-gathering programs and research into severe accident phenomena so that they focus on issues for which added knowledge will reduce uncertainty with regard to plant risk.

Uncertainty that stems from both incomplete knowledge of phenomena and the stochastic nature of some of the physical processes involved requires that the accident analysis be probabilistic. Incomplete knowledge of the phenomena leads to what will be referred to herein as model uncertainty. For a given context (i.e., series of events leading up to the point in time under consideration), the particular outcome of a single event in the accident progression may not be known. A number of possible outcomes can often be defined for each event considered. For example, an accident mitigating system, such as the carbon filters, can (1) operate as designed and retain all absorbed halogens; (2) overheat and release part of the adsorbed halogens; or (3) burn and release all deposited radionuclides. With a given aerosol loading and airflow, the expected filter response can be determined with reasonable accuracy using available engineering models. It is frequently the case that more than one model can be applied to predict the outcome for a particular event. For models that represent complex severe accident phenomena, it is not uncommon for different models to predict different outcomes. Sufficient data to validate these models is typically not available for many severe accident phenomena. The extent of damage resulting from a steam explosion is an example of a phenomenological event which is treated as a model uncertainty. In the context of evaluating accident progressions, a steam explosion can be sufficiently energetic to (1) permanently breach the confinement structure; 
(2) cause a momentary bypass of confinement; or (3) do no significant damage. Even if the conditions associated with the steam explosion are well characterized, a specific outcome cannot usually be assigned. Since there is uncertainty associated with the outcome of the event, there are multiple paths along which the arcident can proceed, given a situation in which a steam explosion can occur. In the APET, each event outcome (hereafter referred to as a branch) has been assigned a branching ratio. Where model uncertainty causes the specification of multiple possible outcomes, the branching ratio (in the point estimate) represents the analyst's level of confidence that the indicated outcome would actually occur based on their knowledge of the phenomiena.

Because each branching ratio represents a relative frequency (i.e., the fraction of the time that a particular outcome would occur in a large number of trials), model uncertainty cannot be consistently represented in the point estimate. If model uncertainty exists, it is expected that the same outcome would occur for every trial. (Which outcome that is has not been established.) The point estimate thus includes the one outcome that will occur plus all those that will not. Therefore, the results include some portion of "incorrect" answers, making interpretation difficult. Each outcome is weighted by a relative frequency that represents the analyst's confidence that it is the correct one. A "best estimate" should perhaps assign (with a relative frequency of unity) the outcome in which the analyst has the greatest confidence. As discussed below, this approach is used in the uncertainly analysis to incorporate model uncertainties.

APET branch points may also represent events for which uncertainty in the outcome is due to processes best modeled as random events. Examples include events that depend on hardware performance or human action. This type of variability in the outcome of an event will be referred to as stochastic uncertainty. These events are treated using traditional reliability analysis techniques. Fault tree analysis has been applied to determine the branching ratios that characterize the failure frequency of active components of the AACS, which are considered in the APET. Human error frequencies have been evaluated for human actions that are modeled in the APET. These evaluations were made on the basis of a formal evaluation method similar to that used in the Level 1 PSA [9-1]. The frequencies thus determined are used as the APET branching ratios for this type of event.

Where the phenomena are governed by processes that are too complex to be reasonably modeled (i.e., no amount of research or data collection would allow resolution of which outcome occurred for a particular condition), they have been represented as stochastic uncertainties. Weather and the probability of a steam explosion occurring are examples. Empirical evidence or data collection have been combined with subjective judgments to evaluate branch points representing these uncertainties. 


\subsection{Method}

In a simple engineering analysis, uncertainty can be propagated analytically. For instance, if the specific heat of a substance is measured using a calorimeter, an expression for this property would be written as a function of measured temperatures and the properties of materials used in the apparatus. Assuming that the dominant source of uncertainty was the thermocouple measurements, the uncertainty in the measured value of specific heat would be expressed as a function of the partial derivatives of the specific-heat expression with respect to the measured temperatures. Using this expression, combined with the known error in the thermocouple readings, an estimate of the uncertainty in specific heat is obtained.

The concepts used to estimate uncertainty in the SRS reactor PSA results differ little from those introduced by the above simple example. However, the risk model to which these concepts are applied is immensely more complex than the simple expression for the specific heat of a substance in terms of calorimeter measurements. The model for risk that was developed to obtain the point estimate is the basis for the uncertainty evaluation. This model actually consists of the ensemble of models from each of the four modules (the Level 1 PRA, the APET, the Source Term Algorithm, and the Consequence Model): Each module has a number of inputs that are uncertain. In some cases, most notably for the accident progression assessment (i.e., the APET), these inputs reflect uncertainty with respect to the most appropriate model to use for a certain phenomena. In such cases, inputs to the modules that represent the analysts' confidence that a particular model for a given phenomena is the correct one to use (e.g., a branching ratio in the APET) become the module input that is treated as being uncertain. Because of the complexity of the risk model, numerical methods must be applied to characterize uncertainty and obtain the equivalent of the model's partial derivatives with respect to the uncertain inputs.

Stratified Monte Carlo Sampling (referred to as Latin Hypercube Sampling, or LHS [9-2]) has been used to evaluate the response of the model to variations in the uncertain inputs. The sampling process randomly selects sets of values for the model-input parameters that are considered to be uncertain. The model, and the module assembly process, is then exercised with each set of values in the sample. The range of results obtained is assumed (based on the LHS design) to characterize the uncertainty in the model outputs. The mapping from input value combinations to risk estimates can be investigated using statistical techniques to obtain estimates of the relative importance of the various uncertainties considered. (Rank regression is used to develop analytical functions that approximate the characteristics of the mapping from LHS sample member to risk estimate.) Latin Hypercube Sampling is preferred over straight Monte-Carlo Sampling, since this process assures that the combinations of input values investigated encompasses the full range of the probability distributions assessed for the input parameters, while maintaining a limited sample size. Use of Latin Hypercube Sampling is more efficient 
than simple Monte-Carlo sampling in that the tails of the input distributions are sampled without requiring large numbers of sample members. It is noted that Monte-Carlo-based techniques, such as Latin Hypercube Sampling, lead to an underestimation of uncertainty in the output variables. This occurs because the methods generally require probability distribution assignments with well defined limits to facilitate the numerical algorithms. If a parameter is believed to have a probability distribution which is not bounded by some inherent physical mechanism, outlier areas of the distributions which were truncated may turn out to produce values for risk outside the range obtained by sampling the more likely values. These outlier values of risk would be lost with present techniques. However, this theoretical limitation is not expected to influence the current results.

To explain how the uncertainty evaluation is accomplished, each module in the risk model ensemble should be viewed as a model with inputs that have some associated uncertainty. In the succeeding discussion, these uncertain inputs are referred to as model parameters. Each module can be thought of as a function of its parameters; i.e., for output $Y$ of the module, and inputs $\mathrm{X}_{1}-\mathrm{X}_{\mathrm{n}}$, the response may be formulated as:

$$
\mathrm{Y}=f\left(\mathrm{X}_{1}, \mathrm{X}_{2}, \ldots, \mathrm{X}_{\mathrm{n}}\right),
$$

where the analytic form of the function $f$ is unknown. The process of evaluating uncertainty involves three steps: identification of important parameters, assignment of probability distributions to those parameters, and propagation of these distributions through the function (computer code) to arrive at a distribution for the output variable. The final step amounts to an empirical characterization of $f$ by constructing the partial (due to the finite number of parameter combinations evaluated) mapping from its inputs $\left(\mathrm{X}_{\mathbf{i}}\right)$ to its output $(\mathrm{Y})$. This process is similar to the generation of a response surface.

First, the analysts identify those parameters within each module that have significant associated uncertainty. The number of parameters is typically large (on the order of one hundred or more). Selection of the parameters to be included in the uncertainty evaluation is thus made on the basis of the analysts' judgment as to the importance of the uncertainty in a parameter relative to the results obtained for that module. This information car be obtained, in some instances, by selected sensitivity studies exercising e module independent of the others in the ensemble.

The second step is the assignment of probability distribution function (PDFs) to each of the selected parameters. This was done by the cognizan: analysts. For situations involving model uncertainty, guidelines were applied that relate the quantification of uncertainty to the amount and quality of objective evidence (e.g., data and analysis) that support a particular position. Where a continuous parameter was involved (e.g., radionuclide release fraction), the analysts familiar with the area of analysis related to evaluation of the parameters in question performed the 
evaluation directly. The PDFs were designed to express the analysts' confidence that the value of a particular parameter lies within a given range. The distribution was constructed by first obtaining maximum and minimum values for the parameter. Often, these limits may be obtained from known bounds, for example, branch ratios in the APET must be between zero and one. Then, the median value of the distribution was assigned by asking the analyst what value of the parameter was judged to subdivide the range such that it is equally likely that the actual value of the parameter would lie above or below the selected value. Finally, other percentiles of the distribution were assigned if the analyst was willing to further subdivide the range on either side of the median. These PDFs can be developed either by analyst and reviewer consensus, as has been done in the SRS reactor PSA, or groups of experts can be assembled and each group member can produce a PDF. The fractile values can then be arithmetically averaged to produce a group average as was done for the NUREG-1150 study. The latter approach has a tendency to maximize uncertainty.

The third and final step is the uncertainty evaluation. The computer codes described in the previous section have been designed to accommodate Latin Hypercube Sampling of their input parameters. To exercise this capability, the distributions for all the selected parameters are translated into an input file for the code that will generate the Latin Hypercube Sample (LHS) [9-2]. The size of the sample is selected based on the number of parameters that are to be treated as uncertain. For the SRS reactor PSA, the sample was selected to have five hundred members (i.e., five hundred discrete evaluations of the risk model with different sets of input parameters were performed). The sample produced by an LHS run thus consists of five hundred sets of values for the selected parameters. The computer codes in the assembly process (shown in Figure 9-1) are run in sequence. Each code except the source term clustering code (PARTITION) and the consequence code (MACCS) produces five hundred sets of results that are combined by the assembly process to produce five hundred point estimates of risk. This set of results is a representation of the uncertainty in the assessed risk.

\subsection{Sources of Uncertainty}

In this section, the sources of uncertainty within each module of the risk assessment are discussed. Uncertainty is inherent to the models that constitute the PSA, and is considered only within each module. The interfaces between the modules are not considered as sources of uncertainty. The binning of results is required in order to reduce the size of the problem to a manageable level. In reality, errors in the assessed risk could be introduced at each interface. This would occur if a result from a module were placed in an inappropriate bin for consideration in subsequent modules. Quality assurance procedures were used to minimize the likelihood of such errors. Since the results obtained are reasonable, it is believed that no substantial errors are present. Inspection of the results and limited sensitivity studies provide reasonable assurance that such errors (if present) do not significantly affect the results. 


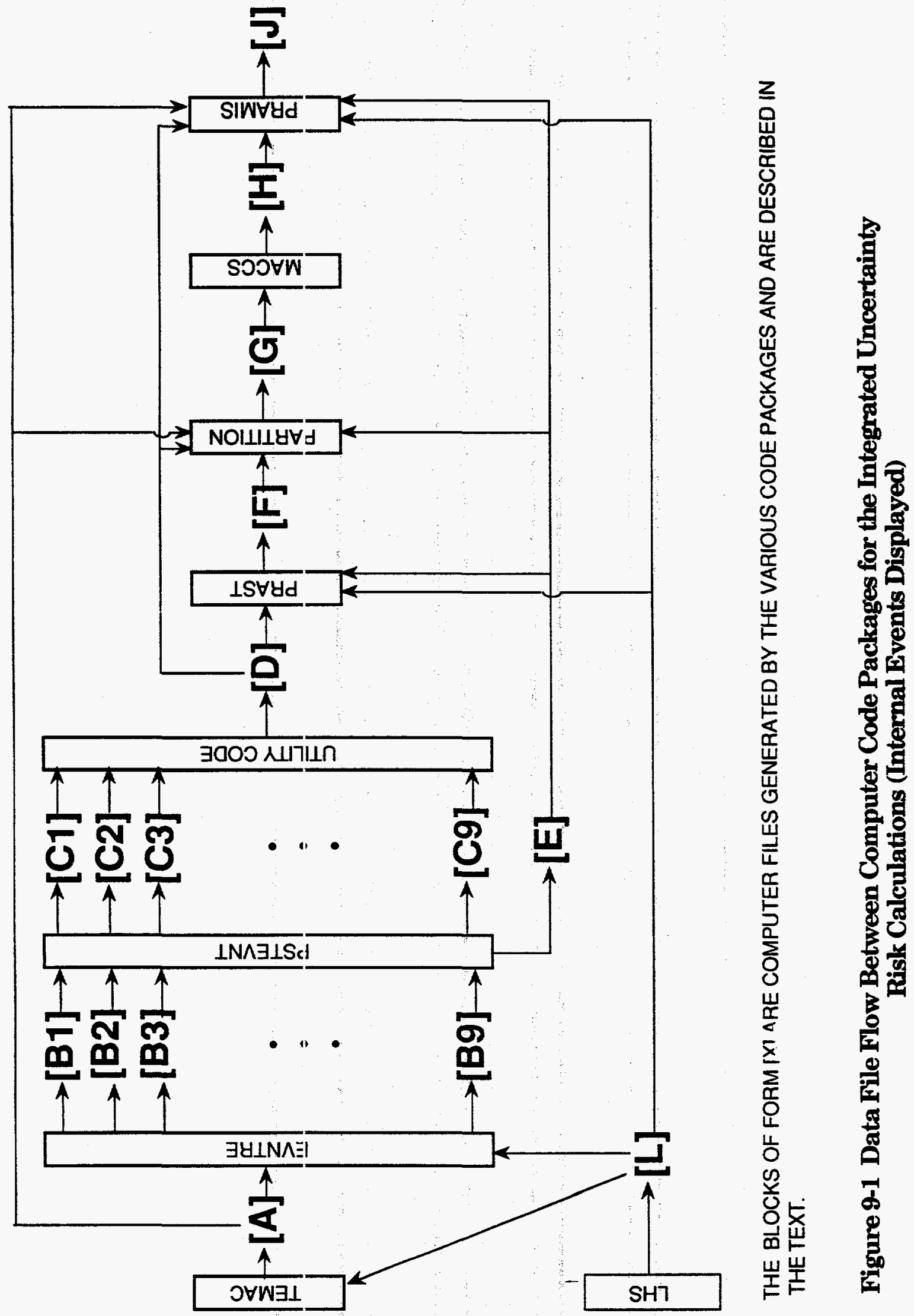




\subsubsection{Plant Damage State Frequency Variable Selection}

For the assessment of the severe core melt frequency (SCMF), the uncertain parameters are the base event failure probabilities and the initiating event frequencies. In the evaluation of uncertainty in the frequency of seismically-induced core damage, these parameters would include those that define the hazard curve and the fragility of equipment. However, the software used in the uncertainty assessment does not currently support the investigation of uncertainty in externally-induced equipment failure (i.e., seismic activity, fire, high winds, and flood) within the automated framework. Manual processing of these parameters to produce base event failure probability distributions or initiating event frequency distributions was required.

To provide a more complete assessment, uncertainty in the Level 1 PSA results was assessed separately from the uncertainty in the Level 2/3 PSA. The Level 1 uncertainty assessment considered essentially all base event probabilities and initiating event frequencies to be uncertain [9-1]. The TEMAC code [9-3] alone was then used to assess the mean SCMF, the associated uncertainty, and the relative importance of the various initiator frequencies and base event failure probabilities, relative to determining the SCMF. These results; as well as investigations of the variables by PDS as discussed below, were used to guide the selection of parameters for inclusion in the Level $2 / 3$ uncertainty analysis. To limit the number of calculations, only a subset of the Level 1 parameters was included in the integrated assessment of risk (i.e., Level $2 / 3$ uncertainty). It was necessary, however, to preserve the SCMF uncertainty due to Level 1 model and data uncertainties.

The variable importance measures as calculated by TEMAC all relate to the variable's importance to the top event (the SCMF). It is intuitive that if a variable is important to the distribution of the SCMF, then it is probably important to the distributions of the sequences in which it occurs. However, when selecting a subset of the Level 1 variables for inclusion in the integrated uncertainty analysis, care was taken that variables which may not have a large affect on the SCMF uncertainty, but have large effects on individual sequences were not summarily omitted. This could happen in plant damage states which are lower level frequency contributors and thus do not have a large affect on the SCMF. Variables which make up the cutsets in this PDS may not show up high in the overall SCMF importance results, and may be dismissed on this basis. Thus, an "accurate" characterization of the uncertainty for this lower frequency PDS may not be made since many (or possibly all) of the variables associated with the PDS would not be sampled. Unfortunately, low frequency does not a priori mean low consequence, and thus an accurate characterization of the distributions of all of the PDSs was necessary. 


\subsubsection{Internal Events PDS Input Parameter Selection}

To generate an accurate characterization of the uncertainty in the internal events plant damage states, the PDS frequency distributions were calculated based on sampling all of the Level 1 parameters, as is normally done to assess the SCNCF distribution. This provided the best available distributions for each of the PDSs. Two methods were then utilized to choose a subset of the Level 1 parameters for inclusion in the integrated uncertainty assessment. First, the overall TEMAC SCMF uncertainty importance measures were consulted, and second, linear rank regressions were run on the PDS distributions formed based on sampling all of the independent Level 1 parameters. These two methods gave an estimate of (1) parameters important to the overall problem; and (2) parameters important to the individual PDS frequency distributions. The rank regression techniques utilized were the same as those used to investigate the importance of parameters to the overall Level 3 consequence measures. These methods are described in Section 9.4. The actual regression results are not presented here.

After choosing a subset of the Level 1 parameters, the PDS frequency distributions were again calculated with TEMAC utilizing mean values for those parameters not in the selected subset. Statistics on the frequency distributions were then :alculated and compared to the same statistics for the base case with all parameters sampled. The mean, median, and 5th and 95th percentiles were compared, with particular attention being given to the mean and median (the outer percentiles were expected to vary significantly just on the basis of a different LHS sample). Significant differences were originally found for a few of the PDSs. More detailed analysis was then performed on the actual events which are involved in the cutsets comprising those PDSs for which the frequency distributions were not adequate, and a different set of parameters was chosen. The TEMAC calculations were then performed again, and the comparison of results was repeated. After several iterations of this process and the inclusion of fifty of the Level 1 parameters, good agreement was achieved between the distributions of the PDS frequencies with all parameters sampled, and with fifty parameters sampled. The event distributions utilized for generation of the PDS frequency distrikutions are identical to those presented in [9-1].

\subsubsection{Seismic Events PDS Uncertainty}

The seismic analysis as described in [9-4] involves a variety of un tain parameters, as does the internal events analysis. Parallel to the in ral events study, a subset of these parameters were random failu of components. Data from the internal events study were utiliz o characterize these random failures. These random failures are, how :, lower level contributors as compared to seismically-induced failu : s. Seismic failure of components is a function of an assessed fragility for e component as well as a defined range of applied seismic accelerations. Evin the component's fragility, and the acceleration and recurrence frequency of the earthquake are uncertain and were described probabilistically. 
In this analysis, no connection between the LHS samples for random failures for the internal events and random failure for seismic events except that the same data could be established. Random correlation could thus not be controlled, nor could any existing correlations be modeled. This meant that random failures in the same component modeled in both analyses were treated independently. To assess uncertainty in the seismic analysis, an LHS sample different from the LHS sample for the rest of the PSA was generated and propagated through the seismic models. After being coupled with the component fragilities, sequence conditional failure probabilities were generated. At this time, those sequence conditional failure probabilities were coupled with the range of possible earthquake accelerations and their associated frequencies (called the Hazard Curves) to generate frequencies of core melt. The uncertainty in the range of Hazard Curves is represented in the seismic analysis by ten discrete Hazard Curves of equal probability.

The seismic sequences have been binned into ten plant damage states (only seven of which have a significant frequency and are carried though the consequence analysis). When all that is desired from the analysis is an estimate of the distribution of the SCMF due to seismic events, all of the sequence conditional failure probabilities may be combined with the ten hazard curves, and statistics generated on the results. For purposes of sampling the PDS frequencies, however, it is important to generate distributions for the PDS frequencies while keeping track of the relationship between the distributions since they are not independent of each other. For this analysis, the seismic analyst assembled the results only up to the point at which the PDS conditional failure probabilities had been combined with the ten hazard curves and then provided a matrix of core melt frequencies which contained information on the LHS sample member, the PDS, and the Hazard Curve utilized for each SCMF datum. This analysis generated 5000 data points in a matrix that was 10 points wide (PDSs), 10 points deep (Hazard curves) and 50 points tall (number of LHS samples for the seismic LHS sample). Figure 9-2 provides a graphical depiction of this three dimensional matrix of data.

This seismic matrix of data provided 500 sample points for each of the seismic plant damage states, as well as all the information needed to keep samples of the plant damage state frequencies consistent among LHS samples as well as between Hazard Curves. To connect the data matrix to the PSA LHS sample, two pointer variables were defined: an LHS sample member pointer variable and a Hazard Curve pointer variable. The LHS sample pointer variable was defined to integrally range from one to fifty, and the Hazard Curve variable was defined to integrally range from one to ten. When the PSA LHS sample was run, these two variables defined 500 combinations picked at random. These two variables were then used to order a 500 member sample of seismic plant damage state frequencies by choosing the correct set of PDS frequencies from the data matrix. To 

illustrate by example, if the seismic LHS pointer variable was twenty and the Hazard variable was one, then from the data generated with the first hazard curve and the twentieth seismic LHS sample member was used. The set of ten PDS frequencies along the PDS row in the matrix was selected and utilized as one sample member in the matrix " $\mathrm{A}$ " as shown in Figure 9-1. The matrix " $A$ " is described in Section 9.3.2, but it essentially contains the matrix of PDS frequency samples for all plant damage states, as well as other information. These frequencies are calculated by the TEMAC code for the internal PDSs utilizing the PSA LHS sample matrix, and, thus, when the seismic PDS frequencies generated by the above method are combined with this matrix, the sample member consistency is retained through the pointer variable connection to the LHS sample. The results thus generated are meaningful only if seismic SCMF uncertainty is dominated by uncertainty unique to the seismic analysis. Since Hazard and fragility are the dominant uncertainties, this is believed to be the case.

This method has advantages and disadvantages. It allows for consistent treatment of the Hazard Curve uncertainty in the seismic PDS sample and the associated connection with the seismic component failures. It does not, however, provide consistency between parallel random failure events in the internal and seismic analyses. For example, a single LHS member may contain the assumption that a particular human action occurred reliably for internal events but unreliably for seismic events. It also only provides one seismic "Level 1" variable in the LHS matrix, which severely restricts the usefulness of the regression analysis which is described in Section 9.4 (with results in Section 10).

\subsubsection{APET Uncertainties}

Uncertain parameters in the accident progression assessment include the APET branching ratios and the APET parameters. Branching ratios in the APET indicate several different types of uncertainty including

(1) failure probabilities for equipment (such as the confinement fans);

(2) human reliability estimates (such as the probability that reactor room sprays would be actuated);

(3) subjective judgment as to whether a certain phenomenon would occur for a given situation (such as how likely it is that a steam explosion would occur during fuel melting); and

(4) subjective judgment as to the effect of phenomena on reactor or confinement systems (such as the size on the leak around the reactor top shield induced by an in-vessel steam explosion).

APET parameters are part of the EVNTRE code input used to evaluate (1) parameters that characterize the performance of the reactor and the 
confinement; and (2) loa.ds on these systems that result from phenomena associated with the acciclent. Examples of APET parameters that might be treated as uncertain include

(1) the temperature at which ignition of the carbon filters would occur;

(2) the level of water in the confinement at which below-grade air flow becomes completely blocked; and

(3) the magnitude of the pressure pulse experience by the filters when a steam explosion occurs in the pump room.

The four types of uncertainties cited above are treated in different manners within the uncertainty assessment. Failure probabilities for equipment are treated as continuous probability of frequency distributions and are modeled as lognormal distributions. This is only a small subset of the APET parameters. Human reliability estimates are also treated as continuous variables with a lognormal distribution. The two types of uncertain parameters whose values are based on subjective knowledge (which may be based on engineering analyses) are treated very differently, however.

The judgment as to whether a certain phenomenon would or would not occur for a given situation is one form of a model uncertainty. An example of this is the question of whether the reactor vessel top fails as a result of a steam explosion, which is a branch in the APET. Assuming that the explosion occurred, the probability of the vessel top failure is determined by the strength of the vessel and the energy release from the steam explosion. For a given explosion in the vessel, failure either would or would not occur, and the accident progression would thus proceed with or without the vessel intact. The same explosion and the same vessel would always produce the same result. Use of a branch ratio to characterize the outcome would imply a failure frequency (i.e., a sometimes failure, sometimes not situation). To avoid treating this as a relative frequency, a different approach is used. Conceptually, the treatment of the uncertainty in the outcome is very simple. The branch ratic for "vessel failure will/won't occur" is assigned a discrete probability distribution with only two values-zero and one. This corresponds to the case where the phenomenon does not occur during the accident (split fraction equals zero) and where it does occur (split fraction equals one). The analyst(s) who performed the analysis are then asked to characterize the quality of the analysis (e.g., the extent of consensus in the result that could be obtained from the scientific community) and the amount of data that supported it. This characterization involved the assignment of an outcome weight based on pre-established guidelines for this assessment. This weight is not varied within the uncertainty analysis. In the LHS sample, the distribution for this branch ratio was composed of a set of zeros and ones, in proportion to the weight the analysts set (e.g., for weight $w$ and 100 LHS samples, the split fraction is equal to one $w * 100$ times and equal to zero $(1-w) * 100$ times). The influence of these uncertain outcomes on the consequences is then investigated using regression techniques as described in Section 9.4. 
Other judgments regarding the effects of phenomena on reactor or confinement systems may best be represented as arising from statistical fluctuations (e.g., a coin toss). Since these are phenomenological uncertainties, it is probably appropriate to consider them as model uncertainties. However, the underlying phenomena may be so complex that mechanistic modeling would never successfully predict the outcome. In such cases, representation as a continuous random variable is more appropriate since no amount of additional research or data gathering could be expected to identify the "correct" outcome for a given situation. The coin toss is a relevant example of a phenomenon for which this characterization is appropriate. It is possible to argue that sufficiently detailed characterization of the forces applied, combined with a model for the motion of a coin could be developed to accurately predict whether a head or tail would result from any given trial. Practically, of course, such an undertaking is impossible. A model that assumes the outcome to be random is adequate for all meaningful applications. Similarly, in this assessment, it was decided that characterization of the outcome of some phenomena was best treated as random. A continuous parameter, representing the frequency of the outcome of interest, was employed.

Consider again the in-vessel steam explosion used as an example above. Under certain conditions during an actual accident, a steam explosion will either occur or it will not. However, our state of knowledge and our ability to physically model the phenomena is such that we do not know whether it will occur, and this is the uncertainty which must be modeled. A continuous probability distribution on the branch ratio for steam explosion occurrence is assessed. Cognizant analysts assessed the relative frequency with which it will occur based on their knowledge of the phenomena involved and frequency estimates based on available data. This treatment provides for the identification of this uncertainty as being important to the risk results. However, it does not lead to the same effect on the results. The potential for a "correct" outcome that may eventually be discerned is not recognized. Rather, the results incorporate the sensitivity to the assessed relative frequency.

To assign a probability distribution to this continuous description of phenomenological uncertainty, the analyst assigns minimum, maximum, and median values, as well as up to two other percentile values, if they can be arrived at. A Maximum Entropy distribution [9-5] was then assessed for the analyst's assignment of distribution values. When assigning only percentiles of a distribution, the maximum entropy technique results in a piece-wise uniform distribution between the assigned percentiles. An example is shown in Figure 9-3.

There are a large number of possible uncertain split fractions and parameters in the APET. To provide guidance on the variables that might be important in the analysis (and to identify the ones that are known to be unimportant) a panel of analysts was assembled, and the APET was examined by question and case for insights into which variables should be 


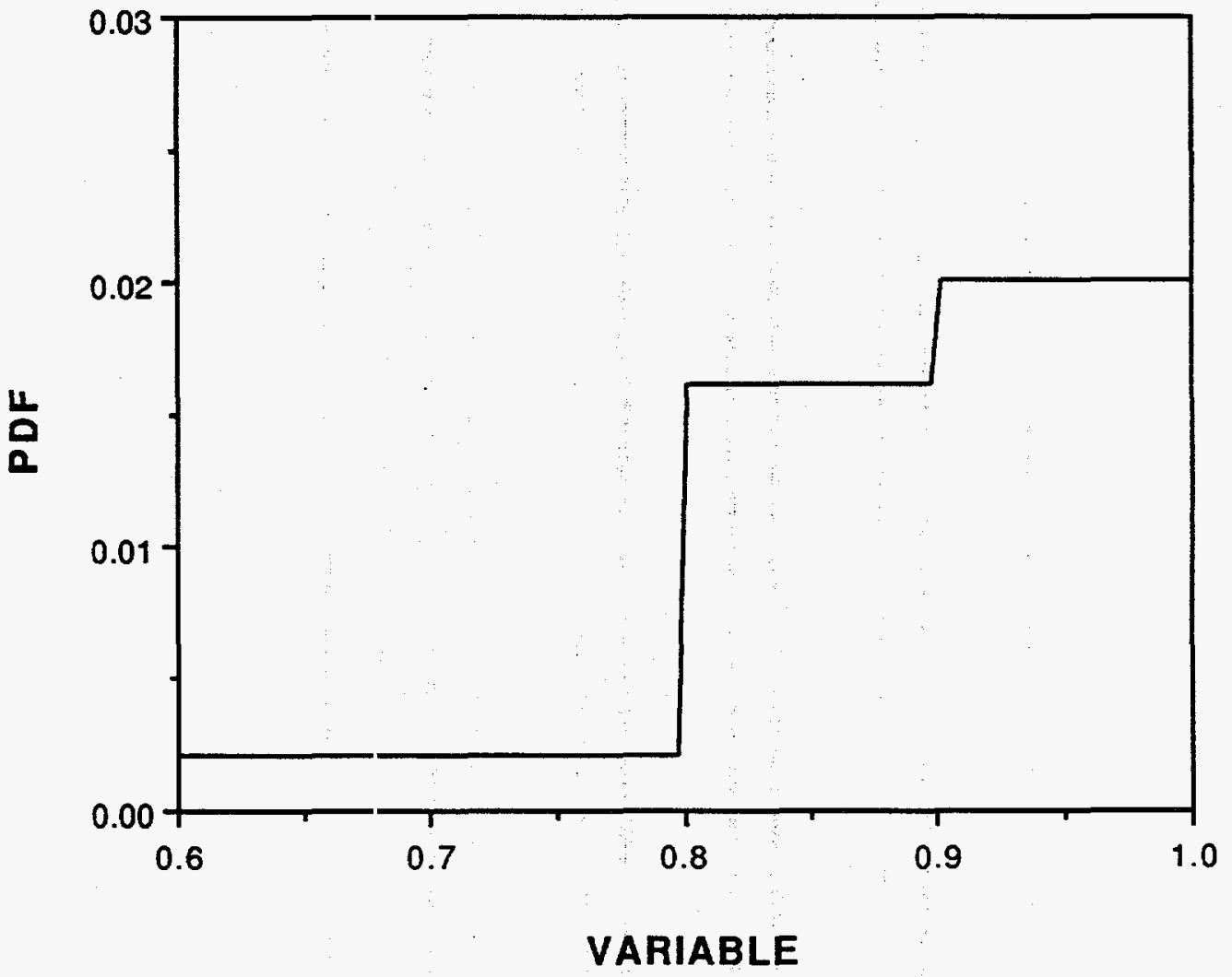

Figure 9-3. Example Maximum Entropy Distribution With Only Quantile Constraints Imposed 
different split fractions which it was felt had a possibility of being important. However, during this assessment of the APET, the variables chosen for inclusion in the uncertainty model also were examined for the possibility of correlation to other variables in the analysis. Variables were selected to be correlated on the basis of knowledge of the relationship between phenomena. This means that it may be known that when a certain phenomena exhibits behavior on the high end of its range of possible behaviors, then some other variable must also exhibit behavior on the high end of its uncertainty range. This occurs often when the two variables describe phenomena which directly affect each other such as the magnitude of a physical shock and a component's failure probability when exposed to that shock. There was no basis for assuming a correlation of other than 1.0, so all assessed correlations were set at 1.0. The assessed correlations reduced the number of independent APET variables sampled to 63 out of the 132 total variables.

These variables describe a wide variety of phenomena represented in the APET. Tables A-1 and A-2 in Reference 9-6 describe the sampled variables and give their distribution types, assessed quantiles, and correlations.

\subsubsection{Source Term Calculation Uncertainties}

Uncertain parameters in the source term assessment are the release fractions and decontamination factors that are part of the source term algorithm. These parameters are listed in Table 9-2. There are a large number of input parameters to the source term algorithm PRAST described in Section 7. As in the case of the selection of variables for the APET, the analysts assessed the potentially important uncertain parameters in the source term algorithm. The selection of parameters here was somewhat more straight forward since the parameters generally describe physical phenomena rather than accident progressions, and calculations had been performed in support of the development of the source term algorithm's parameter values. There are also many fewer PRAST parameters than there are possible APET variables.

The result of this assessment defined 49 source term parameters to be uncertain. Of these 49 , however, only six were defined to be independent. The other 43 variables were defined to be correlated to these six independent variables at a correlation of 1.0 . These six sets of variables describe the following six phenomena:

(1) Time of release for short term releases. These are releases which occur between 600 and 3600 seconds after reactor scram.

(2) The very early release fraction. These are release fractions from the core for various fission product groups under conditions of normal melt, rēcriticality, and transient conditions in the first time period of the accident. 
(3) The early release fraction. These are release fractions from the core similar to (2), but later in the accident.

(4) The fraction of remaining core inventory released during MCCI.

(5) The late release fractions for various fission product groups from the filters if they burn.

(6) The late revolatilization fraction of iodine from the contaminated water storage tank.

Some of these parameters are also used in the APET as part of the filter performance assessment.

\subsubsection{Consequence Calculation Uncertainties}

The consequence assessment also includes a large number of model parameters that are uncertain. These include deposition velocities for radionuclides, dose response curve parameters, and the level of contamination at which farmland would be interdicted. Using currently available methods, an integrated assessment of the uncertainty in risk arising from the uncertainty in these parameters would require an inordinate number of MACCS calculations. Assuming that there were fifty source term groups and 500 LHS sample members in the analysis, 25 thousand MACCS runs would be required. Until a methodology to treat consequence uncertainty in a more expeditious fashion is developed, consequence uncertainties will not be included in the integrated assessment of uncertainty in risk. Unfortunately, it has been shown that consequence uncertairities have the potential to increase overall uncertainty, perhaps by an order of magnitude.

\subsection{Interpretation of Flesults}

Before proceeding with the discussion of how the results from the uncertainty evaluation should be interpreted, further amplification on the process itself is required. Figure 9-1 provides a schematic overview of the assembly process. As suggested by the figure, when the codes are used in the uncertainty-evaluation mode, input is obtained from two sources. The first source is the normal input data file that would be used in generating a point estimate. The second source is the output of the LHS code. LHS code output is represented schematically as matrix " $L$ " of Figure 9-1. It consists of a series of input vectors. Each vector is a set of values for the parameters in the model that have been selected as being uncertain. The combination of input vectors is referred to as the sample. Each vector is thus a sample member. Values from each vector, in turn, are used to replace the nominal input values in successive calculations during the uncertainty study. 


\subsubsection{LHS Sample Generation}

The LHS sample was generated by a two step process. In the first step, the LHS computer code was utilized to generate a sample matrix for the independent LHS variables and a few of the correlated ones. The second step in the process utilized a code built specifically for this PSA named EXTEND, which calculates distributions for variables which are totally correlated to variables in the LHS matrix as the matrix is produced-by the LHS code.

In the production of the sample matrix of independent variables, information from the spreadsheet shown as Table B-2 in Appendix B is utilized by a Macintosh-based code to set up the input file used by LHS to generate the sample matrix. This Macintosh code incorporates the Maximum Entropy Computer code IMPAGE [9-7], and utilizes it to generate maximum entropy distributions to be included in the LHS input file as cumulative distribution functions that LHS can read. This sample matrix contains all of the independent variables as well as a few dependent variables, because the EXTEND code can only calculate distributions for variables which are correlated to other variables and for which exactly the same quantile definitions have been made. A few variables that have unique quantile definitions had to be included in the sample produced by the LHS code.

After LHS produces a matrix which includes the independent variables, the EXTEND code is run to generate the final LHS matrix [L]. The method for producing the correlated samples is straightforward: For two variables which are defined to be totally correlated and had the same quantile definitions made, the LHS sample for the independent variable was examined on an LHS sample member basis; for each sample member, a value from the correlated distribution was produced. This correlated value was produced by comparing the independent variable's sample value with its quantile definitions, and then linearly interpolating between the same quantiles in the dependent variable's range. In this manner, a correlated sample is produced. An examination of the statistics for the LHS sample variables in the matrix [L] has been performed; the EXTEND code was shown to be providing correlated distributions with the correct quantile statistics and which are correlated very close to 1.0 with their respective independent variables.

\subsubsection{Propagation of the LHS Sample Through the PSA models}

When the code constituting each PSA module is run, it substitutes values from the LHS vector for selected parameters, ignoring the values it would have obtained from its input file. The codes automatically repeat their execution of the problem for each vector of inputs found in the LHS output file. The result, indicated schematically in Figure 9-1, is a set of output matrices, and within these matrices, there are results for each sample member in the LHS sample. 
The assembly process for the uncertainty analysis begins with a TEMAC run. TEMAC produces a plant damage state frequency and split fraction matrix, [A], which has 500 sample members. The matrix has $\mathbf{n}+\mathbf{m}$ vectors of values, corresponding to the number of plant damage states (n) plus the number of split fraction:s calculated from the Level 1 results (m) (e.g., a split between small and large process water break sizes for a specific PDS). EVNTRE is then run $\mathbf{n}$ times, once for each plant damage state. Each run results in $\mathbf{5 0 0}$ sets of accident progression bin conditional probabilities, one set for each LHS sample nember in each of $\mathbf{n}$ files ([ $\left.\left.\mathbf{B}_{\mathbf{i}}\right]\right)$.

PSTEVNT performs tvo functions in the assembly process. First, PSTEVNT bins the accident progression bins into source term bins, producing the matrices $\left[\mathbb{C}_{i}\right]$, one matrix for each PDS. Second, it is run to produce a master bin list, which is a list of all of the unique source term bins which occur in any plant damage state in any LHS sample member. This is the matrix $[E]$ in Figure 9-1. The $\left[\mathbf{C}_{i}\right]$ files contain the source term bins by LHS sample member, and each file describes a specific PDS. The PSTEVNT output files are not directly usable by the PRAST, PARTITION and PRAMIS programs, and must be combined into a single large file which contains all plant damage state results for all LHS samples. This is accomplished with a simple utility program which reads the $\mathbf{n}$ PSTEVNT files in and then writes them back out in one big file. This is the matrix [D] in Figure 9-1 which contains the source term bin results by PDS and by LHS sample member. PRAST is then run. PRAST calculates source terms for each of the source term bins in the matrix [D] on a by LHS sample member basis. The result is a source term matrix [F], which contains one set of source terms for each sample member.

A source term bin will have a unique source term for each sample member in which it occurs. Not every source term bin will occur in every sample member. The maximum number of source terms is the product of the number of unique source term bins and the number of members in the LHS sample (this would only occur if every unique source term bin occurred in every LHS sample membir). For example, if there are 10,000 unique source term bins and 500 sample members, a maximum of 5,000,000 source terms could be produced. (Duriag this analysis, for approximately 10,000 unique source term bins with 5010 sample members, the actual number of -ique source terms produced wes on the order of 150,000 . It is recognized ti. his number of unique source terms is far more than would be requ to characterize the uncertainty in the source terms. Rather, this ge number is an artifact of the automated uncertainty approach.) '1e PARTITION program is then run. PARTITION assigns each of th ? source terms to a bin on the basis of similar effects on consequences, a produces the matrix [G], which is a set of grouped source terms, "Partitions". Generally, 20 to 50 partitions are generated. These partition. contain contributions from source terms from many plant damage stat and LHS sample members. Finally, MACCS is run for each partition $t$, predict the consequences of the source term that represents each partition. 
The MACCS results are used to generate the matrix $[\mathbf{H}]$ which contains the mean consequences of interest for each of the partitions.

\subsubsection{Risk Assembly}

Having produced these results, the assembly code PRAMIS was executed. PRAMIS performs the matrix multiplication assembling the matrices [A], [D], [E], and [H] for each sample member. The result is a point estimate of risk for each sample member. (Note that the LHS sample matrix $[\mathbf{L}]$ is input to PRAMIS, but is only echoed back out of the code into the output file to provide a convenient format for reading the input and output variables into the SAS [9-8] package for statistical analyses. This is the matrix [J] in Figure 9-1). These point estimates are actually point estimates of the mean (annual) risk, and contain no information on the exceedance frequency of levels of the consequence measure. This is because the PRAMIS code considers only mean consequence values from the MACCS results. Thus, the 500 point estimates produced provide a sample from the distribution of the mean consequence, incorporating uncertainties from the Level 1 and Level 2 analyses, but not from the Level 3 MACCS consequence runs. To assemble all available risk and uncertainty information from all three levels of the PSA, it is necessary to utilize the PRAMIS code to generate distributions for the PARTITION source term group frequencies (this is normally performed during the PRAMIS calculations, but must be separated out at this point). These distributions are then combined by partition with the CCDF information as it is generated by MACCS, instead of just using the mean MACCS consequence. This calculation must be performed outside of PRAMIS and a small program has been written to accomplish this. These results can be plotted as a family of CCDFs.

The raw results of the combination of the partition frequencies (500 values of frequency for each partition) and the MACCS CCDF information yield 500 separate curves, one for each of the 500 LHS sample members. To produce a meaningful representation of these 500 curves, a value from each curve at many consequence levels along the abscissa may be taken, and for each level of consequence, statistics from the 500 point estimates from the 500 curves may be formed. The statistics of interest are the mean, and the 5th, 50th, and 95th percentiles at each consequence level. Thus, four curves may be plotted to represent the distribution of the actual set of 500 curves which form the most basic risk results. Very little useful information is lost in this process.

\subsection{Individual Parameter Importance to Uncertainty}

Probably the most important information that can be gained from this analysis is the relative importance of various parameters in determining the overall uncertainty in risk. Standard statistical techniques can be applied to the results to obtain this information. The PRAMIS code provides output that can be interpreted by the Statistical Analysis Subroutines (SAS) Package [9-8]. The principal analysis tool is the application of rank regression to the results. 
Assume that rank regression is to be applied in order to determine which uncertain parameters have the greatest role in determining the uncertainty in early fatality risk (EF). There are $\mathbf{M}$ members in the sample (500 were used in the current study). First, the mean risk value for each sample member is assigned a rank within its sample. That sample member with the greatest risk is given the highest rank (i.e., M). That sample member having the lowest mean risk of early fatality is assigned a rank of unity. The remaining sample members are similarly ranked. Expressions for the rank of risk are then written in terms of the uncertain parameters considered. If linear regression is applied, the expressions obtained would be linear as follows:

$$
\begin{gathered}
\mathbf{R k}_{1}=\mathrm{A}_{1} \mathrm{U}_{11}+\mathrm{A}_{2} \mathrm{U}_{21}+\mathrm{A}_{3} \mathrm{U}_{31}+\ldots+\mathrm{A}_{\mathrm{n}} \mathrm{U}_{\mathrm{n} 1} \\
\mathbf{R}_{2}=\mathrm{A}_{1} \mathrm{U}_{12}+\mathrm{A}_{2} \mathrm{U}_{22}+\mathrm{A}_{3} \mathrm{U}_{32}+\ldots+\mathrm{A}_{\mathrm{n}} \mathrm{U}_{\mathrm{n} 2} \\
\vdots \\
\mathbf{R k}_{\mathrm{M}}=\mathrm{A}_{1} \mathrm{U}_{1 \mathrm{M}}+\mathrm{A}_{2} \mathrm{U}_{2 \mathrm{M}}+\mathrm{A}_{3} \mathrm{U}_{3 \mathrm{M}}+\ldots+\mathrm{A}_{\mathrm{n}} \mathrm{U}_{\mathrm{nM}}
\end{gathered}
$$

where

$\mathbf{R} \mathbf{k}_{\mathbf{i}}=$ Rank of the early fatality risk for the ith sample member

$A_{i}=$ Constant

$U_{\mathrm{ji}}=$ Rank of the $\mathrm{jth}$ uncertain parameter in the ith sample member ( $U$ is the LHS output vector)

$M=$ The number of sample members in the sample (i.e., the sample size, 500 in this report)

$\mathrm{n}=\quad$ The number of parameters treated as being uncertain.

These expressions correspond to a system of $M$ simultaneous equations in $\mathbf{n}$ unknowns. This system can be solved for the values of $A_{i}$. The magnitude of the constant $A_{i}$ indicates the relative importance of the $i$ th uncei in parameter.

Non-linear rank regression is more useful in determining the relativ importance of the variouis parameters. Results from this type of analysi are expressed in terms of the fraction of the variance in risk rank that is attributable to variation in the value of a given parameter. These importance results can be used to focus future research with the objective of reducing uncertainty. Importance, as measured by this process, can be used to assign priority to the various research efforts that are contemplated. 
Within the SAS system, there are many packages available to perform regression calculations. The package utilized for this work used a procedure termed "stepwise regression". This routine automates the selection of important variables in a consistent and useful fashion. The basic procedure is to begin with a model with no variables, and then to consider all of the possible input variables and add the most important one to the model. Then all of the remaining variables are considered and the most important of them is added to the model. This process is repeated until a predefined confidence level for limiting inclusion of variables in the model is reached ( $\alpha$-level to enter). As variables are added to the model, checks are also made of the variables in the model to make sure that they are still contributing to the model. At a predefined lower confidence level ( $\alpha$-level for deletion) a variable may be dropped from the model if it no longer contributes.

The stepwise regression calculations were performed with an $\alpha$-level of 0.02 to enter the regression model, and an $\alpha$-level of 0.05 for deletion from the model. Individual $\mathrm{R}^{2}$ values were examined after the regressions were performed, as well as engineering judgment utilized to terminate reporting of the regression results. It was found that for individual $\mathrm{R}^{2}$ values much less than approximately 0.01 , the importance of the variables could not be trusted. This result stemmed from the appearance of certain variables in the regression results that intuitively should not be affecting the answer to any great extent (e.g., Level 1 parameters which showed only slight affects on the PDS frequencies and Level 1 calculated split fractions, but showed up "important" in the regression results at an individual $\mathrm{R}^{2}<0.01$ ). These variables were not reported in the uncertainty contributors sections for the internal and seismic regressions.

\subsection{References}

9-1. M. D. Brandyberry, et al., SRS PSA of Reactor Operations- Level 1 Internal Events, WSRC-RP-89-570, Westinghouse Savannah River Company, Aiken, SC, June 1990.

9-2. R. L. Iman and M. J. Shortencarier, "A FORTRAN 77 Program and User's Guide for the Generation of Latin Hypercube and Random Samples for Use with Computer Models," NUREG/CR-3624, Sandia National Laboratories, Albuquerque, NM, March 1984.

9-3 R. L. Iman and M. J. Shortencarier, A User's Guide for the Top Event Matrix Analysis Code (TEMAC), NUREG/CR-4598, Sandia National Laboratories, Albuquerque, NM, August 1986.

9-4. M. D. Brandyberry and H. E. Wingo, SRS PSA of Reactor OperationsLevel 1 External Events, Westinghouse Savannah River Company, Aiken, SC, June 1990. 
9-5. I. Cook and S. D. Unwin, "Controlling Principles for Prior Probability Assignments in Nuclear Risk Assessment," Nuclear Science and Engineering. Vol. 94k, pp. 107-119, 1986.

9-6. R. T. Bailey, et al., Quantification of Input for the Accident Progression Event Tree, WSRC-RP-92-977, Westinghouse Savannah River Company, Aiken, SC, October 1992.

9-7. S. D. Unwin, IMPAGE: An Information Theory-Based Probability Assignment Generator. Brief Code and User's Guide, Brookhaven National Laboratory, Technical Report A-3829, August 28, 1987.

9-8. SAS /STAT Users Guide, Version 6, Fourth Edition, Volume 2, SAS Institute Inc., Cary, NC, 1989. 


\subsection{SRS K REACTOR RISK RESULTS}

This section presents the results of the risk analysis with an integrated treatment of uncertainty performed for the Savannah River Site K Reactor for both internal and external initiators. Section 10.2 presents the results for internally generated accident scenarios, and Section 10.3 gives the results for accident scenarios which are seismically initiated. The total risk of reactor operation from all initiator types is described in Section 10.4, as well as a comparison of the results with the DOE safety goals [10-1, 10-2]. As described in the Level 1 PSA external events document [10-3], fire initiated accidents are very small contributors to the K-Reactor severe coremelt frequency and are not explicitly included in this analysis.

Section 10.5 discusses similarities and differences between the risk results for K Reactor as assessed in this PSA, and previous results from an earlier estimate of risk. This earlier analysis [10-4], performed in support of the Savannah River Site Environmental Impact Statement (EIS), was a pointestimate calculation of risk, and did not include any uncertainty information on the accident initiator frequencies or accident progressions. It also incorporated reactor upgrades anticipated for reactor startup, whereas this PSA describes $K$ Reactor in approximately a July 1987 condition for Internal Events (a few post 1987 modifications have been included-see Reference 10-4), and June, 1988 for Seismic Events. An estimate of the PSA results after including the effects of several restart upgrades has been made and is also presented in Section 10.5.

The assembly of the various pieces of the analysis which are ultimately combined to provide measures of risk is described in Section 4 of this report. These pieces include the severe core-melt frequency assessment, the accident progression quantification, the source term calculations, and the consequence assessment. The outputs of the analysis include a wide variety of risk measures, of which a selected subset are presented here. These risk measures, such as onsite and offsite prompt or latent fatality risks, are available in different forms depending upon what information is to be conveyed. Special calculations were performed with specific sets of assumptions to produce results for direct comparisons to such measures as the DOE safety goals, or to compare to the previously published EIS risk estimate (which utilized slightly different assumptions than the PSA). Those assumptions which differ between the risk measures presented here will be explicitly defined during the risk results discussion.

\subsection{Formats for Presentation of Risk Results}

There are many different ways to present similar information, some of which are more appropriate than others, depending upon the intended message. In some instances, there are multiple ways to interpret the same information. This section will describe the formats and interpretations used in this report. 


\subsubsection{Complementary Cumulative Distribution Functions}

The Complementary Cunaulative Distribution Function (CCDF) is the most complete description of a measure of risk. A CCDF plot, a form of which is utilized throughout Sections 10.2 through 10.5, is essentially a family of curves, with each curve representing one complete quantification of the full PSA, from accident initiator through consequences. The abscissa of the plot describes the magnitude of the risk measure, and the ordinate describes the frequency with which the risk magnitude will be exceeded. One curve 3 produced for each sample member in the Latin Hypercube Sample (LF S) utilized in the analysis, and thus a complete family of CCDFs for a particular risk measure would, in this analysis, require the plotting of 500 separate curves. As this would impart very little useful information, the next most complete representation of risk would be to present "typical" and "bounding" curves to repsesent the expected range of the risk as well as the predicted mean. This is accomplished by analyzing the family of 500 curves at many points along the risk measure axis. At any one risk level, there will be 500 estimates of the frequency of exceedance of that level of risk; one from each of the 500 CCIDF curves. Statistics can be calculated from this 500-point sample, and the 5th, 95th, and median percentiles calculated, as well as the sample mean. When this is done at many points along the risk axis, many estimates of the 5 th, 95 th, etc. statistics are generated at many values of the risk, and can then be plotted as just a few curves. These curves can be taken as a summary description of the full set of 500 curves in which only a small amount of information is lost.

In the CCDF plots there are two different types of variation, along a curve in the direction of the conssequence measure, and vertically between curves along the exceedance frequency axis. These two types of variation have different sources. For the raw CCDFs, the variation along a curve is caused by meteorological variation only. For the statistical measure CCDFs (mean, 95th, etc.), however, variation along the curve is produced by variability in the weather status at the time of the accident, as well as the frequency of different types of accidents. Thus, the different types of accidents which may occur, coupled with the consequence analysis use of probabilistic models of the weather over a year's time produce the variation along the summary curve. Variation between the curves vertically, however, is produced only by variation in the input parameters for the severe core-melt, accident progression, and source term analyses. The parameters in the se analyses which have been assigned probability distributions and have $\mathrm{k} n$ propagated throughout the full PSA model cause this curve-to-cur $?$ variability. The two forms of variation also have different interpretation The variation along a raw CCDF represents stochastic variability wit: respect to the effect that weather patterns characteristic to the site have or the consequences from a given radiological source term. Variation along a summary CCDF, however, is a mixture of stochastic and model uncertainty since points along each summary curve may be derived from raw CCDFs produced by different LHS sample members. The curve-tocurve variability for both. raw and summary CCDFs is caused by variation 
in parameters which is caused, for the most part, by imprecisely known data or models. This variation is, therefore, mainly non-stochastic in nature. Thus, more accurate models and data would decrease the spread between the curves, but would do little to decrease the variation along the curve.

\subsubsection{Annual Risk}

It is often desired to obtain a single estimate of a measure of risk for comparison or other purposes. A CCDF plot does not accomplish this. It is possible, however, to utilize the $500 \mathrm{CCDF}$ curves to derive 500 estimates of mean or "annual" risk. This is accomplished by integrating each of the $500 \mathrm{CCDF}$ curves and reducing it to a single value; i.e., the mean risk for each curve. This, then, will produce 500 mean risk values, one for each curve. In performing this operation, however, all information relating the frequencies of the various risk levels is lost and all that is left is the average of the risk over a year's time period. Statistics can then be formed on the 500 samples of annual risk, and a mean value formed to represent a "pointestimate" of risk. Note that there is really very little information contained in this point-estimate; it is essentially the mean of the mean (annual) risk.

\subsubsection{Individual and Societal Risk}

Within the following discussions, results will be presented in two forms: as societal risks, which will be the predicted levels of consequence within a population at risk, and individual risk, which can be interpreted as the frequency of the analyzed consequence happening to an "average" individual within the zone of interest for the accident. The societal risk implicitly includes the distribution of the population within the zone of interest for the accident. The individual risk, however, has "averaged out" this population distribution, and cannot actually be thought to apply to any single individual within the zone of influence.

\subsubsection{Fractional Contributions to Risk}

Two methods of calculating the "fractional contribution" attributable to various intermediate results in the PSA analysis to the value of the risk measures have been built into the PRAMIS computer code [10-6] utilized to quantify the SRS PSA. Both of these two methods provide estimates of the fraction of a consequence measure attributable to a Plant Damage State, to a specific Source Term Bin Groups, to Source Term Bins with specified Attributes, and to specified individual Source Term Bins. Utilizing nomenclature defined in Reference 10-6, the two calculational methods will now be described.

For some defined consequence, called $\mathrm{X}$, an $\mathrm{X}_{\mathrm{ij}}$ value may be calculated from accident progressions associated with each of the $j$ Plant Damage States for each of the i LHS sample members. For Internal Events, nine Plant Damage States have been defined for this analysis. Also, 500 LHS sample members are used. This results in a set of consequence measures which may be envisioned as the following $9 \times 500$ member matrix: 


$$
\left[\begin{array}{cccc}
x_{1,1} & x_{1,2} & \cdots & x_{1,9} \\
x_{2,1} & x_{2,2} & \cdots & x_{2,9} \\
\vdots & \vdots & & \vdots \\
x_{5 j 0,1} & x_{500,2} & \cdots & x_{500,9}
\end{array}\right]
$$

Note that these consequence values are all mean annual risk values as discussed above.

The first method for computing a fractional contribution of one of the Plant Damage States to the value of consequence $\mathrm{X}$ will be called the Fractional Contribution to Mean Risk, or FCMR, following nomenclature in [10-6]. The FCMR from Plant Damage State $\mathrm{j}$ is then defined:

$$
\text { FCMRPDS }_{j}=\frac{\sum_{i=1}^{500} X_{i j}}{\sum_{i=1}^{500} \sum_{j=1}^{9} X_{i j}}
$$

This method is essentially the ratio of the annual risk due to PDS group $j$ to the total annual risk.

The second method for computing the fractional contribution to risk will be called the Mean Fractional Contribution to Risk, and will be denoted MFCR, also following [4]. This method computes the fraction as:

$$
\begin{gathered}
\operatorname{MFCR}_{P D S_{j}}=\frac{\sum_{i=1}^{500} Z_{i j}}{500} \\
\text { where } \\
Z_{i j}=\frac{X_{i j}}{\sum_{j=1}^{9} X_{i j}}
\end{gathered}
$$

Thus, the $Z_{i j}$ value is the average contribution of $\mathrm{PDS}_{\mathrm{j}}$ to consequ ce $\mathrm{X}$ for LHS sample member $i$; then these average contributions are avera $d$ to get the MFCRPDS ${ }_{j}$ -

A limited sensitivity study has been performed as part of the PSA: lysis by using the two fractional contribution methods and two differer. LHS samples [10-7]. The MFCR method was found to provide fre onal contribution values which are less sensitive to statistical variatior. than the FCMR method (i.e., MFCR values for the PSA results were similar 
between samples, whereas FCMR results were not always similar). The discussions that follow will utilize the MFCR method.

\subsubsection{Statistical Analyses}

It is possible to investigate the relationships between the consequence variables and the uncertain input variables through use of mutivariate regression techniques. For this PSA, various regression models have been applied to selected consequences, and conclusions on the relative importance of some of the independent variables with respect to the uncertainty in consequences have been drawn. In general, it was discovered that variation in the risk was driven to a large extent by the front-end analyses, i.e., the Plant Damage State frequencies and the associated Level 1 variables. In order to isolate the effects of the Level 2 variable and analyses on the uncertainty, a set of risk calculations were performed with all of the Plant Damage State frequencies set equal to 1.0. This allowed variation in the consequence values to be completely controlled by the conditional probability values of the Source Term Bins. These conditional probabilities are, in some cases, still linked to the Level 1 variables through split fractions calculated from the Level 1 variables. However, it is obvious from the regression results that "masking" the PDS frequencies did allow a more thorough investigation into the importance of the Level 2 variables alone.

As described in Section 9 of this report, many of the analysis variables were correlated (at values of essentially 1.0) to other variables. For purposes of the regression analyses, only independent variables were used as regressors (i.e., a group of correlated variables was represented by a single variable), and no conclusions are possible about the relative importance of individual variables within a set of variables which are correlated.

All regressions were performed on ranked and raw variable data. Similarly to [10-7], the rank regression performed well and the results discussed are in Sections 10.2.3 and 10.3.3.

\subsection{Results for Internal Initiators}

This section describes the Internal Events risk results for both offsite and onsite consequence measures. Section 10.2.1 presents the basic risk results in the form of CCDFs for three offsite consequence measures and two onsite consequence measures, and annualized risk distributions for eleven different measures (Appendix A contains the CCDFs for the other six consequence measures). Section 10.2.2 then describes the important analysis elements contributing to these consequences, and Section 10.2.3 discusses the results of the regression calculations which are designed to estimate the most important sources of uncertainty in the model. Appendix A contains more detail on the derivation of the results discussed here. 


\subsubsection{Risk Results}

This report presents the results of eleven different consequence calculations, six offsite and five onsite. There were other results of less interest calculated which are not presented here. The consequences presented were chosen for various reasons, some to investigate specific answers needed, such as the safety guideline comparisons made in Section 10.4, and others to be consistent with generally recognized measures of reactor risk. The offsite consequences presented here generally parallel those presented in Reference 10-7. The onsite consequences presented are designed to either address DOE safety goals, or to provide more global measures of onsite consequences. The eleven defined consequence measures are given below (CCDFs shown in this Section are marked with an *).

Offsite:

(1)* Total prompl; fatalities within 50 miles of $K$ Reactor (fatalities per reactor-year);

(2)* Total latent cancer fatalities. (fatalities per reactor-year);

(3) Total effective dose equivalent (EDE) whole-body population dose within 50 miles of $\mathrm{K}$ Reactor. (person-rem per reactoryear);

(4)* Prompt fatality individual risk within 1 mile of the site boundary. (per reactor-year);

(5) Latent cancer fatality individual risk within 10 miles of the site boundary. (per reactor-year);

(6) EDE whole-kody population dose within the region (1000 miles from $\mathrm{K}$ Reactor). (person-rem per reactor-year).

Onsite:

(7)* Total prompt fatalities over the site. (fatalities per reactoryear);

(8)* Total latent cancer fatalities over the site. (fatalitie. er reactor-year);

(9) Total EDE whole-body population dose over the site. (perso rem per rea(tor-year);

(10) Prompt fatality individual risk within 1 mile of $\mathrm{K}$ Reactor. (pe reactor-year); 
(11) Latent cancer fatality individual risk within 10 miles of $\mathrm{K}$ Reactor. (per reactor-year).

The most basic risk results for the Internal Initiator class of accidents are presented in Figures 10-1 (offsite results) and 10-2 (onsite results). The CCDFs shown in these figures describe the frequency with which each of the consequence measures is predicted to be exceeded, and its uncertainty band. As described in Section 10.1.1, the plots shown here are actually statistical measures describing the set of 500 CCDF curves generated by the full integrated analysis.

As described in Section 10.1.2, the results can also be presented in the form of annual risk, which essentially reduces each of the 500 CCDFs to a single mean value. These 500 values thus form a set of discrete points that characterize the distribution of the mean (annual) consequence. Table 10-1 presents four statistical measures of the distributions of annual risk for all eleven of the discussed consequence measures.

There are several interesting features of the CCDFs presented here. The offsite 1000-mile latent fatalities CCDF exhibits a very flat shape below approximately 60 cancer fatalities. In the event of a reactor accident this means that latent cancer consequence results of this magnitude $(<60)$ are unlikely. Similar behavior of the latent fatality CCDFs was observed in the results presented in Reference 10-7. It is inappropriate, however, to draw conclusions from differences (or similarities) between CCDFs from analyses of different reactors at different sites, since the shapes of the CCDF curves are very much controlled by the local population distributions at the sites.

For several of the consequence measures, the curves show the mean CCDF curve approaching the 95th percentile curve. This is an expected result and occurs when a few observations with large consequences from the sample are controlling the mean result. There are also several places in the curves where discontinuities exist in the curves. This is not a result of any physical phenomena, but rather a result of the fact that no type of smoothing was attempted for these curves. The discrete CCDFs output by the consequence code at times do not have a large number of points, and also at times exhibit some large discontinuities near their limits.

Table 10-1 contains several statistical measures describing the distributions of many consequence types for internally generated accidents at $\mathrm{K}$ Reactor. While it is not strictly appropriate to compare CCDF shapes from different analyses directly, once the risk information has been integrated down to annual risk, comparisons between reactors may be made.

For offsite consequences, we may compare K-Reactor results with those of $\mathrm{N}$ Reactor as well as commercial reactors. Commercial PSAs do not perform calculations to assess onsite risk, and thus the only comparison which can be made is between $\mathrm{K}$ Reactor to N Reactor. Tables 10-2 and 10-3 show these comparisons. The commercial reactor results shown are taken from the NUREG-1150 plant studies, of which Reference 10-7 is a part. 


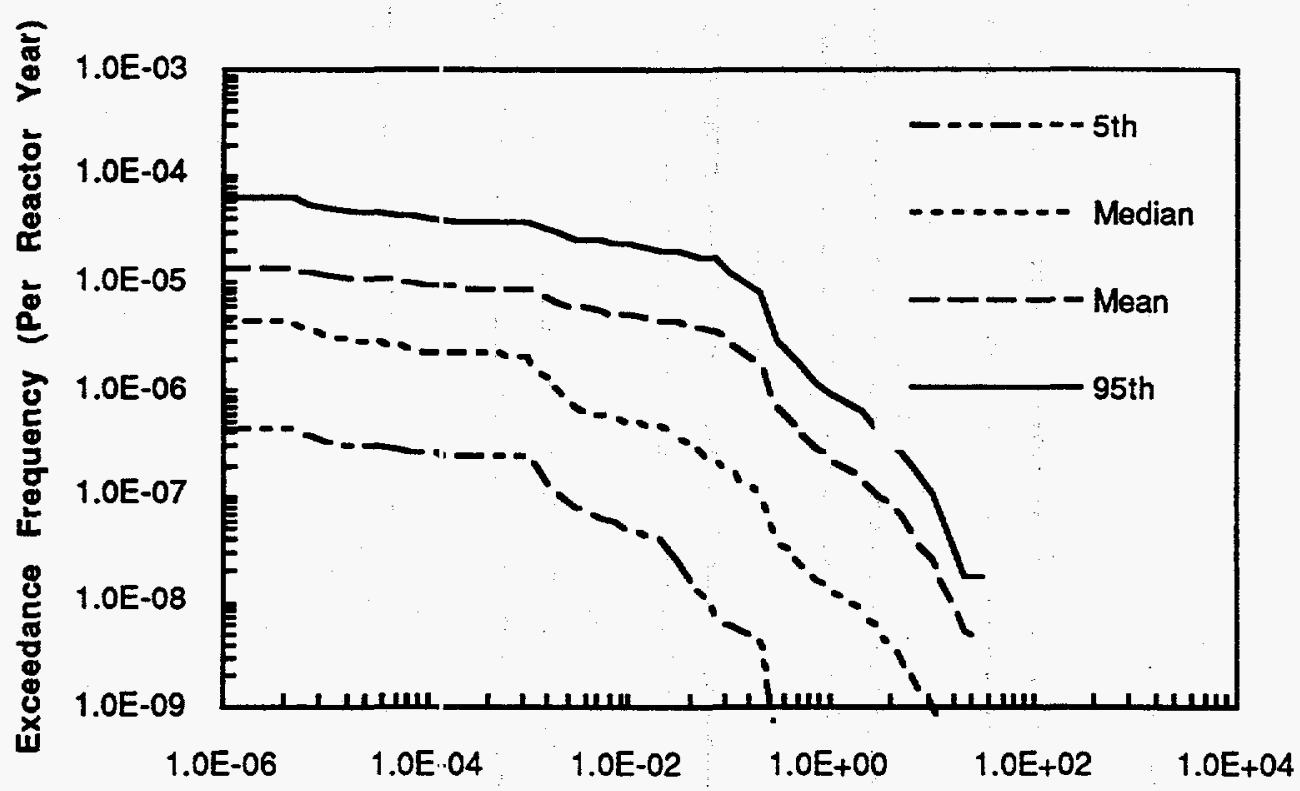

Offsite Prompt Fatalities Within 50 Miles of $\mathrm{K}$ Reactor Due to Internal Initiators

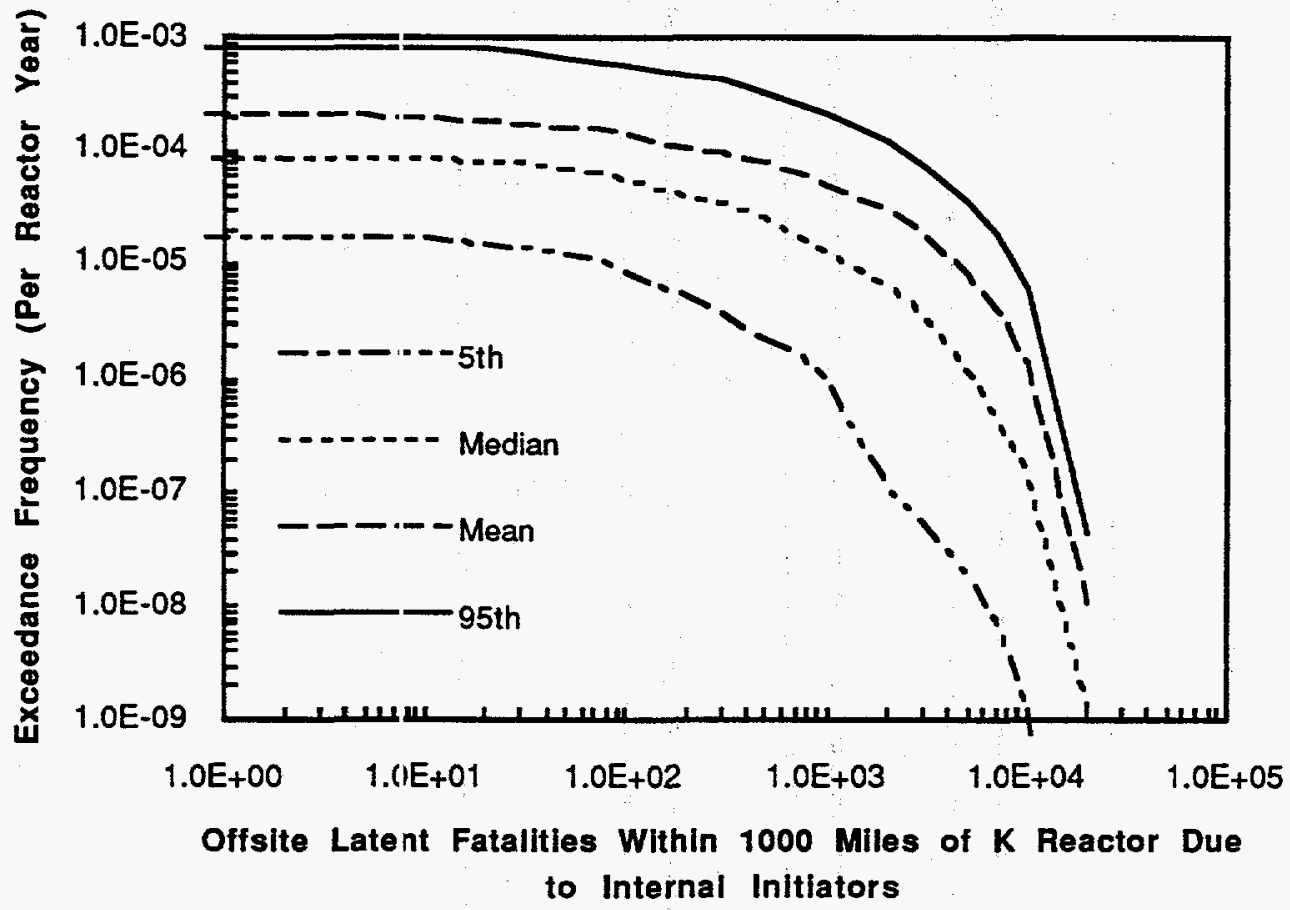

Figure 10-1. Exceedance Frequencies for Risk for K Reactor - All Internal Initiators - Offisite 


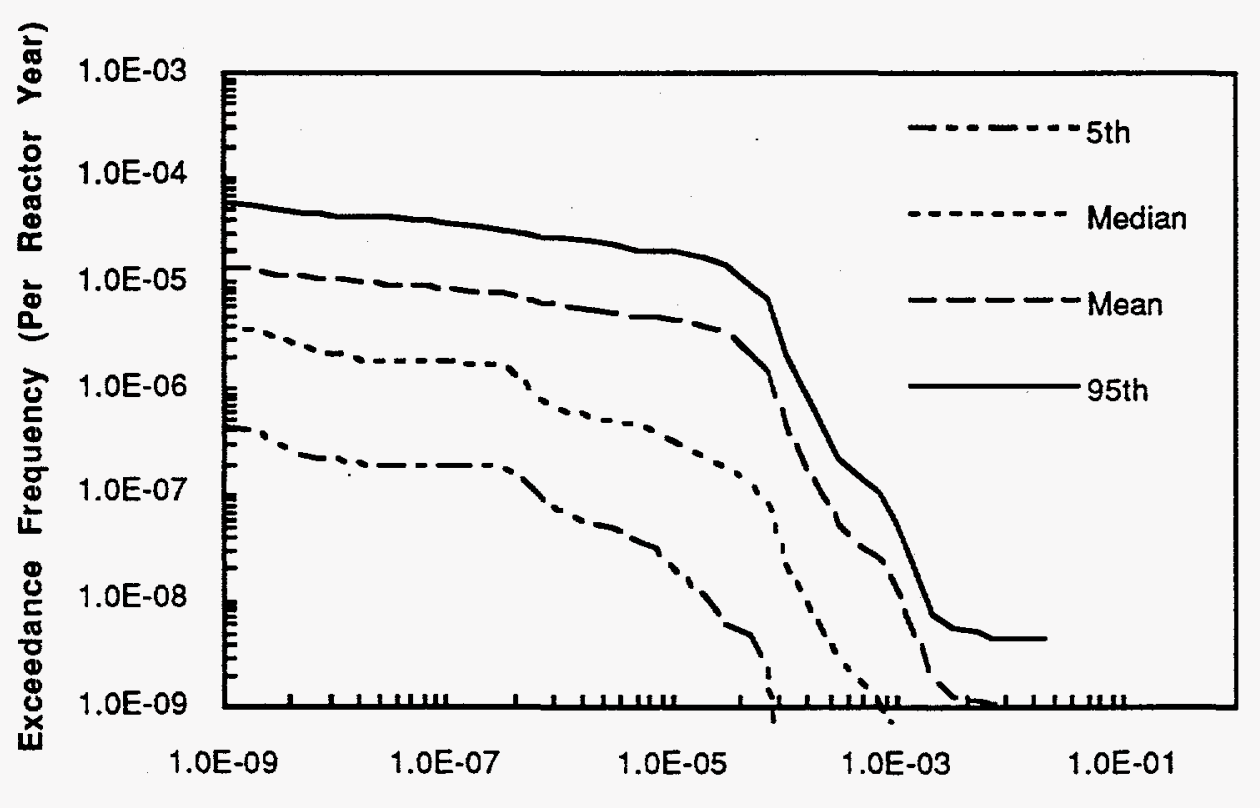

Offsite Prompt Fatality Risk to an Individual Within 1 Mile of the Site Boundary Due to Internal Initiators

Figure 10-1. Exceedance Frequencies for Risk for K Reactor - All Internal Initiators - Offsite ( cont'd) 

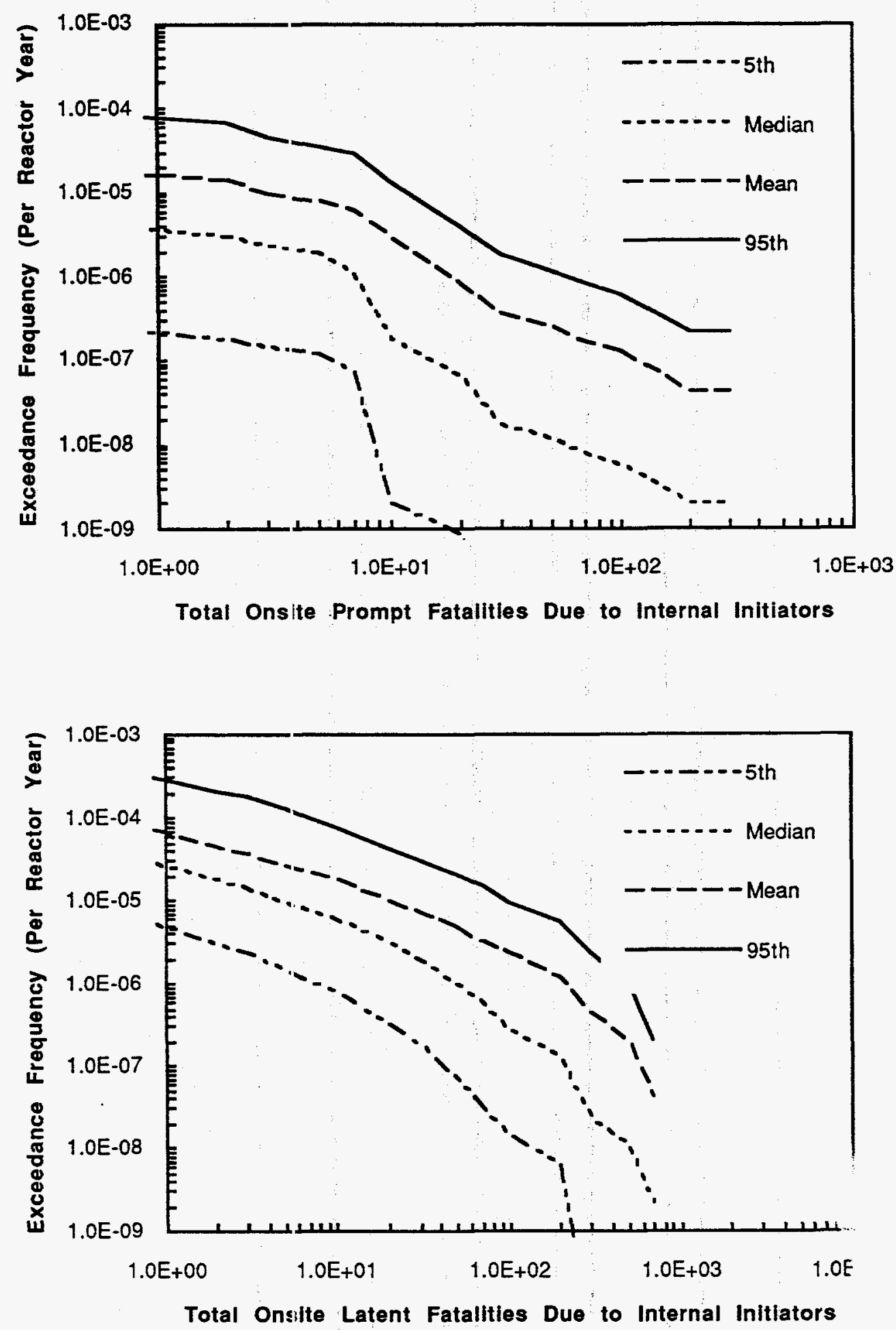

Figure 10-2. Exceedance Frequencies for Risk for $\mathrm{K}$ Reactor - All Internal Initiators - Onsite 
Table 10-1. Distributions of Offsite and Onsite Annual Risk Measures for K Reactor (Internal Initiators, per Reactor-Year)

\begin{tabular}{|c|c|c|c|c|}
\hline Risk Measure & $\begin{array}{c}\text { 5th } \\
\text { Percentile }\end{array}$ & Median & Mean & $\begin{array}{c}\text { 95th } \\
\text { Percentile }\end{array}$ \\
\hline \multicolumn{5}{|l|}{ OFFSITE: } \\
\hline Total Prompt Fatalities (per $R x-Y_{r}$ ) & $4.3 \times 10^{-9}$ & $1.1 \times 10^{-7}$ & $2.0 \times 10^{-6}$ & $8.5 \times 10^{-6}$ \\
\hline Total Latent Fatalities (per $R x-Y r$ ) & $6.9 \times 10^{-3}$ & $6.0 \times 10^{-2}$ & $2.0 \times 10^{-1}$ & 0.92 \\
\hline $\begin{array}{l}\text { Population Dose within } 50 \text { miles } \\
\text { (person-rem) }\end{array}$ & 5.3 & 40 & 110 & 480 \\
\hline $\begin{array}{l}\text { Prompt Fatality Risk Within } 1 \text { mile of Site } \\
\text { Boundary (per Rx-Yr) }\end{array}$ & $1.0 \times 10^{-12}$ & $2.0 \times 10^{-11}$ & $3.0 \times 10^{-10}$ & $1.3 \times 10^{-9}$ \\
\hline $\begin{array}{l}\text { Latent Fatality Risk Within } 10 \text { miles of } \\
\text { Site Boundary (per } R x-Y r \text { ) }\end{array}$ & $2.2 \times 10^{-9}$ & $1.6 \times 10^{-8}$ & $4.7 \times 10^{-8}$ & $2.0 \times 10^{-7}$ \\
\hline $\begin{array}{l}\text { Population Dose Within } 1000 \text { mile } \\
\text { Region (person-rem) }\end{array}$ & 44 & 370 & 1200 & 5700 \\
\hline \multicolumn{5}{|l|}{ ONSITE: } \\
\hline Total Site Prompt Fatalities (per $R x-Y r$ ) & $1.5 \times 10^{-6}$ & $2.3 \times 10^{-5}$ & $1.4 \times 10^{-4}$ & $6.6 \times 10^{-4}$ \\
\hline Total Site Latent Fatalities (per Rx-Yr) & $4.2 \times 10^{-5}$ & $3.0 \times 10^{-5}$ & $1.2 \times 10^{-3}$ & $4.8 \times 10^{-3}$ \\
\hline $\begin{array}{l}\text { Total Site Population Dose (person- } \\
\text { rem) }\end{array}$ & 0.21 & 1.5 & 5.6 & 24 \\
\hline $\begin{array}{l}\text { Prompt Fatality Risk Within } 1 \text { mile of } K \\
\text { Reactor (per } R x-Y r \text { ) }\end{array}$ & $1.6 \times 10^{-9}$ & $2.5 \times 10^{-8}$ & $1.2 \times 10^{-7}$ & $5.6 \times 10^{-7}$ \\
\hline $\begin{array}{l}\text { Latent Fatality Risk Within } 10 \text { miles of } K \\
\text { Reactor (per } R X-Y r \text { ) }\end{array}$ & $2.7 \times 10^{-9}$ & $1.9 \times 10^{-8}$ & $7.5 \times 10^{-8}$ & $3.1 \times 10^{-7}$ \\
\hline
\end{tabular}




\subsection{INSIGHTS AND CONCLUSIONS}

The PSA results presented in this document represent only a summary of the information available from the results of the analysis. This information is in addition to the phenomenological analysis that supported the development and quantification of the PSA model. Documentation of the phenomenological analyses are provided in separate reports as referenced throughout this document. The purpose of this section is to examine the results of the PSA and determine what general conclusions or insights can be drawn regarding severe accident progression in SRS reactors. The top priority is to establish the importance to the consequences and risk of the events and phenomena considered, so as to support risk management strategies. To accomplish this determination, the results of the PSA will be evaluated to answer the following:

(1) How well does the confinement system perform its function of mitigating the consequences of a release of fission products from the reactor core?

(2) How do the different failure modes of systems comprising (or contained within) the confinement affect accident progression, consequences, and risk?

(3) How important are the different aspects of accident phenomenology to the subsequent progression of the accident and to consequences and risk?

It should be noted again that this PSA describes K Reactor in its 1987 configuration. A limiting power level of $2500 \mathrm{MW}$ was chosen to bound what, at the time, was the uncertain outcome of work then in progress to determine the maximum allowed operating power level. Discussion of the three areas above will focus on this operating state, describing the PSA results as produced. This will provide a basis for comparison of these results with those of the ongoing upgrade of the Level 2/3 PSA to the current $\mathrm{K}$ Reactor configuration operating at $720 \mathrm{MW}$. The discussion, however, will be tempered with the knowledge that the PSA may show a very different risk profile at the lower operating power.

\subsection{Confinement Performance}

The K Reactor confinement system consists of active and passive components that form the final barrier to fission product release to the environment. The confinement is not sealed, and its volume is constantly being exhausted to the atmosphere through a filter bank and a $200-\mathrm{ft}$. stack. This is the only "normal" pathway for air, and potential contamination, to leave the building. Other pathways may be opened during the progression of a severe accident due to failure of the exhaust system or due to energetic events within the confinement. These pathways include the heat exchanger bay covers, personnel access doors, and_a transient pathway through the D\&E canal. The fan and filter system may fail due to either energetic events 


\section{Table 10-3. K-Reactor Mean Annual Onsite Consequences Compared to Mean Consequences Calculated For N Reactor (Internal Events)}

\begin{tabular}{lcc}
\hline \multicolumn{1}{c}{ Consequence } & K Reactor & N Reactor \\
\hline \hline Total Site Prompt Fatalities (per Rx-Yr) & $1.4 \times 10^{-4}$ & $1.0 \times 10^{-6}$ \\
Total Site Latent Fatalities (per Rx-Yr) & $1.2 \times 10^{-3}$ & $2.7 \times 10^{-4}$ \\
$\begin{array}{l}\text { Total Site Population Dose } \\
\text { (person-rem) }\end{array}$ & 5.6 & 1.7 \\
$\begin{array}{l}\text { Prompt Fatality Risk Within 1 mile of } \\
\text { K Reactor (per Rx-Yr) }\end{array}$ & $1.2 \times 10^{-7}$ & $7.2 \times 10^{-10}$ \\
$\begin{array}{l}\text { Latent Fatality Risk Within 10 miles of } \\
\text { K Reactor (per Rx-Yr) }\end{array}$ & $7.5 \times 10^{-8}$ & $2.9 \times 10^{-9}$ \\
\hline
\end{tabular}

The results generated in this report utilize methods taken from the NUREG-1150 effort, and thus should not be biased among plants due to the methodology. The N-Reactor study also utilized much of the NUREG-1150 methodology.

As can be seen from the results in the tables, $K$ Reactor exhibits significant consequence differences from some of the other reactors. The largest difference is in the calculated population doses. This reflects the fact that $\mathrm{K}$ Reactor's confinement is often predicted to fail early in the accident scenario from energetic events which are postulated to occur.

The higher doses are also reflected in the total latent cancer fatality mean values. The $\mathrm{K}$ Reactor values for total latent cancer fatalities are significantly higher than any of the other reactors. Reference 10-7 has a useful argument to put the cancer fatality values into perspective. The mean value of 0.20 offsite cancer fatalities per year of $\mathrm{K}$-Reactor operation is a summary of the CCDF curves. From the CCDF curves, the following values may be obtained: 


\begin{tabular}{|c|c|c|}
\hline \multirow[b]{2}{*}{ Consequence } & \multicolumn{2}{|c|}{$\begin{array}{l}\text { Exceedance Frequency } \\
\text { (per reactor-year) }\end{array}$} \\
\hline & Mean & Median \\
\hline $\begin{array}{l}100 \text { latent cancir fatalities } \\
10000 \text { latent canier fatalities }\end{array}$ & $1.4 \times 10^{-4}$ & $5.5 \times 10^{-5}$ \\
\hline & & $1.5 \times 10^{-1}$ \\
\hline
\end{tabular}

To put these seemingly large latent cancer fatalities into perspective, we may consider the following [10-7]:

“... the calculated latent cancer fatalities occur throughout the entire region and cver several decades. Between 400,000 and 500,000 deaths due to cancer occur every year in the U.S. The population within 350 miles of the plant is about 54 million, and the population within 1000 miles of the plant is about 156 million. When spread over two or three decades, event tens of thousands of additional latent cancer fatalities are statistically indistinguishable f:om the general background morbidity due to malignant neoplasms in such a large population."

For K Reactor, the 350-mile population is approximately 32 million and the 1000-mile population is ajproximately 189 million. Current statistics for the U. S. population indicate a cancer fatality rate of approximately 200 per 100,000 population [10-8i]. Thus, in a population of 189 million, nearly 380,000 cancer fatalities would be expected per year. Thus, the calculated latent effects are indistinguishable from "background" cancer deaths in the general population.

The near-field cancer risk, shown in the Latent Fatality Risk Within 10 Miles of Site Boundary consequence measure, is seen to be quite low even though it is still the highest of the reactors shown in Table 10-2. This measure is one of the naeasures compared to the DOE Safety goals in Section 10.5, and it will be seen there that this calculated individual risk meets the safety guideline. $\mathrm{K}$ Reactor is only slightly higher than the Sequoyah and Zion plants.

In contrast to total population dose and resultant latent fatalities, promrt fatalities are strong functions of postulated accident timing, reactor siti: and the distribution of neighboring populations. The calculated ris performance of $\mathrm{K}$ Reactor for prompt fatality consequence measure. compares favorably to the prompt fatality results for the other plants. Table 10-2 shows that the total mean prompt fatalities per reactor-year is approximately in the center of the range of calculated consequences for the five commercial plants. T.he near-field one-mile prompt fatality individual risk compares favorably with the lowest values calculated for the commercial plants. These lower numbers, in the 10-10 range, are nearly indistinguishable from zero for the populations under consideration. 
The N-Reactor comparison is not particularly meaningful for two reasons: the Savannah River Site has a much larger onsite population than the Hanford Site, and it is known that the $\mathrm{N}$ Reactor's postulated accidents are generally much less severe than postulated accidents at $\mathrm{K}$ Reactor. The $\mathrm{K}$ Reactor onsite risks are still quite low, and meet the suggested DOE Safety goals as discussed in Section 10.5.

\subsubsection{Contributors to Risk}

The two measures used to calculate fractional contributions of different parts of the analysis to consequences are described in Section 10.1.4. The following discussions will present only the MFCR results.

There are nine Internal Events Plant Damage States for this PSA as listed in Section 2 of this report. For the eleven different consequence measures defined in Section 10.2.1, Table 10-4 gives the MFCR values as calculated by PRAMIS [10-6] for each of the nine PDSs.

Figure 10-3 shows the data in Table 10-4 for onsite and offsite consequence measures by Plant Damage State. Figure 10-3 indicates that, at least on an average basis, the LOCA with no ECCS and large LOPA states dominate all of the plotted consequence measures. Significant contributions are also made by the transient and loss of river water damage states. These results are, in fact, similar for all consequence measures.

Figure 10-4 gives a sense of the uncertainty in the fractional contribution calculations. There exist 500 values of the fractional contribution for a particular consequence measure (one for each LHS sample member), and the MFCR is the mean of these 500 values. As can be seen from Figure 10-4, for each Plant Damage State, the fractional contribution to consequence (specifically onsite prompt fatalities within one mile of the reactor) varies over a substantial range. Each box in the plot encompasses the middle half of the distribution of the FCR values for one PDS (25th percentile to 75th percentile). The "whiskers" on the boxes reach down to the 5th percentile, and up to the 95th percentile. Outliers (of which there are by definition 25 above and below the whiskers with 500 samples) are plotted as x's. Thus, while the MFCR values discussed here are useful measures of importance in a mean sense, it is necessary to keep in mind that the "answer" as to what is important to the value of a consequence is subject to substantial uncertainty.

Another set of fractional contributions to risk may be calculated for the Source Term Bins and their attributes. These Source Term Bins are an approximate description of the accident progression which are designed to summarize those phenomena which are important to generation of a source term for the accident sequence. The detailed descriptions of the Source Term Bins and attributes are given in Section 7 of this report. There are sixteen dimensions to a Source Term Bin (numbered from 1 to 16), each dimension being characterized by one of two or more attributes, denoted A, B, C, etc. Shown in Table 10-5 are the most important summary scenarios derived from the Source Term Bins for four consequence 
Table 10-4. Mean Fractional Contribution of Internal Events Plant Damage States to Annual Risk

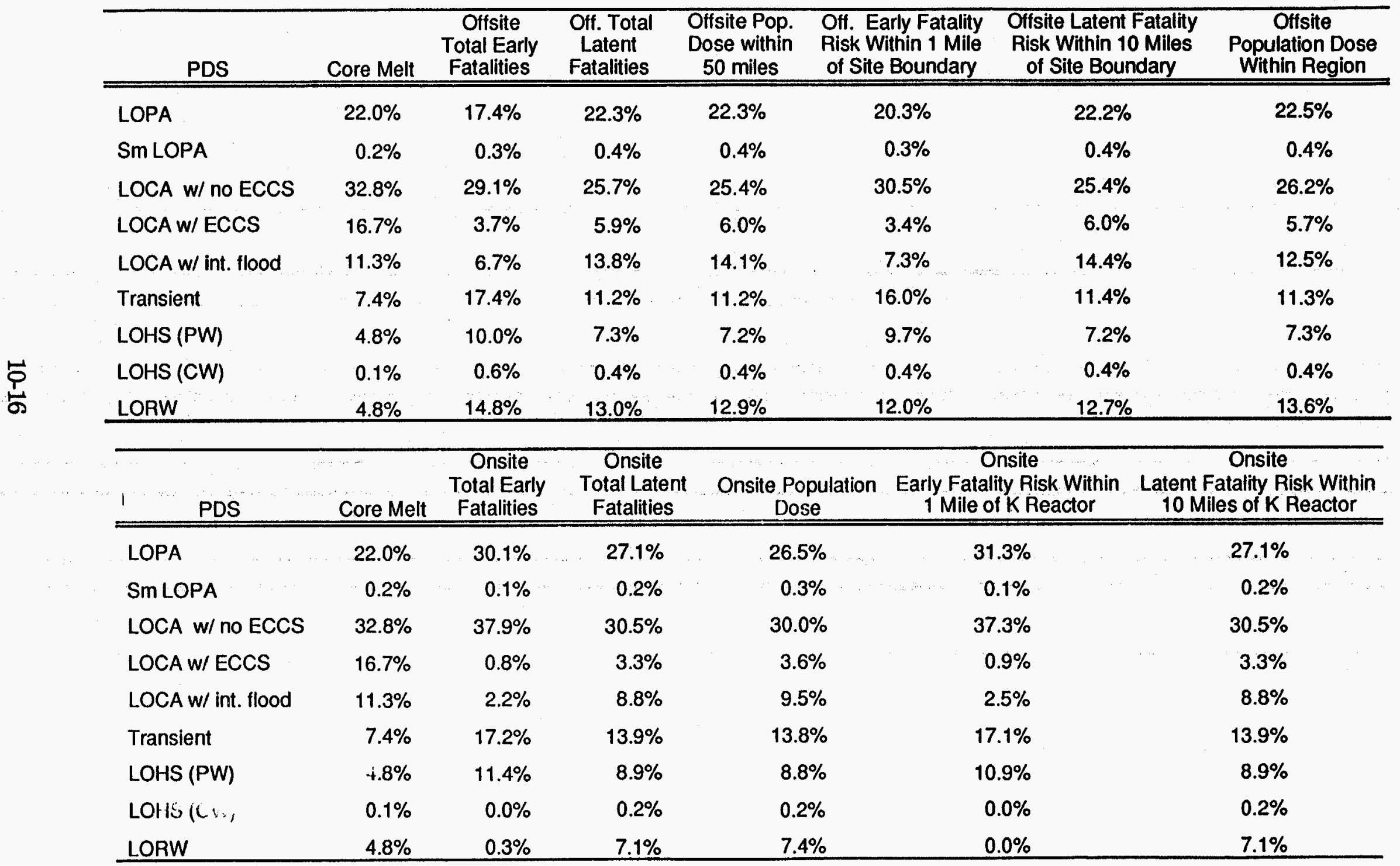




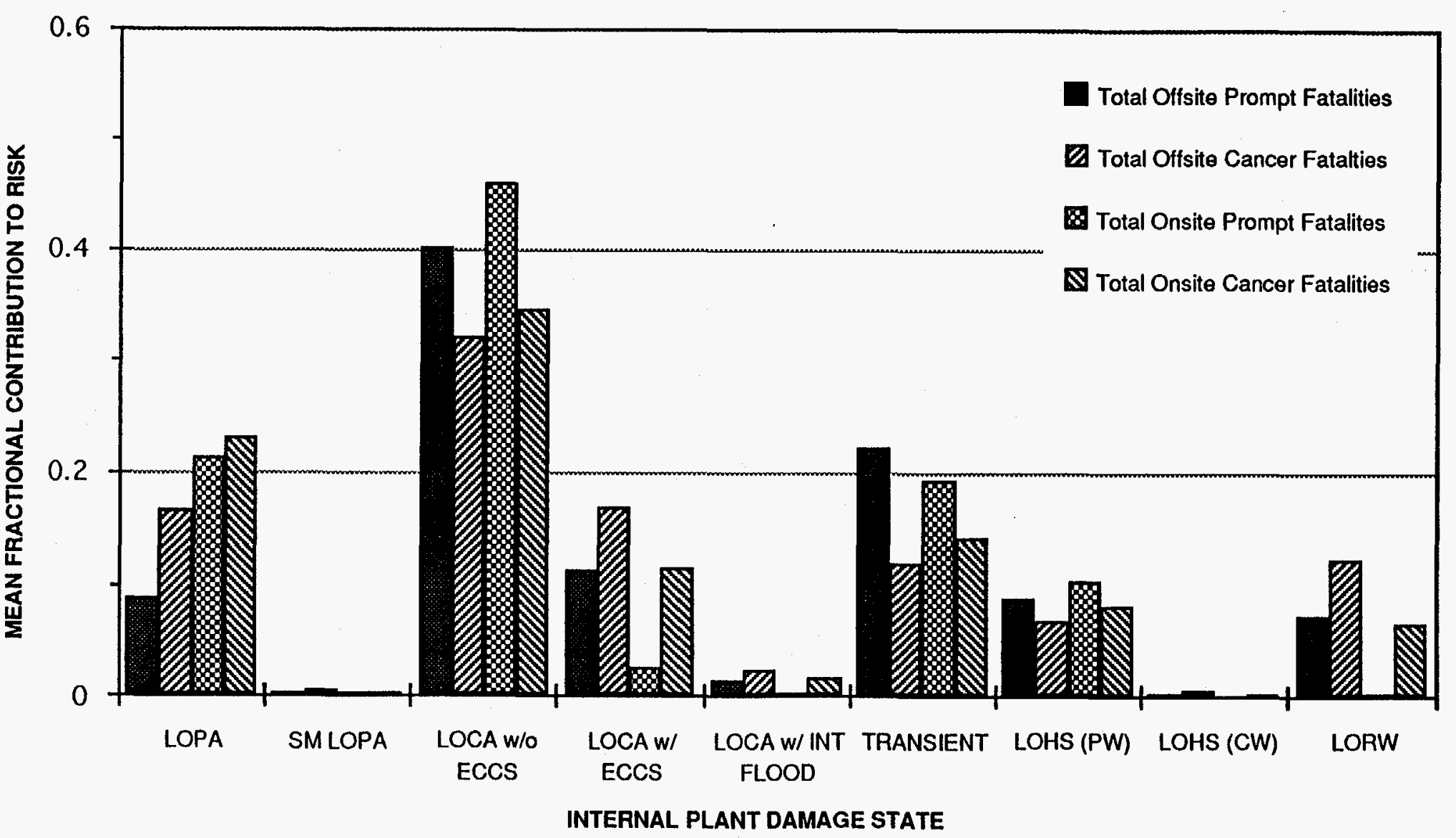

Figure 10-3. Mean Fractional Contribution of Internal Plant Damage States to Selected Consequences 


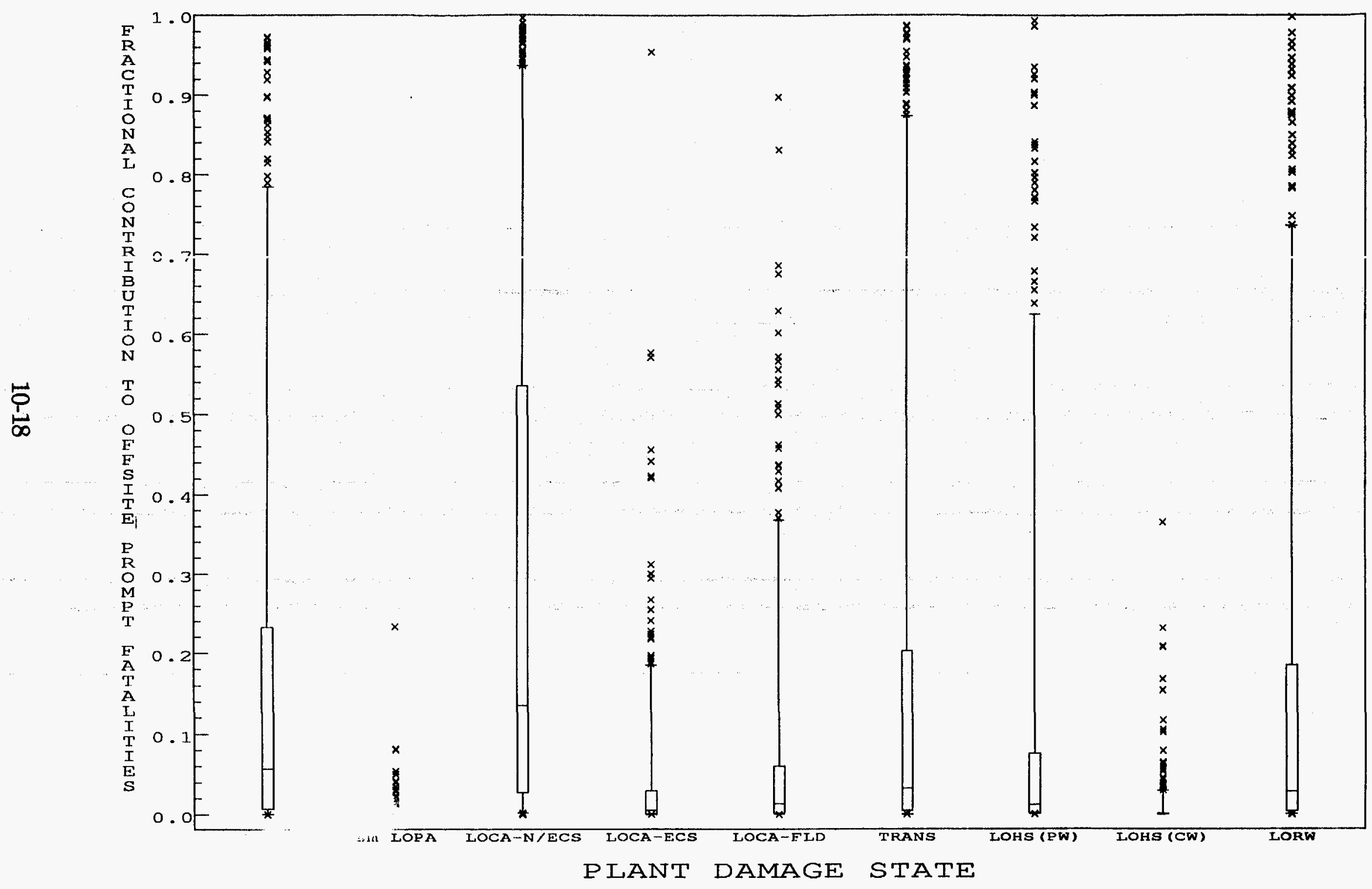

Figure 10-4. Distributions for Fractional Plant Damage State Contributions to Annual Risk: Internal Initiators 
Table 10-5. Summary Source Term Bin Mean Fractional Contributions to Selected Consequence Measures - Internal Initiators

\begin{tabular}{|c|c|c|c|c|}
\hline Scenario & $\begin{array}{c}\text { Offsite } \\
\text { Total } \\
\text { Early } \\
\text { Fatalities }\end{array}$ & $\begin{array}{c}\text { Offsite } \\
\text { Total } \\
\text { Latent } \\
\text { Fatalities } \\
\end{array}$ & $\begin{array}{c}\text { Onsite } \\
\text { Total } \\
\text { Early } \\
\text { Fatalities }\end{array}$ & $\begin{array}{c}\text { Onsite } \\
\text { Total } \\
\text { Latent } \\
\text { Fatalities }\end{array}$ \\
\hline $\begin{array}{l}\text { Early core melt (<10 minutes) } \\
\text { with an energetic in-vessel } \\
\text { recriticality which produces an } \\
\text { in-vessel steam explosion. }\end{array}$ & $7.3 \%$ & $13.1 \%$ & $16.3 \%$ & $16.8 \%$ \\
\hline $\begin{array}{l}\text { Early core melt (<10 minutes) } \\
\text { with either no recriticality or a } \\
\text { "benign" recriticality. A steam } \\
\text { explosion occurs either in- or } \\
\text { ex-vessel. }\end{array}$ & $38.1 \%$ & $30.0 \%$ & $49.4 \%$ & $46.0 \%$ \\
\hline $\begin{array}{l}\text { Later core melt (10 <>120 } \\
\text { minutes) with an energetic in- } \\
\text { vessel recriticality which } \\
\text { produces an in-vessel steam } \\
\text { explosion. }\end{array}$ & $7.1 \%$ & $12.0 \%$ & $2.0 \%$ & $2.6 \%$ \\
\hline $\begin{array}{l}\text { Later core melt (10 <>120 } \\
\text { minutes) with either no } \\
\text { recriticality or a "benign" } \\
\text { recriticality. A steam explosion } \\
\text { occurs either in- or ex-vessel. }\end{array}$ & $6.2 \%$ & $14.3 \%$ & $0.5 \%$ & $0.9 \%$ \\
\hline $\begin{array}{l}\text { Non-energetic core melt with no } \\
\text { other energetic events and } \\
\text { confinement functions normally } \\
\text { (filters may burn late) }\end{array}$ & $37.3 \%$ & $25.5 \%$ & $27.5 \%$ & $29.3 \%$ \\
\hline Total: & $96.0 \%$ & $94.9 \%$ & $95.7 \%$ & $95.6 \%$ \\
\hline $\begin{array}{l}\text { Accidents where the } \\
\text { Confinement is totally bypassed } \\
\text { during the accident }\end{array}$ & $22.0 \%$ & $39.1 \%$ & $28.0 \%$ & $29.0 \%$ \\
\hline
\end{tabular}

measures: onsite prompt and latent fatalities within ten miles of $\mathrm{K}$ Reactor, and offsite prompt and latent fatalities within fifty miles of the site boundary.

The results presented in Table 10-5 demonstrate that with the models of $\mathrm{K}$ Reactor used in this PSA, energetic scenarios drive the risk for all consequences. In scenarios where an energetic recriticality event occurs, an in-vessel steam explosion caused by the recriticality is also modeled to occur. For the cases of a core melt with no recriticality or a benign recriticality, an in-vessel steam explosion may or may not occur. 
For all of these energetic: scenarios, steam explosions of two "magnitudes" are separated in the Source Term Bin; if an explosion occurs, it either fails the confinement or it doesn't. In the MFCR results presented in Table 10-5, the MFCR values from steam explosion scenarios are heavily driven by steam explosions which tail the confinement. Thus, the risks are not only being driven by scenarics involving energetic events, but these energetic events are generally rencering the confinement system ineffective.

Table 10-5 also shows the MFCR results for scenarios where the confinement is totally kypassed; both above- and below-grade. This is generally the result of both failure of the filters and some below-grade damage such as lifting o: the heat exchanger hatch covers by an energetic event.

It is also interesting to note that Table $10-5$ also shows that approximately $28 \%$ of the prompt fatality risks, and $29 \%$ of the latent fatality risks are produced by scenarios in which there are no energetic phenomena and in the confinement remains intact and functioning. These scenarios may, however, include the filters burning late in the accident.

\subsubsection{Contributors to Uncertainty}

An analysis of the consequence results to ascertain which input variables have the greatest influence on the uncertainty in the results has been performed using regression-based sensitivity techniques as described in Sections 9 and 10.1.5. Hegressions have been performed for four of the eleven consequence measures described in this report. These measures are the onsite one mile from reactor individual prompt fatality risk, the onsite 10 mile from reactor individual cancer fatality risk, the offsite 1 mile from site boundary individual prompt fatality risk, and the offsite 10 mile from site boundary individual cancer fatality risk. For this report, it is felt that these four measures encompass the important effects of a severe reactor accident, to the neighboring general public and the onsite workers.

The "conditional" (see Section 10.1.5) stepwise regression results for internal initiators show that Level 2 variable variation in the consequence measures is dominated by the vessel decontamination factor for aerosols, the very early radioisotope release fraction, the lithium melt fractinn, and the fission product revolitalization fraction from the vessel walls. $T$ nsite prompt fatalities, the timing of the release is important for releas hich may or may not occur bifore evacuation begins. The DF for MCC. Ider deep water is important for offsite latent fatalities. The steam exp ion split fraction when the alssembly bottom end fitting fails is importa: or onsite latent fatalities.

The vessel DF for aerosols, the very early radioisotope release fraction, the fission product revolitalization fraction from the vessel walls are il involved with the amount of the reactor fission product inventory whics: is released from the reactor into the confinement. The lithium melt fraction controls whether in-vessel recriticality can occur and the characteristics of 
that event. The early release timing ranges from 600 to 3600 seconds, and since onsite evacuation is modeled to begin at 1800 seconds, it is important to onsite consequences whether the evacuation begins before or after the release.

The "actual" consequence regressions show that the variation in the actual consequence measures is dominated by the small LOCA (bellows break) initiating event frequency (appears in PDS-I3/I4/I5); the large LOPA frequency is also important (appears in PDS-I1). Other consistently important Level 1 variables are the failure-to-shutdown probability (appears only in PDS-I6), the high-stress human error MIA failure probability (appears in any PDS where incident action is necessary), and the process water loss-of-heat-sink initiating event frequency (controls PDS-I7). Mixed in with the Level 1 variables at approximately the same level of importance are the vessel DF for aerosols, the lithium melt fraction, and the very early radioisotope release fraction.

The loss-of-river-water initiating event frequencies would have been expected to contribute before the $\mathrm{PW}$ loss of heat sink (considering the results from the fractional contributions of the LORW PDS and the LOHS (PW) PDS to consequences, see Table 10-2), however, the two LORW event frequencies (with and without grid power) split PDS-I9, which may have diluted their individual effects. They both do appear consistently in the regressions as lower level contributors to the uncertainty.

\subsection{Results for Seismic Initiators}

The Level 1 seismic severe core-melt frequency analysis is described in Reference 10-2, and is performed on the basis of the EPRI hazard curves [10-9] for the SRS. The results from [10-3] have been binned into Seismic Plant Damage States. This process is described in Section 2 of this report.

\subsubsection{Risk Results}

This Section presents both CCDF plots (for five of the eleven consequence measures) and annual risk distributions for the same consequence measures defined in Section 10.2.1. for the Internal Events. These consequence measures have the same definitions as in the Internal Events cases, the main difference in the consequence calculations being a later evacuation timing for seismic scenarios. For Seismic Events, the start of onsite evacuation is assumed to be delayed to one hour after reactor shutdown (versus 30 minutes for Internal Events) and is assumed to be four hours after the start of the radiological release to the environment for offsite evacuation (versus two hours for internals). See Section 8 of this report for more details.

The seismic consequence CCDFs behave very similarly to the Internal Events cases (see Figures 10-5 and 10-6). The offsite latent cancer fatality consequence still exhibits a very flat curve out to approximately 


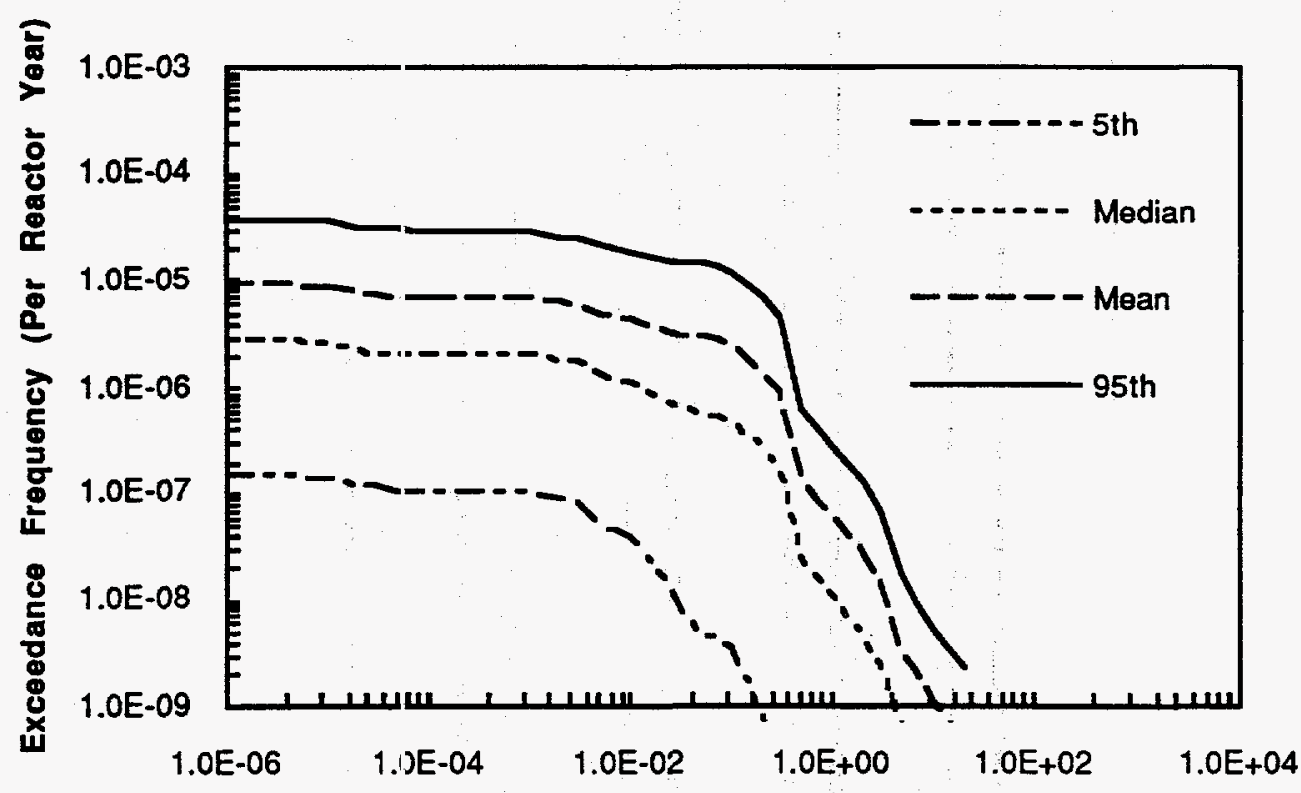

Offsite Prompt Fatalities Within 50 Miles of $K$ Reactor Due to Seismic Initiators

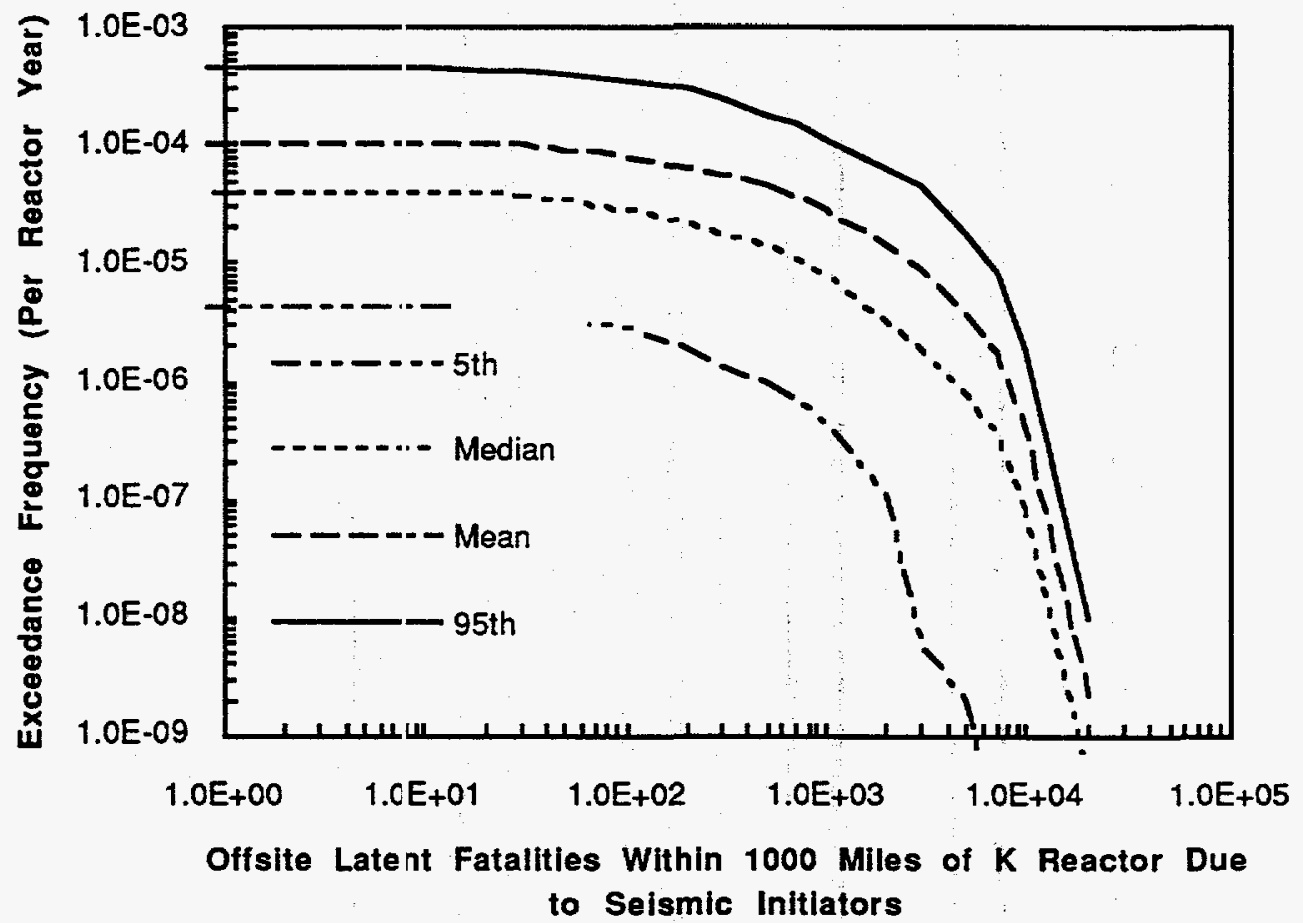

Figure 10-5. Exceedance Frequencies for Risk for $\mathrm{K}$ Reactor - Seismic Initiators - Offsite ${ }^{-}$ 


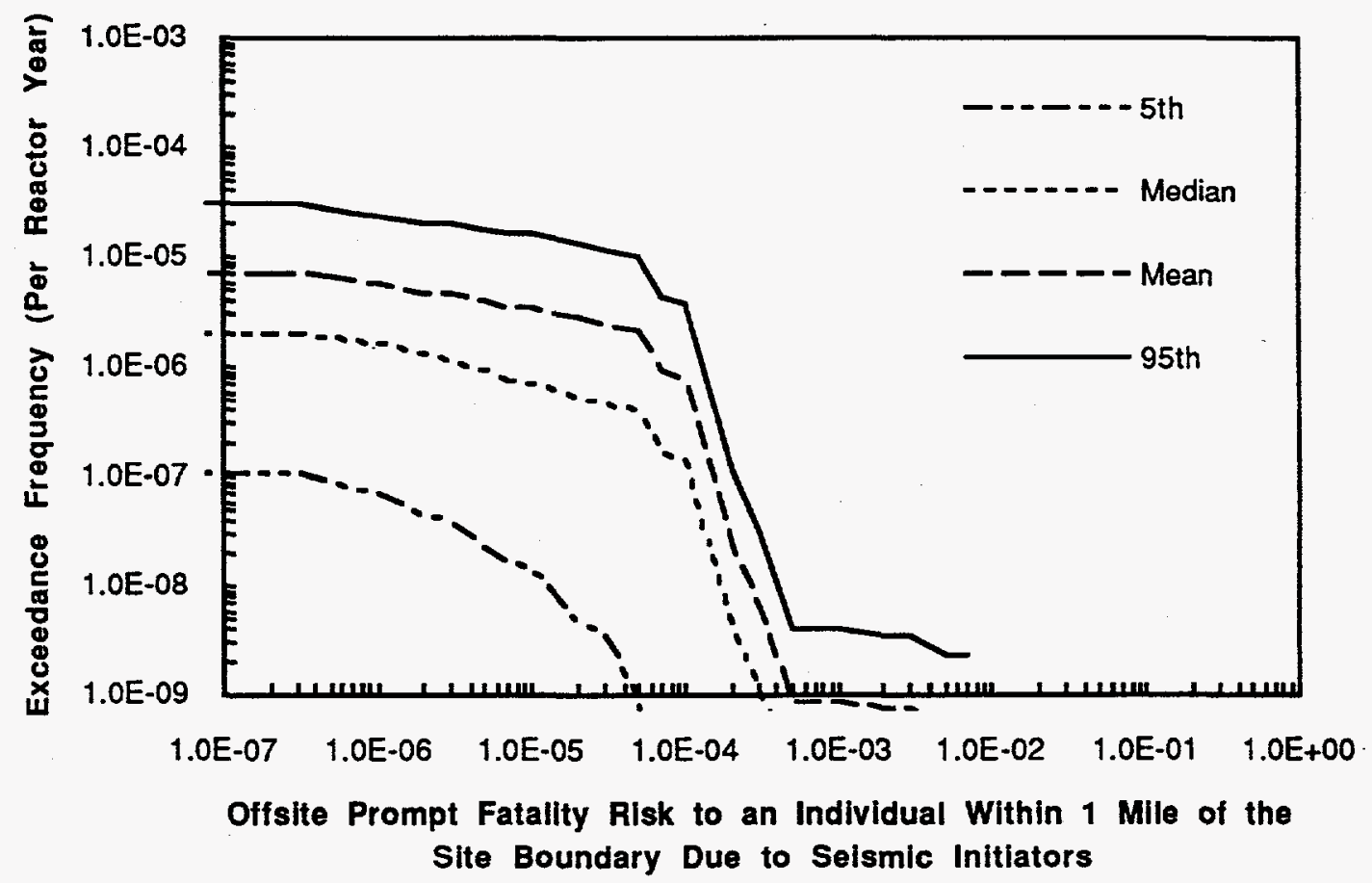

Figure 10-5. Exceedance Frequencies for Risk for K Reactor - Seismic Initiators - Offsite ( cont'd) 

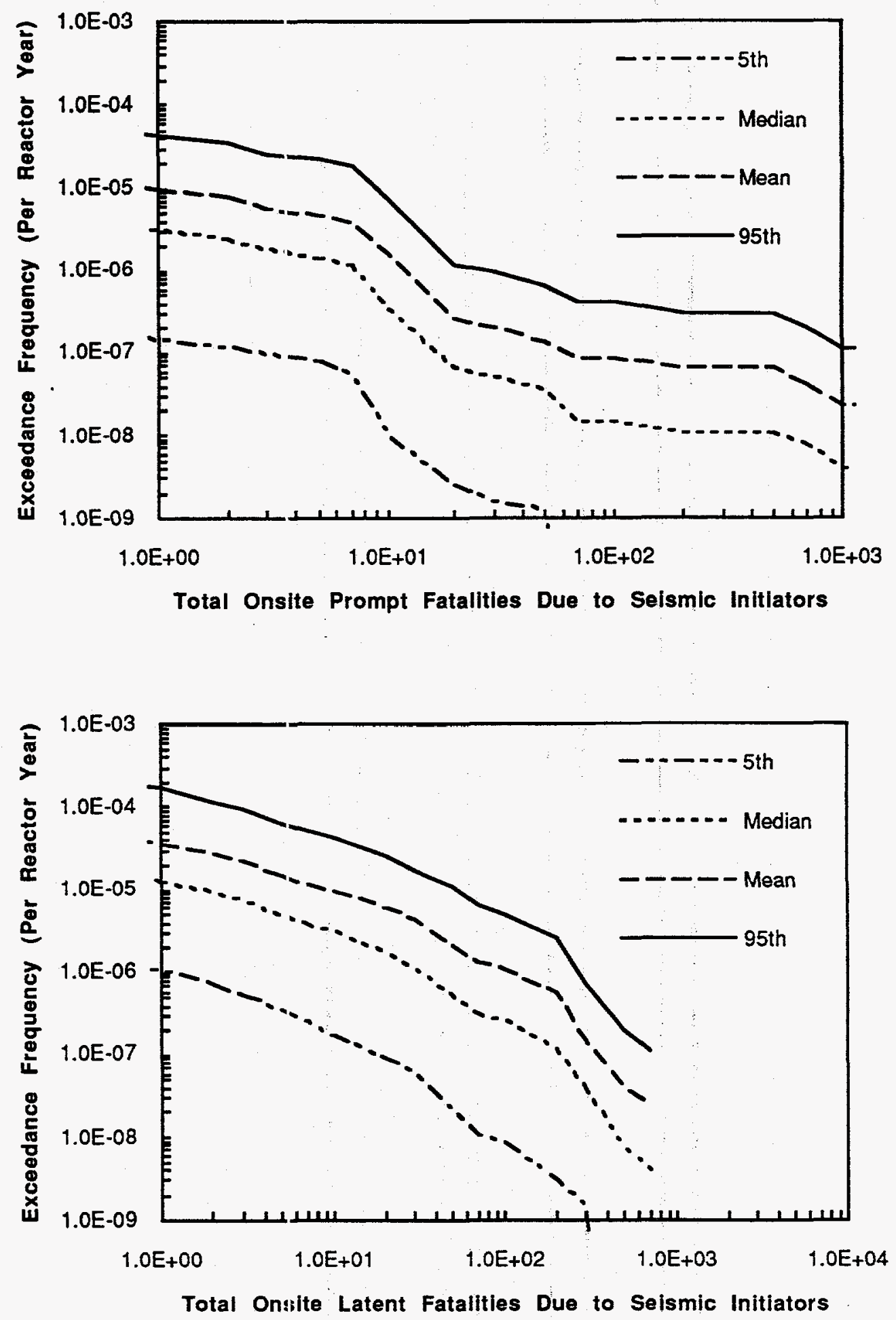

Figure 106. Exceedarice Frequencies for Risk for K Reactor - Seismic Initiators - Onsite 
100 fatalities, indicating a very low probability of generating less than this number of latent fatality deaths in a postulated accident.

The annual risk distributions shown in Table 10-6 may be compared against other calculated reactor risks as was done for the Internal Events risks. Tables 10-7 and 10-8 give the offsite seismic comparisons of $\mathrm{K}$ Reactor to $\mathrm{N}$ Reactor and the five NUREG-1150 plants, and the onsite comparisons to $\mathrm{N}$ Reactor. For the NUREG-1150 plants, the results presented are the results utilizing the EPRI hazard methodology, since this methodology was the basis for the SRS seismic analysis presented in [10-3].

Similar to the Internal Events case, the population doses and latent cancer fatality risk measures are higher than in the other reactor analyses. However, in this case, the total expected latent fatality measure is only a factor of two or so higher than $\mathrm{N}$ Reactor, and less than a factor of ten above Surry. This is within the uncertainty ranges of the analyses. For the ten mile latent cancer fatality individual risks measure, $\mathrm{K}$ Reactor is less than a factor of three higher than both $\mathrm{N}$ Reactor and Surry. Considering the uncertainty ranges, the individual latent fatality risks are to be essentially the same, and are very low.

For prompt fatalities, $\mathrm{K}$ Reactor again compares very favorably against the two analyzed commercial reactors, both for total expected prompt fatalities and the very small 1-mile prompt fatality individual risk.

For the onsite risk comparison to $\mathrm{N}$ Reactor, the reactors and sites are again very different. However, opposite of the Internal Events case, operation of $\mathrm{K}$ Reactor involves less risk from seismically generated scenarios than $\mathrm{N}$ Reactor. For all of the examined consequence measures, those for K Reactor are a factor of two to five less than those for $\mathrm{N}$ Reactor. Again, within the uncertainty bounds, these numbers may as well be the same. The interesting point is the turnaround compared to internally generated scenarios. $\mathrm{K}$ Reactor will be even more resistant to Seismic Events after all of the planned (and many already completed) seismic upgrades are completed.

\subsubsection{Contributors to Risk}

The two measures used to calculate fractional contributions of different parts of the analysis to consequences are described in Section 10.1.4. The discussions that follow will only present the MFCR results.

There are seven significant Seismic Plant Damage States defined for this PSA. For the eleven different consequence measures shown in Section 10.3.1, Table 10-9 gives the MFCR values as calculated by PRAMIS [10-6] for each of the seven PDSs. 
Table 106. Distributions of Offsite and Onsite Annual Risk Measures for K Reactor from Seismic Scenarios (per Reactor-Year)

\begin{tabular}{|c|c|c|c|c|}
\hline Risk Measure & $\begin{array}{c}5 \text { th } \\
\text { Percentile } \\
\end{array}$ & Median & Mean & $\begin{array}{c}\text { 95th } \\
\text { Percentile }\end{array}$ \\
\hline \multicolumn{5}{|l|}{ OFFSITE: } \\
\hline Total Prompt Fatalities (per $R x-Y r$ ) & $3.9 \times 10^{-9}$ & $1.8 \times 10^{-7}$ & $8.7 \times 10^{-7}$ & $4.1 \times 10^{-6}$ \\
\hline Total Latent Fatalities (per Rx-Yr) & $2.2 \times 10^{-3}$ & $3.3 \times 10^{-2}$ & $1.0 \times 10^{-1}$ & $4.1 \times 10^{-1}$ \\
\hline $\begin{array}{l}\text { Population Dose within } 50 \text { miles; } \\
\text { (person-rem) }\end{array}$ & 1.6 & 19 & 58 & 240 \\
\hline $\begin{array}{l}\text { Prompt Fatality Risk Within } 1 \text { mile of } \\
\text { Site Boundary (per } R x-Y r \text { ) }\end{array}$ & $1.1 \times 10^{-12}$ & $4.9 \times 10^{-11}$ & $2.3 \times 10^{-10}$ & $1.1 \times 10^{-9}$ \\
\hline $\begin{array}{l}\text { Latent Fatality Risk Within } 10 \text { miles of } \\
\text { Site Boundary (per Rx-Yr) }\end{array}$ & $6.5 \times 10^{-10}$ & $7.9 \times 10^{-9}$ & $2.4 \times 10^{-8}$ & $9.8 \times 10^{-8}$ \\
\hline $\begin{array}{l}\text { Population Dose Within } 1000 \text { mile } \\
\text { Region (person-rem) }\end{array}$ & 14 & 200 & 620 & 2600 \\
\hline \multicolumn{5}{|l|}{ ONSITE: } \\
\hline Total Site Prompt Fatalities (per $R x-Y r$ ) & $1.3 \times 10^{-6}$ & $3.3 \times 10^{-5}$ & $1.2 \times 10^{-4}$ & $5.7 \times 10^{-4}$ \\
\hline Total Site Latent Fatalities (per $R x-Y r$ ) & $1.0 \times 10^{-5}$ & $1.8 \times 10^{-4}$ & $5.9 \times 10^{-4}$ & $2.5 \times 10^{-3}$ \\
\hline $\begin{array}{l}\text { Total Site Population Dose } \\
\text { (person-rem) }\end{array}$ & $5.5 \times 10^{-2}$ & 0.98 & 3.2 & 14 \\
\hline $\begin{array}{l}\text { Prompt Fatality Risk Within } 1 \text { mile of } \\
\text { K Reactor (per Rx-Yr) }\end{array}$ & $1.1 \times 10^{-9}$ & $2.1 \times 10^{-8}$ & $6.7 \times 10^{-8}$ & $3.1 \cdot-7$ \\
\hline $\begin{array}{l}\text { Latent Fatality Risk Within } 10 \text { miles of } \\
\text { K Reactor (per Rx-Yr) }\end{array}$ & $6.4 \times 10^{-10}$ & $1.1 \times 10^{-8}$ & $3.8 \times 10^{-8}$ & $1.6 x$ \\
\hline
\end{tabular}


Table 10-7. K Reactor Mean Annual Offsite Consequences Compared to Mean Consequences Calculated For Several Reactors (Seismic Events)

\begin{tabular}{|c|c|c|c|c|c|c|c|c|}
\hline & $\begin{array}{c}\text { Consequence } \\
\text { measure }\end{array}$ & K Reactor & N Reactor & Surry & Sequoyah & Zion & $\begin{array}{l}\text { Peach } \\
\text { Bottom }\end{array}$ & $\begin{array}{l}\text { Grand } \\
\text { Gulf }\end{array}$ \\
\hline & Total Prompt Fatalities (per Rx-Yr) & $8.7 \times 10^{-7}$ & $2.2 \times 10^{-9}$ & $7.5 \times 10^{-5}$ & N/A & N/A & $8.8 \times 10^{-5}$ & N/A \\
\hline & Total Latent Fatalities (per Rx-Yr) & $1.0 \times 10^{-1}$ & $6.0 \times 10^{-2}$ & $2.6 \times 10^{-2}$ & N/A & $N / A$ & $9.9 \times 10^{-3}$ & N/A \\
\hline 1 & $\begin{array}{l}\text { Population Dose within } 50 \text { miles } \\
\text { (person-rem) }\end{array}$ & 58 & $4.1 \times 10^{-1}$ & 37 & $N / A$ & N/A & 17 & N/A \\
\hline & $\begin{array}{l}\text { Prompt Fatality Risk Within } 1 \text { Mile of } \\
\text { Site Boundary (per } R x-Y r \text { ) }\end{array}$ & $2.3 \times 10^{-10}$ & N/A & $8.8 \times 10^{-8}$ & N/A & N/A & $5.3 \times 10^{-8}$ & N/A \\
\hline & $\begin{array}{l}\text { Latent Fatality Risk Within } 10 \text { Miles of } \\
\text { Site Boundary (per Rx-Yr) }\end{array}$ & $2.4 \times 10^{-8}$ & $1.7 \times 10^{-8}$ & $1.6 \times 10^{-8}$ & N/A & $N / A$ & $1.1 \times 10^{-8}$ & N/A \\
\hline & $\begin{array}{l}\text { Population Dose Within Region } \\
\text { (person-rem) }\end{array}$ & 620 & 3.2 & 160 & N/A & $N / A$ & 58 & N/A \\
\hline
\end{tabular}


Table 10-8. K-Reactor Mean Annual Onsite Consequences Compared to Mean Consequencess Calculated For N Reactor (Seismic Events)

\begin{tabular}{lcc}
\hline \multicolumn{1}{c}{ Consequence: } & K Reactor & N Reactor \\
\hline \hline Total Site Prompt Fatalities (pe: Rx-Yr) & $1.2 \times 10^{-4}$ & $8.6 \times 10^{-4}$ \\
Total Site Latent Fatalities (per Rx-Yr) & $5.9 \times 10^{-4}$ & $3.0 \times 10^{-3}$ \\
Total Site Population Dos:? (person-rem) & 3.2 & 16 \\
$\begin{array}{l}\text { Prompt Fatality Risk Within 1 nile of K Reactor } \\
\text { (per Rx-Yr) }\end{array}$ & $6.7 \times 10^{-8}$ & $6.1 \times 10^{-7}$ \\
$\begin{array}{l}\text { Latent Fatality Risk Within 10 niles of } \\
\text { K Reactor (per Rx-Yr) }\end{array}$ & $3.8 \times 10^{-8}$ & $1.5 \times 10^{-7}$ \\
\hline
\end{tabular}


Table 10-9. Mean Fractional Contribution of Seismic Events Plant Damage States to Annual Risk

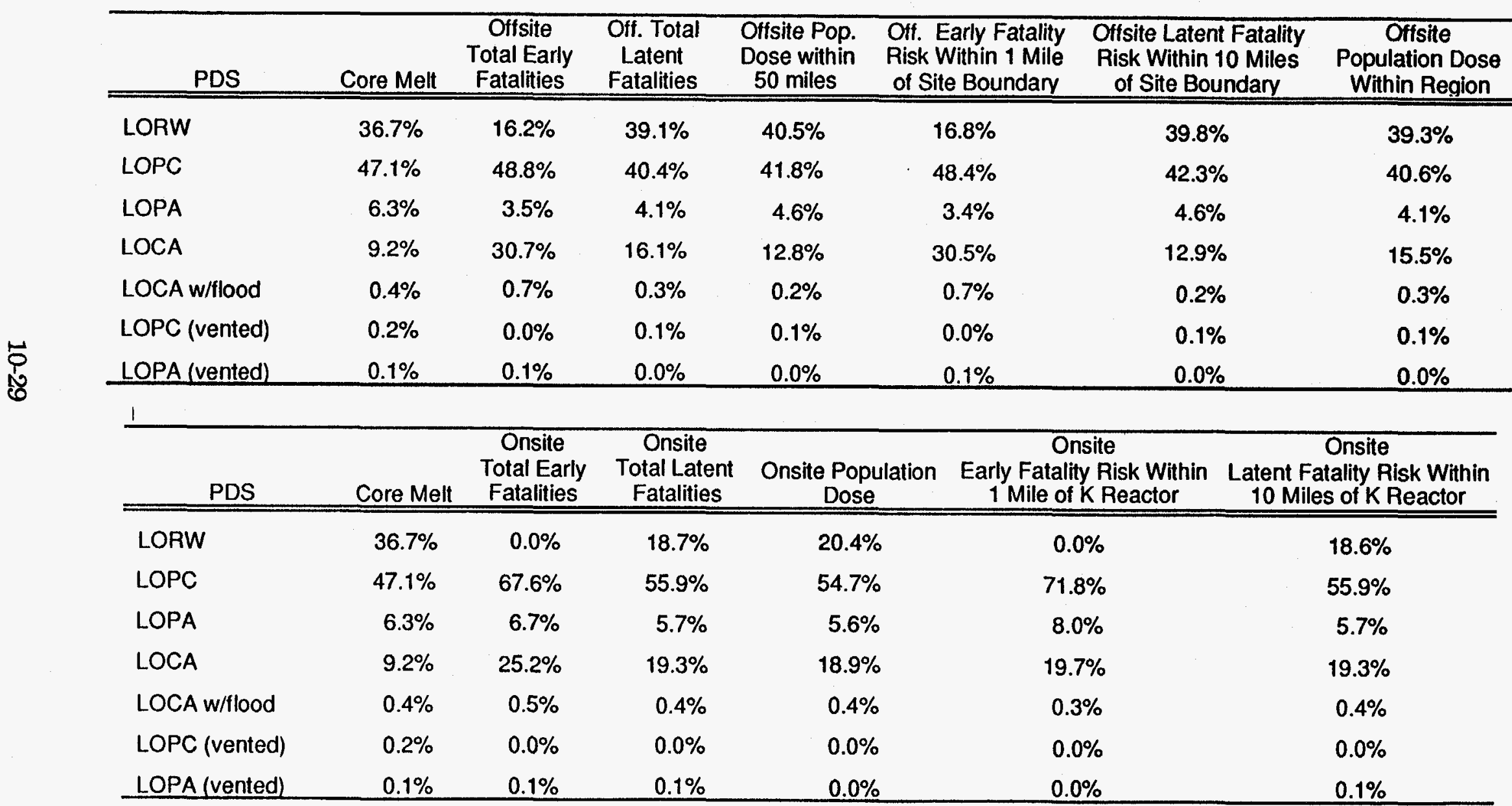


Figure 10-7 shows a subset of the data in Table 10-9 for onsite and offsite risk consequence measures by Plant Damage State. Figure 10-7 indicates that for seismically initiated accident states, the Loss-of-River-Water and Lossof-Primary-Circulation Plant Damage States dominate the risk, both onsite and offsite for the LOPC and offsite for the LORW. The Loss-of-River-Water scenarios are longer term accidents where the SRS electrical power grid is lost, and thus makeup water to the reactor basin from the river is not available. The operators must also fail to recirculate cooling water. Melting then occurs in a little over two hours. However, when the cooling water runs out, cooling to the primary cooling system CAT diesels generators is also lost and thus process water circulation is lost. Soon after the loss of cooling water, the core melts in a full or partially full vessel, with the possibility of recriticality or benign recriticality as well as the attendant steam explosions.

Figure 10-8 gives a sense of the uncertainty in the fractional contribution calculations. There exist 500 values of the fractional contribution to a particular consequence measure, and the MFCR is the mean of these 500 values. As can be seen from Figure 10-8, for each Plant Damage State, the fractional contribution to consequence (specifically onsite prompt fatalities within one mile of the reactor) varies over a substantial range. Each box in the plot encompasses the middle half of the distribution of the MFCR values for one PDS (25th percentile to 75th percentile). The "whiskers" on the boxes reach down to the 5th percentile, and up to the 95th percentile. Outliers (of which there are by definition 25 above and below the whiskers with 500 samples) are plotted as x's. Thus, while the MFCR values discussed here are useful measures of importance in a mean sense, it is necessary to keep in mind that the "answer" as to what is important to the value of a consequence is subject to substantial uncertainty.

Another set of fractional contributions to risk may be calculated for the Source Term Bins and their attributes. These Source Term Bins are an approximate description of the accident progression which summarize those phenomena which are important to generation of the source term for similar accident sequences. The detailed descriptions of the Source Term Bins and attributes are given in Section 7 of this report. There are sixteen dimensions to a Source 'Term Bin numbered from 1 to 16 , each dimension being composed of two o: more attributes, denoted A, B, C, etc. Shown in Table 10-10 are the most important summary scenarios derived from the Source Term Bins for four consequence measures: onsite prompt and la. it fatalities within ten miles of $K$ Reactor, and offsite prompt and lat $t$ fatalities within fifty mile:s of the $\mathrm{K}$ Reactor.

Similar to the Internal Events results, scenarios which involve energeti events dominate the risk for the current external events PSA model. Ir. scenarios where an energetic recriticality event occurs, an in-vessel steam explosion caused by the jecriticality is also modeled. For the cases of a core melt with no recriticality or a benign recriticality, an in-vessel steam explosion may occur. For all of these energetic scenarios, steam explosions 


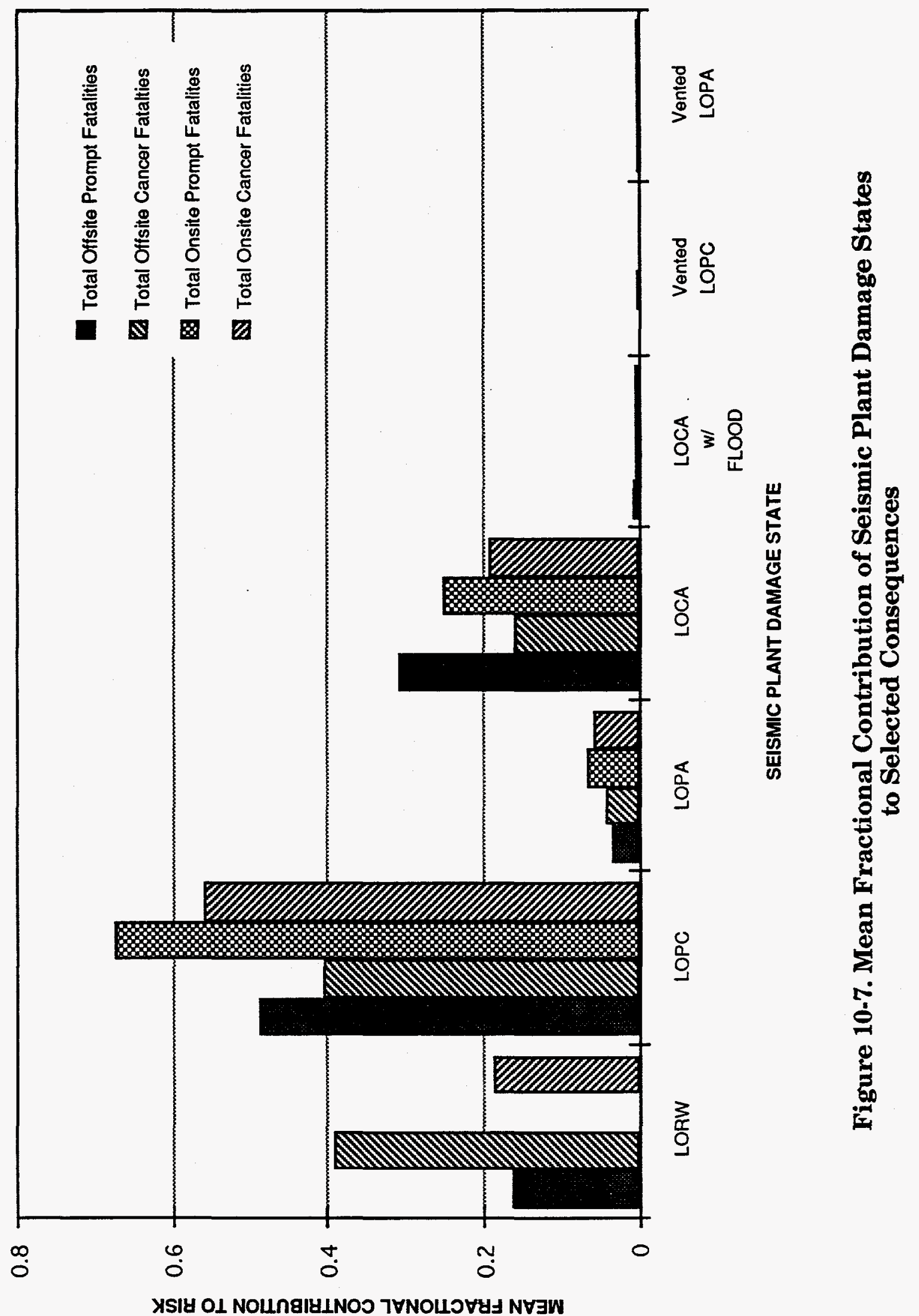




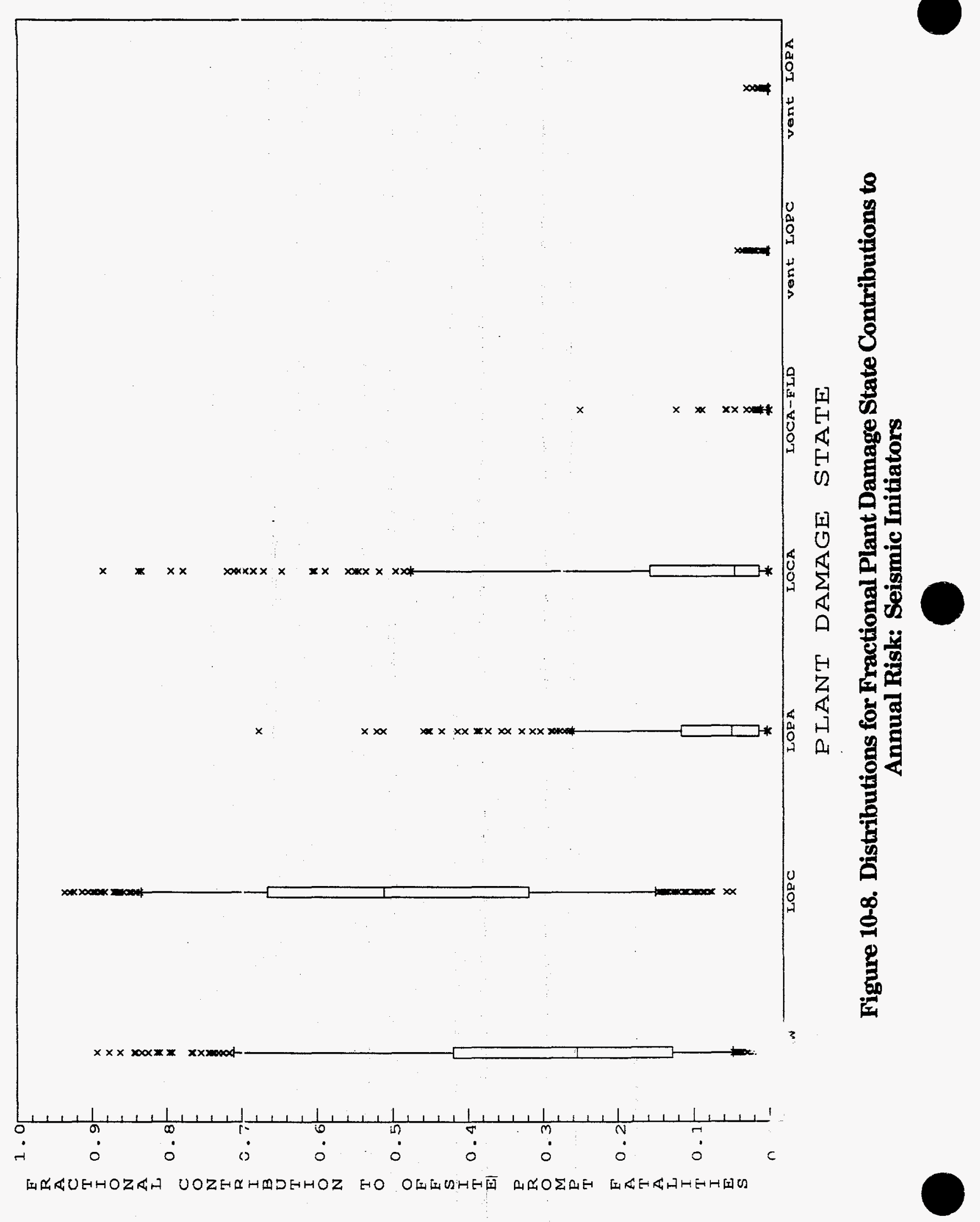


Table 10-10. Summary Source Term Bin Mean Fractional Contributions to Selected Consequence Measures - Seismic Initiators

\begin{tabular}{|c|c|c|c|c|}
\hline Scenario & $\begin{array}{c}\text { Offsite } \\
\text { Total } \\
\text { Early } \\
\text { Fatalities } \\
\end{array}$ & $\begin{array}{c}\text { Offsite } \\
\text { Total } \\
\text { Latent } \\
\text { Fatalities }\end{array}$ & $\begin{array}{l}\text { Onsite } \\
\text { Total } \\
\text { Early } \\
\text { Fatalities }\end{array}$ & $\begin{array}{c}\text { Onsite } \\
\text { Total } \\
\text { Latent } \\
\text { Fatalities }\end{array}$ \\
\hline $\begin{array}{l}\text { Early core melt (<10 minutes) } \\
\text { with an energetic in-vessel } \\
\text { recriticality which produces an } \\
\text { in-vessel steam explosion. }\end{array}$ & $20.1 \%$ & $17.9 \%$ & $25.9 \%$ & $23.2 \%$ \\
\hline $\begin{array}{l}\text { Early core melt (<10 minutes) } \\
\text { with either no recriticality or a } \\
\text { "benign" recriticality. A steam } \\
\text { explosion occurs either in- or } \\
\text { ex-vessel. }\end{array}$ & $41.2 \%$ & $29.1 \%$ & $47.6 \%$ & $40.3 \%$ \\
\hline $\begin{array}{l}\text { Later core melt }(10<>120 \\
\text { minutes) with an energetic in- } \\
\text { vessel recriticality which } \\
\text { produces an in-vessel steam } \\
\text { explosion. }\end{array}$ & $6.2 \%$ & $15.0 \%$ & $0.0 \%$ & $5.7 \%$ \\
\hline $\begin{array}{l}\text { Later core melt (10 <>120 } \\
\text { minutes) with either no } \\
\text { recriticality or a "benign" } \\
\text { recriticality. A steam explosion } \\
\text { occurs either in- or ex-vessel. }\end{array}$ & $5.3 \%$ & $15.3 \%$ & $0.0 \%$ & $5.5 \%$ \\
\hline $\begin{array}{l}\text { Non-energetic core melt with no } \\
\text { other energetic events and } \\
\text { confinement functions normally } \\
\text { (filters may burn late) }\end{array}$ & $0.0 \%$ & $0.0 \%$ & $0.0 \%$ & $0.0 \%$ \\
\hline Total: & $72.8 \%$ & $77.3 \%$ & $73.5 \%$ & $74.7 \%$ \\
\hline $\begin{array}{l}\text { Accidents where the } \\
\text { Confinement is totally bypassed } \\
\text { during the accident }\end{array}$ & $99.6 \%$ & $95.8 \%$ & $98.4 \%$ & $96.6 \%$ \\
\hline
\end{tabular}


of two "magnitudes" are separated in the Source Term Bin: if an explosion occurs, it either fails the confinement or it does not. In the MFCR results presented in Table 10-10, the MFCR values from steam explosion scenarios are heavily driven by steam explosions which fail the confinement. Thus, the risks are not only being driven by scenarios involving energetic events, but these energetic events are generally rendering the confinement system ineffective. However, Seismic Events are already always assumed to disable the above-grade filter system, either by damaging the building or physically removing the filters. Table 10-10 also shows the MFCR results for scenarios where the confinement is totally bypassed, both above- and below-grade. This is generally the result of both a failure of the filters (100\% for seismic) and some below grade damage such as the lifting of the heat exchanger hatch covers by an energetic event. These results show that as modeled, essentially all the risk is produced in scenarios where the confinement is bypassed both above- and below-grade.

It is also interesting to note that Table 10-10 shows that nearly all of the risk is produced by scenarios in which there are energetic phenomena and the confinement which is iyspassed. This is significantly different from Internal Events, but follows directly from the fact that the confinement never functions for the Seismic Event accident scenarios.

\subsubsection{Contributors to Uncertainty}

Stepwise regressions were performed for the seismic results in a manner similar to that for the Internal Events analyses. The conditional seismic regressions show similar, if not more consisient results for the important contributors to uncertainty. The vessel DF for aerosols, the very early radioisotope release fraction, and the fission product revolatilization fraction from the vessel walls are all important as in the Internal Events case. However, hers the fristy fission product release fraction also is consistently important, where for internals, it was only important for offsite prompt fatalities. This is probably due to the different evacuation schemes and the greater time and speed for escape that people have in the Internal Events scenarios. The lithium melt fraction variable also appears as a less important contributor.

Very little information is gained from the "actual consequence" regressions for Seismic Events because the seismic hazard curve pointer variable is so dominant. This variable (its usage is described in Section 9) is a sampling variable which "points" to a specific hazard curve from a sample of hazard curves; it totally dominates the effects of the Level 2 variables. This is somewhat intuitive since the magnitude of the hazard curve utilized controls initiating event frequencies as well as component failure probabilities (through the fragility curves). Also, no other Level 1 seismic variables such as random failures are included in the LHS sample, and thus the hazard curve pointer is the only connection between the Level 1 analysis and the consequences in the regression analyses. Section 9 describes the actual treatnent of seismic uncertainty in the model. 


\subsection{Combined Results for All Initiators}

In Reference 10-7, the results of the Internal, Fire, and Seismic analyses are not combined into an overall value of consequence for any of the consequence measures. Reference 10-10, however, combines the differing results with the caveat that there exist opinions which suggest that the results should not be combined due to the differing maturities of the analyses. For comparison with overall "safety goals" as advocated by the Nuclear Regulatory Commission (NRC) and as have been suggested by the Department of Energy (DOE) [10-1, 10-2], there is little choice but to attempt a melding of the results into overall measures of risk for comparison with the point-estimate safety guideline values. Reference 10-7, however, compares NRC safety goals against Internal and Seismic consequence measures separately.

This analysis takes the position that a point-estimate of risk for comparison to a point safety goal measure can be adequately characterized by combining the Internal and Seismic Events annual result for the analysis (there is no contribution from fires), subject to certain constraints. The constraints are similar to these Reference 10-10, in that the same LHS matrix was used for both of the Internal and Seismic Analyses, and thus the individual results are additive on a sample member basis. This means that the total consequence results presented in this Section have been calculated by adding the Internal and Seismic individual consequence measure results together on an LHS sample member by LHS sample member basis, and the statistics for the combined results are calculated from this combination.

\subsubsection{Background on Safety Guidelines}

The DOE has suggested a set of safety guidelines for offsite general public [10-1] as criteria for comparison when assessing the safety of a nuclear facility. DOE Nuclear Safety Policy was drafted in 1989 for onsite, co-located workers by the Office of Environment, Safety and Health [10-2]. The purpose of this policy as stated in the draft notice was "to provide a selfsufficient framework upon which specific requirements and standards of excellence for individual DOE nuclear facilities can be derived". Two primary, qualitative safety goals were established in the Policy

G1. Assure no significant increase in risk to individuals from the operation of Department of Energy Facilities.

G2. DOE will identify and implement improvements in the safety design and operation of its facilities, beyond the adequate protection standard of the Atomic Energy Act, on the basis that the costs of safety improvements are warranted by the value of the risk reduction achieved.

Issuance of two tiers of guidelines to quantify the primary safety goals for public health and safety as well as that of DOE Facility workers accompanied the Safety Policy as Attachment 2. Four quantitative 
guidelines were issued to be applied to resident and worker populations in the vicinity of a DOE Nuclear Facility. Attachment 2 added "risk assessments employed in estimating how facilities or particular safety issues or accident sequeaces compare with these quantitative goals may employ fully realistic mociels and data" (italics added).

Additionally, three guidelines were offered to furnish distinct targets of excellence, rather than requirements, for severe accident prevention and mitigation at production reactors. These constitute a second tier of supplemental guidelines for some aspects of defense-in-depth. It was further defined, "progress toward meeting these goals should be a consideration in maintaining and upgrading operating production reactors, but these goals are not requirements".

The DOE later rescinded the draft policy document without final publication. Furthermore, continued evolution of safety policy for the DOE sites is shifted to DOE/NE. However, the Continued Operation EIS and supporting Safety Information Document for SRS, and the N-Reactor PSA have compared risk results to the proposed DOE Nuclear Safety Guidelines. Both were issued in April 1990.

Secretary of Energy Notice 35-91 (SEN-35-91), issued in September 1991, specifically treats indiviclual risk levels to the neighboring general public around DOE facilities. T'he two established safety goals are numerically identical to commercial policy codified in 1986.

\subsubsection{DOE Nuclea" Safety Goals}

DOE nuclear safety policy' was set in two formats:

$$
1989 \text {-draft JJOE safety guidelines, and }
$$

$$
\text { 1991-Secretary of Energy notice safety goals. }
$$

This section discusses $\mathrm{DC}$ E guidance in these areas.

The first two safety guidelines are radiological considerations chosen by DOE to quantify the primary safety goal for public health and safety (G1 above). These supplementary guidelines are for individual prompt and latent (cancer) death risk due to accidents and radiological exposures, respectively.

SG1. The risk, to an average individual in the vicinity of a DOE nuclear facility, of early fatalities that might result from accidents should not exceed one-tenth of one percent of the sum of early fatality risks resulting from other accidents to which members of the U.S. population are generally exposed.

SG2. The risk to the population in the area near a DOE nuclear facility of cancer fatalities that might result from radiological exposure originating with the facility should not exceed one- 
tenth of one percent of the sum of cancer fatality risks to which members of the U.S. are generally exposed.

The third and fourth safety guidelines are radiological considerations chosen by DOE to quantify the primary safety goal for DOE workers (G1 above). These supplementary guidelines are for individual prompt and latent (cancer) death risk due to accidents and radiological exposures, respectively.

SG3. The risk, to an average individual worker in the vicinity of a DOE nuclear facility, of prompt fatalities that might result from radiological accidents should not exceed one percent of the sum of prompt fatality risks typical of average occupational death rates in the U.S.

SG4. The risk to the workers in the area near a DOE nuclear facility of cancer fatalities that might result from radiological exposure originating with accidents at the facility should not exceed one-tenth of one percent of the sum of cancer fatality risks to which members of the U.S. population are generally exposed.

Table 10-11 restates the four safety guidelines in terms of basis population group, region to be considered, baseline individual accident/fatality rate, a safety multiplier, and the resultant individual risk.

Table 10-11. Draft DOE Safety Guidelines

\begin{tabular}{|c|c|c|c|c|c|}
\hline Guideline & Risk/Population & Zone & $\begin{array}{l}\text { Ind. Accident or } \\
\text { Fatality Rate }\end{array}$ & $\begin{array}{c}\text { Safety } \\
\text { Multiplier }\end{array}$ & $\begin{array}{c}\text { Quantitative } \\
\text { Individual Risk }\end{array}$ \\
\hline SG1. & $\begin{array}{l}\text { Early Fatality } \\
\text { General Public }\end{array}$ & $0-1$ mile $^{*}$ & $4.0 \times 10^{-4}$ & $0.1 \%$ & $4.0 \times 10^{-7}$ \\
\hline SG2. & $\begin{array}{l}\text { Latent Fatality } \\
\text { General Public }\end{array}$ & $0-10$ miles $^{*}$ & $2.0 \times 10^{-3}$ & $0.1 \%$ & $2.0 \times 10^{-6}$ \\
\hline SG3. & $\begin{array}{l}\text { Early Fatality DOE } \\
\text { Workers }\end{array}$ & $0-1$ mile** & $1.0 \times 10^{-4}$ & $1.0 \%$ & $1.0 \times 10^{-6}$ \\
\hline SG2. & $\begin{array}{l}\text { Latent Fatality DOE } \\
\text { Workers }\end{array}$ & 0 - 10 miles $^{* \star}$ & $2.0 \times 10^{-3}$ & $0.1 \%$ & $2.0 \times 10^{-6}$ \\
\hline
\end{tabular}

* From SRS Boundary + SC-125 Vehicular Traffic

** From K-Reactor Facility Control Perimeter Fence 
The supplementary safety guidelines furnish "targets of excellence" and in that light, help implement defense-in-depth for DOE production reactors. They have less stature than the radiological safety guidelines. Nevertheless, the supplementary guidelines offer a "levelized playing field" assessment of components to DOE production reactor safety from prevention \& mitigation perspectives.

The mortality risk guidelines (SG1 through SG4 above) suggest that the frequency of unmitigated or potentially lethal releases of fission products from large ( $\geq 1000 \mathrm{MW}$ ) production reactors should be less than or of the order of $1.0 \times 10^{-5}$ per year without taking credit for particularly remote siting. The first supplementary safety guideline adopts this frequency for joint effectiveness of severe accident prevention and mitigation:

SSG1. The possibility of an unmitigated release of fission products from the core of a DOE production reactor shall ideally be less than one in one hundred thousand reactor-years $\left[<1.0 \times 10^{-5}\right.$ per reactor-year].

The second of the supplementary guidelines emphasizes the importance of protecting the mission of production reactor operation and avoiding the "public disturbance associated with accidents that have the potential to cause substantial offsite harm". Therefore, it is the intent to make severe reactor accidents as rare as reasonably achievable, and to do so without crediting mitigation:

SSG2. The probability of severe core damage or meltdown at individual DOE production reactors should ideally be less than one per hundred thousand reactor-years $\left[<1.0 \times 10^{-5}\right.$ per reactor-year].

Commentary provided with the supplementary guidelines argues that provision for accident miligation features would be unnecessary to meet the higher level goals if there were little doubt about the likelihood of success of accident prevention. However, it is concluded that there are always uncertainties associated with the future performance of any engineered system. Therefore, the essence of defense-in-depth is diminishing the relative importance of particular contributors to safety, so that some protection persists even if multiple failures in safety systems occur. It should be noted that the [two supplementary] guidelines above a not requirements.

To understand the relative benefit of online and effective mitigation 1 a DOE facility, a final supplementary guideline is provided. The quantita measure is in terms of early offsite fatalities since a reduction in ei offsite fatalities by reducing the release of fission products in seve accidents also reduces the expected latent casualties and biosphe contamination for most weather conditions, compared to unmitigat : releases. The draft supplemental guideline maintains a "reduction in t..e average number of offsite early fatalities expected beyond the facility control 
perimeter, given a severe accident, to one or less, is a simple indicator of substantially effective mitigation.

SSG3. The projected average conditional consequences of the spectrum of accidents that defeat the engineered active systems that perform the core cooling or the emergency reactor shutdown functions at DOE production reactors ideally should be less than one early fatality per accident outside the facility control perimeter [< $1 \mathrm{prompt} /$ severe core-melt accident].

SEN-35-91 discusses both acute and latent individual indices of risk. The risk indices are part of $\mathrm{DOE}$ nuclear safety policy and are, in fact, quantitative nuclear safety goals identical to U.S. Nuclear Regulatory Commission policy promulgated in 1986. The goals are comparable to SG1 and SG2 in Table 10-11, but reflect a different acute fatality rate. Therefore, the SEN safety goals are given as:

$5 \times 10^{-7}$ per reactor year: Acute Individual Risk, and

$2 \times 10^{-6}$ per reactor year: Latent Individual Risk.

The safety policy contained in these quantitative goals is to be applied to the general public within one mile and ten miles respectively, of the DOE reservation boundary.

\subsubsection{Comparison to Safety Goals}

The quantitative safety guidelines are radiological guidelines. The associated commentary identifies three fundamental premises:

- Risk assessments employed in estimating how facilities or particular safety issues or accident sequences compare with these quantitative goals may employ fully realistic models and data; ... with realistic consideration of emergency response.

- Mean or average risks are to be employed in application of these guidelines, and analytic methods are to be consistent with NRC and commercial industry practice.

- The average individual, referring to biological (age and other factors) and locational bases, shall be considered for general public. [By inference, the average worker shall be considered for DOE reservation guidelines].

The revised MACCS methodology for the onsite calculation of the prompt and latent guideline risks described in Section 8 is an interim approach for modeling, more realistically, emergency response.

The prompt fatality and latent fatality guidelines for the general public consider the population in one-mile and ten-mile regions from the DOE reservation boundary, respectively. Included in both populations at-risk is 
vehicular traffic on SC-1\$5. Since 1990 U.S. census data are unavailable at this time, the 1980 census data were scaled by 1.137 to approximate assumed growth patternis.

The prompt fatality and latent fatality guidelines for DOE workers consider the peak afternoon population in one-mile and ten-mile zones from the 105-K building security fince, respectively. Attachment 2 to the Draft DOE Order discussion states "risks posed by a facility to the workers at that facility are limited by radiation protection standards and the ALARA principle: keeping exposures as low as reasonably achievable". Moreover, these risks are claimed to be "entirely voluntary". Thus the guidelines for occupational risk are meant to address workers on DOE reservations by facilities other than the one to which they are assigned and form an intermediate case between the wholly voluntary and involuntary. However, in a manner identical to the SID treatment, all 105 Area workers are considered in the population at-risk based on the assumption of full participation in the emergency response (evacuation) modeled with the MACCS code. The populiation was established based on an assessment of site population as of March, 1990, as noted in Section 8.

Interpretation of SSG1 for SRS workers follows the approach described in Chapter 7 of the N-Reactior PSA [10-10]. "Unmitigated or potentially lethal" release of fission products is assumed to mean no evacuation or sheltering is taken. MACCS calculations for each of the source terms calculates the prompt fatality risk to a hypothetical individual stationed one mile from the reactor in all sixteen compass sectors. The artificial, "installed" population is resident around-the-clock, 24 hours per day, 365 days per year. The probability that this hypothetical population would be exposed to lethal doses from the full set of source terms was taken to represent the probability of a "potentially lethal" release of radiation. The calculated value for the SSG1 comparison is determined by weighting the MACCS code mean value for individual early fatality probability by the source term frequency, and summing over all source terms. A special purpose grid meets the requirements for this caliulation.

SSG2 is a frequency target-of-excellence for accident prevention of severe core damage or meltdown. The internal and external (seismic) initiators considered in this PSA are regarded as representing severe core damage since one or more assemblies are compromised. The values for comparison against the supplementary guidelines are then the internal and exterr al severe core-melt frequencies.

The final supplementary safety guideline (SSG3) is a measure of tr effectiveness of plant mitigation systems to offsite and onsite populations. The guideline examines the expected number of prompt fatalities per accident. Both offsite (greneral public) and onsite (DOE workers) are considered. The offsite component to this quantity is calculated by finding the mean prompt fatality level with MACCS, and weighting it by the ratio of the source term frequency to total severe core-melt frequency. All source term components are summed to yield an aggregate mean value of expected 
offsite prompt fatalities per severe core-melt accident. A similar calculation is made for onsite workers.

A uniform consensus regarding interpretation of the two tiers of DOE Safety Policy, viz. safety guideline and supplementary safety guidelines has not been reached. Moreover, the Department has withdrawn the Draft Notice. Therefore, it is cautioned that computed values for comparison against the SSGs are subject to wide variation depending on the particular set of assumptions undergirding the calculation. The interpretation described above is thought to be consistent at minimum with the approach contained in two previous DOE production reactor PSA studies, Chapter 4 of the Safety Information Document for Savannah River Reactors [10-4] and the N-Reactor PSA [10-10].

Since it is necessary to generate a point-estimate of risk for comparison to the safety measures, the mean values of the annual consequence distributions are the statistics appropriate to use for comparison with these safety guidelines. These mean values are summary representations of the CCDFs shown in Figure 10-9.

The comparison of these K-Reactor values to the safety goals is shown in Table 10-12. As can be seen from these figures and the table, the SRS $\mathrm{K}$-Reactor PSA analysis indicates mean individual risks within the DOE safety guidelines. Section 10.5 provides an estimate of the full PSA consequence results considering the upgraded (restart configuration) reactor.

Table 10-13 compares the supplementary safety guidelines to the calculated $\mathrm{K}$-Reactor values. The results relative to the supplementary guidelines are similar to those found for the N-Reactor PSA. A key finding highlighted by a comparison of Table 10-13 to Table 10-12 is that of onsite individual risk, close-in to K Reactor. The SSG1 value of $1.1 \times 10^{-6}$ per reactor-year is based on a 100\% occupancy, no evacuation/sheltering assumption. With implementation of the Site emergency plan, this risk assessment indicates that a five-fold reduction in the individual prompt fatality risk is achievable $\left(1.1 \times 10^{-6}\right.$ to $\left.1.9 \times 10^{-7}\right)$.

\subsection{Comparison of PSA Results to Previous Risk Estimates for K Reactor}

A single analysis of the actual onsite and offsite consequences of a severe core-melt accident at the Savannah River Site has been performed previous to this PSA. This analysis was performed in support of the Environmental Impact Statement (EIS) for the Savannah River Site, and was called the "Safety Information Document (SID)" [10-4]. This calculation was a pointestimate of risk and included no uncertainty information in the severe coremelt frequency estimation or in the accident progression calculations. CCDFs were formed by including only the uncertainty in weather information from the consequence calculations, and thus single curve CCDFs were produced. 


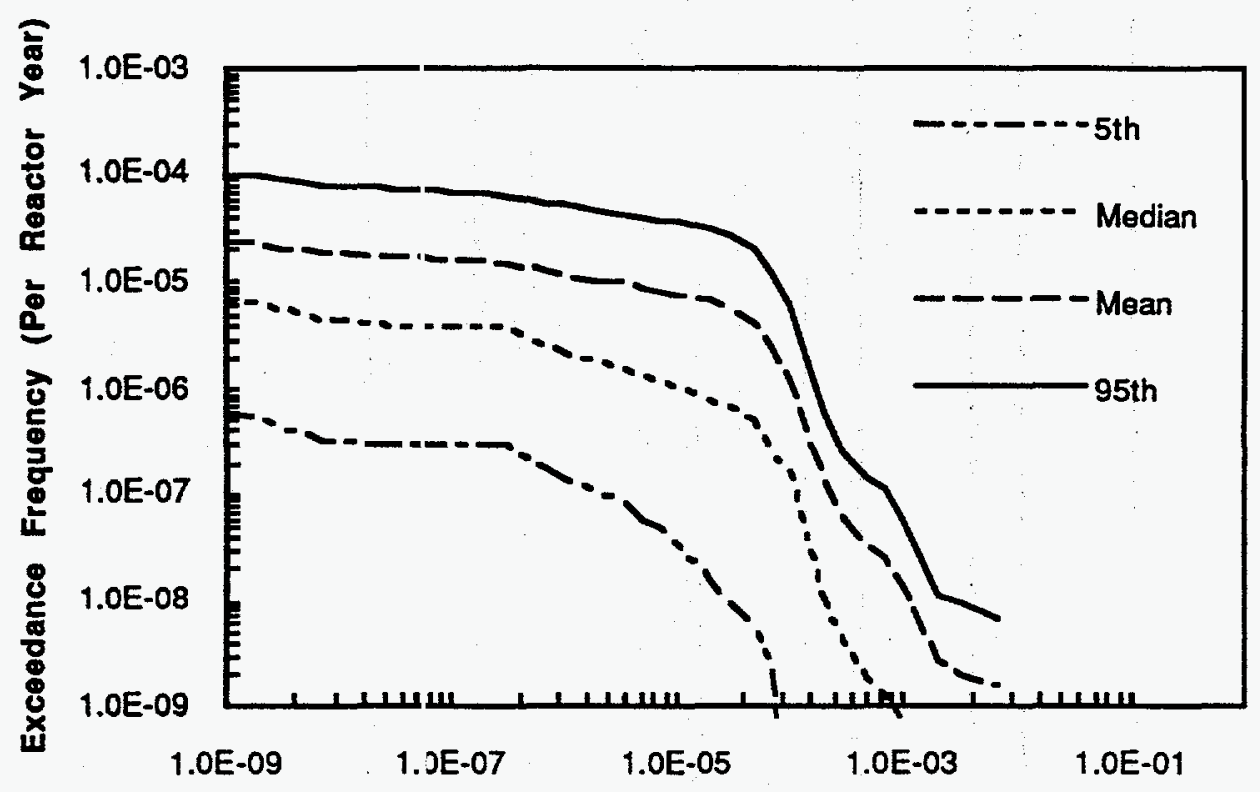

Offsite Prompt Fatality Risk to an Individual Within 1 Mile of the Site Boundary

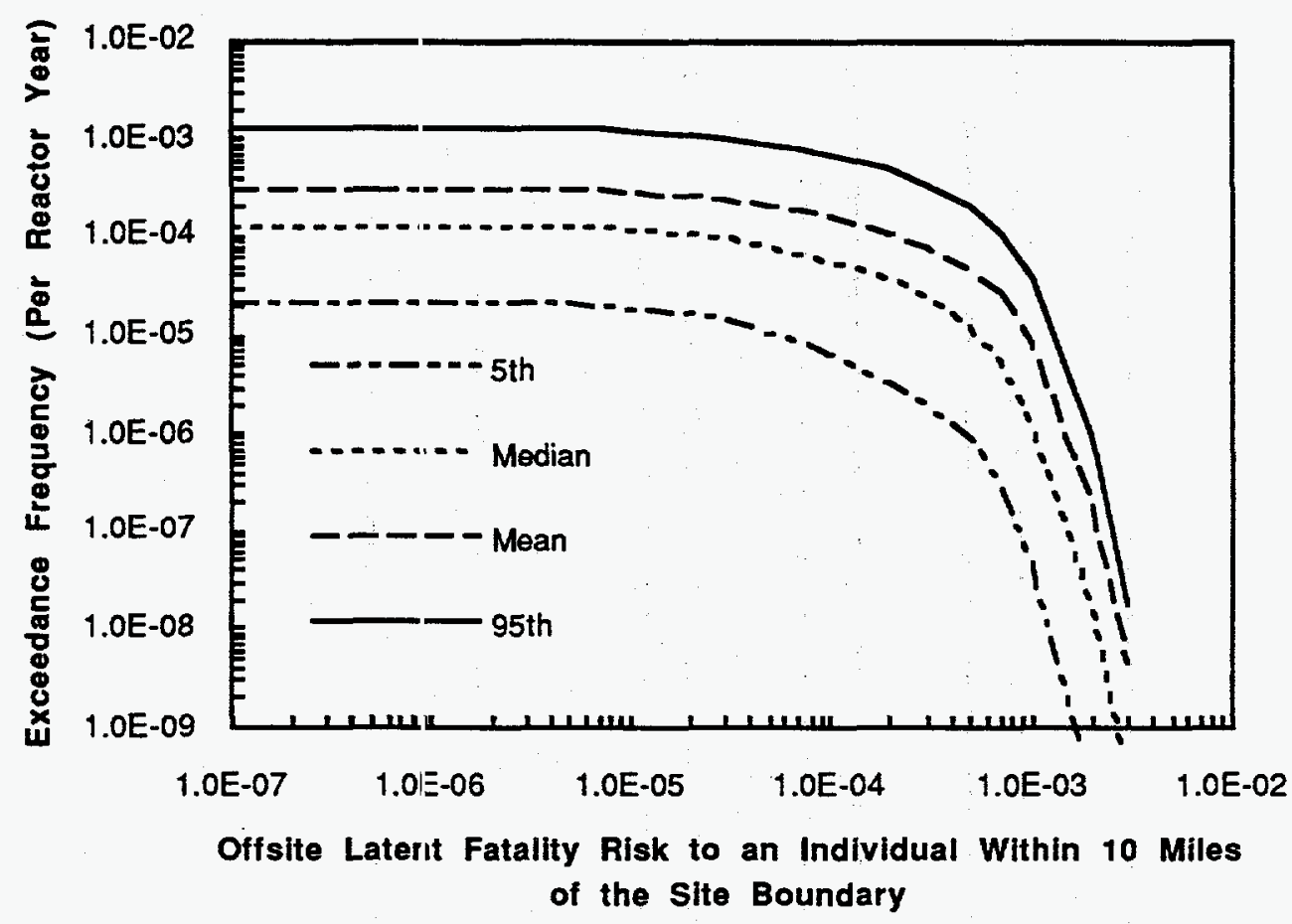

Figure 10-9. Frequency of Exceedance of Risk for DOE Safety Guidelines 

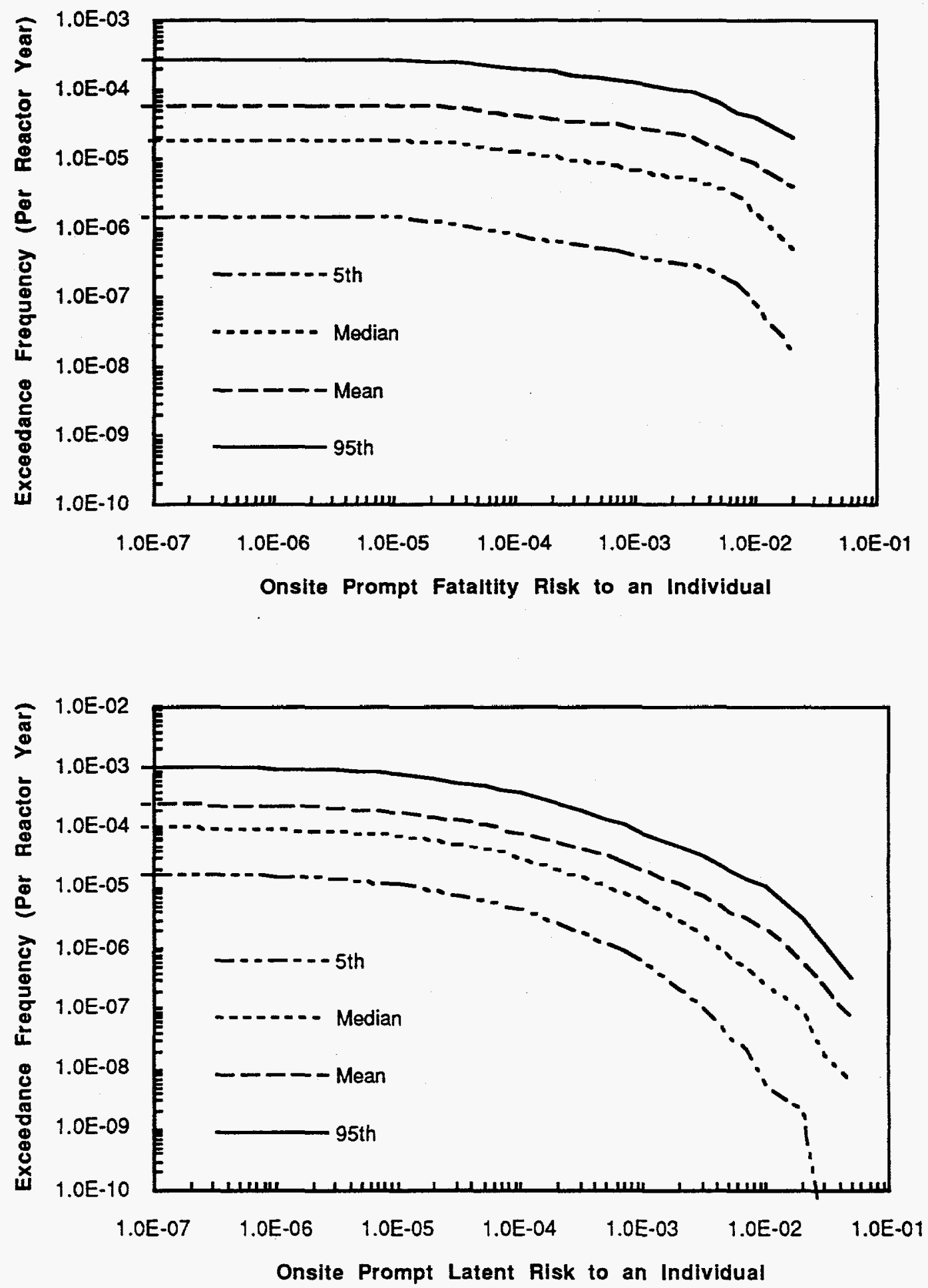

Figure 10-9. Frequency of exceedance of for DOE safety guidelines (cont'd) 


\section{Table 10-12. DOE Safety Goals Versus SFiS K-Reactor Annual Risks}

\begin{tabular}{lc} 
Consequence measure & Guideline or mean value \\
\hline DOE Onsite Prompt Fatality Salety Guideline & $1.0 \times 10^{-6}$ per reactor-year \\
K-Reactor Calculated Mean Value & $1.9 \times 10^{-7}$ \\
\hline DOE Onsite Latent Fatality Safiety Guideline & $2.0 \times 10^{-6}$ per reactor-year \\
K-Reactor Calculated Mean Value & $6.2 \times 10^{-8}$ \\
\hline DOE Offsite Prompt Fatality Salety Guideline & $5.0 \times 10^{-7}$ per reactor-year \\
K-Reactor Calculated Mean Value & $5.3 \times 10^{-10}$ \\
\hline DOE Offsite Latent Fatality Safiety Guideline & $2.0 \times 10^{-6}$ per reactor-year \\
K-Reactor Calculated Mean Value & $7.1 \times 10^{-8}$ \\
\hline
\end{tabular}

Table 10-13. DOE Supplementary Safety Guidelines Compared to K-Reactor Calculated Values

\begin{tabular}{lcc} 
& $\begin{array}{c}\text { DOE } \\
\text { Supplementary } \\
\text { Safety Guideline }\end{array}$ & $\begin{array}{c}\text { K-Reactor } \\
\text { Calculated } \\
\text { Mean Value }\end{array}$ \\
\hline $\begin{array}{l}\text { SSG1 } \\
\text { year) }\end{array}$ & $1.0 \times 10^{-5}$ & $1.1 \times 1.3$ \\
$\begin{array}{l}\text { SSG2 } \\
\text { Frequency of Core Melt (per reactor-year) }\end{array}$ & $1.0 \times 10^{-5}$ & $3.1 \times 10^{--\cdot}$ \\
$\begin{array}{l}\text { SSG3 } \\
\text { Prompt Fatalities Conditional on a Core- } \\
\text { Melt Accident (per severe core-mitt accident) }\end{array}$ & Offsite: 1.0 & 0.01 \\
\hline
\end{tabular}


The following Section compares the results of this PSA, which analyzes $\mathrm{K}$ Reactor without several restart upgrades, with the results of the SID (which included upgrades to the reactor to approximate the restart condition), as well as comparing an estimate of the PSA results under restart conditions with the SID results.

\section{Safety Information Document (SID)}

The Safety Information Document [10-4] (SID), completed in February, 1990, included consequence calculations which compared to the DOE safety guidelines (discussed in Section 10.4). Presented in Table 10-13 are the SID results of K-Reactor risk compared to the DOE safety guidelines. Also in this Table are the base-case PSA results computed in this document, and the upgraded reactor risk estimates which will be discussed in this Section.

Assumptions made for the SID differ in some cases from those made for the PSA described in this document, some of the most important of which are the inclusion in the SID calculations of some reactor upgrades which will be in place at restart and are not included in this PSA. Some other assumptions differ because this PSA has the benefit of more in-depth modeling of many phenomena occurring in severe accidents, and the inclusion of the most recent available models and data.

To estimate the effects of the upgrades which were included in the SID calculations but are not modeled in the PSA, the SID Level 1 accident sequences have been "rebinned" into the base-case PSA Plant Damage States, and new Plant Damage State frequencies have been calculated which reflect the plant upgrades included in the SID. These new frequencies have been propagated through the full Level 3 PSA model to arrive at a new estimate of risk which reflects the changes in the accident frequencies. This is called the "Updated PSA Estimate" in Table 10-14. (This estimate does not, however, model any reactor modifications which would not impact the severe core-melt frequency, but might impact the accident progressions (e.g., confinement upgrades). There are also a few recent restart upgrades which are not included in either the SID or this Updated PSA estimate.)

The updated PSA risk calculations yield important information on the important contributors to risk for the upgraded reactor. Figure 10-10 shows a plot of the Internal Event Plant Damage State MFCR values for the updated case, and Figure 10-11 shows the same for the seismic Plant Damage States. Comparing these two figures against Figures 10-3 and 10-7 respectively, several distinct differences can be observed between the Plant Damage State risk contributors for the upgraded and non-upgraded plants. The most obvious difference is the almost complete absence of contribution from the seismic LOPC PDS. This reduction in contribution is a direct result of upgrading the rotovalve relay cabinet anchoring to preclude relay chatter from closing the rotovalves. Another large change in the seismic risk contributors is the dominance of the LOPA Plant Damage State after including the SID upgrades. It is pertinent to note here that one upgrade 
Table 10-14. Compariscin of DOE Safety Guidelines to Base-Case PSA, Updated PSA \& SID Values

\begin{tabular}{llccc}
\hline $\begin{array}{l}\text { Consequence Measure } \\
\text { Description }\end{array}$ & $\begin{array}{c}\text { Base-case } \\
\text { PSA mean } \\
\text { value }\end{array}$ & $\begin{array}{c}\text { Updated } \\
\text { PSA mean } \\
\text { value }\end{array}$ & SID & $\begin{array}{c}\text { DOE Safety } \\
\text { Guideline }\end{array}$ \\
\hline $\begin{array}{l}\text { Onsite prompt fatality } \\
\text { risk in facilities located } \\
\text { within 1 mile of the } \\
\text { facility under analysis }\end{array}$ & $1.9 \times 10^{-7}$ & $9.7 \times 10^{-8}$ & $1.6 \times 10^{-7}$ & $1.0 \times 10^{-6}$ \\
$\begin{array}{l}\text { Onsite latent fatality } \\
\text { risk within } 10 \text { miles of } \\
\text { the facility under } \\
\text { analysis }\end{array}$ & $6.2 \times 10^{-8}$ & $6.1 \times 10^{-8}$ & $1.4 \times 10^{-7}$ & $2.0 \times 10^{-6}$ \\
$\begin{array}{l}\text { Offsite prompt fatality } \\
\text { individual risk within } \\
\text { one mile of the site } \\
\text { boundary }\end{array}$ & $5.3 \times 10^{-10}$ & $2.8 \times 10^{-10}$ & $5.8 \times 10^{-11}$ & $5.0 \times 10^{-7}$ \\
$\begin{array}{l}\text { Offsite latent fatality } \\
\text { risk within } 10 \text { miles of } \\
\text { the site boundary }\end{array}$ & $7.1 \times 10^{-8}$ & $4.3 \times 10^{-8}$ & $3.4 \times 10^{-8}$ & $2.0 \times 10^{-6}$ \\
\hline
\end{tabular}




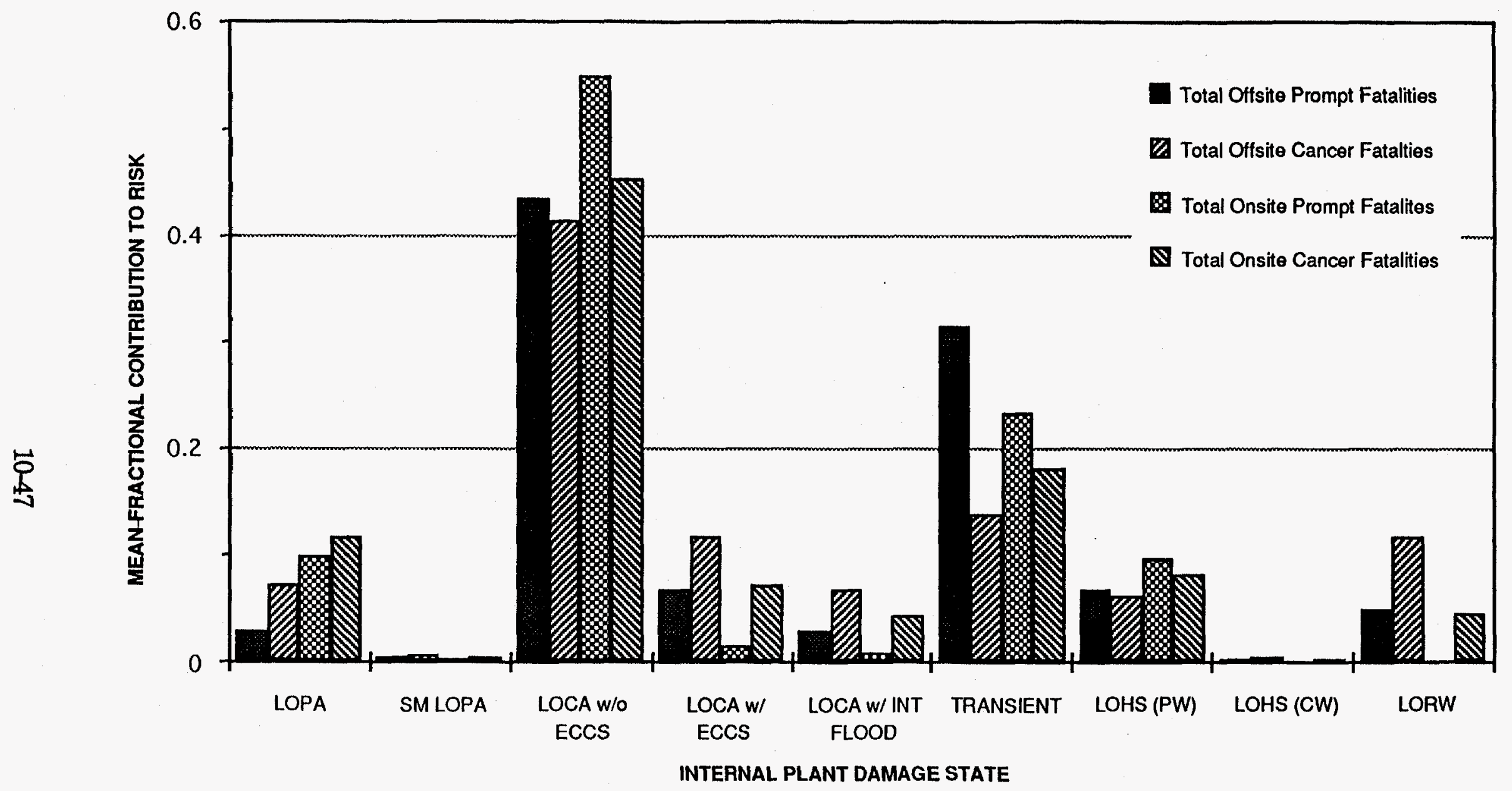

Figure 10-10. Fractional Contribution from Internal SID Plant Damage States to Selected Consequences 


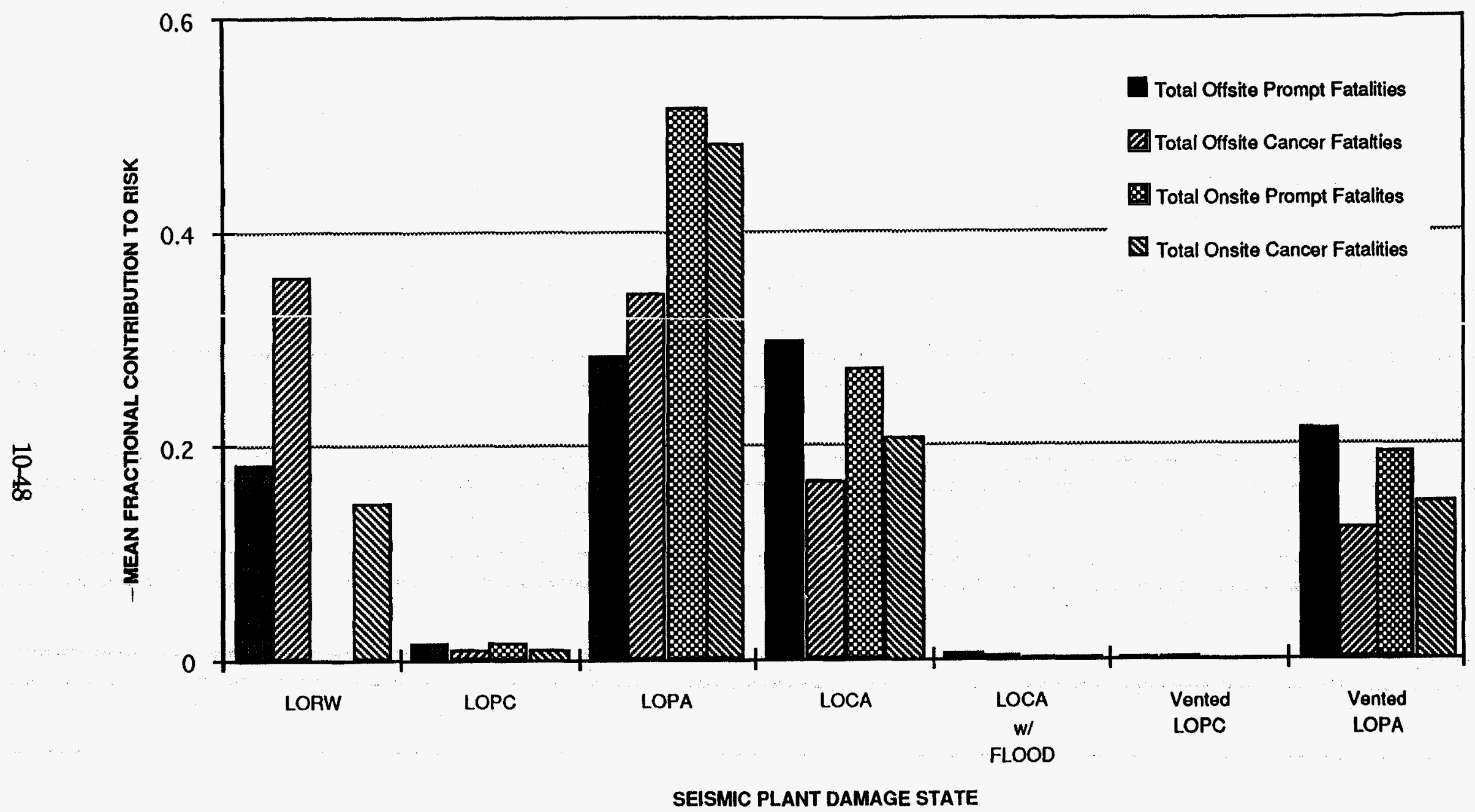

r. . -11. Fractional Contribution from Seismic SID Plant Damage States to Selected Consequences 
which was not included in the SID was seismic bracing of the cooling water piping. This upgrade would have a direct influence on the LOPA frequency, and would undoubtedly decrease its risk importance from what Figure 10-11 indicates.

For the Internal Events Plant Damage State contributions, the effects are not so obvious. The only immediately discernible changes are a decrease in the LOPA importance and an increase in the transient importance. (A decrease in one PDS must always be offset by increases in others since the fractional contributions must always add up to 1.0.) This reflects the addition of the automatic cooling water pump trip to the model. The other Plant Damage States do not change their fractional contributions to risk appreciably. This means that the SID upgrades decreased risk from internally generated scenarios fairly uniformly across the Plant Damage States, unlike in the seismic case, where the decreases were dramatic in specific PDSs.

\subsection{Supplementary Studies}

Additional supporting consequence studies have been concluded as part of the overall quantification of $\mathrm{K}$ Reactor probabilistic safety at historical full power. The studies include evaluation of several economic risk indices, quantification using alternative latent health effect models, and the sensitivity of the risk results to assumptions and parameters used in the consequence models. A summary of the results of these supplementary studies is provided in the following sections.

\subsubsection{Economic Impacts And Land Contamination}

Health effect risks provide a basis to review reactor operation performance against safety guidelines, or target points. However, additional indices of risk are calculable through the MACCS code to provide supplementary perspective on the impacts of hypothetical severe accidents in $\mathrm{K}$ Reactor. These risks may be described as environmental risks. As in the case of health risks, the code provides calculational results in the CCDF format; however only the expected values, or mean level of consequence are discussed here.

Table 10-15 lists mean values for one total economic and four land contamination risk measures for internal and external events, as well as the summed "aggregate" risk. The risks are quantified for a model with a severe core melt frequency of $3.1 \times 10^{-4}$ per reactor-year, so that conditional risks (expected consequences given that a severe accident has occurred) may be approximated by taking the quotient of risks over the core melt frequency. The conditional risks are provided in the last column of the table.

The area impacted by postulated severe accidents occurring in $\mathrm{K}$ Reactor at full historical power may include some SRS DOE reservation land as the airborne plume tranports radioactive material away from the reactor area. 
Table 10-15. Economic and Land Contamination Risks From Severe Accidents; Mean Risk Le:vels - K Reactor Level 2/3 PSA Rev. 0 at 2500 MW

\begin{tabular}{|c|c|c|c|c|}
\hline \multirow[b]{2}{*}{ Risk Measure } & Internal & External & Aggregate & \multirow{2}{*}{$\begin{array}{l}\text { Conditional } \\
\text { (per severe } \\
\text { accident) }\end{array}$} \\
\hline & \multicolumn{3}{|c|}{ 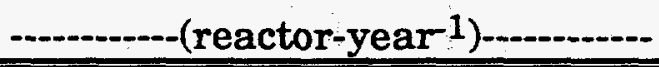 } & \\
\hline Total Economic Costs (\$) & $2.1 \times 10^{5}$ & $9.7 \times 10^{4}$ & $3.1 \times 10^{5}$ & $9.9 \times 10^{8}$ \\
\hline Decontamination Area $\left(\mathrm{km}^{2}\right)$ & $2.2 \times 10^{-4}$ & $1.8 \times 10^{-4}$ & $4.0 \times 10^{-4}$ & 1.3 \\
\hline Interdiction Area $\left(\mathrm{km}^{2}\right)$ & $1.7 \times 10^{-1}$ & $1.0 \times 10^{-1}$ & $2.7 \times 10^{-1}$ & $8.7 \times 10^{2}$ \\
\hline Condemnation Area $\left(\mathrm{km}^{2}\right)$ & $2.1 \times 10^{-1}$ & $7.9 \times 10^{-2}$ & $2.9 \times 10^{-1}$ & $9.3 \times 10^{2}$ \\
\hline Milk Disposal Area $\left(\mathrm{km}^{2}\right)$ & $1.7 \times 10^{0}$ & $1.0 \times 10^{0}$ & $2.7 \times 10^{0}$ & $8.7 \times 10^{3}$ \\
\hline
\end{tabular}


The SRS reservation currently encompasses approximately $790 \mathrm{~km}^{2}$. Ultimately, the plume would transport across the boundary into largely rural and agricultural regions of central western South Carolina and eastern Georgia. Dispersal of radioactivity would be by both rainfall and dry deposition. Offsite environs would bear the significant portion of the decontamination, cleanup and remediation costs at a level depending on the specific meteorology associated with the occurrence of the accident. As in the case of the Chernobyl nuclear accident in 1986 in the Ukraine, the major isotopes constituting the bulk of the environmental hazard during the recovery phase after the unlikely accident would be those of cesium, strontium, and iodine.

The source term partitions contributing the majority of economic and land risk are not specified in this summary document. It is felt that the best application of the environmental risk results is to augment emergency preparedness activities at the Savannah River Site. In such an application, K Reactor based source terms may be "transported" using MACCS overlayed on a geographic information system database to provide isodose and isopleth information for co-located facilities and offsite regions. This PRA application is part of the current activity supported under the risk management program at SRS, but is outside the scope of the current study.

\subsubsection{Alternative Latent Health Effect Models}

The baseline latent health effect models in MACCS 1.5 and FUSCRAC3 are derived from the 1980 BEIR III report [10-11]. The MACCS code now allows sensitivity studies to be performed determining the impact of alternative model and parameter choices on the overal risk estimates. This section discusses several sensitivities performed on the base case.

The total cancer estimates provided in BEIR III consider leukemia, bone, breast, lung, gastrointestinal, thyroid, and several other critical organs. Models for cancer are non-threshold and have linerar-quadratic dependencies. In the early phase following a hypothetical reactor accident, a linear-quadratic model is used to address cancer risk for organ doses below a threshold of $1.5 \mathrm{~Sv}$ (150 rem). Beyond that level, an upper bound linear fit is implemented. In the long-term chronic phase, a linear model is used to evaluate prolonged exposure of addected populations to relatively low doses and dose rate levels.

The BEIR V study [10-12] significantly alters the recommended guidance for modeling latent health effects following the release of radioactivity. The BEIR V report states, on the basis of atomic bomb survivor data and other epidemiological data revisions, that the quantitative releationship between cancer incidence and dose "appears to vary, depending on the type of cancer in question. The dose-dependent excess of mortality from all cancer other than leukemia, shows no departure from linearity in the range below 4 sievert (Sv), whereas the mortality data for leukemia are compatible with a linear-quadratic dose reasponse relationship". Furthermore, the earlier 
BEIR III cancer risk indicators appear low by a factor of three, except for leukemia, which should be increased by a factor of four. Leukemias are not a dominant long-term caricer type from a reactor-related source term, so that for total cancers, a general factor of three is recommended to scale the total cancer estimates provided in the baseline MACCS 1.5 models. Due to the relatively short latency period associated with leukemia, it is the most pronounced cancer type to appear after a short period following a large radioactivity release. The BEIR V guidance also allows a low-LET radiation risk factor reduction by a factor of two or more, if low doses are accumulated over longer periods of time.

The MACCS code models liave been modified by user input to revise several risk estimates for the general public and onsite DOE workers. A target organ for overall latent cancer incidence, "EDE whole-body" was added to the MACCS input. A linear risk model is then used for doses between 0 and $4 \mathrm{~Sv}$. For the onsite and netar-field offsite populations, the BEIR V risk factor of 0.08 latent fatality per person-Sv is used without a dose reduction factor. Full societal risk calculations employ the same risk factor, but are reduced by a factor of two to evalisate the effects of incurred dose over a long time frame of several weeks to several years.

The final latent health effect sensitivity, using updated Lovelace Medical Foundation report recomraendations (LMF-132) and based on the piecewise linear function, was introduced in Chapter 8. To summarize, the dose response functions given in the LMF-132 model are for high exposure and low exposure, respectively. The latter model uses a dose and dose rate reduction factor (DDREF) with a numerical value of two to account for cell and organ repair mechanisms tending to lessen long term impacts from radiation if the received dose is spread out over time. The cutoff criteria for low exposure model application are doses $\leq 0.2$ gray ( $1 \mathrm{~Gy} \sim 1 \mathrm{~Sv}$ ) and dose rates $\leq 0.1 \mathrm{~Gy} /$ hour. During the early phase following the posulated reactor accident, approximately one week duration, the committed dose is used solely in the MACCS model to determine application of the high or low dose model. The chronic phase implements the low dose response model in MACCS, exclusively.

The MACCS model for the LMF-132 sensitivity uses a DDREF of two, a dose threshold of $0.2 \mathrm{~Sv}$ for implementing the DDREF dose response model, and has a linear response for any doses above $0.0 \mathrm{~Sv}$. Most of the organ-specific risk factors are a factor of three higher than their BEIR III counterpart.

Table 10-16 lists the effects of revising the latent health effect model relative to the base case MACCS BEIR III model. The risks presented account for both internal and external events and are the mean levels of consequence taken from the CCDF cutput of MACCS. The mean value for expected societal cancers increasess to 0.73 and 0.77 per reactor year for the BEIR V and LMF-132 models, respectively. The BEIR III result is 0.3 per reactor year. Similarly, the offsite latent fatalities in the region within ten miles $(16.1 \mathrm{~km})$ of the DOE reservation boundary would increase to $1.5 \times 10^{-2}$ (BEIR V) and $1.1 \times 10^{-2}$ (LMF-132) per reactor year relative to the base case 
Table 10-16. Sensitivity of Societal and Individual Latent Risks To Health Effect Models - K Reactor Level 2/3 PSA Rev. 0 at 2500 MW

\begin{tabular}{|c|c|c|c|c|}
\hline \multirow[b]{2}{*}{ Risk Measure } & \multicolumn{4}{|c|}{ Mean Values of Risk (per reactor-year) } \\
\hline & $\begin{array}{c}\text { DOE Safety } \\
\text { Goal }{ }^{1} \text { /Draft } \\
\text { Guideline }^{2}\end{array}$ & $\begin{array}{l}\text { Base Case BEIR- } \\
\text { III (Linear- } \\
\text { Quad.) }\end{array}$ & $\begin{array}{l}\text { Revised BEIR V } \\
\text { Model ( Linear) }\end{array}$ & $\begin{array}{l}\text { Lovelace Medical } \\
\text { Foundation -132 } \\
\text { (Piecewise } \\
\text { Linear) }\end{array}$ \\
\hline $\begin{array}{l}\text { Total Latent Fatalities ( } 0 \\
\text { - } 1610 \mathrm{~km} \text { radius) }\end{array}$ & - & 0.30 & 0.73 & 0.77 \\
\hline $\begin{array}{l}\text { Total Latent Fatalities } \\
\text { (Within } 16.1 \mathrm{~km} \text { of SRS }\end{array}$ & - & $4.2 \times 10^{-3}$ & $1.5 \times 10^{-2}$ & $1.1 \times 10^{-2}$ \\
\hline \multicolumn{5}{|l|}{ Reservation Boundary) } \\
\hline $\begin{array}{l}\text { Individual Latent Risk } \\
\text { To Members of General } \\
\text { Public (Within } 16.1 \mathrm{~km} \\
\text { of SRS Reservation } \\
\text { Boundary) }\end{array}$ & $2 \times 10^{-6}$ & $7.1 \times 10^{-8}$ & $2.3 \times 10^{-7}$ & $1.7 \times 10^{-7}$ \\
\hline $\begin{array}{l}\text { Individual Latent Risk } \\
\text { To DOE Workers Within } \\
16.1 \mathrm{~km} \text { of K Reactor) }\end{array}$ & $2 \times 10^{-6}$ & $1.1 \times 10^{-7}$ & $4.0 \times 10^{-7}$ & $2.9 \times 10^{-7}$ \\
\hline $\begin{array}{ll}1 & \text { Reference } 10-1 \\
2 & \text { Reference } 10-2\end{array}$ & & & & \\
\hline
\end{tabular}


value of $4.2 \times 10^{-3}$. Similar increases are found for individual offsite and onsite risks, however, all values remain below the SEN-35-91 DOE Safety Goal offsite and draft DOE Safety Guideline onsite individual risk value of $2 \times 10^{-6}$ per facility-year.

The BEIR V model as applied here is observed to be conservative with respect to the more detailed LMF-132 model for close-in latent health effects by $20 \%-30 \%$. Far-field effects, (general societal impacts to the populations $>50$ miles from SRS) are indistinguishable between the two models. The revised health effects models are observed to increase predicted latent cancer fatalities by a factcr of 2.5 to 3 over earlier estimates.

Latent health effect risk to the general public within fifty miles of $\mathrm{K}$ Reactor [approximately equal to the population within the Ingestion Planning Zone (IPZ)] is low. The expected level of cancer fatalities per reactor year from severe accidents is 0.03 . The population numbers about 610 thousand. Thus, on an individual risk basis, the average person bears a $4.5 \times 10^{-8}$ per reactor year latent fatality risk, or a $0.002 \%$ incremental risk of cancer fatality from $\mathrm{K}$ Reactor operation relative to current levels of cancer fatality incidence in the United States $\left(\sim 2 \times 10^{-3}\right.$ per individual per year).

\subsubsection{Sensitivity To Parameter Values}

The base case model for evacuation of non-essential workers from $K$ Reactor and the rest of the peak mid-afternoon work force at Savannah River is:

- $\quad$ For internal events, begin evacuation 0.5 hour after scram at 8.5 $\mathrm{MPH}$ for worlsers 0 to 5 miles from $\mathrm{K}$ Reactor;

- For seismic events, the start time is doubled ( 1 hour), and the exit speed is halved (4.25 MPH); and

- All workers greater than five miles from $\mathrm{K}$ Reactor shelter beginning at one hour from scram, and remain sheltered for twelve hours.

A sensitivity study was performed that doubled, then quadrupled the base case timings for the 0 to 5 -mile evacuation, i.e. beginning the start to evacuation at one and two hours after shutdown in the case of internal initiators, and delaying to two and four hours for external initiators. The results are shown in Takle 10-17 for total onsite acute and latent fatalities, total EDE, and the two individual onsite risk measures (prompt and latent) corresponding to the DO $\Xi$ draft safety guidelines.

The total acute and latert fatalities expected per reactor-year are insensitive to the delay in the starli on evacuation. The differences observed from the base case are $12 \%$ for acute fatalities and $6 \%$ for latent fatalities for the factor of two and four cases. The overall mean EDE for SRS workers increases from 0.088 person-Sv per year in the base case to 0.100 person-Sv 
Table 10-17. Sensitivity of Onsite Risks To Evacuation Timing K Reactor Level 2/3 PSA Rev. 0 at $2500 \mathrm{MW}$

\begin{tabular}{|c|c|c|c|c|}
\hline \multirow[b]{2}{*}{ Risk Measure } & \multicolumn{4}{|c|}{ Mean Values of Risk (per reactor-year) } \\
\hline & $\begin{array}{c}\text { DOE Safety } \\
\text { Draft Guideline }\end{array}$ & $\begin{array}{l}\text { Base Case } \\
\text { Timing } 1\end{array}$ & $\begin{array}{l}\text { Delay By } \\
\text { Factor of } 2\end{array}$ & $\begin{array}{l}\text { Delay By } \\
\text { Factor of } 4\end{array}$ \\
\hline $\begin{array}{l}\text { Total Prompt Fatalities (SRS } \\
\text { Reservation) }\end{array}$ & - & $2.6 \times 10-4$ & $2.4 \times 10-4$ & $2.9 \times 10-4$ \\
\hline $\begin{array}{l}\text { Total Latent Fatalities (SRS } \\
\text { Reservation) }\end{array}$ & - & $1.8 \times 10^{-3}$ & $1.7 \times 10^{-3}$ & $1.9 \times 10^{-3}$ \\
\hline $\begin{array}{l}\text { Total Onsite Population } \\
\text { (EDE, person-Sv) }\end{array}$ & - & 0.088 & 0.090 & 0.100 \\
\hline $\begin{array}{l}\text { Individual Prompt Risk To } \\
\text { SRS Workers (Within } 1.6 \\
\text { km of K Reactor) }\end{array}$ & $1 \times 10^{-6}$ & $1.9 \times 10^{-7}$ & $2.3 \times 10^{-7}$ & $2.6 \times 10^{-7}$ \\
\hline $\begin{array}{l}\text { Individual Latent Risk To } \\
\text { DOE Workers (Within } 16.1 \\
\text { km of K Reactor) }\end{array}$ & $2 \times 10^{-6}$ & $1.13 \times 10^{-7}$ & $1.11 \times 10^{-7}$ & $1.22 \times 10^{-7}$ \\
\hline $\begin{array}{l}\text { 1 Base Case timing uses } 0.5 \\
\text { internal events for non-esse } \\
\text { the start time is doubled, an } \\
\text { from } K \text { Reactor shelter begin }\end{array}$ & at one $h$ & to b & $\mathrm{cod} f$ & hours. \\
\hline
\end{tabular}


per year in the factor-of-four case. The reason for the relatively weak dependence of dose and latent effect to the evacuation timing is that the major component is from the sheltered population. The sheltered component does not change for any of the sensitivity cases.

Acute fatality risk within one mile of $\mathrm{K}$ Reactor is increased by $\sim 40 \%$ (1.9 $\times 10^{-7}$ to $2.6 \times 10^{-7}$ per reactor year per individual) by the change in evacuation timing. This trend is expected since the timings impact directly the evacuating worker close uptake through inhalation, cloudshine, and groundshine. There is little sensitivity identified in individual worker latent risk by delaying the evac1uation. This is due mostly to sheltered worker dose again comprising the majority of the contribution to the ten-mile latent risk.

Figure 10-12 indicates the change in individual prompt and latent fatality risk as the recommended direction for evacuation becomes less followed. The base case consists of all but ten non-essential workers moving away from $\mathrm{K}$ Area on the recommended roadway. These ten move away on each of the available alternate roads. The ten workers represent individuals misinformed, intentionally avoiding onsite security recommendations, or evacuating earlier than prescribed. The study indicates that increasingly uncoordinated evacuation, in the initial period after reactor shutdown, will lead to individual prompt fatality risk levels approaching and potentially exceeding DOE draft safety guideline values as the evacuation becomes less managed. The latent risk (bottom of Figure 10-12) is less affected. This is due to the basis onsite population for the latent goal extending 10 miles from $\mathrm{K}$ Area and being driven by overall population dose. Thus, it is less impacted by local (0-2 miles) evacuation patterns after a severe accident.

\subsubsection{Impact of Thitium In The Source Term}

The combined severe core-melt frequency from internal and seismic initiators is $3.1 \times 10^{-4}$ per reactor-year. The expectation value for EDE wholebody collective dose to the general public from the sixty fission product isotopes and water ingestion of tritium is $3.0 \times 10^{1}$ person-Sv/reactor-year. The average EDE dose computed, therefore with MACCS, given a core melt has occurred, is $9.7 \times 10^{4}$ person-Sv. The full-range societal grid with a radius of $1610 \mathrm{~km}$ (1001) miles) is the basis for this expectation value, and both Internal and Seismic Events are included.

The tritium inventory is assumed to be released with the timing and release fraction of the noble gases. Once in the environment, the tritium transports as tritiated water, i.e. the species HTO. It is thus subject to exchange mechanisms with water in the biosphere. Based on a series of best-estimate FUSCRAC3 calculations over the same grid as used in the MACCS calculations, the tritium whole-body dose per atmospheric release of the full $70 \mathrm{MCi}$ inventory is $6.6 \times 10^{3}$ person-Sv $\left(0.66 \times 10^{6}\right.$ person-rem $)$. The MACCS calculations do include effects of inhalation, skin absorption, and water ingestion of tritium, but these contributors to the tritium dose are small 



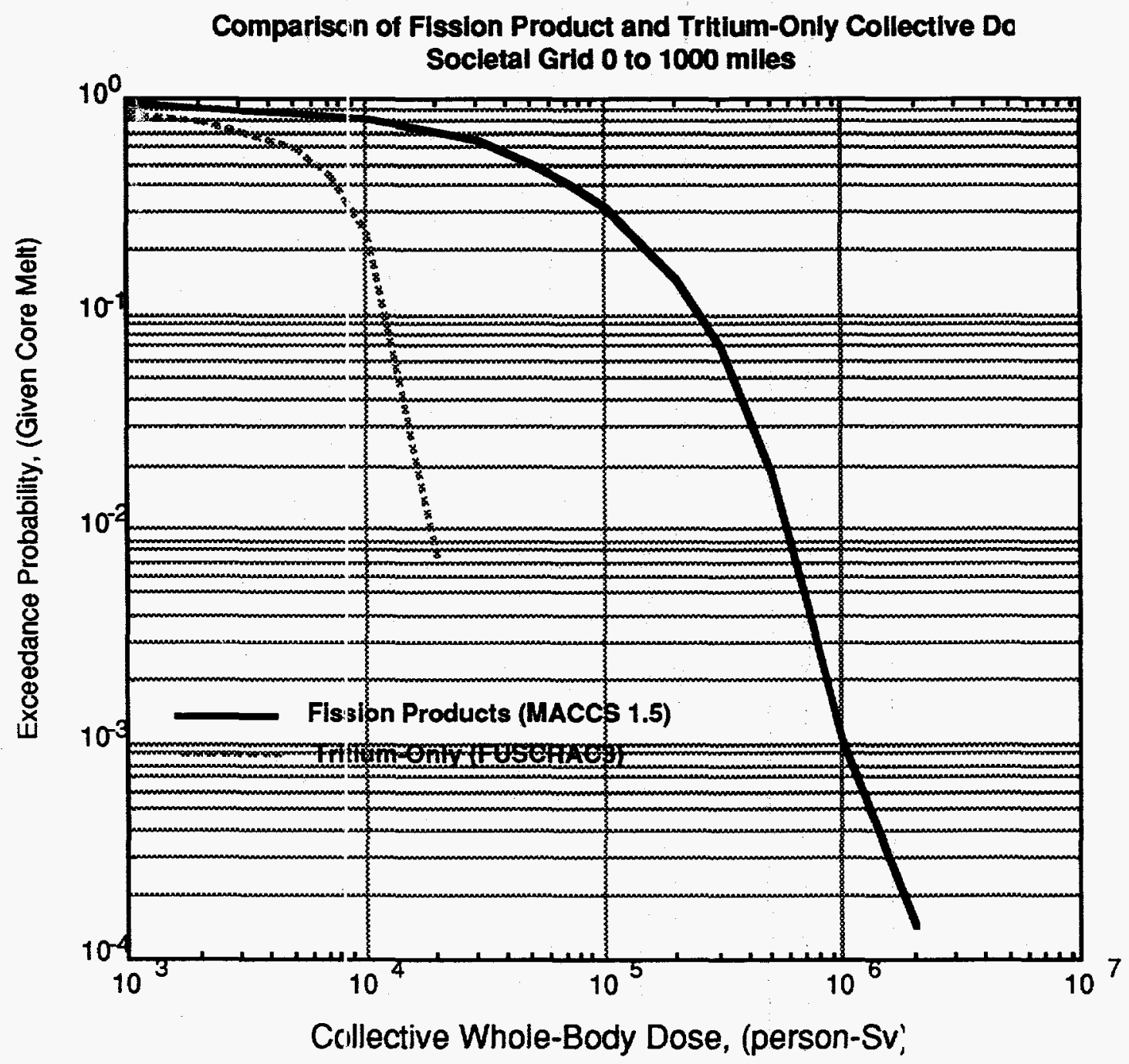

Component:

Expectation Values of Collective Dose (person-Sv)

Tritium:

$6.7 \times 10^{3}$

Fission Product + Water Ingestion Tritium:

$9.7 \times 10^{4}$

Figure 10-13. Collective Whole-Body Dose, (person-Sv) 
compared to the food pathway dose component. Relative to the fission product component, the tritium population dose is less than $7 \%$ of the full fission product inventory dose. Figure 10-13 compares conditional CCDFs for the tritium-only source term, and the EDE whole-body societal dose from the other 60 fission products + tritium inhalation/skin absorption/water ingestion. The latter is computed by dividing the MACCS-based CCDF for the societal EDE whole-body dose with the SRS K-Reactor severe core-melt frequency.

It is concluded that while the tritium component to the K-Reactor population term may not be ignored, it is small compared to the uncertainty bands about the central estimate. Adding the tritium component of dose, and subsequent tritium-related latent fatalities, injuries, etc. is not justified given the uncertainty margins discussed in this chapter.

\subsection{References}

10-1 Secretary of Energy Notice 35-91 (SEN-35-91), Nuclear Safety Policy, U.S. Department of Energy, September 1991.

10-2 U. S. Department of Energy, DOE Nuclear Safety Policy, Draft Notice DOE N 5480.PP (May 2, 1989) Attachments 1 and 2.

10-3 M. D. Brandyberry and H. E. Wingo, SRS PRA of Reactor OperationsLevel 1 External Events, Westinghouse Savannah River Co., Aiken SC, WSRC-RP-89-733, June 1990.

10-4 Reactor Operation Safety Information Document, Westinghouse Savannah River Company, Aiken SC, WSRC-RP-89-820, April 1990.

10-5 M. D. Brandyberry, et al., SRS PRA of Reactor Operations- Level 1 Internal Events, Westinghouse Savannah River Co., Aiken SC, WSRC-RP-89-570, June 1990.

$10-6$ R. L., Iman, J. D., Johnson, and J. C. Helton, A User's Guide for the Probabilistic Risk Assessment Model Integration System (PRAMIS), Sandia National Laboratories, Albuquerque, NM, NUREG/CR-5262, SAND88-3093, November 1989.

10-7 R. J. Breeding, et al., Evaluation of Severe Accident Risks: Surry Unit 1-Main Report, Sandia National Laboratories, NUREG/CR4551, SAND86-1309, Vol. 3, Rev. 1, Part 1, October 1990.

10-8 U. S. Department of Commerce, Statistical Abstract of the United States: 1989, U. S. Bureau of the Census (109th Edition), Washington D.C., 1988.

$10-9$ Seismic Hazard Methodology for the Central and Eastern United States, Vol. 1, Parts 1,2, (Revision 1), NP-4726-A, Electric Power Research Institute, Palo Alto, CA, November 1988. 
10-10 A. L. Camp, et al., Level III Probabilistic Risk Assessment for $N$ Reactor, Sandia Netional Laboratories, Albuquerque NM, WHC-MR0045 (SAND89-2102), April 1990.

iv-11 National Research Council Committee on the Biological Effects of Ionizing Radiations (BEIR III),The Effects on Populations of Exposure to Low Levels of Ionizing Radiation,, National Academy of Sciences, National Academy Press, Washington, D.C. (1980)

10-12 National Research Council, Committee on the Biological Effects of Ionizing Radiations (BEIR V),Health Effects of Exposure to Low Levels of Ionizing Radiation,, National Academy of Sciences, National Academy Press, Washington, D.C. (1990) 


\subsection{INSIGHTS AND CONCLUSIONS}

The PSA results presented in this document represent only a summary of the information available from the results of the analysis. This information is in addition to the phenomenological analysis that supported the development and quantification of the PSA model. Documentation of the phenomenological analyses are provided in separate reports as referenced throughout this document. The purpose of this section is to examine the results of the PSA and determine what general conclusions or insights can be drawn regarding severe accident progression in SRS reactors. The top priority is to establish the importance to the consequences and risk of the events and phenomena considered, so as to support risk management strategies. To accomplish this determination, the results of the PSA will be evaluated to answer the following:

(1) How well does the confinement system perform its function of mitigating the consequences of a release of fission products from the reactor core?

(2) How do the different failure modes of systems comprising (or contained within) the confinement affect accident progression, consequences, and risk?

(3) How important are the different aspects of accident phenomenology to the subsequent progression of the accident and to consequences and risk?

It should be noted again that this PSA describes K Reactor in its 1987 configuration. A limiting power level of $2500 \mathrm{MW}$ was chosen to bound what, at the time, was the uncertain outcome of work then in progress to determine the maximum allowed operating power level. Discussion of the three areas above will focus on this operating state, describing the PSA results as produced. This will provide a basis for comparison of these results with those of the ongoing upgrade of the Level 2/3 PSA to the current $\mathrm{K}$ Reactor configuration operating at $720 \mathrm{MW}$. The discussion, however, will be tempered with the knowledge that the PSA may show a very different risk profile at the lower operating power.

\subsection{Confinement Performance}

The K Reactor confinement system consists of active and passive components that form the final barrier to fission product release to the environment. The confinement is not sealed, and its volume is constantly being exhausted to the atmosphere through a filter bank and a $200-\mathrm{ft}$. stack. This is the only "normal" pathway for air, and potential contamination, to leave the building. Other pathways may be opened during the progression of a severe accident due to failure of the exhaust system or due to energetic events within the confinement. These pathways include the heat exchanger bay covers, personnel access doors, and_a transient pathway through the D\&E canal. The fan and filter system may fail due to either energetic events 
inducing pressure loads, or adverse temperature conditions. The random failure probability of the exhaust fans or dampers is increased after loading of the filters following a severe accident causes exhaust air temperature to increase. The filter compartments have been assumed to fail should a seismic event occur. This assumption is based on the assessed fragility of the compartments being jnuch lower than that of any other component or structure. More severe seismic events were found to cause damage to the confinement structure.

The PSA results allow characterization of the relative probabilities that these systems are available and function as designed, or fail in various combinations. These resilts have been assembled into a Confinement Performance Matrix presented in the next subsection.

\subsubsection{Confinement Performance Matrix}

Table 11-1 presents the results of calculations designed to generate the conditional probabilities of the confinement being in various states over the spectrum of severe accidents considered in this PSA. Five different states are considered:

(1) The building is structurally failed (seismic or missile failure).

(2) The AACS is completely bypassed (a direct unfiltered path from confinernent to atmosphere exists for both early and late releases).

(3) The AACS has only a late bypass failure (any structural failure that only occurs after volatile releases are deposited on the filters-filter combustion is excluded).

(4) The filters bither burn or desorb large fractions of their accumulated halogen inventory sometime during the accident.

(5) The AACS is retaining aerosol and halogen releases.

For the seismic plant damage states, the only two possibilities modeled are failure of the building and bypass of the filter system due to either damper closure or filter failure. The building failure probabilities are results $\mathrm{c}$ : the seismic building fragility and seismic hazard calculations, and are it directly to the Level 2 PSA [1]. As stated above, the filters or damper. e always assumed to fail for a seismic event, and thus the "Complete Ar. 3 Bypass" column in the table is the complement of the "Building Failu Probability" column. Insights into Level 2 PSA seismic confinemer. performance are limited with the present simplified model.

The internal events confinement performance results show several interesting trends. Complete bypass of the confinement system is generally caused by energetic events. Steam explosions are the principle contributor. The complete-bypass resilts in the internal events portion of Table 11-1 


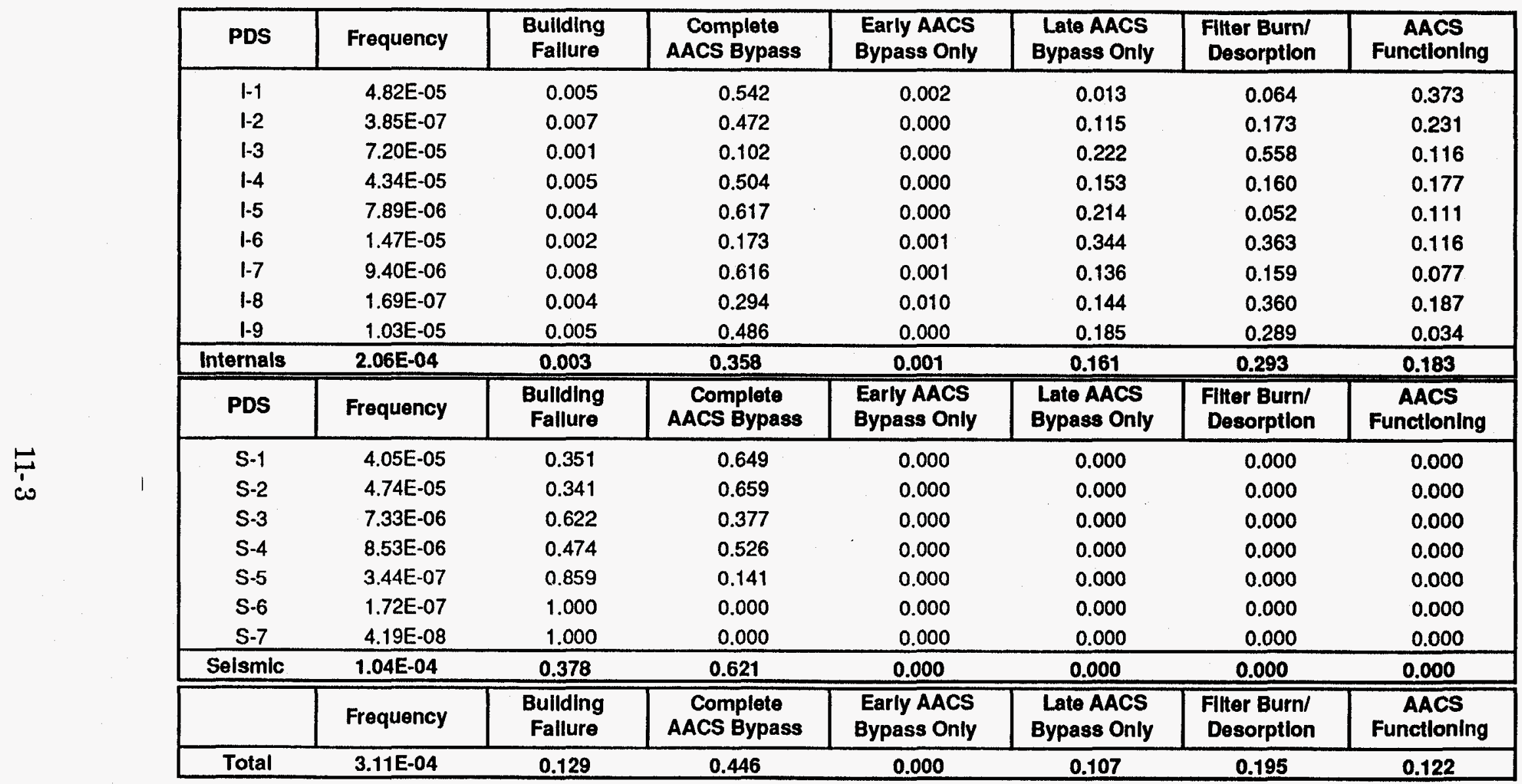

Table 11-1. Fractional Contributions to Confinement Failure Modes in the K-Reactor Level 2 PSA 
show the importance of steam explosions to confinement integrity. For a steam explosion to happen, water is required, either in the vessel or in the pump room. All of the plant damage states that exhibit a large probability of complete bypass have either significant water in the vessel at fuel melt or significant water on the confinement floor.

The presence of water has both negative and positive influences on confinement performanie. Negatively, steam explosions can induce confinement bypass. Positively, core debris may quench in water, limiting fission product releases. Dispersal of the debris by a steam explosion can enhance the probability that the debris will quench. Thus, a steam explosion may open a corfinement bypass, but at the same time limit the release of fission products from the core debris. Scrubbing of fission products by in-vessel water and by water accumulated at the -40 -level in the confinement also acts to reduce fission product release for accident progressions involving water. These effects probably reduce the apparent importance of the steam explosion phenomenon from the perspective of its impact on risk. The conf:nement performance results illustrated in Table 11-1 may portray the importance of steam explosions more accurately.

Core melt occurs in a viessel full of water for both the large and small LOPAs. Significant water is also on the confinement (pump room) floor for these PDSs. The small LOCA/partial ECCS and the LOCA/fld states also have water in the vessel. and significant water on the pump room floor. Core melt also occurs with a full vessel of water for those LOHS cases in which the Bingham pumps are inoperative. Recriticality may be important in driving the in-vessel events, but the primary effect on confinement response is from the steam explosions (notwithstanding where they originate).

A logical complement of this effect is the filter burn/desorb results in Table 11-1. Only those sicenarios where the AACS system remains intact long enough to accumulate a significant fission product inventory can have a filter burn or desorption. The LOCA/no ECCS, the ATWS, and the secondary LOHS dominate the filter burn/desorb column. For the LOCA and secondary LOHS, the driving effect is fuel melt in a dry vessel. Subsequent heatup of the melt prior to vessel failure drives off all of the volatile fission products early in the accident. For the ATWS, $r$ ingle progression dominates, but for the scenarios where the filters $k$ the

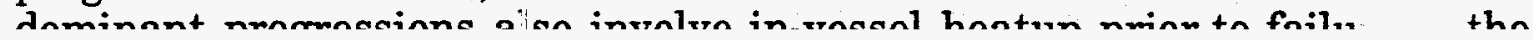


early evolution of volatile fission products and subsequent burning of the filters and results in higher consequences than other PDSs with similar frequencies and higher confinement bypass fractions. This result indicates that high fission product release from the fuel without scrubbing, and the possible burning of the filters is more important than confinement damage caused by energetic events.

\subsubsection{Confinement System Effectiveness}

The $\mathrm{K}$ Reactor confinement was designed to mitigate events involving limited (i.e., 3\%) fuel melt (this was the original design basis), not severe accidents involving complete core melt. Thus, the high probabilities of failure indicated in the confinement performance matrix are not surprising for the accidents analyzed in this PSA. The confinement is, however, reasonably effective for those accident scenarios where it is predicted to survive. In the absence of large energetic events damaging the confinement boundaries or the fan and filter system, all of the released fission products are predicted to be drawn to the filters. The filter system is an effective removal mechanism for aerosols and halogens. However, the filter system is not effective for noble gases and tritium, and these radionuclides are modeled as being exhausted up the stack. This is realistic for the noble gases and conservative for tritium, since much of the tritium would form tritiated water and would therefore be retained within the confinement far more effectively than the current model suggests.

An idea of the effect of the unmitigated release of noble gases and tritium can be gained from an examination of the input to the source term partitioning computer code. This input lists the results of a series of consequence calculations that assume the unmitigated release of each of the 61 radioisotopes considered in the consequence calculations individually. The consequence calculations are site specific, but involve no evacuation or relocation, and model both onsite and offsite populations. For each of the radioisotopes, an early-fatality, early-injury, and latent-fatality result is calculated. Comparing consequences from the two noble gases modeled $(\mathrm{Xe}, \mathrm{Kr}$ ) and the total inventory of Tritium, to the consequences from releasing the total reactor inventory of Iodine, it is found that Tritium causes essentially no early effects, and long term latent effects on the same order of those of the iodine release. Release of the noble gases causes very little effect on either early or latent fatalities, except for $\mathrm{Kr}-88$, which causes early effects similar to that of iodine, and very little latent effect (due to its short half-life). Table 11-2 presents consequence results for these isotopes, scaled to the effects of Iodine.

Actual consequence values for the above runs are not presented here because they are not comparable to the other consequence measures discussed in this report. The effects discussed above will be more applicable to the onsite population (but will be mitigated by an effective evacuation plan), and less so for the offsite population (due to this population's remoteness). The results suggest that noble gas release will have little effect 
on the offsite population, and that Tritium release will have an effect similar to that of iodine for: long-term latent fatalities.

\section{Table 11-2. PARTITION Input Consequence Estimates for Unmitigated Release of I Iotal Inventory of Selected Isotopes}

\begin{tabular}{lccc}
\hline & \multicolumn{3}{c}{$\begin{array}{c}\text { Consequences scaled to those from releasing } \\
\text { total inventory of all Iodine isotopes }\end{array}$} \\
\cline { 2 - 4 } Isotope & $\begin{array}{c}\text { EARLY } \\
\text { FATALITIES }\end{array}$ & $\begin{array}{c}\text { EARLY } \\
\text { INJURIES }\end{array}$ & $\begin{array}{c}\text { LATENT } \\
\text { FATALITIES }\end{array}$ \\
\hline \hline I & 1.00 & 1.00 & 1.00 \\
TRITIUM & 0.00 & 0.00 & 4.88 \\
KR-85 & 0.00 & 0.00 & 0.00 \\
KR-85M & 0.00 & 0.00 & 0.00 \\
KR-87 & 0.02 & 0.04 & 0.04 \\
KR-88 & 0.60 & 0.46 & 0.18 \\
XE-133 & 0.00 & 0.00 & 0.03 \\
XE-135 & 0.00 & 0.00 & 0.00 \\
\hline
\end{tabular}

\subsubsection{Early Confinement Failure Mechanisms}

Typically, the only mechanisms for breaching the confinement in the early stages of an accident involve energetic events such as steam explosions and hydrogen combustion. These events may produce pressure spikes and shock waves, as well as छenerate missiles. There are five major pathways in which an energetic event may cause a breach of the confinement:

(1) The filter system. A pressure increase which propagates to the filters may fail the filter elements or fan casings, creating a direct pathway to the atmosphere.

(2) The heat exchanjer bay access covers. These very heavy, thick concrete plugs which cover the exterior access hatches for removing and rejlacing heat exchangers may be removed by as little as a 4 psi overpressure in the heat exchanger bay.

(3) Personnel access itoors and two roll doors from the heat ex ger bay and pump room into the balance of the confinement. 3se doors have low failure thresholds. While they do not open c. st pathways to the environment, they do connect to volumes $v$. I may be open to atmosphere.

(4) Reactor room cieiling. The reactor room ceiling is a mass e structure that supports the control and safety rod dri:e mechanisms. Openings in this ceiling accommodate insertion of the control and safety rods. An extremely low probability event 
would be an in-vessel steam explosion that propelled the top of the reactor as a "missile", causing gross failure of the reactor room ceiling and subsequent failure of the "top-hat" [see (5) below]. This low probability event is shown in Table 11-1 as "Building Failure" for internal events.

(5) The building "top-hat", The most fragile above grade location subject to permanent damage from over-pressurization is the top of the reactor building, called the top-hat, which houses the control and safety rod drive mechanisms. Confinement studies indicate that pressurization of the top-hat to its assessed 5 psi capacity, though unlikely, can occur.

The additional pathway that can allow temporary bypass of the confinement is the D\&E canal, which connects the reactor room to the disassembly basin room. The canal is normally sealed with 12 inches of water ( 1 inch of water if the confinement heat removal system has been actuated). Pressurization of the reactor room by an energetic event or due to closure of the exhaust system dampers, would depress this water and cause an intermittent release of material into the disassembly room which is open to atmosphere. The consequences of such a pathway are minor relative to the consequences of opening of the permanent pathways described above.

\subsubsection{Late Confinement Failure Mechanisms}

Later in the course of an accident, if early energetic events do not occur or if the confinement has survived them, there are other mechanisms for failing the filter and fan systems. These late failure modes are related to overheating and excessive differential pressure for both the fans and filters and to late energetic events.

During the accident progression, the filters may have been loaded with radionuclides. These radionuclides constantly produce heat which must be removed by the air flowing through the filters. A significant effect of loading the filters is a degradation in the airflow due to plugging of the HEPA filter with aerosols. Depending upon the loading on the filters, these two effects (blockage and heating) may cause the filter temperature to rise to the point at which the carbon filters begin to desorb their trapped halogen inventory. If the flow reduction is severe enough, the filters may burn.

The current modeling of the filter system behavior includes assumptions that potentially lead to poorer predictions of performance than may actually be achieved. The Demister ${ }^{\circledR}$ element in the filter is assumed to remove 100 percent of the water droplets in the exhaust stream, and to be completely ineffective in retaining fission products and inert aerosols. Neither assumption is completely accurate. The effect of relaxing the water removal assumption would be to allow water to collect on the HEPA filter. As mentioned in Section 5, water loading on the HEPA will potentially cause a large increase in filter flow resistance. However, sensitivity studies conducted with the MELCOR/SR filter model indicate that this water would 
evaporate before the HEPA or charcoal filters could attain temperatures at which filter or fan failure becomes a significant concern. Thus, this assumption has little significance.

Allowing the Demister ${ }^{(3)}$ elements to retain aerosols may have a large positive impact on filter compartment performance. Aerosols retained on the Demister ${ }^{\circledR}$ elements will not reach the HEPA elements. On the Demister ${ }^{\circledR}$ elements, the loading contributes little to increasing flow resistance. The capacity of the filter compartments to retain aerosols may thus be understated. This effect would reduce the probability of filter desorbtion and/or burning, ultimately increasing the "AACS functioning" probabilities in Table 11-1.

Another mechanism for degrading filter airflow is to fail the fans. Random failure of the fans is modeled within the 30 day period following the accident. This failure probability is enhanced based upon predicted adverse temperature and radiation environments.

A late phase phenomenological event that affects the probabilities of late failure of the fan and filter systems is Molten-Core Concrete Interaction (MCCI). This phenomenon occurs when molten core material interacts with the concrete confinement basemat to produce large amounts of aerosols and hydrogen, as well as additional fission product release. Combustion of the hydrogen may cause bypass of the confinement system by lifting the heat exchanger hatch covers if not previously lifted. The resulting elevated temperatures also increase the probability of fan and filter failure.

MCCI may cause filter failure in two additional ways, depending upon previous progression of the accident. If the molten core material still contains a substantial fraction of the radionuclide inventory, then the violent high-temperature reactions will drive off all of the volatile elements, and some of the semi-volatiles. This will cause substantial filter loading, resulting in the heating and flow degradation discussed above. If most of the volatile and semi-volatile products have already been released and are on the filters, then the large volume of aerosols produced by the MCCI reactions can be pulled to the filters and plug them. Even if these late aerosols are not very radioactive, if the filters were previously loaded, they may desorb or burn. PDS-I3 (LOCA /no ECCS) exhibits this effect stron " Two of the three most probable sequences for this PDS have MCCI ar. 1 late or very late filter burn (shown in the summary trees in Appendix A).

\subsection{Importance of System Failure Modes}

The nine internal events and seven seismic Plant Damage States (PDSs) described within this document involve a wide variety of differing system conditions and resulting phenomena. Some of the phenomena considered in this analysis are the result of the system condition (e.g., recriticality requires some water in the reactor vessel). Several of the more important 
system effects are described in the following subsections in terms of their ultimate effects on risk.

\subsubsection{Primary System Integrity}

The integrity of the primary cooling system boundary is failed initially in PDSs 3, 4, and 5 for internal events and PDSs 4, 5, 6, and 7 for seismic events (described in Section 2). A large break in the primary cooling system provides a pathway for either very quick emptying of the vessel, or for most of the ECCS flow to exit to the pump room level. The size of the break and inflow rate of ECCS will affect the timing of the melt, the level of water in the vessel at melt, and the level of water on the pump room floor. In-vessel water level affects the potential for recriticality. Pump room water level can affect steam explosions, hydrogen burns, decontamination factors for MCCI, flooding of the primary cooling pumps, and in-vessel cooling of the melt in the effluent piping.

Integrity of the primary system during the late accident phases controls potential pathways for fission product transport through the building. If both the bottom and top of the vessel fail, a direct path from below to above grade is opened. Airflow through the vessel will affect cooling of deposited fission products, and thus the potential for revolatilization from the vessel walls.

\subsubsection{Primary Coolant Pumps}

The status of the primary coolant pumps has a substantial effect on the invessel melt progression. Accidents where the primary pumps fail cause melting to occur early in a full vessel of water. This provides a mechanism for recriticality to occur. Accidents where the primary pumps do not fail may allow a slow boil off of the coolant inventory or may cause fragmentation of the fuel during melt ("melting as particulate"). Fragmentation may allow fuel debris to be swept into the moderator space and on to the heat exchangers where it ultimately degrades flow by blocking the heat exchangers. An analysis of a potential reactivity excursion brought on by the particulate debris being swept up into the moderator was necessary. The conclusion of the analysis was that for reactor vessel conditions associated with $2500 \mathrm{MW}$ operation, void feedback quickly damped the transient.

\subsubsection{Reactor Shutdown}

The reactor achieves shutdown for all PDSs except for the ATWS. The ATWS is modeled as a single rod withdrawal at power and at full coolant flow. As described above, the resulting particulate melt phenomena raised the possibility of an energetic reactivity excursion which required analysis. The conclusion of the analysis required that a small probability be given to the possibility of a reactivity excursion. A reactivity excursion was assumed to produce a steam explosion with sufficient energy to fail the reactor vessel. 


\subsubsection{Cooling Water Supply}

Cooling water supply afferts the two loss of pumping accidents, where the below-grade area is flooded due to the large volumes of secondary cooling water being discharged within the building. Secondary cooling water, however, is also a supply to the ECCS and provides cooling to the primary coolant pump DC diesels. Loss of cooling to the primary coolant pump diesels (such as in the LORW) causes loss of the primary coolant pumps and subsequent loss of flovr in the primary system. What follows is a melt in a full vessel of water instead of a slow boiloff as would be the case if the primary pumps still operated. This leads to accident progressions which include recriticality events (since there will be water in the vessel) instead of melt in a dry vessel. The results of this PSA show, however, that melt and heatup in a dry vessel generates higher consequences than an energetic recriticality which subsequently causes a steam explosion and disrupts the vessel and mielt geometry. This is due to the fact that a dry vessel heatup causes the entire core to achieve very elevated temperatures, where the recriticality invislves raising only approximately 25 percent of the core to very high temperatures. In addition, the presence of water mitigates the consequences of that 2.5 percent release.

\subsubsection{Seismic Events}

The effects of seismic events on the accident progression are modeled through introduction of building failure probabilities, and from introduction of the possibility of multiple pipe failures (i.e., both primary and secondary). The seisinic progressions parallel internal events, except for the cases that are "vented" (Plant damage states PDS-S6 and S7 as described in Section 2). These PDSs are different in that the plenum and/or the above grade primary coolant piping are assumed to be broken due to building collapse, which allows steam to escape, and a longer heatup to take place than would be possible with an intact upper primary system. These PDSs, however, are low frequency and do not contribute substantially to risk.

\subsection{Importance of Acciclent Phenomenology}

The PSA considers and evaluates many thousands of possible accident progression sequences. Many of these sequences are similar, and their differences are not important to confinement response or risk. The use of binners allows the analyst to concentrate only on the phenomena with potential significance. A large number of different phenomenological issues are considered, iricluding such phenomena as steam explosions, recriticality, hydrogen production and combustion, failure of structures, fission product transport and MCCI. The volume of information requires the use of automated methods for investigating the importance of input variables and assumptions to the analysis results. The PSA structure used for this work lends itself to these investigations using three basic tools: (1) summary tree production such as presented in Appendix A; (2) multiple regression techniques to assess the importance of specific variables to the 
results, and (3) output from the PRAMIS code characterizing fractional contribution to risk values for PDSs, source term partitions, source term bin attributes, and the source term bins themselves.

These three tools allow different facets of the accident progression to be analyzed. The PRAMIS results provide a wealth of information that may be assimilated as needed (specialized assessments may also be run if desired). The summary tree approach requires that an analyst cognizant of the problem devise a summary binner which is appropriate for investigating the phenomena of interest. The pictorial representation and ability to combine progressions at the level desired provide a powerful tool for investigating the severe accident progression. This cannot, however, be related directly to risk. The multiple regression approach allows investigation of those variables in the analysis that were assigned uncertainty distributions. For these variables, importance to uncertainty in risk may be investigated, but not necessarily the overall contribution of the variable and its value to the bottom line risk results. The results of regression analyses may also be dependent upon the ranges of the distributions assigned to the variables. An important variable assigned a narrow uncertainty band may not appear as important in regression analyses.

The following discussions will use (except where noted) two consequence measures for analyzing the importance of phenomena: (1) 1 mile offsite prompt fatality individual risk; and (2) 10 mile offsite latent fatality individual risk. References to "prompt risk" and "latent risk" in the following will refer to these two measures.

Table 11-3 shows the PRAMIS fractional contribution to risk values for both the prompt and latent risk measures for the first 15 of the 16 source term bin attributes that are described in Section 7 of this report. The interpretation of the values in this table is as follows: if the fractional contribution to risk for a specific dimension of an attribute is 0.50 , then the phenomena associated with this attribute occurred in sequences which caused fifty percent of the risk for that consequence measure. This is different than the conditional probabilities associated with the summary trees. The conditional probabilities on the summary trees essentially show the percentage of the time that each phenomenon will happen-not how it relates to risk.

It is apparent from Table 11-3 that most of the risk for these consequences comes from sequences whose timings are early (Dimension 1, Attribute A). For prompt risk, over 82 percent of the risk comes from sequences where there is no energetic recriticality event (Dimension 2, Attribute A). This value is only 66 percent for latent risk, but this is still quite dominant. Nonenergetic recriticality is included with the normal melt attribute. From the summary trees in Appendix A, it can be seen that the conditional probability of the different recriticality events varies greatly depending upon the PDS. On an overall internal events PSA basis, however, the fractional occurrences are approximately 31 percent energetic recriticality, 23 percent 


\begin{tabular}{|c|c|c|c|c|c|c|c|c|c|c|c|c|c|c|c|c|}
\hline & & & & & & & Sol & rce Te & $\mathrm{rm}$ Bin & Dimen & sion & & & & & \\
\hline & Attribute & 1 & 2 & 3 & 4 & 5 & 6 & 7 & 8 & 9 & 10 & 11 & 12 & 13 & 14 & 15 \\
\hline $\begin{array}{l}\text { Offsite Prompt } \\
\text { Fatality Risk Within } \\
\text { One Mile of K } \\
\text { Reactor }\end{array}$ & $\begin{array}{l}A \\
B \\
C \\
D \\
E \\
F\end{array}$ & $\begin{array}{l}0.81 \\
0.12 \\
0.07\end{array}$ & $\begin{array}{l}0.82 \\
0.17 \\
0.01\end{array}$ & $\begin{array}{l}0.32 \\
0.39 \\
0.21 \\
0.07\end{array}$ & $\begin{array}{l}0.01 \\
0.00 \\
0.22 \\
0.77\end{array}$ & $\begin{array}{l}0.16 \\
0.05 \\
0.79\end{array}$ & $\begin{array}{l}0.22 \\
0.00 \\
0.77\end{array}$ & $\begin{array}{l}0.79 \\
0.02 \\
0.01 \\
0.18\end{array}$ & $\begin{array}{l}0.56 \\
0.00 \\
0.04 \\
0.39\end{array}$ & $\begin{array}{l}0.27 \\
0.33 \\
0.34 \\
0.05\end{array}$ & $\begin{array}{l}0.02 \\
0.07 \\
0.06 \\
0.25 \\
0.15 \\
0.44\end{array}$ & $\begin{array}{l}0.48 \\
0.18 \\
0.00 \\
0.35\end{array}$ & $\begin{array}{l}0.05 \\
0.21 \\
0.74\end{array}$ & $\begin{array}{l}0.25 \\
0.03 \\
0.00 \\
0.34 \\
0.00 \\
0.38\end{array}$ & $\begin{array}{l}0.48 \\
0.06 \\
0.47\end{array}$ & $\begin{array}{l}0.09 \\
0.91\end{array}$ \\
\hline $\begin{array}{l}\text { Offsite Latent } \\
\text { Fatality Risk Within } \\
\text { One Mile of K } \\
\text { Reactor }\end{array}$ & $\begin{array}{l}A \\
B \\
C \\
D \\
E \\
F\end{array}$ & $\begin{array}{l}0.66 \\
0.22 \\
0.12\end{array}$ & $\begin{array}{l}0.69 \\
0.30 \\
0.01\end{array}$ & $\begin{array}{l}0.28 \\
0.27 \\
0.38 \\
0.07\end{array}$ & $\begin{array}{l}0.01 \\
0.00 \\
0.39 \\
0.60\end{array}$ & $\begin{array}{l}0.23 \\
0.08 \\
0.69\end{array}$ & $\begin{array}{l}0.39 \\
0.00 \\
0.60\end{array}$ & $\begin{array}{l}0.60 \\
0.01 \\
0.03 \\
0.36\end{array}$ & $\begin{array}{l}0.63 \\
0.00 \\
0.08 \\
0.00 \\
0.29\end{array}$ & $\begin{array}{l}0.32 \\
0.13 \\
0.44 \\
0.10\end{array}$ & $\begin{array}{l}0.00 \\
0.01 \\
0.09 \\
0.31 \\
0.03 \\
0.55\end{array}$ & $\begin{array}{l}0.28 \\
0.32 \\
0.00 \\
0.40\end{array}$ & $\begin{array}{l}0.09 \\
0.32 \\
0.59\end{array}$ & $\begin{array}{l}0.43 \\
0.02 \\
0.00 \\
0.29 \\
0.00 \\
0.27\end{array}$ & $\begin{array}{l}0.28 \\
0.04 \\
0.68\end{array}$ & $\begin{array}{l}0.09 \\
0.91\end{array}$ \\
\hline
\end{tabular}

Table 11-9. ..tional Contributions of Source Term Attributes to Risk (Internal Events) 
benign recriticality, and 46 percent no recriticality. This implies that for prompt risk, 55 percent of the prompt risk is driven by scenarios where there is no recriticality event. This would tend to imply that recriticality events play a somewhat lesser role in risk than a normal melt progression. This may be due to the assumed mitigation of the releases accompanying a recriticality event by the surrounding water.

Dimension 8 in Table 11-3 describes the role of energetic events at vessel failure as related to risk. It can be seen here that approximately 60 percent of the risk is driven by scenarios where the confinement is breached due to an energetic event at vessel failure (attribute A). This may be either from an in-vessel event or an ex-vessel event. The remaining 30-40 percent of the risk is associated with scenarios where there is no energetic event at vessel failure (attribute D). The conditional probability of an energetic event over all internal events is approximately 60 percent. Thus, it is apparent that risk is strongly related to the probability of confinement failure from energetic events at vessel failure.

Two sensitivity studies were performed that considered the occurrence of recriticality and steam explosion events. These studies will be described next.

\subsubsection{Steam Explosions}

Steam explosions may occur either in-vessel or ex-vessel. In-vessel explosions may occur within fuel assemblies (1) as molten fuel drops into the bottom end-fitting; (2) within the vessel/moderator space as a result of a reactivity excursion, recriticality, or normal melt/slumping; or (3) in the effluent piping as the melt falls into the water in the pipe. They may occur ex-vessel when molten material exits the vessel, either through the tank bottom or the effluent piping, and drops into water on the pump room floor. The sensitivity study described here set the probability of occurrence of all steam explosions to zero in the APET. The idea behind this was to consider the overall contribution to the accident progression from steam explosions.

The APET was run for all internal events PDSs after incorporating the above modification. Source terms were then generated as usual for the resulting source term bins. At this point, to avoid having to make timeconsuming MACCS runs, an ability of the PARTITION code to generate pseudo consequences was used to provide a crude risk estimate of the sensitivity. (First, the base-case PSA was also run through PARTITION in this manner to establish a comparison basis.) Table 11-4 provides the mean early and latent fatality measures from these PARTITION runs for the base case, this no steam explosion case, and a no recriticality case (described in the next section). Based on this PARTITION-estimate consequence, eliminating all steam explosion reduced the early fatalities by 27 percent and the latent fatalities by 22 percent over the base case. 


\subsubsection{Recriticality}

Two defined types of recriticality events may occur as melted fuel accumulates in the assembly bottom end fittings. These are classified as energetic and benign recriticalities on the basis of the power ramp rate and ultimate temperature achieved in the melt mass. For recriticality of any type to occur, the vessel nuust contain approximately one meter or more of water, and the melt must be cooled in the bottom end fittings as it accumulates. Further, a large fraction of the lithium target material cannot melt and mix with the fuel, or a recriticality is precluded. A sensitivity study was performed where the accident progression analysis was run with the probability of occurrence of recriticality set to zero in the APET. The sensitivity of the risk results to recriticality events is low. The risk for both early and latent fatality measures is reduced less than 7 percent when recriticality is precluded. This conclusion is further supported by the PRAMIS and conditional probability results presented earlier in this section for recriticality.

\section{Table 11-4. Sensitiviț̣ Case PARTITION-Generated Consequence Measures}

\begin{tabular}{lcc}
\hline \multicolumn{1}{c}{ Case } & $\begin{array}{c}\text { Early Fatality } \\
\text { Measure }\end{array}$ & $\begin{array}{c}\text { Latent Fatality } \\
\text { Measure }\end{array}$ \\
\hline \hline Base-Case & 0.00876 & 0.3172 \\
No Steam Explosion & 0.00642 & 0.2460 \\
No Recriticality & 0.00815 & 0.2971 \\
\hline
\end{tabular}

\subsubsection{Phenomenological Uncertainties}

The results just described, and, in fact, many of the results discussed throughout this documerit, are presented in terms of mean results. In Section 10, the two PDS box and whisker plots attempt to give a feel $\mathrm{f}_{\mathrm{i}} \quad \mathrm{w}$ widely these mean results actually vary among LHS sample mer rs within the analysis. The events being modeled within this analysis e either inherently uncertain/random types of events, or the current state knowledge concerning them lends itself only to a characterization of $\mathrm{t}$ ranges of possible values that parameters describing the phenomena $\mathrm{m}_{\mathrm{i}}$ take on. Thus the numejical results presented here must be considere. within the context of their uncertainty, and point estimates must be use with caution and cognizance of this uncertainty. It is believed, however, that as tools for gaining insights into the problem, point estimate characterizations have utility for describing general results and overall 
trends in the accident progression. This is the context in which the above described results are presented.

\subsection{Source Term Analysis}

A simple analysis of the internal events source terms has been performed to examine the relationship between the frequency-weighted mean source term for a given plant damage state and risk. The PARTITION computer code [11-2] was used to weight each of the source terms from a given plant damage state according to its frequency and then sum over all source terms to create a single source term for each plant damage state. This one source term represents the mean source term for each plant damage state from all contributing accident progressions. This source term does not correspond to any specific accident progression within the PDS, and as such, it is not "representative" in any real sense. Comparing these average source terms, however, may reveal trends between PDSs. The differences in the source terms may also be compared to differences in the "Mean Fractional Contribution to Risk" (MFCR) value calculated by the PRAMIS code. The MFCR is similar to the mean source terms calculated here, in that it is a single averaged value meant to be used to exhibit trends between the PDSs. The difference between the MFCR and the mean source term, is that the source terms are not only frequency weighted, as is done here, but are also consequence weighted from the mean results of the MACCS runs. Thus, comparisons of the average PDS source terms and the PDS MFCR values are measures of the impacts of the source term variation between PDSs on the consequences.

Table 11-5 displays excerpts of the results of the source term analysis described above, as well as the MFCR values for two different consequence measures. It is apparent from Table 11-5 that the expected fraction of iodine released does not vary a great deal from one plant damage state to another. PDS-I3 (LOCA w/o ECCS) has the greatest expected fraction of iodine released (35.3\%) while PDS-I5 (LOCA/flood) has the smallest (18.6\%). These are very different accidents. The LOCA without ECCS addition is essentially a melt in an empty vessel with little or no water on the pump room floor. The flooded LOCA scenario involves melt with anywhere from a partially full vessel to an essentially full vessel, and a large amount of water on the pump room floor (at least three feet). These differing conditions provide different in-vessel melt heat-up conditions, different probabilities of recriticalities, steam explosions, MCCI, etc., different decontamination factors both in-vessel and ex-vessel, and potentially different confinement transport phenomena. As can be seen in Table 11-5 as well, the melt timings are dissimilar.

The MFCR values for two risk measures are included in Table 11-5. These two measures provide an indication of the effectiveness of onsite evacuation plans (Onsite prompt fatality individual risk), and overall source term impact (Offsite latent fatality individual risk). As can be seen in Table 11-5, the fractional contributions to prompt fatalities are not highly correlated to the plant damage state frequencies or to the iodine release fractions. As 
indicated in Figure 11-1, however, a definite inverse relationship exists between the plume timirg and the prompt fatality consequence measure. Short times to release leøid to high prompt consequences, and longer times lead to lessor prompt comsequences. Variation between the consequences for PDSs with the same approximate timing seems to follow the SCMF percentage.

Onsite evacuation is modeled to occur $\mathbf{3 0}$ minutes after reactor shutdown. For PDSs I1, I3, I6, and I7, the five minute release timing allows no evacuation before the innmediate onsite population is impacted by the plume. Releases for PDS-I8 and -I9 do not begin until 120 minutes after shutdown, and thus there is no possibility for prompt fatalities to occur, which is why the MFCR values are 0.0 in Table 11-5. Table 11-5 also shows the expected time of release for PDS-I2, PDS-I4, and PDS-I5 to be 38, 40 and 38 minutes, respectively. The time of release for these plant damage states is uncertain and varies from 20 minutes to 60 minutes [11-3]. Therefore, the possibility of prompt fatalities exists in only a portion of the source terms that are associated with PDS-I2, -I4 and -I5.

Figure 11-1 also shows the relationship between the Latent Fatality MFCR measure, the plume total Iodine release fraction and the percentage of the SCMF attributed to the FDS. It is evident that the magnitude of the latent fatalities is controlled for the most part by the SCMF, with some variation due to changes in the iodine release fraction. This is expected given the small variation in the mean iodine release fraction.

Table 11-5. Characteristics and Effects of Mean Internal Event Plant Damage State Source Terms

\begin{tabular}{|c|c|c|c|c|c|c|c|c|}
\hline PDS & $\begin{array}{l}\text { Mean } \\
\text { Fraction } \\
\text { of SCMF }\end{array}$ & $\begin{array}{c}\text { Mean } \\
\text { Plume 1 } \\
\text { Iodine RJP }\end{array}$ & $\begin{array}{c}\text { Mean } \\
\text { Plume 2 } \\
\text { Iodine RF }\end{array}$ & $\begin{array}{c}\text { Total } \\
\text { Iodine } \\
\text { RF }\end{array}$ & $\begin{array}{c}\text { Plume } 1 \\
\text { timing } \\
\text { (min) }\end{array}$ & $\begin{array}{c}\text { Plume 2 } \\
\text { timing } \\
\text { (min) }\end{array}$ & $\begin{array}{c}\text { MTCR: } \\
\text { Consq. } \\
\# 1^{*}\end{array}$ & 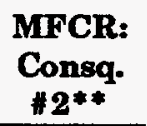 \\
\hline PDS-I1 & $22.0 \%$ & $1.4 \%$ & $18.0 \%$ & $19.4 \%$ & 5 & 13 & $23.1 \%$ & $18.7 \%$ \\
\hline PDS-I2 & $0.2 \%$ & $2.9 \%$ & $17.1 \%$ & $20.0 \%$ & 38 & 47 & $0.0 \%$ & $0.5 \%$ \\
\hline PDS-I3 & $32.8 \%$ & $14.5 \%$ & $20.8 \%$ & $35.3 \%$ & 5 & 19 & $44.8 \%$ & $28.8 \%$ \\
\hline PDS-I4 & $16.7 \%$ & $3.4 \%$ & $19.4 \%$ & $22.8 \%$ & 40 & 48 & $2.6 \%$ & $18.9 \%$ \\
\hline PDS-I5 & $11.3 \%$ & $1.4 \%$ & $17.2 \%$ & $18.6 \%$ & 38 & 44 & $0.3 \%$ & $2.8 \%$ \\
\hline PDS-I6 & $7.4 \%$ & $4.0 \%$ & $20.2 \%$ & $24.2 \%$ & 5 & 17 & $18.7 \%$ & $11.6 \%$ \\
\hline PDS-I7 & $4.8 \%$ & $4.0 \%$ & $18.8 \%$ & $22.8 \%$ & 5 & 12 & $10.4 \%$ & $6.8 \%$ \\
\hline PDS-I8 & $0.1 \%$ & $10.9 \%$ & $20.9 \%$ & $31.8 \%$ & 120 & 131 & $0.0 \%$ & $0.3 \%$ \\
\hline PDS-I9 & $4.8 \%$ & $5.2 \%$ & $22.3 \%$ & $27.5 \%$ & 120 & 130 & $0.0 \%$ & $11.6 \%$ \\
\hline
\end{tabular}


These results provide a picture of the average response of consequences to average accidents in $K$ Reactor. No conclusions on the relationships between specific phenomena and these average results are made. Specific phenomena important to accident progression in $\mathrm{K}$ Reactor have been previously discussed in this section.
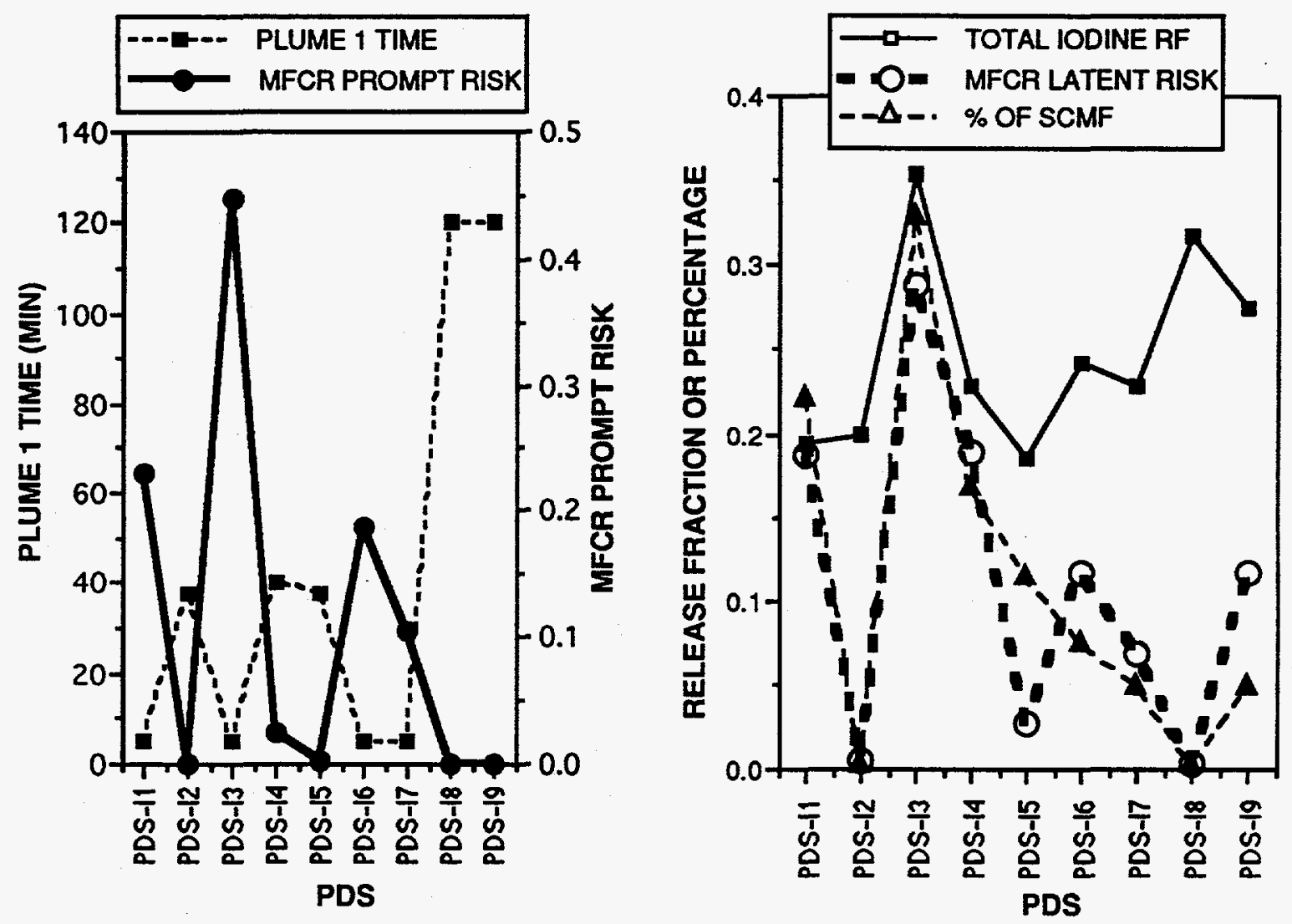

Figure 11-1. Mean PDS Source Term Parameter Relationships to
Consequence Measures

\subsection{Conclusions}

A full scope PSA for the 1987 configuration of $\mathrm{K}$ Reactor operating at $2500 \mathrm{MW}$ has been completed. The results presented in Section 10 show that the risks associated with the operation of $\mathrm{K}$ Reactor are well below the guidelines set forth by DOE. The sensitivity studies presented in Section 11.3 showed that the risk results are moderately insensitive to energetic events (recriticality and steam explosions) within the accident progression. This is probably due to the competing effects associated with these phenomena. An important conclusion may be that no single phenomenon determines the overall risk. The risk results were dominated by core melt frequency more than any other single factor. The results also showed that the AACS is not effective in confining released fission products to the reactor building under 
most severe accident conclitions; however, in many cases, it is effective in delaying potential releaseis.

The results presented within this report provide a basis for analyzing the risk of reactor operation under the 1992 restart configuration-a task that is currently under way. It is expected that the lower operating power will reduce the values calculated for risk due to a number of factors including (1) the reduced SCMF fiom the Level 1 analysis; (2) the lower fission product inventories; (3) the delay in release due to reduction in the speed of the accident progression; and (4) the anticipated survival of many of the confinement system components due to reduced thermal and energetic challenges.

\subsection{References}

11-1. M. D. Brandyberry and H. E. Wingo, SRS PRA Of Reactor Operation Level 1, External Events, WSRC-RP-89-733, Westinghouse Savannah River Company, Aikien, SC, June 1990.

11-2. R. L. Iman, PARTITION: A Program for Defining Source Term/Consequence Analysis Interface in the NUREG-1150 Probabilistic Ri:k Assessments. U.S. Nuclear Regulatory Commission Report NUREG/CR-5253, SAND88-2940 RG, Sandia National Laboratories, Albuquerque, NM, 1990.

11-3 D. P. Kearnaghan, The Production Reactor Algorithm for Source Terms (PRAST), A Computer Code Used in Estimating Source Terms for SRS Reaistors, WSRC-RP-92-700, Westinghouse Savannah River Company, Aiken, SC, September 1992. 


\section{APPENDIX A EXTENDED DISCUSSION OF RESULTS}

\section{A.1. APET Questions}

The questions in the Accident Progression Event Tree (discussed in Section 4), are described in the following Table. 
Table A-1. Event Descriptions for the Savannah River Reactor Accident Progression Event Tree

QUESTIONS ASKED IN THE EVENT TREE

PRIOR QUESTION

INPUT TO LATER

DEPENDENCIES

QUESTIONS

1. What type of charge is present?

None

$34,39,60,63$

2. What is the initiating event?

None

$18,20,22,25,26,27,28,33$,

34. 36. 39.51.55. 78. 102

3. Did a seismic event cause an initiating event or

None

$12,25,39,48,49,50$

4. Did an incident action occur?

None

14,19

5. Is the reactor shut down?

None

6. What is the extent of core damage?

None

$26,33,35,41$

7. What size is the break in the primary cooling water system?

None

34,39

25

None

21

8. What is extent of the break in the secondary cooling water system?

None

21 cooling system at melt initiation?

10. What is the stmt.... of the plant cooling water at melt init: ".tin

None

$18,19,20,21,32,37,38,54$,

115

1: .... we Bingham pumps operating at melt initiation?

None

$18,22,24,25,26,27,28,30$, 36,39 
Table A-1., continued

QUESTIONS ASKED IN THE EVENT TREE

PRIOR QUESTION

INPUT TO LATER DEPENDENCIES QUESTIONS

12. How many filter compartments are online at melt initiation?

3

None

4,10

None

None

11

$2,10,11,14$

4,10

$2,10,14$

$8,9,10$

$2,11,17$
39,49

49,50

$18,20,25,27,28,36,37$

53

52

22

29,96

38

None

None

None

22. How much water is on the pump room floor at melt initiation? 
Table A-1., continued

\section{QUESTIONS ASKED IN THE EVENT TREE}

23. How much water is on the motor room floor at melt initiation

[if level $>3$ feet, includes pump room]?

24. What is the status of the Contaminated Water Storage Tank [CWST] at melt initiation?

25. How much water is available in the Reactor vessel during core melt?

26. Is water in the reactor vessel at saturation temperature during core melt?

27. Does fuel melt as other than particulate?

28. Does a power excursion occur because particulate fuel debris is swept up into the moderator region?

29. Do Lithium targets melt with fuel?

30. Does fuel debris accumulate in a heat exchanger during core melt?

31. Does recriticality occur in a heat exchanger during core melt?

32. Is a heat exchanger breached during core melt?

33. Is an in-vessel steam explosion large enough to cause damage to occur during core melt?

PRIOR QUESTION DEPENDENCIES

INPUT TO LATER QUESTIONS

None

11

$2,3,7,11,14$

$2,5,11$

$2,11,14,25$

$2,11,14,25,27$

18,27

11,27

29,30

$10,30,31$

$2,5,25,27,28$
53

None

$27,28,33,34,35,36,40,43$, 44,45

46

$29,30,33,41,52$

$33,35,36,39,41,47$

$31,42,79$

$31,32,41$

32

None

$34,35,36,39,41,47,48,49$, $52,81,82,86$ 
Table A-1., continued

$\begin{array}{lcc} & \text { PRIOR QUESTION } & \text { INPUT TO LATER } \\ \text { QUESTIONS ASKED IN THE EVENT TREE } & \text { DEPENDENCIES } & \text { QUESTIONS }\end{array}$

34. Does hydrogen burn occur in-vessel during core melt?

35. Does the top of the Reactor vessel fail during core melt?

36. Does the bottom of the Reactor vessel fail during core melt [very early vessel failure]?

37. Is the ECCS adding water during core melt?

38. Is the Reactor Room Spray System operating during core melt?

39. Is there an ex-vessel hydrogen burn during core melt?

40. How much water is available in the Reactor vessel after the in-vessel melt process is complete?

41. Does core debris accumulate in the assembly bottom fittings after the in-vessel melt process is complete?

42. Does recriticality of molten core occur in the Reactor vessel after completion of in-vessel melt?

43. Does in-vessel steam explosion large enough to cause damage occur after completion of in-vessel melt?

$1,2,6,25,33$

36,41

$5,25,28,33$

$36,37,38,40,41,44,45,47$, $48,49,50,71,73$

$2,11,14,25,28,33,34$ 35

$40,41,43,45,52,64,69,76$, $79,81,82,86,115$

$10,14,35$

$40,43,44,45,55,56,60$, $63,68,78$

$10,19,35$

51

$1,2,3,6,11,12,13,28$ 33

$25,35,36,37$

$5,27,28,30,33,34,35$, 36,40

$29,40,41$

$25,36,37,40,41,42$
$42,43,46$

$43,44,45,46,47,64$

$44,45,46,47,48$ 
Table A-1., continued

\section{QUESTIONS ASKED IN THE EVENT TREE}

44. Does top of the Reactor vessel fail from in-vessel steam explosion after completion of in-vessel melt [early vessel failure] ?

45. Does the in-vessel steam explosion fail bottom of the Reactor vessel after completion of an in-vessel melt [early vessel failure]?

46. Is the core debris coolable in the reactor after completion of in-vessel melt?

47. Is confinement damaged by a missle after completion of in-vessel melt?

48. What is the extent of above-grade confinement breach [or filter failure] after completion of in-vessel melt?

49. Does the filter system function after completion of an in-vessel melt?

50. Does the fan system function after completion of an in-vessel melt?

51. Is the Reactor Room Spray System operating after completion of an in-vessel melt?

52. Does the CHRS operate after completion of an invessel melt?

53. Is the Water Disposal System operating after completion of an in-vessel melt?
PRIOR QUESTION DEPENDENCIES

NPUT TO LATER QUESTIONS

$25,35,37,40,42,43$

$45,46,47,48,49,50,51,55$ $68,69,71,73,77,78,115$,

119

$25,35,36,37,40,42, \quad 46,55,56,60,6364,68,69$, 43,44 $76,78,79,81,82,86,115$

$26,40,41,42,43,44$, 45

$56,60,63,68$

$28,33,35,42,43,44$

$48,49,50,51,68,106$

$3,33,35,39,43,44,47$

71, 73, 108

$3,12,13,33,35,39,43$, 44,47

$3,13,35,39,44,47,49$

$71,73,90,91,92,93$

$2,38,44,47$

$71,73,102,119$

$16,27,33,36$

53,54

$15,23,52$

None 
Table A-1., continued

54. Is makeup provided for the CHRS function after

57. How much water is on the pump room floor at completion of an in-vessel melt and heatup?

58. How much water is on the motor room floor at completion of an in-vessel melt and heatup?

59. What is the status of the Contaminated Water Storage Tank [CWST] at completion of an in-vessel melt?

60. Does molten core debris flow out of one Reactor vessel through effluent piping after completion of an in-vessel melt and during heatup?

61. Does a steam explosion that fails the pipe occur when molten core debris enters Reactor effluent piping?

62. How does Reactor effluent piping fail [late vessel failure]?
10,52

$2,37,44,45$

$37,40,45,46$

None

$62,79,80,83,85$

102

102

None

None

$62,77,83,84,87,89,90,91$

None

None

$1,37,45,46$

$61,62,63,64,69,115$

60

62

$57,58,60,61$
$64,69,76,77,78,79,81,82$, $83,101,115$ 
Table A-1., continued

\begin{tabular}{lcc} 
QUESTIONS ASKED IN THE EVENT TREE & $\begin{array}{c}\text { PRIOR QUESTION } \\
\text { DEPENDENCIES }\end{array}$ & $\begin{array}{c}\text { INPUT TO LATER } \\
\text { QUESTIONS }\end{array}$ \\
\hline
\end{tabular}

63. Does the Reactor bottom shield fail from weight and temperature of core debris during heatup [late vessel failure]?

64. What is one maximum temperature of core debris during in-vessel heatun?

$1,37,45,46,60$

$36,42,45,60,62,63$

None

None

None

66. What amount of the iodine is released from the core debris as $\mathrm{I}_{2}$ during heatup?

67. What fraction of Iodine is released from the core debris as $I_{2}$ during heatup.

68. How much water is available in the Reactor vessel to mitigate release during heatup?

69. What is the level of decontamination by the vessel and vessel water after completion of in-vessel melt and during heatup?

70. What is the level of retention within the vessel after completion of an in-vessel melt and during heatup?

71. What is the level of decontamination by confinement [excluding filters] after completion of ail ili-vessel melt and during heatup?

None

None

None

$37,40,44,45,46,47$

69

$36,44,45,60,62,68$

None

None

None

$35,44,48,49,50,51$

None
$64,76,77,78,83,101,115$, 
Table A-1., continued

\section{QUESTIONS ASKED IN THE EVENT TREE}

72. What is the level of retention of inventory in confinement [excluding filters] after completion of an in-vessel melt?

73. What fraction of radionuclides bypass the filters after completion of an in-vessel melt?

74. What is the level of confinement bypass of radionuclides after completion of an in-vessel melt?

75. What is level of voltile/aerosol radionuclide deposition on the confinement filters after completion of an in-vessel melt?

76. Does one core debris breach vessel and fall on to the pump room floor?

77. What is the extent of the connection between the Reactor room and pump room at Primary System failure?

78. What is the flow rate to above-and below-grade from the ECCS when core debris drops to the pump room floor?

79. Does recriticality of core occur when core debris drops to the pump room floor?

80. Does a steam explosion occur when core debris drops to the pump room floor?
PRIOR QUESTION DEPENDENCIES

None

INPUT TO LATER QUESTIONS

None

$35,44,48,49,50,51$

None

None

None

49

None

$44,58,62,63,76$

$2,37,44,45,62,63$

$29,36,45,57,62,64$
$36,45,62,63$

None 76

80,82

$57,64,76,79$

$81,82,84,85,86,101$

$77,79,80,81,82,83,84$, $101,102,104,115$

$89,90,91,100,106,110$, $111,112,115$ 
Table A-1, continued

\section{QUESTIONS ASKED IN THE EVENT TREE}

81. Is there a hydrogen burn when core drops debris to the pump room floor?

82. What is the magnitude of pressure shock from steam explosion or hydrogen burn?

83. What is the magnitude of pressure inside confinement volume from steam explosion or hydrogen burn?

84. Does an ex-vessel steam explosion [or hydrogen burn] destroy pump room dams when core debris drops to the pump room floor?

85. Does a steam explosion [or hydrogen burn] damage below-grade exhaust ducts when core debris drops to the pump room floor?

86. Does an ex-vessel steam explosion [or hydrogen burn] destroy roll door when core debris drops to the pump room floor?

87. Does an ex-vessel steam explosion [or hydrogen burn] breach walls to disassembly basin when core debris drops to the pump room floor?

88. What is the $\quad f$ below-grade confinement brea

8y. Lues the path for airflow from below-grade to the filter system exist after core debris drops to the pump room floor?

PRIOR QUESTION DEPENDENCIES

INPUT TO LATER QUESTIONS

$33,36,43,45,62,64$ 76,80

$33,36,43,45,62,64$, $76,79,80,81$

$57,58,62,63,76,81$, 82

$58,76,80,82$

$57,80,81,82$

$33,36,43,45,80,81$

58,82

$89,100,107$

$80,81,83$

106,109

$58,77,85,86,87$
$89,100,112$

$82,83,85,86,88,90,91$

$83,84,85,87$

$88,90,91$

97

$89,100,107$ 
Table A-1., continued

\section{QUESTIONS ASKED IN THE EVENT TREE}

90. Does a below-grade steam explosion or hydrogen burn damage the filter system when core debris drops to floor?

91. Does below-grade steam explosion or hydrogen burn damage the exhaust fans when core debris drops to the floor?

92. What is the temperature of the filters after initial deposition of radionuclides?

93. How many exhaust fans operate after completion of an in-vessel melt and deposition of radionuclides on the filters?

94. What is the performance of confinement filters after completion of an in-vessel melt and initial deposition of radionuclides?

95. Are confinement filters operable after completion of an in-vessel melt and initial deposition of radionuclides?

96. What is the elapsed time from vessel failure until the start of MCCI?

97. How much water is on the pump room floor after core debris is on the pump room floor [start of MCCI]?

98. How much water is on motor room floor after core debris is on the pump room floor [start of MCCI]?
PRIOR QUESTION INPUT TO LATER DEPENDENCIES QUESTIONS

$49,50,58,77,81,83$

$91,92,95$

$49,50,58,77,81,83$,

92,93

$49,50,90,91$

93

$50,91,92$

$104,111,119,121,123,126$, 127

None

$95,126,131$

$49,90,94$

18,64

None

84

$101,102,103,105,117,121$, 123

None

$100,106,110,111,112,115$, 117 
Table A-1., continued

QUESTIONS ASKED IN THE EVENT TREE

PRIOR QUESTION DEPENDENCIES

INPUT TO LATER QUESTIONS

99. What is the status of the CWST after core debris is on pump room floor?

100. Does the path for airflow from belowgrade to the filter system exist after core debris is on the pump room floor?

101. Is the core debris cooled after the core debris is on the pump room floor?

102. Does core-concrete interaction occur after core debris is on the pump room floor [i.e., can the core debris be cooled]?

103. What fraction of radionuclides retained by in-vessel water are re-released?

104. Does sustained hydrogen burn occur after core debris is on the pump room floor?

105. What is the below-grade air temperature after core debris is on the pump room floor [after MCCI starts]?

106. What is the magnitude of the hydrogen burn that occurs after core debris is on the pump room floor [after MCCI starts]?

107. What is the condition of below-grade vent ducts following start of MCCI and possible hydrogen burn?

None

None

$77,85,86,87,98$

$104,105,106,108,109$

$62,63,64,76,80,97$

102

$2,51,54,55,76,97$, 101

$103,104,106,113$

97,102

None

$76,93,100,102$

105, 106

$95,97,100,104$

None

$47,77,88,95,98,100$, 102,104

85,106

$110,111,112$ 
Table A-1., continued

\begin{tabular}{lcc} 
QUESTIONS ASKED IN THE EVENT TREE & $\begin{array}{c}\text { PRIOR QUESTION } \\
\text { DEPENDENCIES }\end{array}$ & $\begin{array}{c}\text { INPUT TO LATER } \\
\text { QUESTIONS }\end{array}$ \\
\hline
\end{tabular}

108. What is the extent of above-grade confinement $48,100,106$

$109,121,123$

breach after core debris is on the pump room floor [after MCCI]?

109. What is the extent of below-grade confinement breach after core debris is on the pump room floor [after CCI]?

110. Does below-grade hydrogen burn damage the filter system after core debris drops to the floor [MCCI starts]?

111. Does below-grade hydrogen burn damage the exhaust fans after core debris drops to the floor [MCCI starts]?

112. Does a path for airflow from below-grade to the filter system exist after core debris is on the pump room floor [start of MCCI]?

113. What quantity of radionuclides which may potentially be released from core debris, is released after MCCI starts?

114. What level of radionuclides which may potentially be released from core debris are released after MCCI starts?

115. What fraction of radionuclides initially deposited in-vessel are revolatilized after core debris drops to the floor?

$88,100,106,108$

$77,95,98,106,107$

$77,93,95,98,106,107$ 110

$77,86,87,98,107$

$121,123,125$

102

None

None

None

$10,36,37,44,45,60$, $62,63,76,77,98$
None 
Table A-1., continued

\begin{tabular}{lcc} 
& PRIOR QUESTION & INPUT TO LATER \\
QUESTIONS ASKED IN THE EVENT TREE & DEPENDENCIES & QUESTIONS \\
\hline
\end{tabular}

116. What fraction of radionuclides initially deposited

None

None

in-vessel are revolatilized after core debris drops to the floor?

117. What is the retention of the radionuclide

97,98

None

inventorv/MCCI aerosols in a below-grade water pool?

118. What is the level of retention of radionuclide

None

None

inventory/MCCI aerosols in a below-grade water pool?

119. What is the retention of radionuclides by the reactor room sprays?

120. What is the level of retention of radionuclides by the reactor room sprays?

121. What is the fraction of radionuclide release/MCCI aerosols that bypass filters?

122. What is the fraction of radionuclide release/MCCI aerosols that bypass filters?

123. What is the level of retention of inventory in confinement [excluding filters] after core debris is on the pump room floor?

$44,51,63,93,95,109$

None

None

None

$93,95,97,108,109$ $110,111,112$

None

None

None

$93,95,97,108,109$,

None

111,112

None

None confinement [excluding filters] after core debris is on thic jump room floor? 


\section{Table A-1., continued}

\section{. QUESTIONS ASKED IN THE EVENT TREE}

125. What is the level of volatile/aerosol radionuclide deposition on confinement filters after core debris is on the pump room floor?

126. What is the temperature environment of the exhaust fans after core debris is on the pump room floor and filters are loaded following MCCI?

127. Do Confinement exhaust fans operate [\# hours] after core debris is on the pump room floor and filters are loaded following MCCI?

128. What is performance of confinement filters after core debris is on the pump room floor and filters are loaded following MCCI?

129. Do all exhaust dampers [inlet to filters] remain open for 30 days?

130. Do exhaust fans continue to operate for $\mathbf{3 0}$ days?

131. Do filters continue to perform function for $\mathbf{3 0}$ days?
PRIOR QUESTION DEPENDENCIES

INPUT TO LATER QUESTIONS
None

$93,94,95,110,111$

127

$93,111,126$

130,131

None

129,131

95,128

131

126,127

131

$94,95,127,128,129$,

130

None 


\section{A.2. Internal Events}

\section{A.2.1. Summary Event Trees}

As discussed in Section 4 summary forms of the APET for internal events plant damage states have been produced. These Summary Trees are presented below as Figures A-1 to A-9. 
PDS-11 (LOPA - 4.82E-05/R-Yr) Summary Tree

11-4-1992

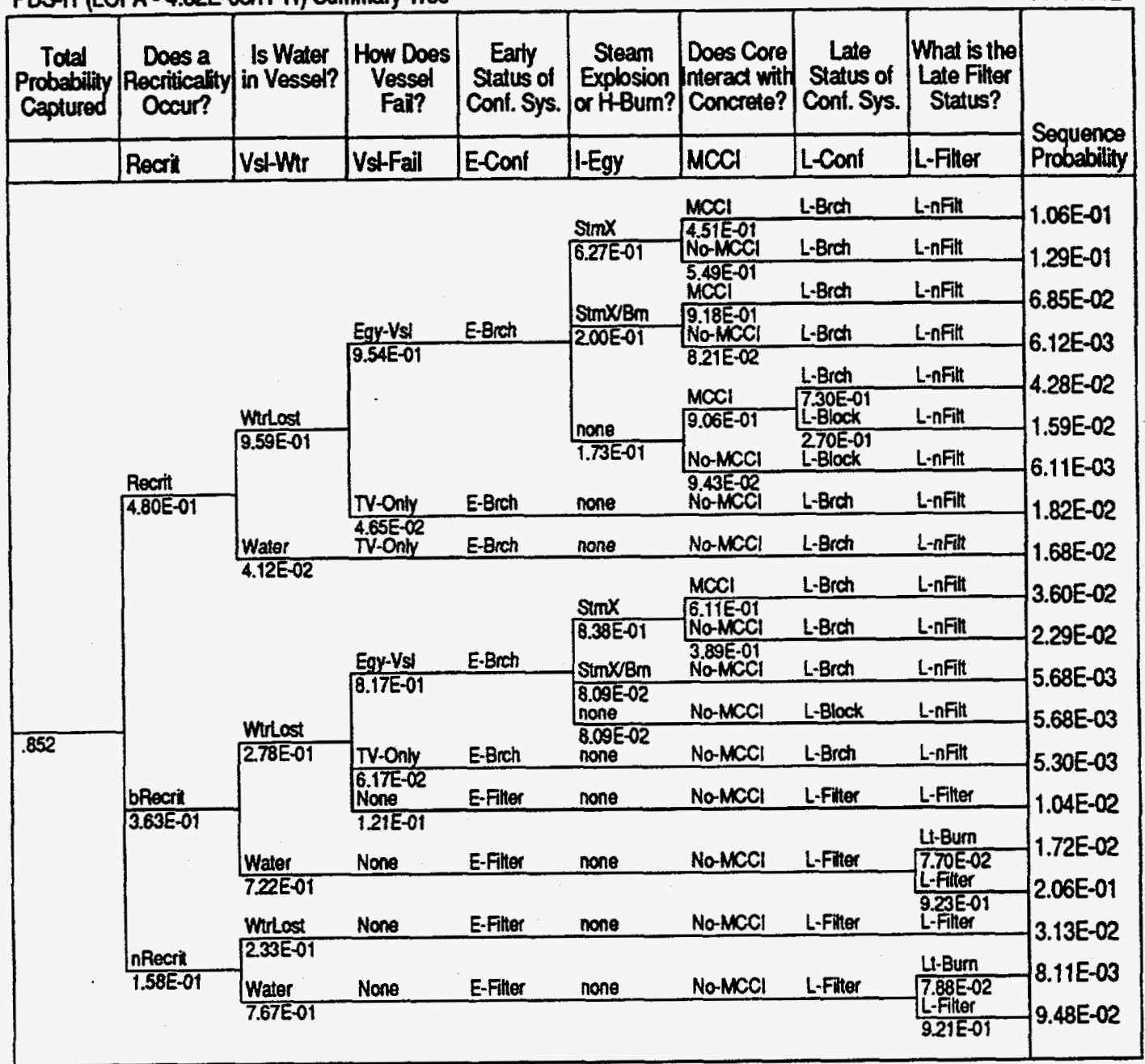

Savannah River Site Production Reactor PRA

\section{A-1. Summary Tree for PDS-I1}


PDS-12 (Small LOPA - 3.85E-07/R-Yr) Summary Tree

11-4-1992

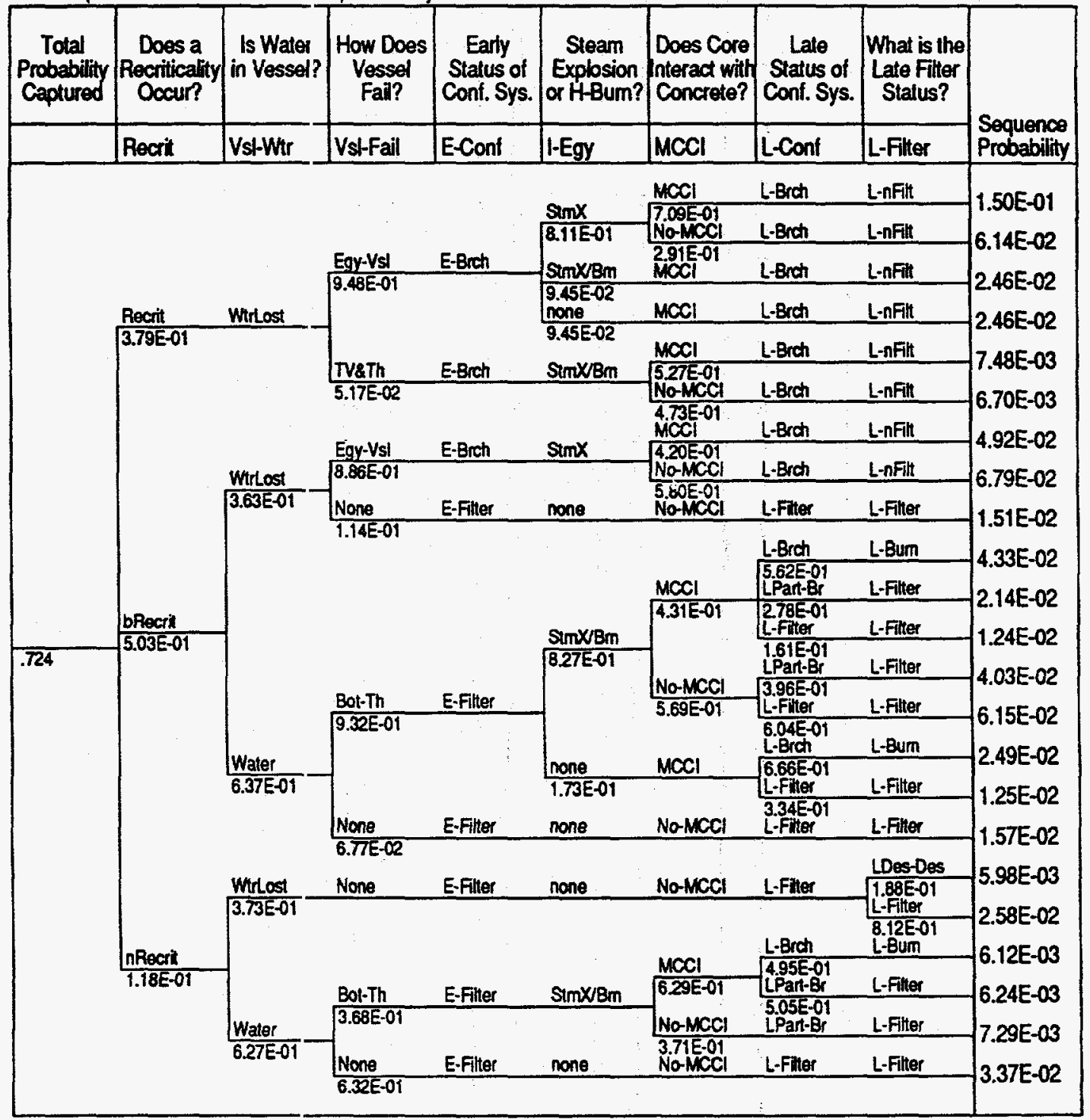

Savannah River Site Production Reactor PRA

\section{A-2. Summary Tree for PDS-12}


PDS-13 (LOCA without EC - 7.20E-05/R-Yr) Summary Tree

$11-4-1992$

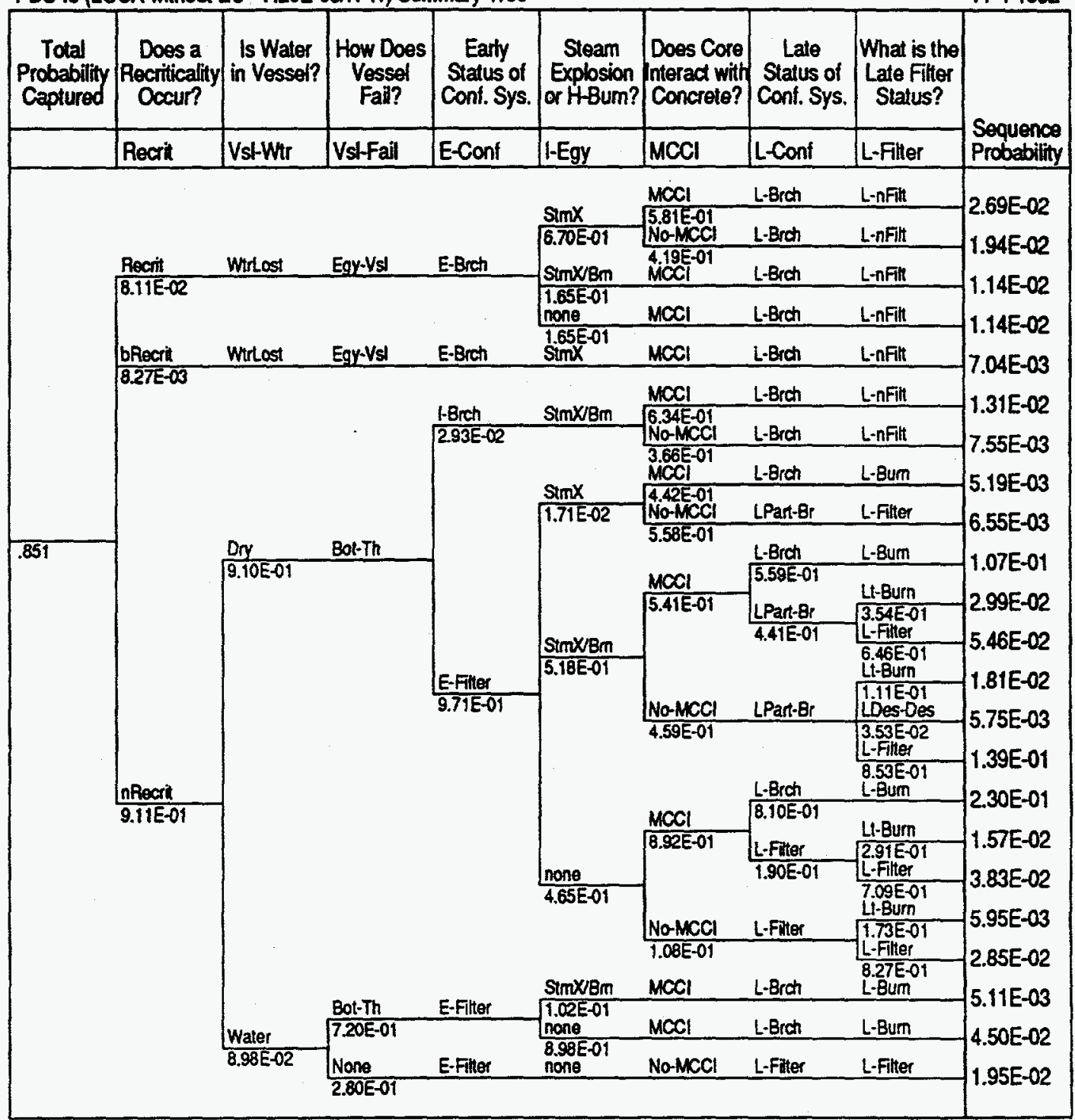

Savannah River Site Production Reactor PRA

\section{A-3. Summary Tree for PDS-I3}


PDS-14 (Small Break LOCA with ED - 4.34E-05/R-Yr) Summary Tr

11-4-1992

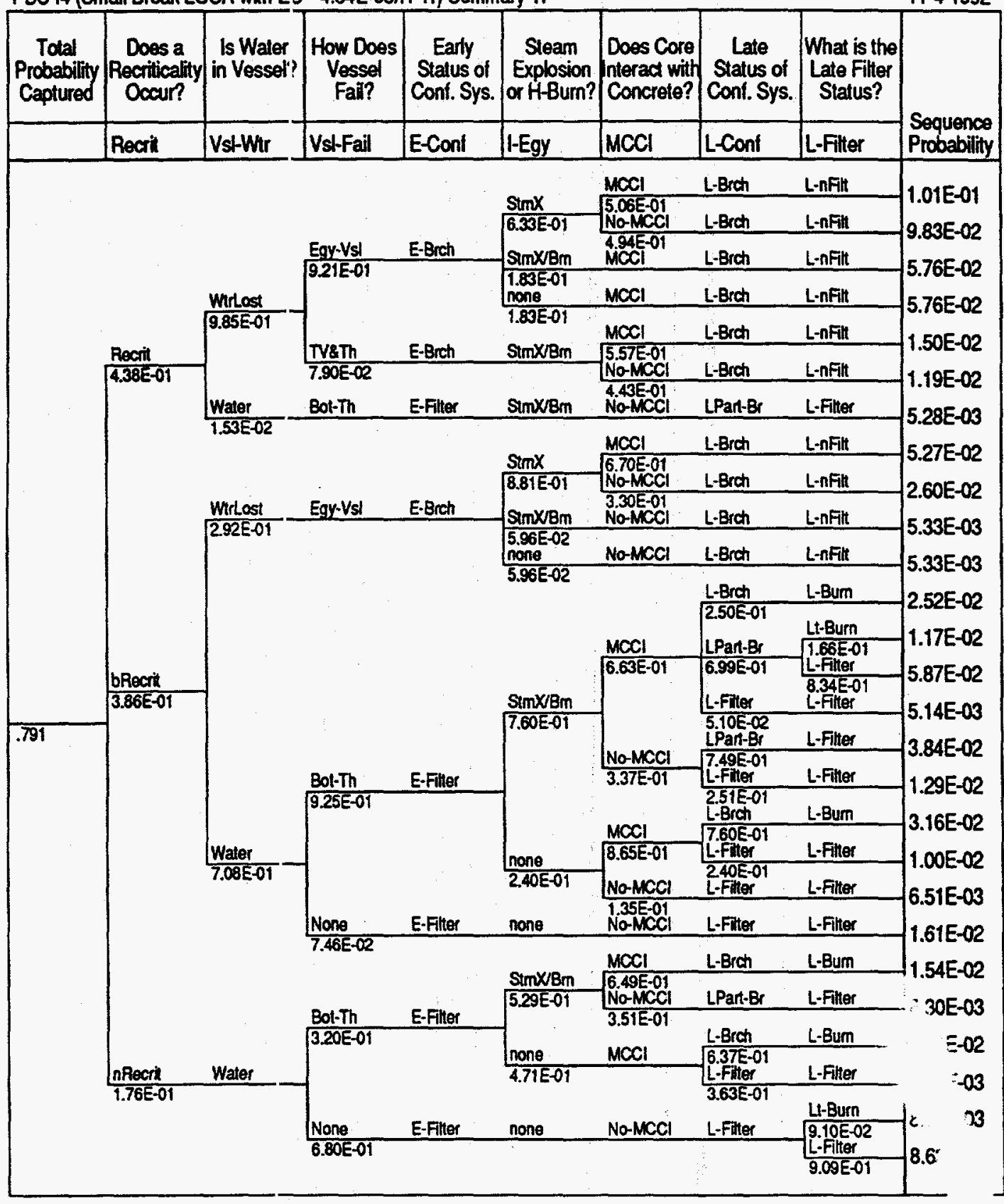

Savannah River Site Production Reactor

\section{A-4. Summary Tree for PDS-I4}


PDS-15 (LOCA with Intenal Flooding - 7.89E-06/R-Yr) Sum Tre

11-4-1992

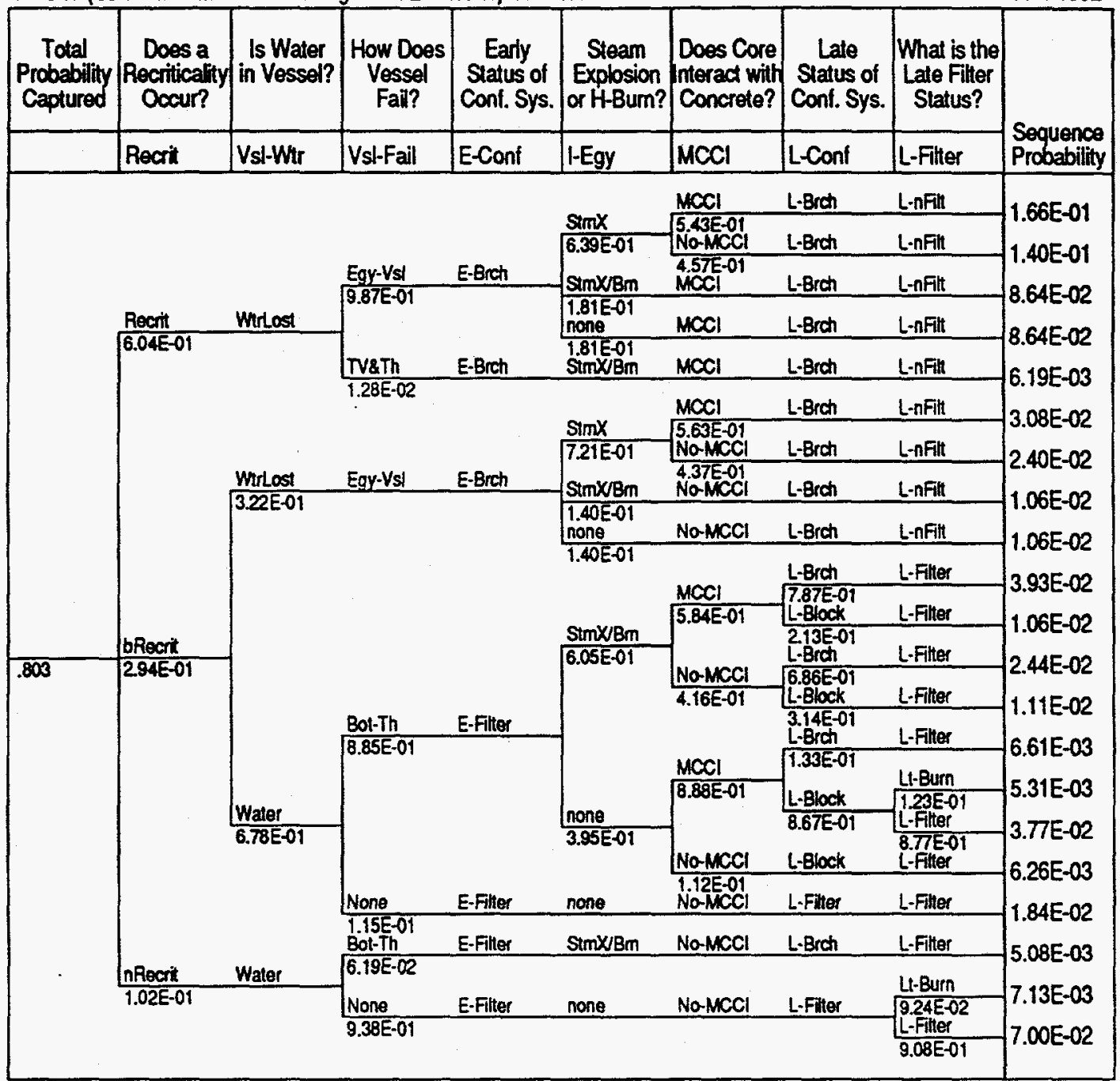

Savannah River Site Production Reactor PRA

\section{A-5. Summary Tree for PDS-I5}


PDS-16 (Localized Transient - 1.47E-05/R-Yr) Summary Tree

11-4-1992

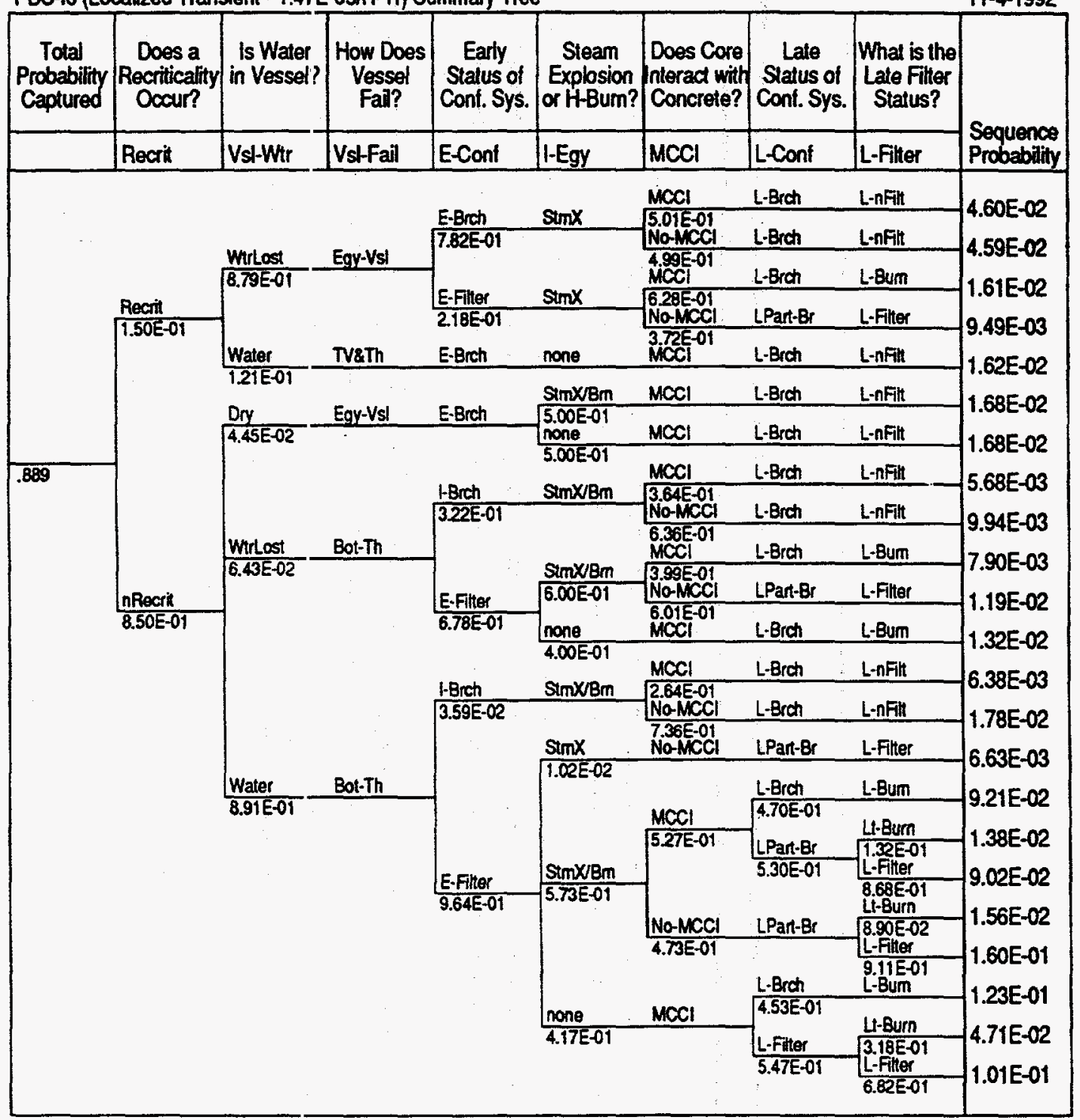

Savannah River Site Production Reactor PRA

\section{A-6. Summary Tree for PDS-I6}


PDS-17 (LOPC - 9.40E-06/R-Y) Summary Tree

11-4-1992

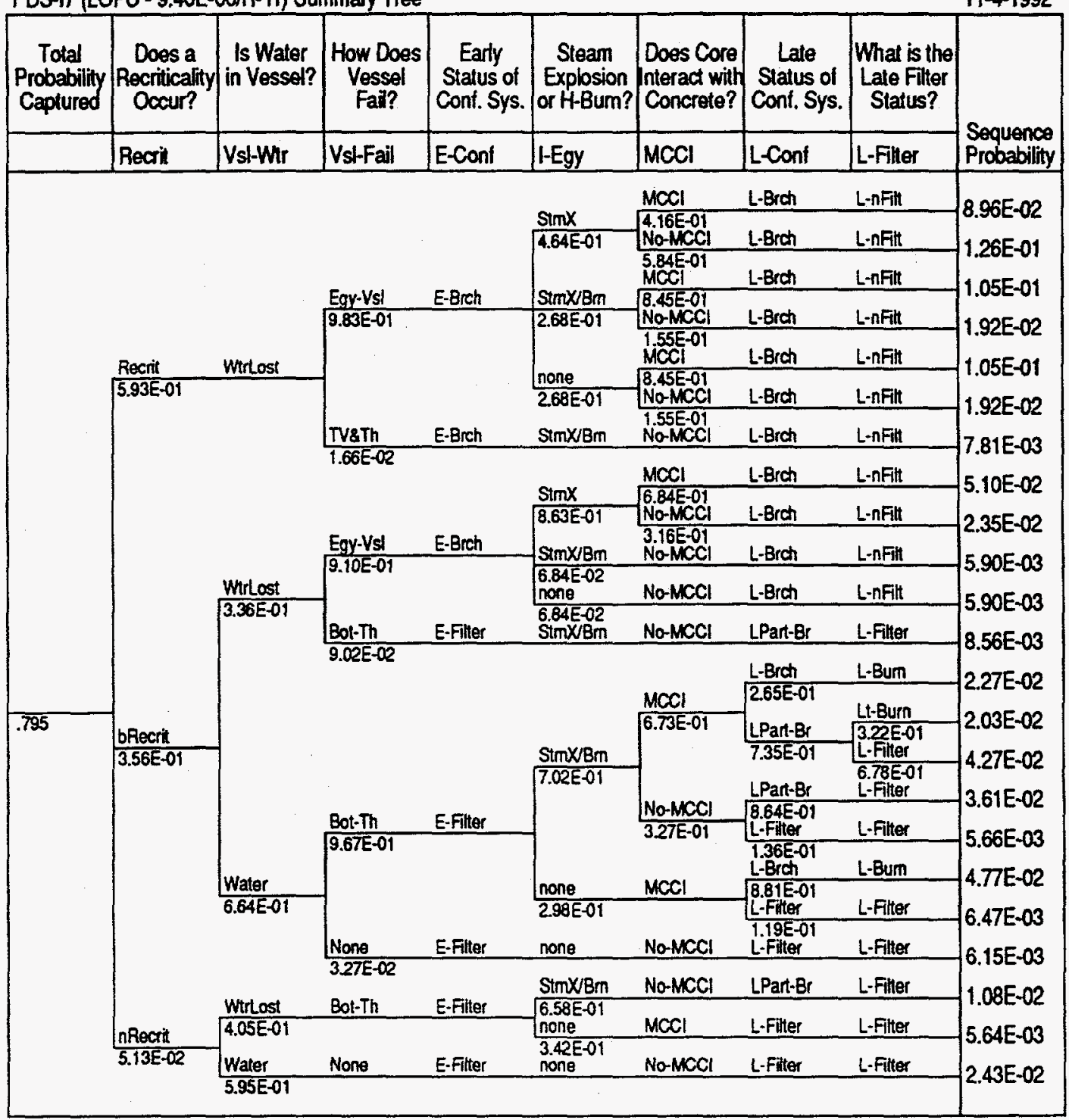

Savannah River Site Production Reactor PRA

\section{A-7. Summary Tree for PDS-I7}


PDS-18 (LOHS - 1.69E-07R-Yr) Summary Tree

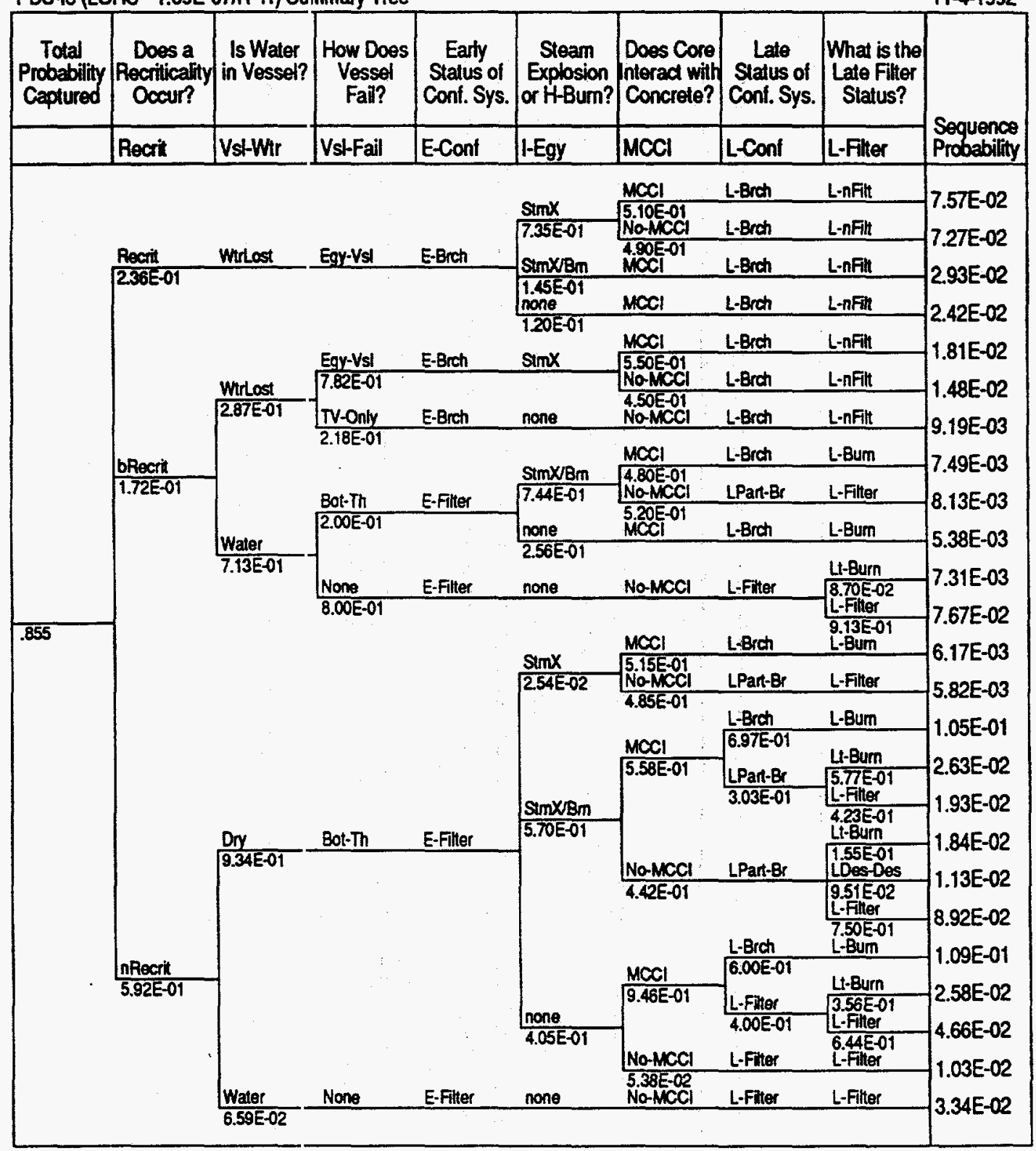

Savannah River Site Production Reactor PRA

\section{A-8. Summary Tree for PDS-I8}


PDS-19 (Loss of River Water - 1.03E-05/R-Yp) Summary Tree

11-4-1992

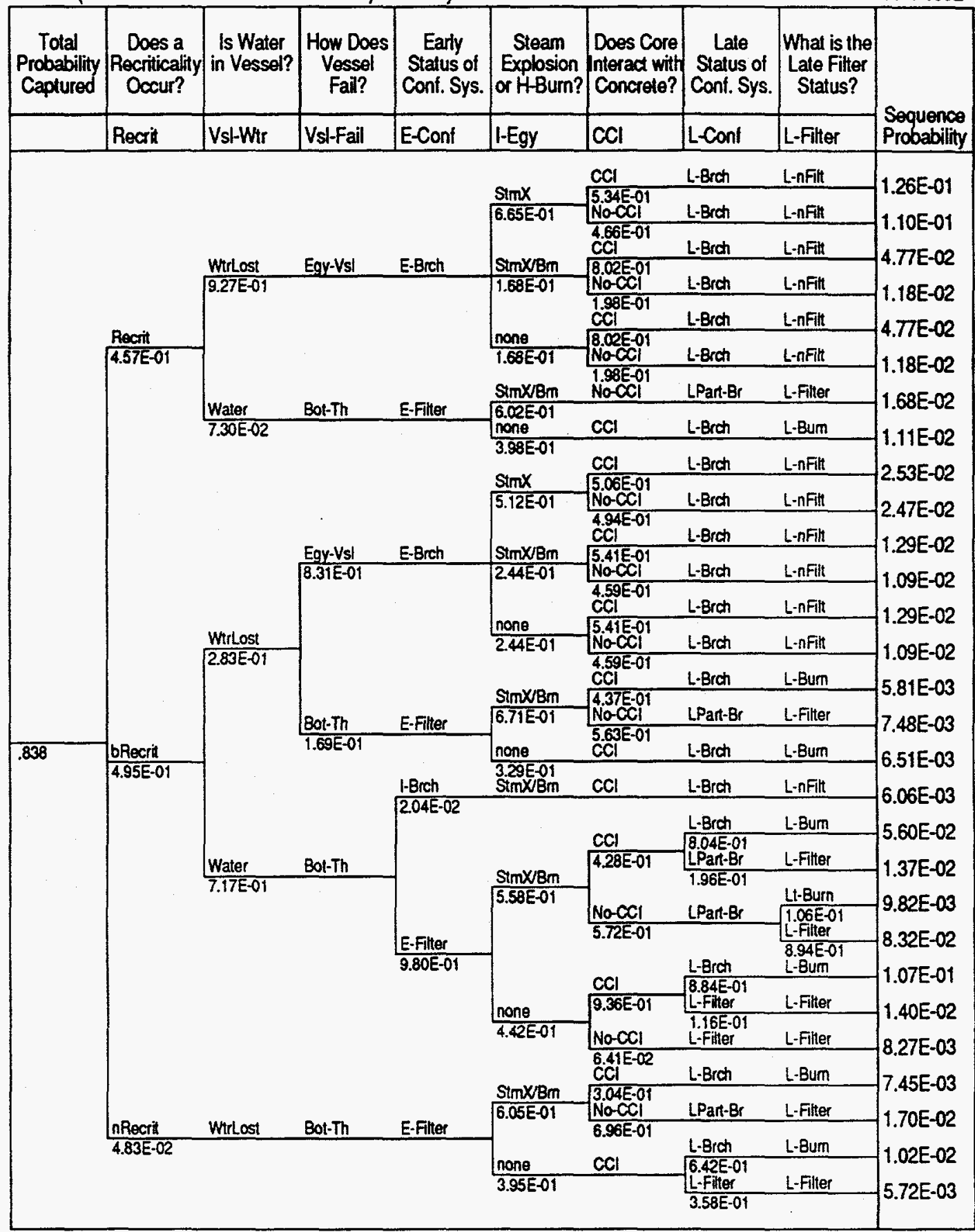

Savannah River Site Production Reactor PRA

\section{A-9. Summary Tree for PDS-19}




\section{A.2.2. CCDFs}

CCDFs for six consequence measures not presented in Section 10 are shown here. Only internal events are involved. 

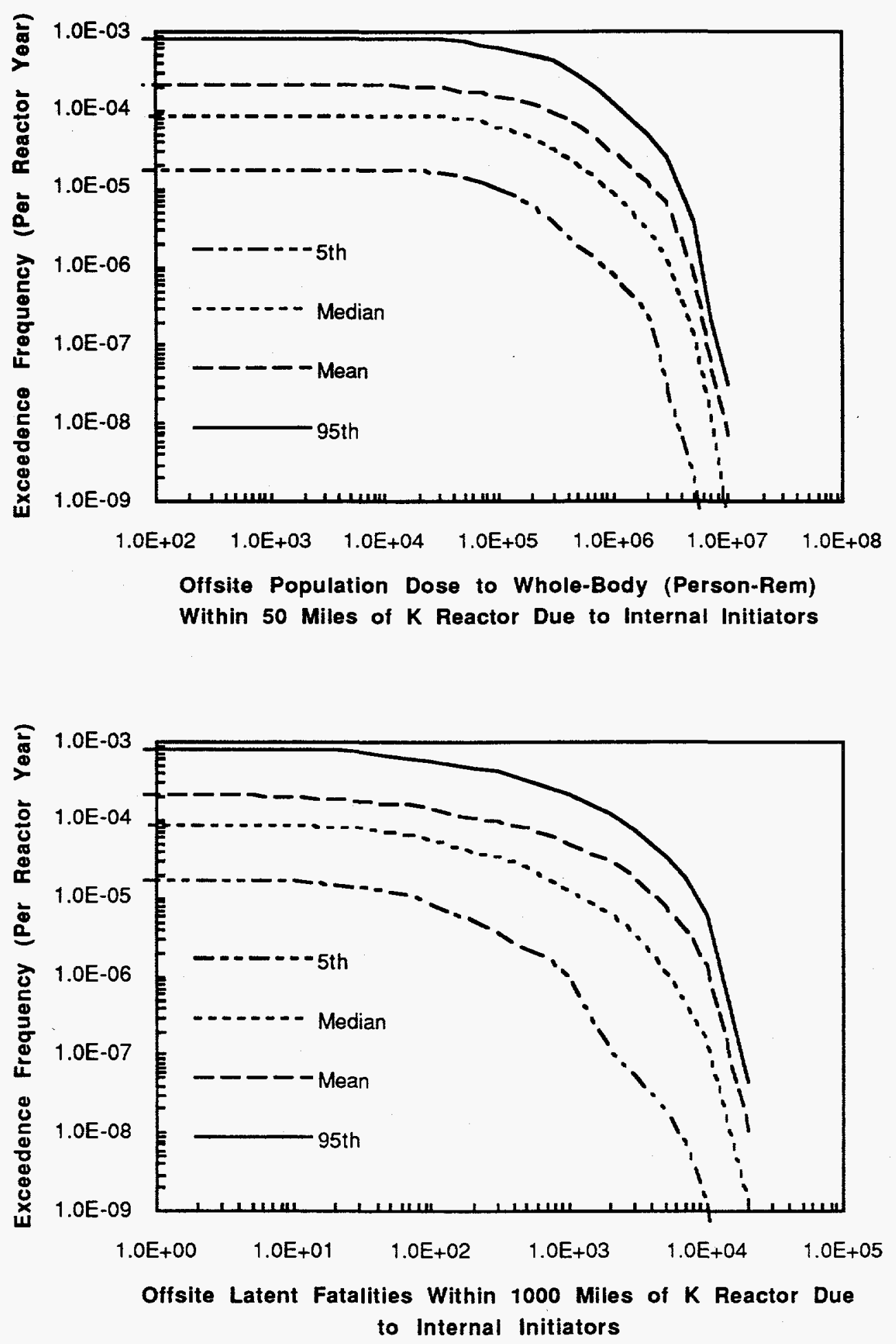

Figure A-10. Exceedance Frequencies for Risk for K Reactor -All Internal Initiators - Offsite 


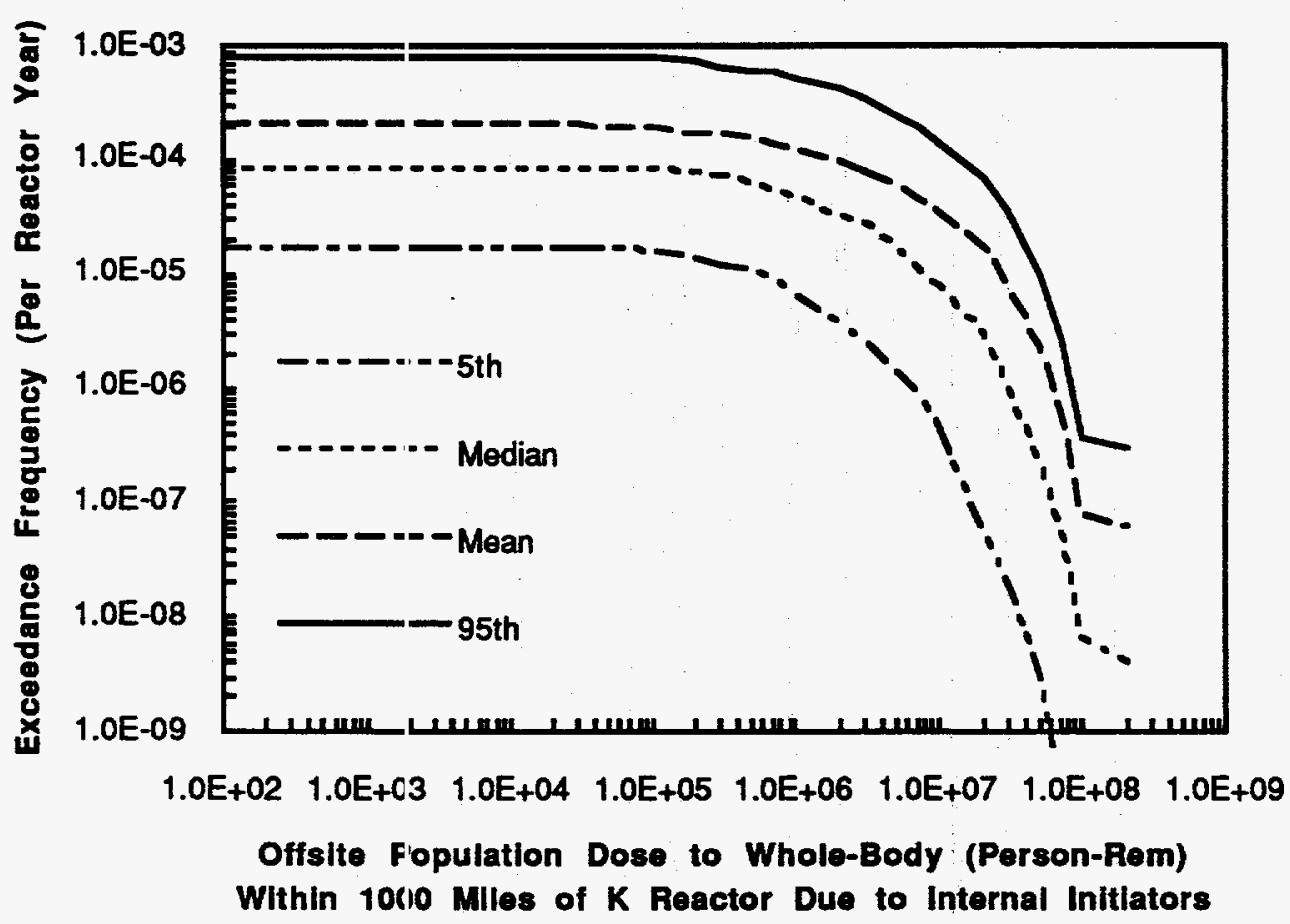

Figure A-10. Exceedance Frequencies for Risk for $\mathrm{K}$ Reactor - All Internal Initiators - Offsite (cont'd) 

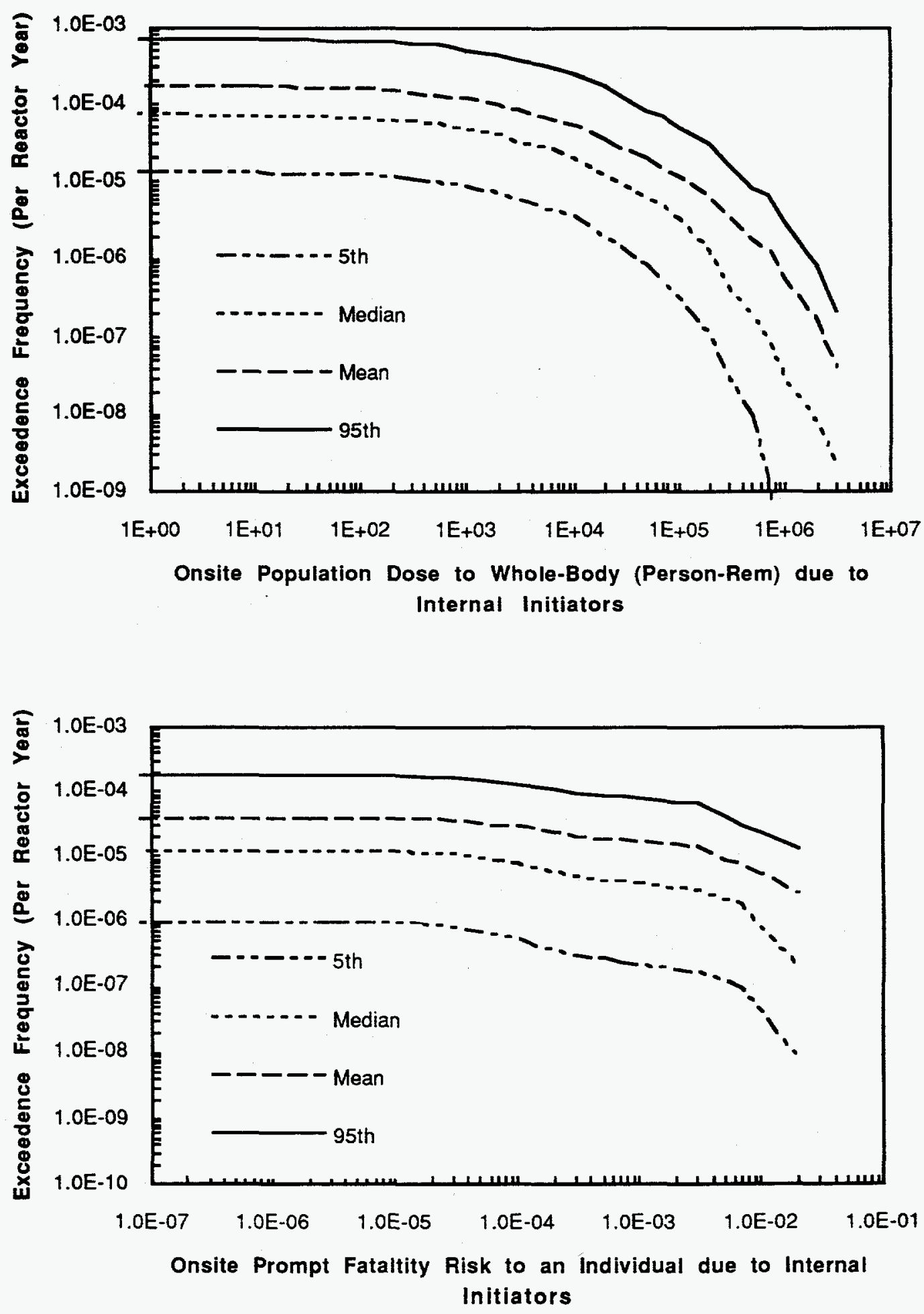

Figure A-11. Exceedance Frequencies for Risk for K Reactor - All Internal Initiators - Onsite 


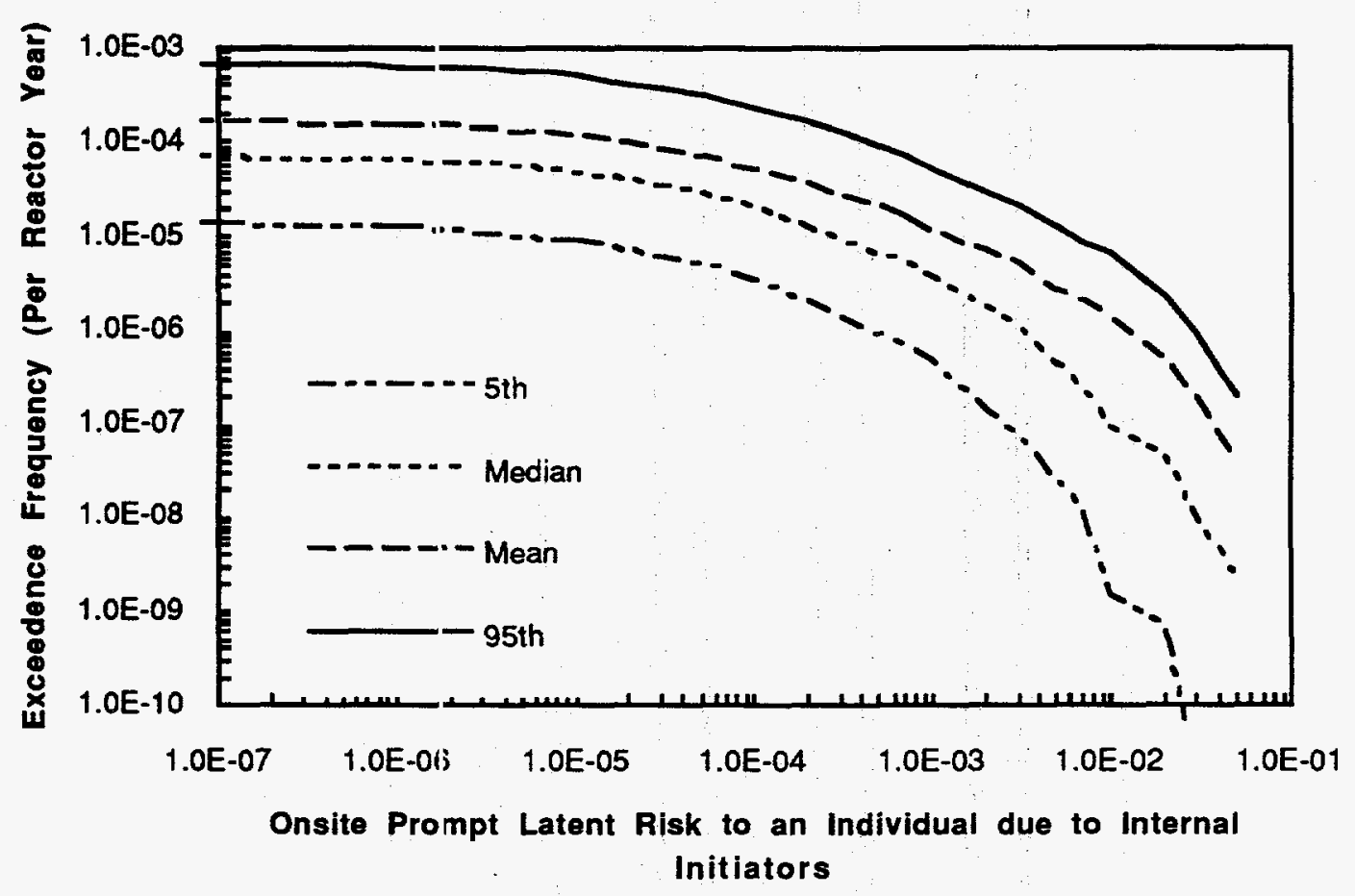

Figure A-11. Exceedance Frequencies for Risk for K Reactor - All Internal Initiators - Onsite (cont'd) 


\section{A.3. Seismic Events}

\section{A.3.1. Seismic Summary Event Trees}

As for the internal events (see Section A.2.1), a summary APET has been produced for each of the seven seismic plant damage states. These trees are shown in Figures A-12 through A-18. 
POS-S1 (Loss of River Water - 4.15E-05/R-Yr) Summary Tree

11-5-1992

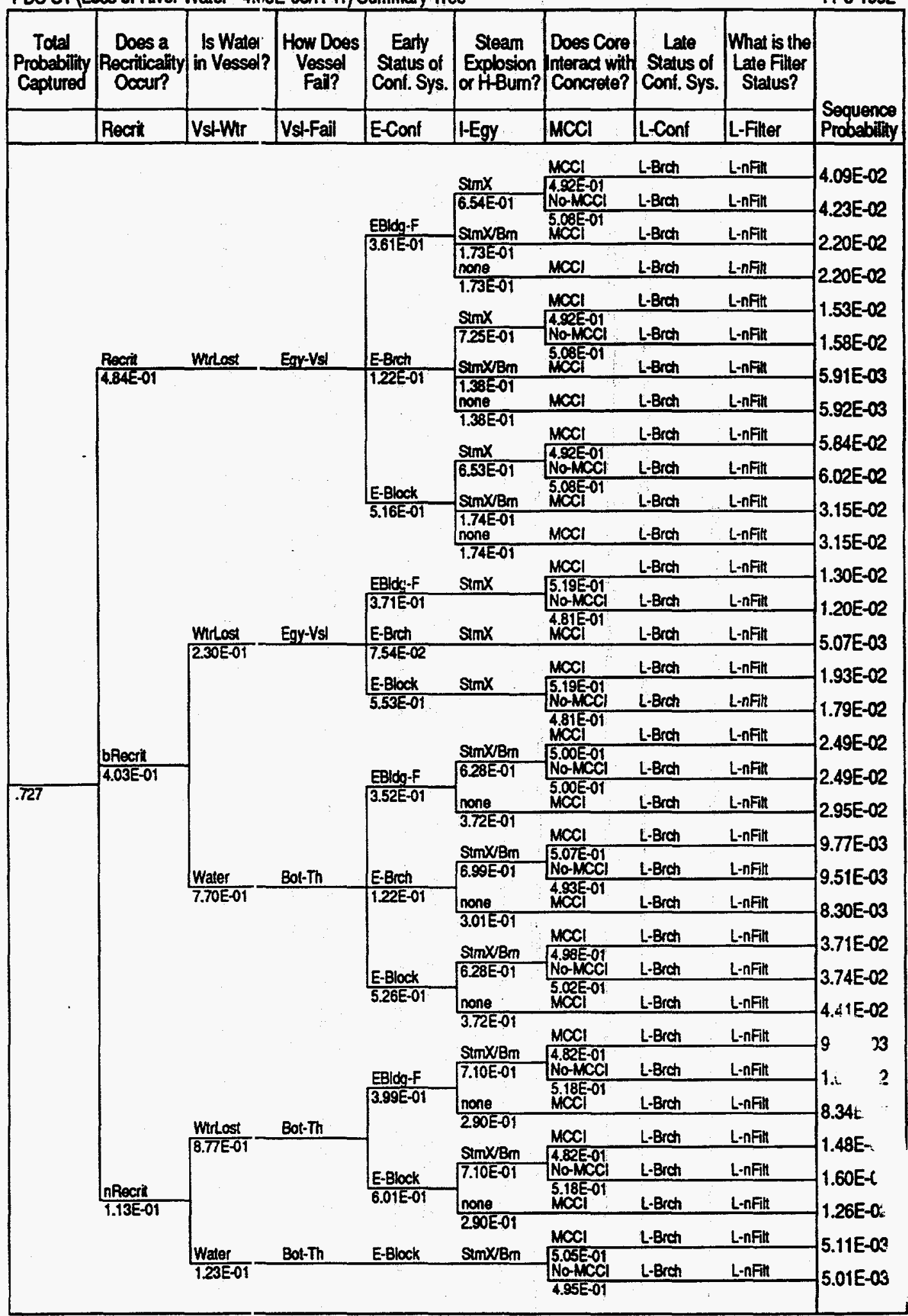

Savannah River Site Production Reactor PRA

A-12: Summary Tree for PDS-S1

A-32 
PDS-S2 (LOPC - 4.74E-05/R-Y) Summary Tree

11-5-1992

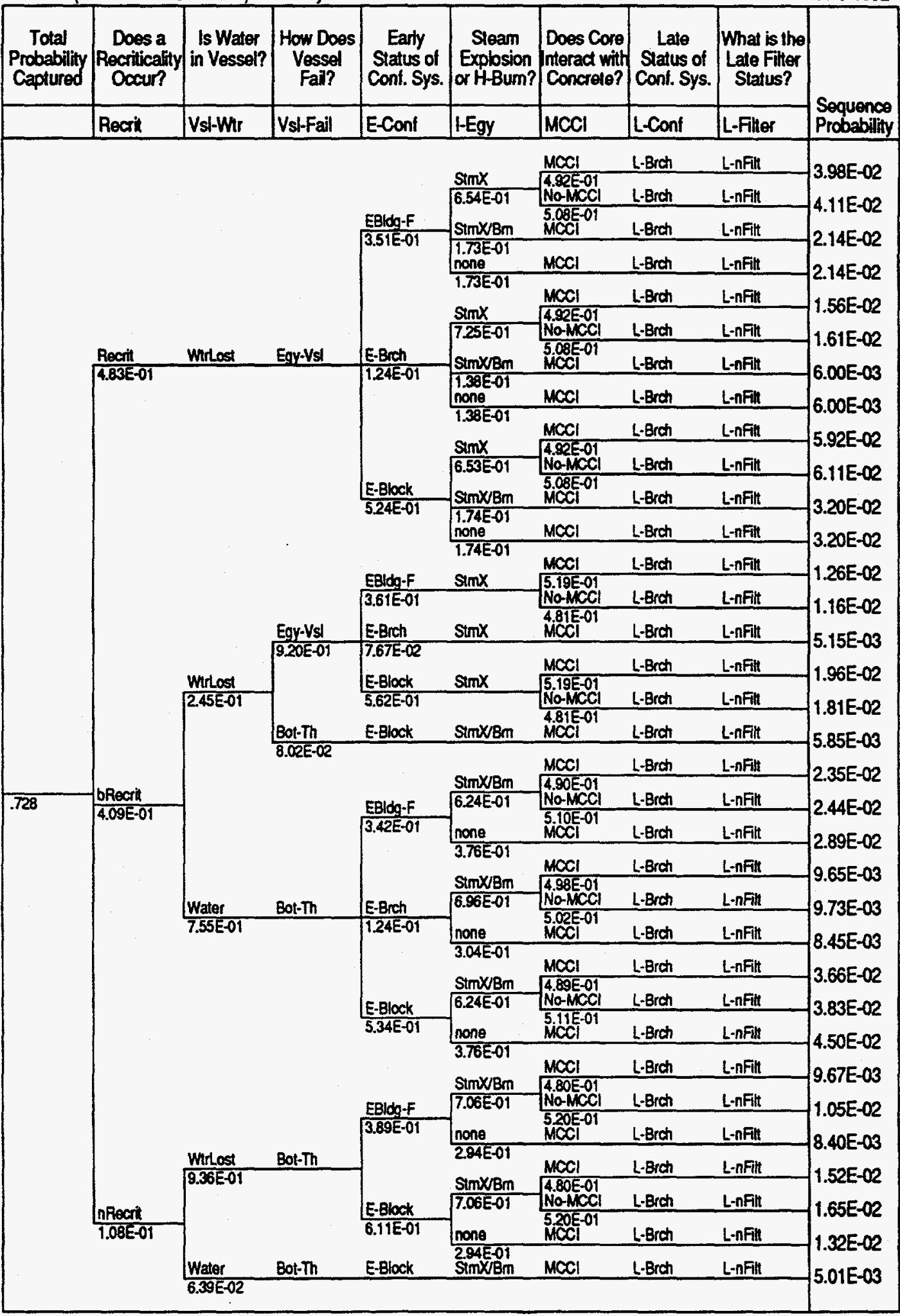

Savannah River Site Production Reactor PRA

A-13. Summary Tree for PDS-S2 
PDS-S3 (LOPA - 7.33E-06R-Yr) Summary Treo

11-5-1992

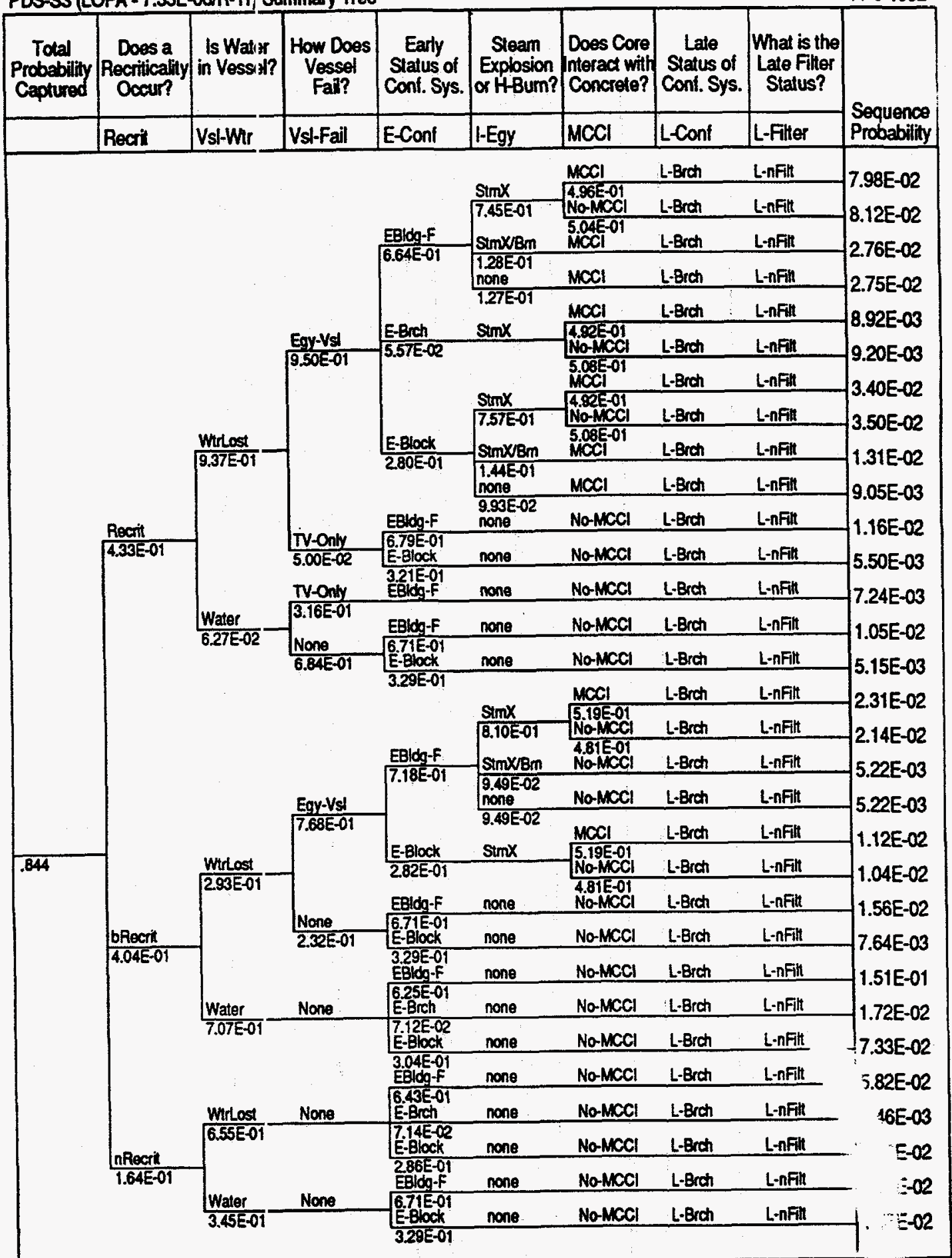

Savannah River Site Production Re. . i PRA

\section{A-14t. Summary Tree for PDS-S3}


PDS-S4 (LOCA - 8.53E-06/R-Y) Summary Tree

11-5-1992

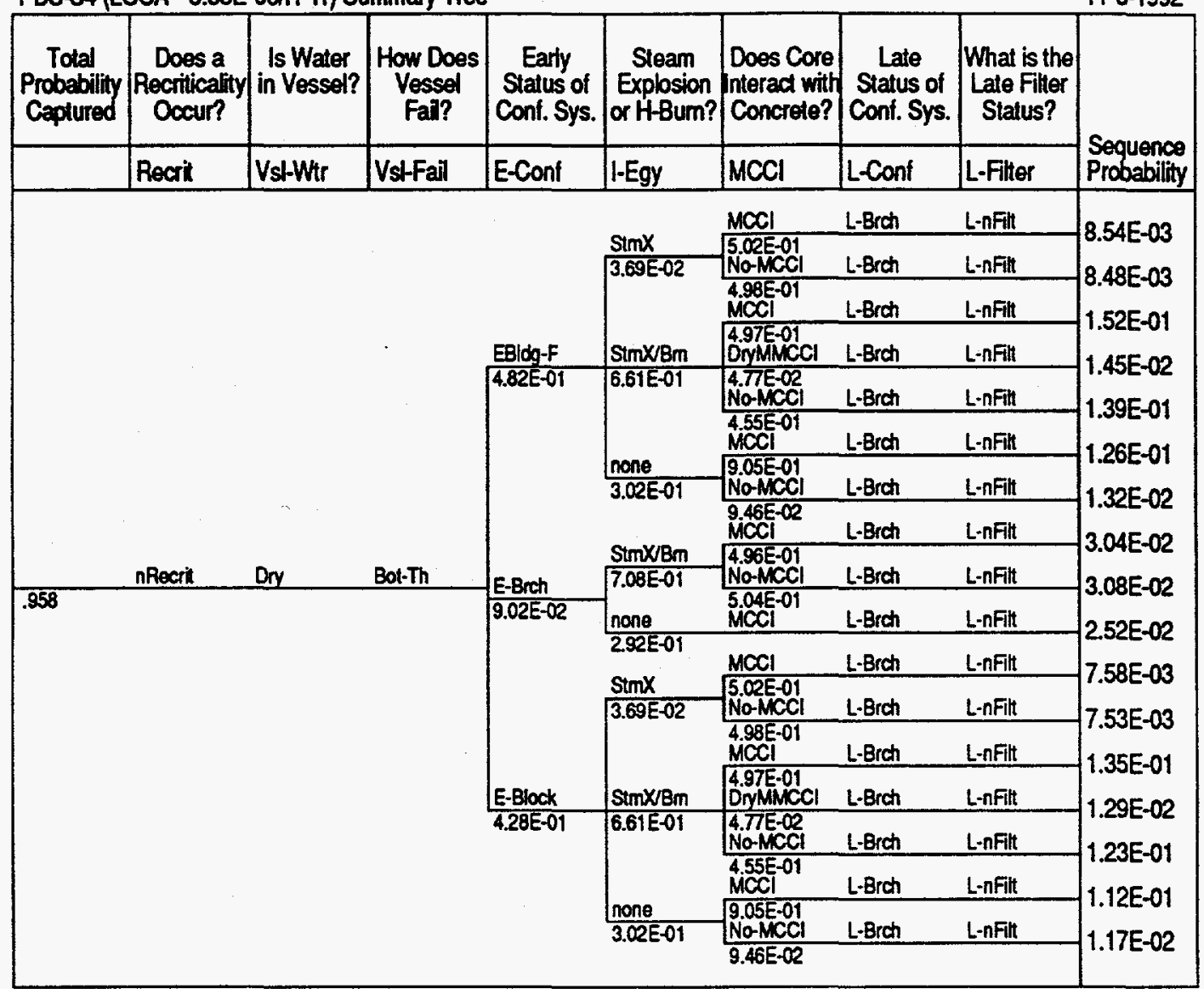

Savannah River Site Production Reador PRA

\section{A-15. Summary Tree for PDS-S4}


PDS-S5 (LOCA with Flooding - 3.14E-07/R-Y) Summary Tree 11-5-1992

\begin{tabular}{|c|c|c|c|c|c|c|c|c|c|}
\hline $\begin{array}{c}\text { Total } \\
\text { Probabiity } \\
\text { Captured }\end{array}$ & $\begin{array}{c}\text { Does a } \\
\text { Recriticality } \\
\text { Occur? }\end{array}$ & $\begin{array}{l}\text { Is Wate' } \\
\text { in Vessel? }\end{array}$ & $\begin{array}{c}\text { How Does } \\
\text { Vessel } \\
\text { Fall? }\end{array}$ & $\begin{array}{c}\text { Early } \\
\text { Status of } \\
\text { Conf. Sys. }\end{array}$ & $\begin{array}{c}\text { Steam } \\
\text { Explosion } \\
\text { or H-Bum? }\end{array}$ & $\begin{array}{l}\text { Does Core } \\
\text { Interact with } \\
\text { Concrete? }\end{array}$ & $\begin{array}{c}\text { Late } \\
\text { Status of } \\
\text { Cont. Sys. }\end{array}$ & $\begin{array}{l}\text { What is the } \\
\text { Late Filter } \\
\text { Status? }\end{array}$ & \multirow{2}{*}{$\begin{array}{l}\text { Sequence } \\
\text { Probability }\end{array}$} \\
\hline & Recrit & Vst-Whr & VstFail & E-Conf & I-Egy & $\mathrm{MCCl}$ & L-Conf & L-Filter & \\
\hline & & & & \multirow{3}{*}{$\begin{array}{l}\text { EBidg-F } \\
\begin{array}{|l}\text { 8.62E-01 } \\
\text { E-Brch } \\
2.53 E-02 \\
\text { E-Block } \\
1.12 E-01\end{array}\end{array}$} & none & No-MCCl & L-Brah & L-nFilt & \multirow{3}{*}{$\begin{array}{l}8.41 E-01 \\
2.47 E-02 \\
1.09 E-01\end{array}$} \\
\hline & nRecrit & Dry & None & & none & No-MCCI & L-Bran & L-nFilt & \\
\hline .975 & & & & & none & $\mathrm{No}-\mathrm{MCCl}$ & L-Brch & L-nFilt & \\
\hline
\end{tabular}

Savannah River Site Production Reactor PRA 
PDS-S6 (Vented LOPC - 1.72E-07/R-Yr) Summary Tree

11-5-1992

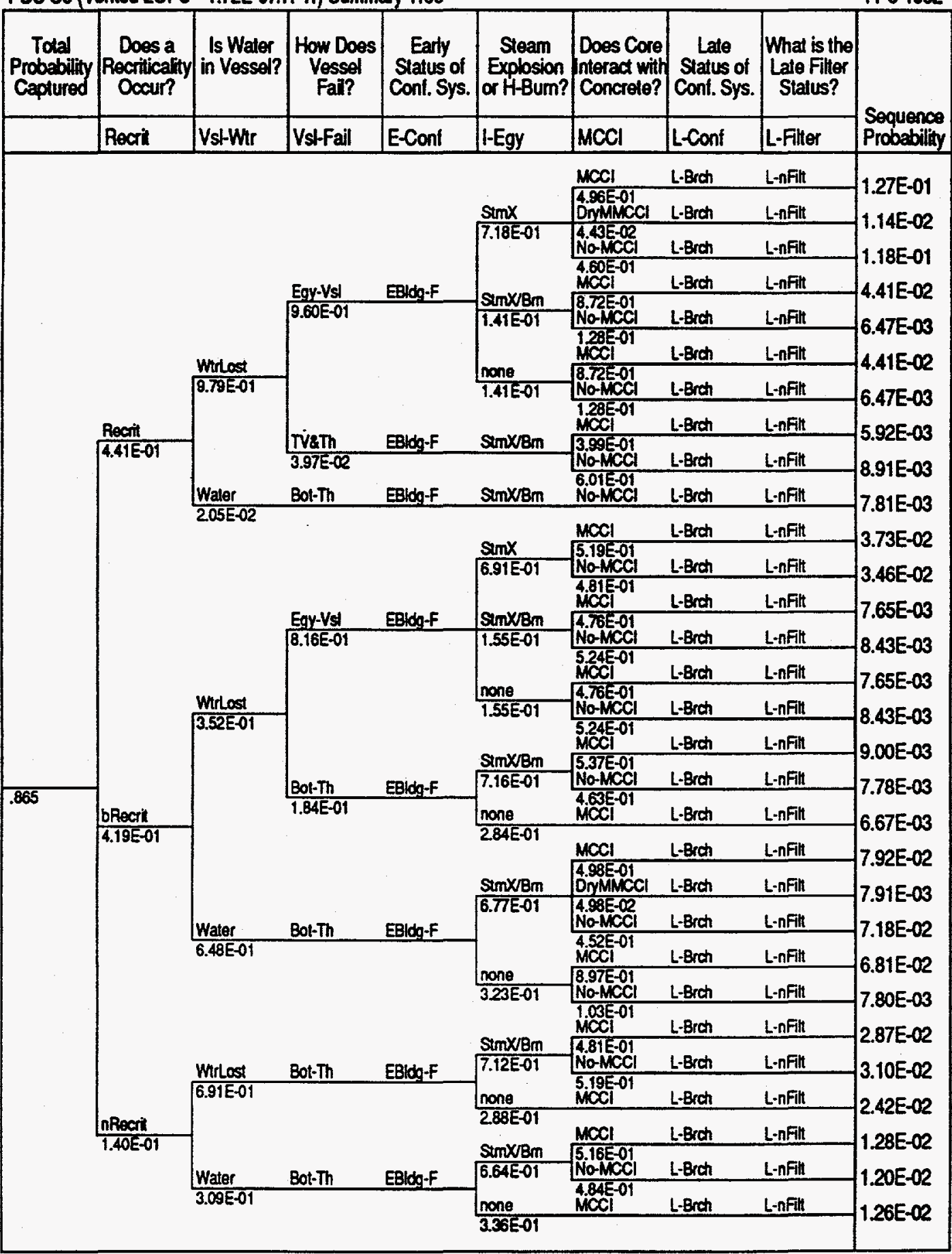

Savannah River Site Production Reactor PRA 


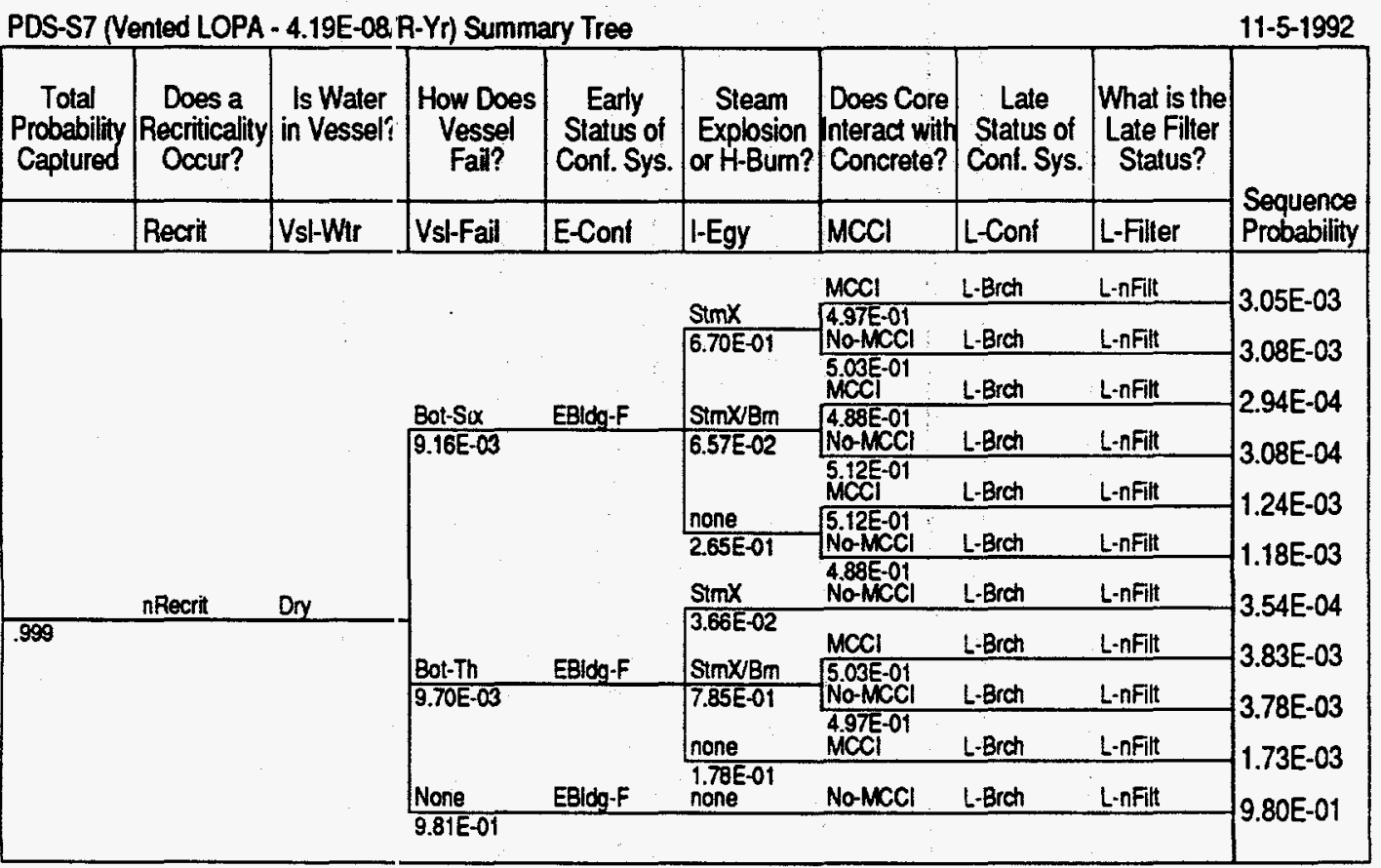

Savannah River Site Production Reactor PRA 


\section{A.3.2. $\quad C C D F s$}

CCDFs for six consequence measures not shown in Section 10 are presented here. Only seismic events are involved. 

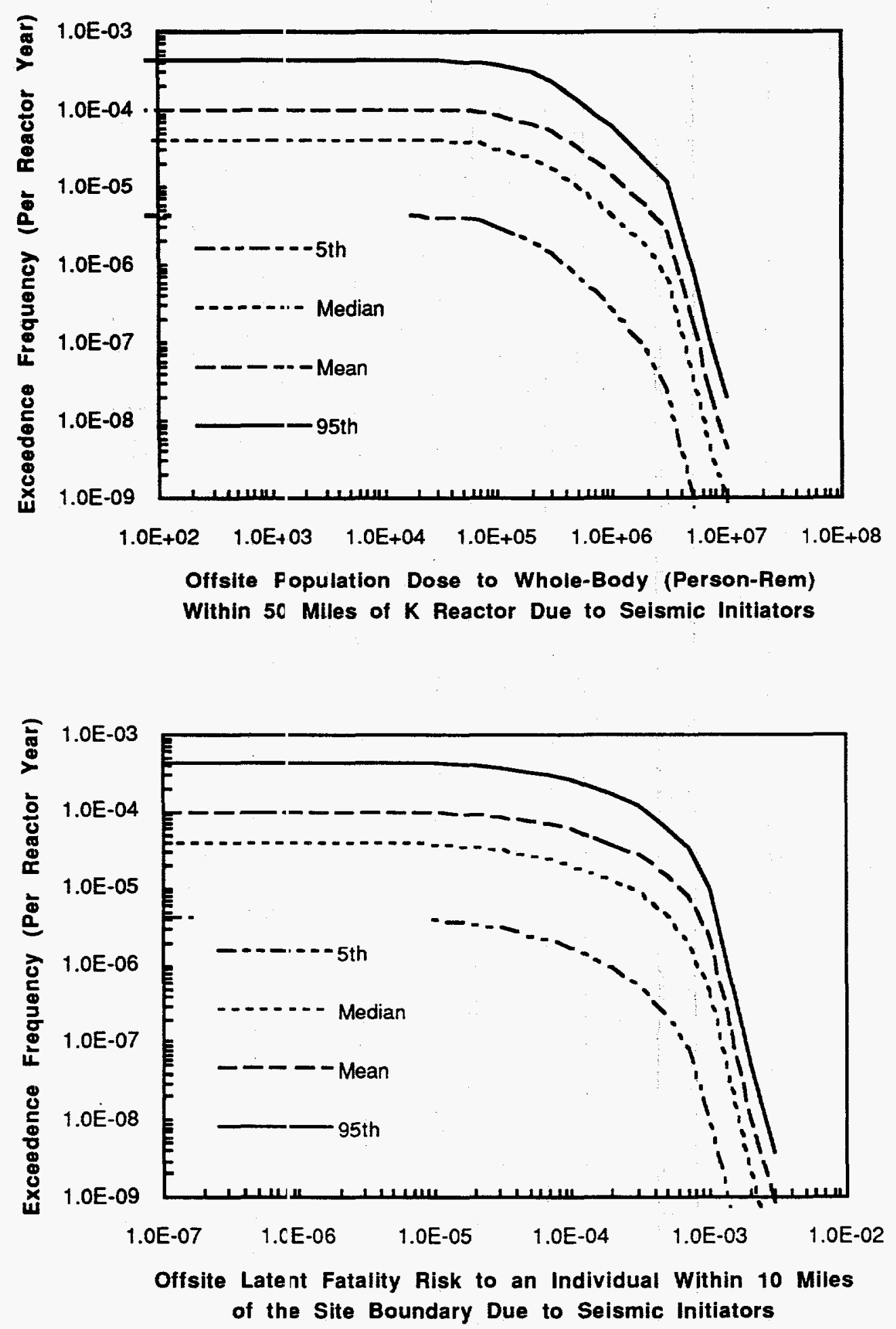

Figure A-19. Exceedanca Frequencies for Risk for SRS K Reactor - Seismic Initiators - Offsite 


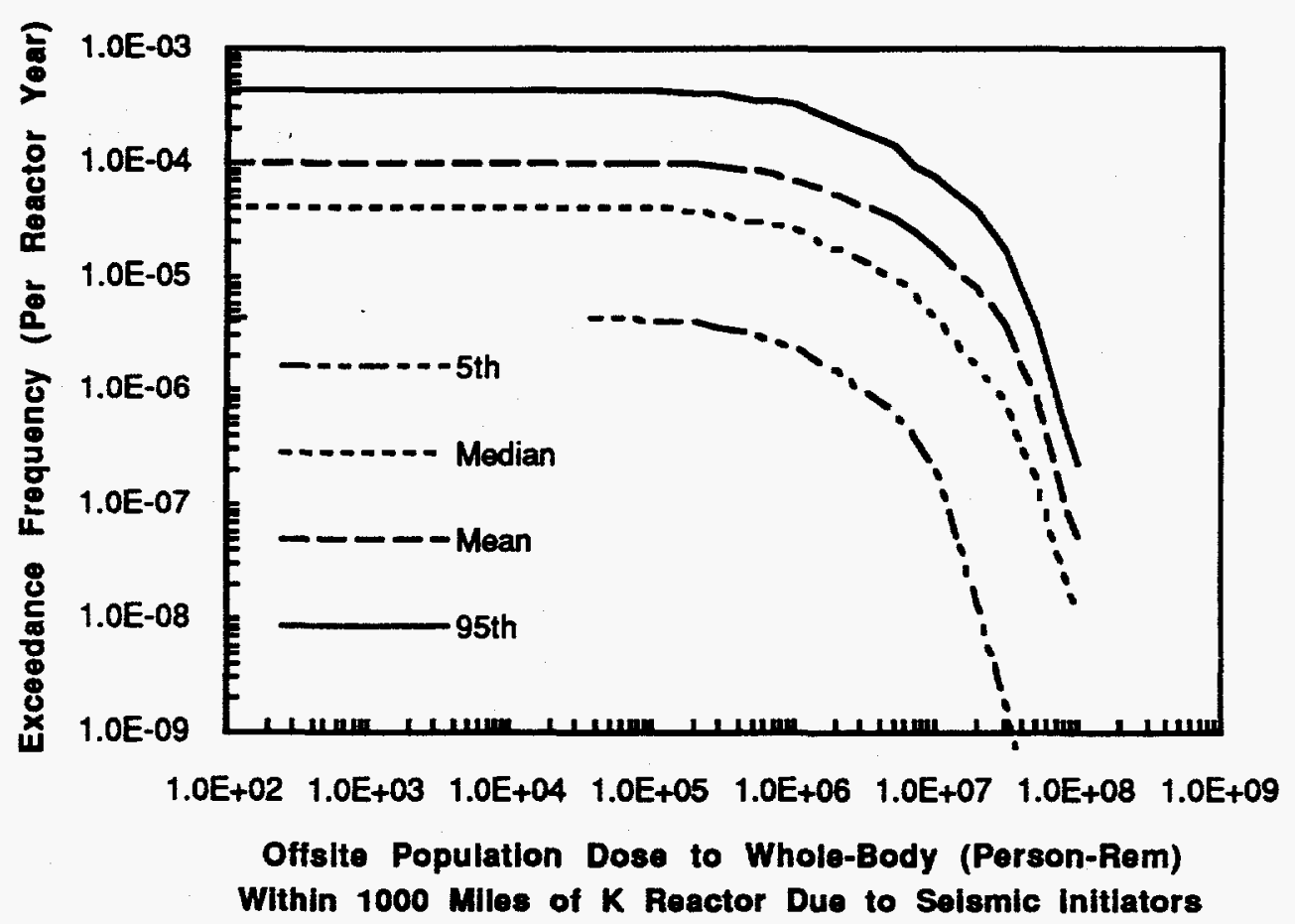

Figure A-19. Exceedance Frequencies for Risk for SRS K Reactor Seismic Initiators - Offsite (contd) 

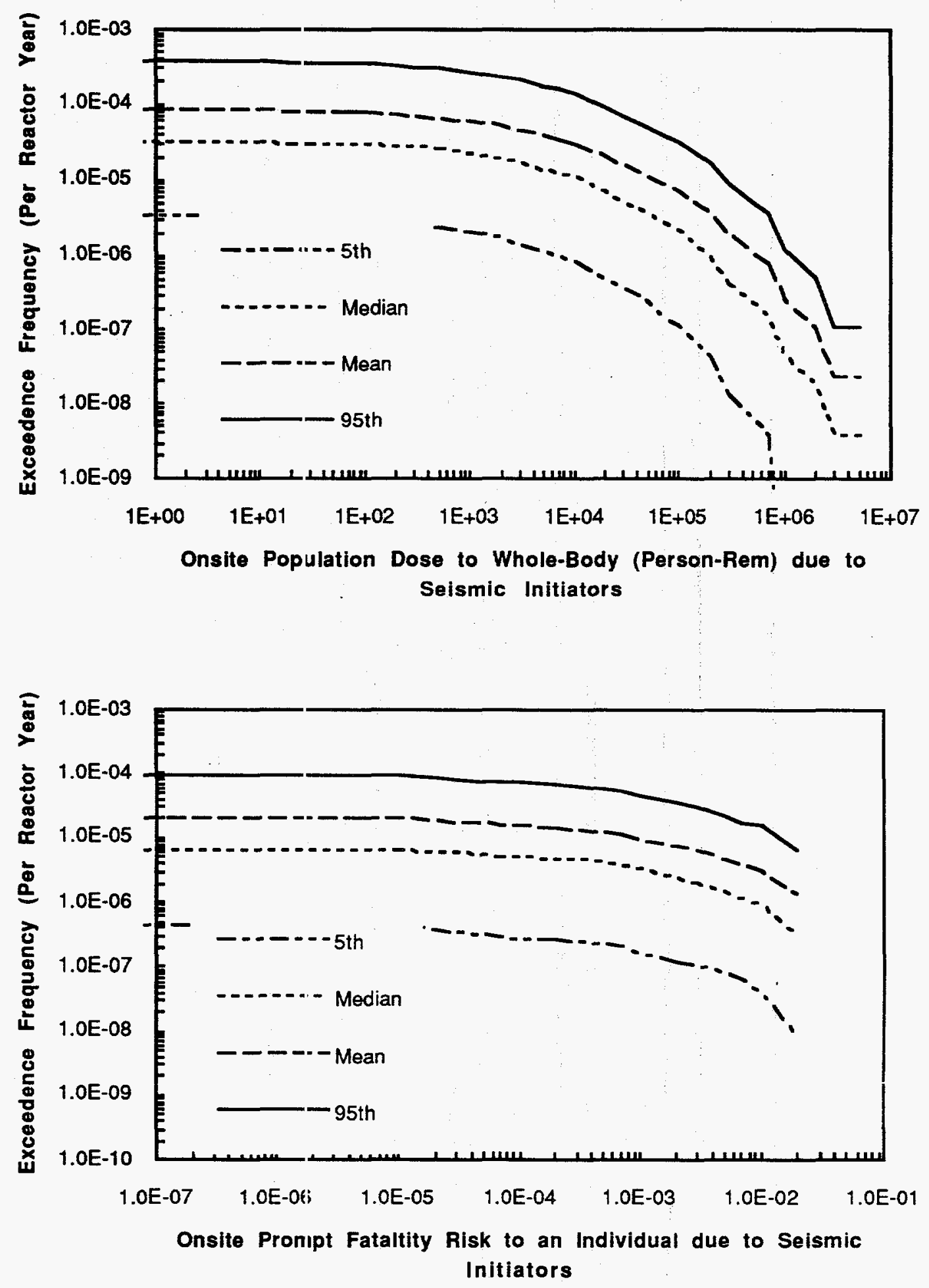

Figure A-20. Exceedance Frequencies for Risk for SRS K Reactor - Seismic Initiators - Onsite 


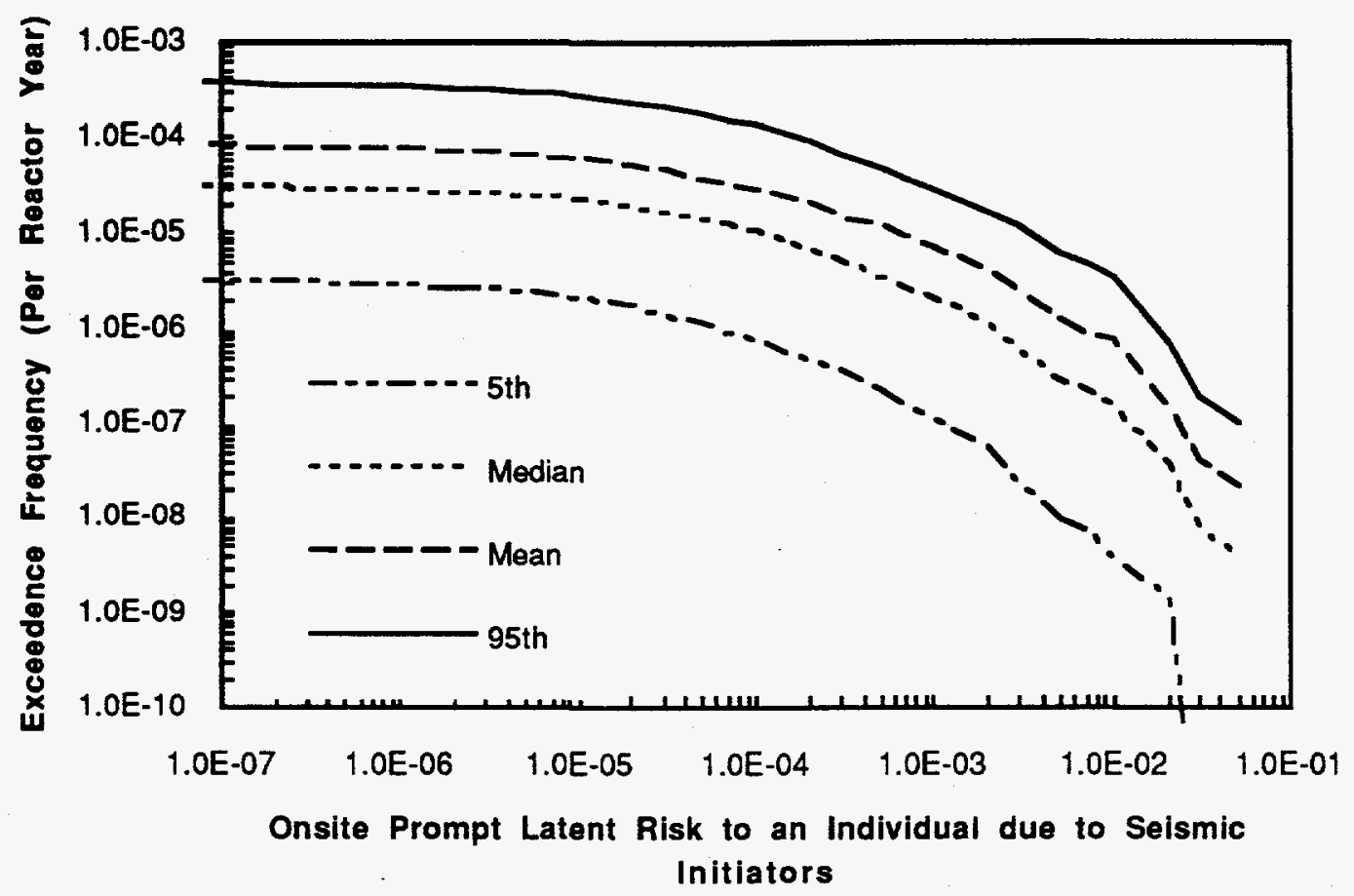

Figure A-20. Exceedance Frequencies for Risk for SRS K Reactor - Seismic Initiators - Onsite (cont'd) 